\title{
Studien zum Gottesbild \\ im Johannesevangelium
}

\author{
Herausgegeben von \\ VERONIKA BURZ-TROPPER
}

Wissenschaftliche Untersuchungen

zum Neuen Testament 2. Reihe

Mohr Siebeck 


\title{
Wissenschaftliche Untersuchungen zum Neuen Testament - 2. Reihe
}

\author{
Herausgeber/Editor \\ Jörg Frey (Zürich) \\ Mitherausgeber/Associate Editors \\ Markus Bockmuehl (Oxford) · James A. Kelhoffer (Uppsala) \\ Tobias Nicklas (Regensburg) · Janet Spittler (Charlottesville, VA) . \\ J. Ross Wagner (Durham, NC)
}

483

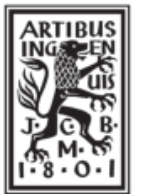





\title{
Studien zum Gottesbild im Johannesevangelium
}

\author{
Herausgegeben von \\ Veronika Burz-Tropper
}

Mohr Siebeck 
Veronika Burz-Tropper, geboren 1984; 2002-08 Studium der Kath. Fachtheologie und der Kath. Religionspädagogik an der Karl-Franzens-Universität Graz; 2011 Promotion; seit 2014 Projektleiterin einer vom FWF geförderten Hertha-Firnberg-Stelle am Institut für Bibelwissenschaft an der KTF der Universität Wien.

ISBN 978-3-16-156962-3 / eISBN 978-3-16-156963-0

DOI 10.1628/978-3-16-156963-0

ISSN 0340-9570 / eISSN 2568-7484

(Wissenschaftliche Untersuchungen zum Neuen Testament, 2. Reihe)

Die Deutsche Nationalbibliothek verzeichnet diese Publikation in der Deutschen Nationalbibliographie; detaillierte bibliographische Daten sind im Internet über http://dnb.dnb.de abrufbar.

(c) 2019 Mohr Siebeck Tübingen. www.mohrsiebeck.com

Dieses Werk ist seit 04/2020 lizenziert unter der Lizenz „Creative Commons Namensnennung - Nicht kommerziell - Keine Bearbeitungen 4.0 International“ (CC BY-NC-ND 4.0). Eine vollständige Version des Lizenztextes findet sich unter: https:// creativecommons.org/licenses/by-nc-nd/4.0/deed.de

Das Buch wurde von satz\&sonders in Dülmen gesetzt, von Laupp \& Göbel in Gomaringen auf alterungsbeständiges Werkdruckpapier gedruckt und von der Buchbinderei Nädele in Nehren gebunden.

Printed in Germany. 


\section{Inhalt}

Vorwort $\ldots \ldots \ldots \ldots \ldots \ldots \ldots \ldots \ldots \ldots \ldots \ldots \ldots \ldots \ldots \ldots$, VII

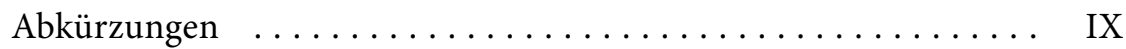

Veronika Burz-Tropper

Einführung $\ldots \ldots \ldots \ldots \ldots \ldots \ldots \ldots \ldots \ldots \ldots \ldots \ldots \ldots \ldots \ldots$

Hermann Spieckermann

Gottes-Rede im Prolog des Johannesevangeliums.

Erkundungen zum alttestamentlichen Hintergrund

Jutta Leonhardt-Balzer

Die Aufnahme frühjüdischer Rede von Gott im

Johannesevangelium

Veronika Burz-Tropper

Joh 1,18 als Paradigma einer Theo-Logie des

Johannesevangeliums $\ldots \ldots \ldots \ldots \ldots \ldots \ldots \ldots \ldots$

Olivia Rahmsdorf und Ruben Zimmermann

Pas de deux.

Christologie als Theologie im Johannesevangelium $\ldots \ldots \ldots \ldots$

Jan van der Watt

An attempted coup?

No, the Father is made known by his Son $\ldots \ldots \ldots \ldots \ldots \ldots$

Michael Theobald

Ein Gott oder „Zwei Götter im Himmel“?

Zum Wandel der johanneischen „Parakletsprüche“ ........ 123

Reinhard Feldmeier

Der Vater des Gottessohnes und der Vater der Gotteskinder $\quad \ldots \ldots \quad 147$ 
Christiane Zimmermann

Gottes rekreatorisches Handeln bei Paulus und Johannes I.

Das „Lebendigmachen“ und das „aus Gott/ von oben

Gezeugtwerden" ...................... 161

Christina Hoegen-Rohls

Gottes rekreatorisches Handeln bei Paulus und Johannes II.

„Neue Schöpfung" und „Ewiges Leben“ _............... 187

Johannes Beutler SJ

„Gott ist Liebe“.

Sinn und Bedeutung der zentralen Gottesprädikation im

ersten Johannesbrief . . . . . . . . . . . . . . . . . . . . . . 227

Jörg Frey

Zwischen der Majestät auf dem Thron und dem Gott, der Liebe ist.

Gott in der Johannesapokalypse und im Johannesevangelium $\ldots 245$

Autorinnen und Autoren $\ldots \ldots \ldots \ldots \ldots \ldots \ldots . \ldots \ldots$

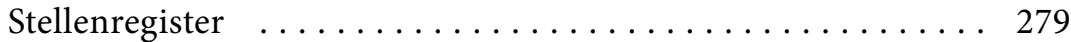

Autorenregister ....................... 297

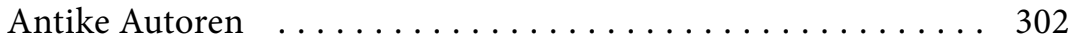

Sachregister ......................... 303 


\section{Vorwort}

Am 23. und 24. Februar 2017 fand an der Katholisch-Theologischen Fakultät der Universität Wien eine Fachtagung zum Thema „Gott - Allein. Symposion zum Gottesbild im Johannesevangelium“ statt. Titel wie Untertitel bezeichnen den Blick, mit dem auf das vierte Evangelium geschaut wurde. Es ging also um den Blick auf Gott selbst. Angesichts der „hohen Christologie“ des Johannesevangeliums wird seine "Theo-Logie“ als eigenständiges Thema selten ins Zentrum gerückt. Ziel des Symposions war es, sich auf die Konturen des Gottesbildes im Johannesevangelium $\mathrm{zu}$ konzentrieren und dieses aus unterschiedlichen Blickwinkeln $\mathrm{zu}$ beleuchten. Die Christologie konnte und sollte nicht ausgeklammert werden, dennoch erwies sich das Anliegen als fruchtbar, zunächst den Blick einmal auf Gott-Vater zu richten und erst von dort her christologische Verbindungslinien zu ziehen.

Namhafte Vertreter und Vertreterinnen aus den Forschungsfeldern des Johannesevangeliums wie der Gottesfrage konnten für die Tagung in Wien gewonnen werden. Der vorliegende Sammelband bündelt die Ergebnisse der beiden Tage, die bei sehr angeregter Diskussion, die in Einzelpunkten auch durchaus kontroversiell geführt wurde, produktiv und konstruktiv verliefen. Den Kolleginnen und Kollegen sei nochmals für ihre Mitwirkung an der Tagung ebenso wie für die Bereitschaft zur vorliegenden gemeinsamen Publikation gedankt.

Mein ganz besonderer Dank gilt auch Herrn Prof. Dr. Jörg Frey für die freundliche und unkomplizierte Aufnahme des Tagungsbandes in die zweite Reihe der „Wissenschaftlichen Untersuchungen zum Neuen Testament" und dem Verlag Mohr Siebeck für dessen kompetente verlegerische Betreuung.

Schließlich geht mein Dank auch an jene Institutionen und Menschen, die zur Realisierung der Tagung wie des Sammelbandes ihren Beitrag im Hintergrund geleistet haben. Besonders zu erwähnen ist die finanzielle Unterstützung durch die Projektmittel meines Hertha Firnberg-Projektes (Austrian Science Fund [FWF]: T 627 G21) sowie durch den Verein der Freunde und Förderer der Katholisch-Theologischen Fakultät der Universität Wien und der Erzdiözese Wien. 
Mein ganz besonders herzlicher Dank gilt der Organisationsassistentin am Institut für Bibelwissenschaft der Katholisch-Theologischen Fakultät, Frau Katharina Rötzer, für die immer hilfsbereiten und perfekten organisatorischen wie drucktechnischen Hilfestellungen, die zum sehr guten Gelingen der Tagung wie des Bandes ganz wesentlich beigetragen haben!

Wien, im Juni 2018

Veronika Burz-Tropper 


\begin{abstract}
Abkürzungen
Für Abkürzungen siehe Siegfried. M. Schwertner, Internationales Abkürzungsverzeichnis für Theologie und Grenzgebiete, Berlin ${ }^{3} 2014$. Weitere verwendete Abkürzungen:

AJEC Ancient Judaism and Early Christianity

SAPERE Scripta Antiquitatis Posterioris ad Ethicam Religionemque pertinentia/Schriften der späteren Antike zu ethischen und religiösen Fragen

ThKNT Theologischer Kommentar zum Neuen Testament

TOBITH Topoi Biblischer Theologie/Topics of Biblical Theology

VvAa Forum Exegese und Hochschuldidaktik: Verstehen von Anfang an
\end{abstract}





\section{Einführung}

\section{Veronika Burz-Tropper}

Das Wiener Symposion „Gott - Allein. Symposion zum Gottesbild im Johannesevangelium" hat sich an zwei Tagen dem Thema Gott, d.h. der Theo-Logie im strikten Wortsinn gewidmet und zwar vor allem anhand einer neutestamentlichen Schrift, nämlich des Johannesevangeliums bzw. des Corpus Johanneum. Drei Vorbemerkungen scheinen deshalb notwendig: Eine zum Johannesevangelium, eine zum Gottes-Bild und eine zur „Theo-Logie“ verstanden im strikten Wortsinn als Rede von Gott.

\section{Drei notwendige Vorbemerkungen}

\subsection{Das Johannesevangelium ${ }^{1}$}

Wenn wir das Johannesevangelium, das mit einer Entstehung von 90-110 n. Chr. wahrscheinlich das jüngste Evangelium im Kanon ist, ${ }^{2}$ aufschlagen, eröffnet sich in vielfältiger Weise eine ganz andere Welt, als sie uns aus dem Markus-, Matthäus-, und Lukasevangelium, den drei synoptischen Evangelien, bekannt ist. Im Gegensatz zu diesen bietet das Johannesevangelium lange Reden und Dialoge Jesu, die meist um eine Kernaussage kreisen. Die Reden Jesu enthalten häufig Wiederaufnahmen

\footnotetext{
${ }^{1}$ Vgl. dazu Veronika Burz-Tropper, Ein profilierter Blick auf das Evangelium, in: Ingrid Penner/Franz Kogler (Hg.), Aus der Quelle schöpfen: Ideen und Materialien zum Johannesevangelium, Linz 2016, 10-13: 10.

${ }^{2}$ So die altkirchliche Meinung (vgl. etwa Irenäus AdvHaer III 1,1) und auch die Mehrheit der Forscherinnen und Forscher heute. Vgl. diesbezüglich aber etwa Michael Tнеовадd, Das Evangelium nach Johannes. Kapitel 1-12 (RNT), Regensburg 2009, 92-94, der zu bedenken gibt: „Wer voraussetzt, dass der Evangelist die Synoptiker nicht kannte und diese auch keinen nachweisbaren Einfluss auf ihn ausübten, wird für sein Buch einen Entstehungszeitraum in Betracht ziehen, zu dem diese literarischen Verhältnisse passen." (S. $92 \mathrm{f}$.) Er kommt nach seinen Überlegungen schließlich zu folgendem Schluss: „All das führt tatsächlich zu einer Datierung des Buches um 90 n. Chr., vielleicht auch etwas früher (80-90). Für die Redaktionsprozesse, die sich dann noch nach Abfassung des Evangeliums auf ihm ablagerten, dürfen weitere Jahre veranschlagt werden." (S. 94)
} 
ein und desselben Motivs; manchen Leserinnen und Lesern erscheinen sie zudem aufgrund ihres deutlich reduzierten Wortschatzes als monoton. Der johanneische Jesus redet größtenteils ganz anders als der der synoptischen Evangelien. Das zeigt sich v. a. im viel stärker metaphorischen, bildhaften Charakter der Reden und Dialoge, die mitunter dem unmittelbaren Verstehen Schwierigkeiten bereiten.

Für viele Bibelleserinnen und -leser ist das Johannesevangelium das anspruchsvollste und tiefsinnigste Evangelium. Andererseits tun sich viele Leserinnen und Leser alles andere als leicht mit diesem Text und finden nicht wirklich Zugang zum vierten Evangelium. Jeder Leser und jede Leserin, der bzw. die sich mit dem Johannesevangelium auseinandersetzt, wird bestätigen, dass man sich zumindest immer wieder an ihm reiben kann. Auch die exegetische Diskussion beschäftigt sich im hohen Maß mit dem vierten Evangelium - spätestens seit Rudolf Bultmann. ${ }^{3}$ Johannesforscher und -forscherinnen sind herausgefordert durch sein einzigartiges Profil: Zum einen versucht das Evangelium, durch die beanspruchte Authentizität des geliebten Jüngers ${ }^{4}$ eine unmittelbare Verbindung zu Jesus herzustellen, zum anderen bietet es aber eine klar nachösterlichprofilierte Glaubenserkenntnis, ${ }^{5}$ die den Boden für die späteren christologischen Lehrentscheidungen darstellt.

Im Kanon gibt es noch vier weitere Schriften, die dem Autor Johannes zugeschrieben werden, die drei Briefe sowie die Apokalypse. Vor allem der erste Johannesbrief steht in einem - wie auch immer bestimmbaren Zusammenhang mit dem Evangelium. ${ }^{6}$ Und auch die Offenbarung des Johannes hat uns mit ihrem - sehr eigenen - Gottesbild im Verlauf der Tagung beschäftigt.

\footnotetext{
${ }^{3}$ Rudolf Bultmann, Das Evangelium des Johannes (KEK 2), Göttingen ${ }^{21} 2011$ und DERs., Der religionsgeschichtliche Hintergrund des Prologs zum Johannesevangelium, in: ders. (Hg.), Exegetica. Aufsätze zur Erforschung des Neuen Testaments. Ausgewählt, eingeleitet und herausgegeben von Erich Dinkler, Tübingen 1967 (erstveröffentlicht 1923), 10-35.

${ }^{4}$ Vgl. dazu etwa Theobald, Evangelium (Anm. 2) 81-92; Udo Schnelle, Das Evangelium nach Johannes (THKNT 4), Leipzig ${ }^{4} 2009,3-6$.

${ }^{5} \mathrm{Vgl}$. dazu etwa Schnelle, Evangelium (Anm. 4) $26 \mathrm{f}$.

${ }^{6}$ Die exegetische Mehrheitsmeinung geht davon aus, dass das Johannesevangelium die erste Schrift im Corpus Johanneum ist und die drei Johannesbriefe nachfolgende Briefe sind, wobei der erste u. a. als Kommentar zum Evangelium verstanden wird. Vgl. diesbezüglich auch die Anm. 56 im vorliegenden Beitrag von Jörg FreY, Zwischen der Majestät auf dem Thron und dem Gott der Liebe ist. Gott in der Johannesapokalypse und im Johannesevangelium, S. 263 in diesem Band. Anders hingegen Udo Schnelle, Die Reihenfolge der johanneischen Schriften, NTS 57 (2011) 91-113, der als erste Schrift des Corpus den ersten Johannesbrief sieht.
} 


\subsection{Das Gottesbild}

Die Verwendung von Bildern ist ein wesentliches Merkmal der johanneischen Sprache - das ist mittlerweile auch in der Forschung zum Johannesevangelium Konsens. ${ }^{7}$

„[J]edes Reden von Gott [ist] nur ein schwaches und immer zugleich auch unzutreffendes Abbilden dessen, wer und wie ,Gott' wirklich ist, trotz allen menschlichen Bemühens darum und aller Offenheit jener Personen, die aus tiefem Glauben, mit vollem Einsatz und oft höchster Kunstfertigkeit von ihm in den biblischen Schriften Zeugnis abgelegt haben. “ 8

Was Georg Fischer in seinen Theologien des Alten Testaments in Bezug auf die alttestamentlichen Schriften sagt, gilt ebenso für die neutestamentlichen, wie - so meine ich - generell für jedes Reden, Schreiben und auch Darstellen Gottes.

In der christlichen Tradition ${ }^{9}$ setzte sich bekanntermaßen das alttestamentliche Bilderverbot (Ex 20,4 f.; 34,17; Lev 19,4; Dtn 4,15-19; 5,8) nicht durch. Von frühchristlicher Zeit an bis etwa ins 12. Jahrhundert behalf man sich mit einer sinnbildlichen Darstellung von Gottvater (v. a. durch die Hand Gottes, aber auch durch das Bild des brennenden Dornbuschs und der Feuersäule). In vielen Darstellungen ist Gottvater in menschli-

\footnotetext{
${ }^{7}$ Allerdings gibt es keinen Konsens bezüglich der methodischen Erfassbarkeit der johanneischen Bildlichkeit. Vgl. etwa Ruben Zimmermann, Christologie der Bilder. Die Christopoetik des vierten Evangeliums unter besonderer Berücksichtigung von Joh 10 (WUNT 171), Tübingen 2004, 86: „Einerseits wurde die Bildlichkeit unter dem Leitbegriff des ,Rätselhaften und Änigmatischen' beschrieben. Diese beiden Begriffe sind jedoch im strengen Sinn keine sprachlichen Kategorien, so dass mit solchen allgemeinen Klassifikationen für eine in der Exegese notwendige methodische Kontrollierbarkeit wenig gewonnen wird. Anders bei dem metapherntheoretischen Ansatz, der vielfach ausgehend von moderner Linguistik und Sprachphilosophie mit einer präzisen Methodik und Begrifflichkeit arbeitet, allerdings kaum für alle Formen der joh Bildlichkeit hinreichend ist. Dies gilt besonders dann, wenn sich die ,Uneigentlichkeit' einer Aussage nicht auf syntaktischer und semantischer Ebene als impertinente Prädikation beschreiben lässt, sondern wenn sie über die Sprachkonvention der Kommunikationsgemeinschaft vermittelt wird. Hier hilft schließlich der Symbolbegriff weiter, da sich ein Symbol gerade durch die Usualität der Bedeutungszuschreibung konstituiert. Um Symbole erkennen und verstehen zu können, ist deshalb die Rekonstruktion des vom Autor und seinen (impliziten) Lesern gekannten Symbolwissens notwendig, wobei insbesondere die Symboltradition, d. h. die konventionelle Kopplung von Sinnbereichen (Bildfeldern), weiterhilft."

${ }^{8}$ Georg Fischer, Theologien des Alten Testaments (NSK.AT 31), Stuttgart 2012, 250.

${ }^{9}$ Vgl. im Folgenden v. a. Wolfgang Braunfels, Gott, Gottvater, in: Engelbert Kirschbaum (Hg.), LCI 2. Allgemeine Ikonographie, F - K, Rom 1994, 165-170 sowie Wolfgang Augustyn, Die Darstellung der Trinität: Das schwierige Gottesbild im Spiegel der Bildüberlieferung, in: Eckhard Leuschner/Mark Hesslinger (Hg.), Das Bild Gottes. In Judentum, Christentum und Islam. Vom Alten Testament bis zum Karikaturenstreit, Petersberg 2009, $45-80$.
} 
cher Gestalt einfach mitgemeint, wenn Christus gezeigt wird. Die Ikonographie Gottvaters spiegelt sich in der Ikonographie Christi. Man war sich gewiss, dass in Christus Gottvater erschienen ist. Man berief sich dazu auf Paulus (2 Kor 4,4; Kol 1,15), der Christus als Bild des unsichtbaren Gottes bezeichnet sowie auf die Worte des johanneischen Jesus: „Wer mich sieht, sieht den Vater" (Joh 14,9). Bis zum 12. Jahrhundert sind daher Darstellungen von Gottvater, die sich im Aussehen von der Gestalt Christi unterscheiden, selten. Erst im Rahmen der verschiedenen Ausformungen der Dreifaltigkeit wurde im Mittelalter der Typus Gottvaters als bärtiger Greis, als Hohepriester und als Papst entwickelt. Der Gnadenstuhl ist schließlich eine ganz eigene Darstellung Gottes bzw. der Trinität, die die heilsgeschichtliche Zusammengehörigkeit von der liebenden Allmacht Gottes und dem Erlösungstod Christi am Kreuz sinnenfällig macht.

Als Bild im Hintergrund hat uns bei der Tagung immer wieder die moderne Gnadenstuhldarstellung des deutschen Künstlers Matthias Buchenberg, fotografiert von Bernhard Jott Keller, begleitet, die sich in der bayerischen Kreisstadt Marktoberdorf im Allgäu befindet. ${ }^{10}$ Diese Gnadenstuhldarstellung von Matthias Buchenberg bot sich für die Beschäftigung mit dem Gottesbild im Johannesevangelium m. E. besonders gut an, da es sich dabei um eine Gnadenstuhldarstellung ohne die leidende Christusfigur am Kreuz handelt, sondern sich nur das blanke Kreuz in den Händen des Vaters befindet. Das passt zu einer Beschäftigung mit dem Johannesevangelium - hat doch gerade hier das Kreuz als Erhöhung ${ }^{11}$ des Sohnes, der sein Leben souverän hingibt, weil sein Vater die Welt liebt und alle, die an ihn glauben, das Leben haben sollen, eine besondere Bedeutung.

\subsection{Das Problemfeld „Neutestamentliche Theologie“ und „Theo-Logie} in der neutestamentlichen Wissenschaft"

Bekannt ist, dass es eine Menge an Theologien des Neuen Testaments, meist in monographischer Form, gibt. ${ }^{12}$ Insofern ist zunächst einmal zu

\footnotetext{
${ }^{10}$ Siehe die Homepage des Künstlers: https://www.matthiasbuchenberg.de/arbeiten (zuletzt abgerufen am 24.06.2018) bzw. meine Projekthomepage http://johannesevangeliumprojekt.univie.ac.at/ (zuletzt abgerufen am 24.06.2018), wo sich auch Detaildarstellungen finden, die mir von den beiden Künstlern freundlicherweise zur Verfügung gestellt wurden.

${ }^{11}$ Vgl. dazu etwa Joachim KügLER, Das Johannesevangelium, in: Martin Ebner/Stefan Schreiber (Hg.), Einleitung in das Neue Testament (KStTh 6), Stuttgart 2008, 208-228: $222 \mathrm{f}$.

${ }^{12}$ Vgl. nur Rudolf Bultmann, Theologie des Neuen Testaments (UTB 630), Tübingen ${ }^{9}$ 1984; Hans Conzelmann, Grundriß der Theologie des Neuen Testaments (UTB 1446),
} 
klären, was denn nun genau unter diesem Begriff zu verstehen ist: Begriffe wie „Theologie des Neuen Testaments“ oder „neutestamentliche Theologie" sind grundsätzlich als Systematisierungsbegriffe im Rahmen der "Biblischen Theologie“ zu verstehen. ${ }^{13}$

Ich bringe hier ein Beispiel für die Definitionen einer Theologie des Neuen Testaments bzw. die Formulierung ihrer Aufgabenstellung, die mir in meiner Auseinandersetzung mit dem Thema wichtig geworden ist. Joachim Gnilka hält am Beginn seiner „Theologie des neuen Testaments“ fest:

„Um zu erklären, worin die Aufgabe besteht, eine Theologie des Neuen Testaments zu entwerfen, empfiehlt es sich, die beiden in diesem Begriff vereinigten Wörter aufzugreifen. Denn es läßt sich gerade so eine Besonderheit dieses hier vorliegenden Versuches, eine Theologie des Neuen Testaments zu schreiben, anzeigen. [...] Theologie ist der Logos, die Rede von Gott. Wir haben die Unbekümmertheit, als Theologen von Gott zu reden, verloren. Und das ist gut so. Man kann von Gott nicht reden wie von einem Baum, einem anderen Menschen und anderen äußeren Wirklichkeiten, die ihr Wort durch sich selbst erzwingen, weil sie im Raum unserer Erfahrungen an einer bestimmten Stelle einfach vorkommen, bemerkte K. Rahner. Unser unbekümmertes Reden von Gott, das seine Unverfügbarkeit mißachtete oder gedankenlos übersah, hat mit dazu beigetragen, daß das Wort ,Gott' aus der ernsthaften Rede der Menschen zurückgedrängt wurde und fast nur noch in Floskeln und gedankenlosen Worthülsen nistet. Dieser Hintergrund macht das allgemeine und gewöhnliche Problem aus, eine Theologie, auch die des Neuen Testaments, zu konzipieren. Redet auch das Neue Testament unbekümmert von Gott? Man könnte äußerlich diesen Eindruck gewinnen, wenn man sieht, daß das Wort ,Gott' ( $\theta \varepsilon o ́ \varsigma)$ hier 1318mal vorkommt. Das Neue Testament aber redet vom Handeln Gottes in Jesus Christus und damit von den Erfahrungen, die Menschen im Glauben an dieses befreiende und rettende Handeln gemacht haben und diese bezeugen. Neutestamentliche Theologie läßt sich demnach umreißen als Beschreibung des rettenden Handelns Gottes in Jesus Christus, wie es im Neuen Testament oder: in seinen einzelnen Schriften bezeugt wird." ${ }^{14}$

Tübingen ${ }^{6}$ 1997; Joachim Gnilka, Theologie des Neuen Testaments (HTKNT.S 5), Freiburg 1994; Ferdinand Hahn, Theologie des Neuen Testaments. Band. 1: Die Vielfalt des Neuen Testaments. Band. 2: Die Einheit des Neuen Testaments (UTB 3500), Stuttgart ${ }^{3} 2011$; Eduard LoHse, Grundriß der neutestamentlichen Theologie (Theologische Wissenschaft 5), Stuttgart ${ }^{3}$ 1984; Udo Schnelle, Theologie des Neuen Testaments (UTB 2917), Göttingen u. a. ${ }^{2} 2014$.

${ }^{13}$ Vgl. dazu Bernd Janowski, Biblische Theologie. Exegetisch, in: RGG ${ }^{4}$ I. A-B 1998, 1544-1549 sowie Ders./Michael Welker, Vorwort, in: Ingo Baldermann u. a. (Hg.), Einheit und Vielfalt biblischer Theologie (JBTh 1), Neukirchen-Vluyn 1986, 5-8.

${ }^{14}$ Gnilka, Theologie (Anm.12) 9 mit dem Verweis auf Karl Rahner, Grundkurs des Glaubens, Freiburg u. a. ${ }^{2} 1984,55$. 
Eine weitere Durchsicht von Einleitungen in Neutestamentliche Theologie(n) zeigt des Weiteren, dass "Gottes-Rede“ - d.h. die Theo-Logie im strikten Wortsinn - in der neutestamentlichen Wissenschaft bisher wenig in den Blick gekommen ist. ${ }^{15}$ Christologie, Pneumatologie sowie Ekklesiologie, Soteriologie und auch Eschatologie waren immer wichtiger.

Bereits vor mehr als 40 Jahren hat Nils Dahl "theo-logy“ im strikten Wortsinn als "the neglected factor" in der neutestamentlichen Theologie bezeichnet. ${ }^{16}$ Als Grund für die spärliche Behandlung des Gottesthemas in der neutestamentlichen Wissenschaft führt Dahl ganz grundsätzlich die Geschichte der christlichen Theologie an, die absolut christozentrisch geprägt war/ist. Innerneutestamentlich liegt es seiner Meinung nach daran, dass es kaum thematische Formulierungen bezüglich Gott, d. h. keine Gotteslehre im engen Sinn gibt und dass Erwähnungen Gottes eigentlich immer in Kontexten vorkommen, die andere Themen behandeln. ${ }^{17}$ Er hält fest: „There is no uniform New Testament doctrine of God, but rather considerable diversity; one need only contrast the letters of Paul and the Book of Revelation, or the Lucan and the Johannine writings. This variety, however, ought to have been cause for investigations, not for neglect." 18

Gerade die Vielfältigkeit der neutestamentlichen Gottesrede, die bei einem genaueren Blick in die Schriften zu Tage tritt, sollte zur Beschäftigung mit ihr herausfordern und in neuerer Zeit ist in der neutestamentlichen Wissenschaft durchaus ein Aufbruch hin zur Thematik "Gott" erkennbar. Das zeigen beispielsweise die Habilitationsschrift von Christiane Zimmermann „Die Namen des Vaters“ $(2007){ }^{19}$, das Projekt von Reinhard Feldmeier und Hermann Spieckermann, die im Jahr 2011 als Göttinger Neu- und Alttestamentler gemeinsam eine umfangreiche Monographie zur biblischen Gotteslehre ${ }^{20}$ herausbrachten, und auch das Büchlein von Kurt Erlemann, Wer ist Gott? Antworten des Neuen Tes-

\footnotetext{
${ }^{15}$ Bei Schnelle, Theologie (Anm.12) findet sich bei der Besprechung jeder neutestamentlichen Schrift bzw. deren Autor die Abfolge Theologie, Christologie, Pneumatologie, Soteriologie, Anthropologie, Ethik, Ekklesiologie und Eschatologie.

${ }^{16}$ Nils DAHL, The Neglected Factor in New Testament Theology, in: ders. (Hg.), Jesus the Christ. The Historical Origins of Christological Doctrine. ed. Donald H. Juel, Minneapolis 1991 (1975), 153-163.

${ }^{17}$ Vgl. DERS., Neglected Factor (Anm. 16) $155 \mathrm{f}$.

${ }^{18}$ Ders., Neglected Factor (Anm. 16) 156.

${ }^{19}$ Christiane Zimmermann, Die Namen des Vaters. Studien zu ausgewählten neutestamentlichen Gottesbezeichnungen vor ihrem frühjüdischen und paganen Sprachhorizont (AJEC 69), Leiden u. a. 2007.

${ }^{20}$ Vgl. Reinhard Feldmeier/Hermann Spieckermann, Der Gott der Lebendigen. Eine biblische Gotteslehre (TOBITH 1), Tübingen 2011.
} 
taments $(2008)^{21}$. Daneben gibt es eine Reihe an kleineren und größeren Arbeiten, die sich der Gottesvorstellung in einzelnen neutestamentlichen Schriften widmen. ${ }^{22}$

\section{Warum das Johannesevangelium?}

Bestärkt in meiner Auswahl des Johannesevangeliums als Basis für eine Untersuchung zur Theo-Logie haben mich u. a. Birger Olsson, der 1997 festhielt, dass es keine „thorough presentation of God in the Johannine Writings" ${ }^{23}$ gibt, auf der anderen Seite aber „a number of books of Johannine Christology “24. Und des Weiteren François D. Tolmie, der 1998 konstatierte: „Strangely enough, the way in which God is presented in the Fourth Gospel has not received much attention in Johannine research. In comparison to the number of studies devoted to Jesus and the Paraclete, the number of studies devoted to God seems almost insignificant." 25

Die Johannesforschung war und ist vor allem durch einen christologischen Schwerpunkt gekennzeichnet. ${ }^{26}$ In den letzten 20 Jahren wurden nur wenige Annäherungen an die Theo-Logie im Johannesevangelium unternommen und es wurden immer nur gewisse Aspekte der Frage nach Gott im Johannesevangelium behandelt.

\footnotetext{
${ }^{21}$ Kurt Erlemann, Wer ist Gott? Antworten des Neuen Testaments, Neukirchen-Vluyn 2008.

${ }^{22} \mathrm{Vgl}$. dazu ZimmermanN, Namen (Anm. 19) 5 Anm. 22.

${ }^{23}$ Vgl. Birger Olsson, Deus Semper Maior? On God in the Johannine Writings, in: Johannes Nissen/Sigfred Pedersen (Hg.), New Readings in John. Literary and Theological Perspectives. Essays from the Scandinavian Conference on the Fourth Gospel Arhus 1997 (JSNTSup 182), Sheffield 1999, 143-171. Das Anliegen seines Aufsatzes formuliert er S. 146 folgendermaßen: „I will analyze the three Johannine ,definitions" of God (God is light/ spirit/love), add a section on the monotheism in the Johannine movement, and offer some final remarks."

${ }^{24}$ Ders., Deus Semper Maior? (Anm. 23) 143.

${ }^{25}$ Fraçois D. Tolmie, The Characterization of God in the Fourth Gospel, JSNT 69 (1998) 57-75: 57. Tolmie selbst nähert sich in seinem Artikel dann dem Thema der Charakterisierung Gottes im JohEv aus narratologischer Sicht an.

${ }^{26}$ Das zeigt sich im Übrigen auch in diversen neueren Forschungsüberblicken zum Johannesevangelium: Konrad Haldimann/Hans Weder, Aus der Literatur zum Johannesevangelium 1985-1994. Dritter Teil: Theologische Akzentuierungen (I), TRev 71 (2006) 91-113: 103-113; DIEs., Aus der Literatur zum Johannesevangelium 1985-1994. Dritter Teil: Theologische Akzentuierungen (II), TRev 71 (2006) 192-218: 192-206; Klaus SCHOLTISSEK, Johannes auslegen IV. Ein Forschungsbericht, SNTSU 29 (2004) 67-118: 94-100.
} 


\subsection{Forschungsstand zu Gott im Johannesevangelium}

Seit den 90er Jahren des letzten Jahrhunderts hat sich der Befund bezüglich Beiträgen zum Gottesthema im Johannesevangelium etwas geändert, da in der Zwischenzeit einige Beiträge zu Gott als Vater im Johannesevangelium - dem wohl häufigsten Gottesbild im vierten Evangelium - publiziert worden sind. Verwiesen sei auf die von Adele Reinhartz herausgegebenen Beiträge der Johannes-Gruppe der SBL 1998 in der Reihe Semeia, ${ }^{27}$ die sich unter verschiedenen Gesichtspunkten mit der Gott-Vater-Thematik im Johannesevangelium auseinandersetzen. Für den deutschsprachigen Raum sind Edith Zinggs Dissertation „Das Reden von Gott als,Va-

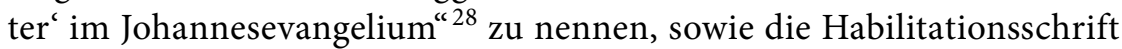
der leider an Krebs verstorbenen Frances Back „Gott als Vater der Jünger im Johannesevangelium“ ${ }^{29}$.

Zudem sind seit dem Jahr 2000 drei englischsprachige Monographien erschienen, die sich explizit mit Gott im Johannesevangelium auseinandersetzen: „The God of the Gospel of John“" ${ }^{30}$ von Marianne M. Thompson (2001), "God in the Fourth Gospel. A Hermeneutical Study of the History of Interpretations“ ${ }^{31}$ von Tord Larrson (2001) sowie „Johannine Exegesis of God. An Exploration into the Johannine Understanding of

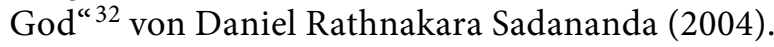

Thompson beschäftigt sich in ihrer Monographie zunächst im ersten Kapitel (17-55) damit, was es denn überhaupt heißt, über Gott zu sprechen. Dabei setzt sie sich sowohl mit dem jüdisch-hellenistischen als auch mit dem paganen Bereich auseinander. In einem zweiten Kapitel „The Living Father" (57-100) geht sie näher auf die Beschreibung Gottes als Vater ein. In drei weiteren Kapiteln widmet sich Thompson den Themen „Knowledge of God“ (101-143), „The Spirit of God“ (145-188), sowie „The Worship of God“ (189-226).

Larsson nähert sich dem Gottesthema im Johannesevangelium in seiner Dissertation exegesegeschichtlich an, wie der Untertitel bereits zu erkennen gibt. Er setzt sich mit sechs Exegeten in drei verschiedenen

\footnotetext{
${ }^{27}$ Adele Reinhartz, God the Father in the Gospel of John (Semeia 85), Atlanta 1999.

${ }^{28}$ Edith ZINGG, Das Reden von Gott als „Vater“ im Johannesevangelium (HBS 48), Freiburg i. Br. u. a. 2006.

${ }^{29}$ Frances BACK, Gott als Vater der Jünger im Johannesevangelium (WUNT 2,336), Tübingen 2012 .

${ }^{30}$ Marianne M. Thompson, The God of the Gospel of John, Grand Rapids 2001.

${ }^{31}$ Tord Larrson, God in the Fourth Gospel. A Hermeneutical Study of the History of Interpretations (ConBNT 35), Stockholm 2001.

${ }^{32}$ Daniel Rathnakara Sadananda, The Johannine Exegesis of God. An Exploration into the Johannine Understanding of God (BZNW 121), Berlin u. a. 2004.
} 
Perioden hinsichtlich ihrer Darstellung der johanneischen Theo-Logie auseinander. Es handelt sich dabei um Luther und Calvin (15./16. Jahrhundert), Westcott und Holtzmann (19. Jahrhundert) sowie Bultmann und Brown (20. Jahrhundert). Bemerkenswert ist, dass im Gegensatz zur aktuellen Johannesforschung bezüglich Gott „Vater" bei keinem der sechs Exegeten eine wesentliche Rolle zu spielen schien. ${ }^{33}$

Die 2004 publizierte, aber bereits 1997 approbierte Dissertation von Daniel Rathnakara Sadananda geht der Frage nach, ob das Johannesevangelium christologisch oder theologisch geprägt ist und versucht ein theologisches "Re-reading" ${ }^{34}$. Sadanandas Charakterisierung Gottes im Johannesevangelium ist allerdings ganz klar von einer christologischen Ausgangsposition geleitet. Das wird allein schon deutlich durch die Kapitelüberschriften in seinem Hauptteil. So trägt das erste Kapitel zu Joh 20,24-29 den Titel „Is Jesus God?“, seine Ausführungen zu Joh 5,17-30 überschreibt er mit „Is Jesus Equal to God?“, diejenigen zu 8,21-59 mit „Is Jesus Pre-existent?“35

Die Durchsicht dieser drei Monographien macht deutlich: Trotz vielversprechender Titel wurde das Gottesbild des Johannesevangeliums nur spärlich behandelt. ${ }^{36}$ Gott wird zwar zum Thema, die Debatte konzentriert sich aber meist auf bestimmte Aspekte des johanneischen Gottesbildes: Bei Thompson ist es vor allem der Vater, der in den Blick kommt, des Weiteren die Fragen der Gotteserkenntnis und des Geistes Gottes und der Anbetung Gottes. Larsson untersucht das Thema exegesegeschichtlich und nicht wirklich inhaltlich. Sadananda wiederum ist von einer klar christologischen Ausgangsbasis geleitet. Grundsätzlich fällt auf, dass sich - soweit mir bis jetzt ersichtlich - die wissenschaftliche Diskussion im Moment hauptsächlich auf den englischsprachigen Raum beschränkt.

\footnotetext{
${ }^{33}$ Das konstatiert bereits ZINGG, Reden (Anm. 28) 7.

${ }^{34}$ Sadananda, Exegesis (Anm. 32).

${ }^{35}$ Auch in den weiteren Überschriften ist Sadanandas christologische Perspektive erkennbar.

${ }^{36}$ Vgl. diesbezüglich auch schon den guten Überblicksartikel Jörg FreY, Was trägt die johanneische Tradition zum christlichen Bild von Gott bei?, in: ders./Uta Poplutz (Hg.), Narrativität und Theologie im Johannesevangelium (BThSt 130), Neukirchen-Vluyn 2012, 217-257.
} 


\section{Anliegen und Inhalt}

Mit der Tagung bzw. dem vorliegenden Band und mit meinem Projekt zur „Gottes-Rede im Johannesevangelium“ insgesamt, ist ein breiterer Zugang in der Erforschung des johanneischen Gottesbildes angestrebt. Es soll vor allem auch die deutschsprachige Wissenschaft in dieses wachsende Forschungsfeld eingebracht und eingebunden werden. Ich freue mich sehr, dass ich eine Reihe namhafter Johannesforscherinnen und Johannesforscher sowie Expertinnen und Experten im Bereich der biblischen GottesRede für die Wiener Tagung gewinnen konnte.

Der vorliegende Band bietet eine Nachlese der erkenntnisreichen und spannenden Tagung, die uns dem biblischen Gott etwas näher kommen ließ. Wir haben keinesfalls unbekümmert von ihm gesprochen: Die ersten beiden Beiträge beschäftigen sich mit den Kontexten, aus denen heraus die johanneische Theo-Logie entstanden sein dürfte.

Hermann Spieckermann führt mit seinem Beitrag "Gottes-Rede im Prolog des Johannesevangeliums. Erkundungen zum alttestamentlichen Hintergrund“ anhand von Arnold Schönbergs Werk „Moses und Aron“, das „das theologische Problem des Verhältnisses von Gott und Wort [verdichtet]" (S. 21), in das Thema Gott und Wort ein. Denn mit deren Identität und Differenz beginnt das Johannesevangelium. Unter drei alttestamentlichen Aspekten wird auf den Johannesprolog geblickt. Betrachtet werden das Verhältnis des Wortes zur Schöpfung, sein Verhältnis zur Weisheit und schließlich die Fleischwerdung des Wortes, wobei eine intensive Auseinandersetzung mit den Prätexten von Joh 1 erfolgt. $\mathrm{Zu}$ nächst sind das v. a. Gen 1 und Jes 9, wobei darauf hingewiesen wird, „dass die Schöpfungstheologie von Gen 1 bereits in Ps 33 eine theologische Vertiefung erfahren hat, die für Joh 1 entscheidend gewesen ist “ (S. 25); dann werden die alttestamentlichen Texte von der personifizierten Weisheit Spr 8 und Weish 9 behandelt, die deren unmittelbare Nähe zu Gott zum Ausdruck bringen. Sie werden als mögliche Prätexte für die enge Verbindung von Logos-Wort und Gott in Joh 1 gesehen. Schließlich erläutert Spieckermann noch Ez 36f. und Ez 11. Er kommt zum Schluss, dass man „[d]as neue Herz aus Fleisch in Ez 11 und Ez 37 [...] nicht als die unabdingbare Voraussetzung für die Vorstellung der Fleischwerdung des Logos in Joh 1,14 betrachten können [wird]. Aber unter den Verheißungen des Neuwerdens des Verhältnisses zwischen Gott und Israel im Alten Testament ist das Herz aus Fleisch eine unerwartete und einschneidende Wendung, die der Überraschung der Fleischwerdung des Wortes im Johannes-Prolog nahekommt." (S.38) Das alttestamentliche 
Fazit Spieckermanns lautet schließlich: Der Kern der Gottes-Rede im Johannesprolog ist Gottes Welt-Liebe.

Jutta Leonhardt-Balzer beleuchtet „Die Aufnahme frühjüdischer Rede von Gott im Johannesevangelium“. Sie zeigt auf, dass sich der Autor des Johannesevangeliums mit seiner Gottes-Rede im Spannungsfeld von Partikularismus und Universalismus („konkrete[r] Gott Israels [und] Schöpfer und universale[r] Herr [...] der Weltgeschichte“ [S. 44]) bewegt, das eine der großen Herausforderungen der frühjüdischen Theologie ist. Schließlich geht die Autorin der Frage nach, von welchem Gott ( $\theta \varepsilon o ́$ ) das Johannesevangelium überhaupt spricht. Leonhardt-Balzer beleuchtet, dass der Gebrauch des Nomens mit und ohne Artikel dem Griechischen der damaligen Zeit entspricht und ähnlich wie bei Philo und generell in der hellenistisch-jüdischen Theologie dazu dient, eine Unterscheidung in Bezug auf Gott zu machen: konkret zwischen dem transzendenten Gott und dem Logos. Im Evangeliencorpus bezieht sich $\theta$ có ৎ im Munde der Menschen „durchgehend und unreflektiert auf den Gott der jüdischen Tradition“ (S. 52) und auch der johanneische Jesus nimmt mit $\theta$ có ৎ „traditionelle Erwartungen“ (S. 53) auf. Nach Leonhardt-Balzer findet sich im Thomasbekenntnis Joh 20,28 dann das johanneische Bekenntnis zusammengefasst: Jesus wird als ó kúpı́c $\mu$ ov kaì ó $\theta \varepsilon o ́ \varsigma \mu$ als der Gott der Tora bekannt; das wird auch schon deutlich im Prolog (z. B. durch die Metaphern Licht und Leben oder die Beschreibung der Inkarnation über die Tradition des Zeltheiligtums). Joh 14,9 macht schließlich deutlich, dass Jesus „die sichtbare Manifestation des jüdischen Gottes“ (S. 54) ist. Generell zeigt sich der Autorin zufolge also, dass das Johannesevangelium bekannte Gottes-Motive, -Traditionen und -Vorstellungen aufnimmt, diese dann aber durch die Deutung auf Jesus radikal umdeutet. Jesu Verkündigung im Johannesevangelium fordert heraus: Denn durch die radikal christologische Deutung der bekannten Gottes-Vorstellungen und -Traditionen wird deutlich, dass sich in dem Menschen Jesus der Gott Israels und der ganzen Schöpfung findet; allerdings nicht als eine weitere Ausdrucksform, sondern „[d]er Name des Gottes Abrahams, des Gottes vom Sinai, ist Jesus“ (S. 58).

Die nächsten vier Beiträge beschäftigen sich ausschließlich mit dem Johannesevangelium, drei davon aus je unterschiedlichen Blickwinkeln vorwiegend mit der Frage nach der Theo-Logie bzw. dem Verhältnis von Christologie und Theologie und einer mit der Bedeutung der Parakletsprüche für das johanneische Gottesbild.

Veronika Burz-Tropper zeigt in ihrem Beitrag „Joh 1,18 als Paradigma einer Theo-Logie des Johannesevangeliums“ ausgehend von der An- 
nahme, dass der Prolog des Johannesevangeliums die Funktion hat, die nachfolgende Lektüre zu leiten, inwiefern der letzte Prologsatz Joh 1,18 zum hermeneutischen Schlüssel für eine theo-logische Lesart des vierten Evangeliums werden kann. Jesus als der Logos und Exeget des Vaters ist in erster Linie nicht christo-logisch, sondern theo-logisch zu deuten. Der

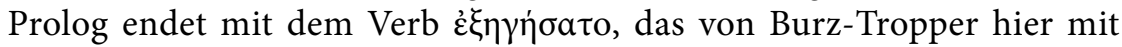
„auslegen“ übersetzt wird. „Das authentische Auslegen des Vaters durch den Sohn in seinem Sprechen und Wirken erschließt diesen (d.h. den Vater) in einem über das Kognitive hinausgehenden Sinn." (S.68) Der Abschluss des Prologs steht in engem Zusammenhang mit dessen Beginn und auch mit den VV. 14 und 17, so wie der Prolog insgesamt mit dem Thomasbekenntnis Joh 20,28 einen Rahmen um das Evangelium bildet. Gerade dadurch wird die zugespitzte Christologie des vierten Evangeliums deutlich, die aber gerade wegen „ihres monotheistischen Denkrahmens Rede von Gott ist" (S. 70). Methodische Basis der theo-logischen Lektüre des Johannesevangeliums sind Intertextualität und Intratextualität, wobei von der Autorin vor allem der Zusammenhang von Joh 10,30 und Joh 14,6b.7.9 mit Joh 1,1.18 betont wird. Als mögliche Arbeitsfelder einer Theo-Logie des Johannesevangeliums werden drei exemplarische Beispiele angeführt: Gott, der Vater, die Einzigkeit und Unsichtbarkeit Gottes sowie Überlegungen zu den sieben johanneischen Ich-bin-Worten, die gerade unter Berücksichtigung des Zusammenhangs von 1,18 mit den Aussagen von 10,30 und 14,6b.7.9, „nicht nur unter christologischem und soteriologischem, sondern auch unter theologischem Aspekt" zu sehen sind (S. 77).

Olivia Rahmsdorf und Ruben Zimmermann widmen sich in Anlehnung an den „Solotanz zu zweit“ aus dem Ballett unter dem Titel „Pas de deux. Christologie als Theologie im Johannesevangeliums“ der „intimen Verschränkung der Gottesrede [...] mit der Christologie“ (S. 81) im vierten Evangelium. Nach dem Johannesevangelium gelangt man nur über die Christologie zur Theologie, da nur der „monogenetische Gottesbetrachter" seinen Vater auslegen kann und „[d]er einzige Gott [...] nur durch den einziggeborenen Sohn, den wahren Exegeten, geschaut werden [kann]" (S. 84). So nehmen Rahmsdorf und Zimmermann die gemeinsame Bewegung von Vater und Sohn in den Blick: Zuerst geht es dabei um die generelle Seins- und Handlungseinheit der beiden, die anhand der Bildertheologie des Johannesevangeliums exemplarisch an Kapitel 10 beschrieben wird, wo v. a. durch das einleitende Tür- und Hirtengleichnis bereits das „Ineinander von Vater und Sohn“ entfaltet wird. Schließlich werden weitere "Anschauungsfelder der Christo-Theologie“ 
skizziert: Lebensspender, Schöpfungswerke (z. B. Gang über das Wasser), Doxa, Richter und als weitere Motive Liebe und Bräutigam. Wichtig bleibt aber, dass bei aller Verbundenheit von Vater und Sohn „doch auch die Unterschiedenheit" (S. 96) der beiden gewahrt wird, was in Anlehnung an das Pas de deux als die Variationen der Tänzer beschrieben wird. Als deren größte nennen Rahmsdorf und Zimmermann die Inkarnation des Sohnes. Einer Identität von Vater und Sohn widerspricht nach der Autorin und dem Autor das Evangelium insofern, als der Vater immer wieder als klares Gegenüber Jesu dargestellt ist. Das Johannesevangelium bietet demnach nicht so sehr ontologische Theologie als vielmehr hermeneutische Theologie, insofern es Auskunft gibt über den Zugang zu Gott-Vater über seinen Sohn, was die Christologie nicht mehr als Konkurrentin, sondern als Teil der Theologie verstehen lässt. Am Ende weist die „Coda: Joh 17,21: Die Einheit geht über auf, alle“ darauf hin, dass „[d]ie christo-theologische Erzählweise und Metaphorik [über]gehen auf Jünger und Lesende [...] und [d]ie Jesus- bzw. Gottesprädikate [...] nicht exklusiv, sondern integrativ" (S. 100) sind.

Jan G. van der Watt beschäftigt sich in seinem Beitrag „An Attempted Coup? No, the Father is made known by his Son" mit der Frage, inwiefern die Annahme, dass der johanneische Jesus Gott-Vater in seiner Stellung bedroht, die auf Textebene v. a. von den jüdischen Gegnern vertreten wird, tatsächlich konzeptionell mit der johanneischen Beschreibung des Verhältnisses von Vater und Sohn zusammenhängt. Van der Watt zeigt, dass Metaphern wie Vater und Sohn, der Sohn liebt den Vater, Sendung des Sohnes etc. nicht verwendet werden, um die Position Gott-Vaters in Frage zu stellen, sondern dass diese ausschließlich dazu dienen, aufzuzeigen, dass Jesus in einer einzigartigen intimen Beziehung zum Vater steht, die sonst niemand für sich reklamieren kann. Im Johannesevangelium ist eine Spannung zwischen hoher und niedriger Christologie zu erkennen bereits von Joh 1,1 an: Jesus wird auch mit dem Begriff Gott charakterisiert, gleichzeitig aber vom Vater unterschieden, der eine höhere Stellung innezuhaben scheint. Diese Spannung setzt der Autor in Relation zur Spannung, die in Bezug auf den jüdischen Monotheismus und die Frage der Präsenz von anderen machtvollen Wesen im göttlichen Raum besteht. Laut van der Watt spielt in diesem Zusammenhang die Engellehre eine wichtige Rolle. Er macht deutlich, dass für das Johannesevangelium Engel funktional keine Rolle haben, denn: „The angels are functionally replaced by Jesus as the one who will make the Father known, so that the unseen God may become visible and functionally observable. John does not discard angels but rhetorically emphasizes that it is Jesus who now mediates 
the Father." (S. 107 f.) Schließlich ist die Rede davon, dass die johanneische Christologie eine auf Gott hin transparente ist, um so deutlich zu machen, dass Jesus gerade nicht die Stellung des monotheistischen Gottes bedroht, sondern dass er als unterschieden von Gott wahrgenommen werden muss.

Michael Theobald setzt sich in seinem Beitrag unter dem Titel „Ein Gott oder ,zwei Götter im Himmel'? Zum Wandel der johanneischen ,Parakletsprüche“" mit den fünf Parakletsprüchen des Johannesevangeliums auseinander, deren Beitrag zum johanneischen Gottesbild bisher noch kaum bedacht wurde. Die fünf Parakletsprüche (Joh 14,16f.; 14,25f.; 15,26f.; 16,8-11; 16,[12]13-15) werden „im jeweiligen rhetorischen Kontext“ und „im Relecture-Prozess der drei [Abschieds-]Reden“ (S. 126) interpretiert. So wird deutlich, dass es nach der ersten Abschiedsrede Gott ist, der den Parakleten sendet, nach der zweiten und dritten aber Jesus; d.h. es besteht „ein klares Gefälle von der gezielten Theozentrik der ersten Rede zur unterschwelligen göttlichen Zweisamkeit von Vater und Sohn in den beiden folgenden Reden" (S. 144). Außerdem lässt sich nach Theobald auch eine fortschreitende Personifizierung des Parakleten erkennen. Insgesamt werden Entwicklungen aufgezeigt, „die im Kontext frühjüdischer ,Zwei-Götter-Lehre (Peter Schäfer) von hoher Brisanz waren“ (S. 127) und ein Gottesbild erkennen lassen, „das reicher und spannungsreicher ist, als es eine Etikettierung mit dem Stichwort Christologische Theozentrik erahnen lässt" (S. 127). Binitarische Gottesvorstellungen spielten gerade dort, wo das Christentum kaum Berührung mit dem Judentum hatte, so z. B. im babylonischen Judentum, anders als im palästinisch-rabbinischen Judentum, weiter eine große Rolle und kommen offenbar auch als Traditionen der johanneischen Gemeinde in der zweiten und dritten Abschiedsrede „nahezu ungefiltert nach oben“ (S. 146). Von einer Aufweichung des Monotheismus kann aber nach Theobald nicht gesprochen werden.

Drei weitere Beiträge widmen sich der Gottesfrage im Johannesevangelium im Zusammenhang mit paulinischem Denken. Einer beschäftigt sich mit der Frage nach dem Mittler und den Konsequenzen der Vermeidung dieses Begriffes für das johanneische Gottesbild, zwei weitere mit Gottes rekreatorischem Handeln.

Reinhard Feldmeier setzt sich in seinem Beitrag „Der Vater des Gottessohnes und der Vater der Gotteskinder" mit dem Begriff des Mittlers auseinander. Denn die Rede von Jesus als Mittler ,ist zumindest missverständlich und birgt die Gefahr, den soteriologischen Mehrwert preiszuge- 
ben, welchen die biblische Rede von Gott als Vater hat und den die Alte Kirche mit ihren oft so schwer nachvollziehbaren Streitigkeiten um die Trinität zu bewahren gesucht hat" (S. 148). Zunächst wird auf den christologischen Monotheismus des Paulus eingegangen, der den Begriff des Mittlers nur im negativen Sinn gebraucht, nämlich abwertend für Mose in Gal 3,19f. Das ist insofern erstaunlich als es gerade in der antiken Metaphysik die Einheit des Göttlichen ist, die nach einem Mittler verlangt, vorgestellt als daimones (halbgöttliche Mischwesen, die an göttlicher und menschlicher Sphäre Anteil haben). Die Dämonologie des Xenokrates war in neutestamentlicher Zeit gerade im Mittleren Platonismus weit verbreitet. Jesus wird nach dem Hymnus im Philipperbrief (Phil 2,6-11) aber gerade nicht als ein Zwischenwesen unter Gott installiert, sondern der Vater übererhöht den Sohn. Auch im Johannesevangelium bietet sich der Mittlerbegriff scheinbar an, widerspricht aber bei genauerem Hinsehen „dem Verhältnis von Vater und Sohn und dann auch dem zwischen dem Sohn und den Gläubigen" (S. 153f.). Für das Johannesevangelium greifen Kategorien der Über- und Unterordnung nicht, um das Verhältnis von Vater und Sohn zu beschreiben, dass „der eine im anderen gegenwärtig wird und beide so als ,Vater ' und ,Sohn' erst durch die Beziehung zum anderen ganz sie selbst werden. [...] Die strikte Unterscheidung von Vater und Sohn hat bei Johannes ihre Pointe nicht in der Trennung von dem einen Gott und seinem Mittler, sondern in der Begegnung von Vater und Sohn, sie zielt nicht auf ein Untereinander, sondern auf ein Ineinander." (S. 154) Nach Feldmeier ist diesbezüglich die Dynamik der johanneischen Gottes-Rede - v. a. in den Abschiedsreden - zu beachten, die die Verbundenheit von Vater und Sohn als ein Netz gegenseitiger Liebe beschreiben, in das auch die zu Jesus Gehörenden eingebunden werden.

Christiane Zimmermann geht in ihrem Beitrag „Gottes rekreatorisches Handeln bei Paulus und Johannes I: Das ,Lebendigmachen und das ,aus Gott/von oben Gezeugtwerden“" aus von der Tatsache, dass die Vorstellung, dass Gott der Schöpfer von Welt und Menschen ist, auch die Basis des göttlichen Handelns am und für die Menschen darstellt. „So ist es folgerichtig, dass die Christuserfahrung, die als fundamentale Neuäußerung Gottes gegenüber den Menschen verstanden wurde, ebenfalls in entsprechenden schöpferischen Bildern ausgedrückt wird.“ (S. 161) Zimmermann untersucht sodann zwei Lexeme dieses neuschöpferischen Agierens Gottes: Das erste - „lebendig machen“ - kommt sowohl bei Paulus (1 Kor 15,22; 2 Kor 3,6: Röm 4,17; 8,11) als auch Johannes (Joh 5,21; 6,63 ) vor. Ihre Auseinandersetzung mit den Stellen macht deutlich, dass bei beiden Autoren „Geist Gottes [...] das entscheidende Medium zur Par- 
tizipation an der Leben spendenden Macht Gottes und Christi“ (S. 173) ist, wenn auch in unterschiedlicher Form. Das zweite Lexem erscheint nur im Johannesevangelium: „aus Gott gezeugt-/geborenwerden“ oder „von neuem/von oben gezeugt-/geborenwerden“. Dabei ist auffällig, dass die Verben immer nur in passivischer Form erscheinen. Zimmermann bespricht vor allem den Prolog, der „nicht nur von der Exklusivität des Verhältnisses Gott-Logos, Vater und Sohn handelt, sondern eben auch von der Ermöglichung der Inklusion der Glaubenden in dieses Gottesverhältnis“ (S. 177), und Joh 3, wo die Frage des „Wie“ dieser Inklusion zum Thema zwischen Jesus und Nikodemus wird. Die Autorin macht deutlich, dass die beiden Metaphern „den Neuanfang der Beziehung Gottes mit den Menschen auf der Basis des Christusereignisses [verdeutlichen]", dieser „rekreatorische Akt“ Gottes als Vater ermöglicht den Menschen die "größtmögliche Nähe und Würde“ (S. 185f.).

Christina Hoegen-Rohls beleuchtet in ihrem Beitrag „Gottes rekreatorisches Handeln bei Paulus und Johannes II: ,Neue Schöpfung' und ,Ewiges Leben“" zwei nominale Ausdrucksformen in ihrer Bedeutung für die Gottesrede. Zunächst wird die „neue Schöpfung“ bei Paulus untersucht. Sie kommt an zwei Stellen - 2 Kor 5,17 und Gal 6,15 vor. Die genaue Betrachtung der beiden Stellen und ihrer unmittelbaren Kontexte durch die Autorin zeigt, dass "neue Schöpfung" ein Lexem der paulinischen Gottesrede ist und es um Gott als Schöpfer aus dem und durch den Tod geht. „Ewiges Leben“ begegnet sowohl bei Paulus als auch Johannes, wobei es bei Johannes mit 21 Belegen in Evangelium und erstem Brief weit häufiger vorkommt als bei Paulus (und den übrigen neutestamentlichen Schriften). Die fünf Belege bei Paulus in Röm 2,7; 5,21; 6,22f. und Gal 6,8 zeigen, dass Gott hier als „Heiligender und Richter Neuschöpfer seiner Geschöpfe“ (Röm) bzw. als „Rufender und Richtender Neuschöpfer seiner Geschöpfe" vorgestellt wird und es sich primär um ein zukünftiges Leben handelt. Was die Rede vom „ewigen Leben“ bei Johannes betrifft, macht Hoegen-Rohls deutlich, dass es sich dabei um einen zentralen Begriff der johanneischen Gottesrede handelt, insofern auch der Begriff „Leben“ allein synonym benutzt wird und sowohl auf den Bereich des Vaters und des Sohnes wie auch auf den Bereich der Menschen referiert. „[A]ls Lexem der Gottesrede im engeren Sinne, meint ,(ewiges) Leben' grundlegend das, was Vater und Sohn ausfüllt, was sie in sich tragen und besitzen[.]" (S. 215) Untersucht werden diesbezüglich dann Joh 5,26; 17,2; 1,4; 1 Joh 5,20; 1,2; 5,12; und Joh 3,15-18 sowie 3,36 und 5,24. Zudem verdeutlicht die Untersuchung der beiden Lexeme, dass „beide neutestamentlichen Theologen [...] in ihrer differenzierten 
Rede von ,neuer Schöpfung' und ,ewigem Leben' [spiegeln], dass Gott in seinem rekreatorischen Handeln nicht allein agiert" (S. 225), sondern dass die Person Jesu dabei eine - jeweils unterschiedliche - Rolle spielt.

Die beiden den Band abschließenden Beiträge setzen sich mit den weiteren Schriften des Corpus Johanneum auseinander:

Johannes Beutler widmet sich in seinem Beitrag ",Gott ist Liebe“ - Sinn und Bedeutung der zentralen Gottesprädikation im ersten Johannesbrief “ einer der drei Wesensbeschreibungen Gottes mit einem Wort, die sich im johanneischen Schrifttum finden (neben "Gott ist Geist" in Joh 4,24 und "Gott ist Licht" in 1 Joh 1,5). Gerade der zweifachen Aussage "Gott ist Liebe“ im ersten Johannesbrief (1 Joh 4,8.16) kommt bei der Frage nach dem Gottesbild bei Johannes eine besondere Bedeutung zu. Sie darf nach Beutler als ein "Spitzentext [...] des Neuen Testaments“ (S. 227) bezeichnet werden. Die Aussage und Einsicht, dass Gottes Wesen Liebe ist, hat eine lange biblische Tradition, wie ein Blick auf Dtn 6,4f. oder Dtn 7,12f. oder in die alttestamentlichen Prophetenbücher von Hosea bis Ezechiel zeigt. Ein Blick auf die Exegese Augustins von 1 Joh 4,8 schärft den Blick für die Aussage "Gott ist Liebe“ im Brief selbst, die Beutler in einer detailreichen Exegese erarbeitet. Überraschend ist dabei durchaus die Schlussfolgerung des Briefschreibers: „Die rechte Antwort der Gläubigen auf die erfahrene Liebe Gottes besteht zunächst nicht darin, dass sie nun ihrerseits Gott lieben, sondern darin, dass sie einander lieben." (S. 237) Beutlers Exegese zeigt, dass der Briefverfasser keine vom göttlichen Handeln absehende Wesensaussage Gottes machen wollte, sondern der liebende Gott als solcher nur in der Zuwendung zu den Menschen erkennbar ist - es handelt sich dabei um einen Weg von oben nach unten.

Jörg Frey schließlich beschäftigt sich in seinem Beitrag "Zwischen der Majestät auf dem Thron und dem Gott, der Liebe ist. Gott in der Johannesapokalypse und im Johannesevangelium" mit dem Gottesbild der Johannesoffenbarung und des vierten Evangeliums. Was die Apokalypse betrifft, werden der Gott Israels, die fundamentale Theozentrik, die zeitübergreifende Wirklichkeit und Geschichtsmächtigkeit Gottes, die Dualität von Gott und dem Lamm, die Weltherrschaft und das Weltgericht Gottes sowie Gottes Einwohnung in seinem Volk (Neuschöpfung und Vollendung) behandelt. Für das Johannesevangelium kommt ebenfalls der Gott Israels in den Blick, des Weiteren die Unsichtbarkeit Gottes und seine Offenbarung, sowie die Einheit von Vater und Sohn (Christozentrik und Theozentrik). Einen eigenen Aspekt bildet die bleibende Theozentrik. Auffällig für das Evangelium ist nach Frey das Zurücktreten anderer Gottesprädikate, wobei andererseits „doch eine größere Breite 
von Gottesaussagen erreicht [wird]“ (S. 269), was an den drei nominalen Gottesprädikationen (Geist, Licht und Liebe) deutlich wird. Die offensichtlichen Differenzen der beiden Bücher in ihrer Perspektive auf Gott sowie fundamentale Gemeinsamkeiten (Gott Israels, fundamentale Theozentrik und hohe Christologie) werden zusammenfassend dargestellt. Für den Autor fordert die sich daraus ergebende und nicht aufhebbare Grundspannung zwischen der Majestät auf dem Thron und dem Gott, der sich als Liebe erwiesen hat zur „theologische[n] Frage nach der Gewichtung dieser unterschiedlichen Aussagen innerhalb des biblischen Kanons und im Rahmen einer christlichen Theologie" (S. 275) heraus.

Der Titel des Symposions "Gott - allein“ wurde bewusst provokant formuliert, um zu vermeiden, dass die Überlegungen zum johanneischen Gottesbild wieder auf den gewohnten Schienen der Christologie fahren und unter dieser auch die Theo-Logie subsumiert wird. Klar ist, dass Gott im Johannesevangelium nie allein ist, weil er als liebender Vater immer schon in einem Beziehungsgeschehen steht und stehen will: zum Logos-Sohn Jesus und durch diesen zu den Gläubigen, seinen Kindern (vgl. Joh 1,12; 20,17). Im Bewusstsein dessen zeigen die Beiträge, dass die Theo-Logie im Johannesevangelium ein weiter zu bedenkendes Thema ist und nicht länger „neglected factor“ bleiben sollte. 


\title{
Gottes-Rede im Prolog des Johannesevangeliums
}

\author{
Erkundungen zum alttestamentlichen Hintergrund
}

\author{
Hermann Spieckermann
}

\section{Vorüberlegungen und Vorhaben}

Gott und Wort kommen nicht zum ersten Mal im Prolog des Johannesevangeliums zusammen. Beide sind bereits im Alten Testament eng und vielfältig aufeinander bezogen. Das Wort gilt als von Gott bevorzugtes Medium der Kundgabe seines Willens und seiner Wahrheit. Zugleich missbrauchen es unberufene Mittler im Dienst der Lüge. Obwohl die Prophetie viel über die Gefährdung des Wortes in der Spannung zwischen Wahrheit und Lüge weiß, wird dem Wort im Alten Testament hohe Wertschätzung zuteil. Dies gilt in seiner hebräischen wie griechischen Version. ${ }^{1}$ Den Logos-Spekulationen philosophischer Schulen in hellenistisch-römischer Zeit hat sich das Judentum vor Philo von Alexandrien nicht geöffnet. Zwar genießt schon in der älteren hebräischen Weisheit das rechte Wort Achtung, ${ }^{2}$ und Ansätze zu einer Wort-Gottes-Theologie finden sich vor allem im Bereich der Prophetie, ${ }^{3}$ des fortgeschrittenen

\footnotetext{
${ }^{1}$ Zum Wort in der hebräischen Überlieferung vgl. Gillis GerLeman, dābār, THAT 1 (1971) 433-443; Jan Bergman/Heiner Lutzmann/Werner H. Schmidt, dābōar , ThWAT II (1977) 89-133; zur griechischen Überlieferung vgl. Albert DebrunNer/Hermann Martin Kleinknecht/Otto Procksch/Gerhard Kittel/Gottfried Quell/Gottlob Schrenk, $\lambda \dot{\varepsilon} \gamma \omega$, $\lambda$ ó $о$ os, $\dot{\rho} \tilde{\mu} \alpha \kappa \tau \lambda$, ThWNT IV (1942) 69-147; zum philosophiegeschichtlichen Hintergrund in Verbindung mit dem biblischen Befund sowie Philo vgl. Gerard Verbeke/Jan-Adolf BüHNER, Logos, HWPh 5 (1980) 491-502; zu neueren hermeneutischen Annäherungen an das Wort vgl. Tilo Schabert/Rémi Brague (Hg.), Die Macht des Wortes, München 1996.

${ }^{2}$ Vgl. Spr 10,$19 ; 11,13 ; 12,6 ; 16,20 ; 24,26 ; 25,11$.

${ }^{3}$ Vgl. Jes 2,3 par. Mi 4,2; Jes 40,8; 50,4; 55,11; Jer 1,9; 5,14; 15,16; 23,28-30; Am 3,7 sowie die häufige Verwendung der Wortereignisformel „und es geschah das Wort JHWHs an ..." im Jeremia-, Ezechiel- und Sacharjabuch.
} 
Deuteronomismus ${ }^{4}$ und der Gebetsliteratur. ${ }^{5}$ Aber von einer elaborierten Theologie des Wortes kann nicht die Rede sein.

Will man einen paradigmatischen Mittler des Wortes Gottes benennen, ist es Mose, den die deuteronomistische Theologie zugleich zum Ahnherrn der Prophetie gemacht hat (Dtn 18,15-22; 34,10). Mit der hier dokumentierten Präferenz des durch Propheten vermittelten Wortes hängt gewiss zusammen, dass gerade diese Theologie das mit dem Wort rivalisierende Medium - das Bild - in Ausweitung des Fremdgötterverbotes strikt verbietet (Ex 20,3-6 par. Dtn 5,7-10). ${ }^{6}$ Doch wie wenig dadurch die Probleme lauterer Vermittlung von Willen und Wort Gottes aus der Welt sind, bezeugt dieselbe Literatur zur Genüge. Jesaja muss sich sagen lassen, dass sich Gott mit der Realisierung seines Willens beeilen möge (Jes 5,19), da seine Drohungen gegen die menschengemachten Pläne wirkungslos zu sein scheinen (Jes 29,15; 30,1); der junge Samuel, theologiegeschichtlich gesehen gelehriger Schüler des Mose und der Propheten, wird zum exemplarischen Empfänger des Gotteswortes in einer Zeit, in der sich keine Offenbarung Bahn bricht (prs Niphal; 1 Sam 3,1) und keiner da ist, der in die Bresche (peres) tritt (Ez 22,30; Ps 106,23; Sir 45,23); und schließlich sind für Kohelet alle Worte erschöpft, kein Gotteswort ordnet mehr die Fülle der Eindrücke und gewährt Erkenntnis (Koh 1,8), denn Gott selber sucht, was entschwunden ist (Koh 3,15).

Der Prolog des Johannesevangeliums hebt mit der Identität und Differenz von Wort und Gott, $\lambda$ ó ursprunghaftes Verhältnis zum Wort ( $\dot{\varepsilon} v$ ả $\rho \chi \tilde{n}$, Joh 1,1). Beide, Gott und

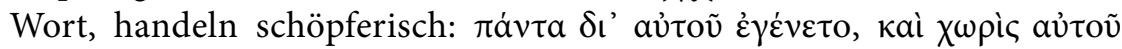

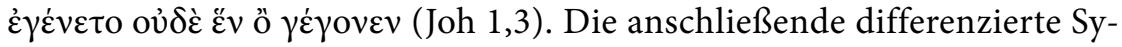
nergie von Wort, Leben und Licht gegen die Finsternis klingt ebenfalls protologisch (Joh 1,4-5), wird aber sogleich überführt in das Zeugnis des Täufers Johannes vom soteriologischen Handeln der Licht gewordenen Person, die schöpferisch handelt wie das protologische Wort (Joh 1,2.10), ohne dass ihr Name genannt würde. Aber das Licht ist schon transparent auf die Person, denn man kann doch allein $\delta \imath^{\prime}$ av̉ंoṽ (Joh 1,7) „durch ihn“, nicht etwa durch das Licht glauben. Den Menschen, die diese Licht-

\footnotetext{
${ }^{4}$ Dtn $4 ; 6,6 ; 9,5.10 ; 10,2-4 ; 13,1 ; 17,18-19 ; 27,3.8 .26 ; 28,58.69 ; 29,8.18 .28 ; 30,1.11-14 ;$ 1 Kön 17; 2 Kön 24,2.

${ }^{5}$ Vgl. Ps 33,4-6; 56; 105; 106,12.24; 119; 130,5; 147.

${ }^{6}$ Vgl. Walther Zimmerli, Das zweite Gebot (1950), in: Ders., Gottes Offenbarung. Gesammelte Aufsätze (TB 19), München ${ }^{2} 1969,234-248$; Matthias KöcKert, Die Zehn Gebote, München 2007, 55-65.
} 


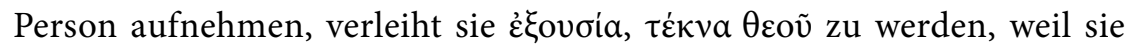
aus Gott geboren sind ( $\dot{\varepsilon} \kappa \theta \varepsilon \circ \tilde{v} \dot{\varepsilon} \gamma \varepsilon v v \eta \dot{\theta} \theta \eta \sigma \alpha v$, Joh $1,9-13$ ). Es ist diese Licht-Person in ihrer Identität mit dem protologischen $\lambda$ ó $\gamma$ oc, von der ge-

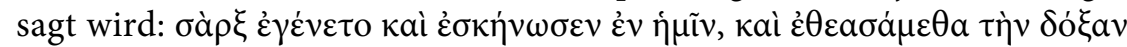

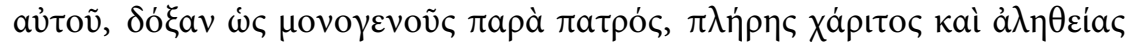
(Joh 1,14). Der Eigenname dieser Person, Jesus Christus, fällt dann zum ersten Mal zusammen mit dem Namen des Mose, beide Namen verbunden mit spezifischen Realitäten, die mit ihren Namen identisch sind:

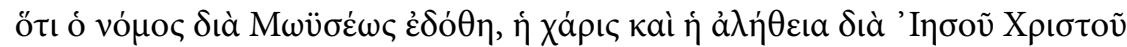

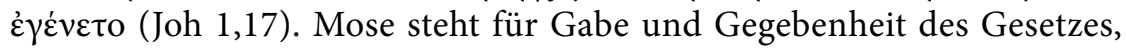
asyndetisch daneben Jesus Christus für das Gewordensein von Gnade und Wahrheit, ein Fleisch-Werden des protologisch-soteriologischen WortLichtes im Einziggeborenen, er selbst, Jesus Christus, Gott im Schoß

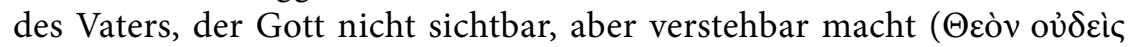

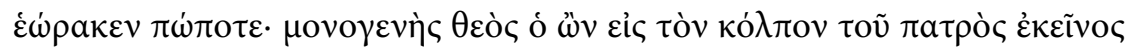

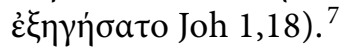

Kein Geringerer als Arnold Schönberg verdichtet das theologische Problem des Verhältnisses von Gott und Wort in seinem Werk „Moses

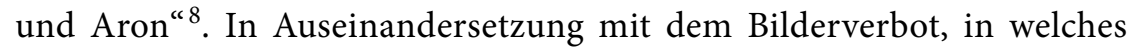
Schönberg auch die Problematik der Sprachbilder hineinnimmt, und unter verfremdendem Gebrauch der Erzählung vom Goldenen Kalb in Ex 32 stellt er sich an einem Wendepunkt in seinem Leben der Frage der Möglichkeit des Verhältnisses von Gott und Wort. Das Werk ist eine Herausforderung an die Theologie. Schönberg, 1874 in Wien geboren und 1951 in Los Angeles gestorben, 1898 zum Protestantismus konvertiert, aber nie davon überzeugt, ${ }^{9} 1916$ stolz darauf, Kaiser und Vaterland im Krieg gedient zu haben, muss im Sommer 1921 erleben, dass die Gemeindeverwaltung von Mattsee im Salzburger Land alle jüdischen Sommerfrischler zum Verlassen des Ortes auffordert. Nach längerem Vorlauf ringt Schönberg nun intensiv um sein jüdisches Erbe und rekonvertiert 1933 im

\footnotetext{
${ }^{7} \mathrm{Zu}$ Joh 1,1-18 vgl. Reinhard Feldmeier/Hermann Spieckermann, Menschwerdung (TOBITH 2), Tübingen 2017, 278-296 (dort weitere Literatur).

${ }^{8}$ Text: Arnold Schönberg, Moses und Aron. Oper in drei Akten, Mainz u. a. 1957. Das Werk, 1928 als Oratorium verfasst, war zunächst als Teil einer Trilogie geplant, die unvollendet geblieben ist. Schönberg hat das Oratorium zur eigenständigen Oper weiterentwickelt; auch für sie hat er den dritten Akt nicht vertont. Zu dem Werk und zum zeitgeschichtlichen Kontext vgl. Arnold Schönberg, Stile herrschen, Gedanken siegen. Ausgewählte Schriften, hg. von Anna Maria Morazzoni, Mainz 2007, 431-436; Eberhard Freitag, Arnold Schönberg (rm 202), Reinbek ${ }^{12} 2004$, 126-136; Alexander L. Ringer, Arnold Schönberg. Das Leben im Werk, Kassel 2002, 168-183.196-205.260-274.

${ }^{9} \mathrm{Vgl}$. SCHÖNBERG, Stile herrschen (Anm. 8) 432.
} 
Pariser Exil. Schönbergs „Moses und Aron“ ist ein Zeugnis dieses Ringens und seiner Auseinandersetzung um Identität und Aufgabe des Judentums in seiner Zeit.

„O Wort, du Wort, das mir fehlt!“ sind Moses letzte Worte am Ende des zweiten Aktes von Schönbergs "Moses und Aron“. Schon vorher wird seine Verzweiflung immer stärker, weil Moses Mund, sein Bruder Aaron, aus dem reinen, unvorstellbaren Gottes-Gedanken Bilder macht, die Mose für Götzenbilder hält. Dies manifestiert sich vor allem im Goldenen Kalb, dessen Anfertigung Aaron veranlasst hat (vgl. Ex 32,2-6). Aber in Moses Augen sind auch die Tafeln, die Wolken- und Feuersäule wie der Dornbusch metaphorische Repräsentationen Gottes, über die es zwischen Mose und Aaron zum Streit kommt. Es sind Bilder, so argumentiert Aaron, in denen der Ewige nicht sich, aber den Weg zu sich zeigt. Hingegen sind sie für Mose der Sündenfall der Verbildlichung Gottes. Diese Bilder - das Goldene Kalb ist allein deren unüberbietbare Perversion - treiben Mose zum Äußersten. Er zertrümmert die Tafeln. Er will Gott um Demission bitten. Und nach Aarons weiterem Plädoyer für die Unverzichtbarkeit der Bilder prallt Moses Ausruf „Götzenbilder" hart auf Aarons Antwort „Gottes Zeichen“. ${ }^{10}$ Für Mose wird der reine Gottes-Gedanke Wort im Gesetz. Dieses Wort ist Gottes-Rede im Sinne des genetivus subiectivus und des genetivus obiectivus. Im Wort sagt Gott den reinen Gedanken, und das Wort wahrt die Reinheit des Gottesgedankens. Für Aaron hingegen ist auch das Wort nur Bild - kein einschränkendes "nur“, sondern die einzig mögliche Option: Bild allein. Gottes Wort im Bild ist wie alle Bilder eine Notwendigkeit, „um für den Ewigkeitsgedanken zu zeugen“. Aaron sieht seine Bestimmung darin, das Wort „schlechter zu sagen, als ich es verstehe. Wissende jedoch werden ihn immer wiederfinden!“

„Läßt du diese Auslegung zu?“ fragt Mose Gott. „Darf Aron, mein Mund, dieses Bild machen?" Mose bedarf keiner Antwort Gottes mehr, denn jäh fährt in ihn die Erkenntnis, dass auch sein unvorstellbarer Gott, der unaussprechliche Gedanke, ein Bild ist. „So war alles Wahnsinn, was ich gedacht habe, und kann und darf nicht gesagt werden!" Der verzweifelt zu Boden sinkende Mose schreit „O Wort, du Wort, das mir fehlt! “11 Gibt Mose hier die gerade noch gebrauchte Anrede Gottes auf? Ist das

\footnotetext{
${ }^{10}$ SCHÖNBERG, Moses und Aron (Anm. 8) 29.

${ }^{11}$ Alle vorhergehenden Zitate: Schönberg, Moses und Aron (Anm. 8) 28-29. Mit dem letzten Zitat enden der zweite Akt und die Vertonung der Oper. Der dritte Akt, der nur aus einer Szene besteht und mit dem sich Schönberg immer wieder beschäftigt hat, enthält Aarons Tod. Moses erklärt die Wüste als Ziel des auserwählten Volkes für die Vereinigung
} 
jetzt angeredete Wort ein von Gott klar zu unterscheidender Adressat? Kann Mose überhaupt das Wort anreden, da es ihm doch fehlt? Das Wort, das vielleicht nicht nur im Moment fehlt, sondern ein Fehler des Denkens ist, das Gott im reinen, bildlosen Gedanken sucht?

Ist nicht Schönbergs Mose mit seinem Kampf für die Reinheit des Gottesgedankens im Wort der zwischen Nähe und Identität oszillierenden ursprunghaften Einheit von Logos-Wort und Gott im Johannesprolog verwandt? Und läuft nicht der Prolog auf eine Konstellation hinaus, die zumindest Affinitäten zu Schönbergs Gegensatz von Wort und Bild erkennen lässt? Schließlich ist nach Joh 1,17 das Gesetz als Inbegriff des Wortes Gottes durch Mose gegeben, während die Fülle von Gnade und Wahrheit in Jesus Christus fleischgewordenes Wort geworden ist. Klingt nicht auch diese in Joh 1,17 grammatisch unbestimmte Zuordnung wie ein Gegensatz? Wird man nicht fragen müssen, ob Moses Vermittlung des Wortes Gottes als Gesetz und die Fleischwerdung des Wortes in Jesus Christus eine Unvereinbarkeit darstellen, die Schönbergs Mose auf den Plan gerufen hätte, wenn er mit dieser Verbildlichung konfrontiert worden wäre?

Die Vorüberlegungen haben schlaglichtartig das Verhältnis von Gott und Wort im Alten Testament in den Blick genommen, ferner im Johannesprolog und schließlich in Schönbergs "Moses und Aron“, wo allein das Wort die Reinheit des Gottesgedankens gewährleistet, während das Bild welcher Art auch immer - Götzendienst ist. Unter dem theologisch unkonventionellen Warnzeichen dieses scharfsinnigen Denkers soll nun unter drei alttestamentlichen Aspekten noch einmal auf den Johannesprolog geblickt werden. Es wird der genaue Blick auf das Logos-Wort zunächst in seinem Verhältnis zur Schöpfung, sodann im Verhältnis zur Weisheit sein. Und schließlich gebührt dem Logos-Wort am Ziel des Prologs Aufmerksamkeit, wo es Fleisch im einziggeborenen Gott-Menschen Jesus Christus wird, verstanden als Menschwerdung der Fülle göttlicher Gnade und Wahrheit, dem das Gesetz-Wort des Mose asyndetisch voransteht. Man soll offenkundig verstehen, dass das Gesetz-Wort und das FleischWort nicht identisch sind und dass ihr Verhältnis der Anstrengung des Denkens bedarf. Die drei genannten Aspekte - Schöpfung, Weisheit und Fleisch im Verhältnis zum Logos-Wort Gottes - werden im Folgenden allein unter der Frage in den Blick genommen, was an dem jeweiligen Verhältnis alttestamentlich ist und was nicht alttestamentlich $\mathrm{zu}$ sein

mit Gott. Hier spiegeln sich Schönbergs Gedanken über die Zukunft des Judentums angesichts der zunehmenden Bedrohung durch den Nationalsozialismus. 
scheint. Wenn im Folgenden Altes Testament gesagt wird, ist immer die hebräische und die griechische Version gemeint, ohne dass auch nur eines der Probleme, die diese Vereinfachung auf eine Zweiheit in sich birgt, angesprochen werden könnte.

\section{Gott, Wort und Schöpfung}

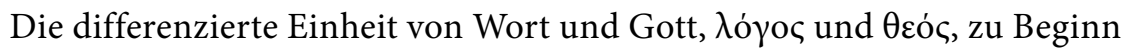
des Johannes-Prologs gemahnt an das Alte Testament. Aber es ist nicht leicht, genau den Prätext zu identifizieren, auf den sich Joh 1 stützt. Unabweisbar ist Gen 1 von Bedeutung. Beide Texte - Gen 1 und Joh 1 eröffnen große Erzählwerke mit einem unterschiedlich hohen Anteil an Reflexionstexten, die nicht selten als Reden gestaltet sind. Die priesterliche Theologie hat Gen 1 mit der Charakteristik des gebietenden, schöpferischen Sprechens Gottes ausgestattet, ohne dass von der eigentlich erwarteten Wurzel $d b r$,reden, sprechen“ bzw. von dābār „Wort“ Gebrauch gemacht würde. Das Pendant zum schöpferischen $\lambda$ ójoc in Joh 1 mag man in Gen 1 im Handeln des Schöpfers unter Gebrauch des Verbs bāra $\bar{a}$ „erschaffen“ erkennen, dessen Subjekt allein Gott ist. Der Schöpfungsakt entzieht sich jeder Anschauung, wie und wodurch Gott etwas erschafft. Man soll am Anfang von Joh 1 offenkundig ein Echo dieses priesterlichen Schöpfungsberichts hören, zumal gleich darauf der Gegensatz von Licht und Finsternis - in Joh 1 in dieser Reihenfolge entgegen der FinsternisLicht-Konstellation in Gen 1,2-5 - bedeutsam wird. Dass für Joh 1 in dieser Hinsicht Jes 9,1 weiterer Referenztext ist, steht außer Frage. Die Finsternis, die das Volk erleidet und in die das Licht Hoffnung bringt, hat die Dimension des Chaos vor der Schöpfung. Gottes schöpferisches Handeln wird in Jes 9 wie in Joh 1 in einen umfassenden soteriologischen

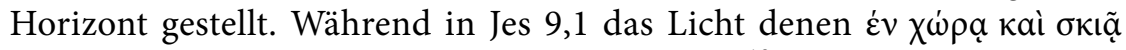
Өavátov „im Land und im Schatten des Todes“12 scheint, apostrophiert Johannes den Zusammenhang von Wort, Leben und Licht als protologisch-soteriologische Trias gegen die Finsternis (vgl. Lk 1,79; Mt 4,16). Dabei wird das Licht im folgenden Zeugnis des Täufers bereits unauffällig personalisiert (Joh 1,6-8), eine Vorbereitung auf die Person, die keine gnostische Lichtgestalt, sondern Fleisch gewordenes Wort sein wird.

\footnotetext{
${ }^{12}$ Dies ist die Wiedergabe der hebräischen Vorlage bĕ'eres salmāwet „im Land der Dunkelheit“. Unvokalisiertes ṣlmwt lässt sich leicht als șêl māwet "Śchatten des Todes" lesen.
} 
So deutlich Gen 1 und Jes 9 im Hintergrund des Anfangs des Prologs stehen, so sehr muss man im Blick behalten, dass die Schöpfungstheologie von Gen 1 bereits in Ps 33 eine theologische Vertiefung erfahren hat, die für Joh 1 entscheidend gewesen ist. Der Hymnus Ps 33 verbindet die Schöpfung mit einer umfassenden theologischen Wahrnehmung des Wortes Gottes. ${ }^{13}$ Gottes dābār „Wort“ steht in V. 4 in unübersehbar prominenter Position. ${ }^{14}$ Nach der Lobaufforderung an die șaddî̀îm „Gerechten" und yěšărîm „Aufrichtigen, Geradsinnigen“ in VV. 1-3 liefert es die Begründung dafür, dass JHWH das Lob gebührt. Sein Wort selbst ist nämlich $y \bar{a} s \bar{a} r$,aufrichtig" und identisch mit seinen Taten, die be ěmûnâ „in Treue" geschehen (V. 4). Gottes Wort wird Tat, gemeinsam bezeugen sie seine Geradheit - eine zur Gerechtigkeit gehörige Eigenschaft - und seine Verlässlichkeit. Deshalb wird sogleich in V. 5 die Trias genannt, die Gott in seinem Wesen und Wirken auszeichnet: hesed "Güte, verlässliche Liebe“, mišpāt „Recht" und șĕdāqâa „Gerechtigkeit" ${ }^{15}$ Diese Trias hat einen langen Vorlauf im Alten Testament und kann deshalb als theologische Konkretisierung dessen dienen, wofür in V. 4 das Wort Gottes steht.

In Ps 33 erfährt die Einheit von Wort und Tat Gottes nach der inhaltlichen Aufschlüsselung durch die theologische Trias in V. 5 ihre weitere Konkretion durch Gottes Schöpfung in VV. 6-9. In V. 6 wird Gottes gebietendem Reden und Wirklichkeit schaffendem Handeln wieder das Wort vorangestellt, das nun mit dem Geisthauch ( $r u \hat{a} a$, $\pi v \varepsilon \tilde{v} \mu \alpha$ ) seines Mundes identifiziert wird. Gottes Schöpfung ist Tat gegen das Chaos, dessen Bezwingung mit Anspielung auf den mythisierten Exodus und die analog mythisierte Jordanüberquerung gesagt wird (Ex 15,8; Ps 78,13; Jos 3,13.16). ${ }^{16}$ In Kenntnis deuterojesajanischer Theologie wer-

\footnotetext{
${ }^{13}$ In dieselbe Richtung denkt auch Ps 148; vgl. Hermann Spieckermann, Heilsgegenwart. Eine Theologie der Psalmen (FRLANT 148), Göttingen 1989, 50-59.

${ }^{14} D \bar{a} b \bar{a} r$,Wort" ist auch noch in V. 6 belegt; beide Male wird es in der Septuaginta mit $\lambda$ ójoc wiedergegeben.

${ }^{15}$ Mišspăt und șĕdāqâ stehen in engem Zusammenhang mit der Charakterisierung von Gottes Wort als y $y \bar{s} \bar{s} a \bar{r} r$, aufrichtig“ in V. 4, weil von der Wurzel $y \check{s} r$ auch das Nomen mêšă $r i ̂ m$ "Aufrichtigkeit" gebildet worden ist, dessen Semantik ganz in das Wortfeld der Gerechtigkeit gehört. Eine ähnliche Verbindung besteht zwischen 'ěmûnâ „Treue, Verlässlichkeit, Wahrheit" und hesed "Güte, Liebe" in VV. 4-5. Häufig wird hesed mit 'ěmet „Treue, Verlässlichkeit, Wahrheit" - semantisch nicht von 'ěmûnâ unterscheidbar - zu einem Wortpaar vereint (Ex 34,6; 2 Sam 2,6; Ps 25,10; 40,11-12; 85,11; 138,2 u. a.). Es ist also deutlich, dass Gottes Wort in Ps 33 die Funktion hat, zu konzentrieren, was in einer vorauslaufenden Theologiegeschichte als fundamentale Charakterisierung JHWHs erarbeitet worden ist; vgl. Reinhard Feldmeier/Hermann Spieckermann, Der Gott der Lebendigen. Eine biblische Gotteslehre (TOBITH 1), Tübingen ${ }^{2} 2017,130-140.261-263$.

${ }^{16} \mathrm{Vgl}$. Spieckermann, Heilsgegenwart (Anm. 13) 96-115.133-150.
} 
den auf diese Weise Protologie und Soteriologie eng verschränkt (vgl. Jes 41,17-20; 42,5-7; 43,1-7; 44,1-5.24-28; 51,9-11). Auf dieser Linie lässt Ps 33 im Folgenden keinen Zweifel zu, dass nur von JHWH und von keiner Macht dieser Welt Rettung zu erwarten ist (VV. 16-17). Dies gilt für die, auf denen JHWHs Auge ruht, nämlich denen, die auf seinen hesed hoffen (V. 18).

Die Angewiesenheit auf Gottes rettendes Wort wird in der Septuagintafassung von Ps 33 (32 LXX) durch die übliche Übersetzung von hesed "Güte, verlässliche Liebe“ mit ع̋ $\lambda$ عo „Erbarmen“ verstärkt (33/32,5.18.22). Selbst șĕdāqâ „Gerechtigkeit" wird in Ps 33/32,5 durch غ̇ $\lambda \varepsilon \eta \mu o \sigma u ́ v \eta$ „Barmherzigkeit“ wiedergeben. Ps 33 gehört in das Umfeld von Gebeten der fortgeschrittenen nachexilischen Zeit, die hesed gerne das Lexem rahămîm „Erbarmen, Barmherzigkeit“ beigesellen. Tritt dann noch das Lexem hnn/hannûn „gnädig (sein)“ hinzu, dokumentiert die Septuaginta ihre Entschlossenheit, alle hebräischen Lexeme mit dem Erbarmungsvokabular wiederzugeben. Als Beispiel sei Ps 51(50 LXX),3 genannt: "Gott, sei mir gnädig (hnn) nach deiner Güte (hesed) und tilge meine Sünden nach der Größe deiner Barmherzigkeit (rōb-rahămîm). “Septua-

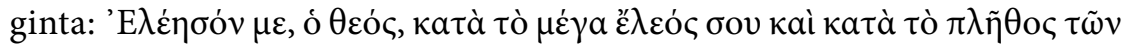

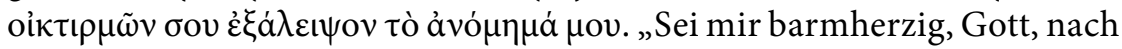
deiner großen Barmherzigkeit, und nach der Fülle deines Erbarmens wisch weg meine gesetzlosen Taten."

An dieser Stelle bleibt festzuhalten, dass Gott im Alten Testament nach dem Zeugnis gewichtiger, in der Regel exilisch-nachexilischer Texte seinen Willen kundtut, in erbarmungsvoller Liebe und Treue die Seinen aus Bedrohung und Schuld zu retten. Dafür stehen theologische Vorstellungen und Sprache bereit, die zumeist eine lange Vorgeschichte haben, unter denen jedoch die Wort-Theologie keinen angestammten Platz hat. Ihr Profil ist vor allem im Raum der prophetischen und der deuteronomistisch geprägten Schriften geschärft worden. Hier nehmen Gottes Rede und Gottes Wort eine zentrale Funktion im Gebot wie im Rückblick auf die leidvolle Geschichte des Ungehorsams und des Gerichts ein, nicht jedoch in Verbindung mit Gottes Rettungswillen und der Eröffnung von Hoffnung oder der Verheißung eines Neuanfangs. Vielmehr ist es

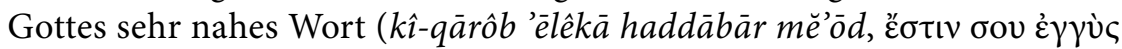

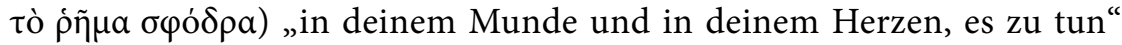
(Dtn 30,14). Es stellt Israel vor die grundlegende Entscheidung für das Leben und das Gute oder für den Tod und das Böse (Dtn 30,15). Mose beschließt sein Lied in Dtn 32 mit der Mahnung, „alle Worte dieser Wei-

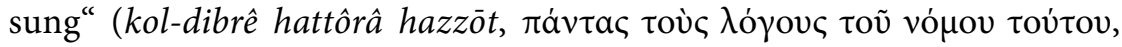


$32,46) \mathrm{zu}$ halten und $\mathrm{zu}$ tun, „denn dies ist kein leeres Wort für euch,

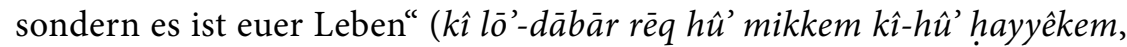

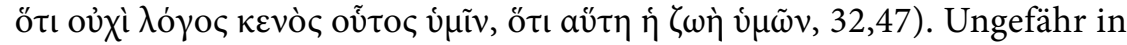
derselben Zeit, aber inhaltlich ohne erkennbare Verbindung steht diese Verheißung mit mahnendem Unterton neben der verheißungsvollen Got-

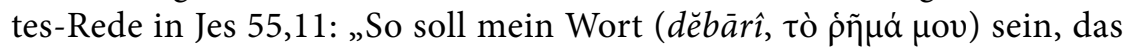
aus meinem Mund hervorgeht; es wird nicht leer zu mir zurückkehren $\left(l \bar{o}^{\prime}-y \bar{a}\right.$ šûb 'èlay rêqām $),{ }^{17}$ sondern es wird tun, was mir gefällt, und es wird ausführen, wozu ich es gesandt habe." In der hebräischen Fassung wird das Verheißungs-Wort zum handelnden Subjekt in Gottes Auftrag, und die Septuaginta wählt mit derselben Intention das passivum divinum ( $\sigma v v$ $\tau \varepsilon \lambda \varepsilon \sigma \theta \tilde{\eta})$. Aber ihr ist hier die gezielte Bevorzugung von $\lambda$ ó $\gamma$ oc gegenüber $\dot{\rho} \tilde{\eta} \mu \alpha$ noch fremd. Es wird im Folgenden zu untersuchen sein, ob es andere Vorstellungskonstellationen im Alten Testament gibt, die eine deutlichere Wort-Theologie in der Gottes-Rede erkennen lassen und deshalb eher in der Lage gewesen sein könnten, auf Joh 1 Einfluss zu nehmen.

\section{Gott, Wort und Weisheit}

Wie ist es überhaupt möglich gewesen, das in Joh 1 von Gott kaum zu unterscheidende Wort im Anfang mit der Fleischwerdung des Wortes im Einziggeborenen zu verbinden? Trotz der Vorbereitung im Johannesprolog ist und bleibt die Kunde von der Fleischwerdung des Wortes in Joh 1,14 ein Überraschungsmoment, welches eine jüdische Leserschaft mit einer eigentlich undenkbaren und blasphemischen Vorstellung konfrontiert. Es stellt sich die Frage, ob es für das Leben und Licht bringende Wort der Gottesgegenwart im Anfang Vorläufer, Vorbilder oder auch nur einen Anstoß in Traditionen des Alten Testaments gibt, die das Verstehen erleichtert haben könnten. Spr 8 und Weish 9 gelten als die Texte, die mit der in ihnen bezeugten prominenten Rolle der personifizierten Weisheit in unmittelbarer Nähe zu Gott für die Verbindung von Gott und LogosWort in Joh 1 als Vorbild gedient haben könnten. Auf diese Texte soll wiederum mit dem Blick des Alttestamentlers geschaut und geprüft werden, welches Rezeptionspotential sie für Joh 1 enthalten.

In Spr 8 wirbt die personifizierte Weisheit (hokmâ, Spr 8,1.12) um die Liebe der erkenntnishungrigen Menschen, denen sie selbst mit ihrer Liebe

\footnotetext{
${ }^{17}$ Die Septuaginta vermeidet die Rede vom nicht leer zurückkehrenden Wort: „es wird nicht zurückkehren, bis, was immer ich gewollt habe, erfüllt worden ist."
} 
in Gestalt ihrer Weg- und Lebenskunde entgegenkommt. ${ }^{18}$ Ihre Heilsgüter in Spr 8,1-21 stimmen mit denjenigen Gottes in Ps 33 weitgehend überein. Darunter sind Recht und Gerechtigkeit besonders prominent. Im Unterschied zu Ps 33 wird von der kognitiv und ethisch orientierten Weisheit in Spr 8 nicht Gottes hesed "Güte, verlässliche Liebe“ favorisiert. Aber die Worte ihres Mundes sind yāšār „geradesinnig“ (Spr 8,8-9), wie es das Wort JHWHs in Ps 33,4 ist. In der masoretischen Fassung wählt die redende Weisheit von Anfang bis Ende das Selbstlob, das zugleich ganz auf die angeredeten Weisheitssucher ausgerichtet ist und diese umwirbt. Die Weisheit will das Suchen derer mit dem Finden belohnen, die die Suche aus Liebe zu ihr unternehmen. Es gibt auch die Suche, die nicht von der Liebe zur Weisheit geleitet ist. Für diese Alternative gibt es klare und harte Worte. Sie gilt als bewusste Ablehnung der Weisheit, charakteristisch für Frevler und Verdrehte (Spr 8,7-8), die die Weisheit hassen, ihr eigenes Leben vergewaltigen und den Tod lieben (Spr 8,36).

JHWH hat im Selbstlob der Weisheit unproblematisch seinen Ort. In Spr 8,22-31 setzt sich die Weisheit zu JHWH in die denkbar prominenteste Beziehung. Er hat sie als rē'sìt darkô „Anfang seines Weges“ erworben/geschaffen (qnh, V. 22). „Ich bin von Ewigkeit her eingesetzt" (nsk Niphal), vor dem Anfang der Urzeiten der Erde (V. 23), hervorgebracht/ geboren (hyl Polal, VV. 24-25). Es ist deutlich, dass die Anknüpfung an Gen 1 und an die Einsetzung des Königs als Sohn Gottes auf Zion in Ps 2,6-7 gesucht und zugleich gründlich überboten wird. Hier präsentiert sich die Weisheit in singulärer Gottesnähe, nicht als Mitschöpferin, sondern als JHWHs Lieblingskind und zugleich als junge Frau, die dafür Sorge trägt, dass JHWHs Schöpfungswerk gelingt und dieses Gelingen zum allseitigen Ergötzen führt. Der von der Kind-Frau Weisheit animierte JHWH tut sein Werk mit Lust und Liebe. Deshalb können und sollen die Menschen die Weisheit lieben, denn sie hat dafür gesorgt, dass JHWHs Schöpfung zum Werk seiner Lust geworden ist. Die abschließend genannten Menschen sind Abglanz der Schöpferfreude, die die allzeit dem Schöpfer gegenwärtige Kind-Frau Weisheit durch ihr Spiel bewirkt hat und die sie besonders wegen der Menschen mit dem Schöpfer teilt. Auch darin ist ihre Stellung exponiert, ohne dass sie in Konkurrenz zum Schöpfer geriete. Das Gegenteil ist der Fall. Die Weisheit spielt auch darin dem Schöpfer in die Hände, dass er an seinen Geschöpfen Gefallen hat. Wer

\footnotetext{
${ }^{18} \mathrm{Zu}$ Spr 8 vgl. Hermann Spieckermann, Lebenskunst und Gotteslob in Israel. Anregungen aus Psalter und Weisheit für die Theologie (FAT 91), Tübingen 2014, 68-79; Feldmeier/Spieckermann, Menschwerdung (Anm. 7) 124-126.
} 
die Weisheit findet, findet Leben und erlangt damit „Wohlgefallen von JHWH“ (rāssōn $m J h w h$, Spr 8,35). Wie bedeutsam ist diese ursprunghafte Nähe von Gott und personifizierter Weisheit, der freilich die Identität mit dem Wort fremd ist, für Joh 1 ?

Die Septuaginta-Version von Spr 8 setzt gegenüber der hebräischen Fassung nicht signifikant andere Akzente, ist jedoch bestrebt, Gottes Stellung gegenüber der Weisheit deutlicher zur Geltung zu bringen. In der Septuaginta ist es am Anfang in Spr 8,1 nicht die Weisheit, die ruft, sondern ein nicht näher bestimmtes $\mathrm{Du}$ - von der hebräischen Verbform tiqrä' her durchaus möglich - eröffnet die Rede, die dann freilich wie in der hebräischen Vorlage ab V. 4 in die werbende Rede der Weisheit einmündet. Das gelingende Leben, das die Weisheit liebevoll den wahrhaft Suchenden schenkt (Spr 8,5-21), wird in der Septuaginta-Version durch den zusätzlichen V. 21a eng mit dem folgenden Abschnitt über die Erschaffung der Weisheit vor allen anderen Schöpfungswerken und ihrer Aufgabe bei der Schöpfung verbunden:

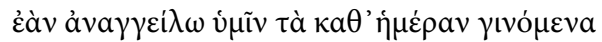

Wenn ich euch berichte von den Dingen, die täglich geschehen,

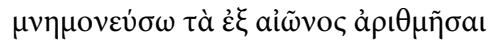

will ich zur Erinnerung (auch) das aufzählen, was von Ewigkeit her ist.

(Spr 8,21a LXX)

Es herrscht also eine Entsprechung zwischen dem protologischen Geschehen und dem, was jeder Weisheitsliebende in der Erkundung seines Lebensweges jeden Tag erfahren kann. Denn nach der Septuaginta-Version gilt:

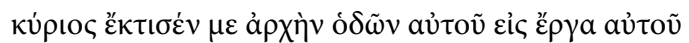

Der Herr hat mich erschaffen als den Anfang seiner Wege auf seine Werke hin.

(Spr 8,22 LXX)

Kennt die hebräische Vorlage in Spr 8,22 „am Anfang“ nur einen Weg Gottes, öffnet Gott nach der Septuaginta-Version in Gegenwart der Weisheit viele Wege, auf denen die bènê 'àdām/vioũ àv $\theta \rho \omega \dot{\pi} \omega \omega v$ „Menschen(söhne)" (VV. 4.31), wenn sie ernsthafte Weisheitssucher sind, Gott finden können. Deutlicher als die hebräische Vorlage sucht die griechische Version von Spr 8 die Nähe zu Gen 1, wenngleich die Erschaffung der Weisheit dort nicht vorkommt. Aber es ist ihre "Gründung“, die čv ả $\rho \chi \tilde{n}$ „,am Anfang“ geschieht (Spr 8,23), eine deutliche Aufnahme des Anfangs von Gen 1,1, verbunden mit der gezielten Präzisierung, nämlich die Einsetzung der Weisheit vor der Erschaffung von Himmel und Erde. Ihre 
gleichsam königliche Inauguration - als Akt des Zeugens bzw. Gebärens mit hyl Polal in Spr 8,24-25, mit $y l d$ Qal in Ps 2,7 formuliert - wird in der Septuaginta-Version von Spr 8 bewusst nicht weiter ausgeführt, denn das Königsein ist allein Gottes Sache. Doch ist die Weisheit zugegen,

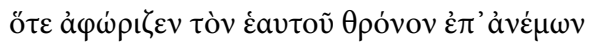

als er seinen eigenen Thron über den Winden aussonderte.

(Spr 8,27b LXX)

Spr 8,27b bietet eine vollständige Umdichtung der sich nicht leicht erschließenden hebräischen Vorlage: „als er einen Kreis über der Urflut schlug", womit wahrscheinlich die Festsetzung des Horizonts über der Urflut gemeint ist. ${ }^{19}$ Demgegenüber scheint die Septuaginta-Version die Vorstellung zu haben, dass an dieser Stelle etwas über die königliche Macht des Schöpfergottes stehen müsse, nichts hingegen über die Weisheit als Gottes Throngenossin. Die Weisheit genießt auch in der Septuaginta-Fassung hohe Achtung. Aber ihrer Unterscheidung von Gott gilt viel Aufmerksamkeit. Die griechische Fassung kennt nicht mehr wie die hebräische Vorlage die Weisheit als Gottes Liebling ('āmôn), die KindFrau, deren ergötzendes Spiel die Schöpferlust inspiriert, so dass das Werk gelingt, vor allem die Menschen, an denen die Weisheit ihre Lust hat (Spr 8,30-31 MT). Stattdessen sagt die Weisheit von sich in der Septua-

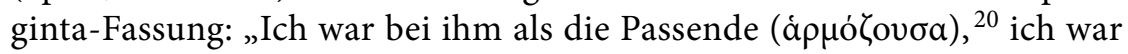
es, an der er seine Freude hatte. Täglich war ich jederzeit froh in seiner Gegenwart, wenn er sich freute, als er die Welt vollendet hatte, und sich an den Menschen(söhnen) freute" (Spr 8,30-31 LXX). Zwar bleibt die Weisheit Quelle der Freude Gottes, aber der Text findet mehr Worte für Gottes Freude an seiner Schöpfung und an den Menschen. Diesen Wege zum Leben nach Gottes Willen zu weisen, ist ihre Aufgabe, was selbst für die „Ausgänge des Lebens“ gilt (Spr 8,35 LXX). ${ }^{21}$

\footnotetext{
${ }^{19}$ Vgl. Wilhelm Gesenius/Rudolf Meyer/Herbert Donner, Hebräisches und Aramäisches Handwörterbuch über das Alte Testament, Berlin/Heidelberg ${ }^{18} 2013,328$ b.

${ }^{20}$ Also eine Person im Einklang mit Gott, vgl. Spr 19,14 und Takamitsu Muraoka, A Greek-English Lexicon of the Septuagint, Louvain u. a. 2009, 92a.

${ }^{21}$ Deutlicher als in der hebräischen Vorlage sind in der Septuaginta-Version Anfang

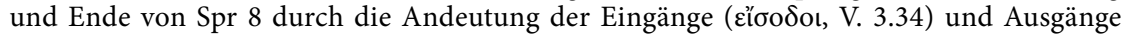
( $\check{\xi} \xi_{o} \delta o l$, V. 35) aufeinander bezogen. Die Weisheit singt ihr Lob „an den Eingängen“ der Stadt (V. 3). Die Eingänge haben in der Septuaginta ihr Pendant in den "Ausgängen“ in Spr 8,34-35 LXX - im Unterschied zur hebräischen Vorlage ( $m s^{\prime}$, nicht $\left.y s^{\prime}\right)$-, und zwar bei der Glückseligpreisung desjenigen, der bei der Weisheit eingetreten ist und der $\tau \eta \tilde{\omega} \nu \sigma \tau \alpha \theta$ -

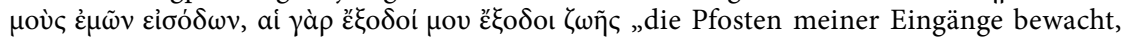
denn meine Ausgänge sind die Ausgänge zum Leben“. Dass auch sie im Zeichen des Lebens stehen, hat Gott den Weisheitssuchern beschieden.
} 
So sehr die personifizierte Weisheit in Spr 8 sowohl in der hebräischen wie in der griechischen Fassung durch ihre singuläre Stellung „als Anfang" bzw. „am Anfang" eine wichtige Funktion für die Beziehung des Schöpfers zu seiner Schöpfung, besonders zu seinen Geschöpfen hat, so sehr wird auf die Unterschiedenheit geachtet, weniger ausgeprägt in der hebräischen Vorlage, stärker in der Septuaginta-Fassung, wo die monarchische Superiorität Gottes gegenüber der Weisheit deutlich akzentuiert wird. Beide Fassungen scheinen als Vorbild für die Relation von Gott und Wort in Joh 1 nicht in Betracht zu kommen. Eine Beziehung zwischen Weisheit und Wort gibt es in Spr 8 überhaupt nicht. Die Theologie des schöpferischen Wortes, die in Ps 33 entwickelt wird, scheint Spr 8 fern zu liegen, obwohl beide Texte zeitlich kaum weit auseinander liegen. Man sollte deshalb in Ps 33 auch nicht zu schnell weisheitlichen Einfluss hineinlesen.

Die Verbindung von Gott, personifizierter Weisheit und Wort hat noch eine Weile auf sich warten lassen. Sie gewinnt in der Weisheit Salomos Gestalt, einem jüdischen Portreptikos wohl aus augusteischer Zeit, der nach außen für die jüdische Religion werben und nach innen das hellenistische Judentum stärken will. Für den Johannesprolog ist die Weisheit wahrscheinlich die weitaus bedeutsamste alttestamentliche Schrift. ${ }^{22}$

Man könnte sofort einwenden, dass zum einen der Johannesprolog

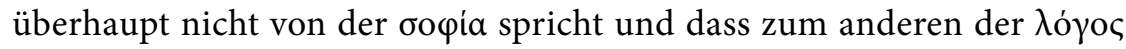
in der Weisheit Salomos keine zentrale Funktion hat, schon gar nicht in Verbindung mit der бopía. Wenn die бopía in der Weisheit Salomos einer Manifestation bedarf, dann leistet das $\pi v \varepsilon \tilde{v} \mu \alpha$ diesen Dienst, nicht der $\lambda$ dójoç. Diese Einwände haben Gewicht. Aber es ist doch dagegenzuhalten, dass die бopía in der Weisheit Salomos in einer engen Verbindung mit der Schöpfung steht und die Schöpfung ihrerseits ein soteriologisches Ziel hat, welches sie mit der oopia teilt. Diesen Zusammenhang stellt die Weisheit nicht in einem bestimmten Text konzentriert her, aber sie nutzt die Verbindung zwischen Schöpfung und Rettung unter Einbeziehung der allenthalben zentralen Thematik der Gerechtigkeit und der Gerechten für den Aufbau der Kapitel 1 - 10. Gleich in der programmatischen Einleitung Weish 1,1-15 wird die Aufforderung an die Herrscher der Erde, die Gerechtigkeit zu lieben (Weish 1,1), auf die Hilfe zugeführt, die die oọía

\footnotetext{
${ }^{22}$ Zur Weisheit Salomos vgl. die neueren Übersetzungen: Felix Albrecht, Die Weisheit Salomos, Göttingen 2015; Karl-Wilhelm Niebuhr (Hg.), Sapientia Salomonis/Weisheit Salomos (SAPERE 27), Tübingen 2015; vgl. ferner SPIeckermann, Lebenskunst (Anm. 18) 18-20.141-164; Feldmeier/Spieckermann, Menschwerdung (Anm. 7) 128-132.
} 
als $\varphi \iota \lambda \dot{v} v \theta \rho \omega \pi$ ov $\pi v \varepsilon \tilde{v} \mu \alpha$ leistet, wenn die Menschen - also nicht allein die Herrscher - es nur wollen (Weish 1,6). Die Menschen sind gefährdet, der Verblendung zu erliegen und mitten im Leben das Geschäft des Verderbens und des Todes zu betreiben. Dies ist zu vermeiden möglich, weil Gott alles zum Sein, also heilbringend, geschaffen und die unsterbliche Gerechtigkeit, nicht den Tod zum Zentrum seines schöpferischen Willens gemacht hat (Weish 1,12-15). Diesem göttlichen Willen dient der menschenfreundliche Geist der бopia.

Hier wie in Weish 6,1-21 wird die Weisheit zunächst in einer Weise charakterisiert, die an Spr 8 erinnert, ohne dass die Weisheit selbst wie in Spr 8 das Wort ergreift. Sie muss sich in der Weisheit nicht selbst rühmen, vielmehr wird sie im Enkomion Weish 7,22-10,21 von keinem geringeren als Salomo gelobt, welcher nicht mit Namen genannt wird, aber gut identifizierbar ist. Salomo wird mit seiner liebevollen Werbung um die Weisheit und seinem Streben nach Gerechtigkeit zum Vorbild für alle Herrscher der Erde. Die Charakterisierung der Weisheit, vor allem aber Salomos Werben um sie, setzt ihre Personifizierung voraus, ohne dass sie besonders apostrophiert wird, weil sie mit dem philosophischen Anspruch der Wesensschau der Weisheit in Spannung geraten könnte. Gerade diesem Ziel dient ihre Charakterisierung durch drei Mal sieben

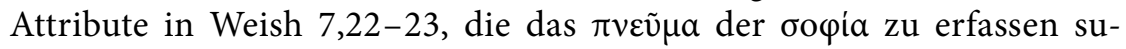

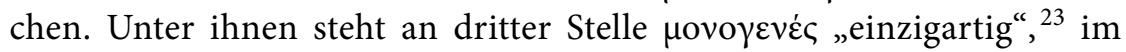

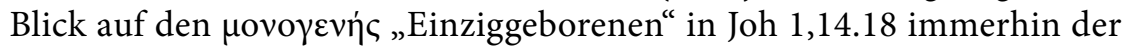
Beachtung wert, zumal in Weish 7,24-8,1 die Charakterisierung des Verhältnisses der Weisheit zu Gott und deren Wirkung auf die Welt folgt. Die Weisheit ist „Widerschein des ewigen Lichtes“ (Weish 7,26) und regiert alles $\chi \rho \eta \sigma \tau \tilde{\omega} \varsigma$,,in guter/gütiger Weise“ (Weish 8,1). Salomo begehrt

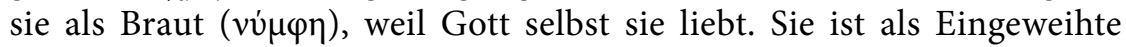

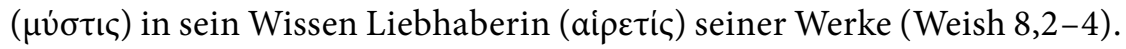
Salomo bittet den "Gott der Väter und Herrn des Erbarmens“ (Weish 9,1),

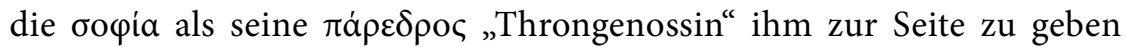
(Weish 9,4). ${ }^{24}$ Zusammen mit dem $\lambda$ ójoç ist sie Gottes Schöpfungswissen. Durch das Wort hat Gott das Ganze gemacht und durch die Weisheit den Menschen instand gesetzt, den Herrschaftsauftrag wahrzunehmen

\footnotetext{
${ }^{23}$ Die neutrische Form des Adjektivs resultiert aus dem Bezug auf das $\pi v \varepsilon v \tilde{\mu} \alpha$ der Weisheit. Es wird bei der Charakterisierung aus philosophischen Gründen favorisiert. Im Folgenden wird wieder unauffällig die personifizierte Weisheit in den Vordergrund gerückt, weil sich Salomo kaum in den Geist der Weisheit verlieben wird.

${ }^{24}$ Die Entsendung der Weisheit von Gottes Thron verdankt sich möglicherweise der Septuaginta-Fassung von Spr 8,27.
} 
(Weish 9,1-3). Nur an dieser Stelle werden Wort und Weisheit einander eng zugeordnet. Im Fortgang des Gebetes in Weish 9 ist es allein die Weisheit, die auf Grund ihres umfassenden Gotteswissens dem wissbegierigen Salomo eine Hilfe sein wird. Da sie bei Gottes Schöpfung anwesend

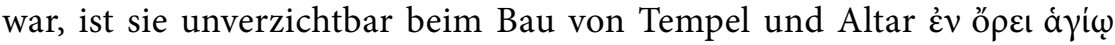

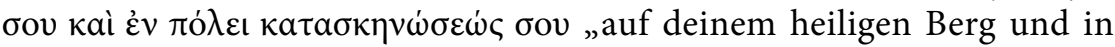
der Stadt deiner Einwohnung" (Weish 9,8) - der Tempel nichts weniger

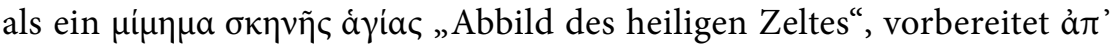

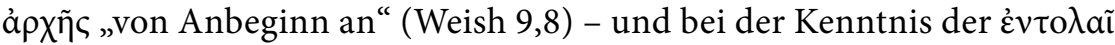

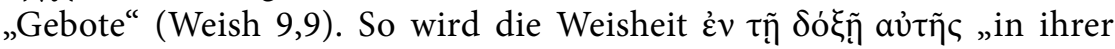
Herrlichkeit" Salomo bewahren (Weish 9,11), eine Herrlichkeit, die vom

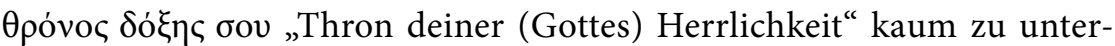
scheiden ist (Weish 9,10). ${ }^{25}$

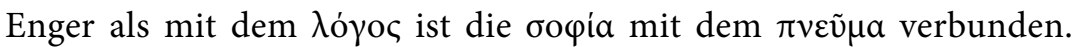
So endet Salomos Gebet in Weish 9,17-18 mit der Betonung der unabdingbaren Notwendigkeit der göttlichen Gabe der Weisheit an den König, wenn die Herrschaft gelingen soll. Die Gabe der Weisheit ist in

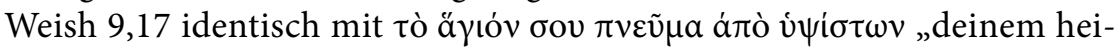
ligen Geist von den Höhen“. Und Geist und Weisheit sind nicht allein um der Herrschenden willen notwendig, sondern die Weisheit ist Gottes rettende Macht in der Welt (Weish 9,18). Die Rettung der Gerechten in der Geschichte des heiligen Volkes (Weish 10) wie die Rettung aller Gerechten ist Gottes Wille, weil $\sigma \omega \tau \eta \dot{\rho} \rho เ$ ai $\gamma \varepsilon v \varepsilon \dot{\sigma \varepsilon \varepsilon \varsigma ~ \tau o v ̃ ~ k o ́ \sigma \mu o v ~ „ d i e ~ S c h o ̈ p f u n g e n ~}$

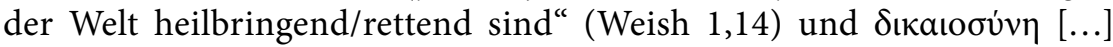

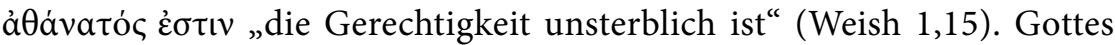
Rettungswille wird in konkreten Rettungstaten immer wieder kontingent erfahrbar, doch die konstante Evidenz seiner Hilfe hängt am Lob der ge-

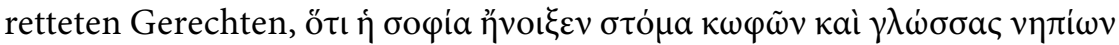

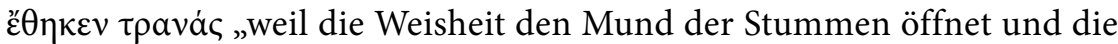
Zungen der Unmündigen klar reden lässt" (Weish 10,21). ${ }^{26}$

\footnotetext{
${ }^{25}$ Auch in Joh 1,14 wird von der Zelt-Vorstellung bei der Fleischwerdung des Wortes als Zeichen wahrer Gottespräsenz Gebrauch gemacht. Man wird sorgsam abwägen müssen, inwieweit dabei priesterliche Herrlichkeitstheologie in Verbindung mit dem Zelt der Begegnung als Prätext dient, oder nicht eher Vorstellungen von der personifizierten Weisheit, die Gott in Sir 24,8-11 im heiligen Zelt dient und deren Herrlichkeit in Weish 9,10-11 derjenigen Gottes zum Verwechseln ähnelt.

${ }^{26}$ Es wäre der Untersuchung wert, ob und in welcher Weise es eine Beziehung von Weish 10,21 zu Spr 31,8-9 gibt. Die hebräische Fassung bietet: „(8) Öffne deinen Mund für den Stummen, für das Recht aller Schwachen. (9) Öffne deinen Mund, schaffe Gerechtigkeit und sprich Recht dem Elenden und Armen. “Die Septuaginta setzt einen neuen Akzent: „(8)

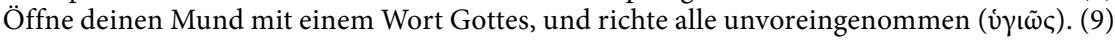


Die Weisheit Salomos wird durch ihre Verbindung von Gott, personifizierter Weisheit und Schöpfungswort ein wichtiger Prätext für Joh 1 gewesen sein. Zugleich hat ein Blick in das theologische Beziehungsgefüge der Weisheit Salomos deutlich werden lassen, welche prägende Kraft in ihr die Verbindung von Weisheit und Gerechtigkeit hat, die Joh 1 fern liegt. Doch dass die personifizierte Weisheit das personifizierte Wort in Joh 1 -

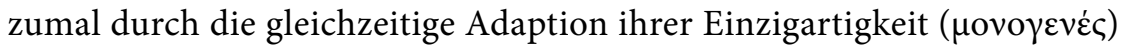

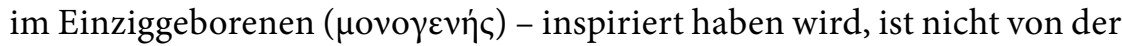
Hand zu weisen.

\section{Wort und Fleisch, Gnade und Wahrheit}

Die Verbindung protologischer und soteriologischer Vorstellungen ist dem Alten Testament in der ganzen Spannweite von der hebräischen bis in die hellenistisch-jüdische Tradition seit der Exilszeit nicht fremd.

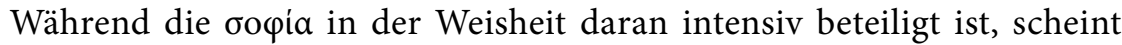
dem $\lambda$ ó $\gamma$ oc in diesem Zusammenhang abgesehen von Ps 33 keine signifikante Bedeutung zugekommen zu sein. Es sind wenige weitere Psalmen zu nennen, in denen Gottes dābār „Wort" eine Hoffnung stiftende Funktion

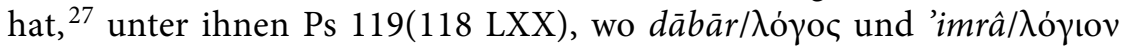
eine prominente Stellung einnehmen. Ps 119, hochwahrscheinlich einmal einer der Psalmen, der in Korrespondenz zu Ps 1 eines der vielen Vorstadien des werdenden Psalters abgeschlossen hat, ist wie Ps 1 ein Tora-Psalm, der unter einer Reihe bekannter Synonyma für Tora zum Gehorsam gegenüber den Geboten anhält, aber zugleich die Verheißung und Hoffnung betont, die in der Bindung an die Tora liegen. Dafür stehen

Öffne deinen Mund und richte gerecht; sprich Recht dem Armen und Schwachen." Hier gewährleistet das Wort Gottes die Wahrung des von Menschen gesprochenen Rechts. Der Bezug auf Gottes Wort in der griechischen Fassung hat Gewicht, denn im hebräischen wie im griechischen Sprüchebuch ist die Vorstellung vom Wort Gottes selten. Dies gilt auch für die Weisheit Salomos. Nach Weish 9,1-3 muss man auf die nächste gewichtige Aussage

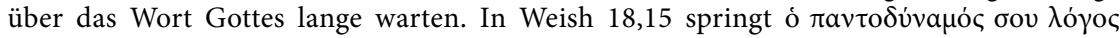

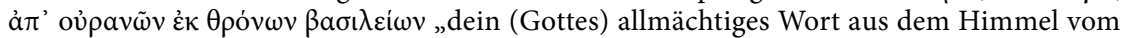
königlichen Thron", um als schrecklicher Krieger Gericht zu halten. Dies ist eine singuläre Formulierung, die kaum mit der Weisheit als Throngenossin Gottes und dem ihr nahen Schöpfungswort in Weish 9 eine enge Verbindung hat.

${ }^{27}$ Es sei auf die Sequenz Ps 105-107 hingewiesen, aber auch auf Ps 56, wo das Lob des Wortes und das Vertrauen auf Gott die Furchtlosigkeit gegen bāśār „Fleisch“ und 'ādām „Mensch“ begründen (Ps 56,4-5.11-12). Eine ähnliche Antithese bietet Jes 31,1-3.

Ps 19(18 LXX) macht die theologische Spannung von Wort und Tora zum Thema. Die Gedankenführung des Psalms dokumentiert, dass es hier keine einfache Lösung gibt. 


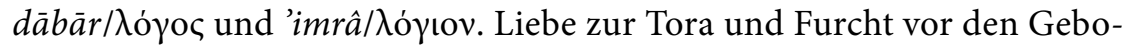
ten der Tora stehen in Ps 119 dicht beieinander (Ps 119,119-120), wobei $b \bar{a} s \bar{a} r$ "das Fleisch“ die Verführbarkeit des Menschen repräsentiert, der in Furcht vor Gottes Geboten lebt (V. 120). Doch die den Menschen zu Gott treibende Liebe ist die größere Macht. Sie lehrt die Einheit von gebietender Tora mit dem Rettung, Hoffnung und Leben gewährenden Wort

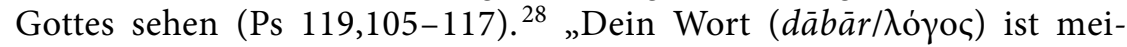

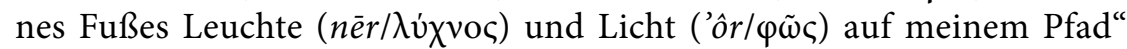

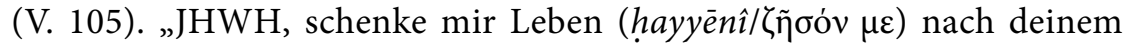

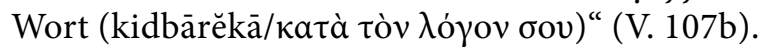

Diese Verbindung von Tora mit Rettung, Hoffnung und Leben muss in Joh 1,17 bei der Konstellation von Mose-Gesetz und Gnade und Wahrheit in Jesus Christus bedacht werden. Ihr folgt in Joh 1,18 die Betonung, dass niemand Gott je gesehen hat. Dies erinnert an Dtn 4, wo von Gott keine Gestalt zu sehen, wohl aber seine Stimme im Wort und in den Worten $\mathrm{zu}$ hören war (VV. 12.15). Und dieses Wort ist als Gottes Tora durch niemand anderen als Mose gegeben. So sind Tora und Wort bei Mose nahe beieinander, aber das Fleisch ist fern. Das Fleisch wird im engen Zusammenhang mit Dtn 4 in Dtn 5,26 erwähnt: „Denn wer von allem

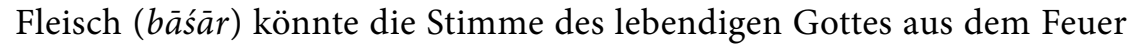
heraus reden hören, wie wir, und am Leben bleiben?" Es ist bereits die Auszeichnung des Gottesvolkes, dass es nicht einfach mit dem Fleisch gleichzusetzen ist und deshalb die Stimme des lebendigen Gottes ohne Verlust des Lebens hören kann. Hat dies für Joh 1,14 Bedeutung?

Die Verbindung von $\lambda$ ó $\gamma \circ \varsigma$ und $\sigma a ́ \rho \xi$, wie sie im Zentrum von Joh 1,14 steht, setzt vor allem die jüdische Sicht des Fleisches als Ort der Schuld und der Gottesferne des Menschen voraus. Kontrafaktisch wird in Joh 1,14 gerade dieses Fleisch zum Ort der Menschwerdung Gottes gemacht. Zwar kann bāśār, in der Septuaginta ganz überwiegend durch $\sigma \alpha \dot{\rho} \rho \xi$ wiedergegeben, auch wertneutral alle Geschöpfe umfassen, doch vornehmlich sind alle Menschen im Blick, wenn es um ihr Schuldigwerden und ihre bewusst gesuchte Gottesferne geht. Beginn und Ende der priesterlichen Sintfluterzählung in Gen 6,9-13 und 9,11-17 vermögen dies gut zu illustrieren. Als Urheber der Verdorbenheit und Gewalt, welche die Erde füllen, wird kol-bāśār „alles Fleisch“ benannt, das

\footnotetext{
${ }^{28} \mathrm{Zu}$ Ps 119 vgl. Hermann Spieckermann, What is the Place of Wisdom and Torah in the Psalter?, in: Scott C. Jones/Christine Roy Yoder (Hg.), „When the Morning Stars Sang“ (FS Choon Leong Seow) (BZAW 500), Berlin/Boston 2017, 291-320, 314-317; vgl. ferner Ps 130,$5 ; 147,15-20$.
} 
seinen Wandel verdorben hat. Unter kol-bāśār werden auch die Tiere subsummiert, die wie der Mensch rûah hayyîm/ $\pi v \varepsilon \tilde{u} \mu \alpha \zeta \omega \tilde{\eta} \varsigma$ verliehen bekommen haben (Gen 6,17). ${ }^{29}$ Die Sintflut soll die Schuldverfallenheit von „allem Fleisch“ aus der Welt schaffen, vermag es aber nicht, weshalb das Fleisch theologisch eine Herausforderung bleibt. In Joël 3,1 sagt Gott als Zeichen der grundlegenden eschatologischen Wandlung zu: „Ich werde ausgießen rûĥ̀ 'al-kol-bāśär meinen Geist über alles Fleisch“, eine Erwartung, die die Wiedergabe in der Septuaginta etwas abschwächt:

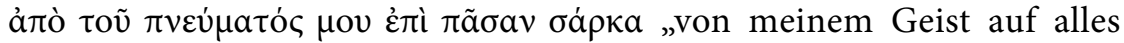
Fleisch" (vgl. auch Joël 3,2). Der Gedanke der Begrenzung ist nicht erst in der griechischen Übersetzung aufgekommen. Er bestimmt schon die folgende Szenerie des Tages JHWHs in Joël 3,3-5. „Alles Fleisch“ kann nicht dem Gericht entgehen. Rettung wird mit der Anrufung JHWHs verbunden, welche auf Zion und in Jerusalem ihren Ort hat.

Eine positive Bestimmung erfährt das Fleisch in den Verheißungen des Ezechielbuches. In Ez 37 sagt Gott dem zu einem Knochenhaufen verdorrten Israel die Restitution zu: „Ich gebe euch Sehnen und lasse Fleisch wachsen an euch, und ich überziehe euch mit Haut und lege Geist in euch, und ihr werdet leben, und ihr werdet erkennen, dass ich JHWH bin" (Ez 37,6; vgl. 37,8). Das Fleisch ist integraler Bestandteil des Körpers und gehört zu seiner Restitution und dem göttlichen Geschenk des Lebens unabdingbar hinzu. Aber das Fleisch hat in Ez 37 keine größere Bedeutung als Haut und Sehnen. Hingegen gewinnt das Fleisch theologisches Gewicht in der zweimaligen Verheißung des neuen Geistes und des Herzensaustausches in Ez 11 und Ez 36:

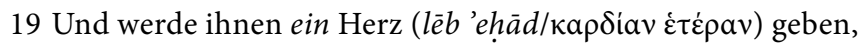

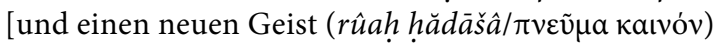

werde ich in euer Inneres geben,]

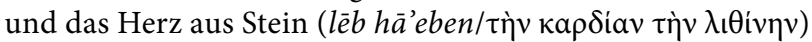

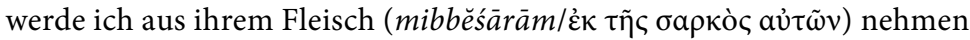

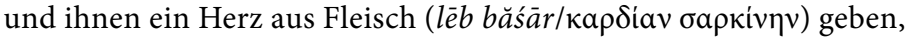

20 damit sie in meinen Satzungen wandeln und meine Gebote halten und sie tun. Und sie sollen mir Volk sein, und ich will ihnen Gott sein.

(Ez 11,19-20)

\footnotetext{
${ }^{29}$ Auf diesem Hintergrund können dann später rûah und bāśār in der Anrede 'ělōhê hārûhōt lěkol-bāśár „Gott der (Lebens-)Geister alles Fleisches“ als positive Charakterisierung des Schöpfers kombiniert werden (Num 16,22; 27,16; ähnlich, aber negativ konnotiert Ps 78,39; Ijob 12,10). In Sir 45,1 findet Mose sogar $\chi$ ápıc "Gnade“ in den Augen alles Fleisches. Eine signifikante Ausweitung des theologischen Gebrauchs der rûhōt „Geister“ im positiven wie im negativen Sinne findet in den Qumranschriften statt. Die hier angedeuteten Entwicklungen sind zum Verständnis von Joh 1 irrelevant.
} 


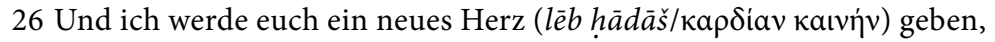

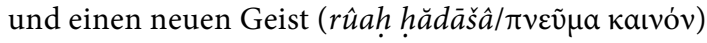
werde ich in euer Inneres geben,

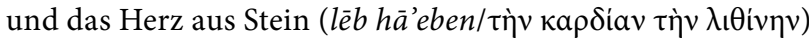

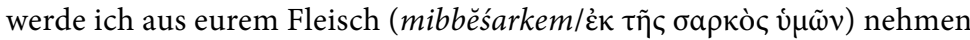

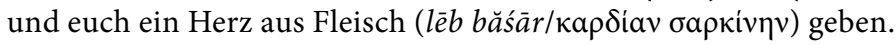

27 Und ich werde meinen Geist in euer Inneres geben und ich werde bewirken, dass ihr in meinen Satzungen wandelt und meine Gebote haltet und tut.

28 Und ihr werdet in dem Lande wohnen, das ich euren Vätern gegeben habe. Und ihr werdet mir Volk sein, und ich will euch Gott sein.

(Ez 36,26-28)

Literarische Genese und literarischer Zusammenhang beider Texte im Ezechielbuch brauchen hier nicht eingehend thematisiert zu werden. ${ }^{30}$ Die folgenden Überlegungen konzentrieren sich allein auf den Austausch des Herzens. Diesen verheißt Gott in Ez 11 offensichtlich in einer weniger geglätteten und deshalb wohl älteren Version als Ez 36. Es liegt auf der Hand, dass in Ez 11,19 die Erwähnung des neuen Geistes aus Ez 36,26 später nachgetragen worden ist. Ez 11,19 konzentriert sich ursprünglich allein auf „das eine Herz", das JHWH geben will, wie er selbst nach Dtn 6,4 einer ist. Der Jhwh 'ehād will im lēb 'ehād gegenwärtig werden. ${ }^{31}$ In Ez 36,26 ist diese Anspielung als zu schwer verständlich erachtet und deshalb lēe 'ehāad gegen lēb hạdāǎ ausgetauscht worden, so dass das Herz neu wird wie der in Ez 36 ohnehin favorisierte Geist.

Dieses Herz wird ein „Herz aus Fleisch“ sein. Das Herz aus Fleisch hat nichts gemein mit dem Herzen, das Gott aus dem Fleisch entfernt hat. Es ist das Herz einer neuen Menschwerdung. ${ }^{32}$ Ez 36,26 sagt dies durch das doppelte Neuwerden des Geistes und des Herzens. Ez 11,19 sagt es noch pointierter allein durch den Herzensaustausch. Ez 11,19 ist vielleicht der alttestamentliche Text, der der Fleischwerdung des Wortes Joh 1,14 am nächsten ist - im Modus der Verheißung, nicht der Realisierung. Ohne

\footnotetext{
${ }^{30}$ Vgl. Anja KLEIN, Schriftauslegung im Ezechielbuch. Redaktionsgeschichtliche Untersuchungen zu Ez 34-39 (BZAW 391), Berlin/New York, 2008, 59-111.140-169.270-348.

${ }^{31}$ Der Septuaginta-Übersetzer des Ezechielbuches verfolgt die Absicht, den Unterschied zwischen dem „Herzen aus Fleisch“ und dem aus dem Fleisch genommenen „Herzen aus Stein" zu verdeutlichen. Vielleicht hat er an der Stelle Ez 11,19 eine hebräische Vorlage gehabt, an der er leicht lesen konnte, was er lesen wollte: nicht lēb 'ehād „ein Herz", sondern

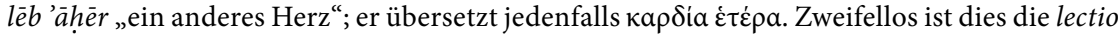
facilior; theologisch sagt sie weniger als lēb 'ehād.

${ }^{32}$ Das Pendant zu den Ezechiel-Stellen bietet Ps 51,12-14, die Neuschöpfung des reinen Herzens und die dreifache Geist-Gabe. Sowohl diese Psalm-Stelle wie die beiden Ez-Stellen sind kühne Entwürfe erbetener und erhoffter Neuwerdung, die sich ähneln, aber dann auch wieder eine beachtliche Eigenständigkeit haben.
} 
die Verheißung des neuen Bundes in Jer 31,31-34 wären die Verheißungen Ezechiels in Ez 11 und $\mathrm{Ez} 36$ kaum denkbar. Wahrscheinlich lässt Ezechiel die Vorstellung aus Jer 31,33, dass JHWH die Tora auf das Herz der Israeliten schreiben und dadurch jede vermittelnde Instanz ausschließen will, bewusst hinter sich. Das Herz muss allererst ausgetauscht bzw. neu werden. Und es ist nicht die Tora, die im Ezechielbuch im Zentrum steht, jedenfalls nicht im Sinne eines Verheißungsgutes. Die Priester haben "meine Tora" entweiht, sagt JHWH (Ez 22,26; vgl. 7,26). Und im ezechielischen Verfassungsentwurf gibt es die tôrat habbayit „die Weisung (für die Anfertigung) des (neuen) Tempels" (Ez 43,12), die gemäß dem priesterlichen Sprachgebrauch aus vielen tôrōt „Einzel-Weisungen“ besteht $(\mathrm{Ez} 43,11 ; 44,5.24)$. Allein diese sechs Belege für Tora gibt es im Ezechielbuch. Sie haben mit dem analogielosen Austausch des Herzens aus Fleisch gegen das Herz aus Stein als neue, also nicht an den Tempel gebundene Ermöglichung der Gottesgegenwart in Israel nichts zu tun. Der Verfassungsentwurf in Ez 40-48 macht das Ezechielbuch zu einem theokratischen Entwurf chronistischer Prägung. Dadurch sind die kühnen Erwartungen des neuen Hirten (Ez 34), des einen, neuen Herzens aus Fleisch ohne Tora-Einschreibung (Ez 36) und der Auferstehung Israels zu neuem Leben (Ez 37) priesterlich-tempeltheologisch eingeholt worden.

Das neue Herz aus Fleisch in Ez 11 und Ez 37 wird man nicht als die unabdingbare Voraussetzung für die Vorstellung der Fleischwerdung des Logos in Joh 1,14 betrachten können. Aber unter den Verheißungen des Neuwerdens des Verhältnisses zwischen Gott und Israel im Alten Testament ist das Herz aus Fleisch eine unerwartete und einschneidende Wendung, die der Überraschung der Fleischwerdung des Wortes im Johannes-Prolog nahekommt. In diesen Zusammenhang gehört auch, dass die Fleischwerdung sogleich mit dem Status des Einziggeborenen von Gott-Vater verbunden wird, ein deutlicher Hinweis, dass die Fleischwerdung des Wortes nur als singuläre Personifizierung der Fülle göttlicher Gnade und Wahrheit angemessen verstanden wird. Sie ist von Gott her kein kontingentes Geschehen, sondern providentielle Tat, die in Raum und Zeit realisiert, was die unvergleichliche Nähe von Gott und LogosWort von Anfang an impliziert hat (Joh 1,15). Dass die Fleischwerdung des Wortes das endgültige Wahrwerden dieser Nähe ist, lässt sich daraus ersehen, dass die Fülle der Gnade und Wahrheit im Alten Testament eine der häufigsten Charakterisierungen von Gott selbst ist, auf

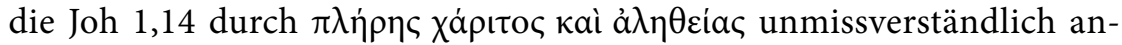
spielt. Im Alten Testament handelt es sich unter anderem um die Formel rab-hesed we'émet „voller Güte/Liebe und Wahrheit“ (Ex 34,6; Ps 86,15; 
vgl. Joël 2,13; Jona 4,2; Ps 51,3; 69,14.17; 86,5; 103,8; Klgl 3,32; Neh 9,17; 13,22). Sie wird im fleischgewordenen, von Anfang an bestimmten Einziggeborenen wahr. Es ist kein Gegenargument, dass die hebräische For-

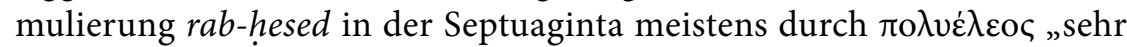
barmherzig" und zuweilen hinzutretendes 'ěmet durch ả $\lambda \eta \theta$ vós „wahr-

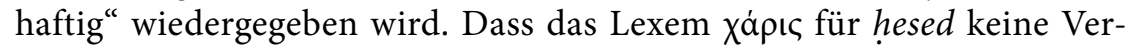
wendung findet, hat seinen Grund darin, dass es dominant für die Übersetzung von hẹen "Gnade, Gunst" gebraucht wird. Aber bereits gegen die Zeitenwende dokumentiert die Weisheit Salomos als genuin helle-

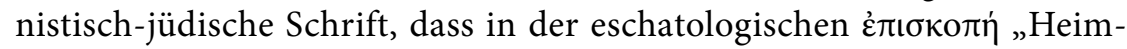

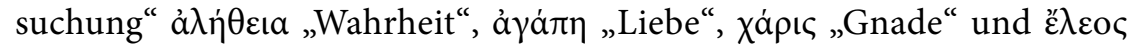
„Erbarmen“ bei denen sind, die Gott in diesem Leben die Treue bewahrt haben (Weish 3,9.13; 4,15). Ihre liebevolle Heimsuchung durch Gott ist die Konkretisierung des Seins „im Frieden“ $(3,3)$ und die Erfüllung ihrer Hoffnung, die schon in der Zeit der Bedrängnis „voller Unsterblichkeit“ gewesen ist $(3,4)$. Nicht von ungefähr ist die Weisheit Salomos zugleich

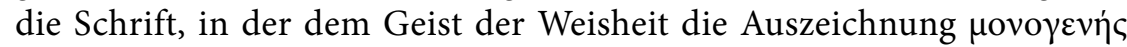
„einzigartig, einziggeboren“ zugesprochen wird. Aufgrund seiner Unbeflecktheit und Reinheit vermag er überall einzudringen (Weish 7,22-25); Er ist „Glanz des ewigen Lichts und unbefleckter Spiegel der Kraft Gottes und Bild seines Gutseins“ $(7,26)$.

Dieser Deutungshorizont ist für Joh 1,14 genauso wichtig wie die unüberhörbare Anspielung auf die Gegenwart der Herrlichkeit ( $k a \bar{a} b o \hat{d}$,

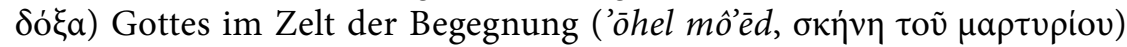

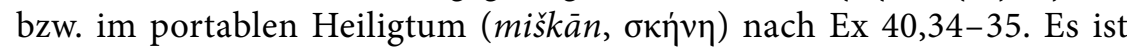
sehr wahrscheinlich, dass die göttliche Einwohnung in Joh 1,14 nicht direkt auf Ex 40 als Prätext zurückgeht, sondern in einer Konstellation wahrgenommen wird, wie sie in Sir 24 bezeugt ist. ${ }^{33}$ Dort ist wieder die personifizierte Weisheit als Gottes Schöpfungswerk bedeutsam, hervorge-

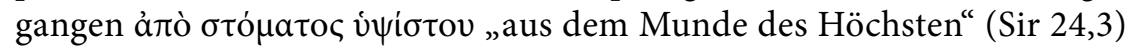
wie Gottes Schöpfungswort in Ps 33,6.9. Sie wohnt und thront $\dot{\varepsilon} v$ vं $\psi \eta \lambda$ oĩ „in höchsten Höhen“ (Sir 24,4). Im Zentrum steht allerdings nicht das Gelingen der Schöpfung, sondern die Suche nach einer àvátavoıৎ „Ruhe“ für die Weisheit auf Erden (24,7). Gott findet den Ort für die Weisheit im Erbteil Jakob-Israel $(24,8)$, und zwar auf Zion in Jerusalem, wo die Weisheit in Gottes eigenem heiligem Zelt vor ihm ihren Dienst verrichtet (24,10-11). Die Parallelität zur Gegenwart göttlicher Herrlichkeitsfülle im portablen Zelt-Heiligtum in Ex 40,34-35 ist unübersehbar, doch die

\footnotetext{
${ }^{33}$ Vgl. Feldmeier/Spieckermann, Menschwerdung (Anm. 7) 126-128.
} 
dort Gott repräsentierende $\delta$ ó $̧ a$ ist nicht Person, wohl aber die Weisheit, die vor Gott im heiligen Zelt nach Sir 24 dient. Diese Kombination ist für den Johannes-Prolog wichtig. In Joh 1,14 wird die $\delta$ óła mit der Einwohnung des Fleischgewordenen „unter uns“ verbunden, der der „Einziggeborene vom Vater" ist.

Dass es sich bei der Fülle der Gnade und Wahrheit in Joh 1,14 um die Anspielung auf die Formel rab-hesed we'ěmet handelt, ist auch daraus zu ersehen, dass die Deutung der Formel in V. 16 zunächst allein die Gnade nachdrücklich apostrophiert, die wir vom Fleischgewordenen in Fülle empfangen, um darauf in V. 17 die asyndetische Zuordnung von dem

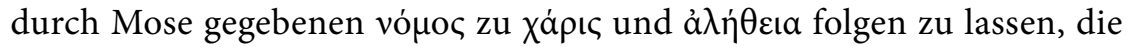
durch Jesus Christus geworden sind, der „einziggeborene Gott im Schoß der Vaters", der als Einziger den unsichtbaren Gott kundmacht (V. 18).

Die asyndetische Zuordnung von Gesetz und Gnade in Joh 1,17 soll offensichtlich sprachlich die Offenheit wahren, die das Verhältnis erfordert, ohne es unbestimmt zu lassen. Gnade und Wahrheit, wie sie in Jesus Christus gegenwärtig geworden sind, stehen in Kontinuität zum Gesetz des Mose. Wäre es nicht so, hätte Johannes seinen Prolog anders konzipieren müssen. Überbietung von Gottes Gnadenzeugnis im Gesetz und Endgültigkeit der im Einziggeborenen gewordenen Gnade Gottes sind Elemente der Intention des Prologs. Der am stärksten apostrophierte Unterschied zwischen Mosegesetz und Christusgnade liegt indessen darin, dass die Menschen den Gnadenschatz des Gesetzes nicht mehr als Gottes Gabe durch einen Menschen bekommen, sondern durch den einziggeborenen Gott Jesus Christus, der in der Unterscheidung von Vater und Sohn als fleischgewordenes Logos-Wort Gnade und Wahrheit Gottes in der Begegnung mit seiner Person erfahrbar macht. Gerade in dieser Individuation des göttlichen Wahrheitswortes im Fleische geschieht das ZurWelt-Kommen der göttlichen Gnade. Gnade und Wahrheit stehen nicht mehr allein im Gesetz, sondern sind selbst Person geworden, Person gewordene lichtvolle Liebe Gottes, die selbst die Entscheidung über die Finsternis der Welt herbeigeführt hat und die Menschen zum Ja zu dieser göttlichen Entscheidung einlädt. Dieses Ja wird leicht gemacht durch den Einziggeborenen, der in Person und Wort den Vater verkündigt. 


\section{Fazit: Gottes Welt-Liebe als Kern der Gottes-Rede im Johannes-Prolog}

Der Johannes-Prolog ist Gottes-Rede, wie das Evangelium seine Präsentation des Gottessohnes versteht, nämlich als Fleischwerdung des Logos, als unlöslicher Zusammenhang von Protologie und Soteriologie. Es ist kein Entwurf, der sich als heilsgeschichtlicher Entwurf angemessen charakterisieren ließe, vielmehr führt der Prolog den Leser in erstaunlich wenigen Versen von der protologisch differenzierten Einheit von Gott und Logos-Wort zur soteriologischen differenzierten Einheit von Gott und Jesus Christus, seinem Einziggeborenen, der Fülle von Gnade und Wahrheit. Der Text beginnt mit einer mythischen Intonation und kommt erstaunlich schnell bei uns an, denen Gott alles geben will, was er hat und ist: Person gewordene Gnade und Wahrheit. Darf man sagen, dass Gott in der Fleischwerdung des Lebens-Logos vollbringt, was er in der LichtWerdung des Lebens-Logos in der Schöpfung bereits gewollt hat?

Man kann in der Fleischwerdung des Logos die Gottes-Rede des Alten Testaments theologisch verdichtet finden. Dies ist nicht die einzige Möglichkeit, aber eine einzigartige, vielleicht nahegelegt durch die Hoffnung und Leben stiftende Kraft des Wortes in Ps 33 und durch das $\pi v \varepsilon \tilde{u} \mu \alpha$

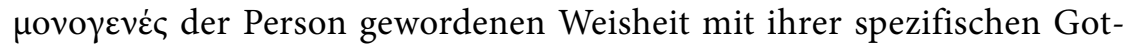
tesnähe in der Weisheit Salomos. Diese Option wird einzigartig durch ihre Verbindung mit dem Herzen aus Fleisch in Ez 11 und Ez 36. Ohne diesen Fund gleich $\mathrm{zu}$ einem Fundament machen $\mathrm{zu}$ wollen, handelt es sich hier jedenfalls um einen kühnen theologischen Gedanken, der die Fleischwerdung des Wortes in Joh 1 zumindest unterstützt haben könnte. Denn das neue Herz aus Fleisch bedarf nicht mehr der Einschreibung der Tora. Deshalb ist sie keineswegs abgetan. Niemand kann die Fleischwerdung des Wortes in Jesus Christus verstehen, der die Geschichte Gottes mit seiner Welt aus der Tora nicht kennt. Als Fleisch gewordener Logos verkündet und tut Jesus Christus, der einziggeborene Gott im Schoß des Vaters, die entscheidende Tat, die Gott in Einheit mit dem Logos von Anfang an gewollt hat. Diese Tat ist der endgültige Erweis der Fülle der Gnade und Wahrheit. Dieser Erweis wird wiederum mit den Worten des Alten Testaments gesagt. Ihr johanneisches Verständnis bringt Joh 3,16 auf den Punkt: „Also hat Gott die Welt geliebt“ - doch wohl von Anfang an -, „dass er seinen einziggeborenen Sohn gab, damit ein jeder, der an ihn glaubt, nicht verloren gehe, sondern das ewige Leben habe“.

Schönbergs Mose singt nie, er spricht. Er spricht von seinem reinen Gottesgedanken im Wort. Philo hätte an Schönbergs Mose wahrschein- 
lich reine Freude gehabt. Schönberg lässt Mose nur eine einzige Stelle singen, nämlich die an seinen Bruder Aaron gerichtete Mahnung: „Reinige dein Denken." Vielleicht musste es so sein, dass Schönberg seinen Text nicht bis zum Ende vertont hat. In der einzigen Szene des dritten Aktes stirbt Aaron, und für das Volk soll nach Moses Willen die Wüste das Ziel sein, weil nur hier die Vereinigung mit Gott denkbar ist. Schönbergs „Moses und Aron“ ist eine Option jüdischen Denkens, deren Problematik sein eigener Mose freilich schon antizipiert. Mose ruft das Wort an, das ihm fehlt.

Vielleicht ist die Fleischwerdung des Wortes die Antwort. Johannes stellt neben das Gesetz durch Mose die Fülle der Gnade und Wahrheit durch Jesus Christus (Joh 1,17). Zugleich formuliert er Gottes Tat im Einziggeborenen mit den Worten, die die Schriften einst für Wesen und Wirken des Vaters eben dieses Sohnes gefunden haben: voller Gnade und Wahrheit. Denkt Johannes im Prolog bei seinem durch Mose gegebenen Nomos daran? Biblische Theologie christlicher Provenienz muss daran denken. Hier tut sich eine Spannung auf, die kaum geringer ist als diejenige, an der Schönbergs Mose, der Streiter für das reine Gotteswort, verzweifelt. Christliche Theologie muss diese Spannung benennen und aushalten. Versucht sie, sich ihrer zu entledigen, gibt sie sich selbst auf. Diese Spannung ist eine theologische Schule der Demut, nicht des Hochmuts. 


\title{
Die Aufnahme frühjüdischer Rede von Gott im Johannesevangelium
}

\author{
Jutta Leonhardt-Balzer
}

\section{Einleitung}

Das Johannesevangelium enthält Verweise auf eine Vielzahl biblischer und frühjüdischer Traditionen und Motive. Schon früh in der historischkritischen Exegese des Evangeliums haben sich Exegeten mit dem Logos bei Philo und Johannes beschäftigt. ${ }^{1}$ Seit den Funden in Qumran reißt der Strom der Veröffentlichungen, die die Texte aus den Höhlen mit den johanneischen Schriften vergleichen, nicht ab. ${ }^{2}$ In dem hier vorliegenden Zusammenhang geht es weniger um eine weitere Detailuntersuchung frühjüdischer Bezüge. Es wird als gegeben vorausgesetzt, dass der Autor des Johannesevangeliums die Traditionen, die ihm zur Verfügung standen, in sein Werk eingearbeitet hat. Hier geht es um die Frage, wie das geschieht. Ziel der Untersuchung ist nicht der Nachweis einer bestimmten Traditionslinie, sondern die Nachverfolgung des Umgangs mit Leser- oder Hörererwartungen, der sich im Evangelium erkennen lässt. Ein solcher Umgang mit Erwartungen zeigt sich besonders deutlich in der johanneischen Aufnahme von traditionellen Gottesbildern. Nun gab es im Frühjudentum genauso wenig ein einheitliches Gottesbild, wie ein einheitliches Judentum. Doch lassen sich bestimmte Tendenzen und Perspektiven erkennen, die einem Großteil der frühjüdischen Traditionen gemeinsam sind.

\footnotetext{
${ }^{1}$ So z. B. Jacob BRyant, The Sentiments of Philo Judeus Concerning the $\Lambda$ ОГО $\Sigma$, or Word of God Together with Large Extracts from His Writings Compared with the Scriptures on Many Other Particular and Essential Doctrines of the Christian Religion, Cambridge 1797. Heinrich Christian Ballenstedt, Philo und Johannes. Oder, neue philosophisch-kritische Untersuchung des Logos beym Johannes nach dem Philo, nebst einer Erklärung und Uebersetzung des ersten Briefes Johannes aus der geweiheten Sprache der Hierophanten, Braunschweig 1802.

${ }^{2}$ Überblick in Jutta Leonhardt-Balzer, The Johannine Literature and Contemporary Jewish Literature, in: Judith Lieu (Hg.), Oxford Handbook of Johannine Literature, Oxford $2018,155-170$.
} 


\section{Die Gottesvorstellung in der biblischen und frühjüdischen Tradition}

Bei allen Unterschieden gibt es einen Fixpunkt im jüdischen Gottesbild: Gott bindet sich an ein bestimmtes Volk. Der Gott der hebräischen Bibel nimmt an dem Schicksal seines Volkes teil, und so wird er einerseits „Gott Abrahams, Isaaks und Jakobs“ genannt, andererseits vertraut er Mose seinen Namen an, offenbart sich Israel am Sinai und zeigt seine Gegenwart im Ablauf der Geschichte Israels: Vom Exodus über die Landnahme, die Königreiche, das Exil und die Rückkehr in das versprochene Land. Gott wird über sein Verhältnis zu bestimmten Menschen erfahrbar. Über die narrative Bestimmung Gottes hinaus verwenden die Propheten und Psalmen Metaphern, um Gott zu beschreiben, z. B. Gott als Ehemann bei Hosea, als Hirte (Ps 23), als Vater des Königs (Ps 2,7-9). Die Rede von Gott wird zunehmend abstrakter, und so ist die Entwicklung zum Monotheismus von ihren Anfängen bis zu ihrer vollen Entfaltung im und nach dem Exil von zunehmendem Universalismus geprägt. ${ }^{3}$ In den frühjüdischen Texten wird zwar Gott auch in der Geschichte Israels erfahren, insbesondere in den apokalyptischen Texten, aber die Vorstellung von Gott wandelt sich zunehmend von dem konkreten Gott Israels zum Schöpfer und universalen Herrn der Weltgeschichte oder dem „Gott der Erkenntnisse“, הדעות אל, der apokalyptischen Weisheitstradition (z.B. 1QS III,15; 4Q299,32,1; 69,3; 4Q417,2,I,8; 4Q418,43,55,5). In der Auseinandersetzung mit griechischer Philosophie entwickeln sich diese Linien zu dem transzendenten Gott. Der Weg geht also vom Gott Israels zum Gott der Welt und zum Gott der Ideen. ${ }^{4}$ Die Übersetzung des Gottesnamens in der Septuaginta als „der Seiende“ ist beredtes Zeugnis dieser Entwicklung (Ex 3,14 LXX: 'E $\gamma \omega \dot{\omega} \varepsilon \dot{\mu} \mu$ o ó $\omega v v)$, doch ist sie nur ein Beispiel. Eine so transzendente Gottesvorstellung findet sich u. a. auch im Werk des jüdischen Philosophen und Exegeten Philo von Alexandrien. Nach dieser Vorstellung ist Gott nicht nur der, dem man sich nicht nahen kann, weil seine Herrlichkeit das Nahen eines unvollkommenen Sterblichen

\footnotetext{
${ }^{3}$ Vgl. Walter Dietrich, Universalität und Partikularität im Horizont des biblischen Monotheismus. Eine Skizze, in: Christoph Bultmann/Walter Dietrich/Christoph Levin (Hg.), Vergegenwärtigung des Alten Testaments. Beiträge zur biblischen Hermeneutik. Festschrift für Rudolf Smend zum 70. Geburtstag, Göttingen 2002, 369-411.

${ }^{4}$ Auch wenn sich der Einfluss des Hellenismus auf das gesamte Judentum des zweiten Tempels erstreckt, ist in dem hier gegebenen Zusammenhang doch zwischen den Denkansätzen der griechischen Diaspora und ihrer bewussten und positiven Aufnahme griechischer Philosophie und den anderen Strömungen im Judentum zu unterscheiden. Nur in dieser Hinsicht soll hier der Begriff „hellenistisches Judentum“ gebraucht werden.
} 
nicht zulässt, sondern Gott ist vom Menschen so weit entfernt, dass der Mensch noch nicht einmal annäherungsweise Gottes Wesen erkennen kann. Nur das „dass“ der Existenz Gottes ist dem menschlichen Verstand zugänglich, nicht das „wie“ (Det. 160; Leg. Alleg. 1.36,51, 3.36; Deus 55. Anthropomorphe Rede von Gott wird vermieden. Doch die Kluft zwischen Gott und Mensch muss überbrückt werden, und so erhalten Mittlerwesen wie Engel und Personifikationen göttlicher Eigenschaften und Hypostasen zunehmende Bedeutung, auch in Traditionen, die nichts mit der griechischen Philosophie zu tun haben (1 Henoch, Qumran).

In nahezu allen literarischen Zeugnissen des zweiten Tempels geht es um die Größe Gottes und wie sich dieser universale Gott zum Menschen stellt. So ist die Balance von Universalismus und Partikularismus eine der großen Herausforderungen frühjüdischer Theologie: der Brückenschlag vom universalen oder transzendenten Gott zum Schöpfer der materiellen Welt bis hin zum Geschichtsgott. Die Universalität Gottes stellt die Frage in den Raum, wie sich dieser Gott zu seinem Volk verhält, und wie ihn das definiert. Umgekehrt führt das zu der brennenden Frage, wie sich Israel bestimmen lässt. Die Abrahamskindschaft spielt dabei eine fundamentale Rolle (vgl. Johannes der Täufer Lukas 3,8, aber auch die Patriarchendarstellung bei Philo), genauso wie die Offenbarung am Sinai. Bei allen Überschneidungen betont der eine Pol eher die Universalität Gottes, der andere seine Partikularität. In diesem Spannungsfeld bewegt sich der Autor des Johannesevangeliums mit seiner Rede von Gott.

\section{Gott Abrahams und Gott des Exodus im Johannesevangelium}

Für das Johannesevangelium steht die Offenbarung Gottes in dem Menschen Jesus von Nazareth im Mittelpunkt. ${ }^{5}$ Dieses ist die Geschichte, in der sich Gott zeigt. Im Menschen Jesus - und nur in ihm - erfahren die Menschen Gott; sie erfahren Gott jedoch ausschließlich durch den Logos. ${ }^{6}$ Wie man in Joh 20,28-31 sieht, ist die Gegenwart Jesu, erfahren im Glauben, fundamental für das Johannesevangelium. ${ }^{7}$ Allein Jesus vermit-

\footnotetext{
${ }^{5}$ Jörg FreY, Joh 1,14, die Fleischwerdung des Logos und die Einwohnung Gottes in Jesus Christus. Zur Bedeutung der „Schechina-Theologie“ für die johanneische Christologie, in: Bernd Janowski/Enno E. Popkes (Hg.), Das Geheimnis der Gegenwart Gottes. Zur Schechina-Vorstellung im Judentum und Christentum (WUNT 318), Tübingen 2014, 231-256.

${ }^{6}$ Vgl. Frey, Joh 1,14 (Anm. 5) 250-256.

${ }^{7}$ Vgl. Jan G. van der Watt, The Presence of Jesus Through the Gospel of John, Neotest. $36(2002) 89-95$.
} 
telt Informationen aus erster Hand über den transzendenten Gott als den Vater, und allein Jesus zeigt Gottes Gegenwart auf Erden im Tod durch das Kreuz. Die Beobachtung, dass der auferstandene Jesus die Kreuzesmale behält, belegt, dass der Tod auf ewig zu der Erfahrung Gottes gehört. ${ }^{8}$

Doch auch die beiden traditionellen Pole der Gotteserfahrung Israels, Abraham und Sinai finden sich im Johannesevangelium. Auch wenn das Johannesevangelium wenig direkte Zitate aufweist, steht seine Gottesvorstellung auf dem Boden von Tora, Propheten und Schriften in ihrer zeitgenössischen Auslegung. Das heißt, die klassischen biblischen Gottesbegriffe - Schöpfer, Gott Abrahams, Gesetzgeber, Hirt, Vater - werden nicht nur aufgenommen und diskutiert, diese Diskussion erfolgt im Rahmen der weiten Bandbreite frühjüdischer Rede von Gott. Das heißt, selbst wenn das Johannesevangelium die biblischen Traditionen aufnimmt, finden sie sich vor einem intellektuellen Hintergrund, der nicht nur vom Gott Israels ausgeht, sondern Gott im Kontext universaler Dimensionen, und ganz konkret im Anschluss an hellenistisch-jüdische Philosophie, beschreibt. Zunächst soll hier der Gott Abrahams untersucht werden.

\subsection{Der Gott Abrahams}

Auch wenn das Johannesevangelium Gott nie "Gott Abrahams" nennt, dient Johannes 8,31-59 der Diskussion der Frage, wie die Glaubenden und ihr Verhältnis zu Gott gegenüber Abraham und seinen Nachkommen stehen. Der Gott, der mit Abraham kommuniziert hat, wird als der präexistente Jesus offenbart (8,56-58). Demnach ist der Glaube an Jesus dem Glauben Abrahams an Gott gleich. Das entspricht nicht nur paulinischer Abrahamsexegese, sondern hat auch Parallelen in der Abrahamsdeutung bei Philo von Alexandrien, der Abraham als Modell des durch Unterweisung voranschreitenden Weisen sieht und somit die Abrahamsnachfolge in einer Haltung entsprechender Weisheit findet. Der "Gott Abrahams“ wird bei Johannes zunächst so partikular wie nur möglich auf Jesus hingedeutet, um dann die Deutung auf das Äußerste universal auszudehnen.

\footnotetext{
${ }^{8}$ Vgl. die Aussagen zu Gottes Gegenwart durch Jesus in allen Aspekten des menschlichen Lebens bei John F. O'Grady, Jesus the Revelation of God in the Fourth Gospel, BTB 25 (1995) 161-165.
} 


\subsection{Der Gott des Exodus}

Ähnliches lässt sich bezüglich des Gottes vom Sinai beobachten. Wie wichtig die Offenbarung Gottes an Mose für das Johannesevangelium ist, zeigt sich darin, dass schon im Prolog das Verhältnis zwischen Mose und Jesus angesprochen wird (Joh 1,17). Dass sich in Jesus der Gott Israels zeigt, wird in Jesu Einzug in Jerusalem deutlich $(12,12-26)$. Unmittelbar danach, in Joh 12,28, verarbeitet das Johannesevangelium die synoptischen Verherrlichungs- und die Getsemaneerzählungen (12,27-36) durch Aufnahme der Sinaioffenbarung in Ex 19,19. Hier wird sie jedoch drastisch umgedeutet: Auf Jesu Gebet erschallt die Bat Qol, eine "Stimme vom Himmel“ ( $\varphi \omega v \grave{~ \varepsilon ̇ \kappa ~ \tau o v ̃ ~ o u ̉ p a v o u ̃) . ~ S i e ~ w i r d ~ g e h o ̈ r t, ~ d o c h ~}$ sie bleibt formlos und unbenannt. Dementsprechend wird sie von der Menge missverstanden - die einen deuten sie als Donner, die anderen als

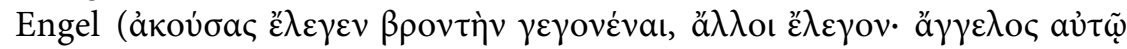
$\lambda \varepsilon \lambda \dot{\alpha} \lambda \eta \kappa \varepsilon v, 12,29)$. In Ex 19,19 spricht Mose und Gott antwortet im Donner. ${ }^{9}$ Die göttliche Stimme im Johannesevangelium liegt formal auf einer Linie mit der Sinaitheophanie. Der Verweis auf die Verherrlichung Jesu nimmt das Motiv der כבזד Gottes am Sinai auf, doch ist im Johannesevangelium die göttliche Herrlichkeit nur durch Glauben an Jesus wahrnehmbar. Diese himmlische Mitteilung enthält keine Informationen über den transzendenten Gott, auch gibt sie keine Gebote an die Menschen weiter. Anstelle dessen heißt es, dass der Vater den Sohn verherrlicht und

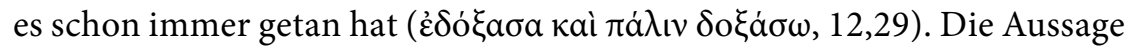
ist an die versammelten Pilger gerichtet, die teilweise aus der Diaspora kommen $(12,20)$. Die Pilger können die Stimme jedoch nicht verstehen. Sie kommuniziert also nicht - wie auf dem Sinai - zwischen Israel und Gott, vielmehr definiert sie das Verhältnis zwischen Jesus und dem Vater und dient als Autorisierung Jesu als Repräsentant Gottes. Die Stimme, und somit die göttliche Autorisierung Jesu, ist nur dem Glauben ver-

\footnotetext{
${ }^{9}$ Das Wort, das bei Johannes für „Donner“ verwendet wird, $\beta \rho o v \tau \eta \dot{~}$, hängt nicht mit der Sinaitheophanie in der LXX zusammen, mit der einzig möglichen Ausnahme von Ps 76,19 (vgl. 76,17-21 mit dem Verweis auf den Exodus). Im NT findet sich der Begriff (abgesehen von Mk 3,17) nur hier und in der Apokalypse, dort immer als eines der akustischen Signale der Gegenwart oder des Handelns Gottes (Offb 4,5; 6,1; 8,5; 10,3-4; 11,19; 14,2; 16,18; 19,6).

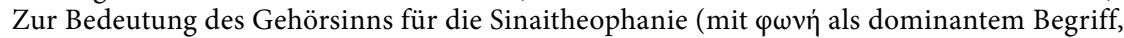
vgl. Ex 19,13.16.19; 20,18): Fraade erwähnt, dass in der Sinaitradition und ihrer Interpretation die visuellen Manifestationen Gottes weniger wichtig sind als die auditive Offenbarung durch die Gebote, die vom gesamten Volk gehört werden, s. Steven D. FraAde, Hearing and Seeing at Sinai. Interpretive Trajectories, in: George J. Brooke/Hindy Najman/Loren T. Stuckenbruck (Hg.), The Significance of Sinai. Traditions about Sinai and Divine Revelation in Judaism and Christianity (Themes in Biblical Narrative 12), Leiden 2008, 247-268: 247.
} 
ständlich (12,36). Somit ist das eigentliche Medium für die Aufnahme des transzendenten Gottes nicht das menschliche Ohr, sondern der Glaube an Jesus. Es handelt sich nicht einmal um den Glauben an den irdischen Jesus, sondern um den an den erhöhten Sohn. Damit ist wiederum - und das im Gegensatz zu der Sinaioffenbarung - die Offenbarung Gottes nicht die Stimme vom Himmel, sondern immer wieder ausschließlich der Sohn.

\subsection{Johannes und die Erscheinung Gottes auf Erden}

Es ist deutlich, dass im Johannesevangelium die biblischen Aussagen über Gott auf Jesus übertragen werden. Diese Praxis hat in der späteren Rezeption dazu geführt, dass spätere dogmatische Aussagen wie der „menschgewordene Gott“ oder „Christi Gottheit“ zu großen Teilen auf johanneischem Boden stehen. ${ }^{10}$ Doch die Vorstellung von Jesus als Manifestation Gottes ist nur teilweise korrekt: Wenn man nach dem transzendenten Gott fragt, gilt was in Joh 1,18 festgestellt wird: „Niemand hat Gott je ge-

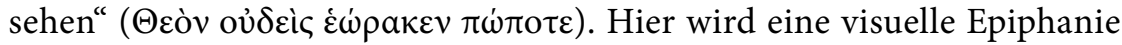
ausgeschlossen. Doch Epiphanien brauchen nicht visuell zu sein; in der

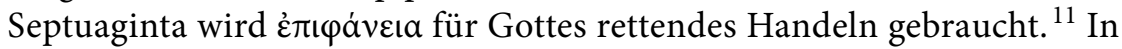
diesem Sinn ist die Geschichte Jesu in jedem Fall eine Epiphanie Gottes. Doch findet sich auch der Begriff è $\pi \iota \varphi$ áveı nirgends im Evangelium, und das Verb paivw wird auch nur im Sinne von "scheinen“ gebraucht, nicht im Sinne von „erscheinen lassen“, „enthüllen“: Das Licht des Logos „scheint in der Dunkelheit" (

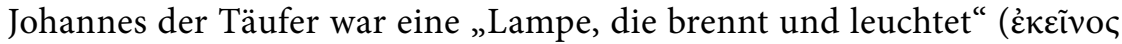

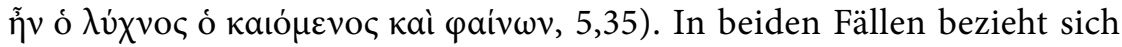
die Metapher auch nicht auf die Erscheinung des transzendenten Gottes, sondern auf die des Logos, oder im Fall des Täufers spiegelt er lediglich das Licht des Logos. Auch das genauere pavepów, „enthüllen“, „bekannt-

\footnotetext{
${ }^{10} \mathrm{Zu}$ den christologischen Aussagen, vgl. FreY, Joh 1,14 (Anm. 5) 231-2.

${ }^{11}$ Dieser Gebrauch entspricht der Bedeutung des griechischen Nomens ėंı $\varphi$ áveı a, s. Dieter Lührmann, Epiphaneia. Zur Bedeutungsgeschichte eines griechischen Wortes, in: Gert Jeremias/Heinz-Wolfgang Kuhn/Hartmut Stegemann (Hg.), Tradition und Glaube. Das frühe Christentum in seiner Umwelt (FS Karl Georg Kuhn), Göttingen 1971, 185-199. Der Begriff beschreibt die entscheidende Intervention in der Schlacht oder in den hellenistischen Schriften das rettende Eingreifen einer Gottheit, nicht notwendigerweise über eine physische Erscheinung, und die LXX und Josephus gebrauchen ihn für die rettenden Taten Gottes (ebd., 193-195). Im NT kommt es nur in Apg 2,20; 27,20; 1 Tim 6,14; 2 Tim 1,9-10; 2 Thess 2,8 vor, mit ähnlicher Bedeutung, doch nie bei Johannes (ebd., 197-199).

${ }^{12}$ Licht wurde nicht nur in der jüdischen Tradition mit Gotteserscheinungen verbunden, sondern auch in der griechischen Religion, s. Eva Parsinou, The Light of the Gods. The Role of Light in Archaic and Classical Greek Cult, London 2000.
} 
machen" wird bei Johannes nie für den transzendenten Gott, sondern immer nur für die Offenbarung in Jesus gebraucht. ${ }^{13}$

Somit lässt sich bisher sagen: Im Johannesevangelium gibt es keine Vorstellung einer wirklichen Präsenz des transzendenten Gottes auf Erden. ${ }^{14}$ Es geht nicht um die Frage: „Was ist die Offenbarung des transzendenten Gottes auf Erden?“ sondern: „Wie wird der transzendente Gott offenbar? Wie wird er erfahrbar?" ${ }^{15}$ Es geht weniger um die ontische als die funktionale Bestimmung Gottes. Der flexible Umgang mit dem Gottesbegriff zeigt sich vor allem, wenn in Joh 10,34 der Psalm 81,6 LXX $(82,6)$ zitiert wird: „Ihr seid Götter.“ Das Zitat dient dem Nachweis, dass Jesu Aussage „Ich und der Vater sind eins" auf dem Boden biblischer Tradition steht. Auch wenn die johanneischen Präexistenzaussagen und das absolute $\dot{\varepsilon} \gamma \dot{\omega}$ cì $\mu$ bei seiner Verhaftung (Joh 18,1-11) Jesus auch ontisch einen anderen Status als den Menschen zuweisen, ja ihn mit dem Sinaigott identifizieren, ${ }^{16}$ ist die Identitätsaussage zum Vater in 10,34

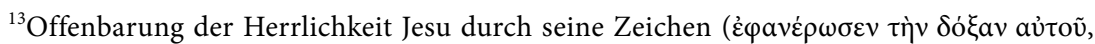

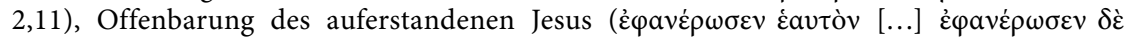

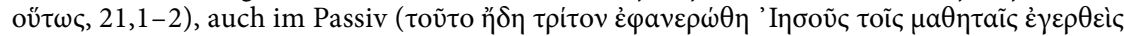

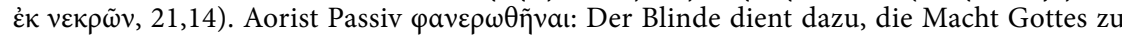

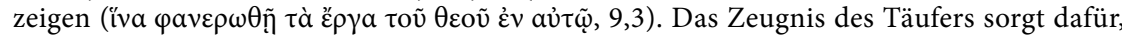

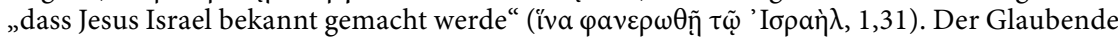

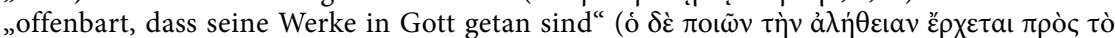

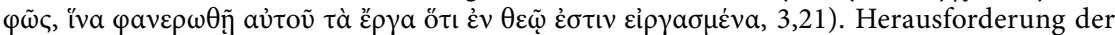

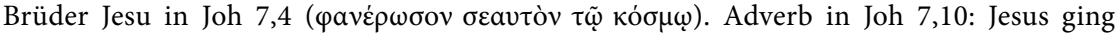

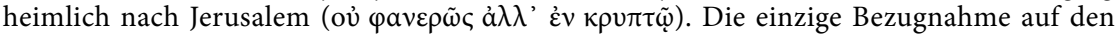
transzendenten Gott findet sich im hohepriesterlichen Gebet in Joh 17, und selbst hier erfolgt die Offenbarung des transzendenten Gottes durch Jesus: „Ich habe deinen Namen

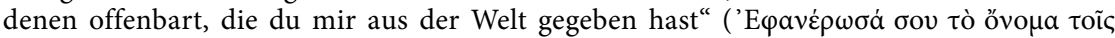

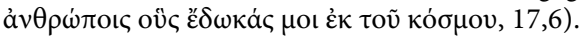

${ }^{14} \mathrm{Zu}$ der Unmöglichkeit, Gott wahrzunehmen, außer in Jesus, s. Marianne M. Thompson, God's Voice You Have Never Heard, God's Form You Have Never Seen. The Characterization of God in the Gospel of John, Semeia 63 (1993) 177-204: 194f.200f.

${ }^{15}$ Die besondere, religiöse Erfahrung antiker Autoren erfährt zunehmend die Aufmerksamkeit der Forschung, s. Frances Flannery/Nicolae Roddy/Colleen Shantz/Rodney A. Werline, Introduction. Religious Experience, Past and Present, in: Frances Flannery/Colleen Shantz/Rodney A. Werline (Hg.), Experientia I. Inquiry into Religious Experience in Early Judaism and Early Christianity (SBLSymS 40), Atlanta 2008, 1-10. Die Art, in der der Text die Erfahrung seiner Leser beeinflussen will, wird von Robin Griffith-Jones, Transformation by a Text. The Gospel of John, in: Frances Flannery/Colleen Shantz/Rodney A. Werline (Hg.), Experientia I. Inquiry into Religious Experience in Early Judaism and Early Christianity (SBLSymS 40), Atlanta 2008, 105-123 untersucht.

${ }^{16} \mathrm{Zu}$ Jesus als dem Repräsentanten des jüdischen Gottes s. Riemer Roukema, Jesus and the Divine Name in the Gospel of John, in: George H. van Kooten (Hg.), The Revelation of the Name YHWH to Moses. Perspectives from Judaism, the Pagan Graeco-Roman World, and Early Christianity (Themes in Biblical Narrative 9), Leiden 2006, 207-223; zur Identität der Herrlichkeit des Logos und des jüdischen Gottes s. 208-211; zu derselben Identität in den
} 
funktional zu verstehen. In ähnlicher Weise deutet Philo die Aussage in Ex 7,1, dass Mose ein Gott für Pharao sei (Sacr. 9) nicht als Wesens-, sondern als Verhältnisaussage. ${ }^{17}$ Wie bei Philo, geht es auch im Johannesevangelium um das Verhältnis zwischen Jesus und dem Vater, und es ist kein Zufall, dass bei Johannes Familienmetaphern für dieses Verhältnis überwiegen. Doch sind Familienmetaphern in dieser absoluten Form in der frühjüdischen Tradition unüblich und tragen daher für das vorliegende Thema wenig aus. In dem hier gegebenen Zusammenhang sollen vielmehr die Aussagen des Evangeliums über Gott genauer untersucht werden.

\section{Jesus und Gott im Johannesevangelium}

Zur Untersuchung des Gottesbildes soll der Begriff $\theta$ có untersucht werden, insbesondere im Mund Jesu. ${ }^{18}$ Die Hauptfrage ist: Von welchem Gott spricht das Evangelium? ${ }^{19}$ Der Begriff $\theta$ cóc selbst hat

Ich-bin-Worten 211-213; und 213-215 zu den Epitheten „Gnade und Wahrheit“ in 1,17. Zu den Ich-bin-Worten als Ausdruck der Identität mit den Aussagen über Gott in der jüdischen Tradition, s. auch Grant Macaskill, Union with Christ in the New Testament, Oxford 2013, 257-263; und Catrin H. Williams, I am He. The Interpretation of 'Anî Hû' in Jewish and Early Christian Literature (WUNT 2,113), Tübingen 2000, 255-304.

${ }^{17}$ Vgl. Jutta Leonhardt-Balzer, Mose als Mittler bei Philo von Alexandrien, in: Erik Eynikel/Elisabeth Hernitschek/Veronika Niederhofer/ /Michael Sommer (Hg.), Mosebilder: Gedanken zur Rezeption einer literarischen Figur im Frühjudentum, frühen Christentum und der römisch-hellenistischen Literatur (WUNT 390), Tübingen 2017, 123-142.

${ }^{18}$ Es gibt relativ wenige Vorkommen des Begriffs $\theta \varepsilon o ́$ (84-mal, zweimal im Plural -

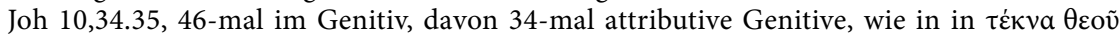

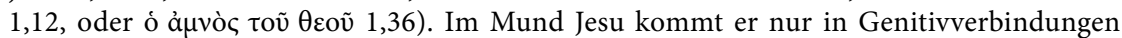
vor, s. Kurt Aland, Computer-Konkordanz zum Novum Testamentum Graece von NestleAland 26 und zum Greek New Testament 3. Hrsg. vom Institut für neutestamentliche Textforschung und vom Rechenzentrum der Universität Münster, unter besonderer Mitwirkung von Horst Bachmann/Wolfgang A. Slaby, Berlin 1977. Von den 84 Vorkommen finden sich 72 in Jesu öffentlichem Auftreten (Joh 1-13), nur 11 in Joh 14-21. Der Übergang wird durch 14,1 erstellt: „Glaubt an Gott und glaubt an mich.“ Gott hat alles in Jesu Hand gegeben $(13,3)$ und von diesem Augenblick an wird Gott durch Jesus verherrlicht $(13,32)$.

${ }^{19}$ Die Frage nach der Bedeutung des Wortes „Gott" bei Johannes wird untersucht von Marianne M. Thompson, The God of the Gospel of John, Grand Rapids 2001, 17-56. Sie zeigt, dass der Begriff $\theta \varepsilon$ ć Person bezeichnet, sondern eine "prediction about the person or reality so named“ (22, Hervorhebung im Original) darstellt. In der jüdischen Tradition, in der das Johannesevangelium steht, hat dieses Wesen einen bestimmten Namen, der nicht ausgesprochen werden darf (23-35). Es kann mit Individuen und Gruppen verbunden werden (25-28), oder durch die Hinzufügung anderer Attribute qualifiziert werden, z. B. Gott der Macht, Gott der Gnade, Gott des Heils (28-32). „Gott“ kann eine funktionale Beziehung ausdrücken, indem Men- 
eine große Bedeutungsbreite. In diesem Zusammenhang fällt es auf, dass ihm im Johannesevangelium bemerkenswert wenige Begriffe zur Erläuterung beigestellt werden. Die Bedeutung des Gottesbegriffs hängt letztendlich nicht nur an den Inhalten, die Jesus vermittelt, sondern auch an der Haltung zu ihm. ${ }^{20}$ Gott und der Teufel werden beide durch Glauben definiert.

\subsection{Der transzendente und der immanente Gott ( $\theta \varepsilon o ́ \varsigma$ und ó $\theta \varepsilon o ́ \varsigma)$}

Außerhalb des Mundes Jesu wird der Begriff $\theta \varepsilon$ có in verschiedenen Bedeutungen und mit unterschiedlichem Wahrheitsanspruch gebraucht. In

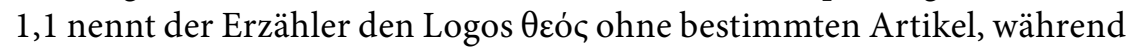

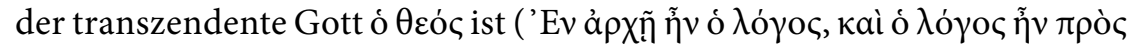

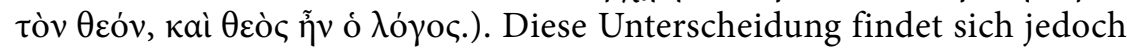

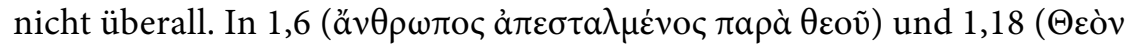

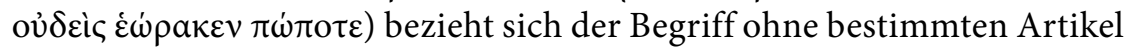
auf den transzendenten Gott. Anderswo wird $\theta \varepsilon$ ć

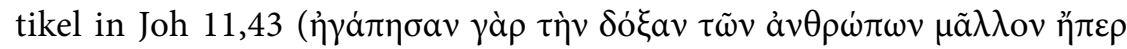

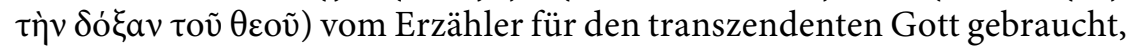
und in 13,3 findet es sich einmal mit und einmal ohne den bestimmten

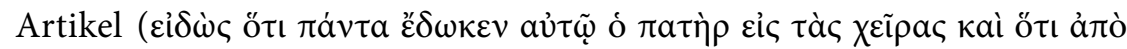

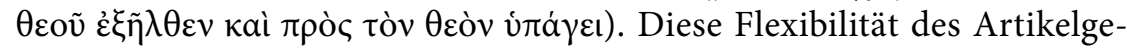
brauchs bei Wörtern, die Eigennamen nahekommen, ist im Griechischen der Zeit üblich, ${ }^{21}$ insbesondere wenn es den Gebrauch der LXX wiederspiegelt, die auch nicht immer den bestimmten Artikel bei $\theta$ có wendet, besonders wenn das Nomen nicht im Nominativ ist. ${ }^{22}$ So findet sich der Ausdruck $\pi v \varepsilon \tilde{v} \mu \alpha$ $\theta \varepsilon o \tilde{v}$ in Gen 1,1, während der Rest von Gen 1 den bestimmten Artikel bei Nominativen gebraucht. Diese Beobachtung betont die Unterscheidung zwischen dem Logos und dem transzendenten Gott in Joh 1,1, denn in 1,1 findet sich $\theta$ có während der Artikel mit тòv $\theta \varepsilon o ́ v$ im Akkusativ gebraucht wird. Auch Philo benützt $\theta \varepsilon o ́ c$ mit und ohne Artikel um eine Unterscheidung bezüg-

schen als Gott für andere Menschen fungieren (32-35), doch werden sie hier auch von dem wahren Gott unterschieden (35-38, 42-48), und Menschen, die als Gott verehrt werden wollen, müssen bestraft werden (39-41). Im Johannesevangelium wird der Gottesbegriff mit der jüdischen Tradition verbunden (48-56).

${ }^{20}$ Vgl. Thompson, God (Anm. 19) 48-52.

${ }^{21}$ Vgl. z. B. Friedrich Blass/Albert Debrunner/Friedrich Rehкopf, Grammatik des neutestamentlichen Griechisch, Göttingen ${ }^{15} 1979,204-205$.

${ }^{22} \mathrm{Vgl}$. Thesaurus Linguae Graecae, http://stephanus.tlg.uci.edu/ (abgerufen am 13.05. 2015). 
lich Gottes zu machen. Im Gegensatz zu Johannes gebraucht er jedoch den Artikel nicht um zwischen Gott und Logos zu unterscheiden, sondern zwischen dem wahren und den falschen Göttern (Somn. 1.228-230). ${ }^{23} \mathrm{Im}$ Johannesevangelium wird gleich zu Anfang dagegen die Nähe zwischen

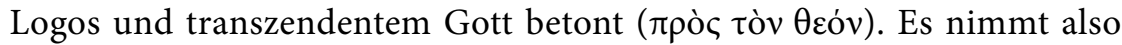
eine in der hellenistisch-jüdischen Theologie übliche Sprechweise auf, um die Unterscheidung zwischen Gott und Jesus und gleichzeitig ihre Zusammengehörigkeit darzustellen.

\subsection{Der Gott der Tradition}

Nach dem Prolog bezieht sich der Begriff $\theta$ có ৎ im Mund anderer Leute als Jesus durchgehend und unreflektiert auf den Gott der jüdischen Tradition - ohne Differenzierung oder Bezug auf seine Transzendenz. Johannes der Täufer erwähnt das „Lamm Gottes“ $(1,29) .{ }^{24}$ Nathanael nennt Jesus den „Sohn Gottes“ $(1,49) .{ }^{25}$ Nikodemus erkennt an, dass Jesus ein "Lehrer von Gott" und dass „Gott mit ihm“ ist $(3,2) .{ }^{26}$ Die Glaubenden fragen, wie sie die „Werke Gottes“ tun können $(6,28) .{ }^{27}$ Petrus bekennt stellvertretend für alle Jünger, dass Jesus der „Heilige Gottes“ ist $(6,69) .{ }^{28}$ Die Juden wollen ihn töten, „weil [...] er sagt, Gott sei sein Vater, womit er sich Gott gleich macht" $(5,18) .{ }^{29}$ Der Erzähler beschreibt Jesu Ziel als „die verstreuten Kinder Gottes zu sammeln“ zusammen mit den Heiden $(11,52) .{ }^{30}$ Mit diesem Ausdruck bezieht er sich auf traditionelle eschatologische Erwartungen. Auch der blinde Mann, den Jesus geheilt hat, gebraucht konventionelle Vorstellungen, wenn er aussagt: „Wenn dieser

\footnotetext{
${ }^{23}$ Peder Borgen, God's Agent in the Fourth Gospel, in: Jacob Neusner (Hg.), Religions in Antiquity. Essays in Memory of Erwin Ramsdell Goodenough (SHR 14), Leiden 1968, 137-148: 146; Donald A. Carson, The Gospel According to John (The Pillar New Testament Commentary), Grand Rapids 1991, 137; Craig S. KeEner, The Gospel of John. A Commentary. Volume 1, Peabody 2003, 373-374; Ernst Haenchen/Robert W. Funk/Ulrich Busse, John. A Commentary on the Gospel of John, Volume 1 (Hermeneia), Philadelphia 1984, 109; Thompson, God (Anm. 19) 52.

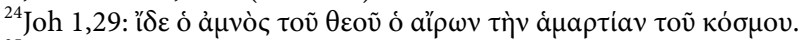

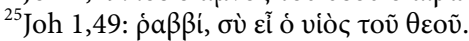

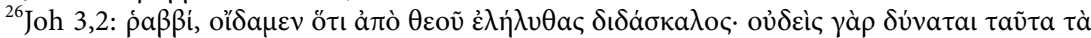

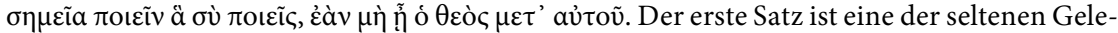
genheiten im Johannesevangelium, in denen sich der Begriff ohne Artikel auf den jüdischen Gott bezieht (hier wiederum im Genitiv und unmittelbar gefolgt von einem Nominativ mit dem Artikel). Dies entspricht dem üblichen frühjüdischen Wortgebrauch.

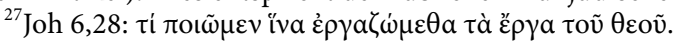

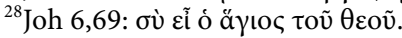

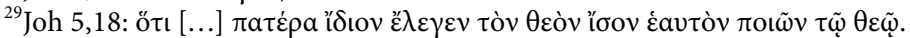

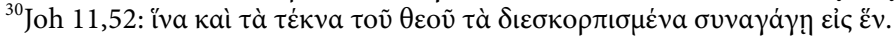


Mann nicht von Gott ist, kann er nichts tun" $(9,33) .{ }^{31}$ Und schließlich drückt Martha ihre Überzeugung aus: „Alles, um das du Gott bittest, wird Gott dir geben“" $(11,22){ }^{32}$

\subsection{Jesu Rede von Gott}

Auch der johanneische Jesus gebraucht $\theta \varepsilon$ ó $\varsigma$, um traditionelle Erwartungen an Gott aufzunehmen. Eine synoptische Tradition findet sich in der Rede von „Gottes Reich“, das nur zweimal im Johannesevangelium vorkommt, beide Male in Joh 3 in speziell johanneischer Form: Geburt „von oben“ oder „aus Wasser und Geist“ ist nötig, um „in das Reich Gottes zu kommen“ (3,3.5). ${ }^{33}$ In den Abschiedsreden (Joh 14-16) sagt der johanneische Jesus, bezogen auf die nachösterliche Lage der Gemeinde, dass die Verfolger der Gemeinde meinen werden, „Gott einen Gefallen zu tun“ $(16,2) .{ }^{34}$ Der nachfolgende Vers qualifiziert das dann: „Sie tun das, weil sie den Vater nicht kennen" $(16,3) .{ }^{35}$ Diese Bemerkung unterscheidet zwischen der Gottesvorstellung der (jüdischen) Verfolger und der wahren Identität des Vaters. Diese Unterscheidung ist wichtig, denn der johanneische Jesus erhebt den Anspruch, den jüdischen (und samaritanischen) Gott zu repräsentieren, wenn er den Jakobstraum und die BethelTradition aus Gen 28,10-22 aufnimmt und sich selbst mit dem Ort identifiziert, an dem der Gott Jakobs präsent ist, auf den die „Engel Gottes“ aufund absteigen (ő $\psi \varepsilon \sigma \theta \varepsilon[. .$.$] toù$

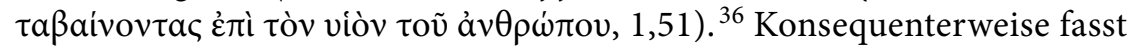
Thomas am Ende des Evangeliums das johanneische Bekenntnis zusammen, wenn er in 20,28 Jesus als den Gott der Tora und Propheten bekennt:

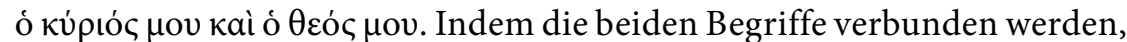
zeigt das Evangelium auf, dass Jesus der Gott der jüdischen Schriften ist. ${ }^{37}$ Dieses Motiv zieht sich durch das ganze Evangelium. Das Bekenntnis des

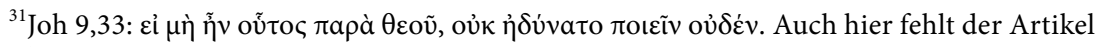
nach einer Präposition mit dem Genitiv.

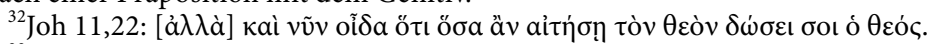

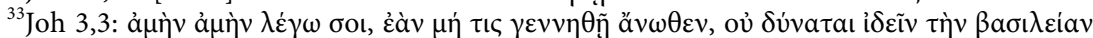
นoṽ $\theta \varepsilon \circ \tilde{v}$.

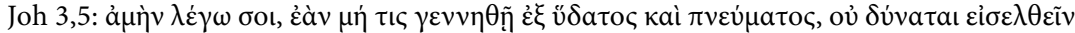

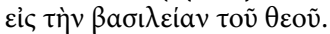

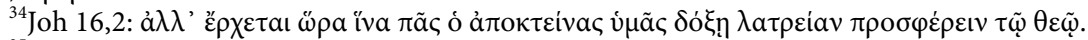

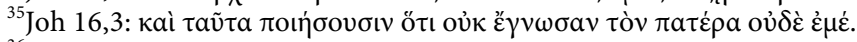

${ }^{36}$ Die Präexistenzaussagen und das absolute $\dot{\varepsilon} \gamma \omega \dot{~ \varepsilon i ̉ \mu ~ b e i ~ s e i n e r ~ V e r h a f t u n g ~(J o h ~ 18,1-11) ~}$ sind schon erwähnt worden.

${ }^{37} \mathrm{Zu}$ dem Titel Kyrios bei Johannes, s. Riemer Roukema, Jesus and the Divine Name (Anm. 16) 216-217.
} 
Thomas bildet eine Inklusio zu Joh 1,1: Der Logos ist der wahre Gott ${ }^{38}$ auch wenn er nicht der transzendente Vater ist. Der Grund, weshalb der Begriff kúpııৎ im Johannesevangelium relativ selten ist, liegt darin, dass die Gottesprädikate auf andere Weise ausgedrückt werden.

\subsection{Gottesprädikate}

Schon die Metaphern im Prolog, Licht und Leben $(1,3)$ enthalten direkte Verweise auf die Gottesattribute, in der Tora wie in der späteren Tradition, und machen es deutlich, dass der Logos der Gott der Schrift ist (Ps 27,1 [26,1 LXX]). Weitere Verweise auf die Tradition folgen sofort, so in 1,14 , wo die Inkarnation über die Traditionen von Wüstenheiligtum und Tempel beschrieben wird: „Und der Logos wurde Fleisch und

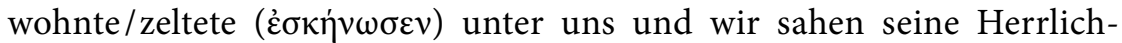
keit, eine Herrlichkeit als des eingeborenen von dem Vater, voll Gnade

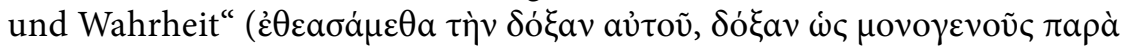

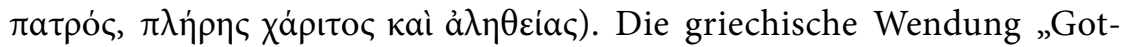
tes Herrlichkeit sehen" findet sich auch schon in der Septuaginta, doch wird in Texten wie LXX Ex 16,7, Num 12,8, Dtn 5,24 und Ps 17,15b,

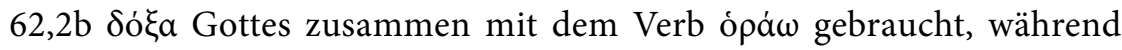
es sich in Joh 1,14 um die Herrlichkeit Jesu zusammen mit dem Verb $\theta \varepsilon \dot{o}$ ua l handelt. Es scheint sich hier um eine Unterscheidung zwischen der menschlichen Wahrnehmung der göttlichen Herrlichkeit in Jesus und einer Vision der Herrlichkeit des transzendenten Gottes zu handeln. Die menschliche Wahrnehmung ist auf Jesus beschränkt. So ist es konsequent, wenn in Joh 6,46 dieselbe visuelle Metapher für denjenigen gebraucht wird, der „bei Gott" ist und „den Vater gesehen“ hat. Doch hier, wo es um Jesu Wahrnehmung des transzendenten Gottes geht, findet sich auch das Verb ópá $\omega{ }^{39}$ Der Bogen schließt sich in 14,9, wo es heißt, dass jeder, der

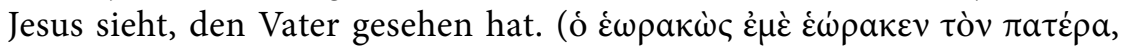
14,9). ${ }^{40}$ Hier wird der menschliche Anblick Jesu mit ó $\rho \alpha ́ \omega$ ausgedrückt. Jesus wird die sichtbare Manifestation des jüdischen Gottes. Funktional gibt es für die Menschheit nur die Erkenntnis Jesu. ${ }^{41}$

\footnotetext{
${ }^{38}$ Vgl. Carson, John (Anm. 23) 135; KeEner, John (Anm. 23) $425 \mathrm{f}$.

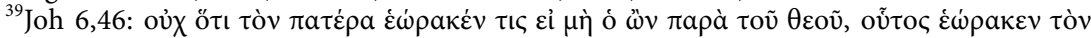
$\pi \alpha \tau \dot{\varepsilon} \rho \alpha$.

${ }^{40}$ Die Einsicht in diese Identität ist jedoch erst nach Ostern durch Glauben möglich, vgl. Christina Hoegen-Rohls, Der nachösterliche Johannes. Die Abschiedsreden als hermeneutischer Schlüssel zum vierten Evangelium (WUNT 2,84), Tübingen 1996, $100 \mathrm{f}$.

${ }^{41}$ So unterschiedliche Traditionen wie 1 Henoch und Ezechiels Exagoge beschreiben ein bestimmtes menschliches Wesen, das eng mit einem himmlischen Gegenstück verbunden
} 
Die Herrlichkeit Gottes wohnt der Tora nach im Tempel und seinem Vorgänger, dem Wüstenheiligtum, und wie immer wieder von Auslegern des Prologs betont wird, nimmt das Johannesevangelium mit dem Begriff $\dot{\varepsilon} \sigma \kappa \eta \dot{v} \nu \sigma \varepsilon v$ diese Traditionen auf $(1,14) .{ }^{42}$ Das Motiv der Identifikation Jesu mit dem Tempel als Ort der Gegenwart Gottes wird in Joh 2,21 fortgesetzt. ${ }^{43}$ Verbunden mit dem Tempelmotiv ist in Joh 1,14 die vielbeachtete Weisheitsspekulation nach Art von Spr 8 und Sir 24,3-12 $2^{44}$ und ihre Verarbeitung zum Logos, wie sie sich bei Philo findet. ${ }^{45}$ Auch die Begriffe „voll Gnade und Wahrheit“, die die Herrlichkeit Jesu charakterisieren, markieren sie als die Herrlichkeit Gottes, wie sie in der Tora offenbart wurde, insbesondere in Gottes Offenbarung an Mose in Ex 24,15-18 LXX. Die Betonung der wechselseitigen „Verherrlichung“ von Vater und Sohn stellt die johanneische Übernahme der biblischen Herrlichkeit Gottes dar $\left(10,36 ;{ }^{46} 8,54 ;{ }^{47} 13,31 ; ;^{48} 13,32^{49}\right)$. Auch hier wird ein wohlbekanntes Motiv der Beschreibung Gottes auf Jesus übertragen.

Ganz besonders deutlich zeigt sich das Vorgehen in der Übernahme der Logosspekulation im Prolog: Von Anfang an wird eine Genesisexegese rezipiert, die Gottes Schöpferwort aus Gen 1 als das planende und

wird. Bei 1 Henoch ist es Henoch, in der Exagoge ist es Mose, vgl. Andrei OrLov, In the Mirror of the Divine Face. The Enochic Features of the Exagoge of Ezekiel the Tragedian, in: George J. Brooke/Hindi Najman/Loren T. Stuckenbruck (Hg.), The Significance of Sinai. Traditions about Sinai and Divine Revelation in Judaism and Christianity (Themes in Biblical Narrative 12), Leiden 2008, 183-199. Doch die Vorstellung eines himmlischen Gegenstücks beinhaltet nicht die einer Identität mit Gott.

${ }^{42}$ Vgl. Frey, Joh 1,14 (Anm. 5).

${ }^{43} \mathrm{Zu}$ Jesus als Tempel Gottes und der johanneischen Verschiebung des Tempels von einem Gebäude zu einer relationalen Vorstellung von Gottes Gegenwart in Jesus und dann im Glaubenden, vgl. Mary L. Coloe, John's Portrait of Jesus, in: Delbert Burkett (Hg.), The Blackwell Companion to Jesus (Blackwell Companions to Religion), Chichester 2014, 64-80: 71-74; DIEs., Temple Imagery in the Gospel of John, Interp. 63 (2009) 368-381. Doch ist es nicht nötig, diese Verschiebung als Hinweis auf eine introvertierte Sekte zu sehen, gegen John A. Draper, Temple, Tabernacle and Mystical Experience in John, Neot 31 (1997) 263-288. Die Konsequenz dieser Verschiebung wird beschrieben bei Dorothy LeE, In the Spirit of Truth. Worship and Prayer in the Gospel of John and the Early Fathers, VigChr 58 (2004) 277-297.

${ }^{44}$ Vgl. Frey, Joh 1,14 (Anm. 5) 243-50.

${ }^{45}$ Vgl. Jutta Leonhardt-Balzer, Der Logos und die Schöpfung. Streiflichter bei Philo (Opif. 20 25) und im Johannesprolog (Joh 1,1-18), in: Jörg Frey/Udo Schnelle (Hg.), Kontexte des Johannesevangeliums. Das vierte Evangelium in religions- und traditionsgeschichtlicher Perspektive (WUNT 175), Tübingen 2004, 295-319.

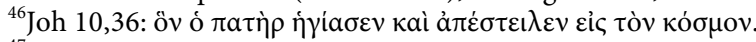

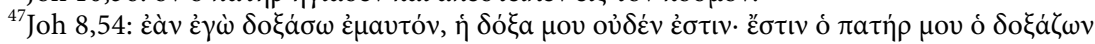

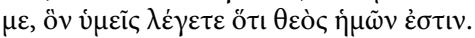

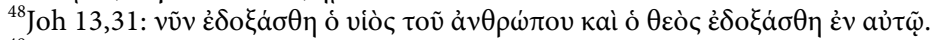

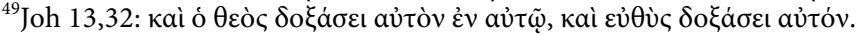


formende Wirken des Logos sieht. ${ }^{50}$ Philo beschreibt in Opif. 18-25 die Rolle des Logos zwischen platonischem Gott und Ideenwelt sowie Ideenwelt und materieller Schöpfung mit zwei Bildern, als Architekt und Baumeister bei der Stadtgründung auf Befehl eines Königs und als Siegel und Abdruck zugleich. ${ }^{51}$ Doch nicht nur der mittelplatonische Logos, auch der stoische Logos, die immanente, im Menschen wirkende Vernunft, hat seinen Niederschlag im Prolog, wenn es in 1,14 heißt, der Logos werde von den Glaubenden gesehen. Der Logos ist das Bindeglied zwischen dem transzendenten Gott und der materiellen Schöpfung. Im Johannesevangelium findet sich eine weitere Parallele zu einem Detail philonischer Logosspekulation, auch wenn der Begriff „Logos“ nach dem Prolog nicht mehr gebraucht wird. In Joh 3,33 und 6,27 wird der Begriff $\sigma \varphi \rho a \gamma i \zeta \omega$, „besiegeln“, zur Bestätigung des Zeugnisses Jesu gebraucht. In 3,33 erfolgt das Besiegeln durch die glaubenden Menschen, in 6,66 durch Gott. Beide Male ist das Objekt des Besiegelns der Menschensohn. In Opif. 18 dient die Metapher des Siegels zur Beschreibung der Beziehung zwischen Logos und Ideen und dann zwischen Ideen und der materiellen Welt. Der Logos ist Siegel und Abdruck zugleich. Im Johannesevangelium liegt zwar der Schwerpunkt auf der Authentifizierung, doch der Aspekt der Vermittlung liegt in der Parallelität der Verwendung der Metapher für Mensch und Gott bezogen auf den Menschensohn.

Joh 1,14 erstellt einen starken Kontrast zwischen dem sterblichen Fleisch des Menschen und der göttlichen Herrlichkeit. ${ }^{52}$ Somit stellt das Johannesevangelium die Gegenwart Gottes unter den Menschen in gleicher Weise dar wie die philonischen Logosspekulation: ${ }^{53}$ Der Logos ist das Bindeglied zwischen dem transzendenten Gott und der materiellen Schöpfung.

Hier, wie in allen vorhergegangenen Motiven zeigt sich der johanneische Umgang mit traditionellen Gottesbegriffen: Bekannte Motive, Traditionen und Vorstellungen werden zunächst deckungsgleich übernommen

\footnotetext{
${ }^{50}$ Leonhardt-Balzer, Logos (Anm. 45) 295-319.

${ }^{51}$ Vgl. Jutta Leonhardt-Balzer, Creation, the Logos and the Foundation of a City. A Few Comments on Opif. 15-25, in: Roland Deines/Karl-Wilhelm Niebuhr (Hg.), Philo und das Neue Testament. Wechselseitige Wahrnehmungen: 1. Internationales Symposium zum Corpus Judaeo-Hellenisticum (WUNT 172), Tübingen 2004, 323-344.

${ }^{52}$ Zur Diskussion der Doketismusfrage in diesem Zusammenhang vgl. Frey, Joh 1,14 (Anm. 5) 234-243.

${ }^{53}$ Der Logos bei Philo ist in der Forschung eingehend beschrieben worden. Zur Forschungsgeschichte und dem johanneischen Gebrauch dieser Tradition vgl. z. B. LeonHARDT-BALZER, Logos (Anm. 45) 295-319.
} 
und dann plötzlich durch Deutung auf Jesus drastisch umgedeutet. ${ }^{54}$ Ein jüdischer Theologe des 1. Jahrhunderts könnte der Logosdarstellung des Prologs bis zu V. 13 folgen, doch die Rede von der Fleischwerdung des Logos ist für Denker wie Philo gänzlich undenkbar. Die einzige „Inkarnation" des Logos, die sich ein Philo vorstellen könnte, wäre die Tora. Schon gar nicht könnte er von dem „eingeborenen Gott“ (Joh 1,18$)^{55}$ reden, ${ }^{56}$ auch wenn Philo gleichfalls den Logos als den einzigen Zugang zu Erkenntnissen über den transzendenten Gott sieht.

\section{Schlussfolgerung}

Die Aufnahme der verschiedenen Motive des Gottesbildes bei Johannes hat gezeigt, dass der Autor die verbreiteten Vorstellungen und Traditionen kennt und als Ausgangspunkt nimmt, um sie dann radikal christologisch zu deuten. Das Mittel, das er dazu gebraucht, ist der unbestimmte Begriff $\theta \varepsilon$ ó, der von dem Leser so lange mit seinen eigenen Vorstellungen gefüllt wird, bis die christologische Präzisierung und Partikularisierung ihm keine andere Wahl mehr lässt, sich mit der johanneischen Fokussierung auf Christus auseinanderzusetzen. Das hat nicht nur seinen Ursprung in der traditionsgebundenen Herkunft des Autors und seiner Kreise. Ein solches Vorgehen hat auch missionarischen Sinn. Das Anknüpfen an bekannte Positionen erleichtert die Kontaktaufnahme. Die drastische Umdeutung wird so in vertraute Vorstellungen und Denkmuster eingebettet. Der Nachteil dieses Vorgehens liegt darin, dass der Übergang zur christologischen Deutung nicht schrittweise vollzogen werden kann. In dem Augenblick, in dem die christologische Festlegung eindeutig zutage tritt, zwingt sie den Leser zu einer Entscheidung für oder gegen die neue Deutung: Jesu Zeugnis ist entweder wahr oder Blasphemie. Daraus folgt

\footnotetext{
${ }^{54}$ Ähnliches zeigt sich in Kapitel 10: Die meisterliche Aufnahme der biblischen Hirtenmetapher von Gott mündet in ihre Umdeutung auf Jesus (10,1-21) und gipfelt in der Aussage, Jesus und der Vater seien eins (10,22-29).

${ }^{55}$ Die Textbezeugung von Joh 1,18 belegt verschiedene Lesarten: „der eingeborene/einzige

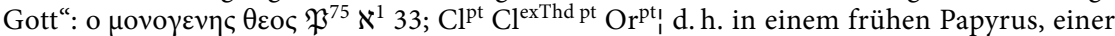
frühen Version des Sinaiticus und den frühen Kirchenvätern. „Der eingeborene/einzige

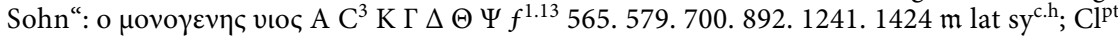

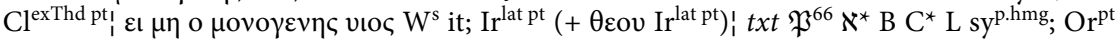
Did'), findet sich in mehr Texten, die aber größtenteils später sind, vgl. Barbara Aland/Kurt Aland u. a. (Hg.), Novum Testamentum Graece, Stuttgart ${ }^{28} 2012$.

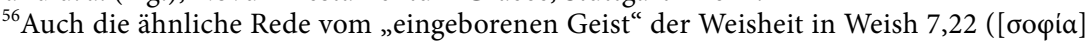

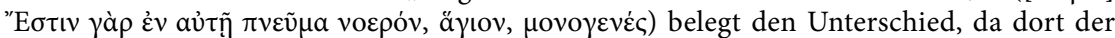
Geist der Weisheit eben nicht Gott ist.
} 
entweder Glaube oder radikale Ablehnung. Genau dieses Phänomen beschreibt das Evangelium in der Reaktion der Juden (z. B. Joh 8). Ihre Heftigkeit resultiert nicht daraus, dass das Zeugnis Jesu ihnen fremd wäre, sondern dass es gerade nicht fremd ist. Der Gott, den Jesus ihnen vermittelt, ist der Gott, den sie kennen - der Gott ihrer Geschichte. Doch der Glaube an Jesus verlangt eine radikale Umgewichtung von Universalität und Partikularität. Auf der Basis der Vorstellung eines transzendenten Gottes und seiner immanenten Form, wie sie aus dem hellenistischen Judentum bekannt ist, entwickelt das Johannesevangelium sein Gottesbild. In der Geschichte des einen Menschen Jesus von Nazareth findet sich der Gott Israels und der ganzen Schöpfung. Dabei ist es gerade nicht so, dass der Vater der Gott Israels ist, dem in Jesus eine zusätzliche Ausdrucksform entstünde - das ist das Missverständnis der Juden in Kap. 8. Gegen dieses Missverständnis betont das Evangelium: Der Name des Gottes Abrahams, des Gottes vom Sinai, ist Jesus. Das ist die Herausforderung der Verkündigung Jesu. 


\title{
Joh 1,18 als Paradigma einer Theo-Logie des Johannesevangeliums
}

\author{
Veronika Burz-Tropper
}

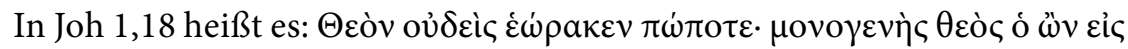

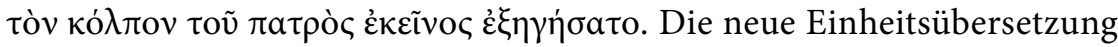
übersetzt diesen Vers wie folgt: Niemand hat Gott je gesehen. Der Einzige, der Gott ist und am Herzen des Vaters ruht, er hat Kunde gebracht.

Jesus wird also am Ende des Johannesprologs - dem Beginn des vierten Evangeliums - als derjenige vorgestellt, der Kunde vom Vater bringt. Für mich ist das der Anlass, das Johannesevangelium auch theo-logisch zu lesen, ja sogar zum Schluss zu kommen, dass das vierte Evangelium intensive Theo-Logie (Gottes-Rede) bietet und weit mehr über Gott-Vater aussagt als bisher in der Forschung beachtet wurde. Jesus als Exeget des Vaters ist für mich in erster Linie nicht christo-logisch zu deuten, sondern theo-logisch. ${ }^{1}$

Joh 1,18 ist der hermeneutische Schlüssel, sozusagen das Paradigma, einer Theo-Logie des Johannesevangeliums. Um die Begründung dieser Ausgangsbasis soll es in diesem Aufsatz primär gehen. Da gerade am Ende des Prologs - und damit an der Schwelle zur eigentlichen Erzählung des Evangeliums - Jesus als derjenige präsentiert wird, der die authentische Auslegung Gottes bringt, muss man das Johannesevangelium auf Jesu Aussagen ${ }^{2}$ bezüglich Gott untersuchen und kann so zu einer erstaunlichen Vielzahl an johanneisch-jesuanischer Gottes-Rede kommen.

Dass es dem Johannesevangelium um eine Beschreibung Gottes geht, hat schon Ludger Schenke vollkommen richtig erkannt: „Von Jesus in seinem tiefsten Sein zu sprechen heißt von Gott sprechen. Für das Johannesevangelium ist die Theologie eben bedeutsamer als die Christologie

\footnotetext{
${ }^{1}$ Dazu passend die Aussage von Udo Schnelle, Das Evangelium nach Johannes (THKNT 4), Leipzig ${ }^{4} 2009,35$ : „[...] an der Stellung und der Interpretation des Prologs entscheidet sich in der Regel das Verständnis des gesamten Evangeliums.“

${ }^{2}$ Jesus offenbart im Johannesevangelium Gott-Vater nicht nur worthaft sondern auch in seinem Wirken. Eine Einschränkung des ohnehin weiten Themas ist aber notwendig und auch durch die Charakterisierung Jesu als Logos gerechtfertigt.
} 
(17,3! Vgl. 17,6; 16,25; 14,6f.), ja die johanneische Christologie ist Theologie. “3

Auch Marianne M. Thompson fasst in ihrer Monographie „The God of the Gospel of John“ den theozentrischen Charakter ${ }^{4}$ des Johannesevangeliums wie folgt zusammen:

"John's fundamental assumption about God is that there is one God, and that this God is the ,only true God', the living Father, the one who alone is God and has ,life in himself ${ }^{\prime}$. As the living God, God is also the source of all life, the creator of all that is. [...] Through focusing attention on the figure of Jesus as the Revealer and Son of God, the one who brings life from God, the Gospel always directs its reader's attention to God. “5

Allerdings haben solche Beobachtungen bislang wenig Resonanz in der gesamten Johannesforschung gefunden und es gibt, soweit ich weiß, zumindest für den deutschsprachigen Raum keine einzige Arbeit, die sich umfassend mit dem Gottesbild des Johannesevangeliums beschäftigt. ${ }^{6}$ Erstaunlicherweise gibt es bislang kaum Arbeiten über Gott im Johannesevangelium, obwohl bereits in den 90er Jahren des letzten Jahrhunderts

${ }^{3}$ Ludger Schenke, Christologie als Theologie. Versuch über das Johannesevangelium, in: Rudolf Hoppe/Ulrich Busse (Hg.), Von Jesus zum Christus. Christologische Studien (FS Paul Hoffmann) (BZNW 93), Berlin u. a. 1998, 446-465: 463. Ob allerdings diese Gleichsetzung von Theologie und Christologie tatsächlich zu 100 Prozent tragfähig ist, muss diskutiert werden. Vgl. auch Konrad Huber, „Wer mich gesehen hat, hat den Vater gesehen" (Joh 14,9). Jesus als Ort der Gottes-Offenbarung im Johannesevangelium, in: Christian Kanzian/Roman Siebenrock (Hg.), Gottesentdeckungen (theologische trends 8), Thaur 1999, 73-87: 76, der ebenfalls betont, dass so sehr Jesus im JohEv auch als Offenbarer dargestellt wird, letztendlich seine Tätigkeit rückgebunden ist an Gottes Wirken und Willen. Huber sieht das besonders deutlich gegeben in den Sendungsaussagen. Michael Theoвald, Gott, Logos und Pneuma. „Trinitarische“ Rede von Gott im Johannesevangelium, in: HansJosef Klauck (Hg.), Monotheismus und Christologie. Zur Gottesfrage im hellenistischen Judentum und im Urchristentum (FS Karl Kertelge) (QD 138), Freiburg u. a. 1992, 41-87: $59 \mathrm{f}$. betont ebenfalls, dass die Sendungsaussagen im JohEv Signal für dessen theozentrischen Charakter sind. Vgl. auch Jean Zumstein, „Niemand hat Gott je gesehen“. Das johanneische Gottesverständnis am Beispiel des Prologs, in: Ulrich H. J. Körtner (Hg.), Gott und die Götter. Die Gottesfrage in Theologie und Religionswissenschaft, Neukirchen-Vluyn 2005, 51-70: 55: „Nach dem Prolog ist die Rede von Jesus nur von Gott her möglich und umgekehrt ist die Rede von Gott nur anhand der Person Jesu durchführbar.“

${ }^{4}$ Zur Frage, ob das JohEv christo- oder theozentrisch ist, vgl. schon Charles K. BARRETT, Christocentric or Theocentric? Observations on the Theological Method of the Fourth Gospel, in: Joseph Coppens (Hg.), La Notion biblique de Dieu. Le Dieu de la Bible et le Dieu des philosophes (BETL 41), Leuven 1976, 361-376, der S. 363 festhält: „John is writing about, and directing our attention to, God."

${ }^{5}$ Marianne M. Thompson, The God of the Gospel of John, Grand Rapids 2001, 239.

${ }^{6}$ Vgl. diesbezüglich auch schon den guten Überblicksartikel Jörg FreY, Was trägt die johanneische Tradition zum christlichen Bild von Gott bei?, in: ders./Uta Poplutz (Hg.), Narrativität und Theologie im Johannesevangelium (BThSt 130), Neukirchen-Vluyn 2012, 217-257. 
zwei renommierte Johannesforscher - Birger Olsson und François Tolmie - ein Desiderat diesbezüglich festgestellt haben. ${ }^{7}$ Seit den 90er Jahren des letzten Jahrhunderts hat sich - wie in der Einführung dieses Bandes gezeigt wurde - der Befund bezüglich Beiträgen zum Gottesthema im Johannesevangelium insofern ein klein wenig geändert als in der Zwischenzeit einige Beiträge zu Gott als Vater im Johannesevangelium der wohl stärksten und häufigsten Metapher für Gott im vierten Evangelium - publiziert worden sind und seit dem Jahr 2000 außerdem drei englischsprachige Monographien erschienen sind, die sich explizit mit Gott im Johannesevangelium auseinandersetzen. ${ }^{8}$

Mein theo-logischer Lektürevorschlag, der auf Joh 1,18 als dem hermeneutischen Schlüssel basiert, wird nun in folgenden Schritten präsentiert: Der Johannesprolog als Eröffnung und Leseanleitung für das gesamte Johannesevangelium (1), Joh 1,18 als Ende des Prologs und das Phänomen der Intratextualität (2), $\mathrm{Zu}$ einer Theo-Logie des Johannesevangeliums exemplarische Arbeitsfelder (3) und Gott im Johannesevangelium - eine nicht zu vernachlässigende Größe (4).

\section{Der Johannesprolog als Eröffnung und Leseanleitung für das gesamte Evangelium}

Der Johannesprolog als der das Johannesevangelium eröffnende Text gehört nach Michael Theobald „wohl zu den biblischen Texten, die sich nicht verbrauchen, auch wenn man sich ein Leben lang mit ihnen befasst“" ; außerdem ist der Johannesprolog sicher einer der am meisten bearbeiteten Texte des Neuen Testaments insgesamt. ${ }^{10}$

\footnotetext{
${ }^{7}$ Siehe dazu meine diesbezüglichen Ausführungen in der Einführung dieses Bandes S. 7.

${ }^{8}$ Siehe dazu Burz-Tropper, Einführung S. 8 f. Aus meiner Forschungsperspektive bedauernswert ist, dass der umfangreiche Band Steven Hunt/François D. Tolmie/Ruben ZimmerMANN, Character Studies in the Fourth Gospel. Narrative Approaches to Seventy Figures in John (WUNT 314), Tübingen 2013 ,articles related to the deity“ (XIII) vermeidet - es finden sich keine Beiträge zu Gott/Vater, Jesus oder Hl. Geist/Paraklet.

${ }^{9}$ Michael TheоваLd, Im Anfang - das Wort. Zum Johannesprolog, in: ders. (Hg.), Studien zum Corpus Iohanneum (WUNT 267), Tübingen 2010, 33-40: 33.

${ }^{10}$ Siehe z. B. die Bibliographie, die Michael Theobald, „Der älteste Kommentar zum Johannesevangelium“ (R. F. Collins)? Zwanzig Jahre Prolog-Forschung, in: ders. (Hg.), Studien zum Corpus Iohanneum (WUNT 267), Tübingen 2010, 41-75: 42-49 für die Jahre 1988 bis Erscheinen seiner Studien anführt, sowie den kürzlich erschienen Band Jan G. vAN DER Watt/R. Alan Culpepper/Udo Schnelle (Hg.), The Prologue of the Gospel of John. Its Literary, Theological, and Philosophical Contexts: Papers read at the Colloquium Iohanneum 2013 (WUNT 359), Tübingen 2016.
} 
Seit Rudolf Bultmann ${ }^{11}$ ist die methodisch-wissenschaftliche Herangehensweise an den Prolog des Johannesevangeliums mit der Frage seiner Genese verbunden, die eine literarische und eine religionsgeschichtliche Seite hat. Zum einen geht es um die Frage: Besitzt der Prolog eine Vorlage? Wenn ja, wie sah diese aus? Welche Verse sind dem Evangelisten zuzuschreiben? Und zum anderen: Aus welcher Geisteswelt kommen der Prolog bzw. seine Vorlage?

Konsens besteht in der Prologforschung lediglich darüber, dass wir es bei dem Text wohl mit einem Hymnus zu tun haben, freilich mit einem überarbeiteten. Uneinigkeit darüber besteht bei der Frage, wie der ursprüngliche Text des Hymnus aussah und worin die Zusätze des Evangelisten bestehen. ${ }^{12}$ Was den religionsgeschichtlichen Hintergrund betrifft, herrscht weitgehend die Meinung vor, dass die im Prolog vorkommenden Vorstellungen eher von alttestamentlichen und frühjüdischen Weisheitsvorstellungen geprägt sind als von gnostischen Erlösungsvorstellungen. ${ }^{13}$ Das Bultmannsche Paradigma eines gnostisch geprägten Täufer-Hymnus ${ }^{14}$ scheint also überwunden zu sein.

Diese diachronen Fragen sollen im Rahmen dieses Beitrages aber nicht beschäftigen, da es mir bei der theo-logischen Lesart des Evangeliums primär um eine synchrone Lektüre geht. ${ }^{15}$ Ich sehe die Funktion des

\footnotetext{
${ }^{11}$ Vgl. dazu etwa Rudolf Bultmann, Der religionsgeschichtliche Hintergrund des Prologs zum Johannesevangelium. Erstveröffentlicht 1923, in: ders. (Hg.), Exegetica. Aufsätze zur Erforschung des Neuen Testaments. Ausgewählt, eingeleitet und herausgegeben von Erich Dinkler, Tübingen 1967, 10-35 sowie die Ausführungen zum Prolog in seinem Kommentar Rudolf Bultmann, Das Evangelium des Johannes. Studienausgabe (KEK 2), Göttingen ${ }^{20} 1985,1-57$.

${ }^{12} \mathrm{Vgl}$. dazu die Auflistung der diversen Rekonstruktionsversuche aus den letzten 20 Jahren und die Ausführungen bei Theoвald, Zwanzig Jahre Prolog-Forschung (Anm. 10) 57-61.

${ }^{13}$ So explizit etwa Klaus Wengst, Das Johannesevangelium. 1. Teilband: Kapitel 1-10 (ThKNT 4,1), Stuttgart 2000, $37 \mathrm{f}$. Siehe dazu auch meinen Artikel Veronika Burz-Trop per, Weisheitliche Traditionen im Johannesprolog revisited, PZB 23 (2014) 83-106.

${ }^{14}$ Rudolf Schnackenburg, Das Johannesevangelium. I. Teil. Kommentar zu Kap. 1-4 (HTKNT 4,1), Freiburg u. a. ${ }^{7} 1992,205-207$ bietet eine kurze Zusammenfassung der Bultmannschen Auffassung und benennt die wesentlichen Kritikpunkte.

${ }^{15}$ Die nachfolgend angeführten Forschungsüberblicke zeigen, dass in den letzten Jahrzehnten die synchrone Herangehensweise an das Johannesvangelium überwiegt. Siehe dazu Klaus Scholtissek, Johannes auslegen I. Forschungsgeschichtliche und methodische Reflexionen, SNTSU 24 (1999) 35-84. DERS., Johannes auslegen II. Methodische, hermeneutische und einleitungswissenschaftliche Reflexionen, SNTSU 25 (2000) 98-140. DERs., Johannes auslegen III. Ein Forschungsbericht, SNTSU 27 (2002) 117-153. DERs., Johannes auslegen IV. Ein Forschungsbericht, SNTSU 29 (2004) 67-118. Udo Schnelle, Aus der Literatur zum Johannesevangelium 1994-2010. Erster Teil: Die Kommentare als Seismographen der Forschung, TRev 75 (2010) 265-303. Konrad Haldimann/Hans Weder, Aus der Literatur zum Johannesevangelium 1985-1994. Zweiter Teil: Synchrone Analysen, in: TRev 67 (2002)
} 
Johannesprologs diesbezüglich mit Johannes Beutler ${ }^{16}$, Michael Theobald ${ }^{17}$, Jean Zumstein ${ }^{18}$ u. a. darin, das Evangelium zu eröffnen ${ }^{19}$ und damit dezidiert eine Leseanleitung zu geben. ${ }^{20}$

75-115. DIEs., Aus der Literatur zum Johannesevangelium 1985-1994. Dritter Teil: Theologische Akzentuierungen (I), TRev 71 (2006) 91-113.

${ }^{16}$ Johannes Beutler, Der Johannes-Prolog - Ouvertüre des Johannesevangeliums, in: ders. (Hg.), Neue Studien zu den johanneischen Schriften (BBB 167), Göttingen 2012, 215-238.

${ }^{17}$ Michael Tнеовацd, Die Fleischwerdung des Logos. Studien zum Verhältnis des Johannesprologs zum Corpus des Evangeliums und zu 1 Joh (NTAbh 20), Münster 1988, 490 charakterisiert den Prolog von der Textsorte her als einen "reflektierte[n] Eröffnungstext“. Vgl. auch seine diesbezügliche Aussage S. 267: „Eröffnungstexte, die an Umfang und gedanklicher Tiefe dem Joh-Prolog gleichkämen, sucht man im zeitgenössischen jüdischen und christlichen Schrifttum vergebens. [...] Aber ein Vergleich mit diesen Texten, die verschiedene Typen von Texteröffnungen repräsentieren, bestätigt nur den ersten Eindruck, daß der Joh-Prolog ein Eröffnungstext sui generis ist."

${ }^{18}$ Jean Zumstein, Der Prolog, Schwelle zum vierten Evangelium, in: ders. (Hg.), Kreative Erinnerung. Relectüre im Johannesevangelium (ATANT 84), Zürich 2004 (1995), 105-126: 115 konstatiert: „Der Prolog fasst nicht den Plot der Erzählung zusammen, sondern er sagt, wie die Erzählung, die sich anschließend entfalten wird, zu lesen ist.“

${ }^{19}$ Der Charakter als Eröffnungstext wird unterschiedlich beurteilt: Für SchnACKEnBurg, Johannesevangelium (Anm. 14) 200 ist der Prolog „eher ein theologischer ,Anfangsbericht", eine gläubige Kundmachung der ,Vorgeschichte', die ihre Wende zur ,Geschichte Jesu' im Ereignis der Inkarnation erreicht." Ludger SCHEnKE, Johannes. Kommentar, Düsseldorf 1998, 18 bezeichnet den Prolog als „Schlüssel zum Ganzen, das Portal, durch das die Leser eintreten sollen in die Welt des JohEv". Auch für Schnelle, Evangelium (Anm. 1) 54f. hat der Pro$\log$ „die Funktion eines programmatischen Eröffnungstextes. Sowohl seine Stellung als auch die vom Evangelisten eingearbeiteten Metareflexionen legen diese Klassifizierung nahe. Am Anfang des Evangeliums dient der Prolog als Lektüreanweisung für den Leser, indem er das vom Evangelisten beabsichtigte Verständnis des Folgenden prägnant formuliert." Nach Christian Dietzfelbinger, Das Evangelium nach Johannes (ZBK.NT 4), Zürich ${ }^{2} 2004,20$ eignet sich die Bezeichnung „Ouvertüre“ für den Prolog des JohEv nur bedingt, sofern man von einer solchen erwartet, dass in ihr alle Motive des folgenden Werkes anklingen. Für ihn ist „Ouvertüre“ dennoch eine „nicht gänzlich, aber immerhin teilweise zutreffende Charakterisierung des Prologs" (ebd. 21). Wengst, Johannesevangelium (Anm. 13) 42 spricht von einem „Vor-Wort in dem prägnanten Sinn, dass er [der Prolog] eine ,Leseanweisung' für die folgende Erzählung gibt“. Für ihn ist es „durchaus berechtigt“, den Prolog als „Ouvertüre“ zu charakterisieren (ebd. 42). Bultmann, Evangelium (Anm. 11) 1 sieht im Prolog eine Einführung, „etwa im Sinn einer Ouvertüre“. Barnabas Lindars, The Century Bible. The Gospel of John (NCBC), London 1972, $81 \mathrm{f.:} \mathrm{„It} \mathrm{is} \mathrm{not} \mathrm{difficult} \mathrm{to} \mathrm{imagine} \mathrm{John} \mathrm{writing} \mathrm{the} \mathrm{Prologue}$ as a curtain-raiser for the Gospel, like the overture of an opera, using a Wisdom poem as his model, and bringing in various themes which he has explored in the course of his work." Vgl. auch Urban C. von WAHLDE, The Gospel and Letters of John. Volume 2. Commentary on the Gospel of John (The Eerdmans Critical Commentary), Grand Rapids 2010, 24; Joachim GnilkA, Johannesevangelium (NEB.NT 4), Würzburg 1983, 13. Bei Raymond E. Brown, The Gospel According to John (I-XII) (AB 38a), New York 1966 findet sich diesbezüglich leider keine definitive Aussage. Charles K. Barret, The Gospel According to St John. An Introduction with Commentary and Notes on the Greek Text, London ${ }^{2} 1978$ äußert sich diesbezüglich in seinen Ausführungen zum Prolog (149-170) nicht.

${ }^{20}$ Grundsätzlich schließe ich mich der exegetischen Mehrheitsmeinung an, dass das Jo- 
Jean Zumstein kommt zum einen über die Analyse der Gattung der „Vorrede“ in der griechischen und lateinischen Literatur der Antike ${ }^{21}$ und zum anderen über die moderne Literaturwissenschaft und die Theorie des Paratextes ${ }^{22}$ zum Schluss: „[d]er Prolog ist eine Vorrede, deren Funktion darin besteht, die Lektüre zu leiten, die Dekodierung der Erzählung zu kontrollieren und Fremdinterpretationen zuvorzukommen “23.

Im Anschluss daran, also die Prologfunktion darin zu sehen, die Lektüre des Nachfolgenden zu leiten, möchte ich v. a. die Aussage am Ende des Prologs in Joh 1,18 ernstnehmen und als Lektüreanleitung für das gesamte Evangelium verstehen. Deshalb erfolgt im nächsten Schritt zunächst ein genauer Blick auf den den Prolog abschließenden Vers.

\section{Joh 1,18 als Ende des Johannesprologs}

\subsection{Textkritische Schwierigkeiten und solche der Übersetzung in Joh 1,18}

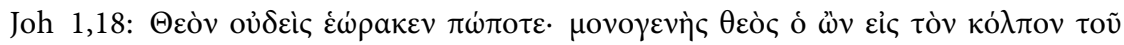

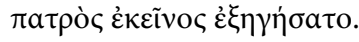

Der Vers liefert den Auslegerinnen und Auslegern einige textkritische und übersetzungstechnische Schwierigkeiten:

a) Nicht wenige Textzeugen $\left(\mathrm{A} \mathrm{C}^{3} \mathrm{~K} \Gamma \Delta \Theta \Psi \mathrm{f}^{1.13}\right.$ 565. 579. 700. 892.

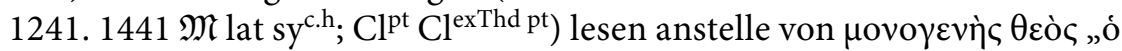

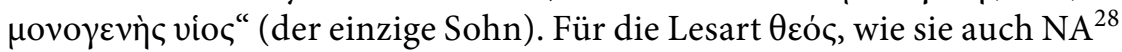
wiedergibt, sprechen v. a. die äußere Bezeugung $\left(\mathfrak{P}^{66} \aleph^{\star} B C^{\star} L\right.$ sy ${ }^{\text {p.hmg; }}$

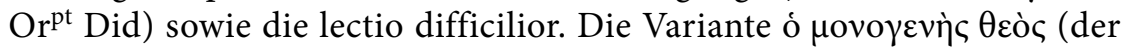
einzige Gott) $\left(\mathfrak{P}^{75} \mathrm{\aleph}^{1} 33 \mathrm{pc}\right.$; $\left.\mathrm{Cl}^{\mathrm{pt}} \mathrm{Cl}^{\mathrm{ex} \text { Thdpt }} \mathrm{Or}^{\mathrm{pt}}\right)$ lässt sich als Abwandlung davon verstehen. Die Lesart mit víoৎ (Sohn) lässt sich als Vereinfachung

hannesevangelium die erste Schrift im Corpus Johanneum ist. Vgl. diesbezüglich auch die Anm. 56 im Beitrag von Jörg Frey S. 263 in diesem Band. Anders hingegen Udo SCHNELLE, Die Reihenfolge der johanneischen Schriften, NTS 57 (2011) 91-113.

${ }^{21}$ Vgl. dazu auch schon Elizabeth Harris, Prologue and Gospel. The Theology of the Fourth Evangelist (JSNTSup 107), Sheffield 1994.

${ }^{22}$ Dazu bezieht sich Zumstein, Prolog (Anm. 18) auf Georges JacQues/Fernand Hallyn, Aspects du paratexte, in: Maurice Delcroix/Fernand Hallyn (Hg.), Introduction aux études littéraires. Méthodes du texte, Paris u. a. ${ }^{4} 1987,202-216$. Das Konzept des Paratextes wiederum stammt vom Literaturwissenschafter Gérard Genette - vgl. dazu etwa Gérard Genette/Dieter Hornig/Harald Weinrich, Paratexte. Das Buch vom Beiwerk des Buches, Frankfurt a. M. 1989, bes. die Einleitung 9-21.

${ }^{23}$ Zumstein, Prolog (Anm. 18) 115. 
in Bezug auf den biblischen Monotheismus charakterisieren, ${ }^{24}$ ebenso die

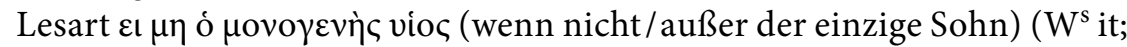
$\mathrm{Ir}^{\text {lat }} \mathrm{pt}\left(+\theta \varepsilon\right.$ oṽ $\left.\mathrm{Ir}^{\text {lat pt}}\right)$. Des Weiteren fügen $\mathrm{W}^{\mathrm{s}} \mathrm{c} \mathrm{sy}^{\mathrm{c}}$ am Ende des Verses ein $\dot{\eta} \mu \tilde{v} v$ an, was gleichfalls als Vereinfachung des objektlosen $\dot{\varepsilon} \xi \eta \gamma \eta \dot{\sigma} \sigma \tau$, das lectio difficilior (die alle ständigen Zeugen bieten) ist, zu verstehen ist.

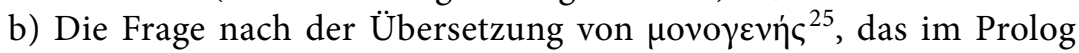
neben unserem V. 18 auch noch in V. 14 auftaucht: Das Adjektiv, das "einzig, einzigartig" bedeutet, kommt im NT insgesamt nur neunmal vor, davon fünfmal im johanneischen Schrifttum (Joh 1,14.18; 3,16.18; 1 Joh 4,9), und ist in allen fünf johanneischen Fällen auf Jesus bezogen. In den übrigen vier neutestamentlichen Fällen geht es immer um Kinder anderer Personen: im Lukasevangelium (Lk 7,12; 8,42; 9,38) im Kontext von Heilungswundern, in Hebr 11,17 um Isaak als Sohn Abrahams. ${ }^{26}$

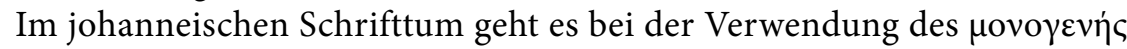
immer um die Verhältnisbestimmung Jesu zu Gott und nicht nur um seine Einzigartig- bzw. Unvergleichlichkeit. Jesus ist als der Sohn „der Einzige“ vom Vater, in seiner Beziehung zu und Sendung von diesem. Ob dabei auch an die Geburt (im Sinne von einziggeboren bzw. einziggezeugt) zu denken ist, lässt sich nicht eindeutig klären. ${ }^{27}$ Joseph Fitzmyer ist der grundsätzlichen Ansicht: „Der ,Logos' ist nach Joh 1,14.18 der ,Einzige vom Vater, und zwar in seiner Eigenschaft als dessen einziger Offenbarer." ${ }^{28}$

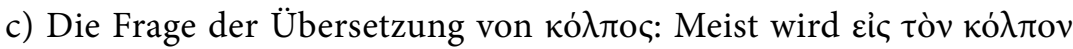

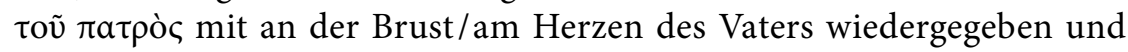
damit die Assoziation hergestellt von einem Kleinkind an der Brust des Vaters oder vom an der Brust Liegen des Freundes beim Gastmahl (vgl. auch Joh 13,23). Es gibt allerdings gute Gründe, die für die Übersetzung

\footnotetext{
${ }^{24}$ Vgl. bspw. Lindars, John (Anm. 19) $98 \mathrm{f}$.

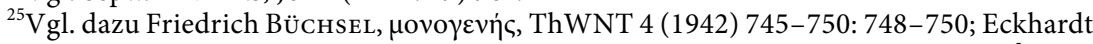

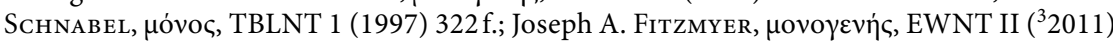
1081-1083.

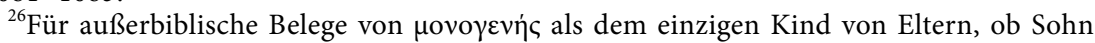

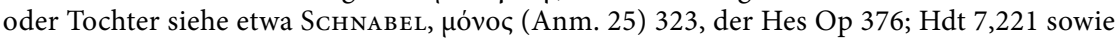
Hes Theog 426 anführt. Fitzmyer, povoүevís (Anm. 25) 1081 verweist darauf, dass sich dieser Gebrauch auch in LXX findet (Ri 11,34; Tob 3,15; 6,10.14; 8,17; möglicherweise auch

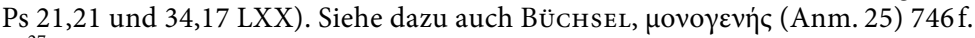

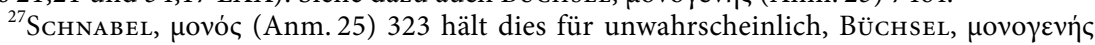
(Anm. 25) 749 f. jedoch für wahrscheinlich; vgl. dazu auch die Ausführungen von Christiane Zimmermann in diesem Sammelband, S. 174f. bes. Anm. 37, die es für mich wahrscheinlicher machen, auch tatsächlich an Geburt zu denken.

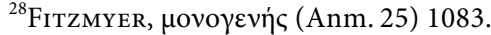


„im Schoß“ sprechen. Der Alttestamentler Hartmut Gese ${ }^{29}$ hat bereits 1977 dafür plädiert, an das Bild des im Schoß ruhenden, mit den Armen gehaltenen Kindes zu denken. Sprachlich ist das durchaus möglich,

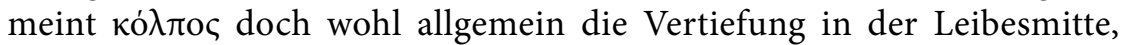
die beim Beugen des Körpers im Sitzen oder Liegen entsteht. Otfried Hofius ist 1989 in einem ZNW-Artikel ${ }^{30}$ darauf eingegangen und versucht, dies noch durch rabbinische Texte zu bestätigen. Joachim Kügler ${ }^{31}$ bemüht sich, in einem Beitrag diese Übersetzung dann auch motivgeschichtlich zu unterstützen. Besonders beachtenswert und bisher wenig rezipiert scheinen Ausführungen Küglers zum Befund in neutestamentlicher Zeit, sowohl im paganen wie auch im biblischen Bereich. Besonders in einer Notiz des Sueton über Kaiser Claudius und dessen Sohn Britannicus wird deutlich, dass eine enge Verbindung der Schoß-Geste mit der Vaterschaftsbestätigung und der öffentlichen Herrschaftsdesignation besteht. ${ }^{32}$ Den Aspekt der Herrschaftsdesignation sieht Kügler schließlich auch für Joh 1,18 gegeben. ${ }^{33}$ Andererseits kommt Bianca Lataire in

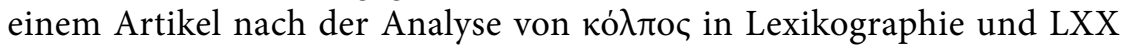
$\mathrm{zu}$ folgendem Schluss:

„[...] the noun is found in contexts of parent-child relationships, especially in connection with the concrete way a parent holds his/her child. It is difficult, however, to determine whether the child is carried in the lap, at the bosom (not to understand as the mother's breast since men also carry infants at their bosom), or in/on the arms. But it is obvious that all of these passages say something about the care, protection and/or love, tenderness and affection of the parent for the child. Is

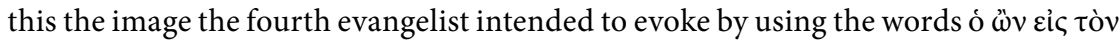

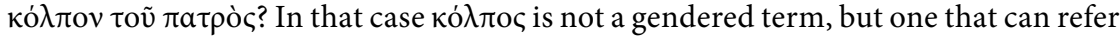
to women and men as parents or nurses. Further research is required to determine whether the fact that John uses kó $\lambda \pi$ ro with regard to Jesus' Father in 1:18 implies a correction of a patriarchal father image with the help of an expression that connotes tenderness, care and affection. “ 34

\footnotetext{
${ }^{29}$ Hartmut Gese, Der Johannesprolog, in: ders. (Hg.), Zur biblischen Theologie. Alttestamentliche Vorträge, Tübingen ${ }^{3} 1989$ (1977), 152-201: 169.

${ }^{30}$ Otfried Hofius, „Der in des Vaters Schoss ist“. Joh 1,18, ZNW 80 (1989) 163-171.

${ }^{31}$ Joachim KÜGLER, Der Sohn im Schoß des Vaters. Eine motivgeschichtliche Notiz zu Joh 1,18, BN 89 (1997) 76-87.

${ }^{32}$ Vgl. Kügler, Sohn (Anm. 31) $83 \mathrm{f}$.

${ }^{33}$ Vgl. KüGLER, Sohn (Anm. 31) 85.

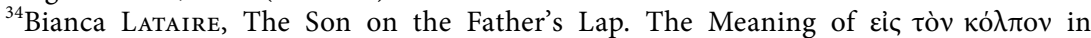
John 1:18, SNTSU 22 (1997) 125-138: 138.
} 
Hier stellt sich die Frage, inwiefern sich diese beiden Positionen - der Aspekt der Herrschaftsdesignation und derjenige von Zärtlichkeit und Liebe vereinbaren lassen.

d) Die Frage der Übersetzung von $\grave{\varepsilon} \xi \eta \gamma \eta \dot{\sigma} \sigma \tau{ }^{35}$ : Außer an unserer Stelle kommt das Verb im NT nur fünfmal im lukanischen Doppelwerk (Lk 24,35; Apg 10,8; 15,12.14; 21,19) vor, wo es in allen Fällen in der Bedeutung „erzählen, berichten“ verwendet wird. In der ursprünglichen Wortbedeutung kann es auch „Anführer sein, leiten, etwas voll und klar bekanntmachen" heißen. Für Joh 1,18 ist die Bedeutung nicht ganz unumstritten. Friedrich Büchsel, ${ }^{36}$ Helge Stadelmann ${ }^{37}$ sowie Gerhard Schneider $^{38}$ betonen in ihren Wörterbuchbeiträgen die Offenbarerrolle Jesu und plädieren für eine Übersetzung mit „erzählen/darlegen“, „bekanntmachen“ „Kunde/Offenbarung bringen“. Die allermeisten deutschen Übersetzungen folgen diesem Vorschlag. Ausnahme ist die Übersetzung der Bibel in gerechter Sprache: „Der Einziggeborene, der im Mutterschoß des Vaters ist, jener ist uns vorangegangen." Ähnlich ist schon Ignace de la Potterie ${ }^{39}$ in Auseinandersetzung mit Marie-Émile Boismard ${ }^{40}$ und René Robert ${ }^{41} \mathrm{zu}$ dem Schluss gekommen, dass das Ende von V. 18 mit ,jener hat den Weg (zum Vater) geöffnet" zu übersetzen sei. Im Gesamt des Johannesevangeliums macht allerdings die Übersetzung mit „,jener berichtete/legte aus/offenbarte/brachte Kunde" mehr Sinn. Michael Theobald ist zudem absolut zuzustimmen: „Der absolute objektlose Gebrauch

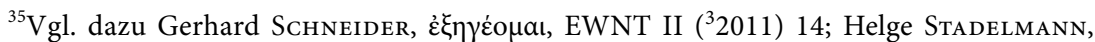

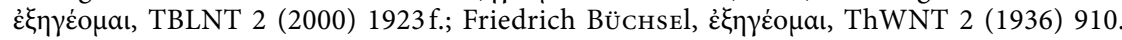
Sehr detailliert am Begriff arbeitet neuerdings Philippe van den Heede, Der Exeget Gottes. Studie zur johanneischen Offenbarungstheologie (HBS 86), Freiburg 2017, 67-80. Dem Autor geht es in seiner Studie vor allem um die Herausstellung Jesu als Exeget Gottes, wobei der Inhalt der Offenbarung $\mathrm{m}$. E. etwas vage bleibt bzw. sich wieder auf Jesus selbst konzentriert.

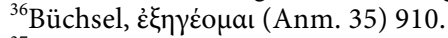

${ }^{37}$ StadelmanN, $\dot{\varepsilon} \xi \eta \dot{\varepsilon}$ oual (Anm. 35) 1924.

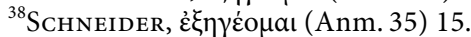

${ }^{39}$ Vgl. Ignace De LA Potterie, „C'est lui qui a ouvert la voie“. La finale du prologue johannique, Bib. 69 (1988) 340-370. Ähnlich dann auch noch Luc Devillers, Le sein du Père. La finale du prologue de Jean, RB 112 (2005) 63-79. Zur Kritik daran vgl. etwa Johannes Beutler, Das Johannesevangelium. Kommentar, Freiburg 2013, 96 Anm. 55: „Der Vorschlag bleibt stark hypothetisch und dürfte daran scheitern, dass im vorhergehenden und folgenden Kontext von der Mitteilung des Wortes bzw. der Kenntnis Gottes und nicht vom Zugang zu ihm die Rede ist." Zu Beutler ist allerdings auch wieder kritisch anzumerken, dass durchaus Rede bzw. Kenntnis von jemandem auch Zugang zu diesem verschaffen können.

${ }^{40}$ De la Potterie führt als Referenz an: Marie-Émile Boismard, Synopse des quatres évangiles en français. III: L’Evangile de Jean, Paris 1978.

${ }^{41}$ De la Potterie führt als Referenz an: René Roвert, La double intention du mot final du prologue johannique, RThom 87 (1987) 435-441.
} 
dieses Verbs kann nur den Sinn haben, den Hörer, der sich als Objekt selbst ergänzen kann, ganz auf die actio des Wortgeschehens selbst zu konzentrieren. " ${ }^{2}$ Völlig zu Recht hat auch Konrad Huber betont, dass das Verb „als letztes Wort des Johannesprologs eine gewisse Betonung “ ${ }^{43}$ erhält.

Mein Übersetzungsvorschlag für Joh 1,18 lautet daher: Gott hat niemand jemals gesehen: Der Einzige (, der) Gott (ist), der Seiende im Schoß des Vaters, jener legte aus. Es geht bei diesem Auslegen, ja nicht nur um inhaltliche Informationen, was die Übersetzung „Kunde bringen“ möglicherweise implizieren könnte. Das authentische Auslegen des Vaters durch den Sohn in seinem Sprechen und Wirken erschließt diesen (d.h. den Vater) in einem über das Kognitive hinausgehenden Sinn.

\subsection{Der Zusammenhang von Joh 1,18 mit Joh 1,1 f.14.17}

Am Ende des Prologs wird Jesus also ganz explizit als der Exeget des Vaters bezeichnet. Mit seiner Aussage, dass Jesus, als der einzige, der auch Gott ist, dessen Auslegung bietet, d. h. ihn den Menschen erschließt, leitet der Vers Joh 1,18 nicht nur über zum folgenden Erzählcorpus des Evangeliums, sondern bildet mit den Eröffnungsversen 1,1f. eine Klammer um den gesamten Prolog.

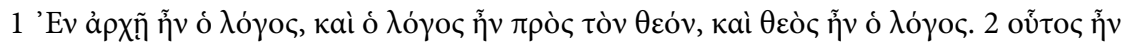

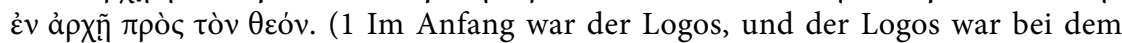
Gott, und Gott war der Logos. 2 Dieser war im Anfang bei dem Gott.)

Die VV. 1 f. ${ }^{44}$ kennzeichnen den Logos ${ }^{45}$, das Wort, als $\theta \varepsilon \varsigma^{46}{ }^{4}$, d. h. Gott.

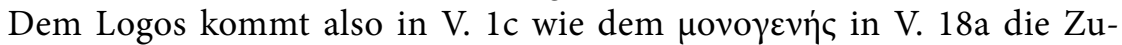

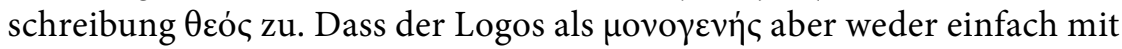

\footnotetext{
${ }^{42}$ Theobald, Fleischwerdung (Anm. 17) 261.

${ }^{43}$ Huber, Gottes-Offenbarung (Anm. 3) 86 Anm. 5.

${ }^{44}$ Mit dem Beginn seines Evangeliums führt der vierte Evangelist seine Leserinnen und Leser an den Uranfang zurück. V. 1 spielt eindeutig auf Gen 1,1 LXX an und geht eigentlich noch darüber hinaus: in die Ewigkeit Gottes. Aus dieser stammt der Logos, das Wort. Aus ihr kommt er in die Welt und wird Fleisch. Vgl. dazu etwa BeutLer, Johannesevangelium (Anm. 39) 78.83.

${ }^{45}$ Für einen kurzen Überblick zum Logosbegriff siehe etwa meine diesbezüglichen Ausführungen in Burz-Tropper, Weisheitliche Traditionen (Anm. 13) 99-104.

${ }^{46} \mathrm{Im}$ NT kommt $\theta$ có insgesamt 1318-mal vor und ist damit das meist verwendete Substantiv. Im Johannesevangelium finden sich 83 Belege, wovon 49 Gott direkt erwähnen, wobei in $1,1 \mathrm{~b}$ und $1,18 \mathrm{~b}$ der Logos als $\theta \varepsilon$ có bezeichnet wird. 32 Belege bringen Genetiv-

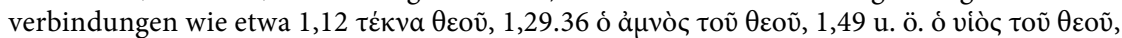

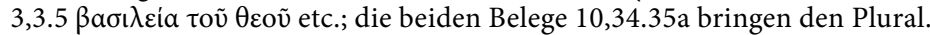


Gott(Vater) identisch ist noch als zweiter Gott neben dem höchsten Gott steht, wird dadurch deutlich, dass in diesen beiden Fällen $\theta \varepsilon o ́ \varsigma$ ohne Artikel benutzt wird. Das bedeutet somit: Der Logos ist vom Wesen Gottes, er ist von seiner Art her Gott, aber nicht mit ihm gleichzusetzen. Mit Udo Schnelle kann festgehalten werden: „Bewußt steht in V. 1c das Prädikatsnomen $\theta \varepsilon$ có, um so gleichermaßen das göttliche Wesen des Logos und seine Unterschiedenheit vom höchsten Gott auszudrücken. “ ${ }^{47}$ Durch diese grammatikalische Konstruktion erhebt das vierte Evangelium den Anspruch, im Rahmen des jüdischen Monotheismus zu bleiben: Der Logos ist vom Wesen Gottes aber nicht mit Gott gleichzusetzen! Der Ort des Wortes ist Gott, im Wort spricht Gott umfassend aus sich heraus. Deshalb kann auch nur der Logos, der erst in V. 17 mit Jesus Christus ${ }^{48}$ identifiziert wird, Gott auslegen, ihn den Menschen erschließen, wie V. 18 sagt! ${ }^{49}$ V. 2 ist als Zusammenfassung von V. 1 zu sehen: Der Logos war schon immer, von Ur-Anfang bei Gott. Zu Recht betont Michael Theobald die Bedeutung von V. 2 für das johanneische Gottesbild, da er die Worthaftigkeit des Wesens Gottes von Anfang an unterstreicht. ${ }^{50}$

Der Begriff Logos wird nach V. 1 erst wieder in V. 14 aufgegriffen,

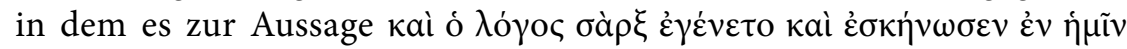
(und das Wort ist Fleisch geworden und hat unter uns gezeltet) kommt. Für viele Ausleger steht hinter dem gesamten Abschnitt 1,14-18 die Exodusüberlieferung, näherhin die Sinaitheophanie, auch wenn die Gestalt des Mose erst in V. 17 explizit zur Sprache gebracht wird. ${ }^{51}$ Schließlich steht der den Prolog abschließende V. 18 in einem Parallelismus zu V. 17,

\footnotetext{
${ }^{47}$ SCHNELLE, Evangelium (Anm. 1) 38f.

${ }^{48}$ Zur Bezeichnung Jesu als $\theta$ có $\varsigma$ vgl. den guten Überblicksartikel Ralph BrUCKer, Jesus als Gott. $\Theta E O \Sigma$ als christologischer Hoheitstitel und seine Implikationen für den neutestamentlichen Monotheismus, in: Wiard Popkes/Ralph Brucker (Hg.), Ein Gott und ein Herr. Zum Kontext des Monotheismus im Neuen Testament (BThSt 68), Neukirchen-Vluyn 2004, 101-138.

${ }^{49}$ Vgl. diesbezüglich auch Veronika Burz-Tropper, Ich bin ... Wer bin ich? Das Christusbild im Johannesevangelium, in: Ingrid Penner/Franz Kogler (Hg.), Aus der Quelle schöpfen: Ideen und Materialien zum Johannesevangelium, Linz 2016, 20.

${ }^{50}$ Vgl. Michael Theobald, Das Evangelium nach Johannes. Kapitel 1-12 (RNT), Regensburg 2009, 111: „Für das Gottesbild des Evangelisten ist diese Aussage von schlechthin nicht zu überschätzender Bedeutung: ,Gott' ist kein stummes Fatum, kein blindes Schicksal, nicht Fortuna. Er ist kein undurchschaubarer, unheimlicher oder drohender Dämon. Er ist immer schon ein sich im Wort äußernder Gott, ein Gott-in-Beziehung. Der Akzent ruht in V. 2 auf dem ,im (Ur-)Anfang bei Gott'. Der Vers unterstreicht die Worthaftigkeit als ,vom (Ur-)Anfang' her zum Wesen Gottes gehörig.“

${ }^{51}$ Vgl. dazu etwa Beutler, Johannesevangelium (Anm. 39) 94. Nicht außer Acht gelassen werden darf aber auch hier die Weisheitstradition - vgl. diesbezüglich Burz-Tropper, Weisheitliche Traditionen (Anm. 13) 96.
} 
machen doch zwei Antithesen den Inhalt dieser beiden Verse aus: Zum einen stehen sich in V. 17 die Gesetzesgabe auf Vermittlung des Mose hin und das Kommen von Gnade und Wahrheit in Jesus Christus gegenüber. Zum anderen wird in V. 18 die Unsichtbarkeit Gottes und seine Schau durch Jesus Christus, den Exegeten des Vaters, ausgesagt. ${ }^{52}$

Außerdem bildet der Prolog insgesamt mit dem Thomasbekenntnis in

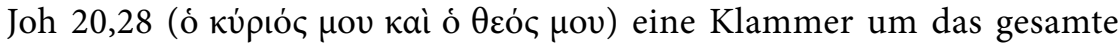
Evangelium, da im Evangelium ausschließlich in diesen beiden Texten Jesus explizit als $\theta$ có bezeichnet wird. ${ }^{53}$

Von diesem Beginn bzw. (Teil des ursprünglichen) Ende des Evangeliums her ist durchaus verständlich, warum die Forschung zum Johannesevangelium dermaßen von christologischen Fragen geprägt ist ${ }^{54}$ : So deutlich wie im Johannesevangelium erfolgt die Bezeichnung Jesu als $\theta \varepsilon o ́ \varsigma$ sonst nirgends im Neuen Testament. ${ }^{55}$

Ich möchte allerdings behaupten, dass die zugespitzte Christologie des Johannesevangeliums aufgrund ihres monotheistischen Denkrahmens Rede von Gott ist. Gerade auf der Basis des Prologs, speziell von 1,18, erscheint eine theo-logische Lesart notwendig und angemessen. Schon Udo Schnelle konstatiert in seinem Kommentar bei der Auflistung zahlreicher intratextueller Bezüge des Prologs zum Rest des Evangeliums: „Schließlich führt V. 18 genau zu dem Punkt, wo die Offenbarungstätigkeit des inkarnierten Logos einsetzt (vgl. zur Gottesschau Joh 5,37; 6,46; 14,9). Jesus Christus erscheint als die einzig authentische Auslegung Gottes." ${ }^{66}$ Das muss auch in Bezug auf das Gottesbild des Johannesevangeliums ernstgenommen werden.

\footnotetext{
${ }^{52} \mathrm{Vgl}$. dazu etwa Beutler, Johannesevangelium (Anm. 39) 96.

${ }^{53}$ Dass hierin eine Inklusion zu sehen ist, kann als Konsens der Forschung angesehen werden. Vgl. nur Beutler, Johannesevangelium (Anm. 39) 93; Schnelle, Evangelium (Anm. 1) 54; Theobald, Evangelium (Anm. 51) 136; Hartwig Thyen, Das Johannesevangelium (HNT 6), Tübingen ${ }^{2} 2015,106$.

${ }^{54}$ Dass die christologische Frage einen Schwerpunkt der Johannesforschung bildet, zeigt sich auch in diversen neueren Forschungsüberblicken zum Johannesevangelium. Siehe etwa Haldimann/Weder, Literatur 3,1 (Anm. 15) 103-113; dies., Literatur 3,2 (Anm. 15); SCHOLTissek, Johannes auslegen IV (Anm. 15) 94-100.

${ }^{55} \mathrm{Vgl}$. BruCKer, Jesus (Anm. 48).

${ }^{56}$ SCHNelLe, Evangelium (Anm. 1) 37.
} 


\subsection{Methodische Herangehensweise}

Jeder Text geht nach seiner Fertigstellung und Veröffentlichung einen eigenständigen Weg und faktisch stirbt der Autor für den Text. ${ }^{57}$ Mit anderen Worten: Auch biblische Texte sind jedenfalls mehrdeutig und interpretationsoffen. ${ }^{58} \mathrm{Zu}$ beachten ist dabei allerding, dass Umberto Eco, auf den sich viele Exegetinnen und Exegeten in ihren Arbeiten berufen, Wert darauf legt, „dass die intentio lectoris ihre Leitlinie und ihre Grenze findet in der intentio operis “ ${ }^{59}$. Helmut Utzschneider zitiert diesbezüglich Eco:

„Die Initiative des Lesers besteht im Aufstellen einer Vermutung über die intentio operis. Diese Vermutung muß vom Komplex des Textes als einem organischen Ganzen bestätigt werden. Das heißt nicht, daß man zu einem Text nur eine einzige Mutmaßung aufstellen kann. Im Prinzip gibt es unendlich viele. Zuletzt aber müssen sich diese Vermutungen an der Kongruenz des Textes bewähren, und die Textkongruenz wird zwangsläufig bestimmte voreilige Vermutungen als falsch verwerfen. “60

Auf Basis von Joh 1,18 ist es durchaus legitim, das Johannesevangelium auch theo-logisch zu lesen. Man muss den Versuch unternehmen, der Frage nachzugehen, ob die theo-logische Lesart der Textkongruenz des Evangeliums standhält. Ich möchte das im Folgenden an einigen Beispielen erläutern, zunächst aber noch kurz meine diesbezügliche methodische Herangehensweise der Intratextualität im Kontext der Intertextualität darlegen.

\footnotetext{
${ }^{57}$ Vgl. Wilhelm EgGer/Peter Wick, Methodenlehre zum Neuen Testament (Grundlagen Theologie), Freiburg ${ }^{6} 2011,55$. Dort wird festgehalten: „Der Leser übernimmt die Führung und wird zum Interpreten, der vor, während und nach der Lektüre unabhängig vom Autor Bezüge herstellen kann. Rückfragen an den Autor sind nur zu dessen Lebzeiten möglich. Nach dem biologischen Tod des Autors fällt auch diese Möglichkeit weg. Dann gehört der Text ganz seinen Lesern (und somit seinen Interpreten). “Zu Autorintention, Leserrezeption und Textsinn vgl. näherhin Thomas SöDING, Wege der Schriftauslegung. Methodenbuch zum Neuen Testament. Unter Mitarbeit von Christian Münch, Freiburg 1998, 237-248.

${ }^{58} \mathrm{Vgl}$. dazu etwa Thomas Hieke/Tobias Nicklas, „Die Worte der Prophetie dieses Buches". Offenbarung 22,6-21 als Schlussstein der christlichen Bibel Alten und Neuen Testaments gelesen (BThSt 62), Neukirchen-Vluyn 2003, 7 oder auch schon Helmut UtzschneIDER, Das hermeneutische Problem der Uneindeutigkeit biblischer Texte - dargestellt an Text und Rezeption der Erzählung von Jakob am Jabbok (Gen 32,23-33), ET 48 (1988) 182-198, der sich dezidiert der Mehrdeutigkeit biblischer Texte widmet.

${ }^{59}$ Helmut Utzschneider, Text - Leser - Autor. Bestandsaufnahme und Prolegomena zu einer Theorie der Exegese, BZ 43 (1999) 224-238: 234.

${ }^{60}$ Umberto Eco/Günter Memmert, Die Grenzen der Interpretation, München 1992, 49 zitiert nach Utzschneider, Text (Anm. 59) $234 \mathrm{f}$.
} 


\subsubsection{Intertextualität und Intratextualität}

Das Phänomen „Intertextualität“ ${ }^{\text {61 }}$, das ursprünglich aus der Literaturwissenschaft kommt, wurde und wird auch zur Interpretation biblischer Texte herangezogen. ${ }^{62}$ Der Begriff der „Intertextualität“ wurde 1967 von Julia Kristeva geprägt und hat sich rasch zu einem Modebegriff der Literaturwissenschaft entwickelt. Mit ihm wird auf verschiedenste Weise von textübergreifenden Bezügen gesprochen. ${ }^{63}$ Ganz grundsätzlich ist davon auszugehen, dass jeder Text immer auf dem Hintergrund „bestimmter Prätexte oder in Korrelation mit anderen Texten" ${ }^{\text {"64 }}$ gelesen wird und selbst auch entstanden ist.

Jean Zumstein formuliert dann näherhin:

„Das Phänomen der ,Intertextualität' besteht in dem Zusammenspiel zwischen einem Hypotext oder Bezugstext einerseits und einem Hypertext oder Rezeptionstext andererseits. Diese recht allgemeine Definition kann auf folgende Weise präzisiert werden. Wenn das Zusammenspiel innerhalb eines literarischen Werkes selbst zu beobachten ist, wird in einem engeren Sinn von ,Intratextualität' gesprochen; wenn sich dieses Phänomen hingegen zwischen unterschiedlichen literarischen Werken entfaltet, wird stricto sensu von ,Intertextualität' geredet. “65

Ausgehend vom Prolog werden in den Kommentaren immer wieder intratextuelle Zusammenhänge mit dem Rest des Johannesevangeliums gesehen: etwa $\zeta \omega \eta \dot{\eta}, \varphi \tilde{\omega} \varsigma$, die Präexistenz und die Gottheit des Logos/Jesu, der Dualismus Licht - Finsternis, das Zeugnis des Täufers. ${ }^{66}$ Soweit ich die Forschungslage überblicke, wurde das bisher aber nicht auf die TheoLogie bezogen.

\footnotetext{
${ }^{61}$ Vgl. dazu einführend u. a. Manfred PFister, Konzepte der Intertextualität, in: Ulrich Broich/Manfred Pfister/Bernd Schulte-Middelich (Hg.), Intertextualität. Formen, Funktionen, anglistische Fallstudien (Konzepte der Sprach- und Literaturwissenschaft 35), Tübingen 1985, 1-30, Susanne Gillmayer-Bucher, Intertextualität. Zwischen Literaturtheorie und Methodik, PZB 8 (1999) 5-20, des Weiteren Michael Schneider, Gottes Gegenwart in der Schrift. Intertextuelle Lektüren zur Geschichte Gottes in 1 Kor (NET 17), Tübingen 2011, 45-128 und Annette Merz, Die fiktive Selbstauslegung des Paulus. Intertextuelle Studien zur Intention und Rezeption der Pastoralbriefe (NTOA/StUNT 52), Göttingen 2004, 5-71.

${ }^{62}$ Einen guten diesbezüglichen Überblick bietet SCHNeIDER, Gottes Gegenwart (Anm. 61) 84-128.

${ }^{63}$ Vgl. Gillmayer-Bucher, Intertextualität (Anm. 61) 5.

${ }^{64}$ Jean Zumstein, Intratextualität und Intertextualität in der johanneischen Literatur, in: Oda Wischmeyer/Stefan Scholz (Hg.), Die Bibel als Text. Beiträge zu einer textbezogenen Bibelhermeneutik (NET 14), Tübingen 2008, 217-234: 217.

${ }^{65} \mathrm{Ebd} .217 \mathrm{f}$.

${ }^{66}$ Siehe etwa die diesbezüglichen Ausführungen bei Schnelle (Anm. 1) 37 oder beispielsweise Schnackвenburg, Johannesevangelium (Anm. 19) $223 \mathrm{f}$. in Bezug auf den Gegensatz Licht - Finsternis oder in Bezug auf den Täufer (226-228).
} 


\subsubsection{Der Zusammenhang von Joh 10,30 und Joh 14,6b.7.9 mit den Prologaussagen Joh 1,1.14.18}

Bevor wir uns nun johanneisch-jesuanischen Aussagen über Gott widmen, muss noch auf den Zusammenhang der Stellen Joh 10,30 und Joh 14,6b.7.9 mit den Prologaussagen Joh 1,1.14.18 eingegangen werden. ${ }^{67}$

Joh 10,30:

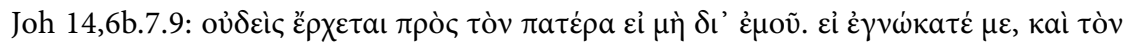

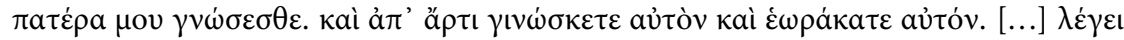

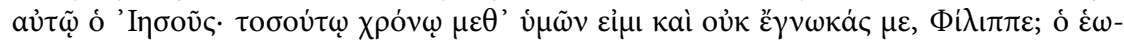

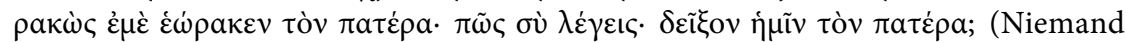
kommt zum Vater, wenn nicht durch mich. Wenn ihr mich erkannt habt, werdet ihr auch den Vater erkennen. Und von jetzt an kennt ihr ihn und habt ihn gesehen. [...] Es sagt ihm Jesus: So lange Zeit bin ich mit euch und du hast mich nicht erkannt, Philippus? Wer mich gesehen hat, hat den Vater gesehen: Wieso sagst du: Zeig uns den Vater?)

Beide Aussagen machen deutlich, dass es für das Verständnis Jesu bzw. Gottes auf die Leserschaft des Evangeliums ankommt - ein Phänomen, das in den letzten Jahren in der Intertextualitätsforschung immer stärker gesehen worden ist. ${ }^{68}$ Für 10,30 sehe ich den Zusammenhang mit

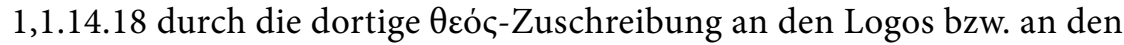

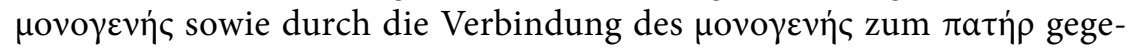
ben. Der Zusammenhang von 1,1.14.18 und 14,6b.7.9 ist, wie ich meine, unbestreitbar aufgrund des Motivs des Sehens sowie ebenfalls aufgrund

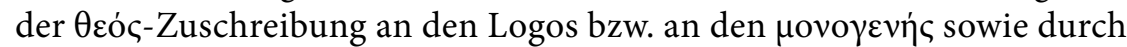

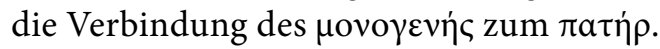

Wir haben es bei Joh 10,30 und Joh 14,6b.7.9 mit zwei Aussagen zu tun, die klassischerweise immer für die sogenannte "hohe Christologie“ des Johannesevangeliums in Anspruch genommen werden. Sie sind aber auch in Hinblick auf die Theo-Logie wichtig und für die "theo-logische“ Lektüre des vierten Evangeliums von Bedeutung.

Für die Leserschaft ist von Joh 1,1 an - d. h. wirklich von Anfang an klar, dass Jesus der Logos $\theta \varepsilon$ có (Gott) ist und er als der бà $\rho \xi \xi \dot{\varepsilon} \gamma \dot{\varepsilon} v \varepsilon \tau o$

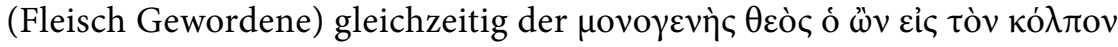

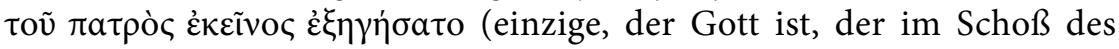
Vaters Seiende, jener hat ausgelegt) ist. Insofern darf sowohl die Aussage

\footnotetext{
${ }^{67}$ Ebenfalls in direktem Zusammenhang mit 1,18 stehen 5,37; 6,46 sowie 8,55, auf die hier näher einzugehen allerdings den Rahmen sprengen würde.

${ }^{68}$ Vgl. dazu etwa die Ausführungen bei SchneIder, Gottes Gegenwart (Anm. 61) 55-74.
} 
in Joh 10,30 als auch jene in Joh 14,6.7.9 die Leserinnen und Leser nicht überraschen. ${ }^{69}$ Gott hat sein Wort, seinen einzigen Sohn in die Welt geschickt, weil er diese liebt (vgl. 3,16), um ihr das Leben, das Heil zu verkünden, ja zu geben. ${ }^{70}$ Jesus als der einzige, der in einer ganz einzigartigen Beziehung zum Vater steht, weil er von Uranfang als Logos bei Gott war und selbst $\theta \varepsilon$ có ist, kann Gott authentisch auslegen, d.h. den Menschen erschließen. Von 1,18 her ist sowohl die Aussage 10,30, dass Jesus und der Vater eins sind, als auch diejenige in 14,6.7.9, dass niemand zum Vater kommt, außer durch Jesus und folglich wer Jesus sieht, auch den Vater sieht, absolut logisch. Udo Schnelle versteht Joh 10,30 als den „Basissatz joh. Theologie und Christologie“, der „nicht zufällig in der Mitte des Evangeliums [steht], denn er bildet die Mitte des johanneischen Denkens! " 71 Als diese Mitte kann man Gottes soteriologischen Willen für die Menschen bezeichnen. Gottes liebender Rettungswille ist es, sich in seinem Sohn der Welt zu offenbaren und den Menschen durch den Glauben an den Sohn, der dem Glauben an den Vater entspricht, das Leben zu geben. Wie der erste Johannesbrief zeigen wird, hat dieser soteriologische Wille Gottes auch eine soziale Komponente, denn die Antwort auf Gottes Liebe besteht auch in der Liebe zum Nächsten (1 Joh 4,8-16 vgl. auch schon Jesu neues Gebot Joh 13,34; 15,12). ${ }^{72}$

\footnotetext{
${ }^{69}$ Ein Zusammenhang zwischen den Stellen wird in der Kommentarliteratur kaum gesehen. Beutler, Johannesevangelium (Anm. 39) 317 weist zumindest im Kontext von Joh 10,30 auf 1,18 hin; Lindars, Gospel (Anm. 19) 473 im Kontext von 14,6 und 14,9. Ebenfalls bei den Ausführungen zu 14,9 findet sich bei BARrett, Gospel (Anm. 19) 459 der Hinweis auf 1,18. ThYen, Johannesevangelium (Anm. 53) 624 findet sich zumindest bei der Behandlung von 14,6 ein Verweis auf den Zusammenhang mit 10,30. Schnelle, Evangelium (Anm. 1) 201 verweist bei 10,30 auf 1,1.

${ }^{70}$ Zur johanneischen Lebensthematik vgl. etwa Mira Stare, Durch ihn leben. Die Lebensthematik in Joh 6 (NTAbh 49), Münster 2004 sowie jüngst Nadine Ueberschaer, Theologie des Lebens bei Paulus und Johannes. Ein theologisch-konzeptioneller Vergleich des Zusammenhangs von Glaube und Leben auf dem Hintergrund ihrer Glaubenssummarien (WUNT 389), Tübingen 2017.

${ }^{71}$ SChNelle, Evangelium (Anm. 1) 202. Des Weiteren hält er fest: „In Jesus wurde Gott Mensch, und Gott begegnet nur im Menschen Jesus. Der exklusive Bezug des Vaters auf den Sohn und der einzigartige Anspruch des Sohnes bedingen und ergänzen einander, im Sein und Wirken des Sohnes offenbart sich der Vater selbst. Die christozentrische Theologie des 4. Evangelisten, das Konzept einer Theologie als Christologie erreicht hier einen Höhepunkt $[.]^{\text {“ }}$

${ }^{72}$ Vgl. dazu auch den hier vorliegenden Sammelbandeitrag von Johannes Beutler, „Gott ist Liebe" - Sinn und Bedeutung der zentralen Gottesprädikation im ersten Johannesbrief S. $227-243$.
} 


\section{Zu einer Theo-Logie des Johannesevangeliums - exemplarische Arbeitsfelder}

Aus den bisherigen Überlegungen ergibt sich die Basis, das Johannesevangelium gezielt theo-logisch zu lesen und Bilder und Motive herauszuarbeiten, die Gott-Vater darstellen. ${ }^{73}$ Dabei wird das AT als Hypotext ${ }^{74}$ eine große Rolle spielen und wohl auch jüdisch-hellenistische Literatur in den Blick kommen müssen. Unbestreitbar ist, dass der Evangelist Johannes bzw. die johanneische Schule (= der Personenkreis, der hinter dem Evangelium als Ganzem steht) in hohem Ausmaß den Gott des Alten Testaments als den Gott Jesu präsentieren. ${ }^{75}$ Es stellt sich dann aber durchaus die Frage, inwieweit eigenständige Akzente gesetzt werden und es damit zu einer Weiterentwicklung dieses alttestamentlich-jüdischen Gottesbildes kommt.

\subsection{Gott, der Vater}

Bereits im Prolog wird Gott als Vater bezeichnet, nämlich in den VV. 14.18 als Vater Jesu und indirekt auch als Vater der gläubigen Menschen in V. 12. Tatsächlich ist dann auch in der johanneischen Erzählung im Munde Jesu Vater ( $\pi \alpha \tau \eta \dot{\rho})$ jenes Bild, das am häufigsten

\footnotetext{
${ }^{73}$ In meiner Habilitation, die im Rahmen des vom FWF (Austrian Science Fund) geförderten Hertha-Firnberg-Projektes (T 627 G21) entsteht, geht es dann v. a. um eine motiv- und traditionsgeschichtliche Untersuchung der zentralen johanneischen Theologumena bzw. Gottesbilder.

${ }^{74}$ Johannes und die joh Schule scheinen sehr stark mit dem Alten Testament als Hypotext - vermutlich stärker als die Synoptiker - zu arbeiten. Mit dieser Annahme ordne ich mich ebenfalls ein in den diesbezüglich wachsenden Konsens in der Johannesforschung. Einen zusammenfassenden Überblick bietet Günter ReIM, Studien zum alttestamentlichen Hintergrund des Johannesevangeliums (MSSNTS 22), Cambridge 1974, 83-93. Zum AT als Hypotext vgl. etwa Zumstein, Intratextualität (Anm. 64) 229-231. Vgl. auch schon Marianne M. Thompson, „Every Picture Tells a Story“. Imagery for God in the Gospel of John, in: Jörg Frey/Jan G. van der Watt/Ruben Zimmermann (Hg.), Imagery in the Gospel of John. Terms, Forms, Themes, and Theology of Johannine Figurative Language (WUNT 200), Tübingen 2006, 259-277, die auf Seiten 265-270 „The biblical Context of Johannine Imagery for God" diesen zwar systematisierend bespricht, aber dann im weiteren Verlauf nur auf zwei joh Bilder für Gott eingeht (Vater und Winzer). Die Studie Randolph Bynum, The Fourth Gospel and the Scriptures. Illuminating the Form and Meaning of Scriptural Citation in John 19:37 (NovTSup 144), Leiden 2012 zeigt das grundsätzlich steigende Interesse am Thema Joh und AT anhand der joh Verwendung eines Sacharja-Zitates.

${ }^{75}$ So auch Udo Schnelle, Theologie des Neuen Testaments, Göttingen ${ }^{2} 2014,621$, der das AT als „Fundament des joh. Gottesbildes“ sieht.
} 
für Gott verwendet wird und statistisch sogar öfter auftritt als $\theta \varepsilon$ có ${ }^{76}$ Vorwiegend ist dabei Gott der Vater Jesu. ${ }^{77}$

Edith Zinggs Meinung, die sie in ihrer Dissertation, die sich explizit mit dem Reden von Gott als Vater im Johannesevangelium auseinandersetzt, vertritt, dass „das Gottesbild im JohEv wesentlich auf die eine männliche Metapher ,Vater' beschränkt [ist] "78, halte ich allerdings für unzureichend, da es noch einige weitere Metaphern und Beschreibungen Gottes (vgl. nur die Aussage Joh 15,1: Vater = Winzer) gibt.

Das, was den johanneischen Gott-Vater v. a. ausmacht, ist seine um-

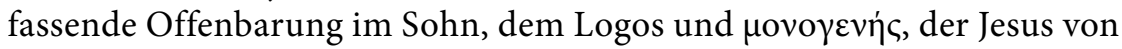
Nazareth ist. Dieser steht in einer Wesens-Einheit mit ihm als Gott-Vater und wirkt aus dieser Einheit heraus (Joh 1,1.18 u. ö.). ${ }^{79}$

\subsection{Die Einzigkeit und Unsichtbarkeit Gottes}

Aus dieser im Johannesevangelium propagierten Wesens- und Wirkeinheit von Vater und Sohn hat sich der Vorwurf des Ditheismus im zeitgenössischen Judentum ergeben (vgl. Joh 5,18; 10,33.36; 19,7). Dem tritt das Evangelium aber ganz bewusst entgegen, denn für den Autor und seine Gemeinde ist klar: Es gibt nur einen Gott (Joh 5,44; 17,3). ${ }^{80}$ Bei der Gottessohnschaft Jesu handelt es sich nicht um die Usurpation der Gotteswürde oder ein Aufheben des Monotheismus, wie der Vorwurf der johanneischen Juden lautet, sondern - um es mit den Worten Udo Schnelles zu sagen, „um eine präzise Bestimmung des Wollens des Vaters“ ${ }^{81}$. Denn Gott hat die Welt so sehr geliebt, dass er seinen einzigen Sohn in die Welt geschickt hat, damit die Glaubenden das Leben haben (vgl. Joh 3,16). Grundsätzlich gilt auch für das Johannesevangelium, was für den alttestamentlichen Gott gilt: Gott ist unsichtbar - niemand hat ihn je gesehen (Joh 1,18; 6,46), aber Jesus als der einzige Sohn hat ihn ausgelegt

\footnotetext{
${ }^{76}$ Insgesamt kommt $\pi \alpha \tau$ ๆn im JohEv 136-mal vor, davon 120-mal als Bezeichnung Gottes. Siehe dazu Kurt Aland, Vollständige Konkordanz zum griechischen Neuen Testament. Unter Zugrundelegung aller modernen kiritischen Textausgaben und des Textus Receptus. Band I. Teil 2. M - O, Berlin/New York 1983, $1105 \mathrm{f}$. sowie die systematisierende Tabelle bei Edith ZINGG, Das Reden von Gott als „Vater“ im Johannesevangelium (HBS 48), Freiburg u. a. 2006, 25.

${ }^{77}$ Mit Gott als dem Vater der Jünger setzt sich explizit Frances BACK, Gott als Vater der Jünger im Johannesevangelium (WUNT 2,336), Tübingen 2012 auseinander.

${ }^{78} \mathrm{ZINGG}_{\text {IN }}$ Reden (Anm. 76) 326.

${ }^{79}$ Vgl. dazu Schnelle, Theologie (Anm. 75) $623 \mathrm{f}$.

${ }^{80}$ Vgl. dazu DERs., Evangelium (Anm. 1) 205.

${ }^{81}$ Ders., Theologie (Anm. 75) 628.
} 
und erschlossen und wer ihn sieht, sieht den Vater (Joh 14,9) und kann einzig durch den Glauben an Jesus und den Vater das Leben erlangen (Joh 6,47 u. ö.). So erschließt sich dann möglicherweise auch Neues über den Gott des Alten Testaments trotz der vielfältigen Übernahme von Motiven und Metaphern. Zumindest die dezidierte Unsichtbarkeit ist durch die johanneisch-jesuanische Gott-Rede ja aufgehoben.

\section{3 $\mathrm{Zu}$ den sieben johanneischen Ich-bin-Worten}

Durch ihre Bilder- und Metaphernsprache ${ }^{82}$ sind vor allem die sieben prädikativen Ich-bin-Worte ${ }^{83}$ des Johannesevangeliums, so der Konsens der Johannesforschung, „das Zentrum der Selbstverkündigung Jesu und Schlüsselworte joh. Offenbarungstheologie und Hermeneutik " ${ }^{84}$, denn in ihnen sagt Jesus aus, wer er ist, was er für die Menschen sein will und wie er von ihnen verstanden sein will. In den Ich-bin-Worten „verdichten sich in einzigartiger Weise Christologie und Soteriologie" ${ }^{\text {85. }}$.

Man sollte jedoch die Ich-bin-Worte nicht nur unter christologischem und soteriologischem, sondern auch unter theologischem Aspekt sehen. Gerade unter Berücksichtigung der Aussagen von 10,30 und 14,6b.7.9, die - wie oben gezeigt wurde - in einem eindeutigen Zusammenhang mit 1,18 stehen, sind die sieben Ich-bin-Worte - Brot des Lebens (Joh 6,35), Licht der Welt (Joh 8,12), Tür (Joh 10,7.9), guter Hirte (Joh 10,11.14), Auferstehung und Leben (Joh 11,25), Weg, Wahrheit und Leben (Joh 14,6) und Weinstock (Joh 15,1.5) - auch Aussagen über Gott(Vater) ${ }^{86}$ In der

\footnotetext{
${ }^{82} \mathrm{Zu}$ Metapherntheorie und biblischer Bildersprache vgl. einführend Ruben ZIMmeRMANN, Metapherntheorie und biblische Bildersprache. Ein methodologischer Versuch, TZ 56 (2000) 108-133 und v. a. Jan G. van Der Watt, Family of the King. Dynamics of Metaphor in the Gospel According to John (BiInS 47), Leiden u. a. 2000, 1-24.

${ }^{83} \mathrm{Zu}$ den Ich-bin-Worten allgemein vgl. etwa Exkurs 3 bei Schnelle, Evangelium (Anm. 1) 139f.

${ }^{84}$ Ders., Theologie (Anm. 75) 646.

${ }^{85}$ Ebd., 646.

${ }^{86}$ Die Untersuchung dieser sieben Ich-bin-Worte wird in meiner Habilitation durch Adaptierung von und in Auseinandersetzung mit Ruben Zimmermanns Zugang, den er in seiner „Christologie der Bilder“ entwickelt, erfolgen. Ruben Zimmermann, Christologie der Bilder. Die Christopoetik des vierten Evangeliums unter besonderer Berücksichtigung von Joh 10 (WUNT 171), Tübingen 2004. S. 86 hält er fest: „Der Bildreichtum des vierten Evangeliums ist nicht mythologisches Beiwerk oder illustratives Ornament, von dem die ,eigentliche Botschaft abgelöst werden könnte: Die Theologie und besonders auch die Christologie des JohEv werden stattdessen gerade in und durch Bildersprache formuliert und vermittelt. [...] Die Bildlichkeit der joh Sprache ist in die Metaphern- und Bildfeldtradition ihres Vor- und Umfeldes eingezeichnet, so dass die traditionsgeschichtliche Rückbindung an diese Bereiche in formaler und theologischer Hinsicht aufschlussreich sein dürfte. [...] Um die theologische
} 
Reihe dieser sieben Ich-bin-Worte nimmt sicherlich das zuletzt genannte Wort (Weinstock in 15,1.5) eine Sonderstellung ein, da in diesem $\mathrm{Zu}$ sammenhang der Vater ganz explizit als der Winzer ( $\gamma \varepsilon \omega \rho \gamma o ́ \varsigma){ }^{87}$ benannt wird. In diesem Fall ist neben der Untersuchung des Bildes vom Winzer für Gott-Vater auch der Frage nachzugehen, wie das Verhältnis von Ichbin-Aussage und Charakterisierung des Vaters zu bestimmen ist. Zentral wird es bei dieser Analyse der für die Gott-Christus-Präsentation verwendeten Bilder und Metaphern darum gehen, den alttestamentlichfrühjüdischen Tiefengrund des johanneischen Gottesbildes auszuleuchten. ${ }^{88}$

\section{Gott im Johannesevangelium - eine nicht zu vernachlässigende Größe!}

Grundsätzlich kann nun festgehalten werden: Das Johannesevangelium bietet genügend Ansatzpunkte, auch seiner Theo-Logie nachzugehen. Auf Basis von 1,18 und der Annahme, dass der Prolog eine Lektüreanleitung für das ganze Evangelium gibt, kommt man nicht umhin, das Johannesevangelium auch theo-logisch zu lesen. Es geht im Johannesevangelium viel mehr als bei den Synoptikern um die Beschreibung der Offenbarung

Tragweite bildhafter Sprach- und Denkformen gerade auch für die joh Christologie im Ganzen zu beurteilen zu können, scheinen einseitige Zugänge zu kurz zu greifen. Nur eine multiple Annäherung an die unterschiedlichen Bildphänomene mit je spezifischen Methoden vermag es, der Komplexität und Vielfalt joh Sprachformen gerecht zu werden, um schließlich ihren Bedeutungsgehalt für die Christologie des Evangeliums beurteilen zu können." Was Zimmermann hier für die joh Christologie aussagt und dann in seiner Habilitationsschrift eindrucksvoll ausführt, muss auch und vor allem für die Theo-logie im Johannesevangelium angewandt werden. Vgl. des Weiteren Ruben ZimmermanN, Imagery in John. Opening Up Paths into the Tangeled Thicket of John's Figurative World, in: Jörg Frey/Jan G. van der Watt/Ruben Zimmermann (Hg.), Imagery in the Gospel of John. Terms, Forms, and Theology of Johannine Figurative Language (WUNT 200), Tübingen 2006, 1-43.

${ }^{87}$ Vgl. dazu Thompson, „Every Picture Tells a Story“ (Anm. 74) 273.

${ }^{88}$ Bereits Silke Petersen, Brot, Licht und Weinstock. Intertextuelle Analysen johanneischer Ich-bin-Worte (NovTSup 127), Leiden 2008 weist in ihrer Untersuchung darauf hin, dass sich gerade bei den „einzelnen Metaphern wiederholt [...] Anknüpfungspunkte in jüdischen Texten, insbesondere der Weisheitsliteratur" (S. 315f.) finden. Zur alttestamentlichen Hirtenmetaphorik exemplarisch Zimmermann, Christologie (Anm. 86) 320-327. Zwar von der Christologie herkommend vgl. Reim, Studien zum alttestamentlichen Hintergrund des Johannesevangeliums (Anm. 74). Er macht dabei drei unterschiedliche Bildfelder zum Hirten im AT fest (König-Hirte-Bildfeld, JHWH-Bildfeld, Messias-Hirte-Bildfeld) und fragt nach möglichen Anspielungen darauf in Joh 10. Zum Motiv der Tür vgl. Veronika BurzTrop per, „Ich bin die Tür“ (Joh 10,7.9). Die Eröffnung neuer Räume durch Jesus (Gott) im Johannesevangelium, PZB 26 (2017) 65-83. 
Gottes (selbstverständlich in Christus) und es wird ganz klar der alttestamentliche Gott beschrieben. ${ }^{89}$

Die Beschreibung Gottes im Johannesevangelium erfolgt primär durch

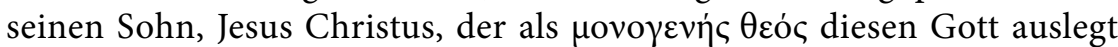
und ihn dadurch erschließt, ja der einzige authentische Künder Gottes ist. Niemand - auch nicht Mose - hat Gott je gesehen, nur durch den Logos Jesus Christus, der von Anfang bei Gott war, wird er sichtbar, denn wer den Sohn sieht, sieht auch den Vater. Der Vater ist es, der diese Wirkeinheit will aufgrund seiner Liebe zur Welt, die durch die heilvolle GottVerkündigung zum Glauben kommen soll und so das Leben gewinnt.

Gott(Vater) ist für das Johannesevangelium also absolut kein neglected factor und deshalb sollte es die "Theo-Logie“ in der Erforschung des Johannesevangeliums auch nicht sein!

\footnotetext{
${ }^{89}$ Diese Arbeitshypothese soll in meiner weiteren Forschung durch die konsequent motivund traditionsgeschichtliche Analyse aller im Johannesevangelium für Gott verwendeten Bilder bzw. der johanneisch-jesuanischen Aussagen über Gott untermauert werden.
} 



\section{Pas de deux}

Christologie als Theologie im Johannesevangelium

Olivia Rahmsdorf und Ruben Zimmermann

\section{Aufforderung zum Tanz}

Der „Pas de deux“ ist ein Höhepunkt im Ballett. In dem „Solotanz zu zweit" bewegen sich die beiden Tänzer (in der Regel Mann und Frau) in einer gleichförmigen Schrittfolge, die das Paar bald wie einen einzelnen Tänzer erscheinen lässt, bald Raum für Variationen und Eigenständigkeit lässt, aber ohne die innige Einheit zu unterwandern. Der Pas de deux eignet sich unserer Meinung nach deshalb als Metapher, um der eigenartig intimen Verschränkung der Gottesrede im Johannesevangelium mit der Christologie Ausdruck zu verleihen. ${ }^{1}$ Die klassischen Teile des Pas de deux geben die Struktur des Beitrags vor: Im Entrée werden wir nach den johanneischen Möglichkeiten fragen, sich Gott zu nähern. Im langsamen Teil des Tanzes, der Adage, steht die gemeinsame Bewegung von Vater und Sohn im Johannesevangelium im Mittelpunkt. Im Anschluss kommen die Variationen der Tänzer zur Aufführung und im Schlusssatz, der Coda, wird es darum gehen, mit Joh 17,21 den Pas de deux in eine Polonaise zu überführen.

\section{Entrée}

Den Einstieg zum Pas de deux weist uns eine der großen Fragen der jüdisch-christlichen Theologie: Wer darf sich überhaupt ein Bild von dem einen Gott machen? Oder spezifischer: Wer kann sich gemäß des

\footnotetext{
${ }^{1}$ Besondere Umstände haben dazu geführt, dass der Titel eine ungeahnte Doppelsemantik erlangt hat. Denn die folgende Choreographie ist letztlich aus einem Pas de deux zwischen Doktorvater und Doktortochter entstanden. Die Gedanken und Formulierungen beider sind in den folgenden Überlegungen zusammengeflossen.
} 
Johannesevangeliums ein Bild von dem einen Gott machen? Naturgemäß allein derjenige, der ihn auch gesehen hat. Das Schauen Gottes ist allerdings nicht jedem vergönnt, wie der Prolog gleich zu Beginn zu verstehen gibt (Joh 1,18): „Niemand hat Gott jemals gesehen." Diese besonders

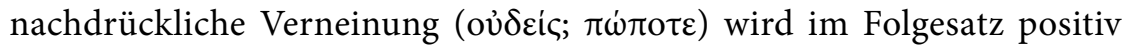
umgelenkt: ${ }^{2}$ „Der einziggeborene Gott, der im Schoß des Vaters ist, jener hat ihn ausgelegt." Während in den meisten Auslegungen von V. 18 die

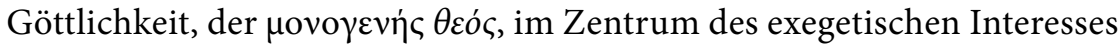
steht, soll hier der räumlichen Dimension Aufmerksamkeit geschenkt werden: Der Einziggeborene befindet sich in unmittelbarer Nähe zum

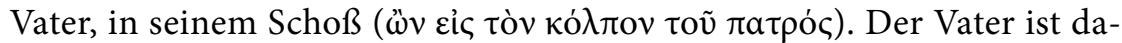
mit auch in Sichtweite des Sohnes. Man möchte fast sagen: „Niemand hat Gott jemals gesehen außer dem Einziggeborenen, der im Schoß des Vaters ist, jener hat ihn ausgelegt." Dem monotheistischen Gottesbild entspricht nach Johannes ein monogenetischer Gottesbetrachter. Der einziggeborene Sohn ist es, der seinen Vater gesehen hat und ihn deshalb für uns auslegen kann, ihn aus der Unsichtbarkeit ans Licht hinausgeführt hat

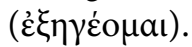

Die Vater-Metapher ist die erste und übergeordnete Metapher, mithilfe derer das Johannesevangelium Gott zu beschreiben trachtet. Schon von dort aus ist zu erkennen: Die johanneische Theologie ist primär und eigentlich relationaler Art. ${ }^{3}$

Wie wird diese Relation zwischen Vater und Sohn im Prolog beschrieben? Der Einziggeborene muss sich seinem Vater nicht erst nähern, um die gemeinsame Bewegung zu vollführen, um den Tanz zu eröffnen. Er

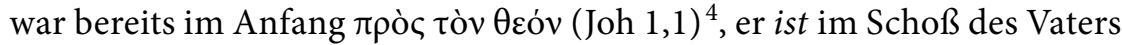

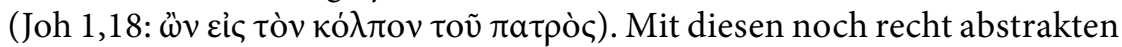

\footnotetext{
${ }^{2}$ Vgl. auch Catrin H. Williams, (Not) Seeing God in the Prologue and Body of John's Gospel, in: Jan G. van der Watt/R. Alan Culpepper/Udo Schnelle (Hg.), The Prologue of the Gospel of John. Its Literary, Theological, and Philosophical Contexts: Papers read at the Colloquium Iohanneum 2013 (WUNT 359), Tübingen 2016, 79-98: 82: „(...) the phrasing of its first clause (,no one has ever seen $\mathrm{God}^{\text {') }}$ encourages the reader to interpret the central thrust of the second part as stating that God is ,seen' in Jesus."

${ }^{3}$ Vgl. Craig R. Koester, Jesus as the Way in the Fourth Gospel, in: Gilbert van Belle/Jan G. van der Watt/Petrus Maritz (Hg.), Theology and Christology in the Fourth Gospel. Essays by the Members of SNTS Johannine Writings Seminar (BETL 184), Leuven 2005, 117-133: 121; Francois D. Tolmie, The Characterization of God in the Fourth Gospel, JSNT (1989) 57-75: $60 \mathrm{f}$.

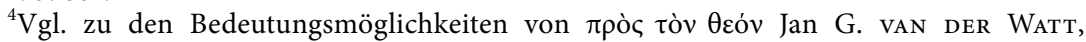
John 1:1 - A „Riddle“ Grammar and Syntax Considered, in: Jan G. van der Watt/R. Alan Culpepper/Udo Schnelle (Hg.), The Prologue of the Gospel of John. Its Literary, Theological, and Philosophical Contexts: Papers read at the Colloquium Iohanneum 2013 (WUNT 359),
} 
Informationen werden wir als Leser des Evangeliums vom Prolog in die Narration entlassen, wir dürfen nun das konkrete Wirken des Sohnes in der Welt beobachten. Aber wir sehen jetzt alles durch die Brille dieser hermeneutischen Eichung des Prologs: Die Bewegung Jesu lässt zugleich die Bewegung Gottes erkennen.

Wie im Auftakt Jesu öffentlichen Wirkens, so wird auch am Ende noch einmal seine Erschließungsfunktion ${ }^{5}$ in der Gottesschau betont: „Wer mich sieht,“ oder vielleicht besser: „beobachtet $(\theta \varepsilon \omega \rho \varepsilon \tilde{v})$, der beobachtet den, der mich gesandt hat" (Joh 12,45). ${ }^{6}$

Jene Funktion wird dann in den Abschiedsreden auf Philippus' Bitte hin, ihm und den übrigen Jüngern den Vater zu zeigen, noch einmal in ähnlichem Wortlaut bestätigt (Joh 14,8f.). Statt des Präsens von $\theta \varepsilon \omega \rho \varepsilon \tilde{v}$ wird nun im Hinblick auf Jesu baldigen Fortgang das Perfekt von ó $\rho \tilde{a} v$ verwendet: „Wer mich gesehen hat, der hat den Vater gesehen." Das Perfekt verstärkt das exklusive Moment dieser Schlüsselfunktion Jesu; wie Ludger Schenke es ausdrückt: „das menschliche Handeln Jesu (war) das

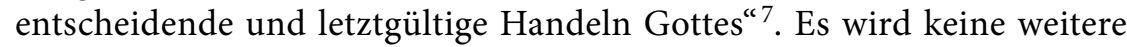
menschliche, ja fleischliche Manifestation des Gotteswortes wie den Sohn mehr geben ${ }^{8}$ und es hat auch davor keinen wie den Sohn gegeben. So legt es das ả $\pi^{\prime}$ áp in der Gegenwart des Sohnes. Hier wird zugleich die epistemologische

Tübingen 2016, 57-78: 63-67 (u. a. „in movement toward“; „in familiar intercourse with“; „in converse with“; , alongside with").

${ }^{5}$ Es wird bewusst auf den Begriff der „Mittlerschaft“ verzichtet, weil einer räumlichen Distanz zwischen Gott und Jesus bzw. Gott und Welt widersprochen wird, die in der Rede von einem Mittler oder Zwischenglied mitschwingt. Im Blick auf Jesus schaut der Betrachter Gott direkt. Der Begriff der Mittlerschaft wird also v. a. in Bezug auf die visuelle Gottesbegegnung vermieden. Im Bitten und Gebet als verbale Begegnung mit Gott kann Jesus aber sehr wohl die Rolle des Fürbitters übernehmen (Joh 17,9: vgl. auch 5,16; 16,23f.).

${ }^{6}$ Jesu Erschließungsfunktion wird im Zusammenhang des jesajanischen Verstockungsbefehls angesprochen, der nicht nur Ohren sondern auch Augen des Volkes verschließen sollte. Allein aus dem heiligen Samen, der bei der Verstockung übrig bleibt, soll Neues entstehen (Jes 6,9-13).

${ }^{7}$ Ludger Schenke, Christologie als Theologie. Versuch über das Johannesevangelium, in: Rudolf Hoppe (Hg.), Von Jesus zum Christus. Christologische Studien (FS Paul Hoffmann) (BZNW 93), Berlin 1998, 445-465: 460; vgl. ferner Jörg FrEY, „Wer mich sieht, der sieht den Vater". Jesus als Bild Gottes im Johannesevangelium, in: Andrea Taschl-Erber/Irmtraud Fischer (Hg.), Vermittelte Gegenwart. Konzeptionen der Gottespräsenz von der Zeit des Zweiten Tempels bis Anfang des 2. Jahrhunderts n. Chr. (WUNT 367), Tübingen 2016, 179-208: 201.

${ }^{8}$ Der Paraklet hat die Aufgaben zu lehren, zu erinnern, zu bezeugen und aufzudecken/zu erhellen, in Wahrheit zu leiten (Joh 14,16-17.26; 15,26; 16,7.13). Damit ist er nicht selbst fleischliche Manifestation, sondern erleichtert und gewährt den Blick auf die einmalige Manifestation Gottes in seinem Sohn. 
Dimension dieses Sehens expressis verbis ausgesprochen: „Wenn ihr mich erkannt habt, werdet ihr auch den Vater erkennen. Von jetzt an erkennt ihr ihn und habt ihn gesehen" (Joh 14,7). Im Sehen des Sohnes wird zugleich der Blick auf den Vater freigegeben. Umgekehrt gilt dann aber auch für uns Exegeten (wie für die übrigen Protagonisten des Johannesevangelium): Der einzige Gott kann nur durch den einziggeborenen Sohn, den wahren Exegeten, geschaut werden (vgl. Joh 1,12). Nur über die Christologie gelangen wir zur Theologie des Johannesevangeliums. Feldmeier/Spieckermann sprechen hier folgerichtig vom „Verweisungsgefüge von Christologie und Theologie". ${ }^{9}$

Wenn wir Gott-Vater ins Zentrum rücken wollen, wie es die Einladung zu diesem Symposion vorgeschlagen hat, so müssen wir uns vom Gottessohn dabei helfen lassen, oder johanneisch gesagt: dabei die Augen öffnen lassen. ${ }^{10}$

\section{Adage}

\subsection{Grundschritt: Seins- und Handlungseinheit}

Die einzigartige Erschließung des Vaters durch seinen Sohn soll nun noch genauer nachvollzogen werden. Wie genau gelangt man durch den Sohn hindurch zum Vater? Philippus möchte ja von Jesus zum Vater geführt werden: „Zeige uns den Vater. Das genügt uns“ (Joh 14,9). Diese Formulierung des Philippus impliziert ein räumliches Getrenntsein von Vater und Sohn ${ }^{11}$ (vgl. Joh 8,19 „Wo ist dein Vater?"). Doch für das Zeigen braucht der Sohn keinen ausgestreckten Arm oder Finger: „Glaubt mir, dass ich im Vater bin und der Vater in mir" (Joh 14,11). Neben solchen abstrakten - und zugegebenermaßen - schwer nachvollziehbaren deklarativen Sprechakten bemüht sich das vierte Evangelium um Konkretion und Anschaulichkeit. Der vierte Evangelist wird nicht umsonst der „Op-

\footnotetext{
${ }^{9}$ Reinhard Feldmeier/Hermann Spieckermann (Hg.), Der Gott der Lebendigen. Eine biblische Gotteslehre (TOBITH 1), Tübingen 2011, 6. Mit Recht wird hierbei auch z. B. auf ein Wort der Logienquelle (Lk 10,22/Mt 11,27) verwiesen, das aber nicht zufällig als das sogenannte "johanneische Logion" bezeichnet wird.

${ }^{10}$ Vgl. Tolmie, Characterization (Anm. 3) 64: "If we turn to the question as to how God is characterized in these chapters (i.e. Joh 1-12, OR/RZ), it should be pointed out immediately that God is characterized primarily in terms of the relationship between him and Jesus."

${ }^{11}$ Vgl. Frey, „Wer mich sieht, der sieht den Vater“ (Anm. 7) 201.
} 
tiker" ${ }^{12}$ unter den Evangelisten genannt. Das Zeigen bzw. entsprechende Sehen des Vaters erfolgt durch ein wahres Feuerwerk der Farben und Bilder. Als ob, in unserer Leitmetapher ausgedrückt, die Tänzer mit ihren Kleidern, Bühnenbild und Beleuchtung ständig in neue Rollen schlüpfen. Das bunte Mosaik der Bilderchristologie ist zugleich eine farbenfrohe Bildertheologie. Blicken wir exemplarisch auf Joh 10, ein Kapitel, das nicht zufällig im Zentrum des Evangeliums steht.

Es ist das Kapitel, in dem nicht nur die Christusfrage explizit gestellt wird (Joh 10,24), sondern auch christo-theologische Spitzenaussagen wie „Ich und der Vater sind eins" (Joh 10,30) formuliert werden. ${ }^{13}$ Aber im Sinne der Bildertheologie des Evangeliums wird das Ineinander von Vater und Sohn vor allem auch durch das einleitende Tür- und Hirtengleichnis entfaltet. Hier verdeutlicht Jesus, dass jeder, der nicht durch die Tür in den Stall hineingeht, ein Dieb und ein Räuber ist, wohingegen derjenige, der durch die Tür geht, der Hirte ist. Dieses Bild funktioniert in zwei Richtungen und wird von Jesus auch in beide Richtungen ausgelegt: Jesus identifiziert sich in einer Art surrealistischer Clustertechnik ${ }^{14}$ in den folgenden $\dot{\varepsilon} \gamma \omega \dot{~ \varepsilon i l \mu t-W o r t e n ~(J o h ~ 10,7.9 .11 .14) ~ s o w o h l ~ m i t ~ d e r ~ T u ̈ r, ~ a l s ~ a u c h ~}$ mit dem Hirten. Er ist die Tür, durch die hindurchzugehen für die Schafe Rettung bedeutet und einen Weideplatz verspricht. Zugleich ist er der Hirte, der nun anstelle der Diebe und Räuber zu seinen Schafen gelangt und auf den die Schafe hören. Nur er als Hirte gelangt durch die Tür zu den Schafen. Ein Türhüter, mit dem sich Jesus nicht unmittelbar durch

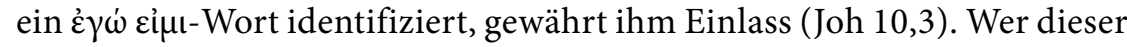
Türhüter ist, lässt das Gleichnis offen. Ist es sein Vater? In Joh 10,29 wird zumindest gesagt, der Sohn erhalte die Schafe aus der Hand des Vaters. Die gehäuften Possessivpronomina in Joh 10,1-18 lassen keinen Zweifel, dass Jesus hier nicht nur als Auftragshirte, sondern zugleich als Herdenbesitzer („meine Schafe“ $[\ldots]$ ) auftritt. Dieses Bilddetail ist wesentlich. Während in Israels Bildfeldtradition die Hirtenmetapher für viele Könige und religiöse Führungsgestalten verwendet wurde, ist es vor allem diese $\mathrm{Zu}$ - und Aneignung, mit der sich der Christus-Hirte in den Bereich Gottes

\footnotetext{
${ }^{12}$ Vgl. Otto SchwankL, Licht und Finsternis. Ein metaphorisches Paradigma in den johanneischen Schriften (HBS 5), Freiburg 1995, 397; ähnlich Romano GuardinI, Das Bild von Jesus Christus im Neuen Testament, Würzburg 1953, 53: „Mann des Auges“.

${ }^{13}$ Zum inneren Zusammenhang und zur wohlkomponierten Struktur des Kapitels mit zwei Redekomplexen (Joh 9,39-10,21; 10,22-42) und vier Redegängen (Joh 9,39-10,6; 10,7-21; 10,22-31; 10,32-42); vgl. Ruben Zimmermann, Christologie der Bilder im Johannesevangelium. Die Christopoetik des vierten Evangeliums unter besonderer Berücksichtigung von Joh 10 (WUNT 171), Tübingen 2004, 254-276.

${ }^{14}$ Vgl. dazu Zimmermann, Christologie (Anm. 13) 412-414.
} 
stellt. Nur Gott allein ist der Herdenbesitzer, wie etwa Regine Hunziker-Rodewald in ihren Untersuchungen zum Hirten im Alten Testament gezeigt hat. ${ }^{15}$ Die vermehrt hörbaren Anspielungen der johanneischen Hirtenrede an die alttestamentliche Hirtenmetaphorik (insbesondere an Ps 94 LXX und Ez 34) entstammen denn auch fast durchweg der Bildfeldtradition des JHWH-Hirten. ${ }^{16}$ Nicht erst die spätere Immanenz-Aussage, sondern bereits die metaphorische Beschreibung lassen Christusbild und Gottesbild ineinander fließen und führen folgerichtig zum Blasphemie-Verdacht (Joh 10,33).

Der Bildersprache korrespondieren die Aussagen über die Einheit und Immanenz von Vater und Sohn (Joh 10,30.38), zunächst in V. 30: ż $\gamma \grave{\omega}$ kaì ò

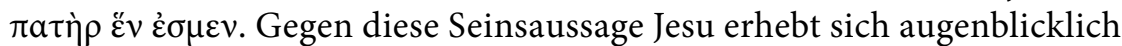
Empörung bei den Juden (Joh 10,31). Jesus reagiert darauf mit einer doppelten Verteidigung. Zunächst verweist er auf seine guten Werke,

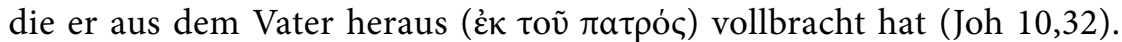
Doch nicht die Werke interessieren seine Kontrahenten, sondern allein sein Seinsanspruch, dieser klingt in ihren Ohren wie pure Blasphemie. Er macht sich selbst zum Gott (Joh 10,33 vgl. 5,17f.; 19,17). In seinem zweiten Einwand versucht Jesus sie mit ihren eigenen Mitteln zu schlagen: der Schrift. Hier würden bereits die Menschen, die das Wort Gottes hören, Götter genannt (Joh 10,34f.| Ps 81,6 LXX). Wie viel mehr sei dann der Gesandte und Heilige Gottes, der Gott gesehen hat, würdig, Gottessohn genannt zu werden? ${ }^{17}$ Doch zu diesem Zeitpunkt und im Angesicht dieser Kontrahenten kann Jesu Argumentation nicht tragen. Jesus weiß um die immense Bedeutung des monotheistischen Bekenntnisses für die jüdische Identität. ${ }^{18}$ Deshalb wiederholt er den Verweis auf seine Werke:

\footnotetext{
${ }^{15} \mathrm{Vgl}$. Regine Hunziker-Rodewald, Hirt und Herde. Ein Beitrag zum alttestamentlichen Gottesverständnis (BWANT 155), Stuttgart 2001, 73-106.

${ }^{16} \mathrm{Vgl}$. dazu ausführlich Ruben Zimmermann, Jesus im Bild Gottes. Anspielungen auf das Alte Testament im Johannesevangelium am Beispiel der Hirtenbildfelder in Joh 10, in: Jörg Frey/Udo Schnelle (Hg.), Kontexte des Johannesevangeliums. Das vierte Evangelium in religions- und traditionsgeschichtlicher Perspektive (WUNT 175), Tübingen 2004, 8-116, sowie DERs., Christologie (Anm. 13) 336-342.

${ }^{17}$ Es handelt sich folglich nicht um eine ironische Relativierung, sondern um einen Schluss a minore ad maius und dabei um eine mehrfache Zuspitzung und Überbietung: Vom Kollektiven (Götter) zum Einzelnen (Gottes Sohn), vom Allgemeinen (jene) zum Speziellen (derjenige, der geheiligt ist), von der Fremdprädikation (Gott als Subjekt) zur Selbstprädikation (Jesus als Subjekt) und von der Logosrede (an die das Wort erging) zur Logosidentifikation (der Sohn als Logos mit Joh 1,1); vgl. Einzelheiten zur Argumentation in Joh 10,34f. bei Zimmermann, Christologie (Anm. 13) 349-351.

${ }^{18}$ Vgl. Thomas SöDing, „Ich und der Vater sind eins“(Joh 10,30). Die johanneische Christologie vor dem Anspruch des Hauptgebotes (Dtn 6,4f), ZNW (2002) 177-199: 185.
} 
„Glaubt den Werken, wenn ihr mir nicht glaubt“ (Joh 10,38). Denn so werden sie zur Erkenntnis gelangen, dass der Vater im Sohn und der

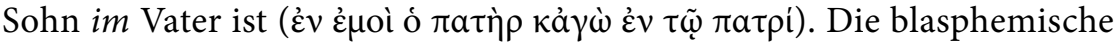
Einheitsaussage wird also in einer doppelten Erweiterung von Jesus ausgelegt: Die Seinseinheit von Vater und Sohn wird einerseits erkennbar an deren Handlungseinheit, der gemeinsamen Bewegung von Vater und Sohn. Andererseits erfährt der ontologische Anstoß, den die Juden an Jesu Aussage nehmen, Milderung durch die Metapher der Immanenz, dem In-Sein Gottes in Jesus und vice versa. Der ungeheure Anspruch auf ópovoía wird durch die metaphorische Beschreibung der żvovoía scheinbar entschärft. Doch der auf Erzählebene vorgeführte andauernde Protest der Juden zeigt, dass im jüdischen Denken offenbar die Kraft der Bilder keineswegs der der abstrakteren, philosophisch wirkenden Seinsaussagen untergeordnet ist.

Im Wissen um die Seinseinheit von Vater und Sohn als Handlungseinheit und reziproke Immanenz ${ }^{19}$ kann die Bitte des Philippus' wiederum nur zurückgewiesen werden. Dieser möchte ja, dass Jesus ihm den Vater zeigt, dass er ihm den Weg zu ihm weist, als sei der Vater an einem anderen Ort als Jesus selbst. Genau hier liegt das Missverständnis des Philippus begründet. Der Vater steht nicht am Ende eines Weges auf dem Jesus Wegbegleiter ist; der Vater steht nicht als Sprecher hinter Jesus als Sprachrohr; ${ }^{20}$ der Sohn vertritt den Vater nicht vor Ort während dessen Abwesenheit, ${ }^{21}$ sondern Jesus selbst ist das Ziel des Weges zu Gott, er selbst ist der Sprecher der Stimme Gottes, in seinen Werken werden die Werke seines Vaters offenbar (vgl. auch Joh 5,17), weil Gott jeweils in ihm präsent ist. ${ }^{22}$ Oder wie Klaus Scholtissek es treffend ausgedrückt hat: „Jesus repräsentiert nicht den Vater, er präsentiert ihn. “ ${ }^{23}$ Der Vater steuert den Sohn nicht via remote control, er spricht und wirkt nicht aus der Ferne durch ihn, sondern aus der Präsenz in ihm. Diese Präsenz wird nicht spürbar, indem man über die Logik der ontologischen Identität von Vater und Sohn nachsinnt. Die ontologische Seinsaussage gibt uns, wie Ludger Schenke feststellt, notwendigerweise ein Paradoxon

\footnotetext{
${ }^{19}$ Wie Reinhard Feldmeier in seinem Vortrag auf dem Symposion veranschaulicht hat, kann diese reziproke Immanenz nur in der gegenseitigen Liebe Verwirklichung finden. Nur in der Liebe gibt es keinen Unterschied zwischen Inhalt und Behältnis - die Immanenz wird zur Perichorese (vgl. Aufsatz S. 158 im Tagungsband).

${ }^{20}$ Vgl. Schenke, Christologie (Anm. 7) 454.

${ }^{21}$ Gegen Schenke, Christologie (Anm. 7) 453.

${ }^{22}$ Vgl. Marianne M. Thompson, The God of the Gospel of John, Grand Rapids 2001, 233.

${ }^{23}$ Klaus Scholtissek, „In ihm sein und bleiben“. Die Sprache der Immanenz in den johanneischen Schriften (HBS 21), Freiburg 2000, 256.
} 
auf, ${ }^{24}$ denn neben den Seinsaussagen kennen wir zugleich die Sendungs-

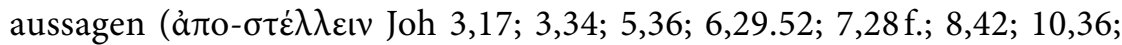
$11,42 ; 17,3.8 .18 .21 .23 .25 ; 20,21)$, die Auskunft über das Herabsteigen und

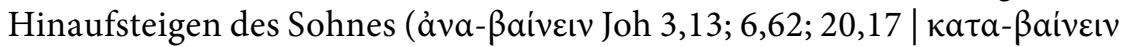
Joh 3,13; 6,38; 6,51), sein In-die-Welt-Kommen (Joh 1,9; 3,31; 9,39; 12,46;

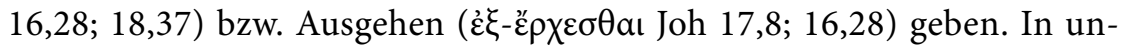
seren Raum-Zeitkategorien widersprechen sich Präsenz, als Anwesenheit ( $\pi \alpha \rho o v \sigma i \alpha)$ und zeitliche oder räumliche Distanz durch Wegbewegung,

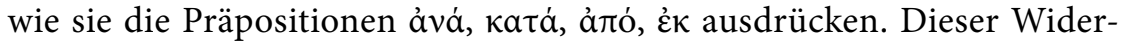
spruch kann nur aufgelöst werden, indem die Seins- und Immanenzaussagen, ebenso wie die Fortbewegungen metaphorisch aufgefasst werden. In den Aussagen über Gott und seinen Sohn wird etwas mit der Sprache dieser Welt auszudrücken versucht, was nun einmal nicht Gegenstand dieser Welt ist. ${ }^{25}$ Deshalb sind die Aussagen, wie Ludger Schenke richtig herausgestellt hat, nur im übertragenen Sinne zu verstehen. Eben dies lehrt uns das vierte Evangelium: Der Vater ist nur über den Sohn zu erkennen, die Theologie nur über die Christologie, der Logos nur über den Mythos, ${ }^{26}$ das Sein nur über das Wirken. Die göttliche Präsenz wird also nur dann spürbar, wenn man des Sohnes Werke sieht und darin die Handlungseinheit von Vater und Sohn in ihrer Dynamik wahrnimmt. Es hilft dabei nicht weiter, das Werk des einen von dem Werk des anderen logisch-ontologisch zu unterscheiden und der Urheberschaft des einen oder anderen zuzuordnen, beide tanzen kongruente Schritte.

Die Einheitsaussage zwischen Vater und Sohn strebt nach metaphorisch-mythischer Veranschaulichung, weil sie in innerweltlichen Sprachkategorien nicht aufgeht. So ist es auch legitim, sie in über das Evangelium hinausgehenden Metaphern weiter auszulegen. Während die Vatermetapher, wie Paul W. Meyer gezeigt hat, Gott v. a. in seiner Rolle als Autorisierungsinstanz veranschaulicht, ${ }^{27} \mathrm{kann}$ die Metapher des gemeinsamen Tanzes, des Pas de deux, etwas über die Art der Ausführung des väterlichen Auftrages durch den Sohn preisgeben. In diesem Tanz werden die Tanzpartner eins, ohne vollständig ineinander aufzugehen, ohne ihre

\footnotetext{
${ }^{24}$ Vgl. SChenke, Christologie (Anm. 7) 459.

${ }^{25}$ Vgl. ebd., $457 \mathrm{f}$.

${ }^{26}$ Selbstverständlich kommt in diesem Mythos ein historisches Ereignis zur Anschauung. Mythographie wird hier nicht als Gegenteil der Historiographie verstanden, sondern als eine besondere Sprachform des geschichtlichen Erzählens.

${ }^{27}$ Vgl. Paul W. Meyer, „The Father": The Presentation of God in the Fourth Gospel, in: R. Alan Culpepper (Hg.), Exploring the Gospel of John. In Honor of D. Moody Smith, Louisville 1996, 225-273: 265; ähnlich Thompson, God (Anm. 22) 231.
} 
jeweilige Identität aufzugeben. Sie stehen in engster Verbindung, ihre jeweils eigenen Schritte bilden eine gemeinsame Schrittfolge. Der eine lässt sich vom anderen führen, führt die Schritte aber gleichsam selbst aus.

An diesem etwas ausführlicheren Beispiel von Joh 10 lassen sich grundlegende Einsichten der Darstellung der Christo-Theologie des vierten Evangeliums erkennen. Es finden sich sehr wohl deklaratorische Spitzenaussagen, die in der späteren Wirkungsgeschichte des Evangeliums die Basis für die sogenannte „Hoch-Christologie“ gebildet haben. Im Evangelium selbst bleiben diese Aussagen jedoch aufs engste mit der metaphorischen und narrativen Darstellung verwoben. Es ist die Ästhetik der Sprachbilder und die Konkretion einer geschichtlichen Erzählung, durch die das Gottesbild durch Jesus anschaulich wird. In der Narratologie, besonders in der Figurenanalyse, hat man hier zwischen "direkter" und „indirekter" Charakterisierung unterschieden. Es ist nun eine literarästhetische Meisterleistung, dass dieser Doppelschritt aus „Telling“, d.h. abstrakterem Beschreiben, und „Showing", d. h. konkretem Zeigen, auch in der Verschränkung zwischen Metaphorik und Narration widergespiegelt wird. ${ }^{28}$

\subsection{Hirte}

Kommen wir nochmals auf die bereits genannte Hirtenmetaphorik aus Joh 10 zurück, um die Seins- und Handlungseinheit von Vater und Sohn sowohl beschreiben, als auch beobachten zu können:

Die Ich-Bin-Worte und das dazugehörige Bildfeld können ebenso wenig wie die darauffolgende Seinsaussage (Joh 10,30) als abstrakte Bestimmung des Wesens Jesu verstanden werden. Sie fordern in doppelter Adressatenschaft ${ }^{29}$ die Deutungsaktivität sowohl der Figuren als auch der

\footnotetext{
${ }^{28}$ Zur direkten und indirekten Charakterisierung via „Showing“ und „Telling“ vgl. Sönke Finnern, Narratologie und biblische Exegese. Eine integrative Methode der Erzählanalyse und ihr Ertrag am Beispiel von Matthäus 28 (WUNT 2,285), Tübingen 2010, 168-171. Wie es Art von Metaphern ist, widerstehen sie einer einseitigen Festschreibung auf den Bereich des „Telling“, denn in ihrer Bildhaftigkeit „zeigen“ sie natürlich mehr als sie abstrakt feststellen. Dennoch hat die Unterscheidung zwischen Rede- und Handlungspassagen für die Interpretation des Johannesevangeliums heuristischen Wert. Jesus kann seine Verbindung zum Vater einerseits mittels Metaphern besprechen, andererseits in Handlungen sichtbar werden lassen. Gerade letztere Erschließungsdimension wird bei „hoch“-theologischen Interpretation häufig übersehen.

${ }^{29}$ Der Theaterwissenschaftler Jens Roselt beschreibt das Phänomen der „doppelten Adressierung" für die Theaterbühne, auf der eine ,interne Kommunikation“ zwischen den Figuren
} 
Evangeliumsleser heraus. Sie können nicht einfach als ontologische Aussage übernommen werden, sondern erfordern eine dynamische Interpretation, die den kalkulierten Widersinn der Metapher in Sinn verwandelt.

Die sich aus dieser dynamischen Interpretation ergebenden christologischen Erkenntnisse können dann an vielen Szenen des Evangeliums noch konkret beobachtet werden. Der Leser sieht und erlebt Jesus als Hirten durch dessen Handlungen. ${ }^{30}$ An verschiedenen Stellen des Evangeliums wird die Führungs- und Leitungsfunktion Jesu als Hirte seiner Herde deutlich: Er ruft seine Jünger einen nach dem anderen in die Nachfolge (Joh 1,35-51); er weist die Tischdiener bei der Hochzeit zu Kana zum Füllen der Wasserkrüge an (Joh 2,7f.); er zeigt Nikodemus, der Samaritanerin und den Schwestern Martha und Maria, worauf es ankommt (Joh 3,1-20; 4,1-42; 12,20-27.32-44); bei der Speisung der 5000 leitet er seine Jünger an, das Volk zu lagern und die übriggebliebene Speise einzusammeln (Joh 6,10.12); kurz darauf führt er sie aus der Seenot (Joh 6,16-20); er schickt seine Brüder auf das Laubhüttenfest (Joh 7,8); er leitet sie zum Liebesdienst der Fußwaschung an (Joh 13,3-19) ${ }^{31}$; er bereitet seine Jünger in den Abschiedsreden auf seinen Weggang vor (Joh 13-16) u.v. m. Jesus ist Herdenbesitzer, insofern er seine Jüngerschar und immer weitere Menschen in seine Nachfolge zieht und sie im Glauben unterweist und insofern sein Vater ihm die Herde übergibt (Joh 10,28f.; vgl. auch 3,35; $6,44 ; 15,16.19 ; 17,6.9 ; 18,9)$.

Der gute Hirte gibt nach Joh 10 sogar sein Leben für die Schafe hin, während den Schafen das Leben in Fülle verheißen und geschenkt wird (Joh 10,10.28). Ein auf Bildebene durchaus fragwürdiges Unterfangen, denn ein toter Hirte könnte kaum noch für die Schafe sorgen. Wer also die metaphorische Theologie begrifflich eng führt, wird kaum zur Erkenntnis gelangen. Die schon bei Tür- und Hirtenmetaphern gesehene Clustertechnik wird hier um weitere Elemente (Lamm, Tempel) angereichert. Die Hirtenrede spielt in der Halle Salomos (des Tempels) und findet zur Zeit

sowie eine „externe Kommunikation“ zwischen Figur und Publikum stattfinden kann (vgl. Jens Roselt, Dialog/Monolog, in: Erika Fischer-Lichte/Doris Kolesch/Matthias Warstat [Hg.], Metzler-Lexikon Theatertheorie, Stuttgart u. a. ${ }^{2} 2004,67-72: 68$ ). Gleiches kann auch für Erzähltexte festgestellt werden (vgl. Fredrik WAGENER, Figuren als Handlungsmodelle. Simon Petrus, die samaritanische Frau, Judas und Thomas als Zugänge zu einer narrativen Ethik des Johannesevangeliums [Kontexte und Normen neutestamentlicher Ethik VI, WUNT 2,408], Tübingen 2015, 185).

${ }^{30}$ Vgl. Zimmermann, Christologie (Anm. 13) 133.

${ }^{31}$ Vgl. zur Verbindung von Hirtenrede (Joh 10) und Fußwaschung (Joh 13) Ulrich HECKEL, Hirtenamt und Herrschaftskritik. Die urchristlichen Ämter aus johanneischer Sicht (BThSt 65), Neukirchen-Vluyn, 2004, 112. 
der Tempelweihe statt (Joh 10,22). In diesem Setting sind die Schafe, von denen Jesus erzählt, als Opfertiere wahrnehmbar (vgl. Joh 10,10: $\theta$ v́w),

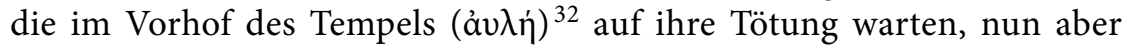
zum Leben herausgeführt werden, wohingegen Jesus selbst im Horizont des gesamten Evangeliums als das Schaf resp. Lamm präsentiert wird, das in den Hof hineingeführt wird (Joh 18,15) und am Ende stirbt. Beim ersten öffentlichen Auftreten ruft schon Johannes (der Täufer): „Seht das Lamm Gottes“ (Joh 1,29.36) und das Unterlassen des Crurifragiums am Kreuz wird mit explizitem Hinweis auf das Paschalamm begründet, dem auch keine Beine gebrochen werden dürfen (Joh 19,36). ${ }^{33}$ Erst in der Verschränkung von Metaphorik und Narration wird somit der Einsatz seines eigenen Lebens (des Hirten) anhand der Kreuzigungserzählung anschaulich (Joh 19,1-34). Und auch die Handlungseinheit mit dem Vater wird selbst im schändlichen Kreuzestod noch durchgehalten: Pilatus hat nicht von sich aus die Macht, Jesus auszuhändigen, sondern erhält sie von oben (Joh 19,11); verschiedene Schriftworte werden erfüllt ( $\pi \lambda \eta \rho \omega \theta \tilde{\eta} v a \mathrm{l}$ / $\tau \varepsilon \tau \dot{\varepsilon} \lambda \varepsilon \sigma \theta$ a Ioh 19,24.28.36) und Jesu letztes Wort bringt diesen kom-

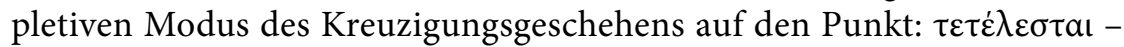
„es ist vollbracht“ (Joh 19,30). ${ }^{34}$ Im Verlauf des Evangeliums war bereits mehrmals von der Erfüllung der Werke des Vaters durch den Sohn die

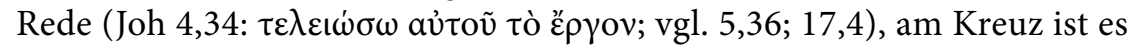
nun endgültig vollendet.

Die Seins- und Handlungseinheit zwischen Vater und Sohn wird aber nicht nur im Tür-Hirten-Schaf-Komplex präsentiert, wie es bisher vielleicht den Anschein hatte.

Einige andere Anschauungsfelder der Christo-Theologie sollen wenigstens noch kurz skizziert werden:

\footnotetext{
${ }^{32}$ Während ’’ aủํ́ kein Terminus technicus für den Schafstall ist, wird der Begriff seit der LXX häufig für den Vorhof der Stiftshütte (vgl. Ex 27,9-19) bzw. die Vorhalle des Tempels (vgl. 1 Kön 6,36; 2 Chr 4,9; Offb 11,2) verwendet, so dass auch hier eine Anspielung wahr-

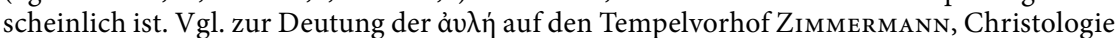
(Anm. 13) 362.

${ }^{33}$ Allerdings ist auch die Passalamm-Deutung wiederum nur eine von vier möglichen Interpretationslinien des „Lammes Gottes“ neben dem Duldungslamm aus Jes 53, dem Lamm des täglichen Tamid-Opfers und dem Substitutionslamm von der Bindung Isaaks, vgl. dazu Ruben ZimmermanN, Jesus - The Lamb of God (John 1:29 and 1:36). Metaphorical Christology in the Fourth Gospel, in: R. Alan Culpepper/Jörg Frey (Hg.), The Opening of John's Narrative (John 1:19-2:22). Historical, Literary, and Theological Readings from the Colloquium Ioanneum 2015 in Ephesus (WUNT 385), Tübingen 2017, 79-96.

${ }^{34}$ Vgl. FreY, „Wer mich sieht, der sieht den Vater“ (Anm. 7) 189.
} 


\subsection{Lebenspender}

Setzen wir mit dem semantischen Feld ein, das für Feldmeier/Spieckermanns Gotteslehre titelgebend war: der Lebensspender, johanneisch mit dem Begriff $\zeta \omega$ o $\pi$ o $\varepsilon \dot{\omega} \omega$ verdichtet ausgedrückt.

Gott wird im Alten Testament als der Lebendige und Lebensspender

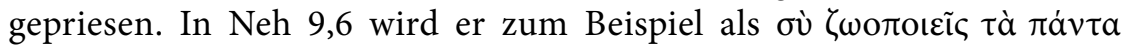
angerufen. Im Zusammenhang des Streites über die Sabbatheilung erklärt Jesus im Johannesevangelium seine Vollmacht, lebendig zu machen, wen er will, gleich wie der Vater die Toten auferweckt und sie lebendig macht (Joh 5,21).

Verbleibt in Joh 5,21 die lebenschaffende Einheit eine Behauptung und in Joh 10,10 die Ankündigung der Lebensfülle eine Verheißung, so wird auf der Ebene der historischen Erzählung in Joh 11 tatsächlich von der Belebung eines Toten erzählt. Seine lebenschaffende Wirkeinheit mit dem Vater stellt Jesus schließlich bei der Auferweckung des Lazarus unter Beweis.

Wie Jesu Wort von der Vollmacht schon betont hatte: Schöpfungstheologisch ist das Ins-Leben-Rufen der Geschöpfe wie des ganzen Kosmos aus dem Nichts Werk Gottes. ${ }^{35}$ Die Einheit von Vater und Sohn ist in Jesu Auferweckung in ihrer ganzen Dynamik erlebbar. Und es ist der Auferstandene, der in enger Analogie zum Schöpfer Adams, den Jüngern

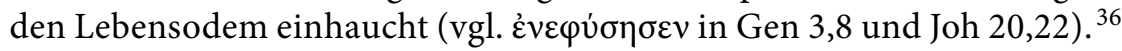

\subsection{Schöpfungswerke wie z. B. Gang über das Wasser}

Auch andere Zeichen können als derartige Sichtbarwerdungen der Handlungseinheit zwischen Vater und Sohn gesehen werden. Die Werke werden explizit als Zeugen für Jesu Identität - und das heißt besonders auch seine göttliche Identität - benannt (vgl. Joh 10,32.37; 14,11).

Wiederum deklarativ (i. S. des „Telling“) hören wir nach Joh 5,19: „Der Sohn kann nichts von sich aus tun, sondern nur, was er den Vater tun

\footnotetext{
${ }^{35}$ S. Gen 2,7; Dtn 4,4; Ps 16,11;21,5; 36,10 u. v. a.; vgl. auch FreY, „Wer mich sieht, der sieht den Vater" (Anm. 7) 185f.; Thомpson, God (Anm. 22) $228 \mathrm{f}$.

${ }^{36}$ Allerdings darf auch die Rolle des Geistes bei der Lebensgabe nicht vergessen werden: $\tau$ ì

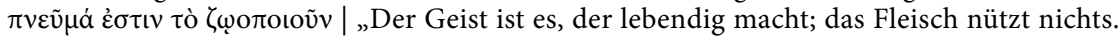
Die Worte, die ich zu euch gesprochen habe, sind Geist und sind Leben“ (Joh 6,63). Auch der Geist, nicht nur Vater und Sohn, wird hier als Lebensspender benannt. Es ist allerdings das göttliche Prärogativ des Geisthauches, das auf den Sohn übergeht (vgl. Thompson, God [Anm. 22] 160): Jesus tauft mit Geist (Joh 1,33); er gibt den Geist unbegrenzt (Joh 3,34); er sendet den Paraklet vom Vater aus (Joh 15,26); er gibt seinen Geist am Kreuz (Joh 19,30); er haucht den Jüngern den heiligen Geist ein (Joh 20,22).
} 
sieht; denn was dieser tut, das tut gleicherweise auch der Sohn." Wenn die Jünger bzw. Leser nun Jesus etwas tun sehen, so erkennen sie darin zugleich die Taten des Vaters.

Doch wie wird das gezeigt (i. S. des „Showing“)? Ein signifikantes Beispiel dieser göttlichen Handlungen ist Jesu Sturmstillung und Gang über das Wasser nach Joh 6,16-20. Die Jünger werden mitten auf dem See von einem Sturm überrascht (Joh 6,19). Plötzlich kommt Jesus auf dem Wasser zu ihnen. Während andere wunderbare Taten wie Heilungen oder Speisungswunder auch von wundertätigen Menschen berichtet werden, bleibt der Gang über das Wasser in jüdischer wie griechischer Tradition $^{37}$ Gott vorbehalten. Ausgerechnet in dieser Szene spricht Jesus zum ersten Mal das absolute „Ich bin es“ (Joh 6,20), mit dem unzweifelhaft auf die Gottesoffenbarung bei Mose und Jesaja angespielt wird. ${ }^{38}$ Mit Udo Schnelle könnte man resümieren: „Jesus offenbart auf dem See seine Gottheit, seine Epiphanie erscheint als rettende Gegenwart.“ ${ }^{39}$ Aus der Perspektive unserer Fragestellung könnte man auch formulieren: Indem Jünger wie Leser Jesus auf dem Meer wandeln sehen, erkennen sie unmittelbar Gottes rettende Gegenwart. Die Handlung Jesu kann gar nicht anders denn als Handlung Gottes wahrgenommen zu werden.

\subsection{Doxa}

Gleichermaßen wird im Aufleuchten der Doxa-Herrlichkeit (Kabod) in Jesus, welche unzweifelhaft den Glanz des Höchsten aufruft (man denke v. a. an die Herrlichkeitsmanifestationen im Kontext von Exodus und Wüstenwanderung in Ex 16,7.10; 24,16f.; 29,43; 33,22; 40,34f.; Lev 9,6.23; Num 14,10.21 f.; 16,19; 17,7; 20,6; Dtn 5,24), ${ }^{40}$ die besondere Wirkeinheit von Vater und Sohn deutlich. Nach Johannes wird der Glanz des Höchsten aber konkret in Fleisch und Zeichen (Joh 1,14; 2,11 etc.), ja sogar

\footnotetext{
${ }^{37}$ Vgl. hierzu einige Parallelen bei Craig S. Keener, The Gospel of John. A Commentary. Vol. 1, Peabody 2003, 674. Selbst Wengst, der bekanntlich wenig um Hoheitschristologie bemüht ist, schreibt hierzu: „Damit stellt ihn Johannes in der Dimension Gottes dar, der seinen Weg auch auf dem Meer nimmt und denen, die er retten will, einen Weg durchs Wasser gibt." (Klaus Wengst, Das Johannesevangelium. 1. Teilband: Kapitel 1-10 [ThKNT 4,1], Stuttgart 2000, 225f.)

${ }^{38}$ Vgl. Catrin H. Williams, „I am he“. The Interpretation of „anî hû" in Jewish and Early Christian Literature (WUNT 113), Tübingen 2001, 225-228.

${ }^{39}$ Udo SchnelLe, Das Evangelium nach Johannes (THKNT 4), Leipzig ${ }^{5} 2016,164$.

${ }^{40}$ Chibici-Revneanu bezeichnet die Herrlichkeitsmanifestationen im Kontext von Exodus

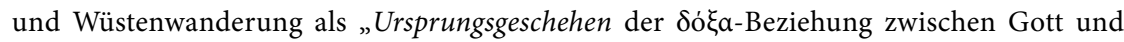
Mensch" (Nicole Chibici-Revneanu, Die Herrlichkeit des Verherrlichten. Das Verständnis der $\delta$ ó $\xi$ im Johannesevangelium [WUNT 2,231], Tübingen 2007, 459).
} 
paradoxerweise im Kreuzigungsgeschehen (= Verherrlichung) (Joh 12) sichtbar. Eine klare Unterscheidung, gar Hierarchisierung von väterlicher und söhnlicher Herrlichkeit ist nach Johannes wiederum unmöglich. Mal ist von der Verherrlichung des Sohnes durch den Vater die Rede (Joh 1,14; $8,54 ; 11,4 ; 12,28 ; 16,14 ; 17,1.5 .22 .24)$, mal von der Verherrlichung des Vaters durch den Sohn (Joh 14,13; [15,8;] 17,4), und an wieder anderer Stelle durchdringen sich beider Herrlichkeiten in einem komplizierten Akt gegenseitiger Verherrlichung (Joh 13,31 f.). Nach Nicole Chibici-Rev-

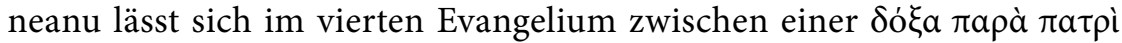
(Joh 17,5) in der (Prä- und Post-)Existenz Jesu beim Vater und einer $\delta \dot{\xi} \xi \alpha$

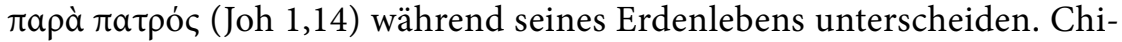
bici-Revneanu geht so weit zu sagen, die $\delta$ ó $\xi \alpha$ Jesu leite sich nicht nur aus der $\delta$ ó $\xi a$ des Vaters her, sondern sei mit ihr identisch. Auch dann, wenn sie auf Erden offenbart wird, bleibe sie der göttlichen Sphäre zugehörig. ${ }^{41}$ Solange Jesus also auf Erden agiert, lässt er die Herrlichkeit Gottes in den konkreten Begegnungen mit den Menschen aufscheinen (z. B. in Joh 2,11; ganz i. S. des "Showing“). Bei seiner Erhöhung zum Vater, am Kreuz, wird er wiederum durch die $\delta o ́ \xi \alpha$ Gottes verherrlicht - eine Herrlichkeit, die er schon besaß, als er vor Beginn der Welt bei seinem Vater war (Joh 17,5; i. S. des „Telling“).

\subsection{Richter}

Spannend ist es weiterhin, das Richteramt in der hier vollzogenen Zuspitzung zu betrachten. Im Rahmen der Schöpfungstheologie kommen dem Schöpfergott konsequenterweise die Hoheitsrechte über seine Schöpfung $\mathrm{zu}$ (s. Sünde und Bestrafung in Gen 3). ${ }^{42}$ Nach atl. Motivik agiert Gott ferner als Bundespartner, der immer wieder Klage gegen das eigene Bundesvolk ebenso wie gegen Fremdvölker erhebt und rechtmäßige Strafen verhängt (u. a. Dtn 32; Jes 40-55; Hos 4; 5; 12,2-14; Mi 6,1-8). ${ }^{43}$ Nach Joh 5,22 hat der Vater das Gericht aber an seinen Sohn übergeben, ja dieser ist sogar primär, wie es heißt „zum Gericht in die Welt gekommen" (Joh 9,39). Bereits im Prolog wird dem göttlichen Logos Anteil am Schöpfungswerk zugesprochen (Joh 1,3.10); es ist von seinem Kommen in das Seine/sein Eigentum die Rede (Joh 1,11). Jesu Hoheitsrechte werden

\footnotetext{
${ }^{41}$ Vgl. ebd., 326.

${ }^{42}$ Vgl. Andrew T. Lincoln, Truth on Trial. The Lawsuit Motif in the Fourth Gospel, Peabody 2000, 186.

${ }^{43}$ Vgl. ebd., 38.
} 
damit noch vor Beginn der eigentlichen Narration wirksam etabliert. ${ }^{44}$ Diesem Telling wird wiederum mit Zuspitzung auf Passion und Kreuz das Showing des Gerichtet-Werdens (Pilatus-Prozess) zur Seite gestellt. Wer dies noch nicht sehen kann, bekommt vor dem Passionsteil noch einen expliziten Hinweis: „Jetzt ergeht das Gericht über diese Welt“ (Joh 12,35). Im verurteilten Sohn bzw. rezeptionsästhetisch zugespitzt in der Haltung zum Sohn wird das göttliche Gericht bereits vollzogen (vgl. Joh 3,18f.). Das Geschick Jesu lässt das göttliche Gericht sichtbar werden, oder wie Andrew Lincoln es formuliert: „In this trial it is through the Logos that God comes to expression as witness and judge: ,He whom God has sent speaks the words of God' (3:34a). "45 Und es ließe sich noch ergänzen: Gott wird im Logos nicht nur als Zeuge und Richter anschaulich, sondern eben auch als Angeklagter.

\subsection{Weitere Motive: Liebe, Bräutigam}

Es wäre nun reizvoll und hinsichtlich der Erhärtung unserer These auch notwendig, weitere Beispiele dieser christo-theologischen Überblendungen vor Augen zu führen.

Man denke an das reiche semantische Feld der Liebe, die nach Johannes synonym mit Gott-Vater stehen kann $(1$ Joh 4,8.16) und narrativ im Liebeshandeln des Sohnes, z. B. der Fußwaschung (Joh 13; 15) entfaltet wird. ${ }^{46}$ Oder der göttliche Bräutigam Israels (Hos 2,21-22; Jes 62,4f.; Jer 2-3) ${ }^{47}$ feiert nun tatsächlich eine Hochzeit in Raum und Zeit (Joh 2,1), bei der Jesus funktional in die Rolle des Bräutigams schlüpft; der Täufer kann im Sinne des Telling den metaphorischen Code nur noch nachschieben als das Fest längst zu Ende ist (Joh 3,29). ${ }^{48}$

Die Beispiele ließen sich reichlich vermehren. Und schon bei diesen skizzenhaften Pinselstrichen bemerken wir wiederum etwas Grundsätz-

\footnotetext{
${ }^{44}$ Vgl. Lincoln, Truth (Anm. 42) 186.

${ }^{45}$ Ebd., 186.

${ }^{46}$ Vgl. Enno Edzard Popkes, Die Theologie der Liebe Gottes in den johanneischen Schriften. Zur Semantik der Liebe und zum Motivkreis des Dualismus (WUNT 2,197), Tübingen 2005.

${ }^{47}$ Vgl. Ruben Zimmermann, Geschlechtermetaphorik und Gottesverhältnis. Traditionsgeschichte und Theologie eines Bildfelds in Urchristentum und antiker Umwelt (WUNT 2,122), Tübingen 2001, 91-233: Kap. 2: Das Bildfeld in alttestamentlichen und (früh-)jüdischen Texten.

${ }^{48}$ Vgl. zur Brautmetaphorik in Joh 2-4 Ruben Zimmermann, Jesus - the Divine Bridegroom, in: Benjamin Reynolds (Hg.), Reading the Gospel of John's Christology as Jewish Messianism: Royal, Prophetic, and Divine Messiahs (AJEC 106), Brill 2018, 358-386.
} 
liches über die Christo-Theologie. Die alttestamentliche Gottesrede, die Gottesprädikate und -handlungen sind zweifellos Voraussetzungen und Basis, ohne die die Metaphorik und Narration des vierten Evangeliums unverständlich blieben. Gleichwohl wird Jesus nicht nur in diese (bereits bekannte) Gottesrede eingezeichnet, sondern zeichnet sie selbst auf neue Weise. Er macht sie neu und tiefer sichtbar. Die Darstellungsweise ist mehr als eine bloße Übertragung alttestamentlicher Gottesprädikate auf Jesus. Die Gotteslehre wird „erinnert, um Neues zu sagen“. ${ }^{49}$ Und gerade in diesem Verschlungensein von Traditio und Innovatio erweist sich die hier wahrnehmbare Schrittfolge als Paartanz mit gleichwertigen Partnern. Es wäre vermessen, hierbei von Vorher oder Nachher, Überoder Unterordnung zu sprechen. Im gemeinsamen Tanz kann nur der Gleichtakt gelten.

\section{Variationen der Tänzer}

Bei aller Verbundenheit von Vater und Sohn in Handlungseinheit und reziproker Immanenz, wird im Johannesevangelium doch auch die Unterschiedenheit von Vater und Sohn gewahrt. Die Einheit von Vater und Sohn, so hatten wir bereits festgelegt, ist keine Identität. Die bleibende Verschiedenheit kommt v.a. in den Variationen der Tänzer zum Ausdruck.

Als größte Variation Jesu innerhalb des Pas de deux mit seinem Vater kann wohl seine Inkarnation bezeichnet werden, seine Fleischwerdung, und damit verbunden, sein Zeitlichwerden, seine Intemporalisierung. Er tritt in die Geschichte ein und ordnet sich den zeitlichen Grundbedingungen des menschlichen Lebens unter ohne selbstverständlich die Verbindung zum Vater zu verlieren. Die Tanzpartner halten sich durchweg an der Hand.

Trotz all der Metaphorik rund um Jesu Wesensbeschreibung und trotz der erzählerischen Ausgestaltung der Figur Jesu, kann man von keiner fiktiven Person sprechen. Jesu Existenz und sein Wirken in der Welt sind für den vierten Evangelisten durchaus historisch und an der Faktizität des Christusgeschehens hängt die gesamte johanneische Heilslehre. ${ }^{50}$ Es

\footnotetext{
${ }^{49}$ So der Titel des Metaphernbandes von Jean-Pierre van Noppen (Hg.), Erinnern, um Neues zu sagen. Die Bedeutung der Metapher für die religiöse Sprache, Frankfurt a. M. 1988.

${ }^{50} \mathrm{Vgl}$. Georg Essen, Historische Sinnbildung. Zeitkonzepte in der Perspektive einer Theologischen Historik, in: Kurt Appel/Erwin Discherl (Hg.), Das Testament der Zeit. Die Apokalyptik und ihre gegenwärtige Rezeption (QD 278), Freiburg u. a. 2016, 59-76: 74-76.
} 
ist demnach allein die Sprache eine mythische, nicht das erzählte Ereignis selbst. Die mythischen Sprachformen sind nötig, um die Tiefe und das Bedeutsame am historischen Ereignis rund um die Person Jesu für die Späteren aufzuheben. ${ }^{51}$ Deshalb ist es so entscheidend, Reden und Handeln, Telling und Showing in den Blick zu nehmen, weil sie sich gegenseitig in dem, was sie über die Relation zwischen Gott, Jesus und den Glaubenden aussagen können, auslegen und vertiefen.

Nur indem Jesus die irdische Begrenzung von Raum und Zeit im Kreuzestod durchlebt, kann er sie für die Menschen, die an ihn glauben, aufheben. Darin aber unterscheidet er sich von seinem Vater, welcher selbst nicht Fleisch wird, nicht anschaulich wird, sich nicht unter die Begrenzung der menschlichen Lebenszeit stellt. Doch ist am Kreuz nicht zugleich auch Gott zu sehen?

Ludger Schenke spricht von einem notwendigen Lernprozess der Jünger: Sie müssen lernen, dass der Mensch Jesus entgegen des Augenscheins, seiner menschlichen Biographie und trotz seines Fleisches Gottessohn ist. ${ }^{52}$ Die Leser des Evangelium müssen u. E. einen umgekehrten Lernprozess durchwandern: Aufgrund des abstrakten Prologes und ihres eigenen christlichen Bekenntnisses (Telling) kennen sie Jesus vornehmlich als $\sigma \omega \tau$ tท่ (Joh 4,42) und Gottessohn. Durch die Erzählungen (Showing) des Johannesevangeliums aber erfahren sie stärker noch als in den anderen Evangelien, dass der Gottessohn zugleich auch vollblütiger Mensch war. Hier könnte man die ganze Palette - wie Udo Schnelle ${ }^{53}$ es genannt hat antidoketischer Erzähldetails aufführen, die die Menschlichkeit Jesu in krasser Weise vor Augen führt (z. B. weint er, hat Durst etc.). Pilatus hat

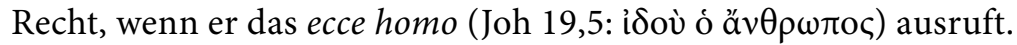

Die Präexistenzaussagen im Prolog stellen dann gegenüber dem Rest des Evangeliums „eine provokante und paradoxe Zuschreibung einer übermenschlichen Qualität von Überzeitlichkeit an den Menschen Jesu dar" ${ }^{54}$, wie Friederike Kunath deutlich gemacht hat. Durch den Gegensatz von Vorzeitigkeit und menschlicher Zeitlichkeit, von Endlichkeit und Überwindung der Endlichkeit zum ewigen Leben hin entsteht in der Per-

\footnotetext{
${ }^{51}$ Vgl. SChenke, Christologie (Anm. 7) 461; Frey, „Wer mich sieht, der sieht den Vater" (Anm. 7) 208.

${ }^{52}$ Vgl. SCHENKE, Christologie (Anm. 7) 450-452.

${ }^{53}$ Vgl. Udo Schnelle, Antidoketische Christologie im Johannesevangelium. Eine Untersuchung zur Stellung des vierten Evangeliums in der johanneischen Schule (FRLANT 144), Göttingen 1987; DERS., Evangelium (Anm. 40) Exkurs 1: Inkarnation, 65-71.

${ }^{54}$ Friederike Kunath, Die Präexistenz Jesu im Johannesevangelium. Struktur und Theologie eines johanneischen Motivs (BZNW 212), Berlin u. a. 2016, 368.
} 
son Jesu eine unauflösbare Spannung, durch deren Bogen er einerseits auf das Engste mit dem Vater verbunden ist, andererseits aber in klar erkennbarer Unterscheidung zu ihm steht.

Das geschichtliche Wirken Jesu, insbesondere seine Zeichenhandlungen zeigen seine Göttlichkeit, sein eigener zeiterhabener Seinsanspruch („Ich und der Vater, wir sind eins“ Joh 10,30) hingegen erweckt bei seinen Gegnern Zweifel und zwar aufgrund seiner menschlichen Biographie, er provoziert den Blasphemievorwurf und begründet letztlich seine Verurteilung zum Tode. ${ }^{55}$ Daran wird eines erkenntlich: Nur wenn Jesus sich in seiner göttlichen Ewigkeit zugleich den zeitlichen Bedingungen der Menschen unterordnet, also in die Zeit eintritt und darin handelt, kann er sich ihnen letzten Endes in seiner göttlichen Ewigkeit offenbaren. Bevor er nicht das Ende der menschlichen Lebenszeit, den Tod, durchlitten hat, wird seine Ewigkeit nicht erkennbar. ${ }^{56}$

Umgekehrt lässt auch der Vater als der führende Tänzer im Pas de deux Unterschiede zu seinem Sohn erkennen, die einer Identität beider widersprechen. Jesus selbst bezeichnet seinen Vater als größer als er selbst

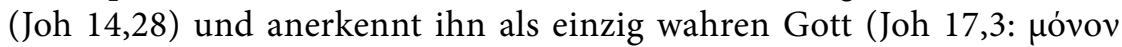

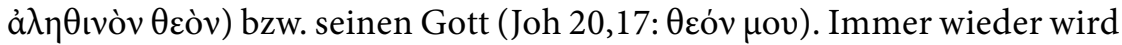
der Vater als klares Gegenüber Jesu gekennzeichnet: Er kennt Jesus und Jesus kennt ihn (Joh 10,15); der Vater liebt den Sohn (Joh 10,17) und der Sohn liebt den Vater (Joh 15,10); der Vater sendet den Sohn (Joh 3,16) und erteilt ihm Aufträge, der Sohn erfüllt diese (Joh 12,49). Der Vater verherrlicht den Sohn (Joh 8,54; 12,28; 17,22), der nur bevor die Welt

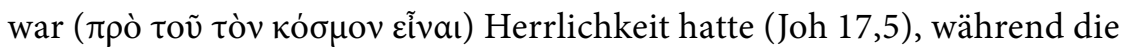
Herrlichkeit Gottes immer besteht (Joh 11,4.40). Die distinkten Merkmale des Vaters werden allerdings, wie wir sehen, immer nur in Relation zum Sohn sichtbar. Zugespitzt formuliert, gibt es nach Johannes insofern auch nicht den Vater ohne den Sohn, nur im Sohn wird auch der differenzierende Blick auf den Vater freigegeben. Der Sohn tritt nicht erst später hinzu, sondern ist von Anfang an als Logos bei Gott (Joh 1,1). Einen Blick auf Gott allein gibt es nach dem vierten Evangelium nicht mehr. Bei der Wanderung auf dem schmalen Grat zwischen der betont engen Verbindung von Vater und Sohn und der notwendigen Verschiedenheit beider,

\footnotetext{
${ }^{55}$ Vgl. SöDING, „Ich und der Vater sind eins“ (Anm. 18) 179.

${ }^{56}$ Das Prädikat der Göttlichkeit wird Jesus denn auch nur im Prolog (Joh 1,1.18) und nach der Auferstehung im Bekenntnis des Thomas (Joh 20,28) zugesprochen, nicht aber während seines vorösterlichen Wirkens (vgl. Thомpson, God [Anm. 22] 233).
} 
die sich in der Vater-Sohn-Metapher besonders nahelegt, ist letztlich nur tanzend Balance zu halten.

Das Ziel des Evangeliums ist es, trotz und mittels dieser Variationen der beiden Tänzer die besondere Relation Jesu zu Gott zu offenbaren, nämlich als vom Vater unterschiedener und doch mit ihm vereinter Sohn. Die Charakterisierung Gottes ist dabei, wie François Tolmie narratologisch festhält, einer der „secondary aspects of the Gospel ${ }^{\text {“ }}{ }^{57}$ In anderen Worten: Über das Johannesevangelium erfahren wir nicht viel Neues über den ontologischen Teil der Theologie, wohl aber über den hermeneutischen Teil der Theologie, den Zugang zu Gott-Vater über dessen Sohn. Auf diese Weise muss die johanneische Christologie nicht mehr als Konkurrentin der johanneischen Theologie verstanden werden, sondern als ein Teil von ihr, nämlich als ihr hermeneutischer Teil.

\section{Coda: Joh 17,21: Die Einheit geht über auf „alle“}

Es mag wenige deutsche Universitäten geben, die einen Vers aus dem Johannesevangelium als Leitspruch vorweisen können. Die Johannes Gutenberg-Universität Mainz hat sich mit Neugründung im Jahr 1946 ausge-

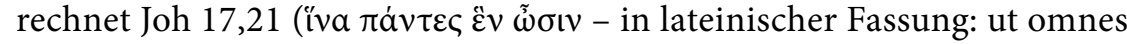
unum sint) als Motto gewählt. Doch wie man unschwer erahnen kann, ist dies nicht der einzige Grund, warum wir diesen Vers nun auch als Überschrift über die Coda des Pas de deux gesetzt haben.

Die im vierten Evangelium beschriebene Einheit zwischen Vater und Sohn hat im Lauf der Rezeptionsgeschichte einen exklusiven Charakter erlangt. Man denke etwa an die Bedeutung des Johannesevangeliums für die dogmatische Christologie und Trinitätslehre.

Ist es folglich die Rolle der Lesenden quasi im Publikum sitzend diesem wunderbaren Pas de deux zuzuschauen, das da auf der Bühne des Evangeliums vorgeführt wird? Kann der bis zur Verschmelzung vorgeführte Gleichschritt dieses göttlichen Tanzes nur betrachtet, bewundert und angebetet werden?

Die Choreographie des vierten Evangeliums will keine Distanz schaffen, sondern letztlich zur Annäherung zwischen Artisten und Publikum beitragen. Im Sinne des Befreiungstheaters („teatro de los oprimidos“)

\footnotetext{
${ }^{57}$ Tolmie, Characterization (Anm. 3) 61.
} 
des Theaterpädagogen Augosto Boal ${ }^{58}$ soll es hier am Ende nicht mehr Akteure und Zuschauer geben, sondern alle sind in das gemeinsame Spiel bzw. hier den gemeinsamen Tanz einbezogen. Der Pas de deux wird zur Polonaise.

Wir können in der Coda diesen Gedanken nur noch anreißen: Wiederum weist die mediale Darstellung selbst den Weg. Die christo-theologische Erzählweise und Metaphorik gehen auf Jünger und Lesende über. Die Jesus- bzw. Gottesprädikate sind nicht exklusiv, sondern integrativ:

- Der im Schoß des Vaters Ruhende (Joh 1,18) lässt den Lieblingsjünger

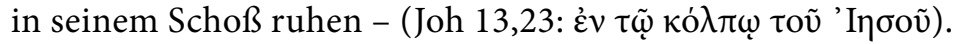

- Aus der Vater-Sohn-Einheit wird die „familia dei“": Die Sohnschaft geht unter dem Kreuz auf den Lieblingsjünger über (Joh 19,26f.). Ziel ist, dass nicht einer Sohn des Vaters, sondern alle "Kinder Gottes“ seien (Joh 1,12).

- Auch die reziproke Liebesgemeinschaft zwischen Vater und Sohn schließt Jünger und Glaubende ein (vgl. Joh 15,9: Gleichwie mich der Vater liebte, so liebte ich auch euch; bleibt in meiner Liebe!)

- Der gute Hirte beauftragt Petrus zum Hirtenamt (Joh 21,15-19).

- Das sterbende Weizenkorn wird zum Vorbild für jeden, der sein Leben verliert (Joh 12,24f.).

- Der Gesandte sendet seine Jünger (Joh 17,18; 20,21).

- Die Jünger sollen „Geheiligte“ sein (Joh 17,17) wie Jesus selbst „Heiliger Gottes“ (Joh 6,69 vgl. 10,36) genannt wird. ${ }^{59}$

Es ist tatsächlich so, als würde das Vortänzerpaar das Publikum in immer neue Schrittfolgen hineinführen, sodass ein bunter und vielperspektivischer Reigen entsteht, der alle zu einem Volk der Tanzenden vereint. Welcher einzig Gott geschaut hat, der ermöglicht so allen Glaubenden schließlich auch Gott durch ihn zu schauen (Joh 14,9) oder wie es schon der Prolog formuliert: die Herrlichkeit zu schauen (Joh 1,14), in die sie mit einem Mal selbst handelnd und lebend einbezogen sind.

Feldmeier/Spieckermann haben in ihrer Gotteslehre diese rezeptionsästhetische Dimension als Übergang vom Gotteswissen in Gotteserkenntnis beschrieben; „der Mensch“, so schreiben sie, „(kann) nur da sein Leben in einem qualifizierten Sinne wahrnehmen (...), wo er Gott als den

\footnotetext{
${ }^{58}$ Augusto BoAL, Theater der Unterdrückten. Übungen und Spiele für Schauspieler und Nicht-Schauspieler, hrsg. und aus dem Brasilianischen übers. von Marina Spinu, Frankfurt a. M. 1989.

${ }^{59}$ Vgl. Zimmermann, Christologie (Anm. 13) 352-355; $438 \mathrm{f}$.
} 
Geber und Retter seines Lebens erkennt und als Herrn über sein Leben anerkennt. Gottes (...) Worte sind ,Lebensmittel" für das wahre Leben. " 60 Man wird hier als Johanneiker sofort an den Schluss des Evangeliums erinnert, das sein Ziel als Gabe des Lebens für den Glaubenden beschreibt (Joh 20,31). Dieses Leben soll tatsächlich erlebt, gesehen, geschmeckt und gehört - und warum nicht auch ertanzt - werden. ${ }^{61}$ Es ist besonders die literarische Ästhetik, mit der der Rezipient ganzheitlich in diesen Prozess der Erkenntnis einbezogen wird. Metaphern brauchen den Betrachter, um nicht in Widersinn abzugleiten; und die rezipientenorientierte Erzählung zieht den Lesenden in einen ständigen Prozess der Identifikation und Abgrenzung hinein.

In dieser Weise wird das Wort tatsächlich „Fleisch“ und zwar das Wort, das Gott selbst ist (Joh 1,1.14).

\footnotetext{
${ }^{60}$ Feldmeier/SpieckermanN, Gott (Anm. 9) 7.

${ }^{61}$ Vgl. zur Sinnenvielfalt Dorothy LeE, The Gospel of John and the Five Senses, JBL (2010) 115-127, sowie jetzt Rainer Hirsch-Luipold, Gott wahrnehmen. Die Sinne im Johannesevangelium (Ratio Religionis Studien 4, WUNT 374), Tübingen 2017.
} 



\section{An attempted coup?}

No, the Father is made known by his Son

Jan van der Watt

\section{Jesus makes himself God}

The claims of Jesus about his relation to God were a bone of contention with his opponents in John's Gospel. ${ }^{1}$ According to the Johannine narrative, Jesus is perceived by his Jewish opponents as threatening the position of their monotheistic God. They clearly made this point throughout the Gospel. Accusing Jesus at the climax of his trial, these Jewish opponents insisted, "We have a law, and according to that law he (= Jesus) ought to die because he has made himself the Son of God" (19:7). This echoes their perception of Jesus from the early stages of the narrative. In 5:18 the narrator informs the implied reader, "This was why the Jews were seeking all the more to kill him, because not only was he breaking the Sabbath, but he was even calling God his own Father, making himself equal

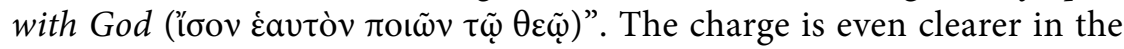
discussions in 10:33 (cf. also 10:36): "It is not for a good work that we are going to stone you but for blasphemy, because you, being a man, make

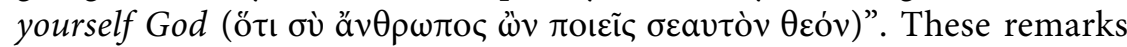
clearly express the view of the Jewish opponents that Jesus threatens the position of God. Within a Jewish context, no other being or god or idol is allowed to threaten the unique position of God.

This is only one side of the response of the Jewish opponents to Jesus. They also express their opinion about Jesus by claiming that Jesus has a

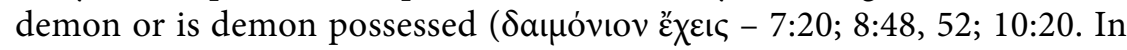
10:21 demon possession is specifically mentioned). Thus, when the opponents regard Jesus' words as blasphemous (10:17-21), militating against their tradition (8:48-52), they accuse him of being under the influence of

\footnotetext{
${ }^{1}$ From here on "John" without any suggestion of a possible author.
} 
the demonic powers of the devil, the prince of this world who stands in opposition to the creator God.

From the above it is clear that the response of the Jewish opponents is presented from two perspectives, namely, that God should not be threatened and that any such efforts are inspired by opposing spiritual powers, headed by Satan, the prince of this world.

To formulate it positively, within the Jewish tradition and according to the first four commandments, the honour of God must be protected. There was no place for another powerful divine figure next to God, no matter who they were or where they came from. Throughout its history, Israel was constantly under pressure to turn to such divine figures and consequently to turn away from their own God, something that incurred the wrath of God. ${ }^{2}$ Add to this the tradition that "subordinate divine beings" (i.e. also angels) were known in the "pre-monistic early Israelite past" as well as in the contemporary pagan cultures. ${ }^{3}$ What is of significance for us is that the presence and activities of such spiritual and even divine figures were related and discussed inter alia within the framework of ancient angelology, which suggest that this should at least be considered as heuristic framework for the Johannine remarks.

In the light of these insinuations by the Jewish opponents, possibly influenced by ancient perceptions of conflicting divine figures including angels, I would like to explore the possibility that Johannine rhetorical descriptions of the relationship between God and Jesus were influenced by and aimed at countering the idea that Jesus might somehow threaten the position of God. It will be suggested that John uses metaphors like Father and Son, the Son loving (i.e. obeying) the Father, or the mission of the Son, doing nothing of his own inter alia as indications that Jesus poses no threat to his Father, excluding a possible "coup", as his opponents want to suggest when they claim that he is making himself God over and against their only God.

\footnotetext{
${ }^{2}$ Walter BRUEggemanN, Old Testament Theology: An Introduction (Library of Biblical Theology), Nashville 2008, argues that the tension between a disobedient people and their God, expecting them to honour the covenant is a basic structure in the development of the message of the First Testament.

${ }^{3}$ Ruth M. M. Tuschling, Angels and Orthodoxy: A Study in Their Development in Syria and Palestine from the Qumran Texts to Ephrem the Syrian (STAC 40), Tübingen 2007, 13.
} 


\section{An attempted coup?}

Tension between high and low Christology is evident from the very first verse of John (1:1) where it is said that "the Word was with God and the Word was God". This tension is confirmed in 1:18 where Jesus is called

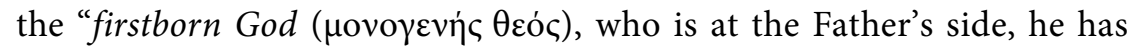
made him known". High and low Christology seems to stand shoulder to shoulder in these verses creating some theological tension. Jesus is described with the term "God" but is also distinguished from God the Father who seems to have the priority position.

I would like to consider this apparent tension within a scenario that relates to perceptions regarding both the necessity and danger within a context of monotheism of allowing other powerful beings into the divine presence. The emergence of monotheism went hand in hand with specific developments in angelology. ${ }^{4}$ Scholars like Meier ${ }^{5}$, Di Tommaso, ${ }^{6}$ Corbin ${ }^{7}$ and Tuschling ${ }^{8}$ point out that with monotheism gaining prominence, the role of angels increased in importance ${ }^{9}$ in order to ensure the continuing "presence" of God on earth, even though it was indirectly. Concepts like the ancient councils of gods, sons of gods, holy ones were common in ancient Eastern contexts, metaphorically describing the divine world in terms of ancient royal courts. With single powerful rulers, the need for numerous servants and representatives existed in order to represent the ruler in his kingdom, since he cannot physically be omnipresent. Di Tommaso ${ }^{10}$ notes that especially in post-exilic times the idea of the monotheistic God's transcendence and "the corresponding sense of his disassociation from the everyday process of the world" stimulated the idea of heavenly beings as divine agents who act on behalf of God.

\footnotetext{
${ }^{4}$ Cf. Jan G. van Der Watt, Angels in the Gospel according to John, Journal of Early Christian History 1 (2011) 185-204.

${ }^{5}$ Sam Meier, Angels and Angel-Like Beings. Hebrew Bible/Old Testament, EBR 1 (2009) $1167-1173$.

${ }^{6}$ Lorenzo DiTommaso, Angels and Angel-Like Beings. Judaism, EBR 1 (2009) 1173-1176.

${ }^{7}$ Henry Corbin, Nécessité de l'angélologie, in: idem (Ed.), Le paradoxe du monothéisme, Paris 1981, 97-190: 100.

${ }^{8}$ Tuschling, Angels (Fn. 3).

${ }^{9}$ The reason was that within monotheism the superiority of God increased to such an extent that other gods or transcendental, supernatural figures were totally subordinate although their presence is still attested, they now fulfill secondary roles and served as messengers or representatives for God. Cf. Meier, Angels (Fn. 5) $1167 \mathrm{f}$.

${ }^{10}$ DiTommaso, Angels (Fn. 6) 173.
} 
Angels were originally predominantly seen as messengers, but their functions broadened to being "supernatural servants of God"11 or "agents of God's will" 12 . Already within the pantheon of gods, the major god could ask the lesser figures to perform a variety of tasks like protecting or guarding the divine, helping or warning, punishing or caring others on behalf of the divine. This situation intensified within monotheism where there was a greater reliance on angels. Discrete categories of divine beings were even differentiated in the First Testament: ${ }^{13}$ a) they rule together (1 Kgs 22:19-23; Job $1: 6-12 ; 2: 1-6$ ); b) they carry messages; ${ }^{14} \mathrm{c}$ ) they protect and save the people of God (Dan 3:25; 2 Macc 11:6-8); ${ }^{15} \mathrm{~d}$ ) they provide assistance to travellers (Gen 24:7, 40; $1 \mathrm{Kgs} \mathrm{19:5-7;} \mathrm{Ex} \mathrm{23:20-23;}$ 32:34; Num 20:16); e) they act in military capacities (Dan 10:12, 20-21); f) they praise to God, also through song. ${ }^{16}$ Representation of the "King" can be found on virtually all levels where the need could be expected.

In other words, based on this metaphorical application of powerful single rulers in ancient royal courts, the monotheistic God was described as having servant-angels like a king had servants who served not only him in his court, but also served as his presence in the outside human world. Tuschling underlines that these servants of God expressed different attributes of God in different ways, i.e. as servants they carried out their commissions ${ }^{17}$ by doing what God requires, ensuring the omnipresence of his divine power. ${ }^{18}$ This also applied to John's narrative; the transcendental God, whom nobody has seen (1:18), had to reveal himself, show his

\footnotetext{
${ }^{11}$ Meier, Angels (Fn. 5) 1171.

${ }^{12}$ Carol A. Newsom, Angels. Old Testament, ABD 1 (1992) 248-253: 252.

${ }^{13}$ See Tuschling, Angels (Fn. 3), Meier, Angels (Fn. 5), 1169-1171; Roy A. StewART, Angel, NBDict ( $\left.{ }^{3} 1996\right)$ 36f. and the variety of articles in Friedrich V. Reiterer/Tobias Nicklas/Karin Schöpflin (Eds.), Angels. The Concept of Celestial Beings Origins, Development and Reception (DCLY), Berlin 2007, for instance Dominica KuREKСhomycz/Reimund Bieringer, Guardians of the Old at the Dawn of the New. The Role of Angels According to the Pauline Letters, 325-356, Albert L. A. Hogeterp, Angels, the Final Age and 1-2Corinthians in Light Of The Dead Sea Scrolls, 377-394; Stefan Schreiber, The Great Opponent. The Devil in Early Jewish and Formative Christian Literature, 437-458; Cecilia Wassen, Angels in the Dead Sea Scrolls, 499-524.

${ }^{14}$ Duane E. F. WATson, Angels. New Testament, ABD 1 (1992) 253-255: 254; Newsom, Angels (Fn. 12) 249f.; Tuschling, Angels (Fn. 3) 81-84; Karin Schöpflin, God's interpreter. The Interpreting Angel in Post-Exilic Visions of the Old Testament, in: Reiterer/Nicklas/Schöpflin (Eds.), Angels (Fn. 13) 189-203; Kurek-Chomycz/Bieringer, Guardians (Fn. 13) 330.

${ }^{15}$ Watson, Angels (Fn. 14) 254.

${ }^{16}$ See Tuschling, Angels (Fn. 3) 7 ff.; Barnabas Lindars, The Gospel of John (NCB), Grand Rapids 1987, 121.

${ }^{17}$ Meier, Angels (Fn. 5) 1169.

${ }^{18}$ Tuschling, Angels (Fn. 3) 1.
} 
power and omniscience and emphasize his majesty, and this was inter alia achieved through mediatory beings. ${ }^{19}$ In John 1:18 this revelation of the unseen God is delineated and restricted, when the "firstborn" God, Jesus, will make his Father known.

A real threat, however, existed within ancient royal courts, namely overthrowing the king, which was often executed by a strong figure within the court. This pattern was also perceived possible in the divine world with its gods and angels, and was therefore a concrete possibility within the metaphorical application within the framework of a monotheistic God. This is indeed what happened within the (Christian) tradition in which John finds himself, as is evident in the presence of the devil or Satan as opposing prince or leader of this world $(12: 31 ; 14: 30)$ who has significant opposing power. This opposing power should be dealt with in the manifestation of the royal power of God on earth (12:31, 14:30).

\section{John and angelology}

We have already mentioned John's acute awareness of the evil side of angelology, but what about servant-angels of God? Is John familiar with the realities described in angelology?

In contrast to the synoptic gospels John mentions angels only three times $(1: 51,12: 29 ; 20: 12-13)$ and they only appear as characters in the narrative in one of these references $(20: 12-13)$. I argued elsewhere in detail $^{20}$ that concrete references to angels in John are toned down in light of Johannine Christology. With Jesus around, angels are functionally no longer required. ${ }^{21}$ Their role as angelus interpres is taken over by Jesus, as are their roles of protection (10:28-30) and honouring God (15:8; 17:1). ${ }^{22}$ The angels are functionally replaced by Jesus as the one who will make the Father known, so that the unseen God may become visible and

\footnotetext{
${ }^{19}$ Tuschling, Angels (Fn. 3) $5 \mathrm{ff}$.

${ }^{20}$ VAN DER Watt, Angels (Fn. 4).

${ }^{21}$ Kurek-Chomycz/Bieringer, Guardians (Fn. 13) 350 conclude that this is to a large extent true of Paul too.

${ }^{22}$ Tuschling, Angels (Fn. 3) 13 mentions that in the earliest period of Christianity "angelic language is borrowed to speak of Christ", which makes this conceptual framework even more possible. She further notes that angels were indeed prominent in some types of early Jewish Christianity and is even seen by some (i.e. Daniélou) as "distinguishing characteristic of Jewish Christianity" (ibid. 55).
} 
functionally observable. ${ }^{23}$ John does not discard angels but rhetorically emphasizes that it is Jesus who now mediates the Father. As such, they functionally move into the background. ${ }^{24}$ Even the evil figure(s) have no claim on Jesus (14:31), but are cast out (12:31). It must be stated clearly that in no way does John suggest that Jesus is an angel: at most, he functionally performs actions often associated with angels. This is actually a logical development in the light of Jesus' task of making the Father known.

Another dimension to be noted is that in vilifying each other both opposing groups motivate their views in terms of concepts related to angels,

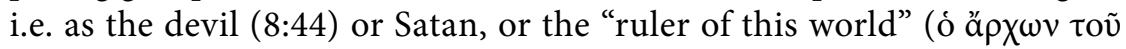

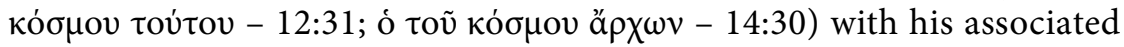
demons $(7: 20 ; 10: 21$; cf. also 9:16 in light of 9:24-34). The devil is, like God, described in royal or political terms, i.e. as a ruler, characterizing the conceptual framework as that of political power. Both groups accuse one another of siding with the devil in opposition to God. This confirms John's frame of mind when dealing with these matters.

\section{The Father in me does his works - transparent Christology}

Having established that the possible response of the Jewish opponents might be formulated in terms of the threat Jesus might pose to God, and that John is presenting his message with awareness of such ideas about angels, the question may now be put: what is the plausibility of the Johannine reflection on the relation between God and Jesus responding inter alia to the idea of a divine threat that Jesus might pose to God? ${ }^{25}$

The perception of the Jewish opponents of Jesus posing a possible threat to their monotheistic God does not seem to be without any warrant. Within the high Christology Jesus is described as claiming to be one with God $(10: 30 ; 17: 11-21)$, is in the Father and the Father in him (Immanenzformel - 14:10-11) and is indeed called God (1:1, 18; 20:28). The closeness and unity between Jesus and God is stated beyond any possibility of contradiction.

\footnotetext{
${ }^{23}$ Cf. Marianne M. Thompson, God's Voice You Have Never Heard, God's Form You Have Never Seen, Semeia 63 (1993) 177-204.

${ }^{24}$ Obviously, another aspect of angelology is also developed in connection with the devil and demons, as was referred to already.

${ }^{25} \mathrm{Cf}$. references in this volume to multiple sources on God in John, but especially Marianne M. Thompson, The God of the Gospel of John, Grand Rapids 2001.
} 
It will be shown in what follows that in light of this possible threat, John seems to be at pains to clearly emphasize that Jesus is in no way a threat to the monotheistic God, but that his status and activities should be perceived differently, even though he may be called the unique God (

Three points will be dealt with, namely, a) the way the Father is made known through the presence of Jesus is not threatening; $b$ ) the role of imagery, specifically familial language, in dealing with the problem and c) eschatological descriptions countering the idea.

\subsection{Jesus makes the Father known}

The relation between the Father and Son is functionally described in the Prologue (1:18) in terms of the Son who makes the Father known ( $\dot{\varepsilon} \xi \eta \gamma \varepsilon \dot{\varepsilon}$ o a - aorist indicative medium). Theologically this statement at the outset of the Gospel delineates as well as limits the way God, the Father, becomes known. ${ }^{26}$ Previously, the Law given through Moses served this purpose (1:17), but grace and truth, which are qualities of a personal God introduce a new situation in which God will be made known in a different personal way. What is intended and how this takes place is explicated in the rest of this Gospel. ${ }^{27}$

In reflecting on his ability to make the Father known, Jesus consistently refers inter alia to the unity (or Immanenz) between him and his Father. ${ }^{28}$ The way this unity should be understood is pointedly described in 14:6-24 where the immanence between the Father and Son is explicitly stated in 14:10-11 (ESV), "Do you not believe that I am in the Father and the Father is in me? The words that I say to you I do not speak on my own authority, but the Father who dwells in me does his works. Believe me that I am in the Father and the Father is in me, or else believe on account of the

\footnotetext{
${ }^{26}$ D. François Tolmie, The Charaterization of God in the Fourth Gospel, JSNT 69 (1998) 57-75. Stan Harstine, The Fourth Gospel's Characterization of God: A rhetorical perspective, in: Christopher W. Skinner (Ed.), Characters and Characterization in the Gospel of John (LNTS 461), London 2013, 131-146.

${ }^{27}$ Cf. Jan G. van der Watt/R. Alan Culpepper/Udo Schnelle (Eds.), The Prologue of the Gospel John: Its Literary, Theological and Philosophical Contexts. Papers read at the Colloquium Ioanneum 2013 (WUNT 359), Tübingen 2016 where the function of the Prologue to formulate central issues that are developed further in the rest of the Gospel is described.

${ }^{28}$ Other concepts like his education $(5: 19-23)$ or his mission also form central themes in explaining why he does what his Father does.
} 
works themselves". The significance of this context is that it also contains an explanation of what is meant by this immanence.

There seems to be some discrepancies in the flow of argumentation in the initial parts of Chap. 14 that seem to create tension between some remarks related to spatial concepts in this section. Jesus remarks that he is going to the house of his Father to prepare a place for his disciples (14:1-4). The disciples indicate that they do not know the way (14:5), leading to the remark of Jesus that he is the way to the Father and nobody comes to the Father but by him (14:6). The flow of the argument follows natural spatial perceptions related to the movement of Jesus going away and coming back and metaphorically that he is the way leading to the Father. The spatial tone however changes in 14:7 where it is stated that to

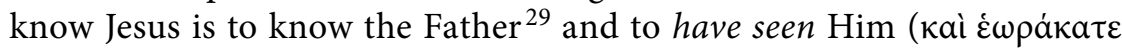
aủtóv - perfect active indicative). Here Jesus is no longer a road leading to the Father, but the Father is seen (is spatially present) when a person knows Jesus. The clue to this apparent tension is given in Jesus' reaction to Philip's request to Jesus to show $(\delta \varepsilon \tilde{\varepsilon} \xi o v)^{30}$ them the Father,

"Whoever has seen me has seen the Father. How can you say, 'Show us the Father'?

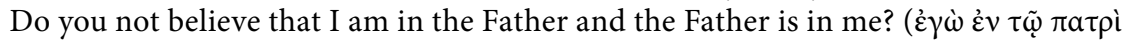

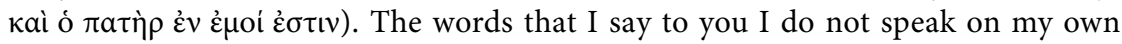

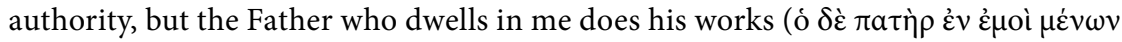

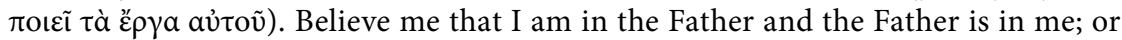
else believe on account of the works themselves" (14:9-11).

Spatial tension is apparent in this remark of Jesus describing his immanence with the Father. He is not the way to the Father but the Father is already present in him and he is in the Father. The way this immanence should be understood is then explained.

a) Jesus does not speak on his own authority, but obviously on the authority of his Father. The structure should be noted - listening to Jesus is actually listening to the Father, hearing the Father's words. In this functional sense the Father is present in Jesus. It is therefore not an objective physical presence, but a revelation of the unseen Father through his messenger, Jesus (cf. 1:18). The way "presence" is perceived should be understood correctly - it is not physical presence, but mediated functional presence. ${ }^{31}$ One can even speak of an integrated presence.

\footnotetext{
${ }^{29}$ Different translations are possible, but this is not central to the argument here.

${ }^{30}$ The word "show" used by Philip may already indicate a shift in spatial emphasis in this passage.

${ }^{31}$ Klaus Scholtissek, In Ihm sein und bleiben. Die Sprache der Immanenz in den johanneischen Schriften (HBS 21), Freiburg 2000, 274 uses the term "modal" to refer to the
} 
b) The above statement is confirmed by the last phrase of verse 10: "the

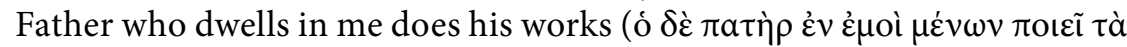

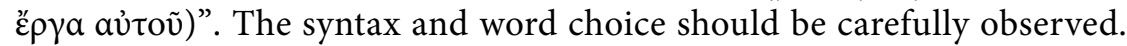
The actor is not Jesus as in the first remark in verse 10, but the Father he is the subject of the sentence - it is him that works. Obviously, these works refer to the actions of Jesus but are nevertheless described as works the Father does. The argument is clear - when Jesus works, people should see the Father in action. By seeing Jesus in action or hearing his words, the disciples should identify the presence of the Father in Jesus, to such an extent that it can be said, as John does in 14:10, that the Father is doing his works when one observes Jesus working. This is mediated, integrated, functional presence, representing a very specific spatial modus. ${ }^{32}$

c) The implications of the statement by Jesus that he is in the Father and the Father is in him (14:10) should be differentiated. The way the Father is in Jesus is different from the way Jesus is in the Father, simply because they have different functions within this functional relationship. The Father is in Jesus as the one who commanded and sent him, gave him words to speak, deeds to do (14:10), enabling him to give life and judge (5:21-23), even to raise himself from death (10:17-18). His functions are "transferred" to Jesus though he remains the source. In this functional relationship, Jesus performs these functions on the authority of his Father. He adds nothing, but obediently does what the Father asks of him, implying that what is seen are not functions originating with Jesus, but with the Father. This impacts on the Christology and position of Jesus Jesus is presented as the representative, the one who makes the reality of the Father known. The action line refers back to the Father - it is he that should be focused on and should become known. Another way of putting it: John uses a transparent Christology, meaning that what is seen does not stop with Jesus, but through Jesus the Father becomes known and can be seen.

This way of expressing the immanence between the Father and Son is not limited to 14:10-11, but is reiterated elsewhere in the Gospel. In 10:30 a direct statement of the unity between the Father and Son is made: "I and

\footnotetext{
functionality. He also describes believers as "Wirkräume und -orte der Liebe des Vaters und des Sohnes" (p. 300). The Son himself is "in ihnen wirkmächtig gegenwärtig". On page 325 he speaks of a "Wirk- und Handlungsgemeinschaft" or on page 326 of a "Wirk- und Willenseinheit".

${ }^{32}$ This is also part of the social conventions and expectations of ancient missionary practices.
} 


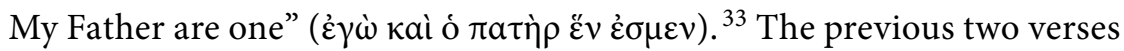
put this remark into perspective. The sheep are under the protection of both the Father and the Son - nobody will snatch them from their hands. This indicates synchronized functional unity. Jesus speaks and does only what he saw from the Father $(3: 32 ; 5: 19,30 ; 12: 49-50)$.

The task of Jesus and everything he does and says by implication refer back to his Father to such an extent that in his behaviour the presence of the Father is integrated and may be observed. Jesus, his words and his deeds are primarily absorbed within and are determined by his relation to the Father.

Though Christology lies at the core focus of John it should be remembered that this Christology is essentially referential - it refers to the Father; it is transparent - the Father should be seen and heard and as such, it is integrated, it is functional in its relation. What now follows is a brief overview to illustrate the extent to which the Father is the focus of this referential, transparent, integrated, functional Christology. Two sets of information will be considered, i.e. the "I am-sayings" as key Christological expressions, and some of the actions of God the Father in relation to his Son.

a) The $I$ am-sayings are key expressions of Johannine Christology. ${ }^{34}$ The aim is not to discuss the significance of these sayings, but to give a brief indication of their embedded heuristic relation with what is said about the Father. A table provides a brief overview of the relation between the "I am-sayings" and the Father.

\footnotetext{
${ }^{33}$ In Chap. 10, just after Jesus' statement the Father and he are one, an argument follows with the Jewish opponents in which they blame Jesus of blasphemy because he makes himself God (in the direct context referring in the first place to 10:28-30) which would imply a ontological unity. SсноцтіSSEK, Sprache (Fn. 31) 274 speaks of "Identitätsaussagen", which is not intended in John. Jesus denies that strongly in his argument, indicating that he called himself Son of God (10:36), based on functional unity - he does the works of his Father and that these works indicate that the Father is in him and he in the Father - an argument he repeats in 14:8-10 to indicate the way the Father may be known by his disciples. The Father is not physically seen in person, but through the words and actions of Jesus.

${ }^{34}$ Cf. David M. BALL, "I am" in John's Gospel. Literary Function, Background and Theological Implications. (JSNTSup 124), Sheffield 1996. Silke Petersen, Brot, Licht und Weinstock. Intertextuelle Analysen johanneischer Ich-bin-Worte (NovTSup 127), Leiden et al. 2008 .
} 


\section{I am-saying}

1 . I am the bread of life $(6: 35$, $48,51)$

2. I am the light of the world $(8: 12)$

$3+4$. I am the door of the sheep $(10: 7,9)$; I am the good shepherd $(10: 11,14)$

5. I am the resurrection and the life (11:25)

\section{I am the way, and the} truth, and the life. No one comes to the Father except through me. (14:6)

7. I am the true vine $(15: 1,5)$

\section{Relation to the Father}

6:32-34: My Father gives you the true bread from heaven. For the bread of God is he who comes down from heaven and gives life to the world.

12:44-46: Whoever believes in me, believes not in me but in him who sent me. And whoever sees me sees him who sent me. I have come into the world as light, so that whoever believes in me may not remain in darkness.

10:14-15, 17-18: I am the good shepherd. I know my own and my own know me, just as the Father knows me and I know the Father; and I lay down my life for the sheep... For this reason the Father loves me, because I lay down my life that I may take it up again. No one takes it from me, but I lay it down of my own accord. I have authority to lay it down, and I have authority to take it up again. This charge I have received from my Father.

10:27-30: My sheep hear my voice, and I know them, and they follow me... and no one will snatch them out of my hand. My Father, who has given them to me, is greater than all, and no one is able to snatch them out of the Father's hand. I and the Father are one.

11:40-42: Did I not tell you that if you believed you would see the glory of God?... Jesus lifted up his eyes and said, Father, I thank you that you have heard me... and 6:57: As the living Father sent me, and I live because of the Father, so whoever (believes in) me, he also will live because of me.

14:7 If you had known me, you would have known my Father also. From now on you do know him and have seen him. and 14:10: Do you not believe that I am in the Father and the Father is in me? The words that I say to you I do not speak on my own authority, but the Father who dwells in me does his works.

$15: 7-10$ By this my Father is glorified, that you bear much fruit... As the Father has loved me, so have I loved you. Abide in my love. If you keep my commandments, you will abide in my love, just as I have kept my Father's commandments and abide in his love. 
A few reflections on the above table are necessary:

The saying, I am the bread of life (6:35) follows the reference to the Father who gives the bread from heaven that brings life. Life comes from God (3:16) and it is his will and commandment to Jesus that people should have life (12:50). Jesus, in his metaphorical function as bread of life, is a gift from the Father in order to mediate this life. This is emphasized a few verses further on (6:57) where the functional chain is explicitly drawn into the discussion - the Father is the living one, the source of life, Jesus lives because of his Father and believers because of Jesus. Indeed, Jesus is not present as bread of life to do his will, but that of the Father who sent him as bread (6:38). Confirming the argument above, Jesus remarks in 6:51 that it is he who gives the bread, although a few verses earlier it was his Father who gives the bread, confirming the integrated unity that functionally overlaps. In this whole process the Father is described as the source of not only the bread and life, but also of making it available through the gift of Jesus. Within this process Jesus is the one who is sent and thus mediates.

Although God is not called light in the Gospel, ${ }^{35}$ he is metaphorically described as light in the letters (1 John 1:5). Nevertheless, Jesus describes himself as light in 8:12 and remarks on that in 12:44-46 where he does so in direct reference to the revelational and integrated relationship between him and the Father.

In the shepherd imagery in Chap. 10 Jesus is identified as the shepherd who lays down his life for his sheep, but he does this on his own authority that the Father has given him (10:17-18). ${ }^{36}$ His knowledge of and love for the Father is mimed by his knowledge of and love for his people. He functionally does what the Father does in protecting the sheep, but it is acknowledged that the Father is greater than all, shifting the focus to the Father. Although Jesus is the shepherd, he makes the Father known by acting like him on the basis of the Father's love and authority.

Jesus, as the resurrection and life, lives because of the Father and on this basis he gives life (i.e. can be the resurrection and life); when he raises Lazarus he asks the Father whom he knows is listening to him. This is to make the glory of the Father known and visible. The Father is described as solid basis behind the life-giving actions of Jesus.

\footnotetext{
${ }^{35}$ Otto SchwankL, Licht und Finsternis. Ein metaphorisches Paradigma in den johanneischen Schriften (HBS 5), Freiburg 1995. Marianne Meye Thompson, "Light" ( $\varphi \tilde{\omega} \varsigma)$ : The Philosophical Content of the Term and the Gospel of John in: Jan G. van der Watt/R. Alan Culpepper/Udo Schnelle (Eds.), Prologue (Fn. 27) 273-83.

${ }^{36}$ The gate saying is not directly linked to the Father as is the good shepherd saying.
} 
The saying of Jesus that he is the way is discussed above and will not receive further attention here.

The Father, as gardener, is integrally part of the vine imagery. The vine is cared for by him and bears fruit to his glory. The frame of the imagery (15:9-17), referring to the reciprocal love ${ }^{37}$ and Jesus keeping his Father's commandments confirms that this I am-saying also functions within the framework of the priority of God and Jesus acting according to his commandments and abides in his love.

The illustrated point is that the clearest Christological sayings in John (i.e. the I am-sayings) function within the framework of the priority of the Father who stands behind who Jesus is and what he does.

b) This priority of the Father that is made known by Jesus is confirmed by the description of the other actions of Jesus, of which a few are listed here: He is educated by the Father, who has shown him everything (13:3; 17:2) and gave him the power and authority to give life and judge and the Father testifies to Jesus (5:37) and sets his seal on him (6:27); his Father gives him those who belong to him to care for $(17: 6,9)$; he was sent by the Father on a mission - Jesus says and does only what the Father commands him and therefore claims that he has made known the words of the Father $(17: 6,14)$; the Father grants his requests $(14: 16)$; he is the (vassal) king in the kingdom of God; he is the Son in the Father's house who prepares place in this house; this Father is his Father and their Father, his God and their God (20:17); Jesus even remarks that he carries the Father's name, which he made known $(17: 12,26)$.

It should be noted that there is a direct contextual connection between the Jewish opponents' charge that Jesus is claiming to take the position of God and the Johannine presentation of Jesus as the one on a mission, revealing the Father. In discussions where the Jews accuse Jesus the immediate response by Jesus in the narrative is to refer to his position as Son of the Father (cf. 5:17-30;10:31-39). This contextually confirms the thematic link between the threat the Jewish opponents see and the presentation of Jesus as the obedient Son on a mission, implying that the idea of a threat must have played a conceptual role in the formulation of the Christology.

The evidence is overwhelming that John presents a Christology that refers to and is fully dependent on the Father. The total dependence on and reference to the Father exclude any hint of opposition or threat, quite the contrary.

\footnotetext{
${ }^{37}$ Cf. Jörg Augenstein, Das Liebesgebot im Johannesevangelium und in den Johannesbriefen (BWANT 134), Stuttgart 1993.
} 


\subsection{The Son can and will never be the Father - familial language}

A second feature in John to exclude the possibility of confusing the person of Jesus with a possible adversary of God should be found in his preference for filial language to political or royal language (kingship). ${ }^{38}$ Royal language is not absent from John on the contrary, as I argued elsewhere. ${ }^{39}$ However, in describing the presence of Jesus, familial language is preferred. Kingship language is more prone to power conflicts and is indeed the space where power struggles belong. John's limitation of the use of royal language is restricting the possibilities for such tension between God and Jesus. Royal and filial language should however not be interpreted as contrasting language, since royal and filial language are complementary a king can be a father, as God, the King $(3: 3,5)$ is the Father of Jesus, his Son, who is also a (vassal) king (18:36-37).

The use of imagery creates certain expectations, i.e. familial imagery is based on social convention and expectations. These expectations are metaphorically applied to God and Jesus, with God being the Father and Jesus the Son. What is socially expected from a father and son is metaphorically applied to God and Jesus. When such an imagery is used, the confines of the imagery should be respected. The father cannot become the son nor the son the father, since this is against the nature and confines of the relationship. Such change does not happen in John where the father-son relationship is maintained. God remains the Father and Jesus the Son and the actions and words of Jesus are described in terms of this relationship. These roles cannot be and are not changed. By means of this familial imagery the permanent distinction between God and Jesus is maintained and a difference in status is expressed.

The familial imagery in John is that of a father, equipping his son and sending him on a mission. ${ }^{40}$ In John this Son is not a threat to his

\footnotetext{
${ }^{38}$ Mira Stare, Ethics of Life in the Gospel of John, in: Jan G. van der Watt/Ruben Zimmermann (Eds.), Rethinking the Ethics of John (WUNT 291), Tübingen 2012, 213-228.

${ }^{39}$ Jan G. VAN DER WATT, Is Jesus the King of Israel? Reflections on the Jewish Nature of the Gospel of John, in: R. Alan Culpepper/Paul A. Anderson (Eds.), John and Judaism. A Contested Relationship (SBLRBS 87), Atlanta 2017, 39-56. Cf. Ulrich Busse, Metaphorik und Rethorik im Johannesevangelium: Das Bildfeld vom König in: Jörg Frey/Jan G. van der Watt/Ruben Zimmermann: Imagery in the Gospel of John: Terms, Forms, Themes, and Theology of Johannine Figurative Language (WUNT 200), Tübingen 2006, 279-317.

${ }^{40}$ Birger Olsson, Deus Semper Maior? On God in the Johannine writings, in: Johannes Nissen/Sigfred Pedersen (Eds.), New Readings in John. Literary and Theological Perspectives. Essays from the Scandinavian Conference on the Fourth Gospel, Århus 1997 (JSNTSup 182), Sheffield 1999, 167 describes the position of Jesus as sent agent as follows: "Statements about Jesus as the Messiah might be interpreted in terms of God's agent and
} 
Father, but is rather the special envoy of the Father who acknowledges his role as such. Jesus is not replacing God, but is making God known his words and behaviour are transparent, allowing people to see, hear and experience God, the Father. ${ }^{41}$ Within this thought structure the Johannine Christology develops as a non-threatening relationship towards the Father.

The very nature of this relationship and mission should briefly be explored in order to determine whether the perceptions of the opponents were correct when opining that Jesus threatens God and his honour.

\subsubsection{The authority is with the Father who sent Jesus}

John emphasizes Jesus' source of authority in different ways. Jesus directly

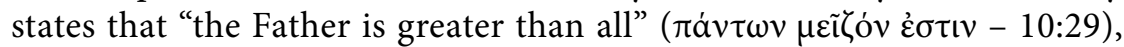
but a verse further (10:30) claims that the Father and he are one (10:30). These two aspects are kept in tense balance within a hierarchical unitary framework in which the Father has priority.

Jesus consistently refers to the Father as having all authority - Jesus himself does not speak or act on his own (authority) ${ }^{42}$. Jesus indeed points out to his Jewish opponents that he came in his Father's name $(5: 43 ; 12: 25)$ as is evident in his works and words. In several instances he underlines that his words and teachings are from the Father and not from himself. In 7:16-18 such a typical remark is found where Jesus says that his teaching is not his and is not done on his authority, but is the teaching of him who sent Jesus (cf. also 14:24). Jesus seeks the glory of the one who sent him, proving that the authority lies with the Father. This attitude of Jesus proves that Jesus is "true, and in him there is not falsehood" (7:18). He acts on the authority of the Father, not against him as threat. In 8:28-29 Jesus confirms that he does not speak on his own authority but as the Father

representative on earth. The Messiah has a particular commission from God. The same may be true of statements about Jesus as the Son of God. Jesus says what God says; Jesus does what God does. Jesus is God's presence and involvement in the world. In Jn 17.3 faith in the one true God is joined with a 'sending theology'."

${ }^{41}$ Hierocles (On duties 4.25.53) gives the following illustration of a way in which ancients thought of the presence of one person through the other: "we might reasonably say that our accomplishments are the deeds of our parents who brought us into existence. It is not the case that we perform some deeds while our parents who brought us into existence perform others".

${ }^{42}$ The Greek phrase ả $\pi$ ' $\dot{\varepsilon} \mu a v \tau o \tilde{v}$ ("of myself”) is translated as "authority" in many English translations. It has the meaning that Jesus does not do it on own accord or own initiative or authority. This is in any case what is required within the conventions of ancient missionary practices. 
taught him, doing what pleases the Father. It is noteworthy to remark that in these verses the Father does not leave Jesus alone, not even when he is lifted up, implying dependence of Jesus on the Father. This line of thought is also reconfirmed in 12:49 where the idea of the commandment by the Father of what to speak is mentioned or in 14:10 where the Immanenz of the Father and Son is described in terms of the willingness of the Son not to speak on his own authority but on that of the Father.

An integral part of the relationship between the Father and Son is metaphorized in terms of mission imagery, also when it comes to authority. The mission of Jesus is metaphorically described as the mission of a son, sent by his father, a social practice that inherently implies hierarchy. The one sent is under the authority of the one who sent, as Jesus states in 13:16: "he who is sent is not greater that he who sent him". A good messenger will also be an obedient messenger. This identifies the Father in a different hierarchical position than Jesus, identifying Jesus as not being the threat of someone who wants to act on his own against the Father.

John seems to go to some lengths to emphasize the priority of the Father in this regard. The referential and transparent nature of Jesus' presence is continuously emphasized. Jesus acknowledges this by way of circular hierarchy, "he who receives me receives him who sent me" (13:20 - RSV) and "He who believes in me, believes not in me but in him who sent me. And he who sees me sees him who sent me" (12:44-45 RSV; cf. also 3:34; 5:36). Jesus did not come to do his own will, but that of him who sent him (6:38; cf. also 6:40; 7:16-17), relativizing the nature of Jesus' activities in terms of his relation to the Father. Indeed, Jesus' teaching is not his own $(7: 14-16)$ but that of the Father.

John finds it necessary to consistently emphasize the position of Jesus as the one who is not greater that the one who sent him, doing what he is asked, confirming himself as an ideal agent. The authority does not lie with him, but with God. His behaviour is simply referential. This consistently contradicts the opinions of the Jewish opponents about Jesus $(10: 31-39)$. Is he the one who challenges the monotheistic God, as the Jewish opponents seem to claim? - on the contrary.

A last remark about authority is necessary: the position of Jesus is indeed aptly illustrated by his role in eschatological judgment. It is stated that the Father has given all judgment to his Son and he judges no one $(5: 22,27)$. This sounds like total transference or even abandonment of this function to Jesus, which arguably might open the door for oppositional tension. The correcting perspective is found in 8:16: "if I do judge, my judgment is true: for I am not alone, but I and the Father that sent me" 
(cf. this remark with 8:28 in the same context). Although the authority and right to judge was given to Jesus by the Father, the judgment remains the judgment of the Father who sent him. Jesus' actions in relation to his Father are consistently described in terms of representative co-operation and not opposition.

\subsubsection{The Father glorifies the Son and the Son in turn glorifies the Father}

The intense and unique relationship between Jesus and his Father, introduced in 1:18, is consistently confirmed throughout the Gospel, underlining the hierarchical relationship - the Father has priority.

A few examples of how the Father supports the Son within this hierarchical relationship should suffice to illustrate this point. In 5:37 Jesus claims that the Father has borne witness to Jesus as the one who seeks the will of the one who sent him (cf. also 8:18). The Father is also the one who consecrated Jesus and sent him into the world (10:36; cf. 17:19), both expressions suggesting the priority of the Father in the process.

The concept of glorification, that has to do with indicating the gravitas or importance of somebody, is also used in the Gospel to profile the relationship between the Father and Son. ${ }^{43}$ Not only does the Father glorify his own name through Jesus $(12: 28 ; 13: 31)$ but Jesus also does likewise (13:31; 17:1, 5); Jesus honours his Father (8:49; cf. also 5:23) and glorifies Him through his behaviour $(13: 31 ; 17: 1,4)$. His Father is the ultimate One who should be glorified (15:8).

Jesus' obedient response to the commandments of the Father is based on his love for the Father, as he remarks in 14:31: "That the world may know that I love the Father; and as the Father commanded me, even so I do" ${ }^{44}$. Reciprocal love is a central theme in the Gospel ${ }^{45}$ and inter alia refers to the true loyalty and commitment to one another, to the point of laying down one's life like a friend (15:13), or by way of imagery, a seed that wants to bear fruit but must first die (12:24). Loving someone

\footnotetext{
${ }^{43}$ Cf. Dorothy LeE, Flesh and Glory. Symbolism, Gender and Theology in the Gospel of John, New York, 2002. Jan G. van DER WatT, Double entendre in the Gospel according to John, in: Gilbert van Belle/Jan G. van der Watt/Petrus Maritz (Eds.) Theology and Christology in the Fourth Gospel. Essays by the Members of the SNTS Johannine Writing Seminar (BETL 184), Leuven 2004, 463-481.

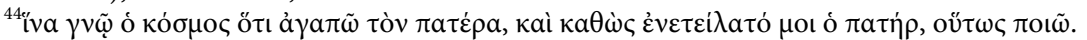

${ }^{45} \mathrm{Cf}$. Jan G. van Der WatT, Radical Social Redefinition and Radical Love. Ethics and Ethos in the Gospel according to John, in: idem, Identity, Ethics, and Ethos in the New Testament (BZNW 141), Berlin 2006, 107-33.
} 
implies complete commitment to the other for the good of the other. Jesus proves this commitment through his deeds because he loves the Father. The above examples do not imply a relationship that is threatened, but consistently confirm the hierarchical, but intimate and mutually beneficial situation.

\subsection{Eschatology: The glory restored that Jesus had!}

The relationship between the Son and the Father is strongly influenced by conventions related to ancient missionary practices and it might be argued that the view of this relationship as it is described above is only one aspect of the relationship, which is of course a valid point to make. However, references to Jesus' pre-existent state seem to be in line with what was described up to now.

Jesus prays in 17:5 to be glorified with the glory he had in the presence of his Father before the foundation of the world, suggesting pre-existence (cf. $1: 1 ; 8: 58)$. At the end of his prayer $(17: 24)$ he restates this fact, with some change in perspective. His followers should be where he is, beholding his glory, which the Father has given him in his love for Jesus before the foundation of the earth. Glory in the sense of gravitas in ancient times was something a person had, largely because others allocated it to that person, i.e. a social phenomenon. Obviously, a person's gravitas was proportionate to the importance of the person who acknowledges and gives that person gravitas. Jesus prays in Chap. 17 to be glorified in the presence of his Father with this glory. The implication is that it is for his Father to decide, implying a hierarchical position. This has a wider application than simply the position of Jesus as agent of the Father.

That the relationship remains hierarchical even after the mission is suggested by the prayer in Chap. 17, but is directly stated in Jesus' words to Mary: "I am ascending to my Father and your Father, to my God and

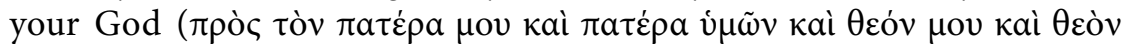
$\dot{v} \mu \tilde{\omega} v)$ " (20:17 - ESV). Jesus identifies his Father as his God, indicating the relationship between him and his Father and especially after the mission. The Father is now the one who cares and protects believers when they are threatened by evil in this world. Though phrases and terms that come terribly close to identification of Jesus with God are used in John, it is stated over and over that God remains God, even for Jesus, the resurrected One. No challenge is envisaged or even suggested as remote possibility in John, even though the Jewish opponents seem to fear for this. But they are liars that do not really know God, John opines. 


\section{Some concluding remarks}

It was stated at the beginning of this essay that perceptions about Jesus, especially from his opponents, might suggest the possibility that Johannine rhetorical descriptions of the relationship between God and Jesus were influenced by and aimed at countering the idea that Jesus might somehow threaten the position of God.

The arguments above suggest the plausibility of a conceptual interrelatedness between the view of the Jewish opponents that is formulated in terms of Jesus threatening the position of their God and the description of the relation between the Father and the Son. Within the dynamics of such a narrative it indeed seems highly plausible to me that the danger of Jesus threatening God or even replacing him might have been an underlying dynamic in the development of Johannine theology, especially in light of the conflict between Jesus and his Jewish opponents described in John. Although I hesitate to speak of the clear intention of the author, as the danger of intentional fallacy consistently warns us, the rhetorical and argumentative weight of the evidence described above leaves me with a more than strong suspicion that such a danger was indeed countered by John through his choice of themes and concepts, his presentation of the presence of Jesus, and not the least his choice for describing the relationship between Jesus and God in terms of a Father that has a Son, with the social conceptions and possibilities associated with such a metaphor. ${ }^{46}$

Within such a metaphorical description, the son can never become the father, but will always remain his son. Within this reality John describes Jesus as the ideal loving Son who always honours and glorifies his Father. Even Jesus' activities on earth are overwhelmingly emphasized as being referential and transparent, and are regarded as misunderstood if they are not interpreted as showing and revealing not Jesus, but the Father. The imagery of mission emphasizes the mediatory role of Jesus even further, since the sender is more important than the one sent. Jesus in no way threatens the Father, but does claim to be in an intimate and unique relation to the Father, something nobody else can claim.

This argument seems plausible, especially in light of the acknowledgment in John of the presence of angelic and spiritual beings, which formed a part of the world view in which the Johannine narrative unfolds. It

\footnotetext{
${ }^{46}$ Obviously the challenges of describing the Christological dynamics in clearer and more exact detail is well known, since it forms one of the pillars of Johannine Christological debates. This is not the focus of theme here and will therefore not receive any further attention, since the purpose here is theo-logy rather than Christ-ology.
} 
might not be the core of the argument, but should at least be taken note of as a plausible part of the dynamics of Johannine thought within the development of the plot. 


\title{
Ein Gott oder „zwei Götter im Himmel“?
}

\author{
Zum Wandel der johanneischen „Parakletsprüche“
}

\author{
Michael Theobald
}

Die fünf so genannten Paraklet-Sprüche der johanneischen Abschiedsreden wurden in den letzten Jahrzehnten vielfach untersucht ${ }^{1}$. Vor allem folgende Fragen sind bearbeitet worden: Welche Funktion haben die Sprüche im Kontext? Fußen sie auf Überlieferung? Besitzen sie synoptische Vorbilder? Woher kommt die Bezeichnung Paraklet? ${ }^{2}$ Wie verhält

\footnotetext{
${ }^{1}$ Erinnert sei an folgende Kommentare, in denen die ältere wie jüngere Literatur leicht auffindbar ist: Raymond E. Brown, The Gospel according to John (XIII-XXI). Introduction, Translation, and Notes (AB 29A), New York u. a. 1970, 1135-1144 (Appendix V: The Paraclete); Rudolf Schnackenburg, Das Johannesevangelium. III. Teil: Kommentar zu Kap. 13-21 (HTKNT 4,3), Freiburg ${ }^{4} 1985,156-173$ („Der Paraklet und die ParakletSprüche"); Jürgen Becker, Das Evangelium nach Johannes II (ÖTK 4,2), Gütersloh u. a. ${ }^{3}$ 1991, 563 („Paraklet und Geistvorstellung“); Udo SCHNELLE, Evangelium nach Johannes (THKNT 4), Leipzig ${ }^{5} 2016$ (1998); Christian Dietzfelbinger, Das Evangelium nach Johannes I - II (ZBK 4,1-2), Zürich 2001; Craig S. Keener, The Gospel of John. A Commentary II, Peabody 2003; Andreas Köstenberger, John (Baker Exegetical Commentary on the New Testament), Grand Rapids 2004; Hartwig Thyen, Das Johannesevangelium (HNT 6), Tübingen 2005; Jean Zumsteın, L'Évangile selon Saint Jean (13-21) (CNT IVb. Deuxième Série), Genf 2007 (deutsche Fassung: Das Johannesevangelium [KEK 2], Göttingen 2016, 537-539 [„Exkurs: Der Paraklet“]); Walter KLAIBER, das Johannesevangelium, Teilband 2: Joh 11,1-21,25, Göttingen 2018. - Ergänzend seien genannt: Martin HasitschKA, Die Parakletworte im Johannesevangelium. Versuch einer Auslegung in synchroner Textbetrachtung, in: SNTSU 18 (1993) 97-112; Christina Hoegen-Rohls, Der nachösterliche Johannes. Die Abschiedsreden als hermeneutischer Schlüssel zum vierten Evangelium (WUNT 2,84), Tübingen 1996, 92-224; Lothar Werr, Das Heilswirken von Vater, Sohn und Geist nach den Paulusbriefen und dem Johannesevangelium. $\mathrm{Zu}$ den neutestamentlichen Voraussetzungen der Trinitätslehre, in: MTZ 47 (1996) 315-324; Michael Theoвald, Gott, Logos und Pneuma. „Trinitarische“ Rede von Gott im Johannesevangelium, in: Hans-Josef Klauck (Hg.), Monotheismus und Christologie. Zur Gottesfrage im hellenistischen Judentum und im Urchristentum (QD 138), Freiburg u. a. 1992, 41-87 (findet sich auch in: DERs., Studien zum Corpus Iohanneum [WUNT 267], Tübingen 2010, 349-388); DERS., Was und wen hat Jesus angekündigt? Das Rätsel um den Parakleten im johanneischen Schrifttum, in: Timo Güzelmansur (Hg.), Hat Jesus Muhammad angekündigt? Der Paraklet des Johannesevangeliums und seine koranische Bedeutung (Cibedo Schriftenreihe 1), Regensburg 2012, 73-207.

${ }^{2}$ Die EÜ 2016 gibt den Terminus zu Recht mit „der Beistand“ wieder (anders Luther 2017: „der Tröster“; in 1 Joh 2,1 wählt sie „Fürsprecher“, die EÜ 2016 bietet dort gleichfalls
} 
sich der johanneische Paraklet zu vergleichbaren Figuren im zeitgenössischen Judentum, etwa zum Erzengel Michael, der für Israel am Thron Gottes eintritt, oder anderen, den Menschen bei Gott beistehenden Anwälten und Fürsprechern? ${ }^{3}$ Warum begegnet die Bezeichnung nur in den Abschiedsreden, nicht auch im ersten Teil des Buches? Auf die letzte Frage antwortete vor Jahren Ulrich B. Müller überzeugend, dass dies mit der Gattung der Abschiedsreden zusammenhinge; im Angesicht des Todes sei es nahe liegend, dass der Sterbende in seinem Vermächtnis auch von seiner Nachfolge spreche, was Licht auf die personifizierende Rede vom Parakleten wirft ${ }^{4}$. Kaum bedacht wurde bislang die Frage nach dem Beitrag der Paraklet-Sprüche zum johanneischen Gottesbild. Die altkirchliche Rezeption vor allem im 4. und 5. Jahrhundert n. Chr. war an der trinitarischen Problematik interessiert. Die Dreiecksbeziehung Gott Jesus - Paraklet bot sich dafür regelrecht an. ${ }^{5}$ Aber schon im Vorfeld spezifisch dogmatischer Probleme stellt sich die Frage, wie die Sprüche Jesus und Paraklet dem einzigen Gott zuordnen und wie sie die christologische Transformation des biblischen Monotheismus ${ }^{6}$ variieren.

\section{Eine Vorbemerkung: Drei Abschiedsreden oder nur eine?}

Lange Zeit herrschte, zumindest in der deutschsprachigen Johannesexegese, ein gewisser Konsens darüber, dass der Abschnitt Joh 13,31-17,26 kein literarisch einheitlicher Block ist, sondern aus verschiedenen Reden besteht, die sukzessive entstanden sind. ${ }^{7}$ Ist die Abgrenzung der ersten Rede Joh 13,31-14,31 klar, so gab es und gibt es Streit um die

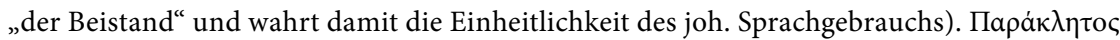
$($ Verbaladjektiv $)=\operatorname{der}($ bei Gericht $)$ Herbeigerufene, lat. der ad-vocatus, der Advokat. Näheres s. Theовald, Jesus (Anm. 1) 118-120 („Welche Übersetzung entspricht dem Terminus ,der Paraklet' am ehesten?").

${ }^{3}$ Vgl. Sigmund MowinckeL, Die Vorstellungen des Spätjudentums vom heiligen Geist als Fürsprecher und der johanneische Paraklet, in: ZNW 32 (1933) 97-130; Nils Johannson, Parakletoi. Vorstellungen von Fürsprechern für die Menschen vor Gott in der alttestamentlichen Religion, im Spätjudentum und Urchristentum, Lund 1940; Otto Betz, Der Paraklet (Arbeiten zur Geschichte des Spätjudentums und Urchristentums Bd. 2), Leiden/Köln 1963.

${ }^{4}$ Ulrich B. MÜLLER, Die Parakletenvorstellung im Johannesevangelium, in: ZTK 71 (1974) $31-77$.

${ }^{5}$ Vgl. Bernd Овеrdorfer, Filioque. Geschichte und Theologie eines ökumenischen Problems (FSÖTh 96), Göttingen 2000, 42-44 u. ö.

${ }^{6}$ Von einer solchen spricht des Öfteren Gerd Theissen, z. B. in seinem Buch: Die Religion der ersten Christen. Eine Theorie des Urchristentums, Gütersloh ${ }^{4} 2008$.

${ }^{7}$ Vgl. neben den Kommentaren von Rudolf Schnackenburg und Jürgen Becker (Anm. 1) auch Christian Dietzfelbinger, Der Abschied des Kommenden. Eine Auslegung 
Gliederung der Kap. 15-16 und die Anzahl der hier enthaltenen Reden. Das sog. Relecture-Modell, das Jean Zumstein und sein Schüler Andreas Dettwiler entwickelten, ${ }^{8}$ brachte einen bedeutenden methodischen Fortschritt: Die Schichtung der Reden wird nicht nur literarkritisch begründet, sondern die späteren Reden werden als Interpretationen der Grundrede 13,31-14,31 transparent gemacht, sodass sich Rezeptionsund Leseprozesse in den johanneischen Gemeinden abzeichnen. Wie an anderen neuralgischen Punkten der Diskussion, z. B. bei der keineswegs einheitlichen Eschatologie des Buchs, ${ }^{9}$ ist auch hier für das Modell die Annahme wichtig, dass das Evangelium ein Gemeindebuch war. Es wurde gelesen und teils kontrovers interpretiert; die Erfahrungen, die man im Umgang mit ihm machte, schlugen sich in Gestalt seiner Réecriture in ihm selbst nieder. Das führte zu der Edition des Buchs, welche die frühe Kirche rezipierte und die uns heute in unseren Textausgaben vorliegt. Dieses vielfach bewährte Modell besitzt gerade für die Auslegung von Joh 13-17 hohen heuristischen Wert.

Allerdings macht sich der Pendelschlag der jüngeren Johannesforschung hin zu einer strikten Endtextexegese, die geneigt ist, jede diachrone Tiefenschärfe methodisch auszublenden, ${ }^{10}$ auch hier bemerkbar.

der johanneischen Abschiedsreden (WUNT 95), Tübingen 1997, 13: „Alsbald stellt sich die Frage, ob die Jetztgestalt der johanneischen Abschiedsreden auch ihre Erstgestalt war oder ob diese Reden, wie vermutlich das ganze Johannesevangelium, einem Entstehungsprozess ausgesetzt waren, in dem sie allmählich zu ihrem jetzigen Umfang herangewachsen sind. Man kann dieser Frage nicht entgehen und man sollte ihr nicht entgehen wollen. Denn schon ein erstes aufmerksames Lesen der Abschiedsreden lässt erkennen, dass wir hier nicht einen bei aller Mannigfaltigkeit der Themen in sich stimmigen Gesamtzusammenhang vor uns haben, in dem ein Element aus dem anderen hervorwächst, ein Gedanken (sic!) zwingend den anderen aus sich heraussetzt, wie man das innerhalb einzelner Abschnitte beobachten kann [...]. Wir nehmen also wahr, dass die johanneischen Abschiedsreden, die in ihrer Jetztgestalt zwar eine zusammenhängende Rede sein wollen und als solche zu würdigen sind, auch als eine Mehrzahl verschiedener Reden angesehen werden können, und man wird beide Gesichtspunkte zu bedenken haben."

${ }^{8}$ Andreas Dettwiler, Die Gegenwart des Erhöhten. Eine exegetische Studie zu den johanneischen Abschiedsreden (Joh 13,31-16,33) unter besonderer Berücksichtigung ihres Relecture-Charakters (FRLANT 169), Göttingen 1995; ZuMSTEIN, Johannesevangelium (Anm. 1) 553-556 („Exkurs: Der Prozess der Relecture in der zweiten Abschiedsrede“); DERs., La mémoire revisitée. Etudes johanniques (MdB 7), Genf 2017, 233-250 („L'adieu de Jésus aux siens").

${ }^{9}$ Vgl. Michael Thеовадd, Futurische versus präsentische Eschatologie? Ein neuer Versuch zur Standortbestimmung der johanneischen Redaktion, in: Ders., Studien (Anm. 1) 534-573.

${ }^{10}$ Extrem ist die Position von Thyen, Johannesevangelium (Anm. 1), der im Johannesevangelium (wie im 19. Jahrhundert schon Ferdinand Chr. Baur) eine symbolistische Dichtung sieht, bei deren Abfassung sich ihr Autor von den drei Synoptikern habe inspirieren lassen. 
Udo Schnelle etwa bekräftigt in der jüngsten Auflage seines Kommentars wieder seine Annahme, dass die Reden auf einen einzigen Autor zurückgingen und interpretiert sie nach dem „Modell äußeren Stillstands bei gleichzeitigem inneren Fortschritt "11. Er schränkt dies zwar dahingehend ein, dass der Evangelist mancherlei „Traditionen seiner Schule sowie von ihm selbst verfasste Texte " 12 integriert habe, bietet aber dazu nicht einmal ansatzweise irgendeine Erklärung. So erfährt der Leser z. B. nicht, welche Texte der Evangelist früher verfasst haben soll und was zu einer solchen Annahme zwingt. In Weiterführung älterer Vorschläge müht sich Stefan Burkhalter ${ }^{13}$ um den Nachweis, dass den Kap. 13-17 ein konzentrischer Bauplan zugrunde läge, der jedem Teiltext seinen unverwechselbaren und notwendigen Ort zuweise. Was in dieser und vielen anderen Studien nicht berücksichtigt wird, ist die Frage nach der rhetorischen Disposition der Reden. Joh 13,31-14,31 ist formal und inhaltlich in sich gerundet und auf keinerlei Fortsetzung hin angelegt, es sei denn die Passionserzählung selbst. Dies lässt sich nicht nur dem berühmten Aufbruchssignal 14,31 entnehmen, sondern auch dem Befund, dass die Rede mit Proömium (13,31-38), Redecorpus (14,1-26) samt Leitwort (= propositio) $(14,2 \mathrm{f}$. und Schluss (= peroratio) $(14,27-31)$ eine innere rhetorische Einheit darstellt. Wer sich mit den beiden Parakletsprüchen 14,13-17 und 14,26 befasst, wird sie von hier aus zu begreifen suchen.

Für die Deutung aller fünf Sprüche ist bedeutsam, sie a) im jeweiligen rhetorischen Kontext und b) im Relecture-Prozess der drei Reden zu interpretieren. Dann gewinnt eine Beobachtung an Gewicht, die in der Regel übersehen wird, aber für die anstehenden Fragen von größter Bedeutung ist: Nach der ersten Abschiedsrede sendet Gott den Parakleten, nach der zweiten und dritten tut dies Jesus, wenn er wieder beim Vater ist. Das Modell der Botensendung bestimmt das Evangelium von Anfang

\footnotetext{
${ }^{11}$ SChNelLe, Evangelium (Anm. 1) 310-313 („Abschiedsreden und Literarkritik“): 313; vgl. DERs., Johannes $16 \mathrm{im}$ Rahmen der Abschiedsreden, in: Joseph Verheyden/Gert Van Oyen/Michael Labahn/Reimund Bieringer (Hg.), Studies in the Gospel of John and Its Christology (FS Gilbert van Belle) (BETL 265), Leuven 2014, 425-446; Ulrich Busse, Die johanneische Abschiedsrede, die soziale Lage der Leserschaft und ethische Implikationen, in: Ruben Zimmermann/Stephan Joubert (Hg.), Biblical Ethics and Application. Purview, Validity, and Relevance of Biblical Texts in Ethical Discourse (Kontexte und Normen neutestamentlicher Ethik 9), Tübingen 2017, 185-206, behandelt Joh 13,31-17,26 gleichfalls als kompakten Block ohne Beachtung der formalen Strukturen.

${ }^{12}$ Schnelle, Evangelium (Anm. 1) 313.

${ }^{13}$ Stefan Burkhalter, Die johanneischen Abschiedsreden Jesu. Eine Auslegung von Joh 13-17 unter besonderer Berücksichtigung der Textstruktur (JuChr 20), Stuttgart 2014.
} 
an. ${ }^{14}$ Die Prädikation „der ihn (sc. Jesus) gesandt hat“ kann für Gott selbst stehen. ${ }^{15}$ Eine Grundfrage der Auslegung der Sprüche lautet, wie die drei einander zuzuordnen sind: der Paraklet zu Jesus, dem entscheidenden Gottgesandten, ${ }^{16}$ der ihn in 14,16 als „den anderen Parakleten“ ankündigt, ${ }^{17}$ und der Paraklet zu Gott und umgekehrt Gott zu Jesus und zum Parakleten.

Die fünf Sprüche sollen im Folgenden der Reihe nach besprochen werden, wobei der Fokus auf der Frage liegt, wie sie das Dreieck von Vater, Sohn und Paraklet von Rede zu Rede variieren. Das wirft beachtliches Licht auf das johanneische Gottesbild, das reicher und spannungsvoller ist, als es seine Etikettierung mit dem Stichwort Christologische Theozentrik erahnen lässt; es zeigen sich hier Entwicklungen, die im Kontext frühjüdischer „Zwei-Götter-Lehre“ (Peter Schäfer) von hoher Brisanz waren.

\section{Die fünf „Parakletsprüche“ in ihrem Kontext}

Die fünf Sprüche besetzen in den drei Reden markante Positionen: ${ }^{18}$ Die beiden ersten rahmen den zweiten Hauptteil der ersten Rede (14,16-17/14,25f.), der dritte leitet zum Finale der zweiten Rede über $(15,26 \mathrm{f}$.) und der fünfte und sechste Spruch, die unmittelbar ineinander übergehen, eröffnen die dritte und letzte Rede (16,7-11/16,12-15).

\footnotetext{
${ }^{14}$ Johannes wurde „Von Gott gesandt“ $(1,6 ; 3,28)$. Die ihn verhören sind „Abgesandte von den Pharisäern“" $(1,24 ;$ vgl. 5,33$)$. Nach Ostern werden die Jünger von Jesus „gesandt" $(20,21$; vgl. bereits 4,38). Vor allem Jesus ist von Gott „gesandt“ (3,17 u. ö.). Von Propheten, die gesandt wurden, ist nirgends die Rede, was dem spezifischen Umgang des Buchautors mit der Geschichte Israels entspricht (vgl. Michael Theobald, Abraham - [Isaak -] Jakob. Israels Väter im Johannesevangelium, in: DERS., Studien [Anm. 1] 282-308).

${ }^{15}$ Vgl. 4,$34 ; 5,24.30 ; 6,38.39 ; 7,16.18 .33 ; 8,26.29 ; 13,16$.

${ }^{16}$ Die Einzigartigkeit Jesu kommt darin zum Ausdruck, dass das Sendungsmodell mehrfach vom Sprachspiel Vater - Sohn überlagert wird. Bemerkenswert ist die Variante, dass es statt „senden“ auch heißen kann, dass der Vater den Sohn „gegeben" hat; vgl. 3,16; 6,32 (dies wird in 14,16 auch vom Parakleten gesagt) (vgl. unten Anm. 22).

${ }^{17}$ Dazu wie zur entsprechenden Prädikation Jesu (des Erhöhten) 1 Joh 2,1 vgl. Theовald, Jesus (Anm. 1) 124-134.

${ }^{18}$ Die Klassifizierung der teils nahtlos in ihre Umgebung eingebunden Worte als „Sprüche“ ist nicht unproblematisch. Die Übergänge zu ihrem Kontext sind derart fließend, dass sie sich kaum von ihm isolieren lassen. Zur Definition von „Herrenworten“ und Sprüchen im vierten Evangelium vgl. Michael Tнеовацd, Herrenworte im Johannesevangelium (HBS 34), Freiburg 2002, 21-53.
} 
2.1 Vom „anderen Parakleten“ „in euch“. Der erste Spruch Joh 14,16f. Im Leitsatz der ersten Abschiedsrede 14,2f. (= propositio) kündigt Jesus sein "Gehen“ im Tod und sein „(Wieder-)Kommen“ an Ostern an. Letzteres ist Thema von 14,15-26, der zweiten Hälfte des Hauptteils der Rede. Sie wird von den beiden ersten "Parakletsprüchen“ gerahmt. Der erste Spruch dient der Einführung der neuen Figur, der zweite benennt seine Rolle im Geschehen des österlichen „Kommens“ Jesu zu den Seinen.

Der Perspektivwechsel vom Abschied hin zum österlichen „Kommen“ kündigt sich bereits in den Futura von VV. 12-14 an und wird im thematischen Auftakt von V. 15 verdeutlicht: „Wenn ihr mich liebt, werdet ihr meine Gebote bewahren ( Tod zum Vater „erhöht“, bei ihm sein wird:

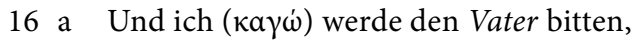

$\mathrm{b}$ und einen anderen Parakleten wird er euch geben,

c auf dass er mit euch ( $\left.\mu \varepsilon \theta^{\prime} \dot{v} \mu \tilde{\omega} v\right)$ sei in Ewigkeit,

17 a der Geist der Wahrheit (

b den (ö) die Welt nicht empfangen kann,

c denn sie sieht ihn (aủ ó) nicht

d und erkennt (ihn) nicht.

e Ihr erkennt ihn (aủtó),

f denn bei euch ( $\pi \alpha \rho^{\prime}$ in $\left.\mu \tilde{v}\right)$ bleibt er,

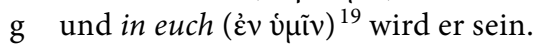

Weil der Paraklet hier ins Buch eingeführt wird, geht es um seine „Person“, noch nicht um seine Tätigkeiten. Die Prädikationen, mit denen er vorgestellt wird - „Paraklet“ (16b) bzw. „mit euch“ (16c) - sind dem Bild Jesu entlehnt. ${ }^{20}$ So fällt indirekt Licht auch auf Jesus.

(1) Ursprünglicher Haftort des Paraklet-Titels - das verrät 1 Joh 2,1 ist das alte österliche Bekenntnis zu Jesus, der zum Thron Gottes erhöht

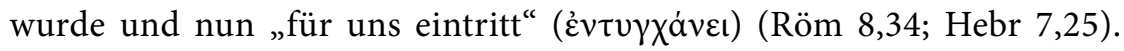
Deshalb heißt es auch in 1 Joh 2,1: „Meine Kinder, dies schreibe ich euch, damit ihr nicht sündigt. Und wenn jemand sündigt, so haben wir einen Parakleten beim Vater, Jesus Christus, den Gerechten. "Diese Funktion des „Fürsprechers" oder "Anwalts" wird Jesus auch nach Joh 14,16 wahrnehmen, wenn er den Vater im himmlischen Thronsaal bitten wird, den Seinen „einen anderen Parakleten“ zu geben. Aber schon jetzt auf Erden

\footnotetext{
${ }^{19}$ Vgl. Mt 10,20: „Der Geist eures Vaters redet in euch.“

${ }^{20}$ Zum „Mit-Sein“" Jesu vgl. Joh 3,22; 6,3; 7,33; 11,54; 13,33; 14,9.30; in den Abschiedsreden noch: 15,$27 ; 16,4 ; 17,12$ sowie 17,24 , wo das Motiv in die eschatologische Vollendung transponiert ist.
} 
ist Jesus ihr „Anwalt“ im Prozess mit der Welt, ihr „Beistand“ im Streit mit dem „Herrscher dieser Welt" $(12,31 ; 14,30 ; 16,11)$. Oder wie es des Öfteren heißt: Er ist „mit ihnen“.

Die innovative Leistung des Autors des Buchs besteht in zweierlei: (a) Er hat die christologische Paraklet-Vorstellung, die an der himmlischen Rolle des Inthronisierten haftete, implizit auf den Irdischen ausgedehnt. (b) Er führt diese Vorstellung auch in die traditionelle Pneumatologie ein, indem er „den Geist“ ( mit personalen Konnotationen stilisiert, zum Nachfolger Jesu, der seine Paraklet-Funktion „in Ewigkeit“ übernimmt.

(2) Das Dreieck unserer Figuren ist in 14,16f. auf seine obere Spitze hingeordnet: Jesus wird im Thronsaal den Vater „bitten“, und dieser wird in Antwort darauf „den anderen Parakleten geben“. ${ }^{21}$ 14,26 heißt es im gleichen Sinn: „der heilige Geist, den der Vater in meinem Namen (sc. auf meine Fürbitte hin) senden wird". Geben und Senden sind wie bei Jesus miteinander kompatibel, der Gesandte Gottes ist zugleich seine Gabe. ${ }^{22}$

(3) Die Klimax des Spruchs ist V. 17 g, „er (sc. der Geist der Wahrheit) wird in euch sein". Die mit der Paraklet-Figur verbundenen personalen Konnotationen - er wird "mit euch" (16c), ja „bei euch" (17f) sein werden hier in die aus Ez 36 stammende Sprache der "Interiorität“23 übersetzt: „Der Geist der Wahrheit“ wird ihnen innerlich sein, sie von innen her erfüllen. Dem entspricht das Sprachspiel "geben“ ( $\delta i \delta \omega \mu)$ und „empfangen“ ( $\lambda \alpha \mu \beta a ́ v \varepsilon เ v)$. Es stammt aus der traditionellen $\pi v \varepsilon \tilde{v} \mu \alpha-R e d e$, die der Autor mit der personifizierenden Paraklet-Rede überlagert.

(4) Warum der Spruch seine Klimax in der Betonung des „In-euchSein" des Pneuma hat, klärt der Fortgang des Spruchs. Jesus lässt die Seinen an Ostern nicht als Waisen zurück, er kommt zu ihnen $(14,18)$ und nimmt Wohnung bei ihnen mit seinem Vater $(14,23)$. Die Antwort auf die Frage, wie dies geschehen kann, ist einfach: Wenn die Seinen die Worte des Gesandten Jesus, die eigentlich Worte Gottes sind, in ihrem Herzen „bewahren“ (14,21.24), sie verinnerlichen, dann wohnen Vater und Sohn in ihren Worten bei ihnen. In welcher Gestalt vergegenwärtigen sich diese Worte, wie vermögen sie - modern gesprochen - den "garstigen Graben“

\footnotetext{
${ }^{21} \mathrm{Zu}$ der hier aufscheinenden Erhörungsgewissheit Jesu vgl. bereits Joh 11,42.

${ }^{22} \mathrm{Vgl}$. Joh 3,16 mit 3,17; außerdem 6,32; zum $\pi v \varepsilon v \tilde{\mu}$ a vgl. auch 7,39 („denn noch nicht war Geist gegeben").

${ }^{23} \mathrm{Ez} 36,26 \mathrm{~b}$ : „und (ich werde euch) einen neuen Geist in euer Inneres geben ( $\pi v \varepsilon \tilde{u} \mu \alpha$ kaıvòv

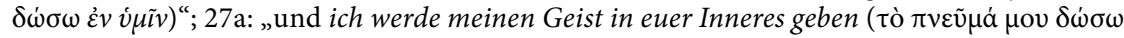
$\dot{\varepsilon} v \dot{v} \mu \tilde{i})^{\prime \prime}$. Hier auch das Verb $\delta i \delta \omega \mu$ wie in Joh 14,16 b.
} 
zwischen dem irdischen Jesus und dem österlich „kommenden“ Jesus zu überwinden? Darauf antwortet der zweite „Parakletspruch“, 14,25f.

\subsection{Der Paraklet als „Lehrer“. Der zweite Spruch Joh 14,25f.}

Mit 14,25f. schließt der Autor das Corpus der Rede ab. Was folgt, ist der Friedenswunsch $(14,27)$ und die peroratio.

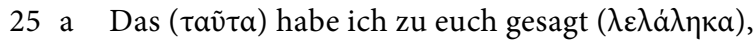

b während ich noch bei euch ( $\pi \alpha \rho^{\prime}$ v $\left.\mu \tilde{v} v\right)$ war $(\mu \varepsilon \dot{v} v \omega v)$.

26 a Der Paraklet aber,

b der Geist, der heilige,

c den der Vater senden wird in meinem Namen,

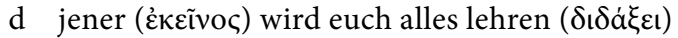

e und euch an alles erinnern (

f was ich euch gesagt habe, ich $(\dot{\varepsilon} \gamma \dot{\omega})^{24}$.

Nach der Vorstellung des „Parakleten“ in 14,16f. wird jetzt seine nachösterliche Aufgabe benannt, was kompositorisch an genau der richtigen Stelle geschieht. Jesus blickt auf das, was er "gesagt“ hat (25a/26f), zurück, weshalb wir am Ende der Rede angelangt sind, über die hinaus - von „nur wenigen" Worten in der Passionserzählung abgesehen (14,30) - nichts mehr zu sagen ist. Es kommt nur noch darauf an, dass alles, was Jesus gesagt hat, in seiner Breite und Tiefe erschlossen wird. Genau das ist die

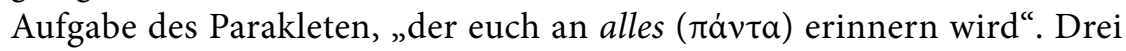
Aspekte sind bemerkenswert:

(1) Der Spruch verarbeitet das alte jesuanische Wort vom Beistand des „heiligen Geistes“ vor den Synagogengerichten, der die Jünger „lehrt“, was sie zu sagen haben (Lk 12,11 f. par. Mk 13,11). Das Motiv des „Erinnerns" fügt er hinzu, ${ }^{25}$ den Grundgedanken der Gegenwärtigkeit des Geistes bewahrt und aktualisiert er. Jetzt ist der Geist der „Lehrer“ und „Interpret“ der Worte Jesu, der sie der Gemeinde aufschließt und ihrem Verstehen nahebringt. Möglich wird das erst post factum im Licht von Ostern.

\footnotetext{
${ }^{24}$ In vielen, auch sehr guten Handschriften fehlt dieses $\dot{\varepsilon} \gamma \dot{\omega}$, bezeugt wird es u. a. vom Codex Vaticanus (B). Betont am Ende des Spruches stehend, unterstreicht es, dass der „Paraklet" nichts anderes als Jesu Worte vergegenwärtigt. Ob das eine nachträgliche Absicherung des Spruches gegen seine mögliche montanistische Vereinnahmung ist? Vgl. unten den textkritischen und -geschichtlichen Exkurs zu 16,13c.e.

${ }^{25}$ Mathias Rissi, „Die Juden“ im Johannesevangelium, in: ANRW II Bd.26, 3. Teilband (1996), 2099-2141: 2114: „Er (sc. der Paraklet) wird keine neue Botschaft bringen, er ist nicht Prophet, sondern Lehrer und Interpret. Unter seiner Führung interpretiert der Evangelist die Jesusüberlieferung für die spezielle Situation seiner Gemeinde."
} 
(2) Während es vom Sohn und Vater heißt, dass sie an Ostern „kom$m e n "$ " um in den äußeren Worten des Evangeliums gegenwärtig zu sein, wird ein solches „Kommen“ vom Parakleten nicht gesagt. Er ist die innere Kraft der Erinnerung, ${ }^{26}$ des Verstehens dessen, was Jesus gesagt und gemeint hat. Sein Nachfolger ist er deswegen, weil er als innerer "Lehrer“ Jesus in der Gemeinde selbst vergegenwärtigt.

(3) Die Theozentrik der Sprüche ist bemerkenswert. In Joh 14,28 erklärt Jesus: „Der Vater ist größer als ich.“ $E r$ ist es, der den Geist auf Fürsprache seines Sohnes gibt bzw. sendet. Der Gott Jesu ist kein anderer als der Gott des Parakleten.

\subsection{Zeugen „von Anfang an“. Der dritte Spruch als Schlussstein der zweiten Abschiedsrede (Joh 15,26f.)}

Die erste Abschiedsrede bedenkt Jesu „Gehen“ im Tod und sein „(Wieder-)Kommen" an Ostern, seine Parusie, und ist also christologisch fokussiert. Die zweite Abschiedsrede blickt auf die Gemeinschaft der Kirche: In ihrer ersten Hälfte, 15,1-17, mit der Bildrede vom Weinstock und seinen Reben und der anschließenden Weisung zur geschwisterlichen Liebe aus der Innenperspektive, in ihrer zweiten, 15,18-25, auf ihre Außenbezüge zur Welt: „Wenn die Welt euch hasst, wisst, dass sie mich vor euch gehasst hat" (V. 18). Leitmotiv der ersten Hälfte ist die Aufforderung zum „Bleiben“ (VV. 4.-7.9f.16). Die zweite Hälfte mahnt, in der Nachfolge Jesu der Welt standzuhalten. Dass dies auch eine positive Seite hat, zeigt der anschließende Parakletspruch VV. 26f., der das Corpus der Rede abrundet, wenn er vom Zeugnis der Jünger spricht, das sie vor der Welt ablegen:

26 a Wenn der Paraklet kommt ( $(\dot{\varepsilon} \lambda \theta \eta)$,

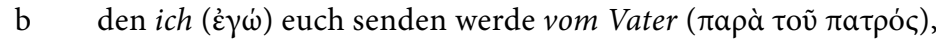

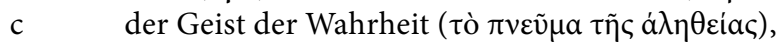

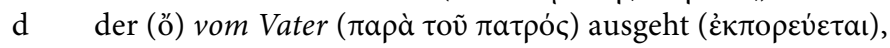

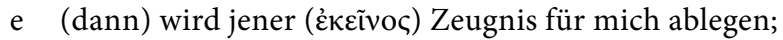

27 a und auch ihr legt Zeugnis ab,

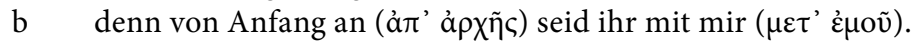

Als erstes fällt auf, dass das Dreieck der Figuren - Jesus, der Vater und der Paraklet - sich gegenüber Joh 14 nicht unerheblich gewandelt hat. Der Aufbau des Spruchs ist zwar analog zu dem des Vorgängerspruchs

\footnotetext{
${ }^{26}$ Michael TheовALD, „Erinnert euch der Worte, die ich euch gesagt habe ...“ (Joh 15,20). „Erinnerungsarbeit“ im Johannesevangelium (2007), in: DERs., Studien (Anm. 1) 256-281.
} 
14,25f.: Zuerst kommt die Präsentation des „Parakleten“ (V. 26a-d), dann die Ansage dessen, was er tun wird, auch hier (wie in 14,26d) von einem

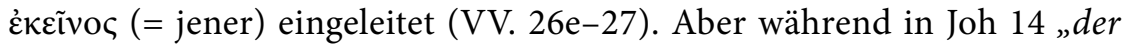
Vater" den „Parakleten“ „geben“ $(14,16)$ bzw. „senden“ wird $(14,26)$, und zwar auf Bitte des (erhöhten) Jesus hin, ist es jetzt Jesus, der ihn (vom Himmel her) in eigener Vollmacht „senden“ wird. Er ist der "Geber des Parakleten “27. Zwar erwecken die beiden Ergänzungen „senden vom Vater her" (V. 26b) und „der vom Vater ausgeht" (V. 26d) den Eindruck einer gezielten Anknüpfung an die theozentrische Perspektive von Joh 14, aber das Dreieck hat sich verschoben.

(1) Die Konnotationen der verwendeten Sprache wecken räumliche Vorstellungen. Der Paraklet „kommt“, er verlässt den himmlischen Thronsaal, um auf Erden für Jesus Zeugnis abzulegen. Jesus bleibt (im Unterschied zu Joh 14) im Himmel, während der Paraklet zu seinem Doppelgänger wird, der ihn auf Erden vertritt. Seiner Sendung durch Jesus entspricht, dass er für ihn Zeugnis ablegt. ${ }^{28}$

(2) Die personalen Konnotationen, die mit der Rede vom Parakleten verbunden sind, scheinen Joh 14 gegenüber verstärkt. Dort war die Pointe, dass der Paraklet die Kraft der Erinnerung ist, die in den Glaubenden wirkt. Jetzt tritt der Paraklet wie eine himmlische Gestalt, ein Engelwesen, auf, das vom Himmel herabkommt und Zeugnis auf Erden für Jesus ablegt. ${ }^{29}$

(3) Der Paraklet kommt nicht einfach „vom Himmel“, sondern „von-

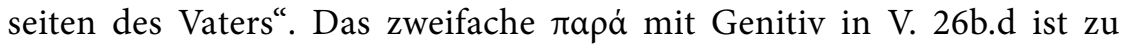
übersetzen mit „vonseiten“, „von ... her" - unter „Beibehaltung $\mathrm{d}(\mathrm{er})$ örtl(ichen) Bed(eutung) bei Verben des Kommens, Gehens, Schickens,

\footnotetext{
${ }^{27}$ Rissi, „Juden“ (Anm. 25) 2114 Anm. 37b: „Für den Evangelisten ist das unmöglich.“

${ }^{28}$ Die Verbindung von $\mu \alpha \rho \tau$ mal).36.37.39.

${ }^{29}$ Betz, Paraklet (Anm. 3) 149-158, meint pauschal, „der johanneische Paraklet sei nach dem Bilde des spätjüdischen Fürbitters Michael geschaffen“ (159); auf 16,25f. trifft das modifiziert - zu; der Erzengel leistet allerdings seinen Dienst im Himmel und „kommt“ nicht zur Erde. - Zur „Himmelfahrt des Jesaja“, die den Geist Gottes in Gestalt eines Engels auftreten lässt, siehe Enrico Norelli, Sulla pneumatologia nell' Ascensione di Isaia, in: Mauro Pesce (Hg.), Isaia, il diletto e la chiesa. Visione ed esegesi profetica cristianoprimitiva nell'Ascensione di Isaia. Atti del Convegno di Roma, 9.-10. Aprile 1981 (TRSR 20), Brescia 1983, 211-276. - Zumstein, Johannesevangelium (Anm. 1) 587 Anm. 177: „Auffällig ist, dass das Neutrum $\pi v \varepsilon \tilde{u} \mu a($,Geist') aus V.26b [ $=26 c]$ dann in V.26c [= 26e] durch ein

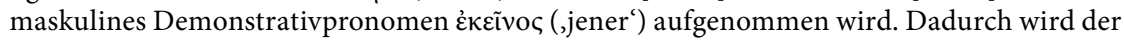
Personcharakter des Parakleten akzentuiert.“"
} 
Herkommens, Ausgehens u. ä.“. ${ }^{30}$ Wenn der Paraklet „ausgeht vom Vater", Jesus ihn „vom Vater her" sendet, ist das räumlich zu denken: Der Paraklet verlässt - beauftragt von Jesus - die „Welt“ des Vaters. Gemeint ist nicht, dass er „aus dem Vater hervorgeht“ (ex patre procedit) - wie Wasser aus einer Quelle - oder wie der Hervorgang des Geistes aus dem Vater in der späteren trinitätstheologischen Debatte auch immer gedacht wird. ${ }^{31}$

(4) Die personale Vorstellung vom Parakleten als einer Art Engelwesen

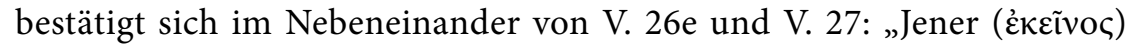
wird Zeugnis für mich ablegen; und auch ihr legt Zeugnis ab. “" ${ }^{32}$ Es ist also gerade nicht so, dass der Paraklet, „der Geist der Wahrheit“, in den Jüngern und aus ihnen spricht, wie das der alte synoptische Topos sagt, der hier verarbeitet ist: „Denn nicht ihr seid es, die reden, sondern der heilige Geist" (Mk 13,11; vgl. Lk 12,12). Der Geist ist in Joh 15,26f. kein Geist der Inspiration, sondern eigenständiger Zeuge, Begleiter der Jünger, der wie sie Zeugnis für Jesus ablegt, ohne dass das Wie benannt wird. ${ }^{33}$

(5) V. 27b begründet das Zeugnis der Jünger damit, dass sie „von Anfang an (ả $\left.\pi^{\prime} \dot{\alpha} \rho \chi \tilde{\eta} \varsigma\right)^{\prime \prime}$ „,mit ihm“ ( $\mu \varepsilon \tau^{\prime} \dot{\varepsilon} \mu$ oṽ) sind. Offenkundig hat dies eine besondere Qualität des Zeuge-Seins im Blick, die den Nachgeborenen versagt ist. Es geht um ein „Mit-Sein“ mit Jesus in einer realen Weise „von Anfang an“, wie das nur von der Erzählfigur der „Jünger“ im Buch selbst gilt, auch wenn eine Präzisierung im Sinne von Augen- und Ohrenzeugenschaft fehlt. ${ }^{34}$ Als "Zeugen von Anfang an“ sind die „Jünger“ für den Glauben der Nachgeborenen Autoritätsfigur - im Unterschied zu ihrem Bild in Joh 14, wo sie die Nachgeborenen im Buch vertreten und repräsentieren. ${ }^{35}$

\footnotetext{
${ }^{30}$ Walter BAUER, Griechisch-deutsches Wörterbuch zu den Schriften des Neuen Testaments und der frühchristlichen Literatur, Berlin/New York ${ }^{6} 1988,1233$.

${ }^{31}$ Zur späteren Rezeptionsgeschichte vgl. Oвerdorfer, Filioque (Anm. 5) 43: „Er ,geht

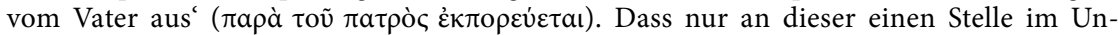
terschied zu den sämtlich futurischen Sendungsaussagen das Präsens steht (noch dazu unmittelbar neben einer futurischen Aussage), ist der sprachliche Ansatz für die spätere Unterscheidung von (ewigem, innergöttlichem) Hervorgang und (zeitlicher, nach ,außen gerichteter, heilsgeschichtlicher) Sendung des Geistes."

${ }^{32}$ Eine beachtenswerte Parallele bietet Apg 5,32a.b: „Und wir sind Zeugen dieser Geschehnisse, und der heilige Geist, den Gott denen gegeben hat, die ihm gehorchen."

${ }^{33}$ Vielleicht ist das Nebeneinander so zu denken, dass der Paraklet die Jünger wie ein "Schutzengel“ begleitet und sie durch sein Wirken für Jesus zu ihrem Zeugnis ermutigt. Vielleicht ist aber auch an das Buch des Evangeliums gedacht, durch das der Geist sein Zeugnis ablegt (siehe unten).

${ }^{34}$ Immerhin heißt es kurz zuvor in 15,20 (vgl. dann auch in 16,4), dass sie - die Jünger selbst gehört haben, was Jesus ihnen gesagt hat.

${ }^{35}$ Das wird u. a. deutlich am Wechsel von der Anrede der „Jünger“ durch Jesus in der zweiten Person (,ihr“: 14,15-20.22.25) hin zu der eher allgemeinen Rede über sie in der dritten
} 


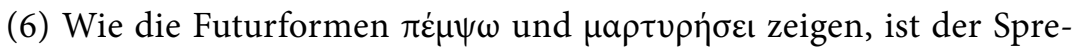
cher Jesus in seiner Abschiedssituation. Deshalb lassen sich auch die aufgewiesenen Verschiebungen im Dreieck nicht so erklären, dass die zweite Abschiedsrede aus der Perspektive des erhöhten Jesus gesprochen, diese also für seine neue Rolle verantwortlich sei. ${ }^{36}$ Auch in Joh 14 blickt Jesus voraus auf seine österliche Erhöhung, aber seine Rolle ist dort eine andere. $^{37}$

\subsection{Der Paraklet als Ankläger (Joh 16,8-11)}

Der vierte und fünfte Spruch, die miteinander und mit ihrer Umgebung derart verwoben sind, dass sie sich kaum von ihr als eigene "Sprüche“ isolieren lassen, bilden mit dem „Themasatz" $16,5-7$ (= propositio) ${ }^{38}$ die Eröffnung der dritten Abschiedsrede (VV. 4e-15), die bis zum Ende von Kap. 16 reicht. ${ }^{39}$ Wie in der ersten Rede geht es wieder um Jesu „Weggang“ im Tod, ${ }^{40}$ nicht aber - wie dort - auch um sein „Kommen“. Stattdessen werden die Jünger ihn nach einer kleinen Weile „sehen“ $(16,16)$ und ihre Trauer wird sich in Freude verwandeln $(16,20)$. Das „Kommen“ ist für den „Parakleten“ reserviert. So knüpft die dritte Rede zwar an die erste an, führt aber auch die ekklesiologische Sicht der zweiten weiter, wenn sie in ihrem Hauptteil die Kehre zum österlichen „Sehen“ Jesu als Überwindung von Trauer durch Freude darstellt und darin eine „Grundstruktur

Person (14,21.23f.: „wer meine Weisungen bewahrt [...]“; „wenn jemand mich liebt [...]“). Dass beide Rede-Formen nebeneinanderstehen, zeigt die Transparenz der Jünger-Figur auf die Leserschaft des Buches hin. - Von Punkt 5 her könnte die Zeugenschaft des Geistes in V. 25e nochmals anders bedacht werden: Vielleicht ist bei ihr an das Evangelienbuch zu denken, welches das Zeugnis der ersten Jünger und das des Parakleten enthält.

${ }^{36}$ SChNelle, Evangelium (Anm. 1) 321: „Die Wirkeinheit von Vater und Sohn bei der Sendung des Parakleten kommt auch in Joh 15,26 zum Ausdruck, jetzt sendet der Sohn den Parakleten. Diese Akzentuierung entspricht der vollkommenen Seins- und Wirkeinheit von Vater und Sohn und ist kein Indiz für tiefgreifende Unterschiede zwischen der ersten und zweiten Abschiedsrede." Zum Umgang mit dem Thema Zeit, dem Ineinander von nachund vorösterlicher Zeit wie ihrer differenzierten Zuordnung in den Abschiedsreden vgl. Hoegen-Rohls, Johannes (Anm. 1) 202-208.

${ }^{37}$ In der zweiten, mittleren Rede (Joh 15), vor allem in der Gleichnisrede vom Weinstock (VV. 1-11), ist die Perspektive nachösterlich.

${ }^{38}$ Jesus kündigt (erneut) seinen Weggang zu dem an, „der ihn gesandt hat", und stellt

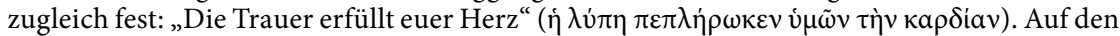
inneren Zusammenhang von beidem hebt der Text ab. Im Negativen erscheint hier schon das Positive: Die Umwandlung der Trauer in Freude im "Sehen“ Jesu, das Thema der Rede.

${ }^{39}$ Auf ihr prooemium $(16,4 \mathrm{e}-15)$ folgt in 16,16-24 ihr Hauptteil und 16,25-33 ihr Schluss (=peroratio).

${ }^{40}$ Deshalb beginnt die neue „Einheit“ mit Joh 16,4e; vom „Weggang“ Jesu war in Joh 15,1-16,4d nirgends mehr die Rede. 
christlichen Seins" ausmacht, die für die Situation der Jüngergemeinde bis zum Ende der Zeiten typisch sein wird. ${ }^{41}$

Die beiden Parakletsprüche im prooemium der Rede sind wie zwei Seiten einer Medaille: Beschreibt der erste Spruch, 16,8-11, das Wirken des Parakleten nach außen (der "Welt" gegenüber nimmt er die Rolle des „Anklägers“ ein), so bedenkt der zweite, 16,13-15, sein Wirken nach innen: In der Gemeinde wirkt er als „Prophet“.

Jesu Ankündigung V. 7, dass sein „Weggang“ den Jüngern, auch wenn

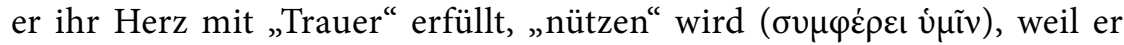
Bedingung für das „Kommen“ des „Parakleten“ ist, fungiert als Scharnier zwischen propositio (VV. 5f.) und erstem Spruch (VV. 8-11):

7 a Aber ich sage euch die Wahrheit,

b es nützt euch,

c dass ich weggehe (àmic่ $\theta \omega)$.

d Wenn ich nämlich nicht weggehe $(\mu \grave{\eta} a \dot{\pi} \pi \dot{\varepsilon} \lambda \theta \omega)$,

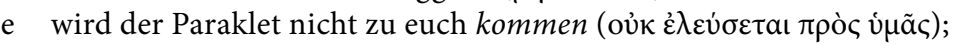

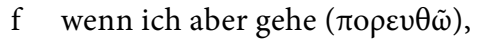

g werde ich ihn zu euch senden ( $\pi \dot{\varepsilon} \mu \psi \omega)$.

8 a Und gekommen $(\dot{\varepsilon} \lambda \theta \dot{\omega} v)$,

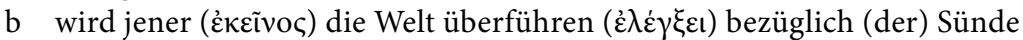

c und bezüglich (der) Gerechtigkeit

d und bezüglich (des) Gerichts;

9 a bezüglich der Sünde,

b denn sie glauben nicht an mich;

10 a bezüglich der Gerechtigkeit,

b denn ich gehe zum Vater

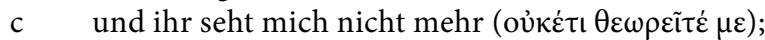

11 a aber bezüglich des Gerichts,

b denn der Herrscher dieser Welt ist gerichtet.

Der vierte Spruch stellt den „Parakleten“ nicht mehr eigens vor, was nach Joh 14,17a; 14,26a-c und 15,26c auch nicht nötig ist. Er sagt, was der „Paraklet“ als „Ankläger“ tun wird, wenn er „gekommen“ ist: Er wird „die Welt überführen“, womit sein „Zeugnis“vor der Welt, von dem der vorige Spruch handelte (Joh 15,26e), nach seiner negativen Seite hin präzisiert

\footnotetext{
${ }^{41}$ Vorbildlich von Dietzfelbinger, Evangelium II (Anm. 1) 174, herausgearbeitet. „Was die Jünger an Ostern erstmals und grundlegend erlebt haben - der Text verzichtet nicht auf die vergangenen Erfahrungen - wiederholt sich in der nachösterlichen Existenz der Gemeinde immer dann, wenn die verlassene und trauernde Gemeinde der Gegenwart Jesu inne wird“; vgl. DERS., Die eschatologische Freude der Gemeinde in der Angst der Welt. Joh 16,16-33, EvT 40 (1980) 420-436.
} 
wird. Wie die Zeugnis-Terminologie juridisch ist, so auch $\dot{\varepsilon} \lambda \dot{\varepsilon} \gamma \chi \chi_{\varepsilon} v^{42}{ }^{42}$ Der "Paraklet" „deckt auf" und „überführt" „die Welt" in dreifacher Hinsicht (V. 8b-d), die VV. 9-11 erläutern: Im Blick auf ihre "Sünde“ (sie glauben nicht an den Offenbarer), im Blick auf die "Gerechtigkeit" (Gott setzt gegen den Anschein der "Welt“ Jesus im Weggang zu ihm ins Recht) und im Blick auf das "Gericht" („der Herrscher dieser Welt" ist im Sieg Jesu gerichtet). Wie sich das ,aufdeckende“ oder „überführende“ Tun des „Parakleten“ an der Welt vollzieht, wird - wie analog im dritten Spruch nicht gesagt. ${ }^{43}$

\subsection{Der Paraklet als Prophet. Das Rätsel von Joh 16,(12)13-15}

V. 12 ist das Scharnier, das den zweiten an den ersten Spruch anbindet. Da der Paraklet bekannt ist, ist der Spruch (wie der vorige) darauf fokussiert, was der Paraklet, wenn er „gekommen“ ist, tun wird:

12 a Noch vieles ( $\pi \mathrm{o} \lambda \lambda \dot{\alpha}$ ) habe ich euch zu sagen,

b aber ihr könnt es jetzt nicht tragen.

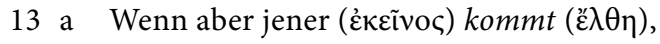

b der Geist der Wahrheit,

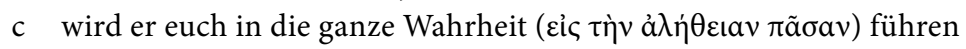

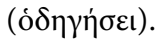

d Denn er wird nicht aus sich selbst reden,

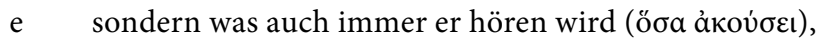

f das wird er reden

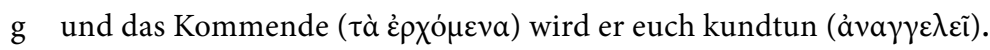

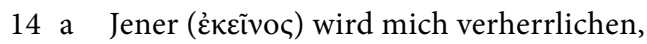

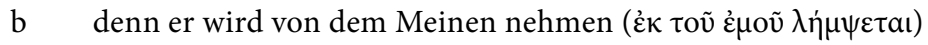

c und euch kundtun (å $v \alpha \gamma \gamma \varepsilon \lambda \varepsilon \tilde{\imath})$.

15 a Alles, was der Vater hat,

b ist mein.

c Deshalb habe ich euch gesagt (vgl. V.14b.c),

d dass er von dem Meinen nimmt

e und euch kundtun wird (åva $\gamma \gamma \varepsilon \lambda \varepsilon \tilde{)})$.

\footnotetext{
${ }^{42}$ Vgl. Joh 3,20; 8,46; außerdem Mt 18,15; 1 Tim 5,20; Jak 2,9, aber auch 1 Kor 14,24.

${ }^{43}$ Vgl. aber Rudolf Bultmann, Das Evangelium des Johannes (KEK 2), Göttingen ${ }^{21} 1986$, 436: „Wenn der Paraklet den Sinn dessen, was geschah, auch nur für die Glaubenden sichtbar macht, so trifft sein $\dot{\varepsilon} \lambda \dot{\varepsilon} \gamma \chi \varepsilon\llcorner v$ doch die Welt, sofern es sich in der Verkündigung der Gemeinde vollzieht. Dieses Wort und sein herausfordernder Anspruch erklingt in der Welt, und die Welt kann seitdem nicht wieder sein, wie sie vordem war" (Kursive von mir); vgl. dazu unten.
} 


\section{Exkurs: Wie V. 13c und e zu lesen ist. Textkritik als Spiegel der Rezeptionsgeschichte der Parakletsprüche}

V. 13c ist unterschiedlich überliefert. „Geleitet" der Geist „euch in der

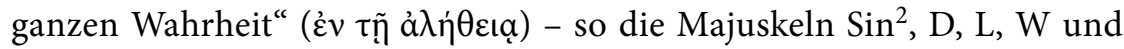
$\Theta$, einige Minuskeln, 1.33.565, sowie lateinische Übersetzungen - oder

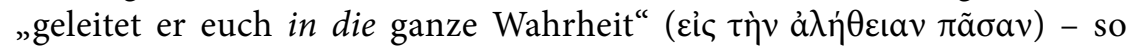
die Majuskeln A und B, Origenes, lateinische Übersetzungen sowie der sog. nachkonstantinische Mehrheitstext, der $\pi \tilde{a} \sigma \alpha \nu$ voraus stellt. ${ }^{44}$ Weil sich die jüngste Ausgabe des Nestle-Aland, Novum Testamentum Graece (28. Auflage), im Text weiterhin für die Fassung mit $\varepsilon v$ etc. entscheidet, ${ }^{45}$ sei für die davon abweichende textkritische Entscheidung zugunsten des

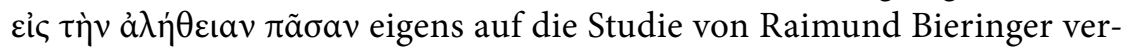
wiesen, der sie ausgiebig und plausibel begründet. ${ }^{46}$ Die äußeren Zeugnisse erlauben zwar keine Entscheidung, wohl aber interne Beobachtungen zu Sprache und Textlogik sowie die Wahrscheinlichkeit, dass viel

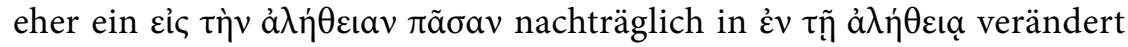

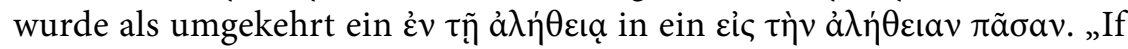
the reading with eic is the preferable reading, then it is possible, though not certain, that the fourth evangelist considered the ,Spirit of truth 'to have the function of a revealer and not just one who repeats the revelation of Jesus. “47 Überdies zeigt Bieringer, dass die Variante in V. 13e mit hinzuzuziehen ist und mit der zuerst besprochenen zusammenhängt: Ist dort mit der besser bezeugten Lesart ${ }^{48}$ das Futur zu lesen: „er wird hören“"

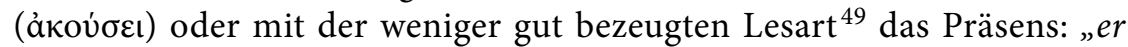

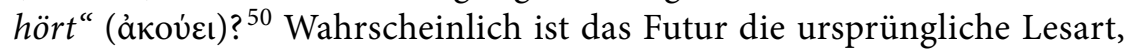
das Präsens sekundär. Wie in V. 13c die nachträgliche Korrektur den Gedanken vermeiden wollte, der Paraklet würde über Jesus hinaus „in

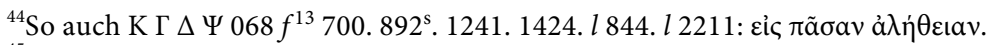

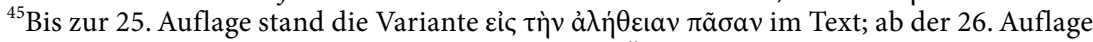
heißt es $\dot{\varepsilon} v \tau \tilde{n}$ ả $\lambda \dot{\eta} \theta \varepsilon ı$. Dieser Lesart folgen jetzt EÜ 2016 („wird er euch in der ganzen Wahrheit leiten“) und Luther 2017 („wird er euch in aller Wahrheit leiten“), von den jüngeren Kommentatoren Zumstein, Johannesevangelium (Anm. 1) 601 Anm. 240; Klaiber, Johannesevangelium II (Anm. 1) 143.

${ }^{46}$ Reimund Bieringer, The Spirit's Guidance into All the Truth: The Text-Critical Problems of John 16,13, in: Adelbert Denaux (Hg.), New Testament Textual Criticism and Exegesis (FS Joël Delobel) (BETL 161), Leuven 2002, 183-207.

${ }^{47}$ Bieringer, Guidance (Anm. 46) 183.

${ }^{48} \mathrm{~B}$ D W $\Theta \Psi$ 1. 579. $l$ 844. $l 2211$ (1) vg.; Epiphanius.

${ }^{49} \operatorname{Sin} \mathrm{L} 33 \mathrm{~b}$ e.

${ }^{50}$ Der Konjunktiv Aorist ảkoúø̣̣ (A K $\Gamma \Delta f^{13}$ 565. 700. 1241. 1424 und Mehrheitstext) ist, da eine grammatikalische Verbesserung, in jedem Fall sekundär.
} 
die ganze Wahrheit“ geleiten, um stattdessen anzudeuten, dass er „in“ der von Jesus offenbarten "Wahrheit" führt, sollte die Präsensform in V. 13e insinuieren, dass der Paraklet jetzt schon von Jesus hört, was er später zu sagen hat. Zu V. 13c wird immer wieder behauptet, dass der Unterschied

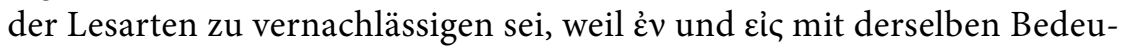
tung alternieren. ${ }^{51}$ Dagegen spricht: Der Unterschied ist in verschiedener Hinsicht signifikant. ${ }^{52}$

Die textkritischen Erwägungen von Bieringer können durch Hinweise zur Rezeptionsgeschichte der Parakletsprüche gestützt werden. Gerade 16,13 ist derart offen, dass er zu historischen Identifikationen einlud. „Wenn jener kommt, der Geist der Wahrheit, wird er euch in die ganze Wahrheit geleiten." Wer ist dieser Prophet, der über Jesus hinaus neue Offenbarungen bringen wird? Die Antworten, die gegeben wurden, sind frappant. So füllten die Anhänger des Montanus, des Mani (216-276/7) und des Muhammad - dieser drei großen „M“ der Antike - die „Leerstelle“ von Joh 16,13 aus, indem sie den angekündigten „Parakleten“ jeweils mit ihrem Meister identifizierten. Von größter Wirkung bis heute ist Sure 61 des Koran, Vers 6: „Als Jesus, der Sohn Marias, sagte: ,Ihr Kinder Israels, ich bin Gottes Gesandter für euch, um zu bestätigen, was schon vor mir von der Tora vorlag, und einen Gesandten zu verkündigen, der nach mir kommt. Sein Name ist hoch gepriesen $" .{ }^{\prime 2}$ Dass Jesus Muhammad ankündigte, arbeitete die islamische Glaubenslehre im Anschluss an die genannte Sure weiter aus. Wenn Joh 16,13 des Weiteren erklärt: „Denn nicht von sich aus wird er (sc. der Paraklet) reden, sondern was er hören wird, wird er sagen und das Kommende wird er euch kundtun", dann sieht die islamische Glaubenslehre darin die Rolle Muhammads als Offenbarer bestätigt. Muhammad als Paraklet sagt nur, „was er vom Himmel vernimmt, nicht etwas, was er vom Menschen gelernt oder mit Hilfe seiner eigenen Vernunft erkannt hat ${ }^{\text {“54. }}$

\footnotetext{
${ }^{51}$ Bultmann, Evangelium (Anm. 43) 442 Anm. 2; so auch Dietzfelbinger, Abschied (Anm. 7) 187.

${ }^{52}$ Immerhin stellt Dietzfelbinger, Abschied (Anm. 7) 187, fest: „Der Streit um die ursprüngliche Lesart ist dogmatischer Art: $\grave{\alpha} \lambda \dot{n} \theta \varepsilon ı \alpha$ könne nicht erst das Ergebnis der Führung sein, die der Geist der Gemeinde angedeihen lässt; das Führen des Geistes bewege sich immer in der Wahrheit." So auch etwa Charles K. BARrett, Das Evangelium nach Johannes

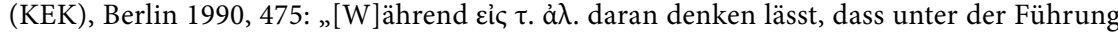
des Geistes die Jünger dazu kommen werden, alle Wahrheit zu kennen, lässt $\dot{\varepsilon} v \tau$. $\dot{\alpha} \lambda$. an eine Führung in der ganzen Sphäre der Wahrheit denken; sie werden in der Wahrheit Gottes gehalten werden, die durch die Sendung Jesu verbürgt wird.“

${ }^{53}$ Übersetzung Hans ZIRKER, Der Koran, Darmstadt ${ }^{2} 2007,345$.

${ }^{54}$ Christian W. Troll, Einführung, in: Güzelmansur, Muhammad (Anm. 1) 11-25: 18.
} 
Setzt die Rezeption der „Parakletsprüche“ mit dem sog. „Montanismus", einer bedeutenden Variante frühchristlicher Prophetie im 2. Jahrhundert schon sehr früh ein, dürfen wir davon ausgehen, dass seine Abwehr sich auch in der Textgeschichte des Evangeliums niederschlug. Das trifft auf die Varianten von Joh 16,13c.e zu, was die Forschung bislang völlig übersah. Es waren die Gegner des Montanismus, die jene Lesarten beförderten, deren Pragmatik bis heute nicht durchschaut ist. Der Paraklet wird die Kirche ,in der ganzen Wahrheit leiten“, welches die Wahrheit Jesu ist (vgl. 14,6); er bringt nach Ostern keine Offenbarung, sondern tut nur kund, was er jetzt schon von Jesus „hört“ (Präsens). Auf diese Weise versuchte man, den Text gegen seine montanistische Lesart zu immunisieren (Exkurs-Ende).

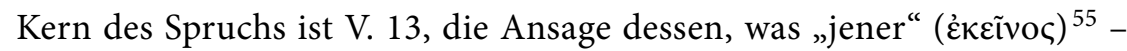
der Paraklet - nach Ostern tun wird. Die VV. 14f. sind Kommentar, der

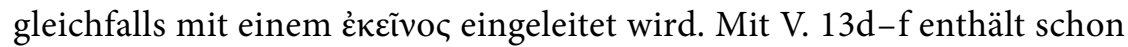
der Kern des Spruchs eine mit oủ үá $\rho$ eingeschobene Erklärung.

(1) "Jener" wird "Geist der Wahrheit" genannt. Das entspricht der Pointe des Spruchs: „Er wird euch in die ganze Wahrheit führen [...] und das Kommende wird er euch kundtun" (13c.g). ${ }^{56}$ Beides gehört zusammen, das „Führen in die ganze Wahrheit" erfüllt sich in der Erschließung

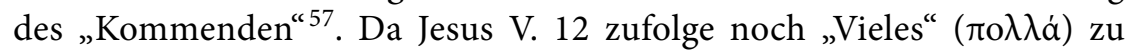
sagen hat, es in der Abschiedsstunde indes nicht sagt, der Paraklet aber nach Ostern „kundtun“ wird, „was auch immer (ö $\sigma \alpha)$ er dann hören wird“ (V. 13e.f), meint die Rede von der "ganzen Wahrheit" ${ }^{58}$ ohne Zweifel einen Zuwachs an Offenbarung, kognitiven Gewinn, zugespitzt: neue Offenbarung.

(2) Die Rolle, die der Paraklet einnimmt, ist die eines Propheten. $\mathrm{Zu}$ dem gibt er Geleit - wie die Sophia, die, „herabgesandt vom Himmel“, Salomon (Weish 9,11), Jakob, ja das ganze Volk auf seinem Weg durch die

\footnotetext{
${ }^{55}$ „Jener" - der Name des „Parakleten“ wird nach Joh 16,7e nicht noch einmal wiederholt.

${ }^{56}$ Zumstein, Jean II (Anm. 1) 139, sieht hier ein „Echo“ von Joh 14,6 (Stichworte: ả $\lambda \dot{\theta} \theta \varepsilon ı$

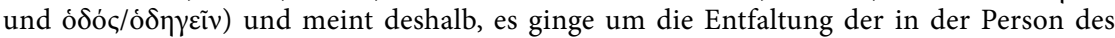
„inkarnierten Christus" manifestierten „Wahrheit“.

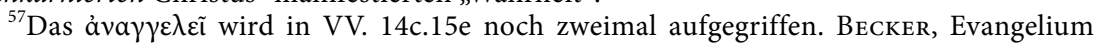
(Anm. 1) 596: „das Kommende, das der Paraklet künden wird“, steht „betont am Schluss der Aussagenkette“.

${ }^{58}$ Nirgends im Evangelium hat der Terminus à $\lambda \dot{n} \theta \varepsilon ı \alpha$ (= Wahrheit) ein Adjektiv bei sich, nur hier.
} 
Wüste „geleitet" (Weish 10,10.17). ${ }^{59}$ Die Personifizierung des Parakleten als eines begleitenden guten Geistes oder Engels setzt sich auf der Linie der vorigen Sprüche fort.

(3) Die Kernaussage des Spruchs ist gewagt. Das zeigen die angebrachten Absicherungen. Bereits V. 13d erklärt, der Paraklet werde „nicht aus sich selbst reden“, sondern nur „was er hören wird“ ${ }^{60}$, und der nachfolgende Kommentar bindet das in V. 14 an Jesus zurück, nicht den Irdischen, sondern den Erhöhten. ${ }^{61}$ Wenn der Paraklet prophetisch redet, „wird er aus dem Meinen nehmen“, mit anderen Worten: Er tut kund, was er vom himmlischen Jesus vernimmt. Der „Paraklet“ ist Sprachrohr des erhöhten Jesus. Indem er ihn zu Wort kommen lässt, „,verherrlicht“ er ihn.

(4) Wie die beiden vorangehenden Sprüche blickt auch der fünfte auf den Erhöhten voraus, der im Himmel bleibt, während der Paraklet ihn auf Erden „verherrlicht“. V. 15a.b, der den Vater in die Legitimation des Propheten, genannt Paraklet, mit einbezieht, verrät, wie das Verhältnis von Vater und Sohn gedacht wird: „Alles, was der Vater hat, ist mein.“ Anders gesagt: Wie Freunden „alles gemeinsam ist“, ${ }^{62}$ so lässt auch der Vater den Sohn an allem teilhaben, was sein ist; er hat keine Geheimnisse vor ihm. Sie sind „Freunde“ und stehen als solche auf gleicher Stufe. ${ }^{63}$ Das

\footnotetext{
${ }^{59}$ Die Wendung „Hineinführen in alle Wahrheit“ lehnt sich an die entsprechende „Funktion der jüdischen Weisheit (vgl. Weish 9,11; 10,10.17) oder des heiligen Geistes (Ps 142,10 ${ }^{[\mathrm{LXX}]}$ ) [an], der auch mit der Weisheit in eins gesehen ist (Weish 9,17)" (BECKER, Evangelium [Anm. 1] 596); vgl. auch SCHNACKenBurg, Johannesevangelium (Anm. 1) $152 \mathrm{f}$.

${ }^{60}$ V. $13 \mathrm{~d}-\mathrm{f}$ formuliert einen Grundsatz des Botenrechts: vgl. Jan-Adolf BüHNER, Der Gesandte und sein Weg im 4. Evangelium (WUNT 2,2), Tübingen 1977, 209; Müller, Parakletenvorstellung (Anm. 4) 73, verweist auf Num 16,28 und apokalyptische Aussagen zur Legitimation von Sehern.

${ }^{61}$ Vgl. die durchgängigen Futura, die auf den lebendigen Austausch des „Parakleten“ mit Jesus in der Zukunft schauen.

${ }^{62}$ Aristoteles, Ethica Nicomachea 1168b; vgl. auch Philo, De Vita Mosis I 156: „Und das ist vielleicht gar nicht zu verwundern, denn wenn nach dem Sprichwort, ,das Eigentum von Freunden ihnen gemeinsam gehört' (Plato, Phaidros 279c), der Prophet aber ein Freund Gottes genannt wird (Ex 33,11), so muss er wohl folgerichtig auch an dessen Besitz teilhaben, soweit es ihm von Nutzen ist [...].“ Vgl. Joh 17,10: „Und all das Meine ist dein und das Deine mein [...]", außerdem 15,15. - Michael TнеовацD, Art. Freundschaft I. Griechischhellenistisch u. im Neuen Testament, LThK ${ }^{3}$ IV (1995)132f.

${ }^{63}$ Das Freundschaftsmodell setzt allerdings Über- und Unterordnungen nicht außer Kraft, wie gerade auch dieser Paraklet-Spruch zeigt, in dem es sich mit der Vater-Sohn-Relation verbindet (vgl. Lk 15,31). In welchem Grad die Gleichheit in der Freundschaft soziale und andere hierarchische Abstufungen verträgt, um noch Freundschaft genannt werden zu können, diskutiert Aristoteles, Ethica Nicomachea 1158b-1159a: „Indes bedeutet Gleichheit

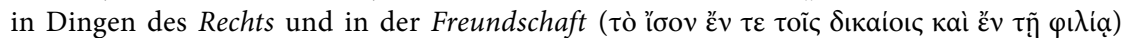
nicht dasselbe. [...] Dies tritt klar hervor, wenn ein beträchtlicher Abstand ( $\pi \mathrm{o} \lambda \dot{v} \delta$ iáo $\tau \mu \alpha)$
} 
wird nicht weiter entfaltet, weil es ein Argument für die Absicherung der gewagten Aussage ist, dass der Paraklet neue Offenbarung bringt: Was er vom Sohn her kundtun wird, ist nicht exklusiv dessen Eigenes, sondern stammt vom Vater und vom Sohn. Beide verbürgen die Wahrheit der Offenbarung des Parakleten.

(5) Was die épxó $\mu \varepsilon v a$, „die kommenden Dinge“ sind, ist umstritten. ${ }^{64}$ Der Gedanke, dass der Paraklet mit der „Enthüllung künftiger Ereignisse“ „etwas völlig Neues über die Offenbarung Jesu hinaus“ 65 bringt, wird in der Regel reflexhaft abgewehrt, weil die Einzigkeit der Offenbarung Jesu gefährdet zu sein scheint. ${ }^{66}$ Im Unterschied zur ersten Abschiedsrede geht es hier aber nicht um die Erschließung der Worte des irdi-

in Hinsicht auf charakterliche Trefflichkeit oder Minderwertigkeit oder Wohlstand usw. gegeben ist. Denn dann sind sie keine Freunde mehr, ja, Freundschaft zu beanspruchen kommt ihnen gar nicht in den Sinn. Am schärfsten fällt dies in die Augen bei den Göttern, denn sie stehen am weitesten über uns, da ihnen alle Güter zu eigen sind. Aber auch bei den Königen tritt es klar hervor. [...] Eine scharfe begriffliche Festlegung, bis zu welcher Grenze Freunde noch Freunde sind ( $\check{\varepsilon} \omega \varsigma$ tivo nicht. Es kann (von der einen Seite) vieles weggenommen werden und es ist immer noch Freundschaft, ist aber der Abstand sehr groß geworden, z. B. bei der Gottheit, so ist es keine mehr.“ Andererseits Ethica Nicomachea 1162a: „Die Freundschaft der Kinder zu den Eltern und der Menschen zu den Göttern bedeutet Freundschaft zu etwas Wertvollem und Überlegenem. Denn sie (die Eltern) sind die Spender der größten Wohltat: ihnen verdanken die Kinder Leben und Nahrung und dann auch Erziehung" (Übers. Dirlmeier).

${ }^{64}$ In 16,4e.f versteht der Leser, wovon Jesus seinen Jüngern anfänglich nichts gesagt hat, worüber er aber jetzt in seiner Abschiedsstunde zu ihnen spricht (es sind die Verfolgungen, die ihnen bis hin zu ihrem Tod drohen: vgl. 16,1-4; vgl. bereits 15,18-25). Dagegen erklärt $16,13 \mathrm{~g}$ nicht (auch nicht der Kontext), was unter den "kommenden Dingen“ zu verstehen sei. Drei Antworten erteilt die Exegese: Angekündigt würden entweder (1) Tod und Erhöhung Jesu (vgl. Joh 18,4) oder (2) nicht näher explizierte nachösterliche, d. h. gegenwärtige Erfahrungen der Leser und Hörer des Buches oder (3) endgeschichtliche Ereignisse im strengen Sinn. Zugunsten dieser dritten Deutung spricht nicht nur die frühjüdische Prägung der Wendung (vgl. Betz, Paraklet [Anm. 3] 190-192, mit Hinweis u. a. auf 1QpHab 2,9f.), sondern auch die temporale Stufung des Spruchs: Wenn die „Kundgabe“ des „Parakleten“ samt allem, was sie ermöglicht, durchgängig mit Verben im Futur angekündigt wird, geschieht sie in der Gegenwart der Leser. Dann aber müssen „die kommenden Dinge“, die der „Paraklet“ ankündigt, aus der Sicht der Gegenwart die eschatologische Zukunft beinhalten. - Ausführlich Jörg Frey, Die johanneische Eschatologie. Band 3: Die eschatologische Verkündigung in den johanneischen Texten (WUNT 117), Tübingen 2000, 195-204; vgl. auch Zumstein, Jean II (Anm. 1) $139 \mathrm{f}$.

${ }^{65}$ SCHNACKenBurg, Johannesevangelium (Anm. 1) 154.

${ }^{66}$ Die Wege der Deutung fallen dann sehr unterschiedlich aus. So besagt nach BultMANN, Evangelium (Anm. 39) 443 die vage Rede von den „zukünftigen Dingen“, „dass die Zukunft nicht in einem vorausgegebenen Wissen entschleiert, sondern durch das in der Gemeinde wirksame Wort jeweils erhellt" werden müsse. Nicht das Verfügen über konkrete Vorstellungen von der Zukunft, sondern „frei und gefasst (zu sein) für die Zukunft“ (ebd.) mache glaubende Existenz aus (entsprechend seiner existentialen Hermeneutik mit ihrem systematischen Vorbehalt objektiven Zukunftsaussagen gegenüber); SCHNACKENBurG, Joh III (Anm. 1) 154 (mit Anm. 26) betont den Bezug der „Wahrheit“ zum Handeln: „Der Geist 
schen Jesus durch den Parakleten, sondern um das, was er vom himmlischen Jesus „hört" und dann „kundtut“ ${ }^{67}$ Dem kognitiven Grundzug von

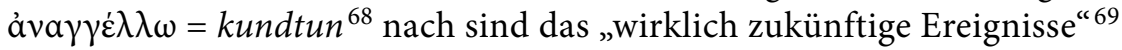
wie vor allem die Auferstehung der Toten und das postmortale Gericht am Ende der Tage, ${ }^{70}$ nicht einfach nur das Ende der Geschichte. ${ }^{71}$

verkündet den Jüngern das Kommende als das auf sie Zukommende, damit sie darnach handeln“; ebd., 155: Die „Wahrheit“ will "getan“ werden (vgl. Joh 3,21; 1 Joh 1,6; 2 Joh 4; 3 Joh 4); Dettwiler, Gegenwart (Anm. 8) 234: „Die in VV. 13f. enthaltene Leerstelle darf nicht durch einen religionsgeschichtlichen Rückgriff auf die Vorstellungen und Bilder der jüdisch-christlichen Apokalyptik angereichert werden“; Dietzfelbinger, Joh II (Anm. 1) 150, unter Hinweis auf das Stichwort „(er)tragen“: Bei den kommenden Dingen, die der Geist ankündigen wird, könne es sich „nicht um apokalyptisches Geschehen, sondern nur um das künftige Schicksal der Gemeinde handeln, das der Geist als das von Gott her kommende und darum tragbare Schicksal verstehbar macht".

${ }^{67}$ Weil der „Paraklet“ das, was er kundtun wird, erst noch „hören“ wird, kann hier nur der $\mathrm{zu}$ Gott erhöhte, gegenwärtige Christus gemeint sein, nicht der Inkarnierte; der Akzent ruht auf dem „Plus“ der Geistkundgabe über die „Offenbarung" Jesu hinaus.

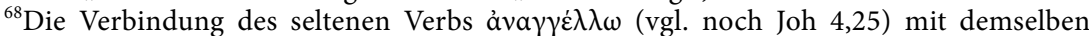

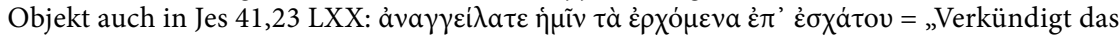
am Ende Kommende!"

${ }^{69}$ Barrett, Joh (Anm. 51) 476; er biegt die Aussage freilich im Sinne der präsentischen Eschatologie des Evangelisten um: „Wenn der Geist die Dinge verkündigt, die kommen müssen, dann verkündigt er sie als bereits wirksam; das Endgericht wird in der Überführung der Welt durch den Parakleten antizipiert." - BECKER, Joh II (Anm. 1) 596, spricht von einer „Apokalyptisierung der Parakletfunktion“ und erinnert dabei an den vorigen „Parakletspruch“. „Da auch V 10 die Parusieerwartung als futurisches Ereignis nicht aufgegeben ist, wird man auch V 13c [hier 13g] mit daran denken“; ebd.: „16,12ff. lassen [...] eine bestimmte Geschichtserfahrung erkennen. Für die Gemeinde dehnt sich die Geschichte (darf man u. a. an Joh 21,22f. erinnern?). Jedoch ist diese Zukunft aufgrund des Geistes als Wegführer für die Gemeinde durchsichtig. Sie führt nicht zur Desorientierung, was auch u. a. angesichts der dauerhaften Anfeindung durch die Welt nur zu verständlich wäre, sondern in die ,Wahrheit". "Vgl. auch MülLeR, Parakletvorstellung (Anm. 4) $67 \mathrm{f}$.

${ }^{70}$ Vielleicht ist auch an dem Ende vorauslaufende innergeschichtliche Ereignisse zu denken wie das Auftreten des „Antichrists“ bzw. von „Antichristen“ im Plural (1 Joh 2,18-23; 4,1-6), die ja als Phänomen der „letzten Stunde“ gelten. Das auch an die Parusie Jesu zu den-

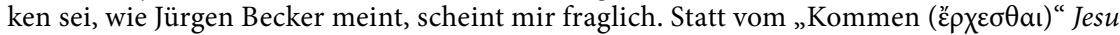

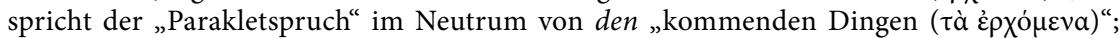
Zumstein, Jean II (Anm. 1) 140, minimiert diesen Unterschied: „la mission prophétique du Paraclet consiste à annoncer, le Christ qui vient', à dévoiler comment l'absent se tient au seuil du présent et comment il habite l'avenir." Vgl. dazu Theobald, Jesus (Anm. 1) $108-110$.

${ }^{71}$ Takashi ONUKI, Gemeinde und Welt im Johannesevangelium. Ein Beitrag zur Frage nach der theologischen und pragmatischen Funktion des johanneischen „Dualismus“ (WMANT 56), Neukirchen-Vluyn 1984, 151: „Es fehlt hier jede Reflexion auf den substan-

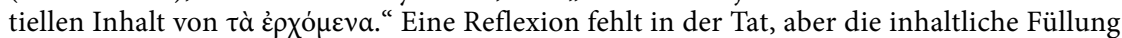
der épXó $\mu \varepsilon v a$ liegt intratextuell von Stellen wie 5,28f. oder 6,39f. her nahe; FrEY, Eschatologie 3 (Anm. 64) 203: „Es wäre verwunderlich, wenn die johanneischen Adressaten den

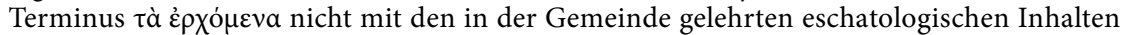


(6) Wenn die „zukünftigen Dinge“ von Joh 16,13g tatsächlich „Auferstehung" und das postmortale „Gericht" meinen, worüber der „Paraklet" nach Ostern sprechen wird, fragt sich, ob dem nicht der Befund entgegensteht, dass schon der irdische Jesus von beidem spricht: sowohl von der "Auferweckung" der Toten (Joh 6,39.40.44) als auch vom Gericht gemäß den Werken „am letzten Tag" (Joh 5,29; 12,48). Doch ist das kein Widerspruch. Wie der zweite Parakletspruch die hermeneutische Metatheorie zum Evangelium bietet - der Geist ist die produktive Kraft der Erinnerung an Jesus, wie sie im Evangelienbuch ihren Ausdruck findet -, so legitimiert der letzte Parakletspruch die Ausgabe letzter Hand des Gemeindebuchs mit seiner nachgetragenen futurischen Eschatologie. ${ }^{72}$

(7) Damit ergibt sich eine Antwort auf die Frage, wie wir uns die in den letzten drei Sprüchen vorgestellte eigenständige Rolle des „Parakleten“ konkret vorstellen sollen. Wie wirkt er als "Zeuge“, als „Ankläger“ und als „Prophet"? ${ }^{73}$ Er wirkt in diesen Rollen vornehmlich durch das Gemeindebuch, das Evangelium. Dieses legt Zeugnis ab von Jesus, es klagt die Welt an und redet prophetisch, indem es die Zukunft in ihren unterschiedlichen Facetten ansagt, als Teilgabe am „ewigen Leben“, als Gericht und als Auferstehung.

\section{3. „Zwei Götter im Himmel“ (Peter Schäfer)? Wandlungen im Gottesbild von Joh 14-15.16}

Die voranstehenden Beobachtungen erlauben es, im Blick auf die hier leitende Frage ein Resümee zu ziehen und weiterführende Perspektiven $\mathrm{zu}$ formulieren.

(1) Die Parakletsprüche der zweiten und dritten Abschiedsrede unterscheiden sich von den beiden Sprüchen der ersten Rede nicht unerheblich. Diese schreiben dem Vater eindeutig nicht nur die Sendung des Parakleten zu, sondern sehen in ihm auch seinen Ursprung. Das wird daran deutlich, dass Jesus den Vater bitten muss, ihn an Ostern zu senden, er kann es nicht in eigener Hoheit. Das ist auch umgekehrt ernst zu nehmen in dem Sinne, dass der Vater seinen Geist nicht unabhängig vom

und den ihnen vertrauten Erwartungen verbunden hätten, auch wenn diese im Evangelium, im Rahmen der Selbstverkündigung Jesu, eher zurücktreten.“

${ }^{72} \mathrm{Zu}$ dieser vgl. Theobald, Eschatologie (Anm. 9).

${ }^{73}$ Sofern es „Propheten“ oder "Lehrer" sind, die dem „Parakleten“ ihre Stimme leihen, stünden deren Auftritt und Lebensstil als Ausweis der Authentizität des von ihnen Kundgetanen zur Debatte. Doch das Corpus Iohanneum lässt dazu nichts verlauten. 
Sohn sendet, sondern aufgrund seiner Fürbitte, die sich in seinem Sterben gleichsam „verleiblicht“. Wenn im Wasser, das aus dem Leib des getöteten Jesus hervortritt, der „Hervorgang“ des Geistes versinnbildlicht wird, ist das auf diesem Hintergrund zu lesen: Gott gibt seinen Leben spendenden Geist nirgends anders als in der Verherrlichung Jesu in seinem Tod. Aber er ist es, der ihn in Antwort auf Jesu Fürbitte gewährt.

(2) Nach der ersten Abschiedsrede ist es Jesus, der mit Ostern in die Herzen der Seinen „kommt“, und zwar in Gestalt seiner Worte, die immer zuerst Worte des Vaters sind, die er getreu als sein Gesandter übermittelt. Auch hierin ist die theozentrische Perspektive gewahrt. Der "Paraklet“ „kommt“ dagegen nicht, er wird den Glaubenden „gegeben“, sie „empfangen“ ihn, er ist ihnen inwendig. Er ist sozusagen die „Kraft“, welche Jesu äußere Worte von innen her aufschließt, metaphorisch gesprochen: Er ist ihr innerer „Lehrer“, der die Seinen „an alles erinnert, was Jesus gesagt hat". Jesu „Kommen“ und der gegebene Geist verhalten sich wie das Außen und Innen ein und desselben Vorgangs zueinander.

(3) In der zweiten und dritten Abschiedsrede verschiebt sich das Gefüge. Nun ist es der himmlische Jesus, der den Parakleten sendet, nicht der Vater. Alle Initiative geht von ihm aus. Dabei ist die Personifizierung des Parakleten weiter fortgeschritten. Er tritt wie ein guter Engel und Wegbegleiter auf Erden auf, ist Doppelgänger des himmlischen Jesus.

(4) Jesus und der Vater sind wie zwei Freunde im Himmel, die - laut Aristoteles - „alles gemeinsam“ haben (Joh 16,15a.b). Sie agieren in göttlicher Zweisamkeit, ohne dass dies in den Sprüchen der zweiten und dritten Rede eigens ausgearbeitet und entfaltet wird. Die Vorstellung dient der Legitimierung des Parakleten, weil er als Prophet über den irdischen Jesus hinaus Neues kundtut. Darauf ruht das Gewicht. Der Wechsel im Bild der göttlichen Zweisamkeit von Vater und Sohn, die sich hier - sozusagen unter der Hand - als selbstverständlich eingestellt hat, ist signifikant.

(5) Es besteht ein klares Gefälle von der gezielten Theozentrik der ersten Rede zur unterschwelligen göttlichen Zweisamkeit von Vater und Sohn in den beiden folgenden Reden. Die Theozentrik der ersten Rede ist gezielt zu nennen, weil sie in ihrem Schluss, der peroratio, ausdrücklich thematisiert wird: „Ihr habt gehört, dass ich euch gesagt habe: Ich gehe und komme zu euch. Wenn ihr mich liebtet, würdet ihr euch freuen, dass ich zum Vater gehe, denn der Vater ist größer als ich" $(14,28)$. Er ist größer als der Sohn, weil er auf seine Fürsprache hin die Rettung der Menschen erwirkt.

(6) Wenn „die Juden“ Jesus vorwerfen, er mache „sich Gott gleich, indem er ihn seinen Vater nenne" $(5,18$; vgl. 10,33; 19,7), spiegelt sich darin 
der massive Vorwurf eines die Einzigkeit Gottes verletzenden Ditheismus - einer Zwei-Götter-Vorstellung - wider, den Teile eines proto-rabbinischen Judentums gegen die johanneischen Gemeinden erhoben, worauf ihr Gemeindebuch reagiert. ${ }^{74}$ Es ist darum bemüht, die göttliche Hoheit Jesu als des inkarnierten Logos und des vom Himmel herabgekommenen Menschensohns vor allem mittels des Gesandtenmodells in die Rede von Gott so zu integrieren, dass keine Zweifel an dessen Einzigkeit aufkommen können. In Joh 15-16 spielen diese Auseinandersetzungen keine Rolle mehr, auch nicht im Abschiedsgebet Jesu Joh 17. Wenn Jesus in diesen Kapiteln wie selbstverständlich als göttliches Wesen im Himmel an der Seite seines Vaters erscheint, stützt dieser Befund die These eines literarischen Nachtrags. Er ist Niederschlag einer Relecture der Basisrede, die sich für innergemeindliche, ekklesiologische Fragen interessiert, nicht aber für die Vorwürfe, die vonseiten eines proto-rabbinischen Judentums gegen die johanneischen Gemeinden erhoben wurden.

(7) Peter Schäfer zeigt in seinem Buch „Zwei Götter im Himmel. Gottesvorstellungen in der jüdischen Antike "75, dass binitarische Gottesvorstellungen nicht nur in der Zeit des zweiten Tempels eine wichtige Rolle spielten, sondern in der "Ambivalenz von Rezeption und Ablehnung " 76 auch in der Epoche des rabbinischen Judentums. Die Ablehnung war dort stark, wo etwa „die Usurpation des jüdischen Menschensohns durch das Neue Testament [...] die Rezeption und Weiterentwicklung dieser ursprünglich elementar jüdischen Idee im Judentum [...] verhindert hat " ${ }^{\text {"77, }}$, so im zunehmend christianisierten Palästina. Ganz anders dagegen das Judentum Babyloniens, wo das Christentum „nur eine sehr untergeordnete Rolle“ spielte: „genau dort lebten die binitarischen Vorstellungen weiter " ${ }^{\text {78. }}$. Es gab im Judentum bis weit in die Spätantike keinen lupenreinen Monotheismus. „Der jüdische Himmel begnügte sich keineswegs immer mit einem Gott, sondern war trotz aller gegenläufigen Tendenzen

\footnotetext{
${ }^{74}$ Vgl. Michael Theoвald, Das Evangelium nach Johannes. Kapitel 1-12 (RNT), Regensburg 2009, 66-70.

${ }^{75}$ Peter SchäFER, Zwei Götter im Himmel. Gottesvorstellungen in der jüdischen Antike, München 2017.

${ }^{76}$ Ebd. 18f. Für die Zeit des zweiten Tempels verweist er etwa auf den Menschensohn von Dan 7, mit dem „erstmals ein Engel die Bühne (betritt), der in einen quasi-göttlichen Status erhoben wird und in dieser Eigenschaft die Interessen des irdischen Gottesvolkes im Himmel vertritt“ (ebd. 14), für das spätere Judentum auf Unterschiede „Zwischen dem rabbinischen Judentum Palästinas auf der einen Seite und dem rabbinischen Judentum Babyloniens sowie der jüdischen Mystik auf der anderen“" (ebd. 16).

${ }^{77}$ Ebd. 17.

${ }^{78}$ Ebd. 17.
} 
und trotz zahlreicher Versuche, diesen Trend aufzuhalten, oft auch mit zwei Göttern oder mit mehreren göttlichen Potenzen bevölkert.“ 79

Dieses Paradigma jüdischer Religionsgeschichte wirft Licht auch auf das Johannesevangelium, dessen Entstehung in die Zeit des werdenden rabbinischen Judentums in den ersten Jahrzehnten nach der Zerstörung des Tempels fällt. Dass es insgesamt mit der Anklage auf Ditheismus ringt, welche den johanneischen Jesusanhängern das Trauma des Synagogenausschlusses beibrachte, zeigt, wie bedrängend nahe ihnen dieses werdende rabbinische Judentum gekommen war. Wenn dagegen die Parakletsprüche der zweiten und dritten Rede Vater und Sohn in göttlicher Zweisamkeit zeigen, ohne das zu problematisieren, kommen binitarische Traditionen der johanneischen Gemeinden nahezu ungefiltert nach oben. Nach dem Modell von Peter Schäfer müssen diese nicht auf eine Absatzbewegung vom Judentum hinweisen. Von einer Aufweichung des Monotheismus, der reicher war, als wir es uns gewöhnlich vorstellen, kann nicht die Rede sein. ${ }^{80}$ Dennoch war hier ein Sprengsatz gelegt, der im Laufe der Zeit dazu beitrug, dass sich das werdende Christentum mit seinem "trinitarisch“ transformierten Monotheismus vom rabbinisch geprägten Hauptstrom des Judentums trennte.

\footnotetext{
${ }^{79}$ Ebd. 151.

${ }^{80}$ Das zeigt auch die selbstverständliche Rede von Vater und Sohn, welche die auf ihrer Gleichheit beruhende Freundschaft überlagert (vgl. oben Anm. 62).
} 


\title{
Der Vater des Gottessohnes und der Vater der Gotteskinder ${ }^{1}$
}

\author{
Reinhard Feldmeier
}

\section{Gott - Allein?}

Der Titel dieser Tagung "Gott - allein“ ist bewusst provokativ formuliert. Er soll verhindern, dass die Johannes-Exegese wieder in die gewohnten Gleise der Christologie einbiegt und dieser die Gottesfrage subsumiert. Gleichwohl fordert ein solcher Titel zur Präzisierung heraus. Denn wenn in diesem Evangelium, das schon in den ersten beiden Versen gleich dreimal das Wort Gott verwendet und auch im weiteren Verlauf weit häufiger auf Gott rekurriert als die anderen Evangelien, wenn also im vierten Evangelium etwas vom ersten Satz an klargestellt wird, dann ist es dies, dass Gott schon $\dot{\varepsilon} v \grave{a} \rho \chi \tilde{n}$, d. h. vom Ur-Anfang an nie „allein“ war. Das zeigt sich schon daran, dass das Evangelium im Gegensatz zum Prätext Gen 1,1, auf den es sich bezieht, nicht mit Gott als Subjekt beginnt, sondern mit dem Logos. Und das bestimmt alles Folgende: Wenn Gott in diesem Evangelium deutlicher als in allen anderen Schriften als Vater verstanden wird, dann deshalb, weil er niemals eine für sich seiende Monade war, sondern immer schon von seiner Beziehung auf ein Gegenüber her gedacht wird - auf den Logos und dann im Evangelium auf dessen Inkarnation in Jesus Christus, den „Sohn“, und durch diesen auf die Christgläubigen, seine „Kinder“. ${ }^{2}$

Das ist alt bekannt und muss doch immer wieder betont werden. Bei einer Pfarrkonferenz wurde ich vor einiger Zeit gefragt, ob wir im inter-

\footnotetext{
${ }^{1}$ Der folgende Beitrag nimmt Gedanken auf, die ich in der gemeinsamen Veröffentlichung mit Hermann Spieckermann (Reinhard Feldmeier/Hermann Spieckermann, Der Gott der Lebendigen. Eine biblische Gotteslehre [TOBITH 1], Tübingen ${ }^{2} 2017$ ) entfaltet habe und die wir derzeit in einer zweiten gemeinsamen Veröffentlichung unter dem Titel „Menschwerdung" (Reinhard Feldmeier/Hermann Spiekermann, Menschwerdung [TOBITH 2], Tübingen 2018) noch weiter ausführen.

${ }^{2}$ Vgl. Barretts Grundsatzurteil: „John directs our attention to God; but he does so by writing a gospel [...] for John, Jesus stands in the centre of his understanding of God." Charles K. BARRETT, Christocentric or Theocentric? Observations on the Theological Method of the Fourth Gospel, in: DERs., Essays on John, Philadelphia 1982, 1-18: 3.
} 
religiösen Dialog uns die Sache nicht einfacher machen könnten, wenn wir in der Christologie das „eines Wesens mit dem Vater" beiseiteließen und zugäben, dass, so wie Mose bei den Juden und Mohammed bei den Muslimen, auch bei uns Christen Jesus derjenige ist, der Gott verkündigt hat. Der Frager verwies sogar ausdrücklich auf Joh 14,28: „Der Vater ist größer als ich." Damit formulierte er nur eine heute auch bei Theologen weit verbreitete Ansicht, nach der die Mitglieder der sog. abrahamitischen Religionen alle an den einen Gott glauben, der dann in der Geschichte durch menschliche Mittler offenbart wurde. Welche besondere Rolle man dabei Jesus im Konzert der anderen „Religionsstifter" zuschreibt, mag variieren; entscheidend ist, dass er der göttlichen Aseität als Offenbarer zugeordnet wird, analog dem muslimischen Bekenntnis: „Es gibt keinen Gott außer Allah und Mohammed ist sein Prophet." Doch eben das ist nicht die Art und Weise, wie das Neue Testament, und hier im Besonderen das Johannesevangelium, Gott vom Christusereignis her versteht.

Dies soll hier in Auseinandersetzung mit der Kategorie des Mittlers deutlich gemacht werden. In die christlichen Dogmatiken wurde der mediator von der lateinischen Theologie des Mittelalters eingeführt, ${ }^{3}$ im reformatorischen Bereich wurde er erstmals von Calvin rezipiert. ${ }^{4}$ Das geschieht bis heute und zwar konfessionsübergreifend - und das bleibt nicht auf die Dogmatik beschränkt. Soweit man in der Exegese überhaupt die Frage nach dem Verhältnis von Monotheismus und Christologie diskutiert, löst man die Spannungen auch dort gerne mit Hilfe der Kategorie des Mittlers und einer damit verbundenen Subordination Christi.

Demgegenüber ist zunächst einmal auf den exegetischen Tatbestand hinzuweisen, dass die meisten biblischen Zeugnisse nicht von Christus als Mittler sprechen (und wo es dennoch geschieht, wie etwa im Hebräerbrief, da werden die problematischen Konsequenzen schnell sichtbar). ${ }^{5}$ Denn die Rede vom Mittler ist zumindest missverständlich und birgt die Gefahr, den soteriologischen Mehrwert preiszugeben, welchen die biblische Rede von Gott als Vater hat und den die Alte Kirche mit ihren oft so schwer nachvollziehbaren Streitigkeiten um die Trinität zu bewahren gesucht hat. Hier soll deshalb zunächst an Paulus gezeigt werden, warum der erste Theologe des Frühen Christentums den Begriff des Mittlers nur pejorativ gebraucht, um dann ausführlicher an Johannes zu erläutern,

\footnotetext{
${ }^{3}$ Vgl. Wolfhart Pannenberg, Systematische Theologie 2, Göttingen 1991, $490 \mathrm{f}$.

${ }^{4}$ Vgl. Johannes Calvin, Unterricht in der christlichen Religion/Institutio Christianae religionis. Nach der letzten Ausgabe übersetzt und bearbeitet von Otto Weber, NeukirchenVluyn ${ }^{5} 1988$, II, $12,1 \mathrm{ff}$.

${ }^{5}$ Vgl. dazu die Ausführungen in Feldmeier/Spieckermann, Gott (Anm. 1) 325-328.
} 
warum dieser den Begriff ganz meidet, was an dessen Stelle tritt und welche Konsequenzen daraus für die johanneische Rede von Gott zu ziehen sind.

\section{Der christologische Monotheismus des Paulus}

Bekanntlich besteht für Paulus nicht der geringste Zweifel daran, dass Gott einer ist. So sagt er in 1 Kor 8,4, wohl unter Anspielung auf Dtn 6,4 in Verbindung mit Dtn 4,35, dass es keinen Gott gibt außer dem Einen. Nur zwei Verse weiter spaltet er dann in 1 Kor 8,6 das Bekenntnis zu dem einen Gott, das Šěmac, christologisch auf, indem er den Vater den einen Gott nennt, aus dem alles kommt und auf den hin wir existieren, und dem er dann Christus als den einen Kyrios parallelisiert, durch den alles existiert und wir durch ihn. Die Frage, wie hier und anderswo bei Paulus der biblische Monotheismus und das frühchristliche Bekenntnis zu Christus als dem Kyrios zusammengehen, beantwortet Udo Schnelle damit, dass er die "Unterordnung Christi“ betont und konstatiert, dass sich "deutlich ein subordinatianischer Zug in der paulinischen Christologie $^{\text {" }}$ zeige $^{6}$. Schnelle weist entsprechend Christus die Rolle eines Mittlers zwischen dem einen Gott und den Menschen zu. ${ }^{7}$

Für eine solche Deutung scheint es auf den ersten Blick gute Gründe zu geben. Der Apostel kann den Gehorsam Christi hervorheben, am deutlichsten in Phil 2,8, und entsprechend an verschiedenen Stellen die Überordnung Gottes betonen. So sagt er in 1 Kor 11,3, dass, so wie der Mann das Haupt der Frau und Christus das Haupt des Mannes ist, so Gott das Haupt Christi ist. Nach 1 Kor 15,23-28 besteht sogar das Ziel der gesamten (Heils-)Geschichte darin, dass sich Christus nach der Unterwerfung aller Mächte zuletzt selbst dem Vater unterordnet (1 Kor 15,28).

Dennoch spricht gegen die daraus scheinbar selbstverständlich folgende Deutung Christi als Mittler schon die Beobachtung, dass der Apostel diesen Begriff für Christus nicht verwendet, sondern ihn nur zweimal in einem deutlich abwertenden Sinn für Mose gebraucht und in diesem Zusammenhang ausdrücklich die Vorstellung zurückweist, dass es für Gott, eben weil er einer ist (Gal 3,19f.), einen Mittler geben könne. ${ }^{8}$

\footnotetext{
${ }^{6}$ Udo Schnelle, Paulus. Leben und Denken, Berlin u. a. ${ }^{2} 2014,426$.

${ }^{7}$ Vgl. ebd., 427-429.

${ }^{8}$ Während es in den philosophischen Konzepten gerade das absolute Eins-Sein des Göttlichen ist, das der Vermittlung in die Vielheit bedarf, ist für Paulus ein Mittler nur dort
} 
Das ist eine bemerkenswerte Begründung, denn in den Mittlerkonzepten, wie sie bereits in Platons Symposion angedacht sind und dann besonders im Mittel- und Neuplatonismus weiterentwickelt werden, steht die Frage im Mittelpunkt, wie das absolute Göttliche, das ,jenseits des Seienden“ seinen Ort hat, ${ }^{9}$ als das mit sich selbst identische Eine mit der vielgestaltigen Wirklichkeit überhaupt in Kontakt treten kann. Dazu bedarf es der daimones, die als halbgöttliche Mischwesen „dazwischen“ ( $\mu \varepsilon \tau a \xi \dot{\text { ) }}$ existieren und so an beiden Sphären Anteil haben. ${ }^{10}$ Xenokrates, Platons Schüler und sein Nachfolger als Leiter der Akademie, hat daraus eine ganze Dämonologie entwickelt, die in neutestamentlicher Zeit vor allem im Mittleren Platonismus weit verbreitet war: Aus dem ersten und zweiten Jahrhundert n. Chr. sind uns noch vier Schriften über das Daimonion des Sokrates erhalten, die belegen, wie prominent die Vorstellung von Mittlerwesen in neutestamentlicher Zeit war, ${ }^{11}$ und zwar sowohl im paganen Bereich wie im zeitgenössischen Judentum. ${ }^{12}$

Es ist in der antiken Metaphysik also gerade die als Selbstidentität verstandene Einheit des Göttlichen, welche nach einem Mittler verlangt. So aber denkt der Apostel nicht. Seine Theologie nimmt ihren Ausgangspunkt nicht bei der göttlichen Transzendenz, die der Vermittlung in die Immanenz bedarf, sondern bei dem Gott, der „in Christus war" (2 Kor 5,19) und sich dort als „Gott für uns“ (Röm 8,31), also als der heilvoll dieser Welt Zugewandte, erwiesen hat. Insofern ist die zunächst so plausibel erscheinende Entschärfung des Monotheismusproblems mit Hilfe der Vorstellung eines Mittlers problematisch, weil sie Gott nicht

von Nöten, wo es eine Vielfalt zu vermitteln gilt, während der eine Gott sich unmittelbar in Verbindung setzt (vgl. Franz Mussner, Der Galaterbrief [HTKNT 9], Freiburg u. a. ${ }^{5} 1988$, 248).

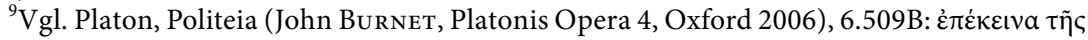
oủoíac.

${ }^{10}$ Vgl. Ders., Symposion (John Burnet, Platonis Opera 2, Oxford 2006), 202d-203a.

${ }^{11}$ Vgl. Pierluigi Donini, Sokrates und sein Dämon im Platonismus des 1. und 2. Jahrhunderts n. Chr., in: Heinz-Günther Nesselrath/Ulrich Berner/Reinhard Feldmeier/Bernhard Heininger/Rainer Hirsch-Luipold (Hg.), Apuleius, De Deo Socratis/Über den Gott des Sokrates (SAPERE 7), Darmstadt 2004, 142-161. In der Schrift des Apuleius werden diese Vorstellungen systematisiert.

${ }^{12}$ Philo siedelt den göttlichen Logos als Mittler zwischen Gott und Abraham klar unterhalb des einen „unnennbaren und unsagbaren Gottes“ an; vgl. Philo von Alexandrien, De Somniis (Philonis Alexandrini opera quae supersunt. Editerunt Leopoldus Cohn et Paulus Wendland 3, Berlin 1898), 1,65f. In De Somniis 1,142f. bezieht er den Terminus $\mu \varepsilon \sigma i \tau \eta \varsigma$ dann auch auf Engel als „vermittelnde Logoi“. In vergleichbarer Weise fungiert im TDan (Jürgen Becker, Die Testamente der zwölf Patriarchen [JSHRZ 3,1], Gütersloh 1974), 6,2 ein fürbittender Engel als „Mittler zwischen Gott und den Menschen“; vgl. dazu Reinhard Feldmeier, Mediator II $\mu \varepsilon \sigma i \tau \eta \varsigma$, in: DDD $\left({ }^{2} 1999\right)$ 557-560: $558 \mathrm{f}$. 
vom Ereignis seiner Zuwendung her versteht, sondern vom Gegensatz zwischen Gott und Mensch ausgeht und Christus in ein Seins- und Machtgefälle zwischen dem höchsten Gott und seinen Geschöpfen einordnet.

Blickt man dermaßen sensibilisiert noch einmal genauer auf Paulus, so sieht man, dass er das Verhältnis Gott - Christus nicht einlinig hierarchisch bestimmt, sondern dass es neben den Stellen, an denen Paulus vom Gehorsam des Sohnes und dessen Unterordnung spricht, auch solche gibt, welche dessen Erhöhung durch den Vater betonen. So installiert Gott nach dem Philipperhymnus (Phil 2,6-11) Jesus nicht als ein Zwischenwesen unter sich. Vielmehr überträgt er demjenigen, der sich seiner Göttlichkeit entäußert und sich gehorsam bis zum Tod am Kreuz erniedrigt hat, seinen eigenen "Namen über jedem Namen“ und stattet ihn dadurch mit all der Macht und Hoheit aus, die ihm selbst eigen sind, so dass sich nun im Himmel und auf der Erde und unter der Erde jedes Knie vor ihm beugt, eine Anspielung auf Jes 45,23 LXX, wo dieser Prätext auf Gott selbst bezogen ist und dessen Einzigartigkeit zum Ausdruck bringt. ${ }^{13}$ Um die Ungeheuerlichkeit dieser Erhöhung herauszustellen, dehnt der Apostel die Sprache aufs Äußerste: Der Gott, der selbst in der Bibel immer wieder der Höchste genannt wird, macht den Gekreuzigten zum „Aller-

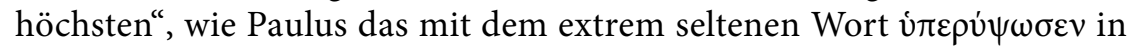
Phil 2,9 sagt. ${ }^{14}$ Gerade darin erweist er seine Herrlichkeit als Vater, wie der Schlusssatz des Hymnus unterstreicht, dass er nicht auf der eigenen Hoheit insistiert, sondern den anderen erhöht. Nebenbei bemerkt: Für

\footnotetext{
${ }^{13}$ So richtig auch Torsten JANTSCH (DERS., „Gott alles in allem“ [1 Kor 15,28]. Studien zum Gottesverständnis des Paulus im 1. Thessalonicherbrief und in der korinthischen Korrespondenz [WMANT 129], Neukirchen-Vluyn 2011, 289), wobei seine Aussage, dass man im Kontext einer entwickelten Trinitätslehre dann doch von Subordination sprechen könne, nicht nachvollziehbar ist.

${ }^{14}$ Die Folgen zeigen sich etwa darin, dass Paulus zentrale Aussagen über Gott und Christus parallelisiert, ja identifiziert: Die Gnade, die Rettung, die Liebe, die Macht, das Gericht, das Evangelium, das Apostolat, der Glaube und anderes werden von ihm gleichermaßen und oft mit gleichen Wendungen sowohl auf Gottvater wie auf Christus zurückgeführt, ohne dass ein signifikanter Unterschied erkennbar würde, etwa dergestalt, dass Christus hierbei nur die vermittelnde Instanz wäre; vgl. die entsprechenden Ausführungen bei Ulrich Mauser, Gottesbild und Menschwerdung. Eine Untersuchung zur Einheit des Alten und Neuen Testaments (BHT 43), Tübingen 1971, 121-145. Deshalb sagt man auch zu wenig, wenn man die Würdestellung Christi nur auf die „Repräsentanz und Offenbarung Gottes der Welt gegenüber" (so Wolfgang Schrage, Unterwegs zur Einheit und Einzigkeit Gottes. Zum „Monotheismus" des Paulus und seiner alttestamentlich-frühjüdischen Tradition [BThSt 48], Neukirchen-Vluyn 2002, 144) beschränkt: Als der „eine Herr“ (1 Kor 8,6) ist Christus viel mehr als nur Repräsentant des einen Gottes, sondern - mythologisch gesprochen - sein Throngenosse, Mitinhaber seiner Macht und Herrlichkeit.
} 
dieses kommunikative Verständnis der göttlichen Macht verwendet der

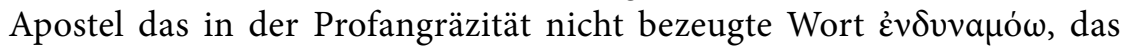
über die amerikanische Gemeindetheologie als empowerment zum Modewort moderner Managementkonzepte geworden ist (Phil 4,13). ${ }^{15}$

An diesem Beispiel wird deutlich: Weil Gott sich in Christus als Vater erweist, sind seine Eigenschaften kommunikative Eigenschaften. Das bestätigt etwa die in verschiedenen Zusammenhängen wiederkehrende Argumentationsfigur des beatum commercium, ${ }^{16}$ des seligmachenden Wechsels. Auch die Argumentation gegen den Mittler in Gal 3,19f. verstehe ich so, dass Gottes Einheit zu seinen kommunikativen Eigenschaften gehört, was der Apostel v. a. in 1 Kor 12,4-31 ausführt und ein Schüler von ihm dann im Epheserbrief noch weiter expliziert. Die Gerechtigkeit Gottes, die nach Röm 3,26 sich darin erweist, dass er die Christgläubigen gerecht macht, gipfelt für den Apostel darin, dass diese von Gott zu „Söhnen“ bzw. „Kindern Gottes“ adoptiert werden und ihn mit Jesu

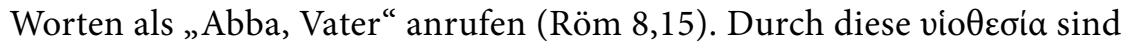
die bisherigen „Sklaven“ nun zu „Miterben Christi“ und „Gottes Erben“ geworden (Röm 8,17, vgl. Gal 4,7). So mündet denn die Entfaltung der Rechtfertigung im Lobpreis des Gottes, der uns mit seinem Sohn alles schenkt und so als "Gott für uns" seine alles überwindende Liebe erweist (Röm 8,31-39). In vergleichbarer Weise nimmt Paulus in Phil 3,20f. noch einmal auf den Christushymnus Bezug und macht deutlich, dass die soteriologische Pointe der Erhöhung Christi darin besteht, dass dieser auch den "Leib unserer Niedrigkeit“ in den "Leib seiner Herrlichkeit“ verwandeln wird.

Das sind nur zwei Beispiele dafür, wie die Verbundenheit mit Christus das paulinische Verständnis Gottes zutiefst bestimmt. Das sei noch an einem letzten Punkt verdeutlicht. Der Apostel kennt die Prädikate, mit denen man in der antiken Metaphysik und z. T. auch im Alten Testament die göttliche Einzigartigkeit im Gegensatz zur Welt auf den Begriff brachte: ewig, unvergänglich, unsterblich, heilig, gerecht etc. Aber diese Adjektive fungieren bei ihm zumeist nicht mehr als exklusive Gottesprädikate, son-

\footnotetext{
${ }^{15}$ Vgl. Norbert Herriger, Empowerment in der sozialen Arbeit. Eine Einführung, Stuttgart ${ }^{3}$ 2006; Andreas KNUF, Empowerment in der psychiatrischen Arbeit, Bonn ${ }^{5} 2011$.

${ }_{16}$ „Erkennt nämlich die Gnade unseres Herrn Jesus Christus, dass er - obgleich er reich war - um euretwillen arm geworden ist, damit ihr durch seine Armut reich würdet" (2 Kor 8,9). „Christus hat uns vom Fluch des Gesetzes losgekauft, indem er um unsertwillen zum Fluch wurde“ $(\mathrm{Gal} 3,13)$. „[Jesus Christus] ist für uns gestorben, damit wir - ob wir nun wachen oder schlafen - zugleich mit ihm leben“" (1 Thess 5,10). Paulus kann dies auch von Gottes Handeln her formulieren: „, [Gott] hat den, der Sünde nicht kannte, für uns zur Sünde gemacht, damit wir in ihm Gerechtigkeit Gottes würden“" (2 Kor 5,21).
} 
dern sind zu inklusiven soteriologischen Prädikaten geworden, welche das neue Sein der Glaubenden in Gegenwart und Zukunft beschreiben. Im Blick auf Gott verwendet Paulus dagegen vor allem Verbformen; ein paar Adjektive stehen bei ihm mehr als sechzig Partizipien gegenüber. Das ist theologisch aufschlussreich. Während Adjektive das göttliche Sein durch Qualitäten definieren, bezeugen Partizipien dieses als Wirkmacht: Als der berufende, der rechtfertigende, der ermächtigende, der auferweckende, der lebendig machende, der heiligende Gott ist er der schöpferische Grund der Verwandlung der "Gotteskinder". So wird er zu ihrem Vater.

\section{Der eine Gott und sein Mittler bei Johannes?}

Auch im Johannesevangelium bleiben Vater und Sohn strikt voneinander unterschieden. Der Vater ist der Sendende, der Sohn der Gesandte. ${ }^{17}$ Der Sohn spricht und handelt nicht aus sich selbst, ${ }^{18}$ sondern sagt, was der Vater ihm gesagt hat (Joh 12,50;15,15) und tut, was er den Vater tun sah (Joh 5,19). Er lebt durch den Vater (Joh 6,57), er erkennt den Vater und ist von ihm erkannt (Joh 10,15). Er ist vom Vater belehrt (Joh 8,28) und sagt, was er vom Vater gesehen hat (Joh 8,38). Immer wieder betont der johanneische Jesus auch, dass er nicht seinen Willen tut, sondern den des Vaters, um dessen Werk zu vollenden. ${ }^{19}$ Der Vater hat das Leben in sich und verleiht solches dem Sohn (Joh 5,26); deshalb besteht ewiges Leben in der Erkenntnis, dass Christus vom Vater gesandt ist (Joh 17,8.25). So kann der Menschgewordene auch sagen, dass der Vater, der größer ist als alles (Joh 10,29), auch größer ist als er (Joh 14,28).

Man hat auch hier versucht, die johanneischen Aussagen mit Hilfe des Mittlerbegriffs zu systematisieren. Das tut etwa Stefan Schreiber, der dabei nicht nur auf einem "Gefälle von Gott zu Jesus" besteht, sondern sich auch gegen den Begriff der Menschwerdung Gottes verwahrt. ${ }^{20}$ Schreiber interpretiert also die Unterscheidung von Gott und göttlichem Logos im Prolog bzw. von Vater und Sohn im Evangelium als ein Machtgefälle zwischen dem einen Gott und seinem Mittler. So einleuchtend das zunächst scheint, so sehr widerspricht es bei genauerem Zusehen dem Verhältnis

\footnotetext{
${ }^{17}$ Vgl. Joh 5,36f.; 6,44.57; 8,16.18; 10,36; 12,49.

${ }^{18}$ Vgl. Joh 5,30; 7,17.28; 8,38.42; 12,49; 14,10 .

${ }^{19}$ Vgl. Joh 4,34; 5,17.30.36; 6,38-40; 9,4; 10,37f.; 14,10.12; 15,24; 17,4 .

${ }^{20}$ Vgl. Stefan Schreiber, Die Anfänge der Christologie. Deutungen Jesu im Neuen Testament, Neukirchen-Vluyn 2015, 196-201.
} 
von Vater und Sohn und dann auch dem zwischen dem Sohn und den Gläubigen, wie es im Johannesevangelium bestimmt wird.

Schon der Logos im Prolog ist, um Michael Theobald zu zitieren, kein „Zwischenwesen“, sondern Gottes „Selbst-Ausdruck“, ${ }^{21}$ und ebenso kommt der „Einziggeborene vom Vater" nicht erst nachträglich zu Gott hinzu. Als „incarnation of God's self-expression “ ${ }^{22}$ kommt der Sohn vielmehr "aus dem innersten Herzen“ des Vaters und macht so erst „jene radikale Anteilnahme Gottes an der Welt denkbar, für die Jesus steht“ ${ }^{23}$ Das Evangelium bringt das zum Ausdruck, wenn es die Logos-Christologie des Prologs sofort durch eine Gottessohn-Christologie ergänzt (vgl. Joh 1,34.49) und im weiteren Verlauf die damit ausgedrückte gegenseitige Verbundenheit von Gott und Jesus als reziproke Immanenz beschreibt:

In mir der Vater

wie ich im Vater.

(Joh 10,38, vgl. 14,10f.; 17,21)

Daher kann das Evangelium das Verhältnis von Vater und Sohn, bei dem der eine im anderen gegenwärtig wird und beide so als „Vater“ und „Sohn“ erst durch die Beziehung zum anderen ganz sie selbst werden, nicht mit Kategorien der Über- und Unterordnung beschreiben. Dominanz ist nicht in der Liebe, sondern die vollkommene Liebe treibt die Unterordnung aus, um es in johanneischer Diktion (1 Joh 4,18) zu sagen. Die strikte Unterscheidung von Vater und Sohn hat bei Johannes ihre Pointe nicht in der Trennung von dem einen Gott und seinem Mittler, sondern in der Begegnung von Vater und Sohn, sie zielt nicht auf ein Untereinander, sondern auf ein Ineinander. Insofern ist es auch zumindest missverständlich, wenn von Bendemann konstatiert: „Der ,Vater ' bleibt im vierten Evangelium im Vergleich zum ,Sohn' der semper maior/immer Größere (vgl. Joh 10,29). “ ${ }^{24}$ Wie bei Paulus erweist sich auch bei Johannes die Größe des Vaters darin, dass er den Sohn erhöht und gerade so nicht auf seiner Überlegenheit besteht. ${ }^{25}$ Deshalb kann der johanneische Jesus

\footnotetext{
${ }^{21}$ Michael Tнеовацd, Die Fleischwerdung des Logos. Studien zum Verhältnis des Johannesprologs zum Corpus des Evangeliums und zu 1 Joh (NTAbh 20), Münster 1988, $491 \mathrm{f}$.

${ }^{22}$ James D. G. Dunn, Christology in the Making. A New Testament Inquiry into the Origins of the Doctrine of the Incarnation, Grand Rapids ${ }^{2} 1996,265$.

${ }^{23}$ Thomas SöDing, Der Gottessohn aus Nazareth. Das Menschsein Jesu im Neuen Testament, Freiburg 2006, 332.

${ }^{24}$ Reinhard von Bendemann, Die Fülle der Gnade - Neutestamentliche Christologie, in: Jens Schröter (Hg.), Jesus Christus (ThTh 9), 71-118: 105.

${ }^{25}$ Der Evangelist lässt Jesus diese Erhöhung durchweg im passivum divinum ausdrücken, weil er sie mit der realen „Erhöhung“ bei der Kreuzigung zusammendenkt (bes. Joh 3,14; vgl. weiter Joh 8,28; 12,32.34).
} 
auch unmittelbar an die Aussagen von Joh 10,29, dass der Vater größer ist als alles, die scheinbar konträre Aussage anhängen:

Ich und der Vater sind eins.

(Joh 10,30, vgl. 8,19; 14,9)

Und deshalb kann auch am Ende des ursprünglichen Evangeliums das Bekenntnis des ungläubigen Thomas stehen, welches dem Auferstandenen nun die beiden Bezeichnungen zuschreibt, welche im Šĕma ${ }^{c}$ allein dem einzigen Gott Israels zukommen (Joh 20,28), ohne dass dies zu Gottes Größe und Einzigkeit in Widerspruch stünde. Statt zu versuchen, das Verhältnis von Vater und Sohn durch ein statisches oben und unten oder größer und kleiner festzuschreiben, gilt es vielmehr, die Dynamik der johanneischen Rede von Gott zu beachten, welche vor allem in den Abschiedsreden zum Ausdruck kommt, wenn diese die Verbundenheit von Vater und Sohn in immer neuen Wendungen als ein Geflecht gegenseitiger Liebe beschreiben, in das auch diejenigen eingebunden werden, die zu Jesus gehören: ${ }^{26}$ So korrespondiert der Liebe Gottes zum Sohn ${ }^{27}$ dessen Liebe zum Vater, ${ }^{28}$ und beider Liebe zu den Jüngern ${ }^{29}$ entspricht die Liebe der Jünger zu Jesus, ${ }^{30}$ auf die der Vater seinerseits mit Liebe antwortet. ${ }^{31}$ Konsequenterweise wird das Ineinander der Liebe, die das Verhältnis von Vater und Sohn bestimmende reziproke Immanenz, von Jesus auch auf sein Verhältnis zu den Glaubenden übertragen:

Ich in meinem Vater

und Ihr in mir

und ich in Euch.

(Joh 14,20)

Ihren vollkommenen Ausdruck findet diese Liebe in der völligen Selbsthingabe Jesu, also in seiner Passion. In ihr gibt der Sohn sein Leben für die Seinen (Joh 10,11.14f.; 15,13) und wird deshalb vom Vater geliebt (Joh 10,17). Und auch die Liebe des Vaters zum Kosmos zeigt sich in der Preisgabe des Sohnes (Joh 3,16). Das wird vom ersten Johannesbrief aufgegriffen und in letzter Konsequenz in dem Satz gefasst:

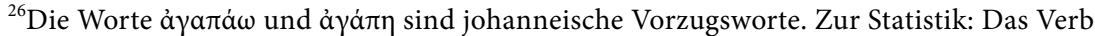
findet sich bei Mk fünfmal, bei Mt achtmal, bei Lk 13-mal, bei Joh 37-mal und im 1 Joh 28-mal. Noch deutlicher ist der Befund beim Substantiv: bei Mk gar nicht, Mt und Lk je einmal, bei Joh siebenmal, im 1 Joh 18 Mal.

${ }^{27}$ Joh 15,$9 ; 16,27 ; 17,23-26$.

${ }^{28}$ Joh 14,31; vgl. 17,2 ff.

${ }^{29}$ Gott: Joh 14,21-23; 16,27; 17,23; Jesus: Joh 14,15.21.23f.28; 16,27.

${ }^{30}$ Joh $14,15.21 .23 ; 16,27$; vgl. Joh 15,$10 ; 17,26$.

${ }^{31}$ Joh 14,21.23; 16,27.
} 
Gott ist Liebe.

(1 Joh 4,8)

Nota bene: Dieser Satz ist Auslegung der Passionsgeschichte, d. h. er ist nicht umkehrbar in dem Sinn, dass das Phänomen der Liebe divinisiert würde. Nicht die Liebe ist Gott, sondern Gott ist Liebe, insofern er in der Sendung des Sohnes als „Sühnung für unsere Sünden“ sich von sich aus der Welt zugewandt (Joh 3,16f.; 1 Joh 4,8-10) und durch „den Sohn als Retter des Kosmos" (1 Joh 4,14) eine von Finsternis beherrschte Welt erst der Liebe wert gemacht hat. Gott ist Liebe somit als die schöpferische Macht der Verwandlung, deren Radikalität auch der erste Johannesbrief als eine Geburt aus Gott beschreibt, durch welche die Sünder zu Kindern Gottes werden und Anteil an seinem ewigen Leben erhalten. ${ }^{32}$ Anders als menschliche Liebe entzündet sich die in der Passion sich erweisende Liebe Gottes nicht am Liebenswerten, sondern sie macht durch ihre $\mathrm{Zu}$ wendung ihr Gegenüber erst liebenswert, wie das Martin Luther auf den Begriff gebracht hat: „Amor Dei non invenit sed creat suum diligibile, Amor hominis fit a suo diligibili. "33

Das Evangelium beschreibt dies als eine stufenweise Verwandlung: ${ }^{34}$ In den Abschiedsreden werden die Jünger zunächst aufgrund der Lebenshingabe Jesu aus „Sklaven“ zu Jesu „Freunden“ (Joh 15,13-15), und das steigert sich nochmals nach Ostern, wenn sie der Auferstandene seine "Geschwister" nennt - mit der Folge, dass er nun auch zum ersten Mal Gott als ihren Vater bezeichnet (Joh 20,17). ${ }^{35}$ Man kann das Evangelium

\footnotetext{
${ }^{32}$ Vgl. 1 Joh 5,1-18; zur Gotteskindschaft im 1. Johannesbrief vgl. weiter 1 Joh 3,1.2.10.

${ }^{33}$ Martin Luther, 28. These der Heidelberger Disputation, WA, 1,354,35f.

${ }^{34}$ Vgl. R. Alan Culpepper, The Prologue as Theological Prolegomenon to the Gospel of John, in: Jan G. van der Watt/R. Alan Culpepper/Udo Schnelle (Hg.), The Prologue of the Gospel of John. Its Literary, Theological, and Philosophical Contexts. Papers read at the Colloquium Iohanneum 2013 (WUNT 359), Tübingen 2016, 3-26: 25: „The transformation of persons is a dynamic and continuing process as they become children of God."

${ }^{35}$ So beginnt nach Ostern, mit Jesu Aufstieg zum Vater „eine neue ,Epoche` im Verhältnis zwischen den Jüngern und Gott als Vater und Jesus als ihrem Bruder." Frances BACK, Gott als Vater der Jünger im Johannesevangelium (WUNT 2,336), Tübingen 2012, 198. Der Sinn der Lebenshingabe Jesu wird in Joh 11,52 dahingehend bestimmt, „die zerstreuten Kinder Gottes zusammenzubringen“. Aus diesem Wort geht nicht eindeutig hervor, ob es diese „zerstreuten Kinder Gottes“ schon zu Jesu Lebzeiten gibt. Der oben dargestellte Zusammenhang des Evangeliums spricht eher dagegen. Schon in Joh 1,12 heißt es, dass diejenigen, die an „seinen Namen glauben“, Gottes Kinder werden, was m. E. deutlich auf die Zeit nach Ostern verweist. Entsprechend wird der Anspruch der Juden, schon Gottes Kinder zu sein, in Joh 8,41f. zurückgewiesen. Dazu passt weiter, dass nach den Abschiedsreden der Geist des Vaters erst nach dem Weggang Jesu zu den Jüngern spricht (Joh 16,12-15), so dass diese dann selbst im Namen Jesu zum Vater beten können (Joh 16,23b.24). Der Geist aber ist nach Joh 3,6-8 die Bedingung für die Geburt von oben.
} 
geradezu als die Geschichte beschreiben, in welcher der Vater Jesu zum Vater der Jünger wird und damit am Ende die Verheißung des Anfangs (Joh 1,12) in Erfüllung geht, dass der menschgewordene Logos denen, die an seinen Namen glauben, die Vollmacht gibt, Gottes Kinder zu werden. In einem von solcher Liebe bestimmten Beziehungsraum ist auch unter den Jüngern jedes Status- und Machtgefälle überwunden, wie Jesus selbst als Kyrios seinen Jüngern bei der Fußwaschung in Joh 13,1-17 anschaulich demonstriert. ${ }^{36}$

Diese Gotteskindschaft greift der erste Johannesbrief auf und führt sie weiter aus. Hat das Evangelium die Liebe primär als das Mit- und Ineinander von Vater und Sohn umschrieben und die Glaubenden in dieses Verhältnis eingebunden, so zielt im ersten Johannesbrief die Verbindung, ja Identifizierung von Gott und Liebe von vornherein auf die Glaubenden (1 Joh 4,9-13) - auf ihr Verhältnis zu Gott und auf ihr Verhältnis untereinander.

\section{Der Vater}

Bezeichnenderweise wird Gott im Johannesevangelium zum ersten Mal bei der Menschwerdung "Vater" genannt (Joh 1,14). Danach kann das Evangelium zwar auch noch $\theta$ có testamentliche Schrift, in der das Appellativum $\theta \varepsilon$ ć quantitativ deutlich hinter der zum Namensäquivalent gewordenen Metapher „Vater“ zurücktritt. ${ }^{37}$ Im Gegenzug wird Christus nicht mehr Logos genannt, sondern er heißt im Evangelium der "Sohn“. Durch diesen doppelten Namenswechsel wird schon terminologisch deutlich gemacht, dass die Menschwerdung auch das Verständnis Gottes selbst tiefgreifend beeinflusst.

Um das recht $\mathrm{zu}$ verstehen, muss die christologische Bestimmtheit dieser Vaterschaft Gottes bedacht werden. Denn die Rede von einem göttlichen Vater ist in den antiken Religionen weit verbreitet und versteht in den jeweiligen Panthea (oder in allegorisierter Weise in den zeitgenössischen Philosophien) das Theologumenon primär von der Stellung eines obersten Gottes als Erzeuger der Götter (und Menschen) bzw. als

\footnotetext{
${ }^{36}$ Bezeichnenderweise spielt gerade in dieser Geschichte der Titel „Kyrios“ eine herausragende Rolle.

${ }^{37}$ Das Appellativum $\theta \varepsilon$ ć findet sich im vierten Evangelium mehr als doppelt so oft wie im ältesten Evangelium, die Rede vom Vater dagegen fast 30-mal so häufig (viermal bei Markus, 115-mal bei Johannes). Gerade letzteres unterstreicht, dass wir es im Johannesevangelium mit einem ausgesprochen christologischen Monotheismus zu tun haben.
} 


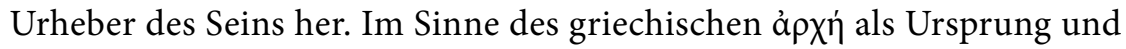
Herrschaft wird damit eine Vorrangstellung verbunden, vergleichbar auf der familiären Ebene dem pater familias als Familienoberhaupt und auf der politischen dem pater patriae als Staatsoberhaupt. Dagegen wird in der biblischen Literatur die Vaterschaft Gottes nicht als Urheberschaft bestimmt, sondern ist Ausdruck seines erwählenden Handelns. ${ }^{38}$ Der Vatername steht dementsprechend auch nicht (oder doch nicht primär) für Gottes Macht, sondern für seinen Beziehungswillen, johanneisch gesprochen: Für die Liebe, die mit der Menschwerdung geradezu zum Bestandteil des göttlichen Namens wird.

In der antiken Metaphysik ist Liebe Zeichen eines Mangels; wer eines anderen bedarf, der ist nicht vollkommen. Deshalb ist Eros bei Platon auch Sohn der Penia und somit nur ein daimon. Biblisch gesehen ist dagegen Liebe nicht ein Mangel an Sein, sondern dessen Steigerung. Gerade als der Liebende ist der himmlische Vater nach Mt 5,48 vollkommen, und 1 Joh 4,18f. schreibt das Prädikat der Vollkommenheit der Liebe zu, die in Gottes vorauslaufender Liebe gründet. In diesem Sinn unterstreichen auch die reziproken Immanenzaussagen bei Johannes, dass Gottes GottSein nicht in selbstbezogener Absolutheit besteht. Man muss in der Interpretation Gottes als Liebe nicht gleich so weit gehen wie Angelus Silesius in seinem Cherubinischen Wandersmann:

„Ich weiß, dass ohne mich

Gott nicht ein Nu kann leben;

Werd ich zunicht, er muß von Not den Geist aufgeben. “" ${ }^{39}$

Dass Gott ohne mich nicht existieren kann ist Häresie, weil damit Gott einer fremden Notwendigkeit unterworfen wird. Aber dieser zum katholischen Glauben konvertierte und zuletzt zum Priester geweihte Johannes Scheffler, dem wir die schönsten Kirchenlieder über die Liebe verdanken, hat doch etwas von dem begriffen, was gerade das Johannesevangelium prägt: Wie zu Gott schon im Uranfang der Logos gehörte, so ist auch der sich in Christus als Vater Offenbarende nicht er selbst ohne das von ihm geliebte Gegenüber, d. h. er will - wenn ich mich mit dieser Modifikation an den Cherubinischen Wandersmann anlehnen darf - nicht leben

\footnotetext{
${ }^{38}$ Das gilt auch schon für die wenigen Stellen, an denen das Alte Testament von Gott als Vater spricht und die bezeichnenderweise mit der Erwählung verbunden sind; vgl. FeLDmeier/Spieckermann, Gott (Anm. 1) 51-92.

${ }^{39}$ Angelus Silesius, Cherubinischer Wandersmann, in: Hans Ludwig Held (Hg.), Angelus Silesius. Sämtliche poetische Werke 3, München ${ }^{3} 1949,7-220: 8$.
} 
ohne seinen „einzig geborenen“ Sohn und mit ihm auch nicht ohne seine Kinder. Darauf beruht die christliche Hoffnung, und deshalb gibt man Entscheidendes preis, wenn man Jesus nur zum Gottesboten macht.

Um nicht missverstanden zu werden: Es geht hier nicht darum, den weit verbreiteten Gebrauch der Rede vom Mittler zu anathematisieren. Aber es soll doch ein Bewusstsein dafür geweckt werden, dass die Vorstellung eines Mittlers vom Gegensatz von Gott und Mensch her denkt, von der Überlegenheit Gottes und den Grenzen des Menschen. Der Mittler hat seinen Platz in einem Seins- und Machtgefälle. Demgegenüber versteht die Rede vom Vater, so wie sie in den neutestamentlichen Schriften bezeugt ist und für Johannes zentral wird, Gott von seiner Zuwendung im Sohn her - als den Liebenden. Das hat die Trinitätslehre mit den Mitteln ihrer Zeit zu verstehen gesucht, und wer meint, diese mit dem Hinweis auf eine unangemessene Ontologie abtun zu können, um stattdessen auf dem „Gefälle von Gott zu Jesus" zu bestehen, der muss sich fragen lassen, ob er in Wahrheit nicht selbst einer unbiblischen Ontologisierung aufsitzt, ${ }^{40}$ weil er das An-sich-Sein der Relation vor- und dadurch überordnet. In einem solchen Denken kann die Beziehung zu einem anderen immer nur ein Zweites sein und deshalb der Glaube an den einen Gott mit der Christologie nur im Sinne der Subordination eines „Vizekönig[s]“41 verbunden werden. Wie sehr dies an dem johanneischen Ineinander von Vater und Sohn vorbeigeht, wurde bereits gezeigt.

Hier sei zuletzt noch einmal auf den ersten Johannesbrief hingewiesen, der in dieser Hinsicht sogar noch weiter geht als das Evangelium. In der Explikation der Aussage, dass Gott Liebe ist, kann der erste Johannesbrief den Spitzensatz "Gott ist Liebe " in 4,16 noch einmal wiederholen und ihn dahingehend entfalten, dass er - als einzige Schrift im Neuen Testament nun auch das Verhältnis der Glaubenden zu Gott durch das im Evangelium noch ausschließlich für den „Sohn“ reservierte Ineinander von Gott und Mensch auf den Begriff bringt:

Gott ist Liebe,

und wer in der Liebe bleibt, bleibt in Gott, und Gott bleibt in ihm.

(1 Joh 4,16, vgl. 1 Joh 3,24; 4,13.15)

\footnotetext{
${ }^{40}$ Vgl. Schreiber, Anfänge (Anm. 20) 212: „Das JohEv denkt in den Kategorien der Beziehung (nicht ontologisch).“ Das ist richtig, aber Schreiber zieht daraus, wie gezeigt, nicht die richtigen Konsequenzen.

${ }^{41}$ Ebd., 103.
} 



\title{
Gottes rekreatorisches Handeln bei Paulus und Johannes I
}

\author{
Das „Lebendigmachen“ und das „aus Gott/ \\ von oben Gezeugtwerden"
}

Christiane Zimmermann

Frühchristliche Gottesvorstellungen entstammen fast ausschließlich der jüdischen Tradition und die Vorstellung, dass Gott die Welt und die Menschen erschaffen hat, bildet die Basis, den Beginn des Handelns Gottes am und für den Menschen. So ist es folgerichtig, dass die Christuserfahrung, die als fundamentale Neuäußerung Gottes gegenüber den Menschen verstanden wurde, ebenfalls in entsprechenden schöpferischen Bildern ausgedrückt wird. Dies gilt sowohl für die Auferstehungserfahrung als auch für die Erfahrung der Hinwendung zum Glauben an Gott als denjenigen, der den Menschen durch die Sendung des eigenen Sohnes heilvoll begegnet ist. Für dieses neuschöpferische Agieren Gottes begegnet in den paulinischen Briefen und im Johannesevangelium das Lexem „lebendig machen“; nur in den Texten der johanneischen Schule wird dafür sogar Zeugungs- bzw. Geburtsmetaphorik verwendet und vom „aus Gott Gezeugt/bzw. Geborenwerden“ oder vom „von neuem/von oben Gezeugt-/Geborenwerden“ gesprochen. ${ }^{1}$ Die beiden johanneischen Syn-

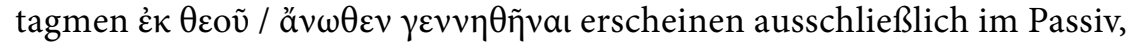

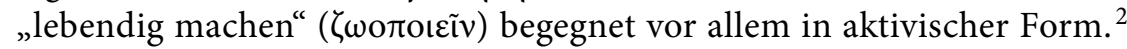
Die Aussage, dass Gott aktivisch „zeugt“ erscheint nicht. Zunächst ist zu klären, inwieweit die passivischen, auf die Glaubenden referierenden Verben auch für eine Bestimmung des paulinischen bzw. johanneischen

\footnotetext{
${ }^{1}$ Im Folgenden werden bei Substantivierung die Schreibweisen „Lebendigmachen“, „Lebendiggemachtwerden“" und ,aus Gott/von oben/von neuem Gezeugtwerden“ gewählt.

${ }^{2}$ Aktivisch: Joh 5,21; Röm 4,17; 8,11; der Geist als Subjekt: Joh 6,63; 1 Kor 15,45; 2 Kor 3,6; das Gesetz als Subjekt, dem die Fähigkeit lebendig zu machen abgesprochen wird: Gal 3,21. Passivisch: 1 Kor 15,22.36; 1 Petr 3,18.
} 
Gottesbildes in Anschlag gebracht werden können, bevor auf ihre rekreatorischen Konnotationen in den jeweiligen Kontexten einzugehen ist.

\section{Einleitende Überlegungen zur Relevanz der Diathesen}

In passivischer Form referieren die Verben „lebendig gemacht werden“ und „aus Gott/von oben/von neuem geboren/gezeugt werden“ im eigentlichen Sinne nicht auf das Handeln Gottes, sondern vielmehr auf das Erleiden einer Handlung durch den Menschen. Werden die Verben passivisch gebraucht, stehen zunächst die Subjekte als patientes, als die die Handlung „Erleidenden“ im Vordergrund, nicht aber Gott als Handelnder.

Neben aktivischen Verben, die Gott als eindeutiges Handlungssubjekt implizieren, erscheinen bereits in den frühjüdischen und dann auch in den frühchristlichen Texten immer wieder derartige Verben im Passiv, deren Agent nicht genannt wird und auch nicht im Fokus der Verbalaussage steht. Als Beispiele seien hier etwa genannt "gerechtfertigt werden“ (Röm 3,28; 6,7; Gal 2,16 u. ö.) oder „auferweckt werden“ (1 Kor 15,16.20.22 u. ö.). Subjekte dieser Verbalaussagen sind jeweils die Menschen. Wenn man aber darüber nachdenkt, wer als agens des Rechtfertigens oder des Auferweckens im Hintergrund der Handlung steht, kommt man häufiger, als man zunächst annimmt, auf Gott. Für derartige passivische Verbalformen hat sich seit Joachim Jeremias die Bezeichnung passiva divina eingebürgert. ${ }^{3}$ Joachim Jeremias verband die Beobachtung, dass Gott als Handelnder in diesen Verbformen sozusagen versteckt wird, mit der im Frühjudentum zu beobachtenden Tendenz der Apokryphisierung des Gottesnamens. Nach Jeremias knüpfte die Verwendung von passiva divina besonders an den apokalyptischen Stil an, der damit vor allem das endzeitliche Handeln Gottes im Blick habe. Gustav Dalman sah in diesen passivischen Formulierungen eine Stilisierung, die aus der Scheu, den göttlichen Namen auszusprechen, entstanden sei und verwies auf Parallelen im ägyptischen Hofstil. ${ }^{4}$ Christian Machholz führte diesen

\footnotetext{
${ }^{3}$ Joachim Jeremias, Neutestamentliche Theologie 1. Die Verkündigung Jesu, Gütersloh 1971, 20-24; vgl. auch bereits Joachim Jeremias, Die Abendmahlsworte Jesu, Göttingen 1960, 194-195.

${ }^{4}$ Gustaf Dalman, Die Worte Jesu 1. Einleitung und wichtige Begriffe, Leipzig ${ }^{2} 1930$, $183-185$ und 190.
} 
Gedanken in einem Aufsatz von 1990 fort und ersetzte die Bezeichnung passivum divinum entsprechend durch passivum regium. ${ }^{5}$

Deutliche Kritik an der Kategorie passivum divinum übte zur selben Zeit Marius Reiser, da das Passiv generell „ein passives Geschehen als solches ohne Berücksichtigung des Agens" im Blick habe. ${ }^{6}$ Der handelnde agens stünde nicht im Fokus der beschriebenen, erlittenen Handlung:

„Vielmehr muß auch bei einem Passiv, als dessen gedachter Agens Gott feststeht, wie bei allen Passiva jeweils neu aufgrund des Sinnzusammenhangs nach den Gründen für seine Wahl und nach seiner Funktion im Kontext gefragt werden. Dabei darf man trotz der Vielfalt der Passivfunktionen die Hauptfunktion des Passivs, ein Geschehen ausdrücklich als nicht agensbezogen zu charakterisieren, nie aus dem Blick verlieren. " 7

Entsprechende Gedanken haben Beniamin Pascut, Peter-Ben Smit und Toon Renssen vertieft. ${ }^{8}$

Dennoch ist ein radikaler Verzicht auf die Kategorie passivum divinum problematisch - gibt es doch passivische Formulierungen, die zwar den patiens, also in der Regel den Menschen, der eine Handlung erleidet, im Vordergrund sehen, die andererseits aber spezifisch theo-logisch denotieren. So kommen etwa beim Passiv „sie werden auferweckt werden“, als Agenten der Auferweckung nur Gott und Christus in Frage. Sie sind aufgrund der besonderen Qualität der Handlung stets impliziert und mit im Blick. Auch steht in einem Kontext, der viele Handlungen Gottes aktivisch beschreibt, Gott durchaus auch als agens einer passivischen Handlung im Hintergrund. ${ }^{9}$ Insofern sind die Texte, die die Metaphern des Lebendiggemachtwerdens und aus Gott bzw. von oben/von neuem Geborenwerdens im agentenlosen Passiv führen, trotz ihrer eigentlichen Referenz auf die Menschen als patientes in die Betrachtung des Gottesbildes miteinzubeziehen. Unterstützt wird diese Entscheidung im Falle der Geburtsmetaphorik zudem durch die Tatsache, dass der Verfasser des

\footnotetext{
${ }^{5}$ Christian Macholz, Das „Passivum divinum“, seine Anfänge im Alten Testament und der „Hofstil“, ZNW 81 (1990) 247-253: 252.

${ }^{6}$ Marius Reiser, Die Gerichtspredigt Jesu. Eine Untersuchung zur eschatologischen Verkündigung Jesu und ihrem frühjüdischen Hintergrund (NTAbh 23), Münster 1990, 255-261: 257.

${ }^{7}$ Reiser, Gerichtspredigt (Anm. 6) 259.

${ }^{8}$ Beniamin PAscut, The So-Called Passivum Divinum in Mark's Gospel, NovT 54 (2012) 313-334; Peter-Ben Smit/Toon Renssen, The passivum divinum. The Rise and Future Fall of an Imaginary Linguistic Phenomenon, FNT 27 (2014) 3-24.

${ }^{9}$ Vgl. hierzu etwa 1 Kor 7,17-24: Den passivischen, auf die Menschen bezogenen Formen

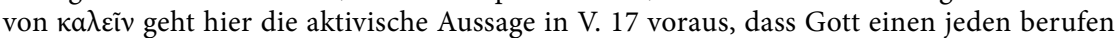

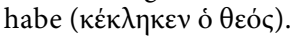


Johannesevangeliums vor allem vom „aus Gott“ bzw. „aus Geist“ oder „aus Wasser und Geist" Gezeugt-/Geborenwerden spricht und damit als Urheber des Gezeugt-/Geborenwerdens wiederholt Gott bzw. den Geist Gottes benennt.

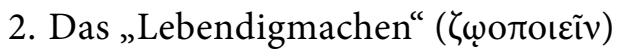

Die aus der jüdischen Tradition ${ }^{10}$ stammende Rede vom „Lebendigmachen“ Gottes findet sich im Unterschied zur Rede vom „aus Gott Gezeugt-/Geborenwerden" sowohl bei Paulus als auch bei Johannes. ${ }^{11}$

In 1 Kor 15,22 ist das „Lebendigmachen“ im Kontext der Auferstehungsthematik klar endzeitlich konnotiert, das "Lebendigmachen“ meint das „Auferwecken“ physisch Toter. Das futurische, also eschatische Lebendiggemachtwerden ,in Christus" wird hier allerdings kontrastiv parallelisiert mit dem Sterben „in Adam“, das wiederum ein metaphorisches

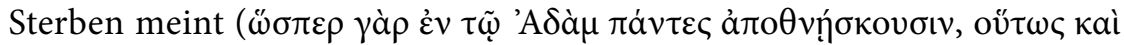

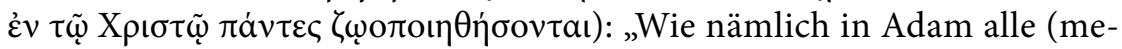
taphorisch) sterben, so werden auch in Christus alle (eschatisch) lebendig gemacht werden". ${ }^{12}$ Dabei gibt 15,21 die Lesevorgabe, Christus als agens des eschatischen Lebendigmachens zu verstehen: Wie durch einen Menschen der Tod gekommen ist, so durch einen Menschen auch die Aufer-

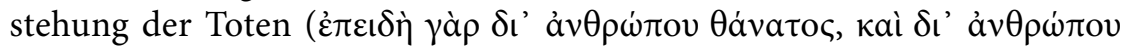

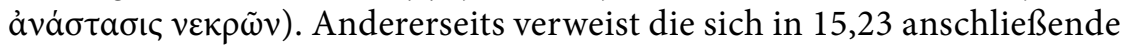
Beschreibung der endzeitlichen Totenauferweckung auf Gott als agens des Lebendigmachens, insofern auch Christus unter denjenigen aufgezählt

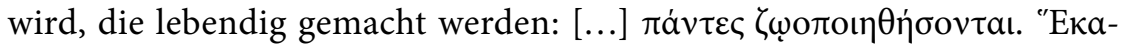

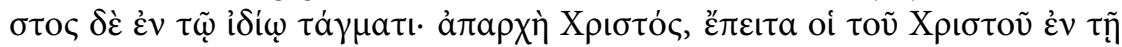

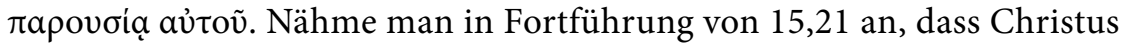
der agens des eschatischen Lebendigmachens ist, dann könnte dies in 15,23 nur für das Lebendigmachen der (Leute) Christi gelten, nicht aber

\footnotetext{
${ }^{10}$ S. dazu Christiane Zimmermann, Die Namen des Vaters. Studien zu ausgewählten neutestamentlichen Gottesbezeichnungen vor ihrem frühjüdischen und paganen Sprachhorizont (AJEC 69), Leiden 2007, 428-435.

${ }^{11}$ Vgl. auch 1 Petr 3,18. Zu den folgenden Ausführungen über das Lebendigmachen bei Paulus vgl. die ausführlichere Behandlung in Christiane Zimmermann, Leben aus dem Tod. Ein Spezifikum in der Gottesrede des Römerbriefes, in: Udo Schnelle (Hg.), The Letter to the Romans (BETL 226), Leuven 2009, 497-514.

${ }^{12}$ Zur Diskussion, ob von diesem Lebendigmachen nur die Glaubenden oder alle Menschen betroffen sind, vgl. Andreas Lindemann, Der Erste Korintherbrief (HNT 9,1), Tübingen 2000, 344. Letzteres wird durch die klare Parallelisierung mit Adam nahegelegt.
} 
für Christus selbst. Insofern ist anzunehmen, dass konzeptionell an Gott als agens des eschatischen Lebendigmachens gedacht ist, ${ }^{13}$ jedoch steht diese Frage nicht im Fokus des Textes, sondern vielmehr die Frage, was Adam und Christus jeweils für die Menschen repräsentieren. ${ }^{14}$

Auch der Geist erscheint bei Paulus als lebendigmachender: In 2 Kor 3,6 kontrastiert der "lebendigmachende“ Geist dem "tötenden“

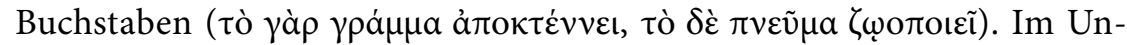
terschied zu 1 Kor 15,22 ist hier nicht die Endzeit, sondern die Gegenwart im Blick, das "Lebendigmachen" referiert auf das "Lebendigmachen" physisch lebender, jedoch metaphorisch „toter" Menschen durch den Geist. Dem Buchstaben (des Gesetzes) wird dagegen die Macht attestiert, den physisch lebenden Menschen metaphorisch zu „töten“. Entsprechend wird in Gal 3,21 dem Gesetz jede Fähigkeit "lebendig zu machen“

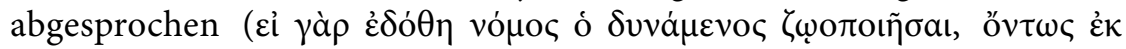
vó

Die Verwendung der Metaphorik von Töten und Lebendigmachen durch Paulus entspricht der auch sonst im jüdischen, frühchristlichen und paganen Bereich zu findenden Applikation anthropologischer Metaphern aus dem semantischen Feld der physischen Existenz des Menschen auf dessen intellektuelles oder religiöses Befinden. ${ }^{15}$ Die Metapher des "Lebendigmachens" physisch lebender, jedoch metaphorisch toter Menschen treibt diese Anwendungsweise ins Extrem, insofern sie die Grenze der menschlichen Existenz in ihrer Totalität ins Auge fasst.

Allein im Römerbrief thematisiert Paulus explizit Gott als agens des „Lebendigmachens“: In Röm 4,17 ist die Rede von Abraham, dem zugesagt wird, dass er zum Vater vieler Völker eingesetzt ist, „weil er auf den Gott vertraute, der die Toten lebendig macht und das Nichtseiende

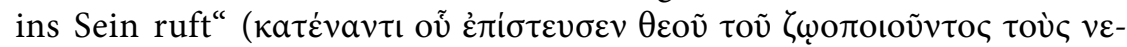

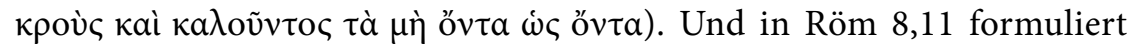
Paulus die Zuversicht, dass wenn der Geist dessen, der Jesus von den Toten auferweckt hat, in uns wohnt, dass eben dieser (Gott) dann auch „eure sterblichen Körper durch seinen in euch wohnenden Geist lebendig

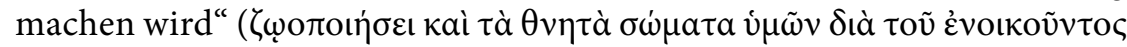

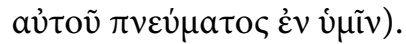

\footnotetext{
${ }^{13}$ Vgl. dazu auch Lindemann, Korintherbrief (Anm. 12) 344.

${ }^{14}$ Vgl. zum repräsentativen Charakter der Aussage von V. 22 bereits Johannes Weiss, Der erste Korintherbrief (KEK 5), Göttingen 1910, 356.

${ }^{15}$ Vgl. etwa Jes 6,9f.; 52,15; Röm 15,21; Mk 4,12 parr.; Joh 9 sowie das platonische Höhlengleichnis, Plato rep. 514a-517a.
} 
Wenngleich beide Aussagen prima vista den Eindruck machen, allein vom Lebendigmachen der physisch Toten zu sprechen, also wie 1 Kor 15,22 die endzeitliche Totenauferweckung zu konnotieren, ist dies auf den zweiten Blick nicht so eindeutig, und das nicht ohne Grund und mit entsprechenden theologischen Konsequenzen. Ein Blick auf die Tradition der Rede vom göttlichen „Lebendigmachen“, sowie eine genauere Analyse der Verwendung des Syntagmas "die Toten lebendig machen“ in Röm ergeben, dass eine Beschränkung des Verständnisses auf die leibliche bzw. eschatische Totenauferweckung der Konnotationsbreite dieser Redeweise hier nicht ausreichend gerecht wird. ${ }^{16}$

In Röm 4,17 ist ein konkreter Bezug des Glaubens an das „Lebendigmachen" Gottes zur Person Abrahams mit einer eschatologischen Interpretation nämlich nicht gegeben. Kommentatoren verweisen zu dieser Stelle stets auf die in der zweiten Benediktion des 18-Bitten-Gebets gepriesene Macht Gottes, die Toten lebendig zu machen, ${ }^{17}$ und verbinden die in Röm 4,17 formulierte Glaubensaussage mit dem in 4,24 formulierten Glauben an die Auferweckung Jesu. ${ }^{18}$ Der in $4,17 \mathrm{~b}$ formulierte Glaube Abrahams an die Macht Gottes, Tote lebendig zu machen und das Nichtseiende ins Sein zu rufen, dient jedoch als Begründung für die in 4,17a formulierte Zusage Gottes, dass Abraham Vater vieler Völker sein werde. Daher ist ein inhaltlicher Zusammenhang zwischen der Beschreibung des Glaubens Abrahams und der Zusage seiner Vaterschaft anzunehmen. Die folgenden Verse in 4,18-22 geben nun eine genauere Erklärung dafür, welche Konsequenzen das Vertrauen Abrahams auf den Gott, „der die Toten lebendig macht“, für Abraham selbst hatte und erklären damit die Funktion dieser Gottesbeschreibung. Die Aussage, dass Gott „die Toten lebendig macht", ist zunächst zwar Ausdruck einer grundsätzlichen Eigenschaft Gottes und damit multitemporal. Abraham vertraute nun aber konkret - nach 4,19 selbst 100-jährig ${ }^{19}$ - auf die Zusage Gottes, noch Vater vieler Völker zu werden $(4,18)$, obwohl sein Leib und der seiner Frau

\footnotetext{
${ }^{16}$ Vgl. bereits ZimmermanN, Leben (Anm. 11); zu Röm 4,17 s. auch Jochen Flebbe, Solus Deus. Untersuchungen zur Rede von Gott im Brief des Paulus an die Römer (BZNW 158), Berlin 2008, 240-260, und Michael Wolter, Der Brief an die Römer (EKKNT 6,1), Neukirchen-Vluyn 2014, 304-308.

${ }^{17}$ Vgl. dazu Zimmermann, Namen (Anm. 10) 434.

${ }^{18}$ Vgl. etwa Heinrich Lietzmann, An die Römer (HNT 8), Tübingen ${ }^{4} 1933$, 55; Otto Michel, Der Brief an die Römer (KEK 4), Göttingen ${ }^{5}$ 1978, 171; Eduard Lohse, Der Brief an die Römer (KEK 4), Göttingen ${ }^{15} 2003$, 155; Klaus HaAcker, Der Brief des Paulus an die Römer (THKNT 6), Leipzig 1999, 108.

${ }^{19}$ Vgl. Gen 17,17; 21,5. Nach hellenistisch-jüdischer Vorstellung dauert das Leben „höchstens 100 Jahre", s. Sir 18,9.
} 
Sara bereits „erstorben“ waren, wie Paulus in 4,19 formuliert: Er spricht

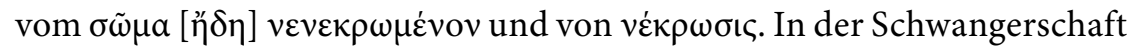
Saras erweist sich daher für Abraham nun ganz konkret die lebendigmachende Macht Gottes am lebenden und doch (hinsichtlich seiner Fortpflanzungsfähigkeiten) „erstorbenen“ Menschen - und insofern auch die schöpferische Macht Gottes, der das Nichtseiende wie Seiendes anspricht, d. h. ins Leben ruft. ${ }^{20}$ Ein rein leiblich-eschatisches Verständnis der Rede vom „die Toten lebendigmachenden Gott" in 4,17 wird der kontextuellen Einbettung dieser Prädikation folglich nicht gerecht, auch wenn einige Verse später, in 4,24c, vom Auferwecken Jesu die Rede ist; dieses wird

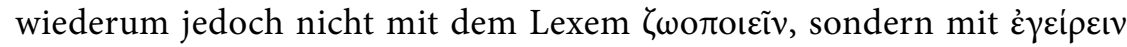
beschrieben. Die inhärente Textlogik zielt daher vielmehr auf den folgenden Vergleich: So wie Abraham grundsätzlich an die lebendigmachende Kraft Gottes glaubte, die sich ihm konkret in der wider jedes menschliche Erwarten eingetretenen Schwangerschaft Saras zeigte, und so wie ihm dieser Glaube zur Gerechtigkeit angerechnet wurde, so wird den Christen der Glaube an die auferweckende Kraft Gottes, die sich ihnen in der Auferweckung Christi zeigte, zur Gerechtigkeit angerechnet. Es lässt sich hier also eine Parallelisierung des lebendigmachenden und auferweckenden Handelns Gottes erkennen, allerdings referiert das Lebendigmachen in 4,17-19 auf ein Lebendigmachen physisch Lebender (wenngleich für die Fortpflanzung „Erstorbener"), das Auferwecken in 4,24 auf das Lebendigmachen (Auferwecken) physisch Toter. Das Argument des Paulus, das auf die Rolle des Glaubens hinsichtlich der Rechtfertigung des Menschen zielt, bedient sich eines Lexems, das sowohl die präsentische als auch perfektive als auch zukünftige, also die grundsätzliche Macht Gottes beschreibt, lebendig zu machen.

Auch der zweite Text des Römerbriefs, der vom „Lebendigmachen“ durch Gott spricht, tut dies in der Spannung von metaphorischer und nicht-metaphorischer Sprache: Röm 8,11 steht im Kontext der Differenzierung der menschlichen Existenz zwischen einer Lebensweise katà

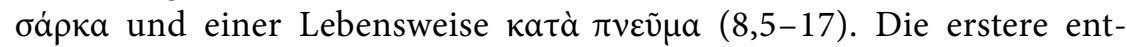

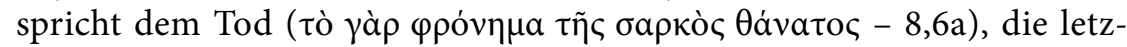

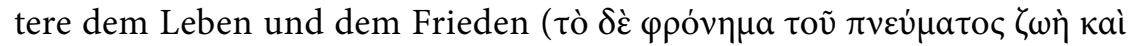
Eìñ $\eta$ - 8,6b). In 8,9 ordnet Paulus die Adressaten des Briefes explizit

\footnotetext{
${ }^{20}$ Dass hier mit „lebendig machen“ auf die zunächst unmöglich erscheinende Geburt Isaaks angespielt wird, findet eine Parallele im Dank der Hanna in 1 Sam 2,6, die Gott nach der ebenfalls unerwarteten Geburt Samuels mit vergleichbaren Bildern preist: „Der Herr tötet und macht lebendig $[\ldots]^{\text {“ }}$
} 
denjenigen zu, die „im Geiste sind, wenn denn der Geist Gottes in euch wohnt". Die Existenz des Geistes Gottes bzw. Christi im Glaubenden ist nach 8,9 und 10 die Voraussetzung des (präsentischen neuen) Lebens ( $\tau$ ò $\delta \dot{\varepsilon} \pi v \varepsilon \tilde{v} \mu \alpha \zeta \omega \dot{\prime}-8,10)$. Wer diesen Geist hat, der hat Leben. In 8,11 heißt es dann: „Wenn aber der Geist dessen, der Jesus von den Toten auferweckt hat, in uns wohnt, dann wird der, der Christus von den Toten auferweckt hat, auch eure sterblichen Körper durch seinen in euch wohnenden Geist

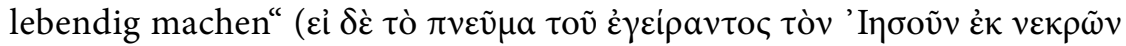

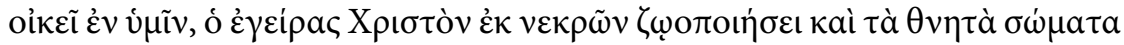

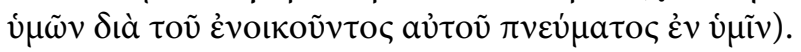

Der Gedanke der Auferweckung erscheint hier (wie auch in 4,17) etwas abrupt eingeführt, ist jedoch mit dem Kontext durch das Motiv des Geistes klar verbunden: Das in 8,9 und 11 dreimal hervorgehobene Wohnen des Geistes im Glaubenden, das in V. 10 mit $\zeta \omega \eta$, dem Leben, identifiziert wird, gewährt die Zuversicht, dass derjenige, der Christus von den Toten auferweckt hat, eben dies auch mit den Glaubenden tun wird. Insofern kommt hier dem Geist und seinem durativen Einwohnen im Menschen eine entscheidende Rolle zu: Er gewährleistet das präsentische neue Leben und ist als solcher die Voraussetzung für das zukünftige Lebendiggemachtwerden der sterblichen Körper.

In Röm 8,11 ist durch die Parallelisierung der Auferstehung Jesu mit

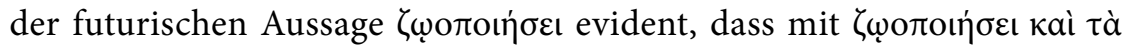
$\theta v \eta \tau \grave{\alpha} \sigma \dot{\omega} \mu \alpha \tau \alpha \dot{v} \mu \tilde{\omega} v$ die endzeitliche Auferweckung der Glaubenden von den Toten angesprochen ist (wie auch in 1 Kor 15,22) - so legen alle heutigen Kommentare den Text auch konsequent und zurecht eschatologisch aus. ${ }^{21}$ Allerdings ergibt sich bei genauerem Blick noch ein weiterer Aspekt: Paulus benennt in 8,11 als Objekte des Lebendigmachens die sterblichen Körper der Menschen, tà $\theta v \eta \tau \grave{~} \sigma \omega \dot{\omega} \mu \alpha \tau \alpha$, wobei durch die Konjunktion kaí, die hier mit „auch“, „sogar“ übersetzt werden muss, impliziert ist, dass die sterblichen Körper nicht die einzigen sind, die

\footnotetext{
${ }^{21}$ Die eschatologische Interpretation legt nicht nur das Futur, sondern vor allem die In-

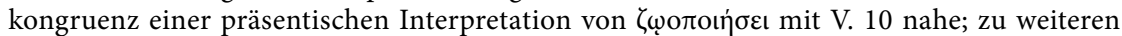
Argumenten gegen ein bisweilen begegnendes präsentisches Verständnis vgl. Daniel G. PoWERS, Salvation through Participation. An Examination of the Notion of the Believers' Corporate Unity with Christ in Early Christian Soteriology (CBET 29), Leuven 2001, 163-164,

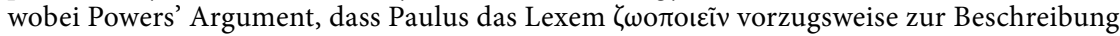
der endzeitlichen Totenauferstehung verwendet, durch 2 Kor 3,6; Gal 3,21 und die oben dargelegte Interpretation von Röm 4,17 entkräftet sein dürfte. Vertreter einer präsentischen

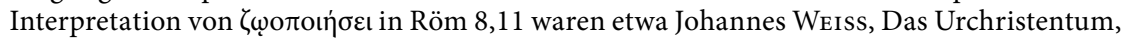
Göttingen 1917, 406, und Lietzmann, Römer (Anm. 18) 80.
} 
„lebendig gemacht“ werden, sondern dass es auch andere Körper gibt, die bereits „lebendig gemacht" worden sind. ${ }^{22}$

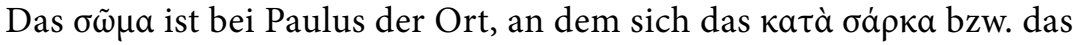

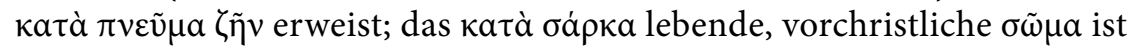
der Verfehlung ausgesetzt und unter dieser Bestimmung aus christlicher Sicht veкpóv. Durch das Innewohnen des Geistes Christi ist das $\sigma \tilde{\omega} \mu \alpha$ nicht mehr der der Verfehlung verfallene Leib, der als solcher metapho-

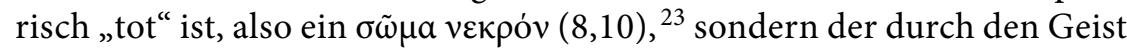
Christi der Verfehlung entzogene, aber immer noch physisch sterbliche

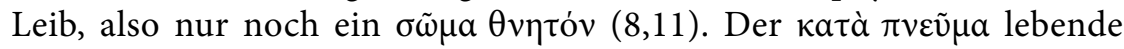
Christ lebt nach wie vor in einem $\sigma \tilde{\omega} \mu \alpha$, aber eben nicht in einem der

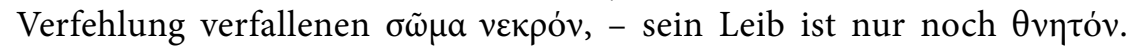
Insofern ist 8,11 dahingehend zu verstehen, dass „der, der Christus von den Toten auferweckt hat, auch eure (durch das Einwohnen des Geistes nicht mehr toten, sondern nur noch) sterblichen Körper durch seinen in euch wohnenden Geist (in der Endzeit) lebendig machen wird“.

Die Differenzierung von „toten“ und durch das Einwohnen des Geistes nur noch „sterblichen“ Körpern wird vorbereitet in Röm 6,12-13, wo Paulus die Glaubenden auffordert, der á $\mu a \rho \tau i a$ keine Macht über den sterblichen Körper ( $\sigma \tilde{\omega} \mu \alpha \theta v \eta \tau o ́ v)$ zu geben, sondern sich Gott zur Ver-

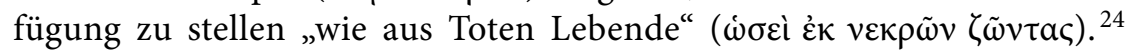
Die Metapher „wie aus Toten Lebende“ impliziert, dass die nun „Lebenden“ vorher metaphorisch "tot" waren. ${ }^{25}$ Das heißt, dass sie einen der

\footnotetext{
${ }^{22}$ Das Verständnis des Verses im Sinne einer Parallelisierung der Auferweckung des sterblichen Leibs Christi mit dem Lebendigmachen der sterblichen Leiber der Christen (derjenige der Christus auferweckt hat, wird auch eure sterblichen Leiber lebendig machen) scheint nicht intendiert, da das für eine derartige Betonung geeignetere Possessivpronomen von Paulus nicht eingesetzt wird (wie aber etwa in 1 Kor 11,24f.; Röm 15,4).

${ }^{23} \mathrm{Vgl}$. auch Röm 6,11. Zur Sicht auf den Körper als „tot“ in der hellenistischen Anthropologie vgl. die Belege bei Wolter, Brief an die Römer (Anm. 16) 388.488-489, der auch die Besonderheiten der christlichen Verwendung benennt. Zur metaphorischen Verwendung von vยкрó ৎ im Sinne von „im Glauben tot“: vgl. Mt 8,22/Lk 9,60 oder Lk 15,24 und 15,32. In

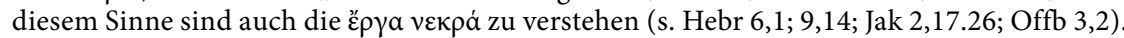

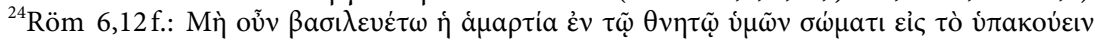

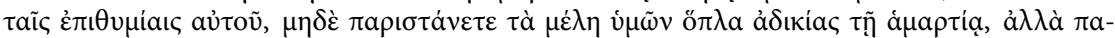

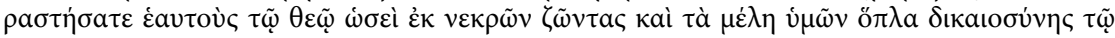
$\theta \varepsilon \tilde{\omega}$. Mit dieser imperativischen Abwehr des Gedankens des Wiedererstarkens der Verfehlung steigert Paulus den bereits in Röm 6,2 noch im Optativ formulierten Wunsch der Abkehr der Christen von der Verfehlung, die in 6,3 auch als bereits vollzogenes „Gestorbensein" im Hinblick auf die Verfehlung formuliert wird. Vgl. auch 2 Kor 5,15.

${ }^{25}$ Wolter verweist auf die Veränderung in der Semantik der Rede von "tot sein“ und „leben“ im Vergleich zu Röm 6,3-11, wo Paulus die Bekehrung als „Tod“ des Lebens vor der Bekehrung verstehe. In Röm 6,13 diene die Todesmetaphorik dagegen der Darstellung
} 


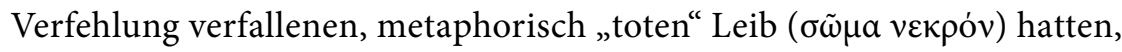
der durch den „lebendigmachenden“ Geist zum metaphorischen „Leben“ gekommen, aber immer noch ein physisch sterblicher Leib ( $\sigma \tilde{\omega} \mu \alpha \theta v \eta \tau$ tóv) ist. ${ }^{26}$ Dass die Glaubenden bereits präsentisch „lebendig gemacht" sind, ist in der Metapher „wie aus Toten lebend“ impliziert.

Setzt man dieses aus Röm 6,12-13 erschlossene Verständnis nun auch

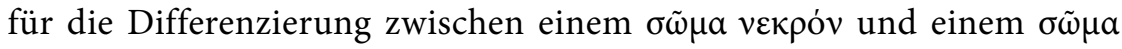
$\theta v \eta$ tov in 8,10-11 voraus, dann klingt auch in 8,11, der im direkten

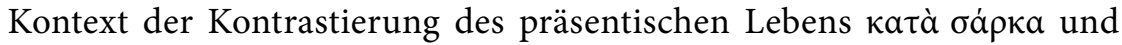

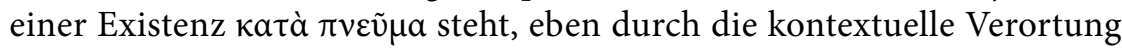
die metaphorische, präsentische Bedeutung des „Lebendigmachens" mit

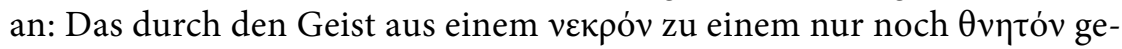
wordene und damit implizit bereits präsentisch „lebendiggemachte“ $\sigma \tilde{\omega} \mu \alpha$ "lebt“ jetzt durch den Glauben an den gestorbenen und auferweckten

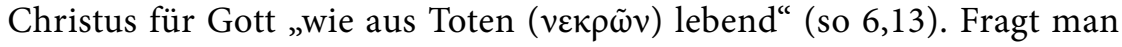
nach dem Moment, in dem das metaphorische Sterben und die Neuausrichtung des Lebens stattfinden, so ist dies das „Hineingetauchtwerden in den Tod Jesu", das ein "Mitbegrabensein mit Christus" impliziert, an das sich der Wandel in der Neuheit des Lebens anschließt (Röm 6,3-4), also die Taufe. Der Glaubende hat also bereits in der Taufe einmal den Weg aus dem Tod ins Leben beschritten; er ist bereits einmal lebendig gemacht worden. Röm 8,11 formuliert dann vor diesem Hintergrund die Zuversicht, dass Gott in der endzeitlichen Auferstehung auch den sterblichen Leib, das $\sigma \tilde{\omega} \mu \alpha \theta v \eta \tau$ tóv, lebendig machen, d.h. zum ewigen Leben auferwecken wird. Der Christ lebt präsentisch durch den Geist in der Hoffnung, dass Gott auch seinem $\sigma \tilde{\omega} \mu \alpha \theta v \eta \tau$ tó $v$ das ewige Leben in der

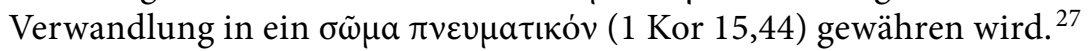

der Zeit vor der Bekehrung, die Bekehrung selbst sei dagegen verstanden als Gewinn von Leben (Brief an die Römer [Anm. 16] 391). In Röm 6,11 beschreibt Paulus allerdings auch den präsentischen Zustand der Glaubenden als einen Todeszustand: Sie sind „der Sünde tot, leben aber (für) Gott“. Daher erklärt sich auch die in V. 12 formulierte Ermahnung, dieser Sünde in dem nun (nur noch) sterblichen Leib keine Macht mehr zu geben. Ergänzend ist festzustellen, dass die Verwendung des Adjektivs veкрó

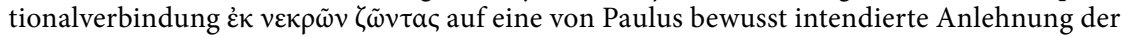

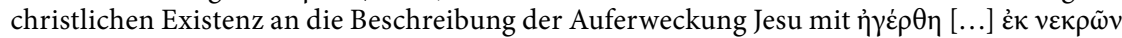

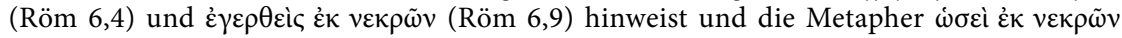
$\zeta \tilde{\omega} \nu \tau a \varsigma$ eine formelhafte Verkürzung des in Röm 6,4b-c Gesagten darstellt.

${ }^{26} \mathrm{Vgl}$. die Metapher in 1 Tim 5,6: $\mathfrak{\eta} \delta \dot{\varepsilon} \sigma \pi \alpha \tau \alpha \lambda \tilde{\omega} \sigma \alpha \zeta \tilde{\omega} \sigma \alpha \tau \dot{\varepsilon} \theta v \eta \kappa \varepsilon v$.

${ }^{27}$ Vgl. dazu auch die Argumentation von Wolter, Brief an die Römer (Anm. 16) 490: „Die Leben aus dem Tod schaffende Geistgabe Gottes steht nicht mehr aus, sondern sie ist bereits erfolgt; die Auferstehungskraft ,wohnt ' bereits jetzt in denen, die zu Jesus Christus gehören. 
Man kann im Römerbrief also eine mehrfache Referenz des LebensBegriffs bei Paulus erkennen, die auf die Rede vom „Lebendigmachen“

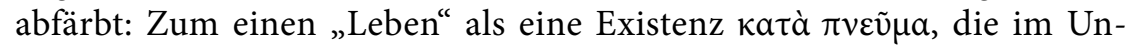

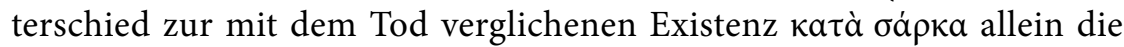
Bezeichnung „Leben“ verdient und präsentisch stattfindet; diese Existenz kann Paulus auch mit der Metapher „wie aus Toten lebend“ 28 (Röm 6,13) beschreiben, die den Gedanken des aus dem metaphorischen „Tod“ „Lebendiggemachtwerdens" impliziert, aber nicht expliziert. ${ }^{29}$ Zum anderen referiert "Leben“ auf das ewige Leben, das der Auferweckung von den Toten folgt, und dessen Verwirklichung noch aussteht. ${ }^{30}$ Die Verwirklichung des endzeitlichen "Lebendiggemachtwerdens“ wird also inauguriert durch das präsentische „wie aus Toten leben“.

Auch wenn Paulus seine Rede vom Lebendiggemachtwerden ins präsentische Leben hineinspielen lässt, ist die von ihm verwendete Metaphorik, mit der er konsequent innerhalb des jüdischen Gottesbildes formuliert, mit dem Blick auf den vorausgehenden Tod, mit dem Blick auf das Kreuz gestaltet. Das eigentliche Leben setzt das Sterben, den Tod, und wenn nur den metaphorischen „Tod“ voraus. Selbst wenn Paulus die Lebenswende wie im Gal als „Neuschöpfung“, als „Anziehen Christi“" bzw. als die Annahme der Sohnschaft beschreibt (Gal 6,15; 3,27; 4,5), gilt doch zunächst: „Ich bin mit Christus gekreuzigt" $(2,19)$. Das eigentliche Leben ist von der Erfahrung des Todes Christi her verstanden, es hat seinen Grund in der Heilsmacht des Kreuzes. Wenn Paulus die Neuheit des Lebens der Glaubenden und das Leben Christi im Glaubenden thematisiert, entwickelt er den Gedanken des eigentlichen Lebens vor dem Hintergrund des vorausgegangenen Sterbens. ${ }^{31}$

Die Verwendung der Rede vom göttlichen Lebendigmachen im Johannesevangelium lässt sich hiervon abheben:

Grundsätzlich findet sich im Johannesevangelium eine auffallende Betonung der bereits präsentisch im Glauben erfahrenen neuen Lebens-

\footnotetext{
Dass ihre ,sterblichen Leiber' lebendig gemacht werden, ist damit nur noch eine Frage der Zeit."

${ }^{28} \mathrm{Vgl}$. auch die Metapher vom „lebendigen Opfer“ in Röm 12,1, das mit einer Metamorphose, einer Erneuerung, identifiziert wird.

${ }^{29}$ Vgl. auch Röm 6,$4 ; 7,10 ; 8,2.6 .10 ; 11,15$.

${ }^{30}$ Vgl. auch Röm 2,7; 5,10.17f.21; 6,22f. Allein in Röm 8,38 scheint Paulus von Leben in einem nicht explizit christlichen Sinne, sondern vom physischen Leben in Opposition zum physischen Tod zu sprechen.

${ }^{31}$ Vgl. etwa Gal 2,19-20; Röm 6,8-11.
} 
wirklichkeit, ${ }^{32}$ die den Tod zugleich zu einer Nebensache werden lässt und ihn de facto nihiliert. So sagt Jesus zu Maria vor der Auferweckung des Lazarus: „ein jeder, der lebt und an mich glaubt, wird in Ewigkeit

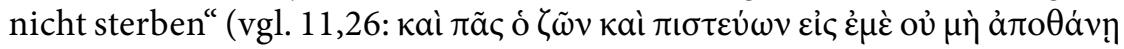

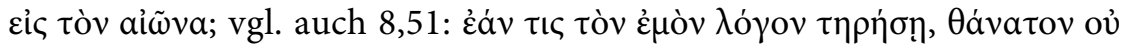

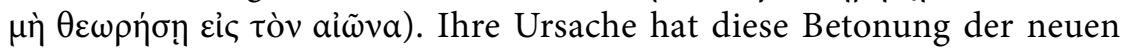
Lebenswirklichkeit im Lebensbesitz von Vater und Sohn und deren pri-

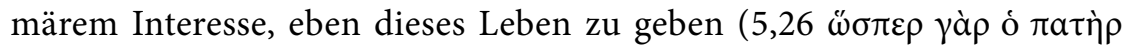

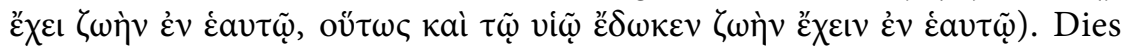
wird bereits im Prolog angedeutet $(1,4)$, durch das Gespräch mit der Samaritanerin über das lebendige Wasser in Joh 4 exegisiert und in den $\dot{\varepsilon} \gamma \omega \dot{\omega} \varepsilon \dot{\mu} \mu$-Worten Jesu „ich bin das Brot des Lebens“ $(6,35.48)$, „ich bin die Auferstehung und das Leben“ $(11,25)$ sowie „ich bin der Weg, die Wahrheit und das Leben" $(14,6)$ christologisch akzentuiert. Jesus lebt wegen des lebendigen Vaters $(6,57)$, er hat das Leben von ihm $(5,26)$, er ist Leben $(1,4 ; 11,25 ; 14,6)$ und er gibt das Leben $(1,4)$. Und der Verfasser des Johannesevangeliums führt an Jesus die Möglichkeit des prä- und postirdischen Lebens vor.

In Joh 5,21 lässt der Verfasser Jesus in einer Rede, die die vielschichtige Handelseinheit zwischen Vater und göttlichem Sohn thematisiert, nun ebenfalls vom „Lebendigmachen“ sprechen: „Wie nämlich der Vater die Toten auferweckt und lebendig macht, so macht auch der Sohn, welche

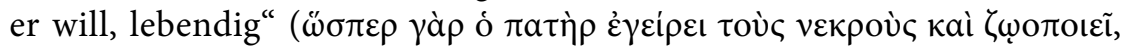

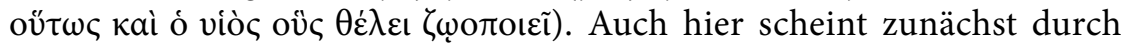

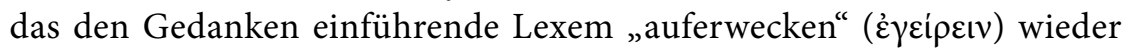
eher die eschatische Totenauferweckung im Blick. Doch folgt in 5,24 die Feststellung, dass jeder, der an Gott glaubt, an den, der Jesus gesandt hat, das ewige Leben bereits jetzt hat und aus dem Tod bereits jetzt ins Leben hinübergegangen ist. ${ }^{33}$ Das resultative Perfekt $\mu \varepsilon \tau \alpha \beta \dot{\varepsilon} \beta \eta \kappa \varepsilon v$ signalisiert die bereits bestehende Überwindung des offensichtlich hier ebenfalls metaphorisch konnotierten „Todes“ und die bereits präsentisch bestehende Partizipation am ewigen Leben. Auch wenn bei der Rede vom „Lebendigmachen" die eschatische Totenauferweckung in 5,21 im Blick sein mag, so

\footnotetext{
${ }^{32}$ Zum johanneischen Lebensbegriff vgl. Christina HoEgen-Rohls, Ewigkeit und Leben. Der biblische Vorstellungskreis III. Johannes, in: Petra Bahr/Stephan Schaede (Hg.), Das Leben. Historisch-systematische Studien zur Geschichte eines Begriffs 1 (RuA 17), Tübingen 2009, 129-152 sowie den Beitrag von Hoegen-Rohls im vorliegenden Band: Gottes rekreatorisches Handeln bei Paulus und Johannes II: „Neue Schöpfung“ und „Ewiges Leben“.

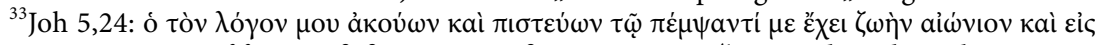

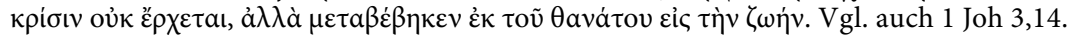


ist diese jedoch nur ein Teilaspekt der in 5,24 festgestellten, grundsätzlich Leben spendenden Macht Gottes und des Sohnes, die sich bereits in der Gegenwart realisiert. ${ }^{34}$

Ebenso wie Paulus spricht auch der Verfasser des Johannesevangeliums davon, dass es konkret der Geist ist „der (den Glaubenden) lebendig macht" (Joh 6,63 - 2 Kor 3,6) und dass der Geist Leben ist (Joh 6,63 Röm 8,10). Der Verfasser des Johannesevangeliums exemplifiziert dies jedoch noch genauer, indem er den Geist und das Leben mit den Worten identifiziert, die Jesus zu den Glaubenden gesprochen hat $(6,63)$. Im verkündigten Wort und dessen Erinnerung „lebt" Jesus daher als Auferstandener in den Glaubenden, und insofern partizipieren die Glaubenden bereits präsentisch am Auferstehungsleben Jesu. Ebenso wie bei Paulus ist also der Geist als Geist Gottes $(4,24)$ das entscheidende Medium zur Partizipation an der Leben spendenden Macht Gottes und Christi, die sich bei Johannes allerdings zusätzlich im Wort konkretisiert. Und während der Geistbesitz für Paulus die kommende Partizipation am ewigen Leben nur präludiert, vergegenwärtigt der Geist dieses ewige Leben für die Hörer der Verkündigung des johanneischen Jesus bereits präsentisch.

Den Anfangspunkt dieser Vergegenwärtigung des ewigen Lebens nimmt der Verfasser des Johannesevangeliums nun zusätzlich wiederum mit einem passivum divinum gezielt in den Blick: Der Prolog nennt dieses Geschehen „Kinder Gottes Werden“ bzw. „aus Gott Gezeugtwerden“. ${ }^{35}$ Der Verfasser des Johannesevangeliums beschreibt die Lebenswende nicht mit dem Blick auf das Kreuz und den Tod, sondern explizit als Lebensanfang aus Gott.

\section{Das „aus Gott“ bzw. „von oben Gezeugtwerden“ (}

Das Johannesevangelium entwirft zunächst in seinen Anfangsversen das Sein des Logos-Jesus beginnend mit der Präexistenz des Logos bei Gott, ${ }^{36}$ fortfahrend mit der Inkarnation des Logos im Kosmos und kulminierend im Bild des Vaters, in dessen Schoß der einzige Sohn liegt $(1,18)$. Die

\footnotetext{
${ }^{34}$ Vgl. Jörg Frey, Die johanneische Eschatologie. Band 3: Die eschatologische Verkündigung in den johanneischen Texten (WUNT 117), Tübingen 2000, 355-356.

${ }^{35}$ Vgl. auch 1 Joh 2,29; 3,9; 4,7; 5,1.4.18.

${ }^{36}$ Vgl. zum Problem Friederike Kunath, Die Präexistenz Jesu im Johannesevangelium (BZNW 212), Berlin 2016.
} 
Wirkung dieser Zeilen basiert auf dem starken Kontrast von Transzendenz und Intimität: Der bei Gott existente Logos begegnet der Welt in der Inkarnation, nur die Glaubenden erkennen und begreifen ihn jedoch

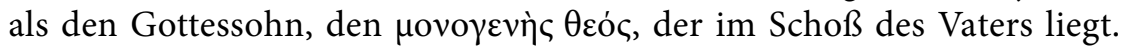
Dieser inkarnierte Logos verkündigt sich im Evangelium als der vom Vater gesandte, in Einheit mit dem Vater bestehende und agierende, und zum Vater zurückkehrende Sohn in einer sonst in den neutestamentlichen Schriften nicht wieder begegnenden Intensität. Der von oben Gekommene hat im Unterschied zu allen anderen den Vater gesehen und gehört $(3,32)$, er allein ist deshalb auch in der Lage, ihn den Menschen zu erklären $(1,18)$.

In 1,14 erscheint im Moment der Inkarnation das Verhältnis des Inkarnierten zu Gott als das des Sohnes zum Vater. Auch das Bild des im Schoß des Vaters Seienden impliziert das Vater-Sohn-Verhältnis. Auf die Einzig-

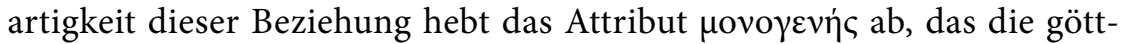
liche Zeugung anklingen lässt ${ }^{37}$ und damit zugleich die Fleischwerdung

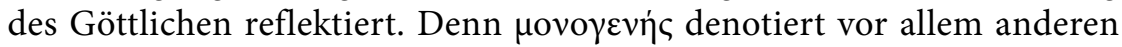
das einzige leibliche Kind, dem keine weiteren Geschwister gefolgt sind und das sich von angenommenen Kindern unterscheidet - so belegt es die

\footnotetext{
${ }^{37}$ Michael Theовадd, Fleischwerdung des Logos. Studien zum Verhältnis des Johannesprologs zum Corpus des Evangeliums und zu 1 Joh (NTAbh 30), Münster 1988, 250-254,

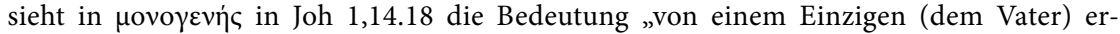
zeugt" impliziert; Turid Karlsen SeIm, Motherhood and the Making of Fathers in Antiquity. Contextualizing Genetics in the Gospel of John, in: Stephen P. Ahearne-Kroll/Paul A. Holloway/James A. Kelhoffer (Hg.), Women and Gender in Ancient Religions. Interdisci-

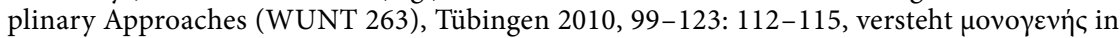
Joh 1,14.18 vor dem Hintergrund antiker medizinischer Texte im Sinne von „geboren unter Abwesenheit einer Mutter" (vgl. dazu auch Orph.hym. 32,1 über die von Zeus geborene Athena); s. auch Dies., Descent and Divine Paternity in the Gospel of John. Does the Mother Matter?, NTS 51 (2005) 361-375. Gitte Buch-Hansen, „It Is the Spirit That Gives Life“. A Stoic Understanding of Pneuma in John's Gospel (BZNW 173), Berlin u. a. 2010, 176, sieht

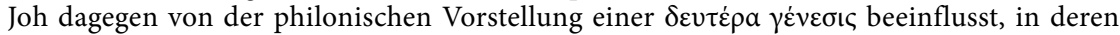

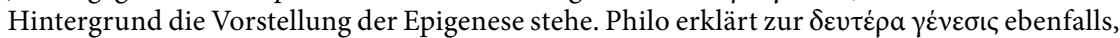
dass keine Mutter involviert sei, sondern nur ein Vater, der der Vater von allem sei $(\mathrm{QE} 2,46)$. Clare K. Rотнschild, Embryology, Plant Biology, and Divine Generation in the Fourth Gospel, in: Stephen P. Ahearne-Kroll/Paul A. Holloway/James A. Kelhoffer (Hg.), Women and Gender in Ancient Religions. Interdisciplinary Approaches (WUNT 263), Tübingen 2010, 125-151, sieht dagegen vielmehr antike biologische Theorien zur Parthenogenese

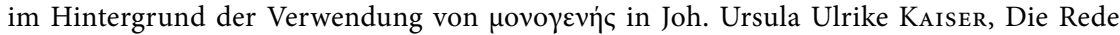
von „Wiedergeburt“ im Neuen Testament. Ein metapherntheoretisch orientierter Neuansatz nach 100 Jahren Forschungsgeschichte (WUNT 413), Tübingen 2018, 236, betont allerdings zurecht, dass das Spezifikum von Joh 1,13 gerade sei, dass göttliche Zeugung eben nicht nach irdischen Kritierien ablaufe, sondern grundlegend anders sei. Ebendies zeigt sich auch

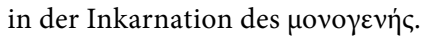


Terminologie in zahlreichen Grabinschriften der Zeit. ${ }^{38}$ Als Inkarnierter

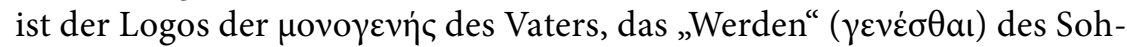
nes im irdischen Sinne ist der Moment der Fleischwerdung, ${ }^{39}$ wohingegen das „Werden“ des präexistenten Logos nicht thematisiert wird: Dieser war „im Anfang" bereits da und bei Gott und er war Gott $(1,1)$. Angesichts der Aussagen von 1,1 lässt sich auch die ohnehin stärker bezeugte Lesart

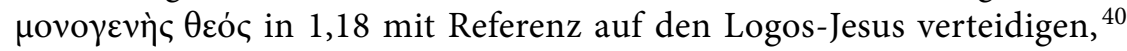
die neben der Inkarnation zugleich die präinkarnatorische Existenz Jesu betont, die ihn zu Gott macht, denn $\theta$ cós ist der Logos von Anfang an $(1,1) .{ }^{41}$

Auch Paulus greift im Zusammenhang mit Christus Geburtsmetaphorik auf und spricht von ihm als „Erstgeborenem“, doch bezieht sich diese Geburt bei ihm auch wieder auf den Tod: Christus ist der „Erstgeborene", insofern er der erste aus dem Tod Auferstandene ist ( $\pi \rho \omega \tau$ tótoко

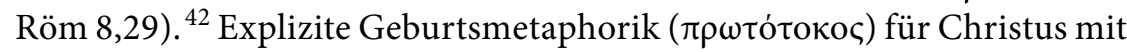
Referenz auf Gott als agens steht bei Paulus zuallererst im Zusammenhang des Todes und bezieht sich auf die Auferstehung Jesu.

Der Verfasser des Johannesevangeliums bezeichnet den Logos-Chris-

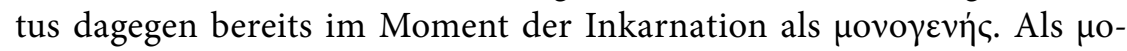

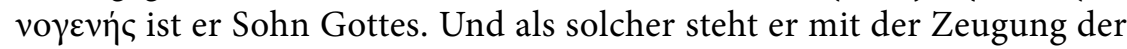
Glaubenden „aus Gott“ (Joh 1,13) in engstem Zusammenhang, ohne dass hier an eine Parallelität im Zeugungsakt zu denken wäre. Der Prolog des Johannesevangeliums beschreibt zu Beginn das schöpferische Agieren des präexistenten Logos $(1,3)$ : „Alles wurde durch ihn und ohne ihn wurde nicht eines, das wurde." Semantisch dominiert das medio-passivische $\gamma \varepsilon v \dot{\varepsilon} \sigma \theta a \mathrm{l}$ in der Vollverb-Funktion im Sinne von „Werden“, „Entstehen“.

\footnotetext{
${ }^{38} \mathrm{Vgl}$. etwa CIG III no. 3989 (= ICG no. 182, s. http://repository.edition-topoi.org/collection/ICG) und MAMA vii no. 92 (= ICG no. 492, s. http://repository.edition-topoi.org/ collection/ICG); Louis Jalabert/René Moutarde (Hg.), Inscriptions grecques et latines de la Syrie, I. Commagène et Cyrrhestique, Paris 1929 (IGLSyr 1), no. 169; Luigi Moretti (Hg.), Inscriptiones graecae urbis Romae, Rome 1968-1990 (IGUR III), no. 1231; IGUR II, no. 862 (alle für Töchter); für einen Sohn vgl. Annales Islamologiques 7 (1967) 201, no. 140. Vgl. bereits TheовадD, Fleischwerdung (Anm. 37) 251. Vgl. auch Tob 3,15; 8,17. Weitere Konnotationen listet Michael Tнеовацd, Das Evangelium nach Johannes, Kapitel 1-12 (RNT), Regensburg 2009, 130.

${ }^{39} \mathrm{Vgl}$. auch die Aussage in Joh 18,37, in der sich $\gamma \varepsilon \gamma \varepsilon \dot{\varepsilon} v \eta \eta$ a auf die Menschwerdung Jesu bezieht.

${ }^{40}$ Vgl. dazu Rothschild, Embryology (Anm. 37) 143-144.

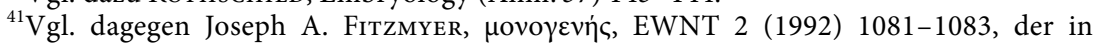
Joh 1,14.18 die „Einzigkeit“ Jesu im Sinne seiner Eigenschaft als „einziger Offenbarer“ des Vaters betont sieht, ebd. 1083 .

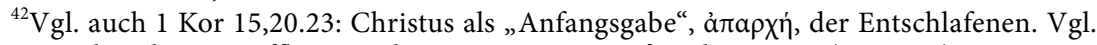
dazu auch Kol 1,18c; Offb 1,5; Hebr 1,6; Wolter, Brief an die Römer (Anm. 16) 533.
} 
Joh 1,10 wiederholt dieses schöpferische Werden nun in Bezug auf den

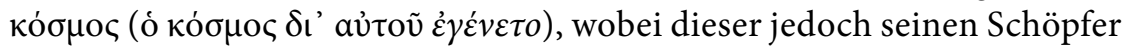
nicht erkennt. Als Steigerung dieses schöpferischen Wirkens des Logos kann nun die Aussage in 1,12f. verstanden werden, dass der Logos einem Teil der Schöpfung, nämlich denjenigen Menschen, die ihn „aufgenommen haben“, „denen, die an seinen Namen glauben“, die Bevollmächti-

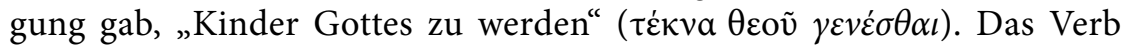
$\gamma \varepsilon v \varepsilon \dot{\varepsilon} \sigma a \mathrm{a}$ erscheint nun in der Funktion eines Hilfsverbs, das ein neues Stadium des Werdens durch das göttliche Handeln am bereits Geschaffenen beschreibt. Joh 1,13 erklärt die Implikationen dieses Geschehens, insofern die Menschen „nicht aus Blut und auch nicht aus dem Willen des Fleisches und auch nicht aus dem Willen eines Mannes, sondern aus/von

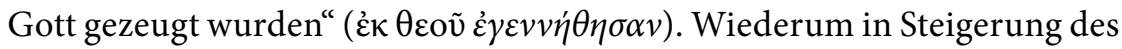

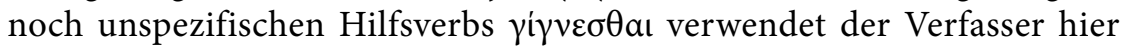
nun das Lexem $\gamma^{\varepsilon v \nu} \tilde{a} \sigma \theta a$, das im Unterschied zum unbestimmten „Werden“ "gezeugt werden“ und "geboren werden" denotiert. ${ }^{43}$ Insofern die Glaubenden „aus Gott gezeugt werden“, können sie zu „Kindern Gottes werden“. Das endgültige „Kinder Gottes Werden“ setzt einen Prozess voraus, in dem sich die Glaubenden auch tatsächlich als „Abbilder“ des göttlichen „Vaters" erweisen. ${ }^{44}$ Diesen aus Gott gezeugten Kindern steht mit dem inkarnierten Logos Christus als das einzige „leibliche“ Kind Gottes,

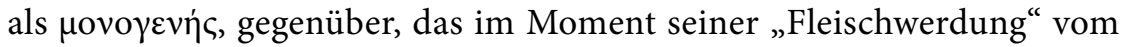
präexistenten Logos zum einziggeborenen Sohn wird. Dem „Fleisch-Werden“ des Logos $(1,14)$ entspricht reziprok das „aus Gott gezeugt Werden“ und „Kinder Gottes Werden“ der Glaubenden (1,12f.). Das Primat der Präexistenz des einzigen Sohnes Gottes als Logos, seiner exklusiven Einheit mit dem Vater stellt das Differenzkriterium zwischen ihm und den irdischen „Kindern Gottes“ dar. Dieses wird ergänzt um die weiteren detaillierten Ausführungen zur Handelns- und Seinseinheit zwischen göttlichem Vater und göttlichem Sohn im sich anschließenden Evangelientext. Noch bevor das Vater-Sohn-Verhältnis zwischen Gott und inkarniertem Gottessohn in 1,14 beschrieben wird, spricht der Prolog in 1,12-13 von

\footnotetext{
${ }^{43}$ Zur Diskussion um die Bedeutung von $\gamma \varepsilon v v \eta \theta \tilde{\eta} v \alpha \iota$ (geboren werden vs. gezeugt werden) vgl. SeIm, Motherhood (Anm. 37) 117-119, die vor dem Hintergrund antiker Zeugungsbzw. Geburtsvorstellungen und -semantiken den Zeugungsakt mittels der Verwendung des Lexems $\gamma \varepsilon v v \eta \theta \tilde{\eta} v a$ in Joh betont sieht. Vgl. dazu auch KAISER, Rede von „Wiedergeburt“ (Anm. 37) 232-238. In Joh 3,4 liegt durch das Motiv des Zurückkehrens in den Mutterleib in der Wahrnehmung des Nikodemus allerdings eher ein Verständnis von "geboren werden“ als von "gezeugt werden" nahe.

${ }^{44} \mathrm{Vgl}$. dazu KaISer, Rede (Anm. 37) 239.
} 
den Glaubenden als von Gott Gezeugten. Die endgültige Etablierung des Vater-Kinder-Verhältnisses erfolgt allerdings erst nach Jesu Tod und Auferstehung. ${ }^{45}$ Der Prolog des Johannesevangeliums handelt also nicht nur von der Exklusivität des Verhältnisses Gott-Logos, Vater und Sohn, sondern eben auch von der Ermöglichung der Inklusion der Glaubenden in dieses Gottesverhältnis - und die Gestaltwerdung dieser Inklusion bestimmt nun auch thematisch einen großen Teil des sich an den Prolog anschließenden Evangeliums. Der Vater im Johannesevangelium ist zwar zunächst und vor allem anderen der Vater Jesu, der das Handeln Jesu im und am Kosmos legitimiert und autorisiert. Dieser Vater agiert in Jesus jedoch von Anfang an mit dem eigentlichen Ziel, von diesem offenbart und damit zum Vater aller Glaubenden zu werden. Diese Vaterschaft wird in 1,12-13 programmatisch angekündigt, durch die Fleischwerdung des Logos in 1,14 ermöglicht, im Verlauf des Evangeliums narrativ umgesetzt und in 20,17 als vollzogen erklärt, indem Jesus Maria Magdalena verkündigt: „Ich gehe hinauf zu meinem Vater und eurem Vater, meinem

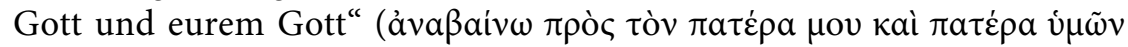

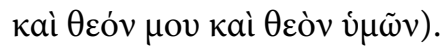

In Joh 3 wird die Frage der Inklusion der Glaubenden in dieses besondere Gottesverhältnis so auch zum ersten großen Gesprächsthema Jesu nach den ersten Zeichenhandlungen, im Gespräch mit dem Pharisäer Nikodemus $\left(3,1-21^{46}\right)$. Der Verfasser entwickelt einen nächtlichen Dialog, in dem Nikodemus Jesus aufgrund seiner Wundertaten als einen

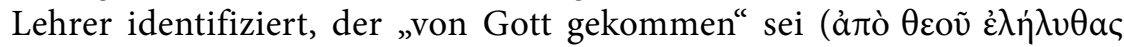
$\delta เ \delta \dot{\alpha} \sigma \kappa a \lambda$ oఢ) und dessen Zeichen aufwiesen, dass „Gott mit ihm“ sei (ó

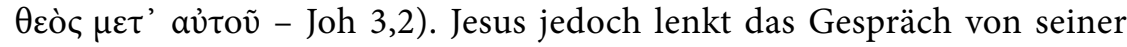
eigenen Person weg auf die Menschen und antwortet Nikodemus, dass keiner das Königreich Gottes sehen bzw. in dieses hineingehen könne, der

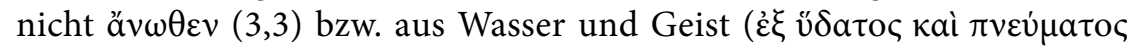
$3,5)$ geboren/gezeugt worden sei $(\gamma \varepsilon v v \eta \theta \tilde{\eta} v a)$. Es geht Jesus also nicht um seine eigene Identität, sondern um die Möglichkeiten, die mit ihm für die Menschen und damit auch für Nikodemus gegeben sind. ${ }^{47}$ Nikode-

\footnotetext{
${ }^{45}$ Vgl. Zimmermann, Namen (Anm. 10) 122.

${ }^{46}$ Zur kompositorischen Geschlossenheit des Textstücks vgl. Frey, Eschatologie 3 (Anm. 34) 244.

${ }^{47}$ So richtig Frances BACK, Die rätselhaften „Antworten“ Jesu. Zum Thema des Nikodemusgesprächs (Joh 3,1-21), EvT 73 (2013) 178-189: 183-184, die auf die vergleichbaren Dialoge in Joh 6,41-44 und Joh 15,5-6 verweist. Otfried Hofius, Das Wunder der Wiedergeburt. Jesu Gespräch mit Nikodemus Joh 3,1-21, in: ders./Hans-Christian Kammler (Hg.), Johannesstudien. Untersuchungen zur Theologie des vierten Evangeliums (WUNT 88),
} 
mus meint, Gott und dessen Präsenz in Jesus erkennen zu können. Die Voraussetzung dazu erfüllt er jedoch nicht, denn die Erkenntnis Gottes setzt nach Jesu Worten die Partizipation am Königreich Gottes voraus und diese wiederum das ä $v \omega \theta \varepsilon v(3,3)$ bzw. aus Wasser und Geist $(3,5$, vgl. 3,8) Gezeugtsein.

Es deutet vieles darauf hin, dass die johanneische Gemeinde mit den Worten Jesu in Joh 3 das Jesus-Logion aus Mt 18,3 (Mk 10,15 par. Lk 18,17) neu gedeutet hat. ${ }^{48}$ In diesem Logion, das vermutlich lautete „Amen, ich sage euch: Wenn ihr nicht wieder werdet wie die Kinder, werdet ihr nicht eingehen in das Reich Gottes", vergleicht Jesus die zum Glauben kommenden Menschen mit Kindern. Die johanneische Gemeinde hat diese Kindermetaphorik ganz offensichtlich in Zeugungsmetaphorik überführt und damit radikalisiert. Die Einheit des göttlichen Vaters und des inkarnierten Sohnes wird durch diese Metaphorik auf die Glaubenden ausgedehnt (Joh 14,11; 17,21), die wie Christus Kinder Gottes sind. Im Blick auf die Herkunft der Zeugungsmetaphorik aus dem Kinder-Logion Mt 18,3 spricht einiges dafür, das åv $v \theta \varepsilon v \gamma \varepsilon v v \eta \theta \tilde{\eta} v \alpha$ เ in zeitlichem Sinne zu verstehen, also als „Wieder-“ oder „Neugeburt “ ${ }^{49}$ bzw. „Wieder-/Neuzeugung". Dennoch wird im Johannesevangelium durch die kontextuelle Einbindung des Syntagmas die lokale Denotation des ä $v \omega \theta \varepsilon v$ betont: Der Verfasser des Textes spielt zunächst mit den verschiedenen Denotationen von ä $v \omega \theta \varepsilon v$, das sowohl „erneut“, „,von Neuem“ bedeuten kann, als auch „Von oben her“. ${ }^{50}$ Wenngleich der nach irdischen Maßstäben denkende Nikodemus das ă $v \omega \theta \varepsilon v$ im ersteren Sinne, ă $v \omega \theta \varepsilon v \gamma \varepsilon v v \eta \theta \tilde{\eta} v a$ also als „Von Neuem geboren werden“ versteht und damit den Übergang des Gesprächs auf eine metaphorische Ebene einleitet, wird im Folgenden vor

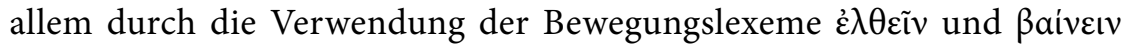
mit ihren Komposita klar, dass $\gamma \varepsilon v v \eta \theta \tilde{\eta} v a$ h hier vor allem in lokaler Weise zu verstehen ist. Diese Komposita geben jeweils einen lokalen Referenzpunkt der Bewegung an: Jesus ist von Gott her gekommen (åmò $\theta \varepsilon o \tilde{v}$

Tübingen 1996, 33-80: 39-40, erklärt die Antwort Jesu als Antwort auf eine in der Frage des Nikodemus implizierte, aber nicht ausgeführte Frage nach dem Heil. Hartwig Thyen, Das Johannesevangelium (HNT 6), Tübingen ${ }^{2} 2015,188-189$, versteht V. 3 dagegen als eine Ausführung Jesu über seine eigene Person (so bereits Wayne A. Meers, The Prophet King. Moses Traditions and the Johannine Christology [NovTSup 14], Leiden 1967, 298-299).

${ }^{48}$ Vgl. Michael Theobald, Herrenworte im Johannesevangelium (HBS 34), Freiburg 2002, 60-97.

${ }^{49}$ Vgl. dazu ausführlich Hofıus, Wiedergeburt (Anm. 47) 40-43.

${ }^{50}$ Vgl. dazu Frey, Eschatologie 3 (Anm. 34) 257-258; Thomas Popp, Das Entscheidende kommt von oben (Geburt von oben) - Joh 3,3-7 (Agr 53), in: Ruben Zimmermann (Hg.), Kompendium der Gleichnisse Jesu, Gütersloh ${ }^{2} 2015,719-724$. 
$\dot{\varepsilon} \lambda \dot{\eta} \lambda u \theta a \varsigma-3,2),{ }^{51}$ so Nikodemus. Diese Aussage wird von Jesus in Spiegelung der nachösterlichen Situation dahingehend präzisiert, dass keiner in den Himmel hinaufgeht (àva-ßaiveı - 3,13) außer dem, der aus dem

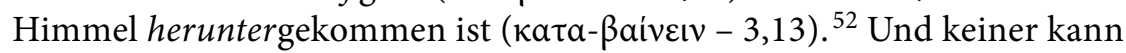
in den Mutterleib hineingehen ( $\varepsilon \dot{i} \sigma-\varepsilon \lambda \theta \varepsilon i v-3,4)$ und ein zweites Mal "geboren werden" ( $\gamma \varepsilon v v \eta \theta \tilde{\eta} v a l-3,4)$, d. h. herauskommen. Im jesuanischen Gegenargument wird nun wiederum das Herauskommen, an dessen Stelle das „Geborenwerden“ ( $\gamma \varepsilon v v \eta \theta \tilde{\eta} v a)$ steht, die Voraussetzung für das Hineingehen $(\varepsilon \dot{i} \sigma \varepsilon \lambda \theta \varepsilon \tilde{\imath} v)$ : Nach 3,5 kann nämlich nur derjenige in das Reich Gottes "hineingehen“, der zuvor "gezeugt" worden ist, und zwar "ä $v \omega$ $\theta \varepsilon v / v o n$ oben “ $(3,3)$ bzw. „aus Wasser und Geist" $(3,5) .{ }^{53}$ Natürlich impliziert das „von oben Gezeugtwerden“ auch einen zeitlichen Faktor, es muss zugleich ein „wieder, erneut Gezeugtwerden“ sein, jedoch verdeutlichen die Bewegungslexeme mit ihrer jeweiligen lokalen Näherbestimmung, dass der Verfasser diesen örtlichen Aspekt des ä $v \omega \theta \varepsilon v$ fokussieren will. ${ }^{54}$ Dem entspricht auch die in Joh 5,24 zu findende Feststellung, dass jeder, der an Gott glaubt, an den, der Jesus gesandt hat, das ewige Leben bereits jetzt hat und aus dem Tod bereits jetzt ins Leben „hinübergegangen“ ist ( $\mu \varepsilon \tau \alpha \beta \varepsilon \dot{\beta} \beta \kappa \varepsilon v)$.

Aber das eigentlich Irritierende an Jesu Ausführungen ist für die Hörer bzw. Leser des Evangeliums weder die zeitliche noch die räumliche

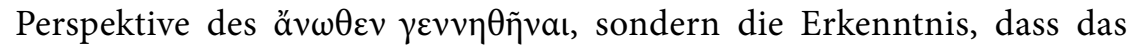

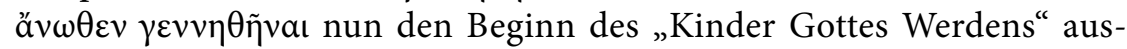
führt, das im Prolog noch ohne Spezifizierung der Modalitäten dieses

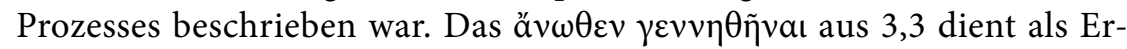

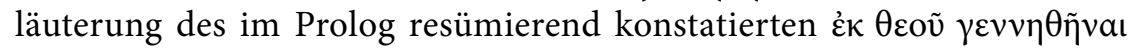
$(1,13)$, das wiederum - auch in seiner kontextuellen Einbettung - die Verständnisrichtung für das äv $\omega \theta \varepsilon v \gamma \varepsilon v v \eta \theta \tilde{\eta} v a$ เ vorgibt. ${ }^{55}$ Das ,,von oben

\footnotetext{
${ }^{51} \mathrm{Vgl}$. Joh $16,27-28$, wo Jesus für denselben Vorgang $\varepsilon_{\xi}^{\xi} \xi \lambda \theta \varepsilon \tilde{\varepsilon} v$ verwendet.

${ }^{52}$ Auch wenn man mit Hofius, Wiedergeburt (Anm. 47) 54, und anderen aufgrund des Sprecherwechsels eine Zäsur zwischen Joh 1,12 und 13 zieht, bleibt die semantische Verbindung mit den vorausgehenden Verben der Bewegung bestehen.

${ }^{53}$ Der Konjunktiv Aorist verweist nicht auf einen bereits festliegenden Zustand, sondern auf das „vom gegebenen Standpunkt aus unter Umständen zu erwartende“, s. Friedrich Blass/Albert Debrunner/Friedrich Rehropf, Grammatik des neutestamentlichen Griechisch, Göttingen ${ }^{17} 1990 \$ 373.1$; Frey, Eschatologie 3 (Anm. 34) 256-257.

${ }^{54}$ Entsprechend wird auch das Wirken des Geistes in Joh 3,8 mit Bewegungslexemen

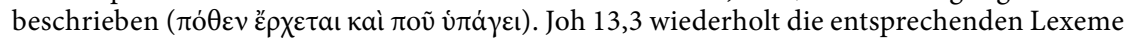

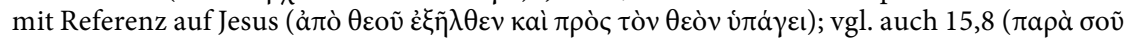
$\dot{\varepsilon} \xi \tilde{\eta} \lambda \theta 0 v)$.

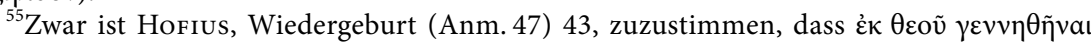
und $\alpha ٌ v \omega \theta \varepsilon v \gamma \varepsilon v v \eta \theta \tilde{\eta} v \alpha$ । nicht eo ipso dasselbe konnotieren müssen, jedoch dürfte der Leser
} 
Gezeugtwerden“, konnotiert so verstanden nun allerdings nicht nur eine zeitliche oder lokale Herkunftsbeschreibung, ${ }^{56}$ es konnotiert auch nicht nur die grundlegende Andersartigkeit des Lebens, ${ }^{57}$ es konnotiert auch nicht nur den Moment der Erkenntnis, dass auch das irdische Leben ein von Anfang an von Gott gezeugtes Leben war. ${ }^{58}$ Das „von oben“, d. h. „aus Gott Gezeugtwerden“ konnotiert die Erhöhung der Glaubenden durch die Exklusivität des göttlichen Vaters. Der Glaubende ist nun nicht mehr nur aus/von einem Menschen („nicht aus Blut, auch nicht aus dem Wollen des Fleisches, auch nicht aus dem Wollen des Mannes“ - 1,13), sondern aus/ von Gott gezeugt.

In Joh 3,5 und 6 nehmen nun Wasser und Geist die Stelle Gottes bei diesem Zeugungsakt ein: „Wer aus Wasser und Geist gezeugt ist“ (દ’à $[\ldots]$

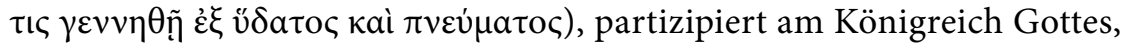
ja am göttlichen Sein, insofern das Erzeugte selbst "Geist" ist (

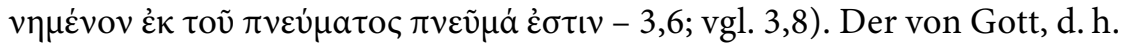
ebenfalls von oben kommende Geist, wird hier zum Mittler der Zeugung aus Gott, und das Gezeugte entspricht auch nicht irdischen Standards,

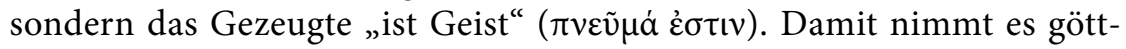
liche Qualitäten an, denn nach 4,24 ist Gott ebenfalls "Geist" ( $\pi v \varepsilon \tilde{v} \mu \alpha$ ó $\theta \varepsilon$ óc). Es spricht vieles dafür, wenngleich auch eindeutige Indizien fehlen, dass hier die Taufe als die rituelle Verortung der "Zeugung aus Gott“ im Leben des Glaubenden angesprochen ist. ${ }^{59}$ Während das „aus Gott Gezeugtwerden" den individuellen, persönlichen Moment des zum Glauben Kommens bzw. der Glaubenswende zu beschreiben scheint, der allein auf göttliche Initiative zurückgeht, ${ }^{60}$ verortet die Gemeinde diese Erfahrung im Ritus der Wasser- sowie Geisttaufe und beschreibt diesen

nach der irritierenden Aussage in 1,13 auf eine genauere Erklärung warten, wie dieses „aus Gott Geborenwerden" genau vor sich geht. Insofern impliziert der Gebrauch der Metapher

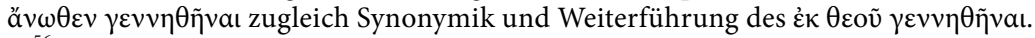

${ }^{56}$ Die lokale Denotation von ả $v \omega \theta \varepsilon v$ hat ebenfalls Parallelen schon in der paulinischen Tradition, etwa im Bild vom „oberen Jerusalem“ als Heimstatt der Christen ( $\dot{\eta}$ äv $\omega$ 'Ispov-

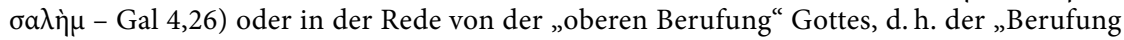

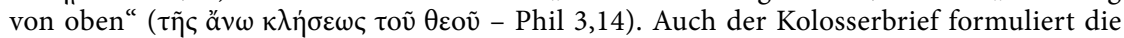
Ausrichtung der Christen auf Gott mit diesem lokalen Referenzpunkt: „wenn ihr also mit Christus auferweckt seid, dann sucht das Obere, denkt das Obere, nicht das auf der Erde"

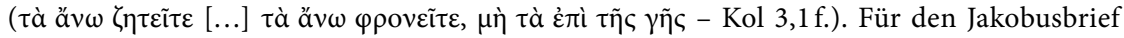

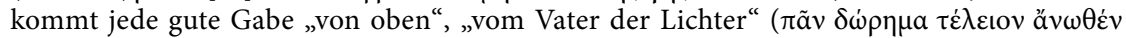

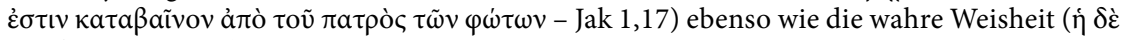

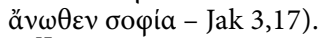

${ }^{57}$ So KAISER, Rede (Anm. 37) 290-291.

${ }^{58}$ Ebd., 231.

${ }^{59}$ Vgl. dazu jedoch Kaiser, Rede (Anm. 37) 9.2.4-7, 257-266 und 271-273 und 10.

${ }^{60}$ Vgl. Hofius, Wiedergeburt (Anm. 47) 59, 73 und 75. 
Moment auch als ein „Lebendigmachen“ $(6,63) .{ }^{61}$ In Verhältnis zu 3,3 gesehen, verdeutlichen diese Verse noch einmal, was die Gotteskindschaft so besonders macht: Es ist die Partizipation am Göttlichen, die der Geist gewährleistet.

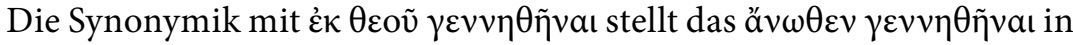
eine Parallele zur Herkunft Christi und verleiht der lokalen Denotation so ihr eigentliches Gewicht, das durch die Verben der Bewegung unterstrichen wird: ${ }^{62}$ Dem Kommen des Logos von Gott her in die Welt entspricht reziprok ein Kommen der Glaubenden aus Gott heraus in die basileia, die sich bereits irdisch zu realisieren beginnt. Dem Fleisch gewordenen Logos entsprechen die Kinder Gottes, die „nicht aus dem Willen des Fleisches“ $(1,13)$ gezeugt sind, die nicht mehr „aus dem Kosmos“ sind $(15,19)$, die durch den Geist an der Göttlichkeit partizipierenden Glaubenden. War Christus als Logos bereits vor seiner Inkarnation "göttlich“, so beschreiten die Glaubenden den umgekehrten Weg und erhalten als irdisch Geborene durch den Geist Teilhabe an Gott, der Geist ist $(4,24)$. Ziel der Sendung des Gottessohnes ist es, den Menschen ihre Bevollmächtigung zu dieser exklusiven Bezogenheit auf Gott deutlich zu machen, die beschrieben wird als ein „aus Gott Gezeugtsein“, das sich im „Kind Gottes

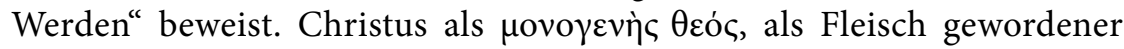
Gott, weist den Glaubenden den Weg zur eigenen Partizipation am Göttlichen, ${ }^{63}$ ermöglicht also die Gotteskindschaft der Irdischen unter der Bedingung des Glaubens. Die Johannesbriefe führen auf ihre Weise die Tragweite dieser Gotteskindschaft in einer vom Antichristen bestimmten Gegenwart aus (s. vor allem 1 Joh 3-5). Zu den endzeitlichen Kindern Gottes, die von Jesus zusammengeführt werden, gehören schließlich alle, die zum Glauben an Gott und Christus gefunden haben (Joh 11,52).

Die Zeugung der Glaubenden aus Gott im Johannesevangelium ist keine Metapher, die sich auf die erste Schöpfung bzw. grundsätzliche Herkunft der Menschen bezieht. In diesem Sinne begegnet sie für das Gottesvolk in einigen frühjüdischen ${ }^{64}$, für die gesamte Menschheit auch

\footnotetext{
${ }^{61}$ Zur Diskussion eines synonymen oder nicht-synonymen Verständnisses von Wasser und Geist vgl. Hofius, Wiedergeburt (Anm. 47) 50.

${ }^{62} \mathrm{Vgl}$. dazu auch das $\mu \varepsilon \tau \alpha \beta a i v \varepsilon ı v$ vom Tod ins Leben in Joh 5,24.

${ }^{63}$ Zur Entsprechung von Geborenem und Gebärender, sowie zur Bedeutung des sozialen Status der Eltern auch für die Kinder vgl. Bruce J. Malina/Richard L. Rohrbaugh, Social Science Commentary on the Gospel of John, Minneapolis 1998, 81.

${ }^{64} \mathrm{Im}$ Sinne des von Gott Geschaffenseins gilt das Gottesvolk als von Gott „erzeugt": Im Lied des Mose richtet dieser die Frage an das Volk „ist nicht er dein Vater, der dich erschaffen hat? (Ist nicht) er (es), der dich gemacht und dich bereitet hat (oủk aủtòc oũtó
} 


\section{in paganen, besonders stoischen Texten der Zeit. ${ }^{65}$ Sie bezieht sich auch nicht nur auf die Erwählung einzelner, hervorgehobener Menschen, ${ }^{66}$}

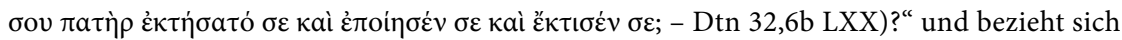
damit auf die Herkunft Israels von Jahwe, dem göttlichen Vater, ohne allerdings das Verb $\gamma \varepsilon v v a \tilde{\sigma} \sigma a \mathrm{l}$ zu verwenden. In Dtn 32,18-19 klagt Moses Israel dann an, diesen Gott, der

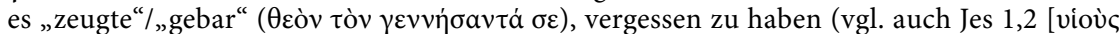

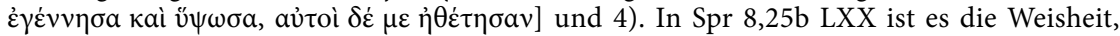
die Gott vor allem anderen „zeugt“, d. h. erschafft ( $\gamma \varepsilon v v \tilde{a} \mu \varepsilon)$. Vgl. auch Ps 110,3 und dazu Anm. 66.

${ }^{65}$ Ansätze zu einer Verwendung der Abstammungsmetaphorik mit Referenz auf Gott als Vater finden sich im paganen Bereich bereits ab dem 3. Jahrhundert v. Chr. besonders in der Stoa, z. T. mit deutlichen semantischen Parallelen zu den johanneischen Formulierungen.

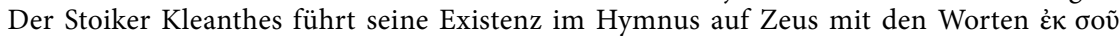

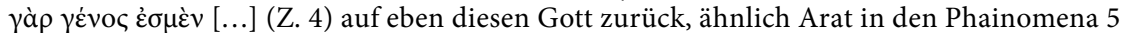
(vgl. Apg 17,28). Epiktet lässt den Beter in Diss. 4,10,16 Gott mit den Worten „du hast mich

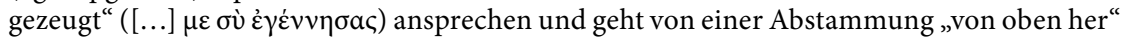

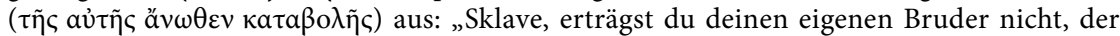
Zeus als Vorfahren hat, (und) wie ein Sohn aus dem gleichen Samen geworden ist und aus der gleichen Abstammung, von oben her ' [...] Erinnerst du dich nicht, was du bist und über wen du herrschst? Über Verwandte, über Brüder der Natur nach, über Abkömmlinge des

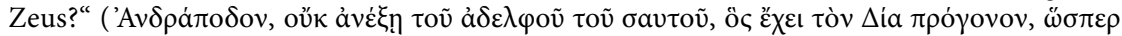

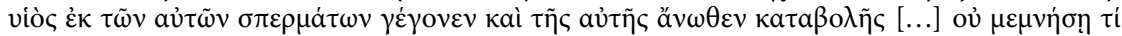

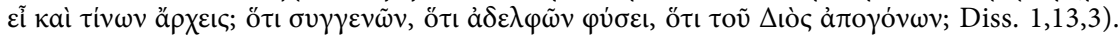
In Diss. 1,3 verwendet Epiktet das Syntagma $\gamma \varepsilon \gamma$ óval vitò toṽ $\theta \varepsilon o \tilde{v}$ und spricht von Gott als Vater der Menschen und Götter. In Diss. 1,3 und Diss. 1,9,13-14 bezeichnet er die Menschen

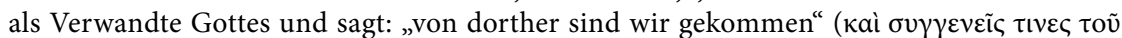

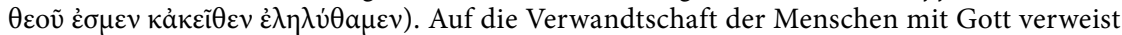
auch Dio Chrysostomus (s. etwa Or. 12,27-34.42.61). Vgl. dazu und zu weiteren Belegen bei Sextus Empiricus: Martin Hengel, The Son of God. The Origin of Christology and the History of Jewish-Hellenistic Religion, London 1976, 24 n. 51; Dietrich Rusam, Die Samenund Vererbungslehre der Stoa als religionsgeschichtlicher Hintergrund für die Bezeichnung der Glaubenden im johanneischen Schrifttum, BZ 59 (2015) 279-287.

${ }^{66} \mathrm{Im}$ Sinne der Auserwählung durch Gott wird bereits in frühjüdischen Texten Geburtsmetaphorik verwendet, etwa, wenn von Israel als „erstgeborenem Sohn“ Gottes (viò $\pi \rho \omega \tau$ т́токо́ „Söhne“ oder „Kinder" Gottes (Dtn 14,1; 32,5.19; Jes 43,6; 45,11; 63,8.16; Hos 2,1), um die sich Gott wie ein Vater kümmert (Dtn 1,31; Jer 3,4), allerdings wird hier keine explizite Zeugungsmetaphorik angewendet (vgl. auch Jub 1,22-25). Diese erscheint jedoch mit Referenz auf die Erwählung bzw. Einsetzung der davidischen Könige in der LXX: Ps 2,7 und Ps 109,3 (110,3 MT) belegen die Vorstellung der Gottessohnschaft des Königs, in beiden Fällen ist ebenfalls von einer „Zeugung" durch Gott die Rede. Während Ps 2,7b-c LXX dem König die Gottessohnschaft bezüglich seiner Amtsausübung als Beauftragter Jahwes ab dem Moment

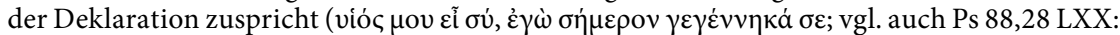

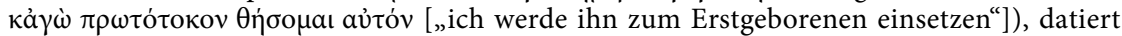
Ps 109,3c LXX die Gottessohnschaft des Königs noch vor der Erschaffung des Morgensterns

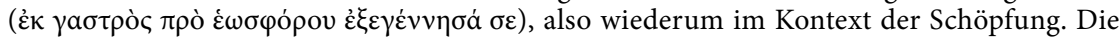
Frage der Bedeutung der Aussage von Ps 109,3c im ursprünglichen hebräischen Text ist allerdings ebenso komplex wie die Frage der Rezeption von Ps 2 und 110 (zu Ps 2 vgl. Annette Steudel, Psalm 2 im antiken Judentum, in: Dieter Sänger [Hg.], Gottessohn und Menschensohn. Exegetische Studien zu zwei Paradigmen biblischer Intertextualität [BThSt 
sondern sie referiert nach johanneischer Darstellung auf die generelle Ermöglichung der Gotteskindschaft. Deren Basis ist das zum Glauben Kommen an den Gott, der seinen Sohn Mensch werden ließ, um sich als Vater nicht nur des Sohnes, sondern aller Glaubenden zu offenbaren und ihnen die Gotteskindschaft im Sinne der Partizipation am Göttlichen $\mathrm{zu}$ ermöglichen. Die Zeugungsmetapher zielt damit einerseits auf die Erwählung, d. h. den besonderen Stand, der den Glaubenden aufgrund der Entscheidung Gottes durch den Logos eröffnet wird, ${ }^{67}$ andererseits auf den Moment der Genese der Verwandtschaft mit Gott, der als Zeugung und Beginn der Kindschaft beschrieben wird, aber zugleich als „Lebendiggemachtwerden“ und „neu Geschaffenwerden“ zu denken ist. Die Zeugungsmetaphorik nimmt dabei stärker als etwa die Terminologie von der neuen Schöpfung bei Paulus die Individualität dieses Vorgangs auf der Seite der Glaubenden in den Blick und sie betont die Verwandtschaft mit Gott. Insofern schließt das „aus Gott“ bzw. „von oben Gezeugtwerden“ Erwählungs- und Schöpfungsgedanken zusammen und spitzt ihn

67], Neukirchen-Vluyn 2004, 189-197; Werner KaHL, Psalm 2 und das Neue Testament. Intertextuelle Aspekte anhand ausgewählter Beispiele, in: Dieter Sänger [Hg.], Gottessohn und Menschensohn. Exegetische Studien zu zwei Paradigmen biblischer Intertextualität [BThSt 67], 232-250; zu Ps 109 vgl. Eberhard Bons, Die Septuaginta-Version von Psalm 110 [Ps 109 LXX]. Textgestalt, Aussagen, Auswirkungen, in: Dieter Sänger [Hg.], Heiligkeit und Herrschaft. Intertextuelle Studien zu Heiligkeitsvorstellungen und zu Psalm 110 [BThSt 55], Neukirchen-Vluyn 2003, 122-145; Michael Tilly, Ps 110 zwischen hebräischer Bibel und Neuem Testament, in: Dieter Sänger [Hg.], Heiligkeit und Herrschaft. Intertextuelle Studien zu Heiligkeitsvorstellungen und zu Psalm 110 [BThSt 55], Neukirchen-Vluyn 2003, 146-170; Lukas Bormann, Ps 110 im Dialog mit dem Neuen Testament, in: Dieter Sänger [Hg.], Heiligkeit und Herrschaft. Intertextuelle Studien zu Heiligkeitsvorstellungen und zu Psalm 110 [BThSt 55], Neukirchen-Vluyn 2003, 171-205; André Rose, L' influence des Septante sur la tradition chrétienne, QLP 46 [1965] 192-211.284-301: 296-301). Zur Beanspruchung der Gottessohnschaft in weisheitlichen Texten vgl. Weish 2,12-18; 5,5; Sir 4,10 und allgemein James D. G. Dunn, Christology in the Making. A New Testament Inquiry into the Origins of the Doctrine of Incarnation, London 1980, 14-16, mit weiteren Verweisen. Zur Gottessohnschaft der Könige im antiken Judentum und seiner Umwelt vgl. Adela Yarbro Collins/John J. Collins, King and Messiah as Son of God. Divine, Human, and Angelic Messianic Figures in Biblical and Related Literature, Grand Rapids 2008.

${ }^{67}$ Vgl. dazu auch die Ausführungen Philos, dessen Logos-Konzept nicht ohne Grund immer wieder als Parallele für die johanneische Rede vom Logos angeführt wird und dessen Gedanken möglicherweise über die griechischsprachigen Synagogen des östlichen Mittelmeerraumes verbreitet wurden; vgl. Folker SIEgERT, Der Logos, „älterer Sohn“ des Schöpfers und „zweiter Gott“. Philons Logos und der Johannesprolog, in: Jörg Frey/Udo Schnelle (Hg.), Kontexte des Johannesevangeliums. Das vierte Evangelium in religionsund traditionsgeschichtlicher Perspektive (WUNT 175), Tübingen 2004, 276-293: 276. Der Logos ermöglicht es den Menschen, Kinder Gottes zu werden (Philo Conf. 145-147). Nach

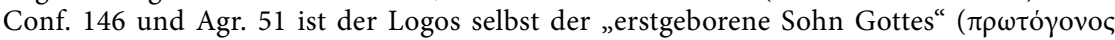
víó), der wahrnehmbare Kosmos als Manifestation des Schöpfers ist dagegen der "jüngere

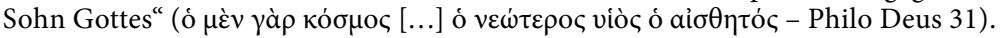


zugleich auf den Aspekt der Integration in die familia dei zu, in der Gott als Vater, Christus als Sohn und die Glaubenden als Kinder in einem engst möglichen Verhältnis zueinander gedacht sind und die Glaubenden durch ihre Partizipation an Gott an der Erhöhung teilhaben.

Die Aufnahme der Glaubenden in die familia dei ist bereits für Paulus zentral, auch wenn er keine Zeugungs- oder Geburtsmetaphorik im Zusammenhang der Glaubenswende verwendet: ${ }^{68}$ In Gal 4,6 und Röm 8,15 sieht er die Aufnahme in der Übergabe des Geistes (seines Sohnes) und der damit verbundenen „Vater"-Anrede Gottes konstituiert. ${ }^{69}$ Das „Kind Gottes Werden" ist auch bei Paulus elementar mit dem Geistempfang in der Taufe verbunden und manifestiert sich in der Bevollmächtigung, Gott ebenso wie sein gesandter Sohn $(\mathrm{Gal} 4,4)$ als „Vater" anzusprechen. Dabei rekurriert Paulus auf die vermutlich auf den historischen Jesus zurückgehende Anrede Gottes als „ $\alpha \beta \beta \alpha^{“} .{ }^{70}$ Die Besonderheit der Gotteskindschaft der an Christus Glaubenden hängt aufs Engste mit der Etablierung der Gottessohnvorstellung für Christus zusammen, ${ }^{71}$ worauf an dieser Stelle jedoch nicht weiter eingegangen werden kann.

Nach paulinischer Vorstellung empfangen die Glaubenden in der Taufe

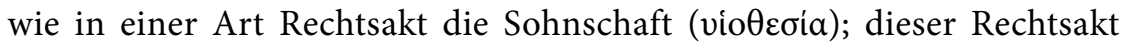
markiert dabei den Übergang von der leiblichen Familie in eine neue (nicht-leibliche) Familie unter Aufrechterhaltung der mit dem Sohnesstatus verbundenen Rechte. ${ }^{72}$ Für die johanneische Gemeinde ist die Taufe hingegen ritueller Ort und Moment der Demonstration der elementaren Verbindung mit Gott, die durch die Metapher des „aus Gott/von oben Gezeugtwerdens" verbalisiert wird und eine nicht nur adoptianistische, sondern physische Relation zu Gott beinhaltet.

Mit der Aufnahme der Zeugungsmetaphorik betont die johanneische Gemeinde, dass die neue christliche Familie die eigentliche Familie ist, die die Bedeutung der leiblichen Familie übersteigt, da in ihr Gott Vater aller Glaubenden ist. Die Aussagen über die Gotteskindschaft der Glau-

\footnotetext{
${ }^{68}$ In Röm 8,22 referiert das aus dem Bereich der Geburtsmetaphorik stammende $\sigma u v \omega \delta i v \varepsilon ı$ auf die Schöpfung.

${ }^{69}$ Durch die kontextuelle Einbettung dieser Vorstellung in Gal 3,23-4,11 ist deutlich, dass Paulus das „Kind Gottes Werden“ als den entscheidenden Schritt in einer Entwicklung des Gottesverhältnisses ansieht, der auf einen Zustand der Unmündigkeit folgt, währenddessen

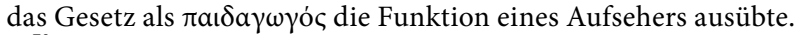

${ }^{70}$ Vgl. dazu ZimmermanN, Namen (Anm. 10) 76-79 und 127-129.

${ }^{71}$ Vgl. dazu etwa Dunn, Christology (Anm. 66) 12-64.

${ }^{72}$ Vgl. dazu Trevor J. Burke, Adopted as Sons (YIO@ELIA). The Missing Piece in Pauline Soteriology, in: Stanley E. Porter (Hg.), Paul. Jew, Greek, and Roman (Pauline Studies 5), Leiden 2008, 259-287.
} 
benden bereits in Joh 1,12-13 machen deutlich, dass diese das eigentliche Ziel der Sendung des Gottessohnes sind, der mit seinem Tod und seiner Auferstehung und der Vermittlung der "Zeugung" die Voraussetzung für die Konstituierung der göttlichen Familie schafft. Die Aussagen über die Gotteskindschaft qualifizieren die Entstehung dieser Kindschaft jedoch zugleich als exklusive Gottestat: Während Gott und Christus, beide, „lebendig machen“, ist es alleine Gott, der die Kinder „zeugt“, ${ }^{73}$ insofern er den Menschen den Glauben anbietet und sie damit in ein neues Verhältnis zu sich stellt. ${ }^{74}$ Der inkarnierte Logos exegisiert den Vater $(1,18)$ und gibt damit den Weg für dieses Geschehen vor $(14,6)$. Daher kann auch nur Gott als „Vater" angesprochen werden, zu dem der inkarnierte Logos und die neugezeugten Glaubenden auf unterschiedliche Weise in einem Kindschaftsverhältnis stehen. Die göttliche Zeugung der Glaubenden ermöglicht diesen die Teilhabe an der reziproken Immanenz von Gott und

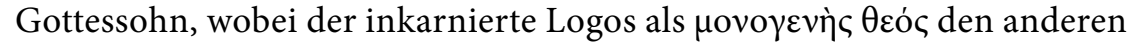
Gotteskindern das Privileg der Präexistenz, Handelns- und Wesenseinheit mit dem Vater, und Gott allen Kindern gegenüber das Privileg der Vaterschaft innehat. Insofern Gott alleine der metaphorische Vater ist, ist auch er alleine derjenige, der für die „Zeugung“ seiner Kinder Verantwortung trägt, wie er für die Inkarnation Verantwortung trägt und wie er für die endgültige Erhöhung aller seiner Kinder Verantwortung trägt.

\section{Schluss}

Die Metaphern des „Lebendigmachens" und „aus Gott“ bzw. „,von oben Gezeugtwerdens"verdeutlichen den Neuanfang der Beziehung Gottes mit den Menschen auf der Basis des Christusereignisses. Das „Lebendigmachen“ beschreibt vor allem in Parallele zum „Auferwecken“ das eschatische Handeln Gottes, das in enger semantischer Verbindung zum Tod zu sehen ist; dennoch zeigt sich bereits bei Paulus eine metaphorische Verwendung des Lexems, die auf ein schon irdisches „Lebendiggemachtwerden" der Glaubenden referiert. Das Johannesevangelium exegisiert eine entsprechende Vorstellung in Joh 5,21-24, insofern der Glaubende

\footnotetext{
${ }^{73}$ Vgl. auch Udo Schnelle, Das Evangelium nach Johannes (THKNT 4), Leipzig ${ }^{4} 2009$, 154.

${ }^{74}$ Prädestinatianische Gedanken werden dabei nicht explizit, s. Frey, Eschatologie (Anm. 34) 257 (vgl. aber dagegen Hofius, Wiedergeburt [Anm. 47] 67 und 80).
} 
das ewige Leben bereits jetzt hat und aus dem Tod bereits jetzt ins Leben hinübergegangen ist.

Das Johannesevangelium interpretiert den bei Paulus in engster Verbindung mit dem Tod gesehenen Heilsvorgang nun dagegen vor allem als Lebensanfang. Es sieht bereits das "Lebendigmachen“, dann aber auch die Lebensgabe an fast allen Stellen entkoppelt vom metaphorischen Tod, der für Paulus den entscheidenden Bildspender für den Wandel im neuen Leben darstellt. Dabei fokussiert die Zeugungsmetaphorik mit den Lexemen „aus Gott“ bzw. „Von oben Gezeugtwerden“ den Neuanfang Gottes mit den Menschen in semantischer Radikalität, die vor allem das „grundlegende Anders-Sein “75 dieses Lebens unter dem Aspekt der Partizipation am Göttlichen in den Blick nimmt. Die Zeugungsmetaphorik impliziert den Aspekt der grundlegenden Erneuerung des Lebens und der Integration in die familia dei, die mit Glaubenswende und Taufe vollzogen und in fundamentaler Beziehung zu Gott als Vater formuliert wird.

Bereits als Schöpfer agierte Gott kreativ, als Vater, der seinen Kreaturen nach ihrer (nebensächlichen, s. Joh 1,13) irdischen eine göttliche Zeugung ermöglicht, bietet er ihnen in einem rekreatorischen Akt darüber hinaus die größtmögliche Nähe und Würde an. Diesen anthropo-theologischen Schritt vollzogen zu haben, ist eine zentrale Leistung des Verfassers des Johannesevangeliums bzw. der johanneischen Gemeinde und Schule. ${ }^{76}$

\footnotetext{
${ }^{75}$ KaISER, Rede (Anm. 37) 290-291.

${ }^{76}$ Für die umsichtige formale Korrektur dieses Textes sowie inhaltliche Anmerkungen danke ich herzlich meiner Mitarbeiterin Hi-Cheong Lee.
} 


\title{
Gottes rekreatorisches Handeln bei Paulus und Johannes II
}

\author{
„Neue Schöpfung“ und „Ewiges Leben“
}

\author{
Christina Hoegen-Rohls
}

Der vorliegende Beitrag beleuchtet die Rede von Gottes neu- und wiederschöpfendem Handeln bei Paulus und Johannes, indem zwei nominale

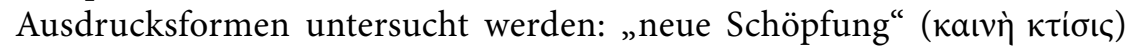

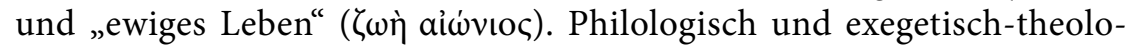
gisch soll genauer bestimmt werden, inwiefern die beiden Syntagmen

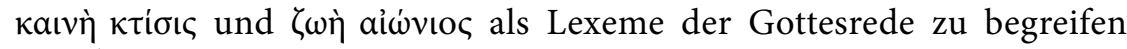
sind. ${ }^{1}$ Wie kommt in diesen Ausdrücken der Gedanke zur Geltung, dass Gott an seiner erschaffenen Schöpfung und seinem erschaffenen Geschöpf erneut kreatorisch handelt? ${ }^{2}$ Hinter dieser Frage stehen weitere,

\footnotetext{
${ }^{1}$ Dieser spezifischen Fragestellung bin ich in meinen bisherigen Untersuchungen zum Thema nicht explizit nachgegangen. Vgl. dazu Christina Hoegen-Rohls, Wie klingt es, wenn Paulus von Neuer Schöpfung spricht? Stilanalytische Beobachtungen zu 2 Kor 5,17 und Gal 6,15, in: Peter Müller/Christine Gerber/Thomas Knöppler (Hg.), „... was ihr auf dem Weg verhandelt habt." Beiträge zur Exegese und Theologie des Neuen Testaments

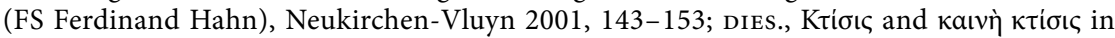
Paul's Letters, in: Alf Christophersen/Carsten Claussen/Jörg Frey/Bruce Longenecker (Hg.), Paul, Luke and the Graeco-Roman World (FS Alexander J.M. Wedderburn) (JSNTSup 217), London 2002, 102-122; DIES., Neuheit bei Paulus. Kommunikative Funktion und theologische Relevanz der paulinischen Aussagen über den Neuen Bund, die Neue Schöpfung und die Neuheit des Lebens und des Geistes (Habil. theol., masch.), München 2003; DiEs., Ewigkeit und Leben. Der biblische Vorstellungskreis III: Johannes, in: Petra Bahr/Stephan Schaede (Hg.), Das Leben. Historisch-systematische Studien zur Geschichte eines Begriffs (Protestantismus und Kultur 2), Tübingen 2009, 129-152.

${ }^{2}$ Dass dabei nicht von „kreatürlichem“, sondern von „kreatorischem“ Handeln Gottes gesprochen werden soll, liegt darin begründet, dass die Rede vom „kreatürlichen Handeln Gottes“ Gott in unsachgemäßer Weise depotenziert: „Kreatürlich“ handelt die Kreatur und somit keineswegs Gott, der nicht Kreatur, sondern creator ist. Was Gott als creator wirkt, ist sein „kreatorisches“ Handeln, auf dessen re-kreatorischen Aspekt sowohl die nominalen

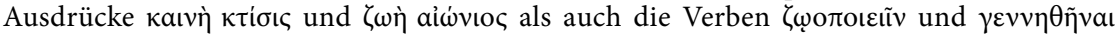
Bezug nehmen. Zum Gebrauch der Verben vgl. im vorliegenden Band den Beitrag von Christiane Zimmermann, Gottes rekratorisches Handeln bei Paulus und Johannes I: Das „Lebendigmachen“ und das „aus Gott/von oben Gezeugt-/Geborenwerden“, S. 161-186.
} 
grundsätzlichere Fragen, die die paulinische und johanneische Rede von Gott betreffen: Was will Gott mit seiner von ihm erschaffenen Schöpfung? Was will Gott für seine von ihm ins Leben gerufenen Geschöpfe? Wann, für wie lange und unter welcher Bedingung will er das, was er will? Und als welcher will er, was er will? Diese Fragen können im vorliegenden Beitrag nicht umfassend behandelt werden. Doch möchte ich in Ansätzen klären, welches Gottesbild hinter der genuin paulinischen Rede von der

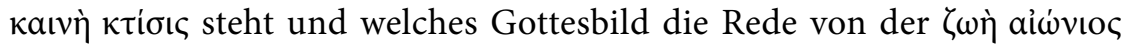
spiegelt, die sowohl Paulus als auch Johannes verwenden. Die Beantwortung dieser komparatistisch ausgerichteten Fragen fördert meines Erachtens eine profilierte Wahrnehmung der johanneischen Gottes-Rede, wie sie der vorliegende Tagungsband anstrebt.

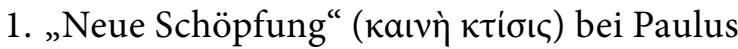 und das damit verknüpfte Gottesbild}

\subsection{Der terminologische Befund}

Bekanntlich verwendet im Neuen Testament nur Paulus das Syntagma

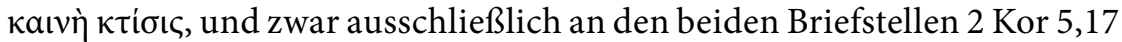
und Gal 6,15. Paulus übernimmt die Wortverbindung nicht aus der Septuaginta. Diese kennt sie so wenig wie andere griechische Schriften aus hellenistisch-jüdischer Zeit. Die von Ulrich Mell postulierte Annahme, Paulus gewinne den Ausdruck aus der antiochenischen Gemeinde, bleibt hypothetisch. ${ }^{3}$ Auch die Suche nach möglichen nicht-griechischen Begriffsparallelen nominaler oder verbaler Art in der rabbinischen Lite-

\footnotetext{
${ }^{3}$ Ulrich Mell, Neue Schöpfung. Eine traditionsgeschichtliche und exegetische Studie zu einem soteriologischen Grundsatz paulinischer Theologie (BZNW 56), Berlin 1989, 316; DERS., „Neue Schöpfung“ als theologische Grundfigur paulinischer Anthropologie, in: Eilert Herms (Hg.), Menschenbild und Menschenwürde, Gütersloh 2001, 345-364: 350-356. Kritisch dazu Margaret E. Thrall, A Critical and Exegetical Commentary on the Second Epistle to the Corinthians, Vol. I: Introduction and Commentary on II Corinthians 1-7, Edinburg 1994, 423.
} 
ratur ${ }^{4}$, in der Literatur von Qumran ${ }^{5}$ und weiteren jüdischen Schriften aus hellenistisch-römischer Zeit ${ }^{6}$ liefert keine tragfähigen Befunde, auf deren Basis eine weitere Verbreitung des Syntagmas angenommen werden könnte. Erst bei Clemens von Alexandrien ${ }^{7}$ und in den Pauluskommen-

\footnotetext{
${ }^{4}$ Der in der rabbinischen Literatur begegnende Ausdruck בריאה חדשה lässt sich nicht für die Herleitung des paulinischen Sprachgebrauchs fruchtbar machen, da er sich noch nicht in tannaitischer Zeit, sondern erst in Rabbinenworten des 4. Jahrhunderts n. Chr. findet. Vgl. dazu Mell, Neue Schöpfung (Anm. 3) 256. Gerhard Schneider, Die Idee der Neuschöpfung beim Apostel Paulus und ihr religionsgeschichtlicher Hintergrund, TTZ 68 (1959) 257-270: 262, geht bei der Suche nach traditionsgeschichtlichen Vorbildern bzw. Parallelen zwischen Paulus und der rabbinischen Literatur davon aus, „daß man von einer endzeitlichen Wiederherstellung im Rabbinat erst vom 3. christlichen Jahrhundert an gesprochen hat". Zu fragen

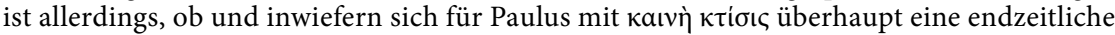
Vorstellung verbindet; vgl. dazu auch Thrall, Corinthians (Anm. 3) 422.

${ }^{5}$ Vgl. dazu Mell, Neue Schöpfung (Anm.3) 111; Thrall, Corinthians (Anm.3) 421; Nadine Ueberschaer, Theologie des Lebens bei Paulus und Johannes. Ein theologisch-konzeptioneller Vergleich des Zusammenhangs von Glaube und Leben auf dem Hintergrund ihrer Glaubenssummarien (WUNT 389), Tübingen 2017, $121 \mathrm{f}$.

${ }^{6}$ Vgl. dazu Ueberschaer, Theologie (Anm. 5) 122f. mit Hinweis auf Siegbert Uhlig, Das äthiopische Henochbuch, JSHRZ V,6, Gütersloh 1984; Klaus BERGER, Das Buch der Jubiläen, JSHRZ II,3, Gütersloh 1974; Christof W. STRÜDER, Identität im Wandel. Konkretionen zu den Abstracta "Neue Schöpfung" und "Gerechtigkeit Gottes" in 2 Kor 5,17.21, in: Reimund Bieringer/Ma. Marilou S. Ibita u. a. (Hg.), Theologizing in the Corinthian Conflict. Studies in the Exegesis and Theology of 2 Corinthians (BToSt 16), Leuven 2013, 177-209. Ueberschaer hebt zu Recht hervor, dass die Belege in äthHen 72,1 („Und er zeigte mir all ihre Vorschrift, wie sie ist, und wie alle Jahre der Welt [sind] und bis in Ewigkeit, bis die neue Schöpfung, die bis in Ewigkeit währt, geschaffen sein wird. “ Übersetzung nach Uhlig, Henochbuch, 638) und in Jub 4,26 („Denn vier Orte auf der Erde gehören dem Herrn: Der Garten Eden und der Berg des Morgens und dieser Berg, auf dem du heute bist, der Berg Sinai, und der Berg Sion wir geheiligt werden in der neuen Schöpfung zur Heiligung der Erde." Übersetzung nach Berger, Jubiläen, 346) nicht in griechischer, sondern äthiopischer Sprache vorliegen.

${ }^{7}$ Vgl. Clemens Alexandrinus. Band 2: Stromata Buch I-IV, hg. v. Otto Stählin (GCS 15), Leipzig 1906, 224; 345. Clemens widerlegt im 8. Kapitel von Buch III die Auffassung, dass es für die Christen keinen Unterschied zwischen gut und böse gebe. In diesem Zusammenhang

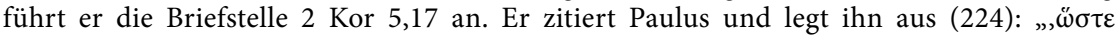

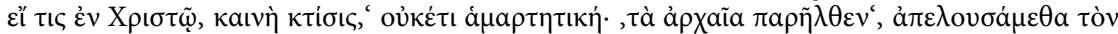

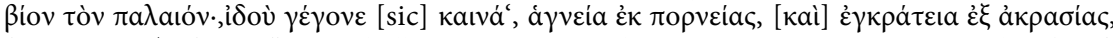

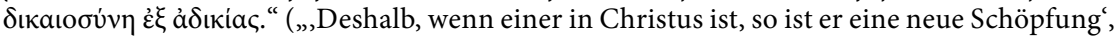
die nicht mehr zum Sündigen bereit ist. ,Das Alte ist vergangen; wir haben das alte Leben von uns abgewaschen. ,Siehe, Neues ist geworden', Keuschheit aus Unzucht, Enthaltsamkeit aus Zuchtlosigkeit, Gerechtigkeit aus Ungerechtigkeit." Übersetzung nach: Clemens von Alexandrien, Teppiche, Buch I-III [BKV 2. Reihe Bd. 17], hg. v. Otto Stählin, München 1936, 294). Im 5. Kapitel von Buch V behandelt Clemens die Frage der Gleichheit und zitiert in diesem Zusammenhang den paulinischen Beleg Gal 3,28, den er mit Hilfe von

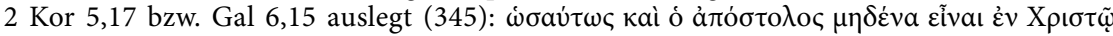

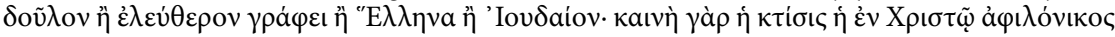

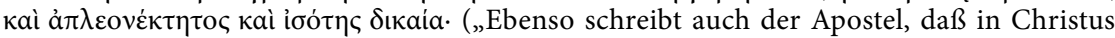
keiner Sklave oder Freier, Grieche oder Jude sei; denn neu ist die Schöpfung in Christus, die frei von Streitsucht und von Habgier und eine gerechte Gleichheit ist." Übersetzung nach:
} 


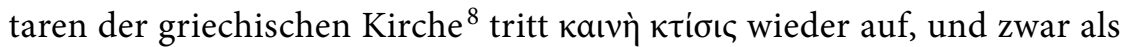
Zitat aus 2 Kor 5,17 und Gal 6,15. ${ }^{9}$ Als Ergebnis der begriffsgeschichtlichen Untersuchungen zur paulinischen Verwendung des Syntagmas kaıvì $\kappa \tau i \sigma ı \varsigma$ ist es daher konsequent, zu formulieren, dass es sich bei der Wortverbindung um eine paulinische Wortbildung, um einen paulinischen Neologismus handelt. ${ }^{10}$

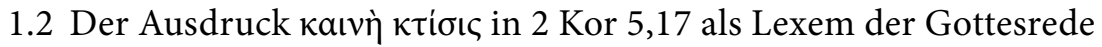

2 Kor $5,17^{11}$

$17 \mathrm{a} \omega \sigma \tau \varepsilon^{12}$

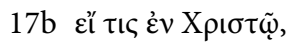

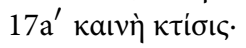

Clemens von Alexandrien, Teppiche, Buch IV-VI [BKV 2. Reihe Bd. 19], hg. v. Otto Stählin, München 1937, 144).

${ }^{8}$ Vgl. dazu Karl StaAв, Pauluskommentare aus der griechischen Kirche, NTAbh 15, Münster 1933, 29: Didymus von Alexandria (ca.313-398) zu 2 Kor 5,17-19; 52: Eusebius von Emesa (gest. um 359) zu Gal 6,15-16); 293: Severian von Gabala (gest. nach 409) zu 2 Kor 5,17; 304: Severian von Gabala zu Gal 6,14-15; 448: Ökumenius von Trikka (6. Jahrhundert) zu Gal 6,15. Vgl. auch die allerdings fragmentarischen Hinweise bei Moyer V. Hubbard, New Creation in Paul's Letters and Thought (SNTSMS 119), Cambridge 2002, 2 mit Anm. 2.

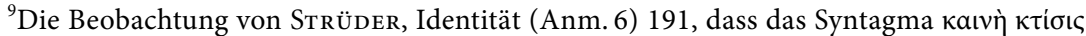
„in die Patristik einging“, muss also dahingehend präzisiert werden, dass der Ausdruck, wie Anm. 7 und Anm. 8 belegen, ausschließlich als Pauluszitat bzw. als Auslegung von Paulus bei

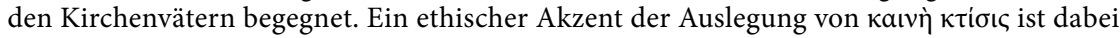
unverkennbar.

${ }^{10}$ So Hoegen-Rohls, Neuheit (Anm.1) 118. Zu diesem Ergebnis gelangen nach erneuter Überprüfung der Begriffsgeschichte auch Torsten JANTSCH, „Gott alles in allem“ (1 Kor 15,28). Studien zum Gottesverständnis des Paulus im 1. Thessalonicherbrief und in der korinthischen Korrespondenz (WMANT 129), Neukirchen-Vluyn 2011, 350 f., sowie Ueberschaer, Theologie (Anm.5) 120-125, die einen ausführlichen Exkurs zum traditionsgeschichtlichen Hintergrund und zum Umfeld der paulinischen Rede von der кaıv̀े $\kappa \tau i$ бıৎ bietet.

${ }^{11} \mathrm{Zu}$ den Prinzipien der Verssegmentierung der zitierten biblischen Texte vgl. Christina Hoegen-Rohls, Schritt für Schritt auf dem Weg in den Text. Die Methode der Verssegmentierung am Beispiel von Joh 4,1-15, VvAa 2 (2016) 27-59.

${ }^{12}$ Die Segmentierung von V. 17a.a' verdanke ich dem Gespräch mit meiner studentischen Hilfskraft Anne-Sophie Münch, Münster. Die Konjunktion $̋ \sigma \tau \varepsilon$ kann im Neuen Testament wie im klassischen Griechisch selbständige Sätze einführen (mit Indikativ, Imperativ oder Konjunktiv). V. 17a.a' wäre ein solcher selbständiger Satz, in dem als finites Verb der Indi-

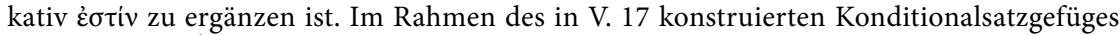
kommt V. 17a.a' die Funktion einer Apodosis zu, die durch die in V. 17b eingeschobene Protasis unterbrochen wird. Die Unterbrechung führt zu einer erhöhten rhythmisch-intonatorischen Dynamik dieses Versteiles, vergleichbar der rhythmisch-intonatorischen Dynamik von V. $17 \mathrm{c}-\mathrm{e}$. Der Vers insgesamt erweist sich so als eine Sprecheinheit von zweimal drei Atemphasen: V. 17a-a'; V. 17c-e. 


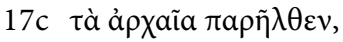

$17 \mathrm{~d}$ íov̀

17 e үغ́jovev kaıvá. ${ }^{13}$

Paulus führt die Gegenüberstellung von vergangenem Altem und „neuer Schöpfung" im Zweiten Korintherbrief in einem weit gespannten Zusammenhang ein, in dem er der korinthischen Gemeinde den Wert und die Intention seines apostolischen Dienstes auseinandersetzt und damit zugleich sein apostolisches Selbstverständnis zur Geltung bringt (2 Kor 2,14-7,4). Die Rede von Gott spielt im Kontext dieser Überlegungen eine grundlegende Rolle, wie sich schon an wenigen markanten Beispielen belegen lässt: Gott ist es, der Paulus zum „Diener des neuen Bundes" - nämlich des "neuen Bundes des Geistes" - ermächtigt (3,5f.; vgl. 4,1$)$ und ihm den „Dienst der Versöhnung“ aufgetragen hat $(5,18)$. Allein Gott ist es daher, vor dem sich Paulus als Apostel zu verantworten

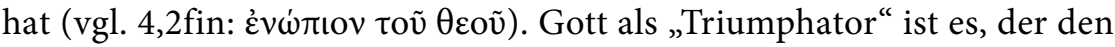
Apostel im Triumphzug für das siegreiche Evangelium von Christus mit sich führt (2,14-17). Gott als der (im Unterschied zu den leblosen Götzen) lebendige Gott ist es, der in seinem Diener (und in der Gemeinde) wohnt, so dass sich diese als Gottes Volk und Gottes Tempel verstehen können $(6,16) .{ }^{14}$ Gerade Gott als Schöpfergott ist es, der den Apostel zum Vermittler von Gotteserkenntnis macht $(4,6)$. Auch die Rede von der "neuen Schöpfung" in 2 Kor 5,17 kann in die Reihe der Gottesaussagen eingezeichnet werden, selbst wenn das Nomen $\theta \varepsilon$ ć

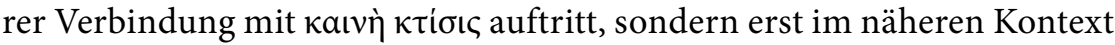
belegt ist (V. 18a). Es lassen sich darüber hinaus jedoch andere sprachliche

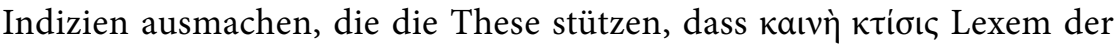
paulinischen Gottesrede ist. Diese sind im Folgenden ebenso wie der explizite Bezug auf Gott in 2 Kor 5,18a zu benennen.

(1) Mit V. 17a.b ist ein Konditionalsatzgefüge konstruiert, in dessen

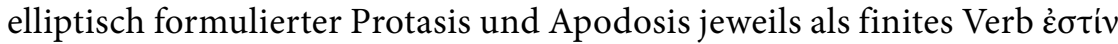
zu ergänzen ist. Die formulierte Aussage kann dann in zweierlei Weise als Definition verstanden werden. Wird grammatisch vorausgesetzt, dass das Subjekt aus V. 17a (irgendeiner/jemand) auch Subjekt von V. 17b ist, dann wird ausgesagt, dass einer, der „,in Christus“ ist, „neue Schöpfung“"

\footnotetext{
${ }^{13}$ Leitend für die Verssegmentierung von V. $17 \mathrm{~d}$ ist wiederum das rhythmisch-intonatorische Prinzip, das die Atempause nach dem formelhaften Imperativ ỉoví berücksichtigt (vgl. Anm. 12).

${ }^{14}$ Zum Kontrast zwischen lebendigem Gott und toten Götzen vgl. Christiane ZimmerMANN, Die Namen des Vaters. Studien zu ausgewählten neutestamentlichen Gottesbezeichnungen vor ihrem frühjüdischen und paganen Sprachhorizont (AJEC 69), Leiden 2007, $407 \mathrm{f}$.
} 


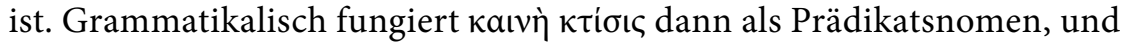
da das in „jemand“ enthaltene Subjekt auf einen Menschen referiert, legt es sich nahe, „neue Schöpfung“ personalisiert als „neues Geschöpf“ zu

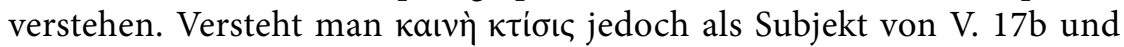
nimmt somit einen Subjektwechsel zwischen V. 17a und V. 17b an, so wird bestimmt, was unter der Voraussetzung, dass ein Mensch „in Christus" ist, der Fall ist: Es hat eine „neue Schöpfung", ein neues Schaffen stattgefunden. Beide Lesarten liegen inhaltlich nahe beieinander, insofern

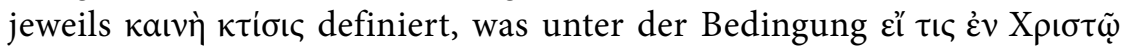
gilt. Doch bietet die zweite Lesart die Möglichkeit, кaıvทे ктібıৎ nicht eindimensional als Aussage über die neue Qualität des an Christus partizipierenden Menschen zu verstehen, sondern als eine Art „Syntagma divinum“, also als Lexem der Gottesrede, mit dem deutlich die Aktivität Gottes als schaffendem Schöpfer hervortritt. Es wäre dabei mit ктíøıৎ nicht nur das Ergebnis, sondern auch der Prozess göttlichen Schaffens im Blick, wie es auch der paulinische Sprachgebrauch im Römerbrief

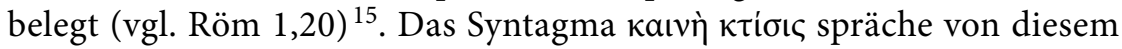
göttlichen Schaffen prägnant als einem neuen Schaffen Gottes.

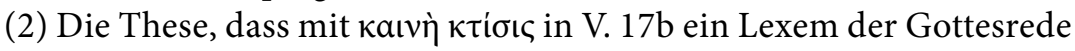
vorliegt, lässt sich durch den Fortgang des Verses erhärten. Mit V. 17c.e schließen sich zwei kurze Aussagesätze an, die durch den antithetischen, chiastisch gebauten Parallelismus rhetorisch akzentuiert werden. Sie erläutern mit Hilfe eines Gegensatzes, was „neue Schöpfung“ bedeutet: Das Alte ist vergangen, Neues ist geworden. Dabei wird durch den formelhaften Imperativ íovi in V. 17d, der als Aufmerksamkeitssignal fungiert und die Funktion einer emphatischen Interjektionspartikel übernimmt, das syntaktische Gewicht auf den zweiten der beiden Aussagesätze gelegt, der inhaltlich das Gewordensein des Neuen thematisiert. Dass dafür sprachlich das medio-passivische Verb $\gamma \varepsilon v \varepsilon \dot{\varepsilon} \sigma$ a genutzt wird, lässt danach fragen, wer als Agens hinter dem scheinbar aktivischen Werden des Neuen steht. Wird der passivische Charakter, den das medio-passivische finite Verb $\gamma \varepsilon$ jovev der Aussage verleiht, ernst genommen, so kann das Prädikat als ein passivum divinum verstanden werden. ${ }^{16}$ Die Aussage

\footnotetext{
${ }^{15}$ Vgl. dazu Hoegen-Rohls, Ktíøı (Anm. 1) 105-112.

${ }^{16}$ Vgl. zu Sache, Bezeichnung und Diskussion um das „passivum divinum“ im vorliegenden Band Christiane Zimmermann, Gottes rekreatorisches Handeln I (Anm. 2) S. 162-164, mit Verweis auf Joachim Jeremias, Die Abendmahlsworte Jesu, Göttingen 1960, 194-195; DERs., Neutestamentliche Theologie I: Die Verkündigung Jesu, Gütersloh 1971, 20-24; Gustaf Dalman, Die Worte Jesu, Leipzig ${ }^{2} 1930$, 183-185.190; Christian Macholz, Das „Passivum divinum“, seine Anfänge im Alten Testament und der „Hofstil“, ZNW 81 (1990)
} 


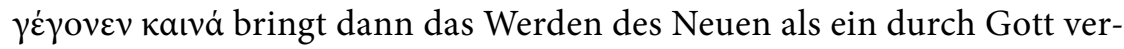

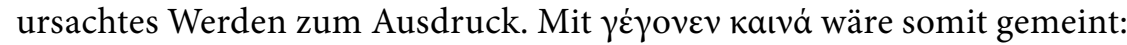
"Neues ist geworden durch Gott."

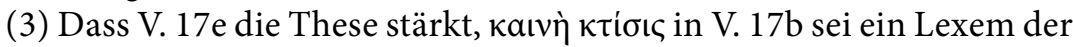
Gottesrede, lässt sich an einer weiteren Beobachtung festmachen. Diese betrifft das rhythmisch-intonatorische Gefälle von V. 17b und V. 17c-e: Wie der Satzakzent von V. 17c-e auf kaıvá, also auf dem durch Gott ge-

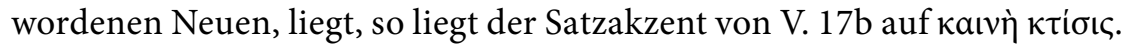
Die zur syntaktischen Position von kaıvá analoge syntaktische Schluss-

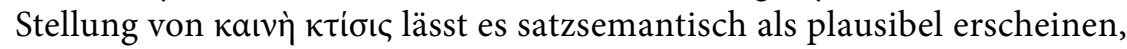
dass nicht nur in V. 17e, sondern auch in V. 17b mit dem Neuheitsterminus Gott zu verbinden ist. Auch wenn also $\theta$ eó erscheint, lässt sich begründen, dass hier vom Gotteshandeln gesprochen

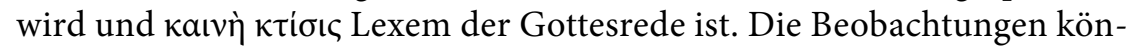
nen zudem dahingehend ausgewertet werden, dass auch кaıvá Lexem der Gottesrede ist.

(4) Dies bestätigt sich, wenn die Anspielung auf die Heilsverheißung aus Jes $43,18 \mathrm{f}$. LXX beachtet wird, die in 2 Kor 5,17 enthalten ist. ${ }^{17}$ Dort heißt es:

Jes 43,18f. LXX

18a Mì $\mu \nu \eta \mu o v \varepsilon v ́ \varepsilon \tau \varepsilon \tau \grave{\alpha} \pi \rho \tilde{\omega} \tau \alpha$

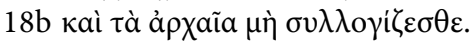

19a íoò̀

$19 \mathrm{~b} \pi \mathrm{r} \iota \tilde{\omega}$ Kaıvà

$19 \mathrm{c} a \ddot{v} v \tilde{v} v a ̉ v a \tau \varepsilon \lambda \varepsilon \tilde{\imath}$,

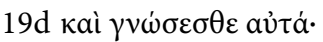

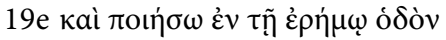

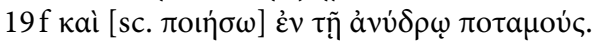

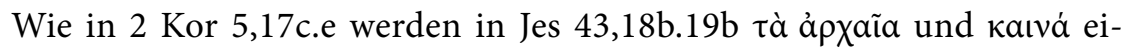
nander gegenübergestellt; wie in 2 Kor 5,17d findet sich in Jes 48,19a der formelhafte, nun deutlich als prophetisches Sprachelement zu erkennende Imperativ i̊ov́. Bemerkenswert für die oben gebotene Einschätzung, dass kaıvá in 2 Kor 5,17e als Lexem der Gottesrede fungiert

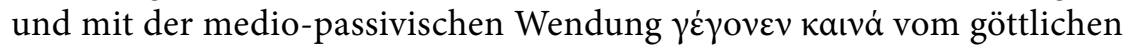

247-253; Marius Reiser, Die Gerichtspredigt Jesu, Münster 1990, 255-261; Beniamin Pascut, The So-Called Passivum Divinum in Marks' Gospel, NovT 54 (2012) 313-333; PeterBen Smit/Toon Renssen, The passivum divinum: The Rise and Future Fal of an Imaginary Linguistic Phenomenon, Filologia Neotestamentica 27 (2014) 3-24.

${ }^{17}$ Vgl. dazu Florian WiLK, Die Bedeutung des Jesajabuches für Paulus (FRLANT 179), Göttingen 1998, 276-280. 
Neuschöpfungshandeln gesprochen wird, ist die aktivische Formulierung

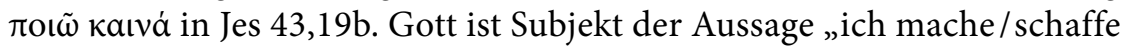
Neues“. Das aktivische Präsens $\pi$ ot $\tilde{\omega}$ greift V. 19e.f durch das aktivische Futur $\pi$ oıń $\sigma \omega$ auf. Subjekt bleibt Gott, dessen neuschöpferisches Handeln im Stilmittel des Parallelismus membrorum ausgedrückt wird: Gott wird Wege in der Wüste hervorbringen und Flüsse im Trockenen. Auch unter traditionsgeschichtlicher Perspektive lässt sich somit wahrscheinlich machen, dass das substantivierte neutrische Adjektiv kaıvá und das mit ihm stilistisch in Form eines Polyptoton verbundene feminine Syntagma kaıv̀ ктiбıc Lexeme der Gottesrede sind, mit denen von Gottes rekreatorischem Handeln gesprochen wird.

\subsection{Gott, der den Sohn auferweckt und die „Gestorbenen“ zur Proexistenz für Christus und zur Inexistenz in Christus führt: Gott als Schöpfer aus dem Tod}

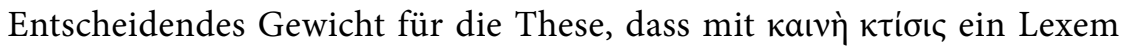
der paulinischen Gottesrede vorliegt, hat die Fortsetzung von 2 Kor 5,17 in V. 18a. Denn der in V. 17 fehlende explizite Verweis auf Gott wird

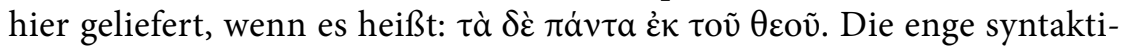
sche und gedankliche Verbindung zum Vorigen wird einerseits durch die Konjunktion $\delta \dot{\varepsilon}$ hergestellt, die hier nicht adversative, sondern explikative Funktion (im Sinne von „und zwar") hat, wenn sie nicht überhaupt als reine Übergangspartikel fungiert. ${ }^{18}$ Andererseits wird die Verknüpfung

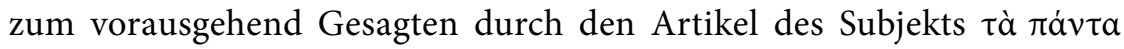
ermöglicht, der in anaphorischer Funktion auf schon Erwähntes verweist und daher prägnant mit „dies (alles) “ wiedergegeben werden kann. ${ }^{19} \mathrm{Da}$ bei scheint Paulus mit der im vorliegenden Gedankengang gut verzahnten Wendung „dies aber alles aus Gott" eine zugleich fast formelhafte Aussage zu gebrauchen. Mit dieser Wendung kann er auch an anderen Stellen seiner Briefe Gottes schöpferisches Handeln bzw. Gottes Sein als Schöpfer

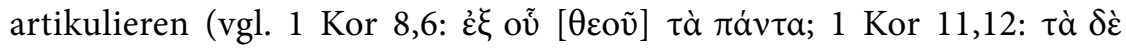

\footnotetext{
${ }^{18}$ Vgl. dazu Friedrich Blass/Albert Debrunner/Friedrich Reh kopf, Grammatik des neutestamentlichen Griechisch, Göttingen ${ }^{17} 1990, \S 447,1$.

${ }^{19}$ Vgl. Blass/Debrunner/Rehkopf, Grammatik (Anm.18) § 252a. Der Ausdruck tà

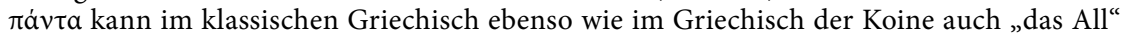
(im Sinne des Universums) bezeichnen. Im vorliegenden Kontext kommt diese semantische Füllung des Begriffs aus Gründen des stringenten Gedankengangs, der sich von 2 Kor 5,14 aus entwickelt, nicht in Frage. Vgl. dazu auch Ueberschaer, Theologie (Anm. 5) $131 \mathrm{mit}$ Anm. 313 .
} 


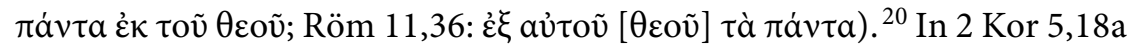

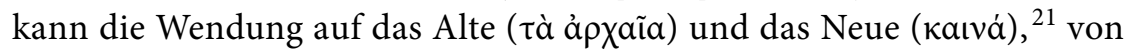
dem V. 17c.e spricht, ganz allgemein Bezug nehmen oder spezifischer auf das dort thematisierte Vergangensein des Alten und Gewordensein des Neuen. Da beide sich komplementär ergänzenden Aspekte den Gedanken

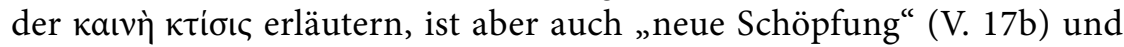

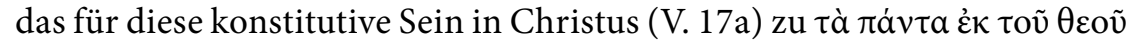
hinzuzurechnen. Wird wiederum beachtet, dass V. 17a, durch $\tilde{\sigma} \sigma \tau \varepsilon$ eingeleitet, eine Folge formuliert, so reicht der Rückbezug von V. 18a noch wei-

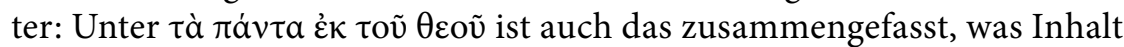
des V. 17 vorausgehenden Gedankengangs VV. 14-16 ist. ${ }^{22}$ Paulus entwickelt hier zunächst in V. 14f. im Blick auf den Tod Jesu den Gedanken der inklusiven Stellvertretung. Er leitet dafür aus der zweifach formulierten These, dass einer (Christus) für alle (Menschen) gestorben sei (V. 14c: عi

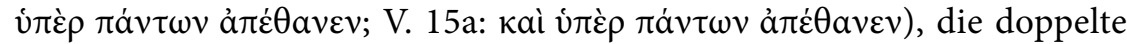
Folge ab, dass damit einerseits alle (Glaubenden) gestorben seien (V. 14d:

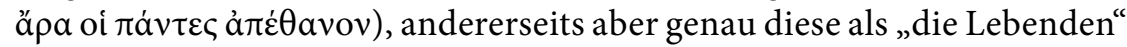
nicht mehr für sich selbst leben, sondern für den, der für sie gestorben

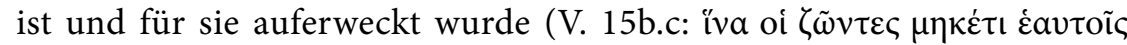

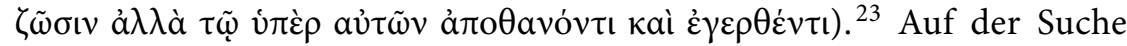

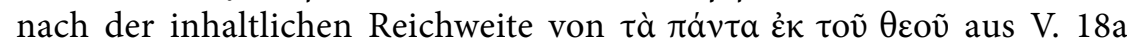
und nach Argumenten dafür, dass кaıvทे ктiбıৎ Lexem der Gottesrede ist, ist in V. $15 \mathrm{c}$ auf den Wechsel des Genus Verbi in den beiden partizipial

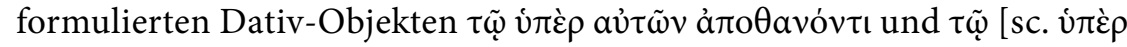

\footnotetext{
${ }^{20}$ Vgl. dazu Zimmermann, Namen (Anm. 14) 360-366.

${ }^{21}$ So ZimmermanN, Namen (Anm. 14) 364.

${ }^{22} \mathrm{Vgl}$. dazu auch Ueberschaer, Theologie (Anm.5) 111-116; Cilliers Breytenbach, Versöhnung. Eine Studie zur paulinischen Soteriologie (WMANT 60), Neukirchen-Vluyn

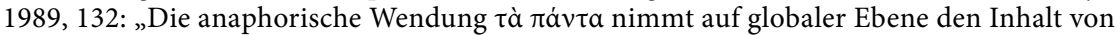
V. 14-17 auf und stellt die universale Bedeutung des Todes Christi, die Neuschöpfung und die durch diese eschatologische Wende ermöglichte neue Beurteilungsweise [...] in einen theozentrischen Zusammenhang."

${ }^{23} \mathrm{Zu}$ der äußerst schwierigen Bestimmung des Verhältnisses zwischen den „allen“ (oi

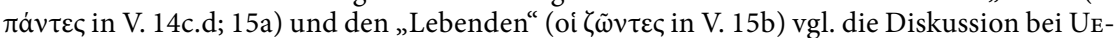
BersChaer, Theologie (Anm. 5) 111-114; BreytenbaCh, Versöhnung (Anm. 22) 125-128. Einerseits scheint Paulus die Intention des Sterbens Christi universal zu verstehen: Es gilt allen (Menschen). Andererseits spricht er doch wohl, wenn er sagt, dass „alle“ gestorben sind, nur von denjenigen, die Christi Sterben für sich im Glauben angenommen haben, die also mit Christus im Glauben metaphorisch gestorben sind (vgl. Röm 6,3f.), so wie es für Paulus selbst gilt, der von sich sagen kann, nicht mehr er lebe, sondern Christus lebe in ihm (vgl. Gal 2,19). Die „Lebenden“ sind dann identisch mit den metaphorisch Gestorbenen, die die universale Intention des Sterbens Christi im Glauben annehmen und umsetzen in ein Leben für den, der für sie starb und auferweckt wurde.
} 


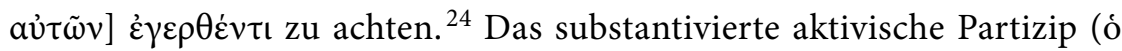

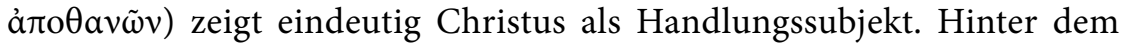

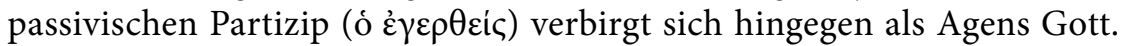

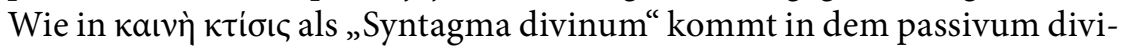
num der Auferweckungsaussage das rekreatorische Handeln Gottes zum Ausdruck. Auch das göttliche Auferweckungshandeln an Christus, mit dem Gott zugunsten der im übertragenen Sinne "Gestorbenen“ handelt,

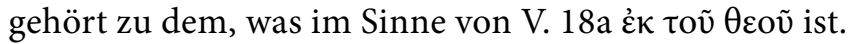

Aus dem realen, physischen Tod Jesu und dem Auferweckungshandeln Gottes gewinnen die metaphorisch Gestorbenen, die de facto physisch Lebende sind, eine neue Lebenshaltung, die sie zugleich in einem tieferen

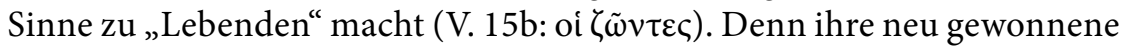
Lebenshaltung entspricht derjenigen Haltung, die Jesus ihnen gegenüber in seinem Sterben und seinem Auferwecktwerden eingenommen hat: die Lebenshaltung eines „Lebens für jemanden“, der nicht man selbst, sondern ein anderer ist (Proexistenz). ${ }^{25}$ Wohin diese neu gewonnene Lebenshaltung der Proexistenz führt, formulieren V. 16 und V. 17 in Form von Folgesätzen $(\ddot{\omega \sigma \tau \varepsilon)}$ als einerseits epistemologische, andererseits ontologische Folge. Die, die für den leben, an dem Gott durch Auferwecken

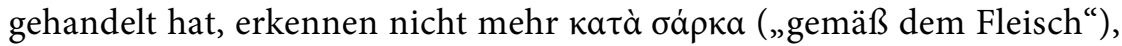
was das Erkennen bzw. Beurteilen von Menschen (vgl. V. 16a: oủ źva

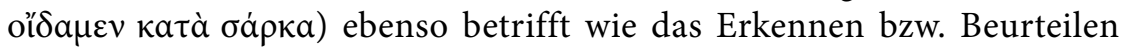

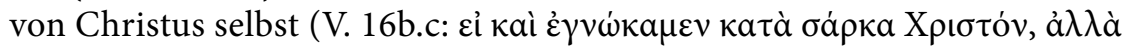

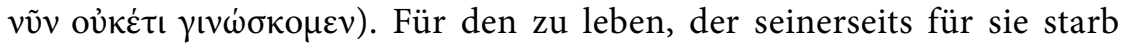
und für sie auferweckt wurde, bedeutet für die Lebenden aber auch, $\dot{\varepsilon} v$

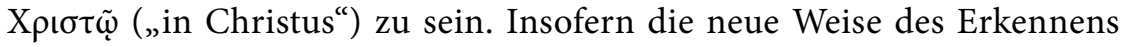
und das neue Sein in Christus Konsequenzen sind, die sich aus Gottes Handeln ergeben, gehören beide Phänomene zu dem hinzu, was V. 18a

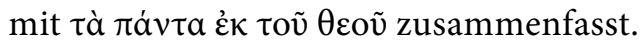

Der Gesamtduktus von VV. 14-17 bringt also Gott in passivischen bzw. medio-passivischen Verbformen sowie in den nomina divina кaıv̀े ктібıৎ und kaıvá als denjenigen zur Geltung, der sowohl an seinem Sohn schöpferisch handelt als auch erneut gegenüber seinen Geschöpfen als Schöpfer agiert. Er agiert dabei nicht als Schöpfer aus dem Nichts, sondern als Schöpfer aus dem Tod. Aus dem realen Tod seines Sohnes schafft er neues

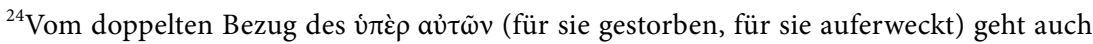
Breytenbach, Versöhnung (Anm.22) 128 aus.

${ }^{25}$ Vgl. dazu Hoegen-Rohls, Neuheit (Anm. 1) 124; Ueberschaer, Theologie (Anm. 5) 116 .
} 
Leben, indem er ihn auferweckt. Aus dem metaphorischen Tod derer, die durch den Tod Christi ebenfalls gestorben sind (nämlich sich selbst bzw. ihrem alten Leben gegenüber), schafft er ein Leben, das sich durch Proexistenz für Christus und durch Inexistenz in Christus auszeichnet.

\subsection{Gott, der die Menschen durch Christus mit sich versöhnt: Gott als Schöpfer durch den Tod}

Wird die Wendung "dies aber alles aus Gott“ aus 2 Kor 5,18a auf VV. 14-17 insgesamt bezogen, so stellt sich die Frage, ob zum rekreatorischen Handeln Gottes auch Jesu Sterben selbst hinzugehört, von dem, wie notiert, in V. 15 auf aktivische Weise gesprochen wird (in Form des finiten Verbs à $\dot{\varepsilon}_{\theta} \theta a v \varepsilon v$ und in Gestalt des substantivierten Partizips ó

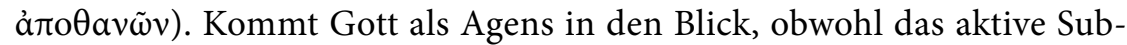
jekt des Sterbens Christus ist (vgl. V. 14a)? Die Frage lässt sich bejahen, wenn man beachtet, wie von Gottes Wirken durch Christus in V. 18b und in V. 19a die Rede ist:

\section{Kor $5,18 \mathrm{f}$.}

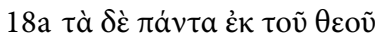

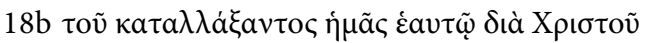

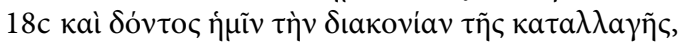

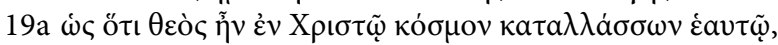

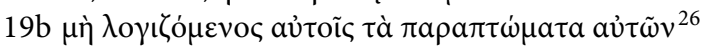

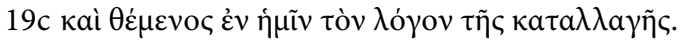

Gott wird in V. 18b genauer bestimmt als der, der die mit „wir“ bezeichnete Gruppe ${ }^{27}$ mit sich versöhnt hat (Aorist), und zwar „durch Chris-

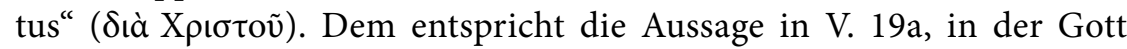

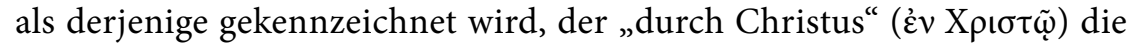
mit „Kosmos“ umschriebene Größ ${ }^{28}$ mit sich versöhnte (periphrasti-

\footnotetext{
${ }^{26}$ Zur Segmentierung der Verse vgl. auch Ueberschaer, Theologie (Anm. 5) 132.

${ }^{27}$ Zur Gruppe der „Wir“ sind entsprechend des adressatenbezogenen brieflichen Sprechens der Passage 2 Kor 5,11-6,2 sicher sowohl Paulus selbst als auch seine korinthischen Briefpartner zu zählen; vgl. dazu auch Ueberschaer, Theologie (Anm. 5) 132, mit Verweis auf Thomas Schmeller, Der zweite Brief an die Korinther, Teilband 1: 2 Kor 1,1-7,4 (EKKNT 8,1), Neukirchen-Vluyn 2010, $333 \mathrm{f}$. Vom eng verzahnten Duktus der Ausführungen her legt es sich m. E. jedoch ebenfalls nahe, in der Größe des persönlich formulierten „Wir" bereits die Menschenwelt als Ganze bezeichnet zu sehen, von der dann in einer grundsätzlichen Weise in V. 19a als Objekt des Versöhnungshandelns Gottes die Rede ist.

${ }^{28}$ „Kosmos“ hat hier aus inhaltlichen Gründen nicht kosmologischen Sinn („Universum“), sondern anthropologische Bedeutung („Menschenwelt“). Vgl. dazu UeberschaER, Theologie (Anm. 5) 132, mit Verweis auf Reimund Bieringer, Sünde und Gerechtigkeit Gottes in
} 
sches Imperfekt). ${ }^{29}$ Beide Aussagen bringen zur Geltung, dass hinter Jesu Sterben, von dem hier abgekürzt durch die beiden jeweils instrumental

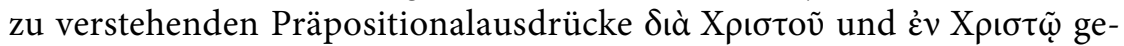
sprochen wird, ${ }^{30}$ Gott als Handlungssouverän steht. Christi Tod ist das Mittel für Gottes rekreatorisches Handeln. Somit schafft Gott nicht nur aus dem Tod, sondern durch den Tod neues Leben. Liest man die Versöhnungsaussagen von V. 18b.19a konsequent von der anaphorisch auf

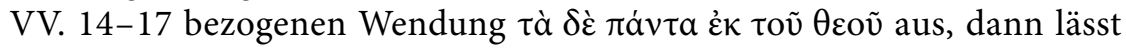
sich plausibel machen, dass Gottes rekreatorisches Handeln durch den Tod nicht Folge, sondern Form und Ausdruck seines Versöhnungshandelns ist: Indem Gott versöhnt, schafft er neu. In seinem rekreatorischen Versöhnungshandeln erweist sich Gott als derjenige, der durch den Tod seines Sohnes eine neue Realität für die Menschen schafft, insofern er ihnen ihre Übertretungen nicht anrechnet (V. 19b). Auf die Frage, als welcher Gott an seinen Geschöpfen rekreatorisch handelt und als welcher er für seine Geschöpfe in der Welt die Realität einer "neuen Schöpfung“" will, ergibt sich von 2 Kor 5,18f. aus die Antwort: als neuschöpfender Versöhner.

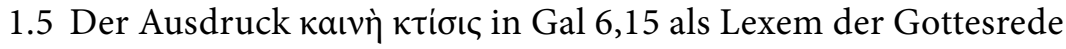

Im Postskript des Galaterbriefes (Gal 6,11-18) gebraucht Paulus den Neu-

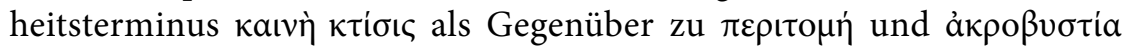
und stellt dadurch eine Parallele her zu einer früheren brieflichen Äu-

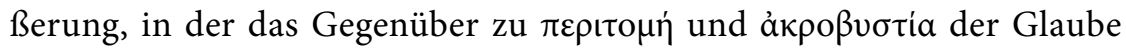
ist. ${ }^{31}$ Beide Aussagen sind sentenzhaft in der rhetorischen Gestalt einer

2 Korinther 5,21, in: Ders./Jan Lambrecht, Studies in 2 Corinthians (BETL 112), Leuven 1994, 429-459: 450f.; Karl Kertelge, „Neue Schöpfung“. Grund und Maßstab apostolischen Handelns (2 Kor 5,17), in: Martin Evang/Helmut Merklein/Michael Wolter (Hg.), Eschatologie und Schöpfung (FS Erich Gräßer) (BZNW 89), Berlin 1997, 139-144: 141; Emmanuel L. Rehfeld, Relationale Ontologie bei Paulus. Die ontische Wirksamkeit der Christusbezogenheit im Denken des Heidenapostels (WUNT 2,326), Tübingen 2012, 250; Jens Schröter, Der versöhnte Versöhner. Paulus als unentbehrlicher Mittler im Heilsvorgang zwischen Gott und Gemeinde nach 2 Kor 2,14-7,4 (TANZ 10), Tübingen 1993.

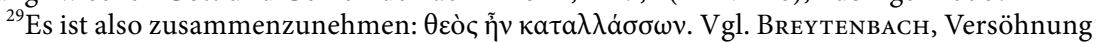
(Anm. 22) 110 f., der ausführt (111): „Die Periphrase $\tilde{\eta} v \kappa a \tau \alpha \lambda \lambda \dot{\alpha} \sigma \sigma \omega v$ umschreibt einen [sic.] Imperfekt und drückt anschaulich aus, daß Gott in der Vergangenheit die Welt mit sich versöhnt hat, ohne daß dabei an einen Abschluß dieser Handlung gedacht ist. Gottes Versöhnung mit der Welt ist ein Dauerzustand.“

${ }^{30}$ Beide Präpositionalausdrücke fungieren dann als Adverbialbestimmung zu toṽ $\kappa a-$

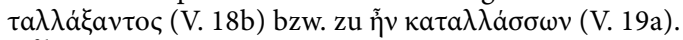

${ }^{31}$ Susanne Schewe, Die Galater zurückgewinnen. Paulinische Strategien in Galater 5 und 6 (FRLANT 208), Göttingen 2005, 198, versteht Gal 5,5f. als „Kurzfassung christlicher 
antithetischen correctio formuliert, in der die Gültigkeit zweier Größen durch eine dritte Größe nach dem Schema „weder - noch, sondern“ korrigiert wird. ${ }^{32}$ Das Kriterium, an dem sich die Geltung der drei genannten

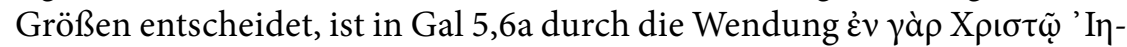
бoṽ unmissverständlich benannt: In Jesus Christus bedeuten bzw. gelten (i̊ox́cเv) ${ }^{33}$ weder Beschneidung irgendetwas (V. 6a) noch Unbeschnittenheit (V. 6b), sondern es gilt allein (ein) Glaube, der durch Liebe wirkt (V. 6c). Dieses Kriterium wird in Gal 6,15 nicht erneut explizit erwähnt. Doch legt es sich nahe, es mitzudenken, und zwar nicht allein aufgrund der Parallelität beider Briefstellen, ${ }^{34}$ sondern auch aufgrund der Tatsache, dass in V. 14 ausdrücklich vom „Kreuz unseres Herrn Jesus Christus“ gesprochen wird. Das explizite, abstrakt gehaltene Kriterium „in Jesus Christus" aus Gal 5,6 ist auch in Gal 6,15 impliziert und dabei durch Gal 6,14 staurologisch konkretisiert:

Gal 6,14f.

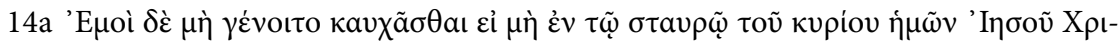
$\sigma \tau$ นõ,

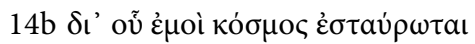

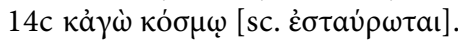

vgl. Gal 5,6

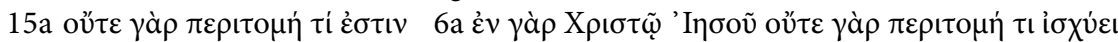

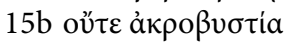

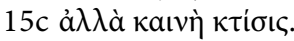

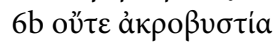

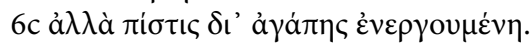

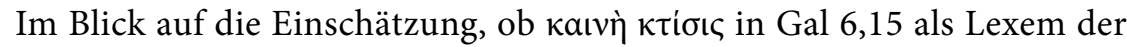
Gottesrede verstanden werden kann, stellt sich das Problem, dass in der schlagwortartigen Formel ${ }^{35}$ von V. 15c, für die (wie für V. 15b) als Prädi-

Glaubensüberzeugung“, die in Gal 6,15 „reformuliert“ werde. Eine solche Reformulierung gilt jedoch nur für Gal 5,6. Denn es ist offenkundig, dass der Zusammenhang von Glaube, Geist und erhoffter Gerechtigkeit, der für Gal 5,5 charakteristisch ist, in Gal 6,15 nicht

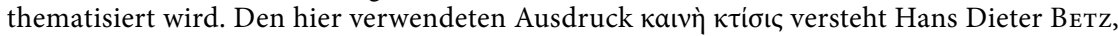
Der Galaterbrief. Ein Kommentar zum Brief des Apostels Paulus an die Gemeinden in Galatien, München 1988, 541, als Zusammenfassung der paulinischen Soteriologie.

${ }^{32}$ Vgl. dazu genauer Hoegen-Rohls, Wie klingt es, wenn Paulus von Neuer Schöpfung spricht? (Anm. 1); Schewe, Galater (Anm. 31) $198 \mathrm{f}$.

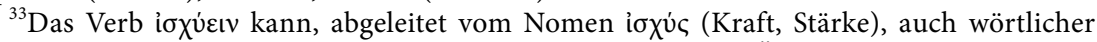
mit „Macht haben“, „Kraft haben“ übersetzt werden. Vgl. die Übersetzung bei Christiane Zimmermann, Gott und seine Söhne. Das Gottesbild des Galaterbriefes (WMANT 135), Neukirchen-Vluyn 2013, 108.

${ }^{34}$ Diese Parallelität hat bei der Textüberlieferung dazu geführt, dass manche Zeugen die Wendung $\dot{\varepsilon} v$ Xpı $\tau \tilde{\omega}$ in Gal 6,15 eingetragen haben. Zum textkritischen Befund von Gal 6,15 vgl. Betz, Galaterbrief (Anm. 31) 541, Anm. 74.

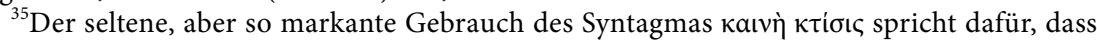
es sich bei diesem Ausdruck um eine den Galatern bekannte Größe handelt, doch lässt sich 


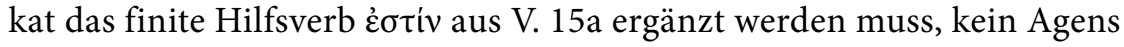
erkennbar ist. Doch lassen sich unter Berücksichtigung von V. 13 und V. 14 Handlungsassoziationen entdecken. So zeigt sich in V. 13, dass die

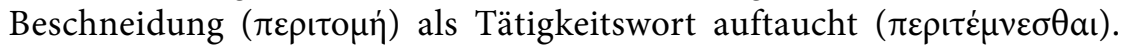

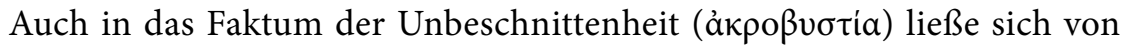

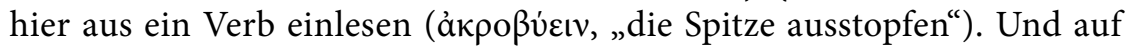

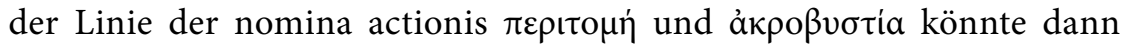

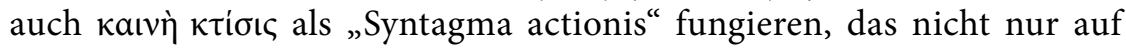
das Ergebnis eines Schaffensaktes, sondern auch auf den Schaffensprozess selbst referiert. Wer wäre Akteur dieses Schaffensprozesses? Zur Beantwortung dieser Frage ist auf die Metaphorik und den Verbgebrauch von

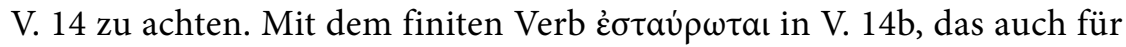
die elliptische Aussage von V. 14c zu ergänzen ist, liegt eine passivische Formulierung vor, mit der Paulus metaphorisch zum Ausdruck bringt, dass er durch das Kreuz Christi, das heißt durch Christi Tod am Kreuz, selbst eine zweifache Kreuzigungserfahrung gemacht hat: Ihm wurde die Welt „gekreuzigt" und er wurde der Welt "gekreuzigt“. Paulus führt mit dieser übertragenen Rede vom wechselseitigen Gekreuzigtwerden das schon in Gal 2,19 verwendete Bild („Ich bin mit Christus gekreuzigt“) weiter, um wie dort den Gedanken zu artikulieren, dass der Glaubende durch die Begegnung mit Christus eine entscheidende Wende erlebt, die zu einer neuen Form von Leben und Identität führt. Geprägt ist diese neue Identität davon, dass - wiederum in übertragenem Sinne - nicht eigentlich mehr das menschliche Ich, sondern Christus selbst im Glau-

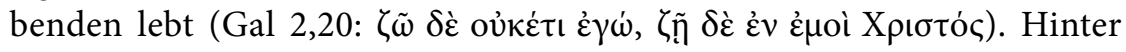
der passivischen Aussage von Gal 6,15 kann daher zunächst Christus als Agens vermutet werden. Insofern das Kreuz, durch das der Glaubende "gekreuzigt" wird, in Gottes Willen gründet (vgl. Gal 1,3f.) und Ziel der von Gott ausgehenden Sendung des Sohnes ist (vgl. Gal 4,4), tritt jedoch auch Gott als Agens in den Blick. Christus und Gott sind somit

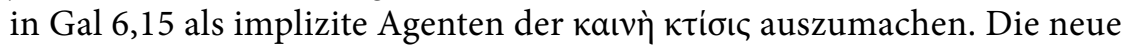
Existenz und Identität des Menschen verdankt sich einem schöpferischen Akt Gottes, der durch den Kreuzestod des Sohnes vollzogen wird. Als welcher Gott wird Gott hier transparent? Wieder, wie in 2 Kor 5,17f.

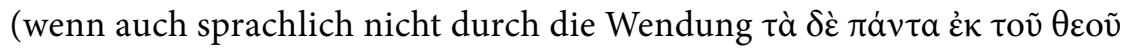
hervorgehoben), steht Gott der Sache nach als Schöpfer durch den Tod im

dies nicht sicher belegen. Vgl. dazu Hoegen-Rohls, Wie klingt es, wenn Paulus von Neuer Schöpfung spricht? (Anm. 1) 146-150; Betz, Galaterbrief (Anm. 31) 542 mit Anm. 76. 


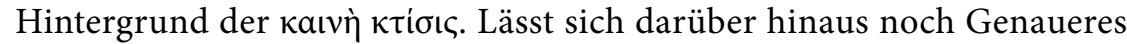
sagen?

\subsection{Gott, nach dessen Willen sich Christus hingibt, der Christus auferweckt und der mit Christus Gnade und Frieden schenkt: Der barmherzige Gott des Friedens als Schöpfer durch und aus dem Tod}

Indem in Gal 6,14 so deutlich vom Kreuz Christi die Rede ist und somit implizit in V. 15 das Gottesbild von Gott als Neuschöpfer durch den Tod seines Sohnes anklingt, verschränkt sich das Postskript des Galaterbriefes inhaltlich in markanter Weise mit dessen Präskript. Schon hier wird in der superscriptio, in der sich Paulus in Form einer antithetischen correctio als einen Apostel vorstellt, der "nicht von Menschen her, auch nicht durch Menschen, sondern durch Jesus Christus und Gott, den Vater" berufen ist, Gott näher bestimmt als der, der Christus „aus Toten“

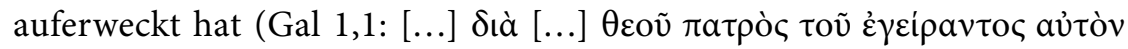

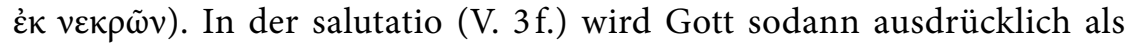
derjenige gekennzeichnet, nach dessen Willen sich die Hingabe Christi für die menschlichen Verfehlungen zum Zwecke der Rettung aus dem bestehenden schlechten Äon ${ }^{36}$ vollzogen hat:

Gal 1,3f.

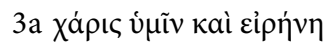

$3 \mathrm{~b}$ ảंò $\theta \varepsilon o \tilde{v} \pi \alpha \tau \rho \grave{c} \varsigma \hat{\eta} \mu \tilde{\omega} v$

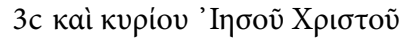

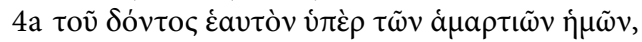

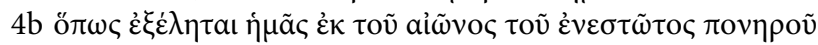

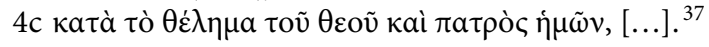

Der briefliche Eingangsgruß, der die kerygmatische Kommunikationssituation etabliert, die für die Paulusbriefe typisch ist, ${ }^{38}$ vergegenwärtigt Gott, den Vater der Glaubenden, und Christus, ihren Herrn, als die das

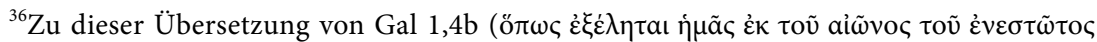

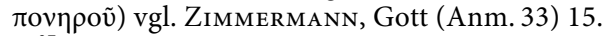

${ }^{37}$ Die Verssegmentierung erfolgt zwischen V. 4a/V. 4b nach dem syntaktischen Prinzip, in allen anderen Fällen (V. 3a/V. 3b; V. 3b/V. 3c; V. 4b/V. 4c) nach dem rhythmisch-intonatorischen Prinzip. Vgl. dazu Hoegen-Rohls, Verssegmentierung (Anm. 11).

${ }^{38}$ Vgl. dazu Christina Hoegen-Rohls, Zwischen Augenblickskorrespondenz und Ewigkeitstexten. Eine Einführung in die paulinische Epistolographie (BThSt 135), NeukirchenVluyn 2013.
} 
briefliche Kommunikationsgeschehen durch Gnade und Frieden wesentlich Mitbestimmenden. Die Wendung xá daher nicht auf die Funktion einer epistolaren Formel reduziert werden. Vielmehr rufen die Näherbestimmmungen in V. 3b.c und V. 4a.b präzise zu Beginn des Galaterbriefes in Erinnerung, dass und in welcher Weise Gnade/Barmherzigkeit und Frieden von Gott und Christus kommen. Die

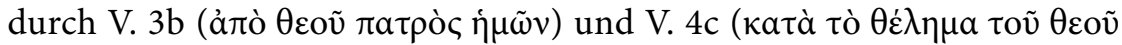

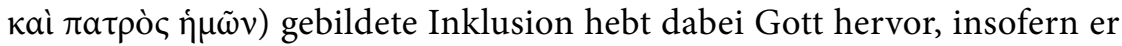
als Spender von Gnade und Frieden als erster genannt und ausdrücklich als derjenige gekennzeichnet wird, dessen Wille für das eschatologische Heilsgeschehen entscheidend ist. ${ }^{39}$

Der die Rettung initiierende Gott der Gnade und des Friedens, der das Präskript prägt, ist es, der auch hinter der kaıv̀े ктíঞı des Postskripts steht. Die Frage, als welcher Gott die Neuschöpfung seiner Geschöpfe will und vollzieht, kann somit folgendermaßen beantwortet werden: als barmherziger Gott des Friedens und als Initiator des in und durch Christus vollzogenen Rettungsgeschehens. Ist er als solcher „Gott allein“? Als Initiator: ja. Doch in der Durchführung seines rekreatorischen Handelns bindet sich Gott an seinen Sohn. Die paulinische Rede

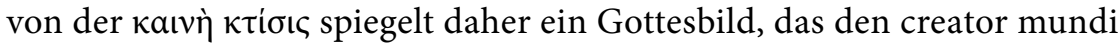
et hominis - aus seinem eigenen Willen heraus - angewiesen sein lässt auf Christus. Gottes rekreatorisches Handeln ist ohne seinen Sohn nicht $\mathrm{zu}$ vollziehen. Gott, der creator, ist in seinem rekreatorischen Handeln nicht autark, Gott allein kann die neue Schöpfung nach paulinischer Auffassung nicht wirken. Es zeigt sich hierbei ein Gottesbild, das den Gedanken der Schöpfungsmittlerschaft Christi auch für die Neuschöpfung aufnimmt.

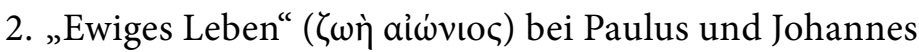
und das damit verknüpfte Gottesbild

\subsection{Der terminologische Befund}

Die Verbindung „ewiges Leben“ begegnet in zahlreichen Schriften des Neuen Testaments. Es finden sich acht Belege des Syntagmas in den synoptischen Evangelien, zwei in der Apostelgeschichte und fünf bei Pau-

\footnotetext{
${ }^{39}$ Vgl. Zimmermann, Gott (Anm. 33) 21.
} 
lus. ${ }^{40}$ Den bei weitem größten Anteil des Vorkommens bieten mit 21 Belegen das Johannesevangelium und der erste Johannesbrief. ${ }^{41}$ Im Vergleich mit der Sprache der Synoptiker, der Apostelgeschichte und der Paulusbriefe lässt sich als Besonderheit der johanneischen Sprache beschreiben, dass Johannesevangelium und erster Johannesbrief das Epitheton „ewig“" (aíúvı૬) keinem anderen Nomen zuordnen als dem Nomen $\zeta \omega \eta \dot{n}$. Leben und Ewigkeit scheinen für die johanneische Theologie daher in einem besonders engen inhaltlichen Zusammenhang zu stehen. ${ }^{42}$ In den synoptischen Evangelien begegnet das Adjektiv „ewig“ hingegen auch in folgenden Verbindungen: „Ewiges Feuer" (Mt 18,8; 25,41), „ewige Strafe“ (Mt 25,46), „ewige Verfehlung“ (Mk 3,29), „ewiges Heil“ (Mk 16,8 v.l.), „ewige himmlische Wohnungen des Jenseits“ (Lk 16,9). Paulus verwendet es in den Wendungen „ewige Fülle der Herrlichkeit“ (2 Kor 4,17) und „ein ewiges Haus, nicht von Händen gemacht, im Himmel“ (2 Kor 5,1).

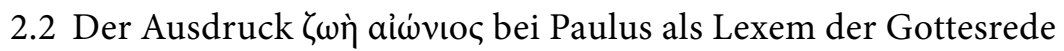

Aufgrund welcher sprachlichen Merkmale wird der Ausdruck „ewiges Leben" bei Paulus als Lexem der Gottesrede erkennbar? In welcher Weise

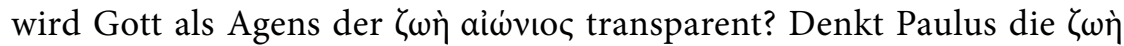
aỉ́vıo als gegenwärtige oder künftige Größe? Die Belege Röm 2,7; 5,21; $6,22 \mathrm{f}$. und Gal 6,8 sind auf diese Fragen hin zu prüfen.

2.2.1 Gott ist als Heiligender und Richter Neuschöpfer seiner Geschöpfe:

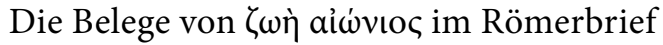

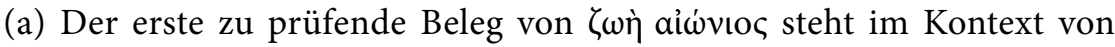
Röm 2,1-16, der von Gottes Gericht handelt. Gott als Agens seines richterlichen Handelns ist für den ganzen Abschnitt bestimmend, insbesondere aber für die Passage VV. 6-11, über die als Überschrift gesetzt werden könnte: „Gottes gerechtes Gericht am Tag des Zorns und der Of-

\footnotetext{
${ }^{40}$ Vgl. dazu Hoegen-Rohls, Ewigkeit (Anm. 1) $131 \mathrm{f}$.

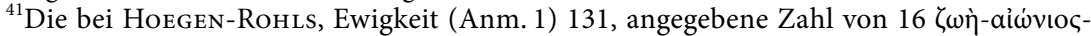
Belegen für das Johannesevangelium muss korrigiert werden: Es entfallen 17 Belege auf das Johannesevangelium (Joh 3,15.16.36; 4,14.36; 5,24.39; 6,27.40.47.54.68; 10,28; 12,25.50; $17,2.3$ ). Vier Belege finden sich im ersten Johannesbrief ( 1 Joh 3,15; 5,11.13.20). Hinzukommen im ersten Johannesbrief die beiden Belege, an denen von $\dot{\eta} \zeta \omega \dot{\eta} \dot{\eta}$ aỉ $\dot{v} v ı \varsigma$ die Rede ist (1 Joh 1,$2 ; 2,25)$.

${ }^{42}$ Vgl. dazu Hoegen-Rohls, Ewigkeit (Anm. 1) 132.
} 
fenbarung ${ }^{\text {“ }}{ }^{43}$ Die kunstvoll aufgebaute Passage,${ }^{44}$ die thematisch an die Eröffnung des Briefkorpus in Röm 1,18 anknüpft, ${ }^{45}$ zielt darauf, Gottes Gerichtsurteil gerade insofern als gerecht zu erweisen, als es unparteiisch, also nicht vom Ansehen einer Person beeinflusst ist (V. 11), sondern sich allein an deren Werken orientiert (V. 6). Entsprechend des klassisch-weisheitlichen Modells eines Tun-Ergehen-Zusammenhangs ${ }^{46}$ gibt es Heil

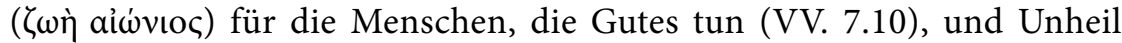
(ỏpүخ̀ kaì $\theta v \mu o ́ c)$ für jene, die Böses tun (V. 8) ${ }^{47}$ Dabei ist bemerkenswert, dass es ausdrücklich das „ewige Leben“ ist, das an das aktivische finite

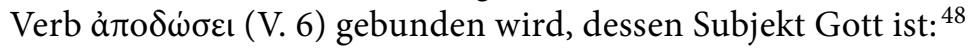

Röm 2,6f.

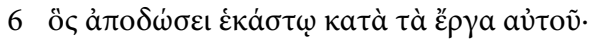

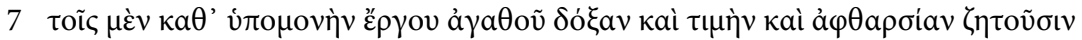

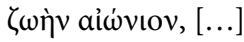

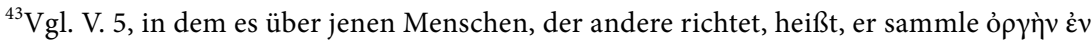

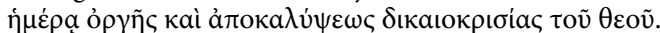

${ }^{44}$ Michael Wolter, Der Brief an die Römer, Teilband I (Röm 1-8) (EKKNT 6,1), Göttingen 2014, 173, demonstriert die chiastische Struktur des Abschnitts wie folgt:

„V. 6 A Gott vergilt jedem einzelnen nach seinen Werken:

V. 7 B Für Menschen, die gute Werke tun,

C gibt es Heil.

V. 8 D Für Menschen, die böse Werke tun,

E gibt es Unheil.

V. 9 E Unheil gibt es,

D für jeden, der böse Werke tut.

V. $10 \mathrm{C} \quad$ Heil gibt es

B für jeden, der gute Werke tut.

V. 11 A Denn Gott kennt kein Ansehen der Person. “

${ }^{45} \mathrm{Zu}$ Fragen der epistolographisch und rhetorisch begründeten Gliederung des Römerbriefes vgl. exemplarisch Hans-Josef KLAUCK, Die antike Briefliteratur und das Neue Testament (UTB 2022), Paderborn 1998, 228-230; Michael Theobald, Der Römerbrief (EdF 294), Darmstadt 2000, 47-62.

${ }^{46}$ Zum Tun-Ergehen-Zusammenhang im Römerbrief als einem apokalyptisch geprägten „Denkstil“ des Paulus vgl. Theobald, Römerbrief (Anm. 45) 123f.; Ulrich Wilckens, Der Brief an die Römer (EKKNT 6,1-3), Bd. 1, Einsiedeln-Neukirchen ${ }^{2}$ 1987, 127-131.

${ }^{47} \mathrm{Vgl}$. Wolter, Brief an die Römer (Anm. 44) 177.

${ }^{48}$ V. 8 zerbricht die syntaktische Konstruktion von V. 6 f. Die Begriffsverbindung „Zorn

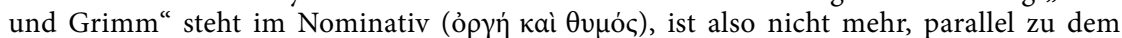

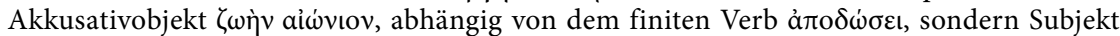

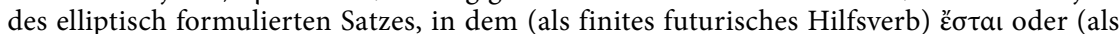
finites futurisches Vollverb) $\gamma \varepsilon v \eta \dot{\sigma \varepsilon \tau a ı ~ e r g a ̈ n z t ~ w e r d e n ~ m u s s . ~ A u s ~ d e m ~ s y n t a k t i s c h e n ~ B r u c h ~}$ kann gefolgert werden, dass „Zorn und Grimm“ nicht auf der gleichen kategorialen Ebene anzusiedeln sind wie "ewiges Leben“. Das heißt: Sie stellen nicht "Gaben“ dar im Sinne von „Unheilsgütern“, sondern umschreiben den Begriff des göttlichen Gerichts in seiner negativen Dimension (Verurteilung, „Unheilsurteil“). Die auf jene Menschen, die Böses/ Schlechtes tun, bezogenen „Unheilsgüter“ werden hingegen erst in V. 9 mit dem Begriffspaar

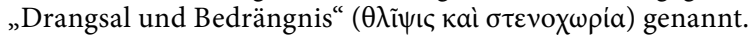




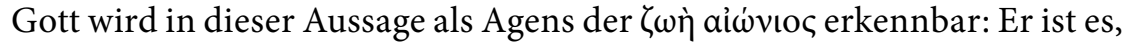
der denen, die in Geduld mit ihren guten Werken nach den eschatischen Heilsgütern Herrlichkeit, Ehre und Unvergänglichkeit streben, das eschatische Heilsgut schlechthin, nämlich das ewige Leben, geben wird. ${ }^{49}$ Herr-

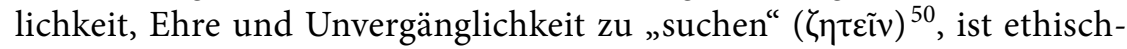

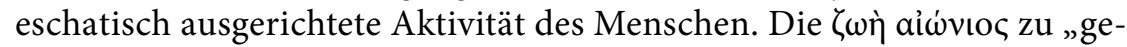
ben“ ( $\delta เ \delta$ óvaı), ist eschatische Aktivität Gottes. Als Gegenstand göttlichen

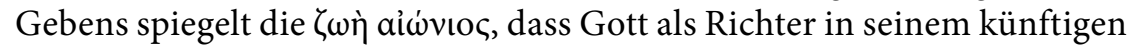

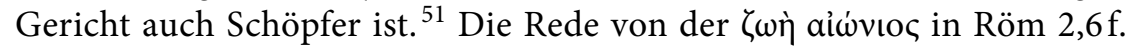
versteht diese als künftige Größe und macht deutlich: So wie Gott protologisch als Schöpfer zu verstehen ist, da er Welt und Mensch erschaffen hat, so ist er eschatologisch als rekreatorisch Handelnder zu begreifen, der für die Glaubenden unvergängliches Leben jenseits des physischen Todes schafft. Als Neuschöpfer will Gott das Leben seiner Geschöpfe auf ewig.

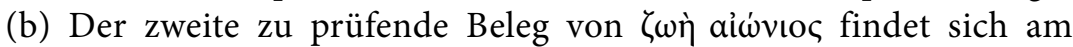
Ende der sog. Adam-Christus-Typologie in Röm 5,12-21, die in der Gedankenführung des Römerbriefes einerseits an die Überlegungen von Röm 5,1-11 anschließt, ${ }^{52}$ andererseits eine neue Argumentationslinie eröffnet, die bis Röm 8,4 verläuft. ${ }^{53}$ Von $5,1-11$ aus gelesen, lässt sich

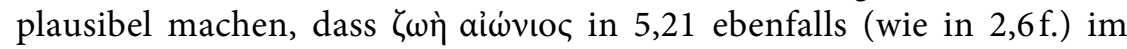
Kontext von Gottes richterlichem Handeln steht und als künftige Größe gedacht wird. Gottes Gerichtshandeln kommt in 5,1-11 explizit durch die Rede vom "Gerettetwerden vor dem Zorn“ zur Sprache (V. 9). In dieser passivischen Redeweise wird, im Sinne des passivum divinum, Gott als Agens erkennbar. Gott als Retter der Glaubenden im Gericht (ausgedrückt durch ỏpүí) setzt fort, was er als Gott der Liebe und

\footnotetext{
${ }^{49}$ „Ewiges Leben“ kann mit Wolter, Brief an die Römer (Anm. 44) 175, auch „als komprehensive Umschreibung für das eschatische Heil in seiner Gesamtheit"verstanden werden, wie sie bereits frühjüdische Schriften kennen (vgl. 4 Makk 15,3; Dan 12,2; PsSal 3,12). „Ewiges Leben“ wäre dann jedoch, wie oben formuliert, insofern „eschatisches Heilsgut

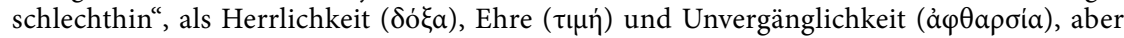

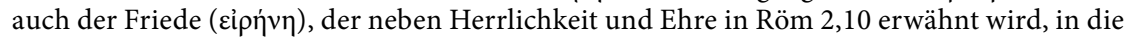

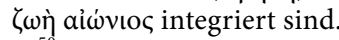

${ }^{50}$ Wolter, Brief an die Römer (Anm. 44) 175, weist zu Recht darauf hin, dass das Verb

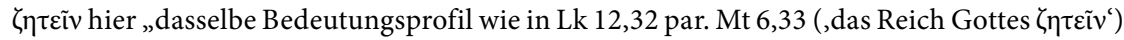

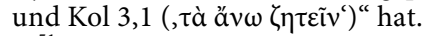

${ }^{51}$ Der Gerichtsgedanke selbst wird auf diese Weise schöpfungstheologisch konturiert.

${ }^{52}$ Vgl. dazu Charles E. B. Cranfield, The Epistle to the Romans Vol. I. Introduction and Commentary on Romans 1-8 (ICC), Edinburgh ${ }^{6} 1975$, 269; Wolter, Brief an die Römer (Anm. 44) 341.362.

${ }^{53}$ Vgl. dazu die argumentationskritische Analyse von Patrick BAHL, Die Macht der Sünde im Römerbrief. Eine Untersuchung vor dem Hintergrund antiker Argumentationstheorie und -praxis, (erscheint in: BHTh), Tübingen 2019, 222-307.
} 
der Versöhnung für seine Geschöpfe will. Als Gott der Liebe und der Versöhnung will er, dass sein Sohn für die Sünder stirbt (V. 8), damit aus diesen Gerechtfertigte (V. 9:

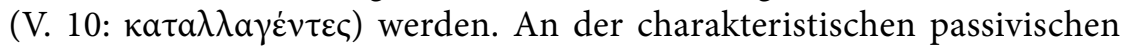
Ausdrucksweise, die sowohl an die passivische Formulierung in V. 9, als

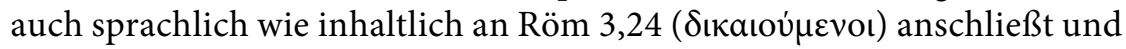

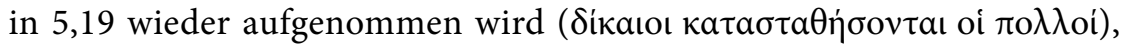
lässt sich Gott als Agens von Versöhnung und Rechtfertigung erkennen. ${ }^{54}$

Als jetzt schon Gerechtfertigte und jetzt schon mit Gott Versöhnte ${ }^{55}$ haben die Glaubenden begründete Hoffnung, auch im künftigen Gericht Gottes Rettung zu erfahren. Dieser Gedanke steht auch hinter der in 5,12-21 entfalteten Adam-Christus-Typologie. Auch hier geht es, wie in 5,1-11, nicht einseitig um das bereits errungene oder einseitig um das künftig zu erringende Heil, sondern um das Zusammenspiel beider

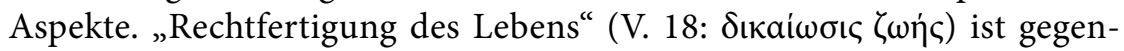
wärtige, in der von Gott gewollten "Rechtstat" des Sohnes (V. 18: $\mathrm{t}_{\mathrm{t}}$ кai $\omega \mu \alpha$; vgl. V. 16) sich realisierende Heilshandlung Gottes, die über das gegenwärtige Leben hinaus für das „ewige Leben“ Bestand hat. Gott als

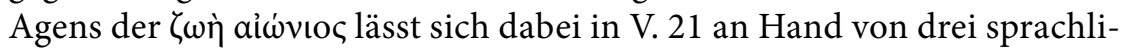
chen Merkmalen erkennen, nämlich an dem finalen „damit“ in V. $21 \mathrm{a}$; an

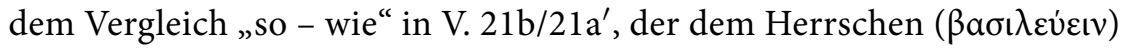

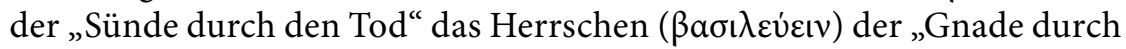
Gerechtigkeit" gegenüberstellt; und an der metonymischen Rede von der "Gnade“:

Röm 5,21

21a iva

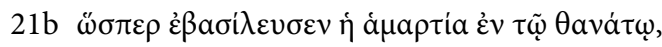

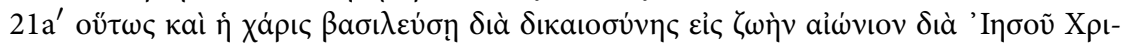

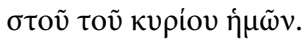

Als Schluss-Satz der Einheit 5,12-21, mit der Paulus in grundsätzlicher und universaler Weise die Geschichte der Menschheit reflektiert, lässt sich V. 21 zwar als gebündelter Ausdruck der in 5,12-21 relevanten Ge-

\footnotetext{
${ }^{54}$ Die Einschätzung des Passiv als passivum divinum teilt dezidiert Wolter, Brief an die Römer (Anm. 44) 357.

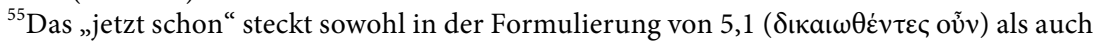

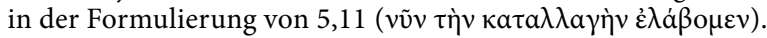


genüberstellung von „Adamseite“ und „Christusseite“ verstehen. ${ }^{56}$ Doch darf nicht übersehen werden, in welcher Weise Gott als Handlungssouverän in dieser Pointe präsent ist. Die Zweckbestimmung in V. 21a schließt an das finale ivva in V. 20 an, mit der Paulus die Funktion des (von Gott gegebenen) Gesetzes bestimmt. Auch der iva-Satz in V. 21a, der in V. 21a' fortgesetzt wird, signalisiert, dass im königlichen Regieren der Gnade Gott selbst am Werk ist. Dafür spricht, dass in V. 15 ausdrücklich von der

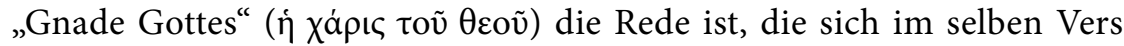

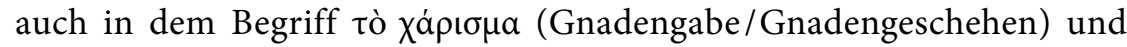

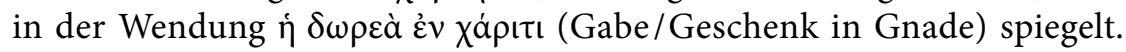
Schon in V. 15 stehen sich somit nicht eigentlich Adam und Christus, sondern Adam und Gott gegenüber. ${ }^{57}$ Dies gilt auch für V. 21. Der Vergleich,

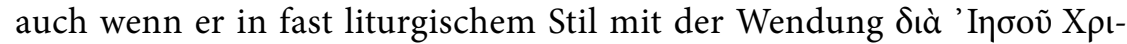

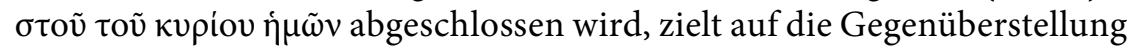
von Adam und Gott. Auf der Adamseite ist die Sünde handelndes Subjekt (V. 21b: غ̇ $\beta a \sigma i \lambda \varepsilon v \sigma \varepsilon v \dot{\eta} \alpha \dot{\alpha} \mu \alpha \rho \tau i \alpha)$, auf der Gottesseite die Gnade (V. 21a.a': îva [...] ๆ Xá Tod herrscht (und so auch im Tod endet, ohne dass davon mehr zu sagen

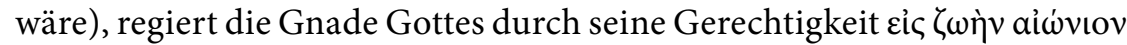
(„mit dem Ziel von ewigem Leben“/,zum Zwecke von ewigem Leben“) ${ }^{58}$.

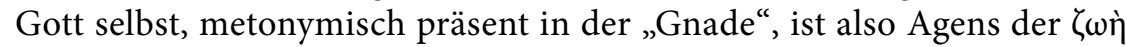
aíuvıç. Wie bei Röm 2,6f. legt es sich nahe, die paulinischen Überlegungen von 5,12-21 als schöpfungstheologische auszuwerten: Gott, der Schöpfer der Menschheit, ist als gnädig-gerechter Retter Neuschöpfer seiner Geschöpfe.

(c) In dem unmittelbar an Röm 5,1-21 sich anschließenden Kontext

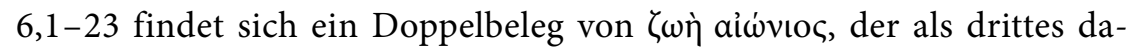
raufhin zu befragen ist, inwiefern er als Lexem der Gottesrede genauer bestimmt werden kann. An der Begrifflichkeit dieser Briefpassage lässt

\footnotetext{
${ }^{56}$ Von „Adamseite“ und „Christusseite“, spricht auch Wolter, Der Brief an die Römer (Anm. 44) 354f.pass. Michael Theoвald, Römerbrief Kapitel 1-11, (SKK.NT 6,1), Stuttgart 1992, 153f.159, hebt hervor, dass die „Adamseite“ von Röm 5,1-11 inhaltlich dem Briefabschnitt 1,18-3,20 entspreche, die als „Unheilsseite“ zu kennzeichnen sei, während die "Christusseite" von 5,1-11 inhaltlich den brieflichen Ausführungen ab 3,21 entspreche, die bis einschließlich 5,11 reichten und als „Heilsseite" entfaltet seien.

${ }^{57}$ So auch Wolter, Brief an die Römer (Anm. 44) 351.

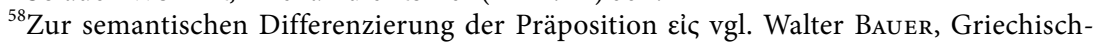
deutsches Wörterbuch zu den Schriften des Neuen Testaments und der frühchristlichen Literatur, hg. v. Kurt Aland und Barbara Aland, Berlin ${ }^{6} 1988$, 459-464. In Röm 5,21 lässt sich eị verstehen als Angabe des Zieles (vgl. Bauer, Wörterbuch, 461f. [4.]), und zwar durchaus im Sinne der Angabe der Bestimmung (vgl. Bauer, Wörterbuch, 462 [4d.]) oder der Wirkung und des Erfolges (vgl. BAuER, Wörterbuch, 462 [4e.]).
} 
sich ablesen, dass noch immer das Thema der Gerechtigkeit des richterlich bzw. gerichtlich handelnden Gottes leitend ist, das die Überlegungen des Apostels seit Eröffnung des Briefkorpus in Röm 1,18 bestimmt. Zur Gerechtigkeit Gottes gehört es, dass er sowohl befreit als auch versklavt, und zwar gerade insofern, als er, der seine Geschöpfe von der Sünde befreit, sie zugleich in eine neue, heilvolle, auf ewiges Leben zielende „Knechtschaft“ ihm gegenüber führt:

\section{Röm 6,22f.}

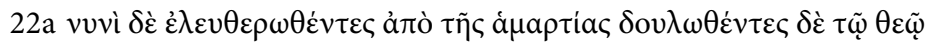

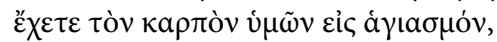

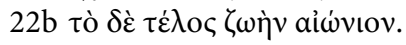

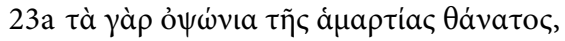

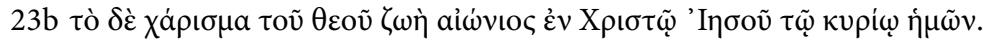

Paulus spricht die römischen Christen in Röm 6,22 mittels zweier passivisch gefasster partizipialer Intitulationen als ,jetzt schon“( $\left.v v v^{i}\right)$ von der

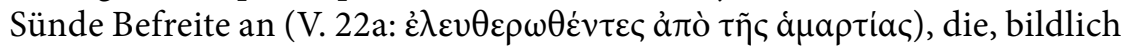
gesprochen, zu „Sklaven gegenüber Gott“ gemacht wurden (V. 22a: סov$\lambda \omega \theta \dot{\varepsilon} v \tau \varepsilon \varsigma \delta \dot{\varepsilon} \tau \tilde{\omega} \theta \varepsilon \tilde{\omega})$. Wiederholt wird damit ein Gedanke, der (ebenfalls passivisch) bereits in V. 18 artikuliert wurde, wobei "Gott“ metonymisch

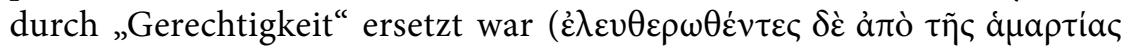

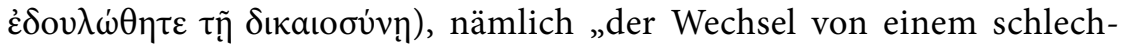
ten zu einem guten Sklavenherrn". ${ }^{59}$ Sowohl in V. 18 als auch in V. 22a

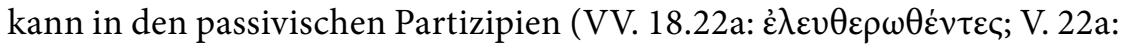
$\delta o v \lambda \omega \theta \dot{\varepsilon} v \tau \varepsilon \varsigma$ ) bzw. in dem passivischen finiten Verb (V. 18: $\dot{\varepsilon} \delta$ ov $\lambda \omega \theta \eta \eta \varepsilon)$ das Stilmittel des passivum divinum und somit Gott als Agens erkannt werden. Gott ist es, der die Glaubenden von der Sünde befreit und sie zu seinen "Gottesknechten" gemacht hat. Dass Gott Subjekt dieses heilvollen Handelns ist, legt sich auch dadurch nahe, dass nicht etwa den römischen Christen, sondern Gott selbst in liturgischem Briefstil dafür gedankt wird, dass sie von ihrem Dasein als „Sklaven der Sünde“ los gekommen sind (vgl. V. 17). Als von Gott Befreite und zu Gottesknechten Gemachte bringen die römischen Christen, wiederum bildlich gesprochen, Frucht, ${ }^{60}$ und

\footnotetext{
${ }^{59}$ So Gerd Theissen/Petra von Gemünden, Der Römerbrief. Rechenschaft eines Reformators, Göttingen 2016, 173.

${ }^{60}$ Wolter, Brief an die Römer (Anm. 44) macht unter Rückgriff auf Röm 1,13 deutlich,

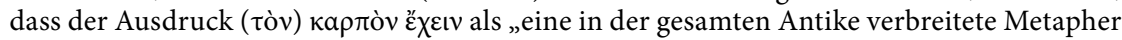
für menschliche Taten und deren Auswirkungen" immer das Hervorbringen (nicht das Haben/Halten) der Frucht meine (402; vgl. 111).
} 


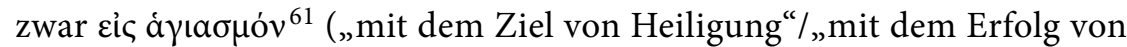

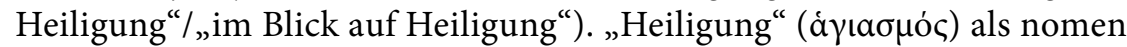
actionis ${ }^{62}$ verweist auf Gott als Handelnden. Gott als Agens der Befreiung von der Sünde und als Agens des neuen, ethisch-eschatisch fruchtbaren Dienstverhältnisses ${ }^{63}$ der Glaubenden ist es, der sie heiligt, was im Sinne des Briefpräskripts so verstanden werden kann, dass Gott sie zu Heiligen, das heißt zu an seiner göttlichen Heiligkeit Teilhabenden macht (vgl. die

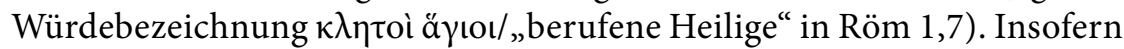
das Ziel ( $\tau$ ò $\tau \dot{\varepsilon} \lambda \circ \varsigma$ ) von Gottes heiligendem Handeln ewiges Leben ist, ${ }^{64}$

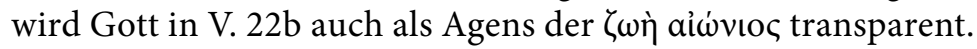

Paulus verleiht in V. 22b einer teleologischen Vorstellung Ausdruck, die zu all jenen Aussagen seiner Briefe passt, in denen eine Heilshoffnung und Heilserwartung für die Zukunft deutlich artikuliert wird - sei es in Form der Rede von der Auferstehung der Toten (1 Thess 4,13-18; 5,1-10; 1 Kor 15,1-49; Phil 3,11), sei es in Form der Rede von der Verwandlung der Glaubenden (1 Kor 15,51-57; Phil 3,20f.) und ihres „Überkleidetwerdens“ mit dem ewigen, von Gott erbauten himmlischen Bau (2 Kor 5,1-10), sei es in Form der Rede von der Hoffnung für die ganze Welt (Röm 8,18-25; Phil 2,9-11). Eine futurische Konnotation von

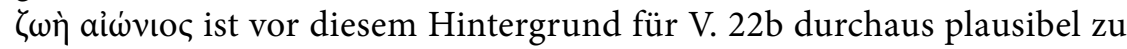
machen. Gilt dies auch für V. 23b? Liest man die Fortsetzung von V. 22 durch V. 23 in kohärentem Rückbezug auf die vorausgegangene AdamChristus- bzw. Adam-Gott-Typologie in 5,12-21, so lässt sich diese Frage positiv beantworten. Unter dem Tod als dem am Ende des Dienstverhältnisses zwischen Sünde und Mensch ausgezahlten „Dienstlohn“ bzw.

\footnotetext{
${ }^{61}$ Zur semantischen Differenzierung der Präposition عị vgl. Anm. 58. In Röm 6,19.22 lässt sich sic verstehen als Angabe des Zieles (vgl. BAUer, Wörterbuch [Anm. 58] 461f. [4.]), und zwar durchaus im Sinne der Angabe der Bestimmung (vgl. Bauer, Wörterbuch [Anm. 58] 462 [4d.]) oder der Wirkung und des Erfolges (vgl. BAuER, Wörterbuch [Anm. 58] 462 [4e.]), möglicherweise auch als Bezeichnung der Beziehung hinsichtlich einer Sache (vgl. BAUER, Wörterbuch [Anm. 58] 463 [5.]).

${ }^{62}$ So auch Wolter, Brief an die Römer (Anm. 44) 400, unter Verweis auf Blass/DebrunNER/ReH KOPF, Grammatik (Anm. 18) \$109,1.

${ }^{63}$ Vom „Dienstverhältnis“, das negativ zwischen Sünde und Mensch, positiv zwischen Gott und Glaubenden besteht, spricht auch Christine Gerber, Vom Waffendienst des Christenmenschen und vom Sold der Sünde, in: Peter Müller/Christine Gerber/Thomas Knöppler (Hg.), „... was ihr auf dem Weg verhandelt habt.“ Beiträge zur Exegese und Theologie des Neuen Testaments (FS Ferdinand Hahn), Neukirchen-Vluyn 2001, 129-142: 141. Vgl. dazu auch Gabriele Wesch-KLeIn, Soziale Aspekte des römischen Heerwesens in der Kaiserzeit (Heidelberger althistorische Beiträge und epigraphische Studien 28), Stuttgart 1998; THEISSEN/VON GEMÜNDEN, Römerbrief (Anm. 59) 160-175, bes. $162 \mathrm{f}$.

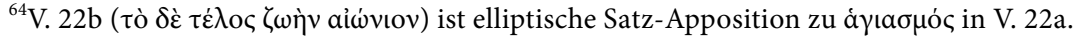




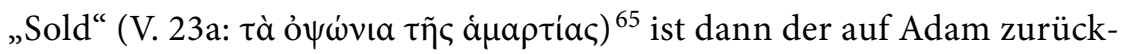

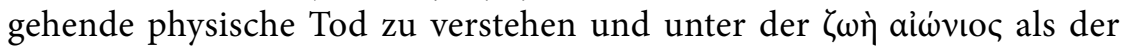
Gabe des Dienstherren Gott an die in seinem Dienst Stehenden das an den physischen Tod sich anschließende, postmortale ewige Leben. Dieses wird künftig den an Christus Glaubenden zuteil. Gott kann dabei als

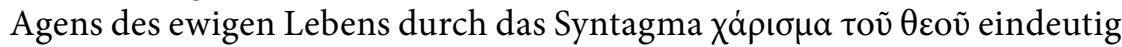

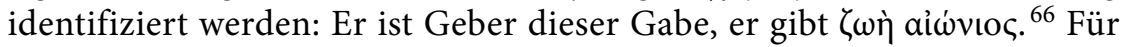

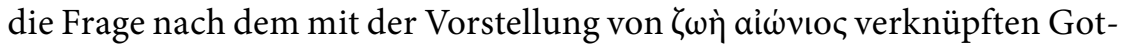
tesbild ergibt sich so erneut die schöpfungstheologische Pointe, dass Gott in seinem richterlichen, die Heiligung der Glaubenden einschließenden Wirken Neuschöpfer seiner Geschöpfe ist, deren schon in der Gegenwart gültige, in Christi Auferweckung gründende "Neuheit des Lebens" (vgl.

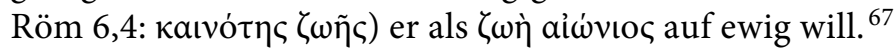

\subsubsection{Gott ist als Rufender und Richter Neuschöpfer seiner Geschöpfe:

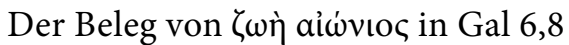

Vom ewigen Leben ist bei Paulus schließlich in Gal 6,7-10 die Rede, und zwar im Zusammenhang des endzeitlich geprägten Bildes vom Säen und

\footnotetext{
${ }^{65}$ Gerber, Waffendienst (Anm. 63) 137-139 mit Anm.40, versteht den Ausdruck tò ỏ $\dot{\omega} v$ vı (Entgelt, Lohn, Sold) dezidiert als Militärmetapher, die das Bild des Soldatendienstes hervorrufe. Zum bildspendenden Bereich führt sie realienkundlich aus (139): „Der pekuniäre Aspekt des Dienstes machte den größten Reiz aus. Verschiedene Summen kamen bis zum Ende der Dienstzeit zusammen: Neben dem dreimal jährlich gezahlten Sold (stipendium), von dem jedoch Geld für die Verpflegung einbehalten wurde, gab es immer wieder donativa, z. B. beim Antritt eines neuen Herrschers, und zum Schluss ein nicht unerhebliches Entlassungsgeld. Der Soldat war allerdings verpflichtet, einen Teil seines Geldes anzusparen, der ihm ebenfalls erst bei der Entlassung ausgezahlt wurde [...]." Von hier aus lassen sich der Sold der Sünde (V. 23a) und die im parallelismus membrorum stehende Gabe Gottes (V. 23b) gleichermaßen als auf ein Ende bezogene Größen verstehen. Diese Überlegung bestärkt das

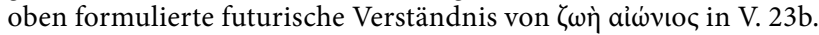

${ }^{66}$ Wolter, Brief an die Römer (Anm. 44). Aber auch hinter der bildlichen Rede vom „Lohn für die Sünde“ wird man Gott als denjenigen vermuten dürfen, der diese Vergütung auszahlt.

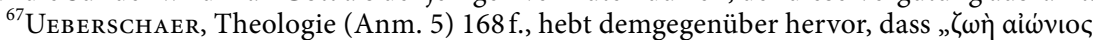
nach Röm 6 nichts anderes als der gegenwärtige soteriologische Gewinn des Glaubens"

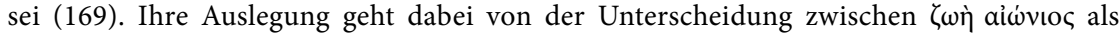
futurischem „Ziel“ und als gegenwärtiger „Gabe“ aus. Dass „Gabe“ etwas Gegenwärtiges sei, begründet sie mit dem Gebrauch der V. 23b abschließenden Wendung $\dot{\varepsilon} v$ X $\tau \tilde{\omega}$ Kvpí $\dot{\eta} \mu \tilde{\omega} v$, mit der nicht die künftige, sondern die bereits gegenwärtige „Lebensgemeinschaft (sc. der Glaubenden) mit Christus" gemeint sei. Dies ist jedoch ebenso wenig zwingend wie die semantische Auffassung von $\chi$ á $\rho \iota \sigma \mu \alpha$ als einer gegenwärtigen Größe. Die Gabe des ewigen Lebens kann durchaus im Rahmen der oben angeführten teleologischen Vorstellung des Paulus die künftige Gabe des endzeitlich handelnden Gottes sein.
} 
Ernten. ${ }^{68}$ Sprichwörtlich wird zunächst die Lebensweisheit formuliert, dass Ernten vom Säen abhängt: Was der Mensch sät, das wird er auch

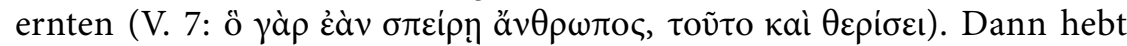
Paulus hervor, dass der, der auf sein Fleisch als Nährboden sät, aus diesem Boden Vergänglichkeit/Verderben erntet (V. 8a). Eine Ernte der Unvergänglichkeit kann es beim Säen auf den Boden der oá $\rho \xi$ nicht geben. Wer hingegen auf den Geist als Nährboden sät, wird ewiges Leben ernten (V. 8b):

\section{Gal 6,8}

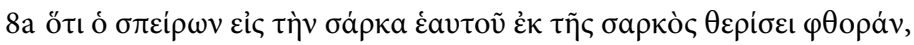

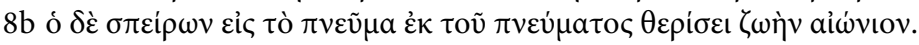

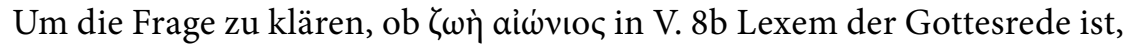
muss die Einbettung von V. 8b in den Mikrokontext des Abschnitts 6,7-10 sowie dessen Stellung als Schlusspassage des größeren Zusammenhangs 5,1-6,10 berücksichtigt werden. Dieser größere Zusammenhang lässt sich epistolographisch als paränetischer Teil des Briefes verstehen, ${ }^{69}$ der unter rhetorischen Gesichtspunkten als exhortatio (Ermahnung, Ermunterung)

\footnotetext{
${ }^{68}$ Zur gemeinantiken Verbreitung des Bildes vom Säen und Ernten vgl. BETz, Galaterbrief (Anm. 31) 521 mit Anm. 155.

${ }^{69}$ Der Beginn des paränetischen Teils des Galaterbriefes ist allerdings umstritten. Er wurde in 4,12 oder in 4,21 gesehen, in 5,1, in 5,2 oder in 5,7, insbesondere aber in 5,13. Darüber informiert auf einem älteren Stand der Forschung mit ausführlichen Nachweisen Otto Merk, Der Beginn der Paränese im Galaterbrief, ZNW 60 (1969) 83-104, der selbst für 5,13 plädiert. Zu 5,13 als Einsatz des ermahnenden Briefteils vgl. aus der neueren Forschung exemplarisch KlaUCK, Briefliteratur (Anm. 45) 237. Zur Problematik, die Paulusbriefe (besonders Römer- und Galaterbrief) in einen „theologischen" bzw. „dogmatischen“ Teil und einen „ethischen“ bzw. „paränetischen“ Teil aufzuteilen, vgl. Schewe, Galater (Anm. 31) 16-26, die Gal 5,13-6,10 unter textpragmatisch-rhetorischer bzw. textstrategischer Perspektive als Höhepunkt des Briefes herausarbeitet und darauf abhebt, dass eine schematische Einordnung dieses Briefteils in „Paränese“ dessen argumentativem Charakter nicht gerecht werde (vgl. 190-192). Dem soll die oben formulierte Einordnung in den paränetischen Teil des Briefes nicht widersprechen. Doch soll darauf hingewiesen werden, dass zwischen Paränese und Argumentation nicht zwingend ein Gegensatz konstruiert werden muss. Auch paränetische Briefteile können selbst argumentative Funktion haben oder argumentierende Briefteile unterstützen bzw. fortsetzen. Vgl. dazu den Hinweis bei Zimmermann, Gott (Anm. 33) $111 \mathrm{f}$. Anm. 2, auf Troels Engeberg-Petersen, Paul and the Stoics, Edinburgh 2000, „der die christliche Lebensführung als das Ziel der Christusoffenbarung in der paulinischen Argumentation sieht". Zu beachten sind auch der Hinweis auf paränetisch endende philosophische Briefe bei BeTZ, Galaterbrief (Anm. 31) 435, sowie die Überlegungen von Jan G. van Der Watt, Paraenesis in 1 John?, in: Christina Hoegen-Rohls/Uta Poplutz (Hg.), Glaube, Liebe, Gespräch. Neue Perspektiven johanneischer Ethik (BThSt 178), Göttingen 2018, 165-180. ZimmermanN, Gott (Anm. 33) 111, weist ferner darauf hin, dass bereits John M. G. Barclay, Obeying the Truth. A Study of Paul's Ethics in Galatians, Edinburgh 1988, "die Aufteilung des Galaterbriefes in einen theologischen und einen paränetischen Briefteil korrigierte".
} 
bezeichnet werden kann ${ }^{70}$ und mit der markanten Aussage „zur Freiheit hat uns Christus befreit" in 5,1a einsetzt. In 5,13a wird dieser Gedanke in Form der direkten Anrede an die Galater, dass sie zur Freiheit gerufen worden seien $(\dot{\varepsilon} \kappa \lambda \eta \dot{\eta} \theta \eta \tau \varepsilon)$, wiederaufgenommen. Verstanden als passivum divinum verweist die passivische Form des finiten Verbs auf Gott als Agens des Rufens, das heißt: „Gott ist der Rufende.“" ${ }^{71}$ Diese im passivum divinum implizierte Rede von Gott greift zurück auf Aussagen zu Beginn des Briefes, in denen Gott explizit als jener vorgestellt wurde, der die Galater und Paulus selbst in Gnade $(1,6)$ bzw. durch seine Gnade $(1,15)$ "gerufen" und damit eine auf seiner Gnade basierende Beziehung zwischen ihnen und sich eröffnet hat. ${ }^{72}$ Gott ist es aber auch, der durch jene Haltung hindurchscheint, die Paulus den Galatern als ihre aus der Freiheit erwachsende Verantwortung zu Bewusstsein bringt, nämlich die Haltung der Liebe (5,13f.), die im Tugendkatalog von 5,22 f. durch Freude und Friede, Langmut, Freundlichkeit und Güte, Treue, Sanftmut und Enthaltsamkeit ergänzt und gemeinsam mit diesen als „Frucht des Geistes“ gekennzeichnet wird. Gott wird in den aufgeführten Tugenden und ihrer Kennzeichnung als Geistesfrucht insofern auf zweifache Weise transparent, als es zum einen kein anderer als eben der Geist Gottes ist, von dem die Tugenden kommen, und als zum anderen die geistgeprägten Tugenden selbst, abgesehen von der Enthaltsamkeit, alle auch „Eigenschaften Gottes bzw. des Gottesreiches sind“73. Gott selbst eignen Liebe, Freude, Friede, Langmut, Freundlichkeit, Güte, Treue und Sanftmut. Der Gott, der die Galater und Paulus zur Freiheit und zu der aus dieser Freiheit erwachsenden Verantwortung ruft, ruft sie gewissermaßen zu seinen eigenen Eigenschaften bzw. in sein eigenes Reich. Diese Pointe legt sich auch

\footnotetext{
${ }^{70}$ Vgl. dazu exemplarisch Betz, Galaterbrief (Anm. 31) 433. Zur Frage des Verhältnisses von Epistolographie und Rhetorik vgl. Christina Hoegen-Rohls, „Rhetorical criticism“. Zur Bedeutung rhetorischer Analyse für das Verstehen neutestamentlicher Texte, PrTh 42 (2007) 93-99.

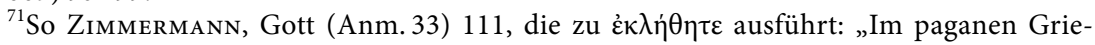
chisch hat diese Formulierung eine Parallele im Entlassen von Sklaven in die Freiheit, die

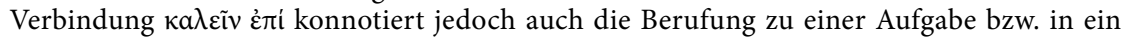
Amt und lässt zugleich auf die Verantwortung schließen, die mit dem Amt, bzw. hier mit dem Zustand der Freiheit übernommen wird."

${ }^{72}$ Vgl. dazu ZimmermanN, Gott (Anm. 33) 29: „Es ist für Paulus ein Grundkennzeichen des jüdischen Gottes, dass er den Bezug zu seiner Schöpfung und den Menschen durch einen Ruf herstellt und damit dem Menschen eine Gottesbeziehung überhaupt erst ermöglicht.“

${ }^{73}$ So ZimmermanN, Gott (Anm. 33) 116, die den Nachweis durch die entsprechenden alttestamentlich-frühjüdischen und paulinischen Textbelege erbringt (116f.) und hervorhebt, dass zwar einige der aufgeführten Tugenden ,auch im Zusammenhang mit Christus belegt [seien], jedoch bei weitem nicht so explizit und häufig wie mit Gott“ (118).
} 
insofern nahe, als der dem Tugendkatalog entgegengesetzte Lasterkatalog (5,19-21) ausdrücklich festhält, dass die, die die „Werke des Fleisches" 74 tun, die Gottesherrschaft nicht werden erben können (vgl. 5,21: $\beta a \sigma ı \lambda \varepsilon i a v$

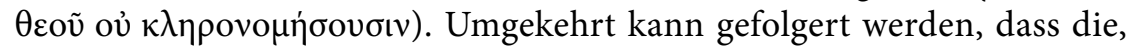
die die Gott gemäßen Tugenden erfüllen, künftig das Gottesreich erben werden. ${ }^{75}$ Damit aber ist das ethische Thema von Tugend und Laster in einen endzeitlichen Horizont gerückt, der Gott als königlichen Herrscher und die Glaubenden als Erben dieser Königsherrschaft denkt.

Vor diesem Hintergrund gewinnt die Warnung, mit der der Abschnitt 6,7-10 einsetzt, ihr theologisches Gewicht: „Irrt euch nicht: Gott

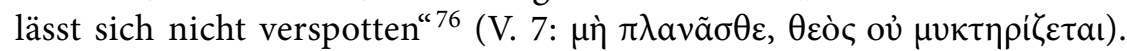
Diese Warnung spielt auf den spöttischen, respektlosen Umgang mit Göttern an, der den Galatern aus ihrer paganen Umwelt bekannt sein konnte. ${ }^{77}$ Paulus warnt somit die Galater davor, Gott jenen Respekt und jene Anerkennung zu verweigern, die ihm als königlichem Herrscher gebühren. Die Warnung impliziert, dass Gott respektloses Verhalten ihm gegenüber ahnden wird, und zwar in seiner richterlichen Funktion. Als Richter wird Gott „Respektlosigkeit und Nichtanerkennung seiner Souveränität im Endgericht vergelten " ${ }^{78}$. Was wird die Strafe sein? In V. 8a lässt sie sich ablesen: Es ist, bildlich gesprochen, das Ernten der $\varphi \theta 0 \rho a ́$ aus der Saat der $\sigma a ́ \rho \xi$, also das Verderben („im Sinne von endgültiger Vergänglichkeit ${ }^{\text {“79}}$ ). Was demgegenüber jene, die auf den Geist säen, ernten

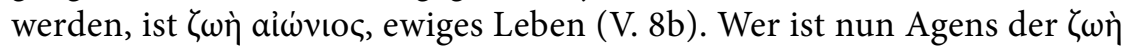
aíwvioc? Trifft es zu, dass es der Geist ist, der ewiges Leben gibt, nicht Gott? ${ }^{80}$ Ausgehend von dem mit V. 7 vorgegebenen Vorstellungsrahmen der richterlichen Funktion Gottes und unter Rücksicht auf den parallelismus membrorum, den die Versglieder V. 8a und V. 8b stilistisch bilden,

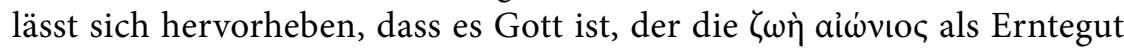

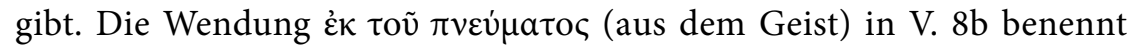
nicht den Geist als Agens der Ernte, sowenig die parallele Wendung ह̇k $\tau \tilde{\eta} \varsigma$ баркòৎ (aus dem Fleisch) in V. 8a das Fleisch als Agens der Ernte

\footnotetext{
${ }^{74}$ Aufgeführt werden in Gal 5,19-21: „Unzucht, Unreinheit, Ausschweifung, Götzendienst, Zauberei, Feindschaften, Streit, Eifersucht, Zornausbrüche, Ränke, Zwietrachten, Parteiungen, Neid, Völlerei, Schwelgerei und was dem ähnlich ist“; zur Übersetzung vgl. ZImmerMANN, Gott (Anm. 33) 115.

${ }^{75}$ Vgl. dazu Zimmermann, Gott (Anm. 33) 120.

${ }^{76}$ Übersetzung nach Zimmermann, Gott (Anm. 33) 125.

${ }^{77}$ Vgl. ZimmermanN, Gott (Anm. 33) 125.

${ }^{78}$ ZimmermanN, Gott (Anm. 33) 125.

${ }^{79}$ ZimmermanN, Gott (Anm. 33) 126.

${ }^{80}$ So Zimmermann, Gott (Anm. 33) 126.
} 
nennt. Angegeben wird mit beiden Wendungen vielmehr der Nährboden als Ort der Saat, aus dem die Ernte erwächst. Eingebracht wird die Ernte, um im Bild zu bleiben, jedoch von jenem Gott, der sich nicht verspotten lässt. Somit ist Gott in Gal 6,8 wie in den behandelten Belegstellen aus

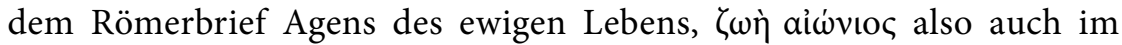
Galaterbrief Lexem der paulinischen Gottesrede. ${ }^{81}$

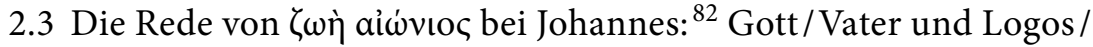 Sohn sind Träger und Inbegriff ewigen Lebens und agieren in ihrem Sendungshandeln rekreatorisch}

Herausragendes theologisches Gewicht hat die Rede vom „ewigen Leben“ bei Johannes. ${ }^{83}$ Anders als bei Paulus, bei dem die Rede von der künftigen

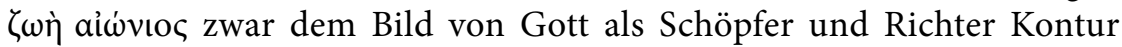
verleiht, ohne damit jedoch zu einem tragenden Begriff paulinischer Theologie zu werden, ist „ewiges Leben“ für die johanneische Gottesrede ein zentraler Begriff. Allein dass der erste Johannesbrief Christus als $\zeta \omega \grave{~}$

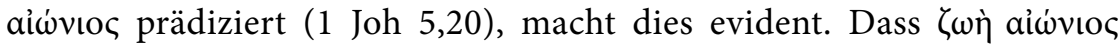
ein zentraler Begriff johanneischer Theologie ist, zeigt sich aber auch daran, dass in der johanneischen Sprache das Syntagma „ewiges Leben“ semantisch synonym zu „Leben“ ( $\zeta \omega \eta$ ) gebraucht werden kann, dem jo-

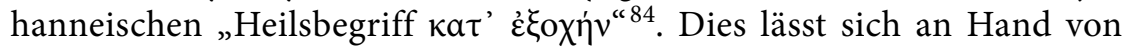
Texten belegen, in denen „Leben“ und „ewiges Leben“ direkt nebeneinan-

\footnotetext{
${ }^{81}$ Es kann in selbstkritischer Auseinandersetzung mit der oben vertretenen Interpretation zu Gal 6,8 gefragt werden, ob das futurische finite Verb $\theta \varepsilon \rho i \sigma \varepsilon ı$ tatsächlich eine künftige Ernte in den Blick nimmt oder im Sinne eines logischen Futurs die für das gegenwärtige

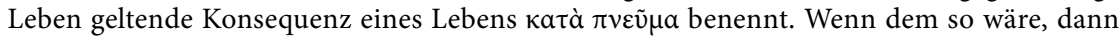
wäre „ewiges Leben“ im Kontext des Galaterbriefes eine bestimmte Art oder Qualität von gegenwärtigem Leben, nämlich das Leben im Geist. Doch scheint mir das Bild vom Säen und Ernten primär futurisch-eschatologisch konnotiert zu sein. Insgesamt ergibt sich daher als Befund für die paulinische Rede vom „ewigen Leben“, dass sie auf eine künftige Größe zielt. Vgl. so auch Jörg Frey, Die johanneische Eschatologie. Band 3: Die eschatologische Verkündigung in den johanneischen Texten (WUNT 117), Tübingen 2000, 267: „[B]ei Paulus wird die $\zeta \omega \eta \dot{\eta}$, wo sie als aỉ $\dot{v}$ เo bezeichnet wird, als zukünftige Gabe verstanden (Röm 2,7; 5,21; $6,22 \mathrm{f} . ; \mathrm{Gal} 6,8)^{\text {“. }}$.

${ }^{82}$ Unter „Johannes“ wird im vorliegenden Beitrag die Überlieferung des Johannesevangeliums und des ersten Johannesbriefes verstanden. Die beiden kleinen Johannesbriefe (2 Joh; 3 Joh) bieten interessanterweise die Lebensterminologie nicht.

${ }^{83}$ Vgl. dazu Hoegen-Rohls, Ewigkeit (Anm. 1); Ueberschaer, Theologie (Anm. 5) 268-341.

${ }^{84}$ Frey, Eschatologie 3 (Anm. 81) 261. Frey formuliert diesen Befund im Blick auf das

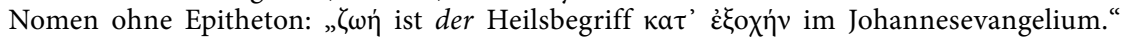

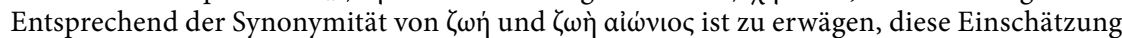
auf beide Begriffe auszudehnen. Dementsprechend müsste dann wiederum umgekehrt das
} 
derstehen (vgl. Joh 3,36; 5,24) ${ }^{85}$ oder in denen „aus sachlichen oder auch

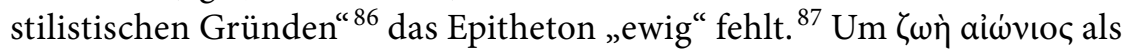
Lexem johanneischer Gottesrede zu konturieren, muss daher auch auf Stellen Bezug genommen werden, die ohne das Epitheton aíúvioৎ von der $\zeta \omega \eta \dot{~ s p r e c h e n . ~}$

Wie „Leben“, so kann auch „ewiges Leben“ im johanneischen Sprechen und Denken auf zwei Bereiche referieren: auf den Bereich Gottes/des Vaters und auf den Bereich des Logos/Sohnes auf der einen Seite; auf den Bereich der Menschen auf der anderen Seite. Referierend auf den göttlichen Bereich, also als Lexem der Gottesrede im engeren Sinne, meint „(ewiges) Leben“ grundlegend das, was Vater und Sohn „ausfüllt“, was sie in sich tragen und besitzen:

\section{Joh 5,26}

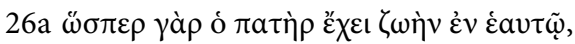

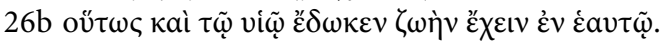

Beide, Vater und Sohn, haben ( $\chi_{\chi \varepsilon} \varepsilon v$ ) das Leben in sich selbst, wobei es der Vater ist, der dem Sohn "gegeben hat", das Leben in sich zu haben. ${ }^{88}$ Mit dem Verb "geben“ kann die johanneische Sprache ausdrücken, was sie

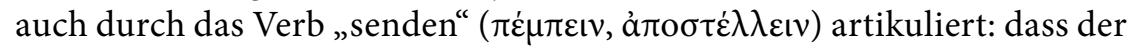
Sohn als Gesandter des Vaters bevollmächtigt ist, den sendenden Vater zu repräsentieren. ${ }^{89}$ Er repräsentiert ihn, indem er die Worte Gottes ( $\tau \grave{\alpha}$

bei Jean Zumstein, Das Johannesevangelium (KEK 2), Göttingen 2016, 635, formulierte Urteil, „der Begriff des ewigen Lebens“ sei „der joh Begriff für das Heil“ ergänzt werden durch den Begriff des Lebens.

${ }^{85}$ Vgl. dazu Hoegen-Rohls, Ewigkeit (Anm. 1) exemplarisch $142 \mathrm{f}$.

${ }^{86}$ Frey, Eschatologie 3 (Anm. 81) 262 Anm. 97.

${ }^{87}$ Die Näherbestimmung durch „ewig“ kann, wie FreY, ebd., im Anschluss an Jan G. vaN

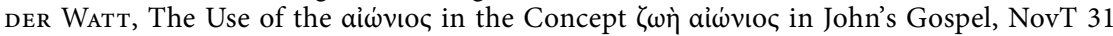
(1989) 217-228, notiert, fehlen ,in den Bezügen auf die göttliche $\zeta \omega \eta \dot{1} 1,4$ und 5,26, aber auch

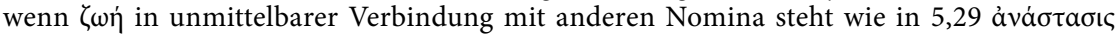

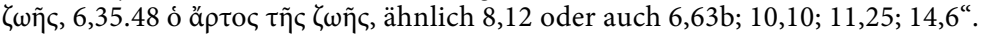

${ }^{88}$ Franz Mussner, ZOE. Die Anschauung vom „Leben“ im vierten Evangelium unter Berücksichtigung der Johannesbriefe. Ein Beitrag zur biblischen Theologie (MThS 1,5), München 1952, 70 f., führt dazu aus: „Dafür, daß Gott selber im Vollbesitz des Leben ist, tritt das vierte Evangelium keinen langen Beweis an; das ist eine Selbstverständlichkeit [...].“

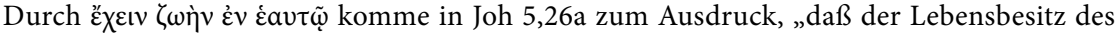
himmlischen Vaters zu seinem innersten Wesen, zu seiner Natur gehört; niemand hat es ihm geschenkt (wie dem Sohn), sondern immer schon besitzt er es. [...] Anders ist es mit dem Lebensbesitz des Sohnes; zwar hat auch dieser nach 5,26 das Leben ,in sich selbst' als etwas, was zu seinem Wesen gehört, aber nur als Gabe des Vaters".

${ }^{89}$ Zum Sendungsgedanken, der in Verbindung mit dem Präexistenz- und Inkarnationsgedanken die gesamte johanneische Theologie (und nicht etwa nur die Christologie bzw. Soteriologie) strukturiert, vgl. Jan-Adolf BüHNER, Der Gesandte und sein Weg im 4. Evangelium 
ṕn $\mu \alpha \tau \alpha)$ spricht $(3,34$; vgl. 12,49$)$, die dieser $\mathrm{zu}$ ihm gesprochen $(12,50)$, ihm gegeben hat $(17,8: \text { : } \varepsilon \delta \omega \kappa \varsigma \varsigma)^{90}$. Er repräsentiert ihn, indem er das

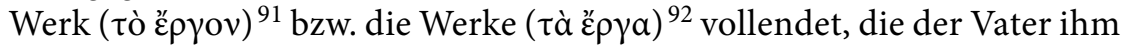
gegeben hat $\left(5,36\right.$ : $\left.\delta \dot{\varepsilon} \delta \omega \kappa \varepsilon v ; 17,4: \delta \dot{\varepsilon} \delta \omega \kappa a \varsigma^{93}\right)$, und indem er das Gebot

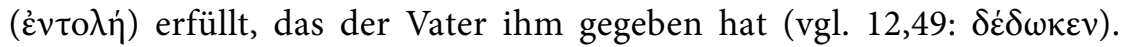
Dieses Gebot, dass der Sohn rede und handle gemäß dem Willen des

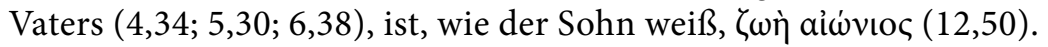

In dem an den Vater gerichteten Abschiedsgebet des Sohnes, das als Rechenschaftsbericht des Gesandten über seine erfüllte Sendung verstanden werden kann, ${ }^{94}$ wird daher umfassend alles $(\pi \tilde{a} v)$, was der sendende

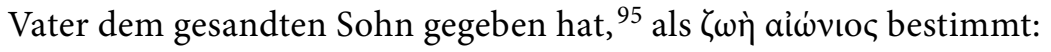

Joh 17,2 (Ausschnitt)

$2 \mathrm{~b} i \mathrm{v} \alpha \pi \tilde{a} v^{96}$

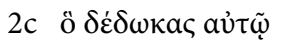

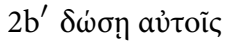

$2 \mathrm{~d} \zeta \omega \grave{v} v$ aì่viov.

"Ewiges Leben“ wird somit in der johanneischen Theologie zu einem Schlüsselbegriff der Gottesrede. Es umfasst Worte, Werke, Gebot und Leben Gottes. Insofern dem Sohn Worte, Werke, Gebot und Leben Gottes

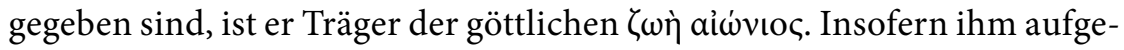
tragen ist, Werk und Gebot Gottes auszuführen und die Worte Gottes zu

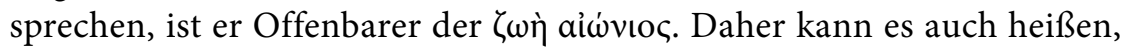
dass er „Worte ewigen Lebens" hat (6,68: $\dot{p} \eta \dot{\mu} \alpha \alpha \zeta \omega \tilde{\eta} \varsigma$ ai $\omega v i$ iov). Insofern er den Glaubenden (V. 2b': aủंoĩ ) Worte, Werke, Gebot und Leben gibt,

(WUNT 2,2), Tübingen 1977; Ferdinand Hahn, Theologie des Neuen Testaments, Band 1: Die Vielfalt des Neuen Testaments. Theologiegeschichte des Urchristentums (UTB 3500), Tübingen ${ }^{3} 2011,605-624$.

${ }^{90}$ Die 2. Person Singular des finiten Verbs resultiert aus der direkten Anrede des Vaters durch den Sohn im Abschiedsgebet.

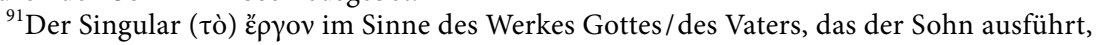
ist in Joh 4,$34 ; 17,4$ belegt.

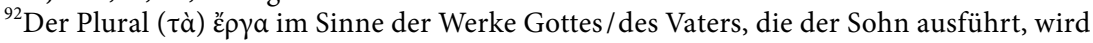
verwendet in Joh 5,20; 6,28; 9,3f.; 10,25.32.37f.; 14,10f.; 15,24. Hermeneutischer Schlüssel dieser Belege ist 14,10: Der im Sohn „bleibende“ (das heißt: ewig präsente) Vater ist es, durch den und in dessen Namen $(10,25)$ der Sohn wirkt. Zu diesem Wirken gehört auch das Gericht, das der Vater dem Sohn gegeben hat $(5,22)$.

${ }^{93}$ Es gilt das in Anm. 90 Gesagte.

${ }^{94}$ Vgl. dazu Jürgen BECKER, Das Evangelium nach Johannes. Kapitel 11-21 (ÖTK 4,2), Gütersloh ${ }^{3}$ 1991, 608-631: 612-614.617f.

${ }^{95} \mathrm{Vgl}$. auch Joh 3,35, wo es heißt, der Vater habe dem Sohn alles in seine Hand gegeben

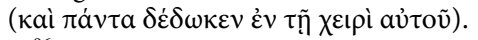

${ }^{96}$ Das Akkusativobjekt $\pi \tilde{\alpha} v$ steht in einem Finalsatz, dessen finites Verb V. $2 b^{\prime}$ bringt. Das

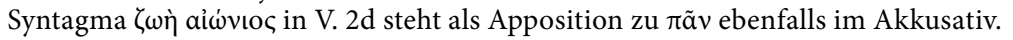


gibt er an sie alles, was der Vater ihm gegeben hat, weiter und ist somit

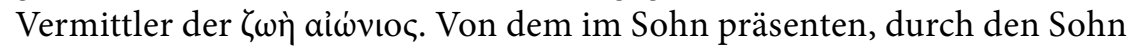
offenbarten und durch den Sohn vermittelten ewigen Leben zeugen die Schriften (vgl. 5,29). Vor allem aber zeugt der Sohn selbst davon: Er sagt von sich ( $\dot{\varepsilon} \gamma \dot{\omega} \varepsilon \dot{i} \mu \mathrm{u})$, dass er das Leben sei (vgl. 11,25; 14,6), das auf dem Hintergrund des Zusammenhangs von 5,26 und 17,2 kein anderes ist als das ewige, göttliche Leben. Von diesem ewigen, göttlichen Leben ist auch bereits im Prolog des Evangeliums die Rede ${ }^{97}$ wenn es vom präexistenten Logos heißt:

Joh 1,4

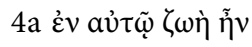

Im präexistenten Logos, der von Ewigkeit (1,1: غ่v ảoxñ) her bei Gott und selbst Gott ist, ist das ewige Leben Gottes anwesend. Dabei macht der Duktus der ersten Prologverse deutlich, dass dieses Leben nicht Zustand oder statischer Besitz ist, sondern eine dynamisch-produktive Größe des Logos, die Schöpfung hervorbringt $(1,3)$. Von hier aus kann auch die Rede von der $\zeta \omega \eta$ des Vaters und des Sohnes in 5,26 genauer erfasst werden. Dass Vater und Sohn das Leben in sich haben, kann auch dort in einem dynamisch-produktiven Sinne meinen, dass sie schöpferisch tätig sind. Dies bestätigt der unmittelbare Kontext, in dem die Lebensterminologie in verbaler Form verwendet wird: Vater und Sohn machen lebendig (vgl. 5,21). ${ }^{98}$

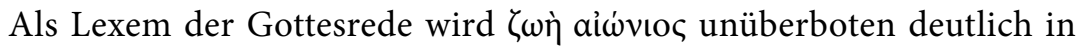
der brieflichen Aussage von 1 Joh 5,20, in der aus dem Evangelienprolog der Aspekt der Gottheit des Sohnes/Logos aufgenommen sowie unter Rückgriff auf den Evangelien- und den Briefprolog die Lebensprädikation rezipiert und zugespitzt wird:

1 Joh 5,20

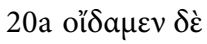

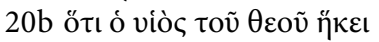

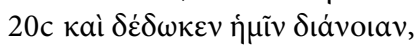

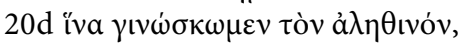

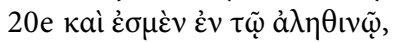

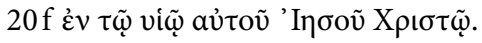

$20 \mathrm{~g}$ oũ̃ó

\footnotetext{
${ }^{97} \mathrm{Vgl}$. Mussner, Leben (Anm. 88) 71.

${ }^{98}$ Vgl. dazu im vorliegenden Band Zimmermann, Handeln I (Anm. 2) S. 171-173.
} 
Mit oũtoc ${ }^{99}$ in V. $20 \mathrm{~g}$ wird zurückverwiesen auf Jesus Christus, den Sohn Gottes (V. 20f), der in die Welt gekommen ist (V. 20b) und den Glaubenden Einsicht verliehen hat (V. 20c), damit sie den Wahren erkennen (V. 20d). Er selbst ist der Wahre (V. 20d), in dem die Glaubenden sind (V. 20e). ${ }^{100} \mathrm{Er}$ ist der wahre Gott und ewiges Leben (V. 20 g). In fast hymnischer Sprache, die in schwebender syntaktischer Mehrdeutigkeit Gott und seinem Sohn das Prädikat „der Wahre“ zuspricht, knüpft der Briefschluss an den feierlichen Beginn des Briefes an. ${ }^{101}$ Dort ist vom Logos des Lebens (1 Joh 1,1) die Rede, was als konsequente lebensterminologische Näherbestimmung des Logos aus dem Evangelienprolog verstanden werden kann. ${ }^{102}$ Wie dem Logos des Evangelienprologs Personalität eignet, so eignet sie dem Logos des Lebens im Briefprolog. ${ }^{103}$ Aber auch das Leben $(\dot{\eta} \zeta \omega \dot{\eta})$ und das ewige Leben

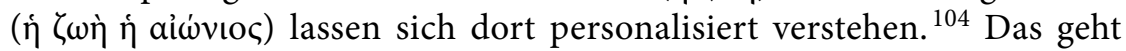
im Blick auf das Leben daraus hervor, dass in einer personalen Weise von seinem Erscheinen gesprochen wird (V. 2a). Im Blick auf das ewige Leben legt sich eine personale Auffassung nahe, da von ihm in einer mit dem Evangelienprolog vergleichbaren Weise gesagt wird, dass es (wie der Logos bei Gott) bei dem Vater war (V. 2e):

1 Joh 1,2

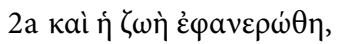

2b кaì $\dot{\omega} \omega \rho \dot{\kappa} \kappa \alpha \mu \varepsilon v$

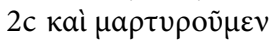

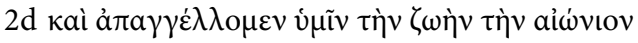

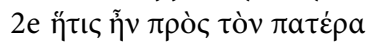

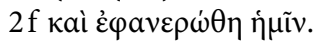

Eben die Inklusion der Verssegmente V. 2a und V. $2 \mathrm{f}$ ist es, die eine inhaltliche Identifizierung von Leben und ewigem Leben plausibel macht. Wie in 1 Joh 5,20 ist mit beiden Begriffen der wahre Gott Jesus Christus bezeichnet, der als Sohn präexistent beim Vater war und von diesem aus

\footnotetext{
${ }^{99} \mathrm{Zu}$ der schwierigen Aufgabe, die Verweisfunktion von oũ̃oc zu bestimmen, vgl. HansJosef KLAUCK, Der Erste Johannesbrief (EKKNT 23,1), Neukirchen-Vluyn 1991, 335.

${ }^{100}$ Auch zu der schwierigen Frage, ob ó ả $\lambda \eta \theta v v o ́ \varsigma$ in V. 20d.e.g auf Gott oder auf Christus zu beziehen ist, vgl. KLAUCK, Johannesbrief (Anm. 99) 337-339.

${ }^{101}$ Zur Frage der Gattungsbestimmung des Briefes, dem bekanntlich ein brieftypisches Präskript fehlt, vgl. KLAUCK, Johannesbrief (Anm. 99) 29-32.

${ }^{102}$ Vom entstehungsgeschichtlichen Verhältnis der Johannesbriefe zum Johannesevangelium ist hier nicht zu handeln. Die oben verwendete Rede einer „Näherbestimmung“ intendiert kein zeitliches Abhängigkeitsverhältnis.

${ }^{103}$ Vgl. dazu Hoegen-Rohls, Ewigkeit (Anm. 1) $140 \mathrm{f}$.

${ }^{104}$ Vgl. Mussner, Leben (Anm. 88) 48.
} 
in die Welt gekommen ist. ${ }^{105}$ Als historisch in die Welt Gekommener konnte er gesehen werden, als solcher wird er bezeugt und verkündigt, als solcher verheißt er sich selbst (1 Joh 2,25). ${ }^{106}$ Es ist daher konsequent, wenn der erste Johannesbrief in Form eines antithetischen parallelismus membrorum formuliert:

\section{Joh 5,12}

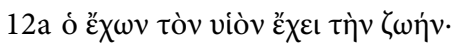

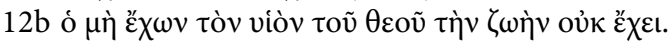

Wer den Sohn hat, hat das Leben; wer den Sohn Gottes nicht hat, hat das Leben nicht. Der Sohn, der selbst Leben hat und ewiges Leben ist, ist Kriterium für das Leben auf Seiten der Menschen. Die Aussage spiegelt im Zusammenspiel mit Joh 5,26b und 1 Joh 5,20 g die Synonymität von

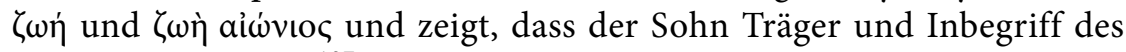
(ewigen) Lebens ist. ${ }^{107}$ Sie macht zugleich deutlich, dass für das johanneische Denken (ewiges) Leben nicht nur im Blick auf Gott/Vater und den Logos/Sohn eine atemporale, zeitunabhängige Dimension ist, sondern auch im Blick auf den glaubenden bzw. nicht glaubenden Menschen. Denn formuliert wird in einem zeitlosen Präsens. ${ }^{108}$ Verwendung findet dabei, wie in Joh 5,26, das für die johanneische Sprache theologisch be-

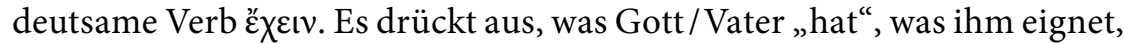
ihn wesenhaft auszeichnet, ${ }^{109}$ es drückt aus, was der Logos/Sohn „hat“, was ihm eignet, ihn wesenhaft auszeichnet, ${ }^{110}$ und es drückt aus, was der glaubende und seinen Glauben bekennende Mensch in seiner Beziehung zu Gott/Vater und Logos/Sohn „hat“, was ihm in dieser Beziehung eignet und ihn in dieser Beziehung auszeichnet: Leben, Leben in Fülle, ewiges Leben. ${ }^{111}$ Dabei ist nirgendwo im Johannesevangelium oder im ersten

\footnotetext{
${ }^{105}$ Von 1 Joh 5,20 aus argumentiere ich mit dieser Deutung gegen Udo Schnelle, Die Johannesbriefe (THKNT 17), Leipzig 2010, 66, der „Leben“ und „ewiges Leben“ in 1 Joh 1,2 als „neues Sein“ der Glaubenden versteht. Zu 1 Joh 5,20 hält er hingegen völlig zu Recht fest: „Jesus Christus ist wahrhaftiger Gott und ewiges Leben“" (183). Beide Stellen müssen meiner Einschätzung nach inhaltlich korreliert werden. Dass es in V. $2 \mathrm{~d}$ heißt, das ewige Leben werde verkündigt, spricht nicht gegen eine personale Auffassung des ewigen Lebens. ${ }^{106} \mathrm{Vgl}$. Mussner, Leben (Anm. 88) 48.

${ }^{107}$ Vgl. dazu Hoegen-Rohls, Ewigkeit (Anm. 1) 149; Schnelle, Johannesbriefe (Anm. 105) 184.

${ }^{108}$ Vgl. dazu Blass/Debrunner/Rehkopf, Grammatik (Anm. 18) $\$ 318.2$.

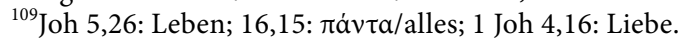

${ }^{110}$ Joh 4,11: lebendiges Wasser; 5,26: Leben; 6,68: Worte ewigen Lebens; 10,18 und 19,10: Vollmacht; 15,13: Liebe; 17,5: Herrlichkeit.

${ }^{111}$ Der Glaubende „hat" Leben (Joh 6,53; 10,10; 20,31), Leben in Fülle $(10,10)$, das Licht des Lebens $(8,12)$, ewiges Leben $(6,40.47 .54)$. Der erste Johannesbrief sagt grundsätzlich: Wer den Sohn bekennt, hat auch den Vater (1 Joh 2,23).
} 
Johannesbrief an das biologische menschliche Leben gedacht (für das selbstverständlich vorausgesetzt wird, dass es von Gott als dem Schöpfer stammt). ${ }^{112}$ Leben, Leben in Fülle und ewiges Leben ist vielmehr jenes von Gott/Vater und Logos/Sohn bestimmte Leben, das gegenüber dem geschöpflichen Leben ein völliges Novum darstellt: Es hat als menschliches Leben Teil am göttlichen Leben, am Logos des Lebens, am wahren Gott, der ewiges Leben ist. Der Welt dieses ewige göttliche Leben zu vermitteln, bestimmt die johanneische Theologie als das eigentliche Ziel des Handelns Gottes:

Joh 3,16

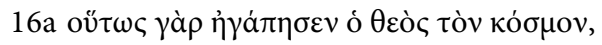

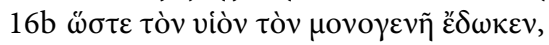

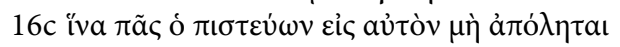
$16 \mathrm{~d} \dot{\alpha} \lambda \lambda^{\prime}$ '

Gottes Handeln gründet nach johanneischer Auffassung in seiner Liebe zur Welt (V. 16a). Es vollzieht sich in der Sendung und Hingabe des Sohnes, auf die das charakteristische Verb "geben“ in V. 16b Bezug nimmt. ${ }^{113}$ Kann dieses Verb in der johanneischen Sprache für die Bevollmächtigung des gesandten Sohnes durch den sendenden Vater stehen, ${ }^{114}$ so referiert es hier, zurückgreifend auf die Aussage in 3,14, dass der Menschensohn erhöht werden müsse ( $\dot{\psi} \omega \theta \tilde{\eta} v a \iota$ $\delta \varepsilon \tilde{)}$ ), auf das Sendungsgeschehen als Ganzes samt seiner Konsequenz des Kreuzestodes. Denn dieser ist es, der von der johanneischen Theologie als Erhöhung verstanden wird. Wie V. 14 durch das dort verwendete passivum divinum erkennen lässt, ist Gott Agens des erhöhenden Handelns. Ebenso artikuliert V. 16b, dass Gott Agens der Hingabe des Sohnes ist: Er hat ihn (hin-)gegeben ( $\check{\varepsilon} \delta \omega-$ $\kappa \varepsilon v)$ - und zwar, damit alle, die an ihn glauben, nicht zugrunde gerichtet

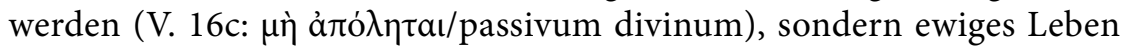
haben (V. 16d). Mit der in V. 16c.d vorgenommenen Gegenüberstellung von vernichtendem Handeln Gottes und göttlichem Leben vermittelndem Handeln Gottes gewinnt Gottes Sendungshandeln ganz grundsätzlich den Charakter richterlichen Handelns. Dies zeigt noch deutlicher die Fortsetzung von V. 16 in V. $17 \mathrm{f}$.:

\footnotetext{
${ }^{112}$ Vgl. im vorliegenden Band ZimmermanN, Handeln I S. 180.

${ }^{113}$ Es ist richtig, dass Michael Theobald, Das Evangelium nach Johannes. Kapitel 1-12 (RNT), Regensburg 2009, 270, hervorhebt, "Geben“ könne nicht auf die "Hingabe“ des Sohnes an das Kreuz eingeschränkt werden, sondern nehme das umfassendere "Senden“ aus Joh 3,17 vorweg.

${ }^{114} \mathrm{Vgl}$. die Ausführungen oben zu Joh 5,26.
} 
Joh $3,17 \mathrm{f}$.

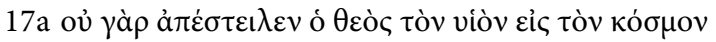

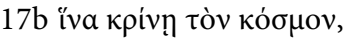

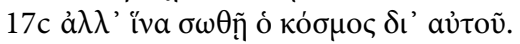

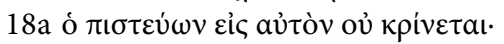

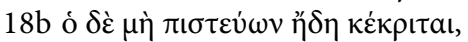

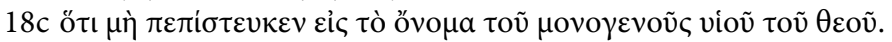

Der Beleg lässt erkennen, dass das johanneische Denken die Vorstellung vom richtenden Handeln Gottes bzw. von Gottes Gericht in auffallender Weise verändert. Es gibt ein solches nach johanneischer Auffassung zwar im künftigen Auferweckungshandeln Gottes, wenn die Glaubenden auferstehen werden zum Leben, die nicht Glaubenden aber zum Gericht (5,28f.). Doch wird in 3,17 deutlich, dass schon die Sendung des Sohnes als solche als gerichtliches Handeln verstanden wird - wenn auch in markanter Brechung: Gerade nicht, um die Welt zu richten (V. 17b), sendet Gott den Sohn in die Welt (V. 17a), sondern damit die Welt gerettet werde durch ihn (V. 17c). Wenn es in 5,22 heißt, dass der Vater niemanden richte, sondern das ganze Gericht dem Sohn gegeben habe (oủò̀

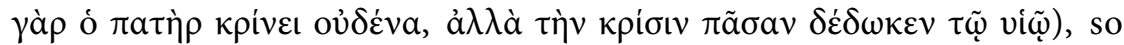
entspricht dies dem Sendungsinstitut: Der Sendende überträgt seine Vollmacht und seinen Auftrag dem Gesandten, der ihn vollgültig vertritt. Es ist daher der gesandte Sohn, der richtet und rettet, in dessen Richten und Retten aber intentional der Vater richtet und rettet. Rettung und Gericht entscheiden sich am Glauben an den Sohn, in dem der Vater wirkt: Wer an den Sohn glaubt, wird nicht gerichtet (V. 18a: ov̉ kpivetal/passivum divinum). Wer nicht an ihn als den einziggeborenen Sohn Gottes glaubt,

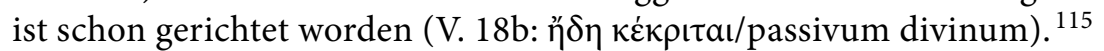

Dass das Sendungshandeln von Vater und Sohn nach johanneischer Auffassung richterliches und rettendes Handeln ist, ist im Blick auf die behandelten Belege unverkennbar. Unverkennbar ist aber auch, dass dieses Sendungshandeln rekreatorisches Handeln ist, insofern die glaubende Bindung an den von Gott gesandten Sohn ein neues, das natürliche menschliche Leben transzendierendes Leben schafft. Dies machen die Belege Joh 3,36; 5,24 deutlich, die den Gerichtsgedanken im Kontext des Lebensgedankens artikulieren:

\footnotetext{
${ }^{115}$ Gegen Theobald, Evangelium (Anm. 113) 272, der sich gegen ein Verständnis des Passiv als passivum divinum ausspricht.
} 
Joh 3,36

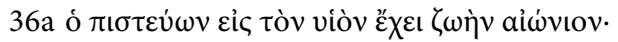

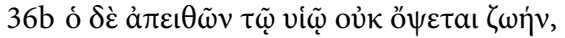

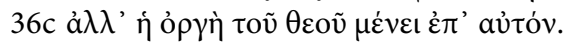

In Form eines antithetischen parallelismus membrorum bringt 3,36 die Auffassung in Übereinstimmung mit Joh 5,26b; 1 Joh 1,20g zur Geltung, dass der Sohn Träger und Vermittler ewigen Lebens ist ${ }^{116}$ und dass die Beziehung zu ihm darüber entscheidet, ob ein Mensch am ewigen göttlichen Leben Anteil hat oder nicht. Der an den Sohn Glaubende hat ewiges Leben (V. 36a). Der dem Sohn Nicht-Gehorchende ${ }^{117}$ wird das Leben nicht sehen (V. 36b). Auf ihm bleibt vielmehr der Zorn Gottes (der hier metonymisch für das Gericht Gottes steht). 5,24 ergänzt, dass, wie die glaubende Beziehung zum Sohn, so auch die glaubende Beziehung zum Vater als dem, der den Sohn gesandt hat, Voraussetzung dafür ist, Anteil am ewigen, göttlichen Leben zu haben (V. 24b), also nicht in das Gericht zu kommen (V. 24c), sondern vom Tod ins Leben hinübergegangen zu sein (V. 24d):

Joh 5,24

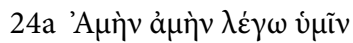

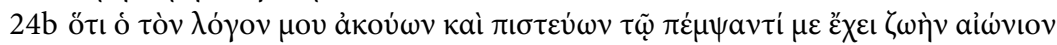

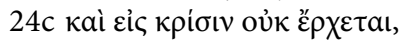

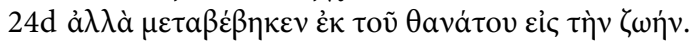

Das resultative Perfekt (V. 24d: $\mu \varepsilon \tau \alpha \beta \dot{\varepsilon} \beta \eta \kappa \varepsilon v)$ im Zusammenspiel mit den

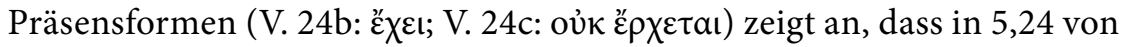
einem Tod die Rede ist, der nicht im Sinne des am Ende des Lebens stehenden physischen Todes gedacht wird, sondern als ein metaphorischer Tod mitten im Leben. Dieser metaphorische Tod bedeutet das Ende des natürlichen menschlichen Lebens, dem gegenüber Gott ein neues, göttliches Leben schafft. Insofern das gesamte Sendungsgeschehen auf solche Neuschöpfung zielt, kann es nicht nur als gerichtliches und rettendes, sondern als genuin rekreatorisches Handeln Gottes bestimmt werden. Damit ist zugleich klar: Rekreatorisches Handeln Gottes ist für die johanneische Theologie kein allein an die Zukunft gebundenes Handeln. Zwar kann das Johannesevangelium, wenn es in mehrdeutiger Weise davon spricht, dass Gott Tote auferweckt (5,21), auch physisch Tote meinen, die zu einem postmortalen Leben auferweckt werden. ${ }^{118}$ Ebenso kann das

\footnotetext{
${ }^{116}$ Vgl. so auch Theobald, Evangelium (Anm. 113) 295.

${ }^{117}$ So die Übersetzung von Theobald, Evangelium (Anm. 113) 289.

${ }^{118}$ Vgl. dazu im vorliegenden Band ZimmermanN, Handeln I (Anm. 2) S. 172-173.186.
} 
vierte Evangelium von Jesus sagen, dass er die Glaubenden künftig, nämlich „am jüngsten Tage“, auferwecken werde (6,40.54). Doch wird an den präsentischen Formulierungen der letztgenannten Stellen grundlegend erkennbar, dass die künftig Auferweckten eben jene sind, die jetzt schon

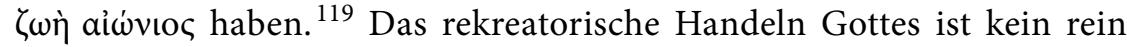
futurisch-eschatisches Handeln für Johannes. Es hat sich vollzogen in der Sendung des Sohnes durch Gott und es vollzieht sich in der glaubenden Beziehung der Menschen zu Gott und seinem Sohn. Eben deshalb kann es im Abschiedsgebet des zum Vater zurückkehrenden Gesandten heißen:

\section{Joh 17,3}

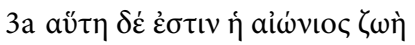

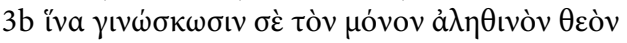

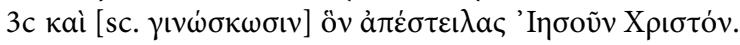

Den einzigen wahren Gott zu erkennen (V. 3b) und den, den er ge-

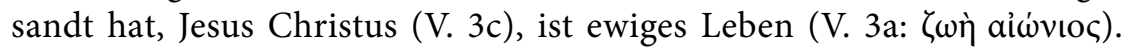
Es ist dieser Beleg, der unmissverständlich klärt, dass „ewiges Leben“ für das johanneische Denken kein temporaler Begriff ist. Ewiges Leben, bezogen auf den Bereich der Menschen, besteht nicht in einem postmortalen Leben „,von uneingeschränkter Dauer"120, sondern in der Gotteserkenntnis. „Ewiges Leben“ erscheint in Joh 17,3 somit - einzigartig innerhalb des Neuen Testaments - als epistemologischer Begriff. Insofern die johanneische Sprache die Verben „erkennen“ ( $\gamma \iota \nu \omega ́ \sigma \kappa \varepsilon เ v)$ und „glau-

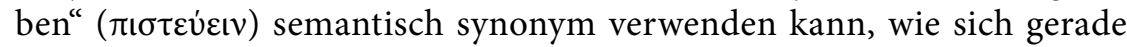
am Abschiedsgebet zeigen lässt, ${ }^{121}$ zielt V. 3 nicht auf eine rein intellektuelle Erkenntnis Gottes ab. Mit Gotteserkenntnis ist vielmehr jene Einsicht gemeint, die aus erkennendem Glauben kommt. Diesen wirkt nach johanneischer Auffassung der das Sendungshandeln von Vater und Sohn fortsetzende Geistparaklet, der nachösterlich in die ganze göttliche

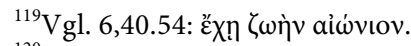

${ }^{120}$ Zumstein, Johannesevangelium (Anm. 84) 635.

${ }^{121}$ Die Synonymität beider Verben geht aus den beiden völlig parallel geführten Finalsätzen 17,21 und 17,23 hervor, in denen die Verben "glauben“ und „erkennen" sich auf denselben Sachverhalt beziehen, nämlich auf die Sendung des Sohnes durch den Vater (V. 21: îva ó

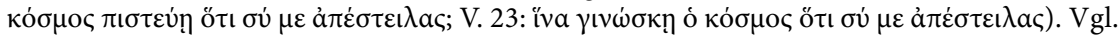
dazu Christina Hoegen-Rohls, Johanneisches Lieben im Gespräch mit lyrischen Texten, in: Dies./Uta Poplutz (Hg.), Glaube, Liebe, Gespräch. Neue Perspektiven johanneischer Ethik (BThSt 178), Göttingen 2018, 181-205: 192f.; Jörg Frey, Glauben und Lieben im Johannesevangelium, in: Hoegen-Rohls/Uta Poplutz (Hg.), Glaube Liebe, Gespräch. Neue Perspektiven johanneischer Ethik (BThSt 178), Göttingen 2018, 1-54: $7 \mathrm{f}$.
} 
Wahrheit einführt (vgl. 16,13). ${ }^{122}$ Wenn „ewiges Leben“ in Joh 17,3 als epistemologischer Begriff verwendet wird, so geschieht dies also auf dem Hintergrund der johanneischen Pneumatologie. „Ewiges Leben“, bezogen auf den glaubenden Menschen, benennt die herausragende Qualität eines Lebens, das dank des Geistes glaubend und erkennend am ewigen göttlichen Leben partizipiert, das in Gott/Vater und im Logos/Sohn zeitlos präsent ist.

\section{Gott allein? Ein komparatistisch geprägtes Fazit zu Gottes rekreatorischem Handeln bei Paulus und Johannes}

Im vorliegenden Beitrag wurden zwei nominale Ausdrucksformen untersucht, um zu bestimmen, wie Paulus und Johannes vom wieder- und neuschöpfenden Handeln Gottes sprechen. Philologisch und exegetisch-

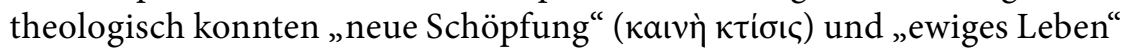

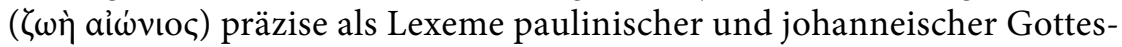
rede bestimmt werden, die jeweils ein bestimmtes Gottesbild transportieren. Es wurde herausgearbeitet, dass sich mit der paulinischen Rede von кaıvทे ктібıৎ das Bild Gottes als neuschaffendem Versöhner und als barmherzigem Gott des Friedens verbindet. Indem Gott Mensch und Welt mit sich versöhnt und indem er seinem Geschöpf als rettender Gott Gnade und Frieden spendet, schafft er seine geschaffene Schöpfung und sein erschaffenes Geschöpf neu. Dabei verbindet Paulus den Gedanken an das durch Gott neu erschaffene Leben mit zwei vollzogenen Toden. Aus dem realen Kreuzestod seines Sohnes und durch diesen Tod, aber auch aus dem metaphorisch verstandenen Tod der Menschen, die im Glauben mit Christus gestorben sind, erzeugt Gott „neue Schöpfung“. Vollzog sich dieses neuschöpferische Handeln Gottes bereits in der Vergangenheit des Todes des Sohnes, so bestimmt es zugleich grundlegend die Gegenwart und verwirklicht sich überall dort, wo Menschen im Glauben

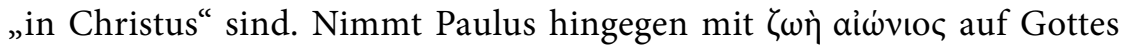
rekreatorisches Handeln Bezug, so denkt er an ein Handeln Gottes, in dem sich gegenwärtiges heiligendes und künftiges richterliches Handeln

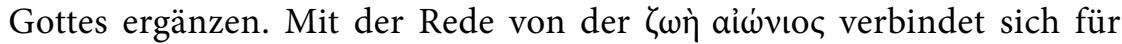
Paulus das Bild Gottes als Richter und Retter, der die Glaubenden schon gegenwärtig zur Teilhabe an seiner Heiligkeit ruft, um ihnen auch künftig

\footnotetext{
${ }^{122}$ Vgl. dazu Christina Hoegen-Rohls, Der nachösterliche Johannes. Die Abschiedsreden als hermeneutischer Schlüssel zum vierten Evangelium (WUNT 2,84), Tübingen 1996.
} 
die Ernte ewigen Lebens zuteilwerden zu lassen. Demgegenüber spricht

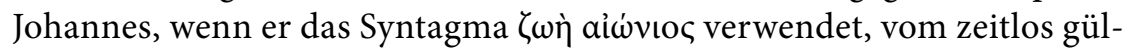
tigen, präsentisch erfahrbaren rekreatorischen Handeln Gottes. Gott, der selbst ewiges Leben ist, gibt den Glaubenden Anteil an seinem ewigen göttlichen Leben. Dabei denkt Johannes dieses rekreatorische Handeln Gottes als Sendungshandeln von Vater und Sohn.

Beide neutestamentlichen Theologen spiegeln in ihrer differenzierten Rede von "neuer Schöpfung" und „ewigem Leben“, dass Gott in seinem rekreatorischen Handeln nicht allein agiert. Erscheint bei Paulus Gottes Sohn als Mittel des rekreatorischen göttlichen Handelns, so tritt der Sohn bei Johannes, da er bevollmächtigter Gesandter des Vaters ist, selbst als rekreatorisch Handelnder hervor. Insofern für Johannes auch der Geist an dem auf die Rekreation des Menschen und der Welt zielenden Sendungshandeln Gottes beteiligt ist, wird bei Johannes nicht nur aus christologischer, sondern auch aus pneumatologischer Perspektive erkennbar, dass es nicht Gott allein ist, der die von ihm gewollte Neuschöpfung seiner Welt und seiner Geschöpfe verwirklicht. 



\section{„Gott ist Liebe“ \\ Sinn und Bedeutung der zentralen Gottesprädikation im ersten Johannesbrief}

Johannes Beutler SJ

\section{Hinführung}

Bei der Frage nach dem Gottesbild bei Johannes kommt der doppelten Aussage im ersten Johannesbrief (1 Joh 4,8.16): „Gott ist Liebe“ sicher eine besondere Bedeutung zu. Sieht man vom Wort Jesu: „Gott ist Geist“ im Johannesevangelium $(4,24)$ ab, dann finden sich nur im ersten Johannesbrief Aussagen, die Gottes Wesen mit einem Wort beschreiben. Wir werden noch sehen, dass sich schon am Anfang des Briefes die Aussage findet: „Gott ist Licht“" (1 Joh 1,5). Ihr gleich ist dann unsere wiederholte Aussage, Gott sei Liebe. Mit Recht zählen solche Aussagen zu den Spitzentexten des Neuen Testaments.

Dass Gottes tiefstes Wesen Liebe ist, bleibt freilich nicht die einsame Einsicht des Verfassers vom ersten Johannesbrief. Ihr geht eine lange Entwicklung voraus, die jüngst u. a. Thomas Söding in der Festschrift Wilhelm Thüsing nachgezeichnet hat. ${ }^{1}$ Von besonderer Bedeutung sind hier die Aussagen im Buch Deuteronomium, in denen die Beziehung Gottes zu seinem Volk Israel in der Sprache der Liebe zum Ausdruck gebracht wird. Auf der einen Seite lässt sich die Verpflichtung Israels seinem Gott gegenüber im „Sch $m a^{c}$ Israel - Höre, Israel“ von Dtn 6,4f. zum Ausdruck bringen: „Höre, Israel! Der HerR, unser Gott, der Herr ist einzig. Darum sollst du den Herrn, deinen Gott, lieben mit ganzem Herzen, mit ganzer Seele und mit ganzer Kraft." Hier kommt eine Bundesbeziehung zum Ausdruck, wie seit längerer Zeit gesehen worden ist. Ihr entspricht auf der anderen Seite, dass Gott sein Volk liebt, wenn es nur seinerseits zu seiner Bundesbeziehung steht. Bekannt ist hier die Aussage von Dtn 7,12f.:

\footnotetext{
${ }^{1}$ Vgl. Thomas SöDing, „Gott ist Liebe“. 1 Joh 4,8.16 als Spitzensatz Biblischer Theologie, in: ders. (Hg.), Der lebendige Gott (NTAbh 31), Münster 1996, 306-357.
} 
„Wenn ihr diese Rechtsentscheide hört, sie bewahrt und sie haltet, wird der Herr, dein Gott, dir dafür den Bund und die Huld bewahren, die er deinen Vätern geschworen hat. Er wird dich lieben, dich segnen und dich zahlreich machen." Das Thema der Liebe Gottes zu seinem Volk kommt bei den Propheten Israels zum Ausdruck, nicht selten im Bild der bräutlichen Liebe, von Hosea ${ }^{2}$ bis Ezechiel (vgl. Ez 16). So braucht das Neue Testament diese Überzeugung nur aufzugreifen und sie nun auf das erweiterte Gottesvolk aus Juden und Heiden anzuwenden. Allen voran ist hier Paulus zu nennen. So kann Paulus den Korinthern am Ende seines zweiten an sie gerichteten Briefes (2 Kor 13,11) wünschen: „[...] seid eines Sinnes, haltet Frieden! Dann wird der Gott der Liebe und des Friedens mit euch sein" (vgl. auch 2 Kor 13,13). Im Römerbrief zeigt sich auch eine trinitarische Dimension des Liebesthemas. Zu Beginn des fünften Kapitels schildert Paulus die Früchte der Rechtfertigung in Glaube, Hoffnung und Liebe. Diese sind nicht einfach "theologische Tugenden" des Menschen, sondern zuvor und vor allem Gabe Gottes. So kann es dann heißen: „Die Hoffnung aber lässt nicht zugrunde gehen; denn die Liebe Gottes ist ausgegossen in unsere Herzen durch den Heiligen Geist, der uns gegeben ist" (Röm 5,5).

Gerade diese Verbindung von Gottes Liebe und Heiligem Geist ist von ausschlaggebender Bedeutung für den wohl einflussreichsten Ausleger der Aussagen im ersten Johannesbrief zu dem Gott, der Liebe ist, den Kirchenvater Aurelius Augustinus. Seine Sicht hat auch über den kirchlichen Rahmen hinaus Beachtung gefunden. Keine geringere Autorin als die Jüdin Hannah Arendt hat ihr 1928 an der Universität Heidelberg ihre Dissertation unter Anleitung von Karl Jaspers gewidmet: „Der Liebesbegriff bei Augustin. Versuch einer philosophischen Interpretation“. ${ }^{3}$ Dieser Arbeit kann hier im vorgegebenen Rahmen nicht im Einzelnen nachgegangen werden.

Auch die exegetische Diskussion um die Interpretation der Aussagen des Augustinus zu dem Gott, der Liebe ist, kann hier nicht nachgezeichnet werden. Beschränken wir uns auf eine Auswahl. Für heutige Leser des Textes von Augustin im Urtext und in einer modernen Sprache leistet die Ausgabe des französischen Jesuiten Paul Agaësse in den Sources Chréti-

\footnotetext{
${ }^{2}$ Vgl. dazu ebd., 310-312.

${ }^{3}$ Hannah Arendt, Der Liebesbegriff bei Augustin. Versuch einer philosophischen Interpretation, Berlin 1929; Neuauflagen: Vorwort und Hg. Ludger Lütkehaus, Berlin 2003; Originalreprint, Hg. und Essay Frauke-Annegret Kurbacher, Hildesheim 2006.
} 
ennes nützliche Dienste. ${ }^{4}$ Der Autor behandelt in seiner Einleitung das Thema der Liebe im Kommentar des Augustinus zum ersten Johannesbrief vor allem unter der Rücksicht der trinitarischen Dimension dieser Aussagen und verweist dabei auf die parallelen Abschnitte im Traktat des Bischofs von Hippo De trinitate, vor allem in den Kap. 8 und 15. Wichtig war für Augustin die Aussage des Paulus in Röm 5,5: „Denn die Liebe Gottes ist ausgegossen in unsere Herzen durch den Heiligen Geist, der uns gegeben ist." Diese Sicht des Paulus führt Augustin zu einer Identifikation der Liebe (dilectio) mit dem Heiligen Geist. So wie der Geist innerhalb der Trinität das Band der Liebe zwischen Vater und Sohn darstellt, so ist eben dieser Geist auch die Kraft und der Urheber der Liebe, die die Gläubigen gegenüber Gott und dem Bruder erweisen.

In einem ausführlichen Artikel geht in neuerer Zeit Robert Dodaro dem Thema "Gott ist Liebe“ im ersten Johannesbrief nach Augustinus nach. ${ }^{5}$ Auch er unterstreicht die trinitarische Dimension der Liebe bei Johannes. Wichtigstes Fazit dieses Artikels scheint mir zu sein, dass es Augustinus in erster Linie auf die Liebe ankommt, die die Gläubigen einander erweisen sollen. Gerade in diesem Sinne handelt der erste Johannesbrief vom Anfang an von der Liebe: „Schließlich artikuliert sich die augustinische Lehre, deus caritas est' nicht im Sinne einer Metaphysik der Trinität oder der Liebe, die nach unzureichenden dogmatischen Schemata betrachtet wird, sondern vor allem in der Sprachwelt einer theologischen Anthropologie, in der die geistliche Dynamik der göttlichen und menschlichen Liebeseinheit im Licht der Heiligen Schrift befragt wird. " ${ }^{6}$

Hier dürfte der Verfasser etwas gesehen haben, was schon vor Augustinus für den Verfasser des ersten Johannesbriefes kennzeichnend war. Geht es in diesem Brief doch um die Weise, wie Menschen glaubwürdig von sich die Gemeinschaft mit Gott behaupten können (dazu im nächsten Abschnitt).

Einem weiteren neueren Autor, dem amerikanischen Jesuiten Roland Teske von der Marquette Universität, ${ }^{7}$ fällt eine eigentümliche Umkehrung der johanneischen Aussage im Kommentar Augustins zu 1 Joh 4,8 (im Abschnitt 7,6) auf. Hier liest Augustin erstaunlicherweise „Die Liebe ist Gott“, wörtlich: „Quomodo ergo jam dudum: ,Dilectio ex Deo est', modo:

\footnotetext{
${ }^{4}$ Saint Augustin, Commentaire de la Première Épître de S. Jean. Texte latin, introduction, traduction et notes par Paul Agaësse (SC 75), Paris 1961.

${ }^{5}$ Robert Dodaro, „Deus caritas est“ nell'esegesi agostianiana della Prima Johannis, Lat. 73 (2007) 333-355.

${ }^{6} \mathrm{Vgl}$. ebd., 354.

${ }^{7}$ Roland Teske S. J., Augustine’s Inversion of 1 John 4:8, AugStud 39 (2008) 49-60.
} 
,Dilectio Deus est ‘ “ Die Formulierung ist so erstaunlich, dass Paul Agaësse sie in seiner Ausgabe unrichtig übersetzt: „Dieu est dilection“ („Gott ist Liebe“). ${ }^{8}$ Wie kommt Augustin zu dieser überraschenden Umkehrung der Aussage in 1 Joh 4,8 (vgl. 16)? Roland Teske verweist hier auf den Kontext der Aussage Augustins. Ausgangspunkt ist, wie gerade zitiert, die Aussage im vorangehenden Vers 1 Joh 4,7, die Liebe stamme von Gott. Wenn man sich fragt, wie die beiden Aussagen miteinander vereint werden könnten, dann ergibt sich, dass der Verfasser des Briefes nicht von der Liebe an sich reden will, sondern von derjenigen, die die Mitglieder der Gemeinde mit Gott und untereinander verbinden soll. Eben diese Liebe ist göttlicher Natur, ja man kann sie Gott nennen. Hinter der Sicht Augustins steht, wie erwähnt, auch Röm 5,5 mit der Aussage des Paulus, die Liebe Gottes sei in unsere Herzen ausgegossen durch den uns verliehenen Heiligen Geist. Der Vers wird an der genannten Stelle auch von Augustin zitiert.

Durch den Blick auf die Exegese Augustins ist nun unser Blick geschärft für die Aussage im ersten Johannesbrief $(4,8.16)$, Gott sei Liebe. Wenden wir uns damit dem Text des Briefes selber zu.

\section{Der Text}

\subsection{Kontext}

Um die Aussagen von 1 Joh 4,8.16 richtig verstehen zu können, muss man sie in den größeren Textzusammenhang des ersten Johannesbriefes stellen. Über dessen Aufbau besteht bis heute kein Konsens, wie ein Blick auf Übersetzungen und Kommentare zeigt. Doch hat sich im Laufe der letzten Jahrzehnte eine Tendenz entwickelt, im ersten Johannesbrief drei Hauptteile zu erkennen, in denen jeweils neu die Frage nach den Kriterien für eine behauptete Gemeinschaft mit Gott beantwortet werden kann. Dahinter steht die Einsicht, dass der erste Johannesbrief in einer Kontroverse zwischen dem Verfasser und seiner Gemeinde auf der einen Seite und anzunehmenden Gegnern auf der anderen entstanden zu sein scheint, die in pneumatischem Hochgefühl die Notwendigkeit eines für sie gestorbenen Christus und zugleich eines Lebens nach dem Liebesgebot bestritten. Ihnen würde in einem Dreischritt geantwortet, der jeweils mit einem Prädikat Gottes verbunden ist: „Gott ist Licht“ (1 Joh 1,5) und

\footnotetext{
${ }^{8}$ Vgl. Paul Agaësse in seiner Ausgabe des Kommentars Augustins zu den Johannesbriefen (Anm. 4) 323 zum Abschnitt 7,6.
} 
die Notwendigkeit, wie er im Licht zu wandeln, Gott ist ein Gott der Gerechtigkeit (ab 1 Joh 2,28), und der Christ hat die Gerechtigkeit zu üben, und "Gott ist Liebe" (1 Joh 4,8), und es gilt gleich ihm in der Liebe zu leben. Hatte schon 1892 Theodor Häring die Gliederung des 1 Joh nach diesen Gottesprädikaten vorgeschlagen und dabei deren Funktion für das Verhalten der Lesergemeinde herausgestellt, ${ }^{9}$ so neigt man heute noch stärker dazu, die anthropologische Dimension des Briefes ernst zu nehmen. So gliedere ich den Brief ${ }^{10}$ dann nach der Einleitung $(1,1-4)$ in die drei Hauptteile: „Erste Reihe von Kriterien für die Gemeinschaft mit Gott und das Leben 1,5-2,27“, „Zweite Reihe von Kriterien für die Gemeinschaft mit Gott und das Leben 2,28-4,6“ und „dritte Reihe von Kriterien für die Gemeinschaft mit Gott und das Leben 4,7-5,13“, vor dem Schluss 5,14-21. Ähnlich und im Anschluss daran gliedert dann die Revidierte Einheitsübersetzung von 2016 den Text. Vorausgegangen waren u. a. der Gliederungsvorschlag ${ }^{11}$ und die Dissertation von Edward Malatesta SJ am Päpstlichen Bibelinstitut „Interiority and Covenant“, ${ }^{12}$ in der er die Formeln vom „Sein in“ und „Bleiben in“ im 1 Joh untersuchte und den Zusammenhang mit der Bundestheologie herausstellte, mit dem Vorschlag der Dreiteilung des Briefes im freien Anschluss an Theodor Häring. Ein ähnlicher Vorschlag findet sich übrigens bei dem Australier John Painter in seinem Kommentar zu den Johannesbriefen von 2002. ${ }^{13}$ Er spricht hier von dreifach wiederholten "tests“ für den authentischen Glauben und die glaubwürdige Liebe, seinerseits im freien Anschluss an das frühe Werk von Robert Law, The Tests of Life, Edinburgh 1909. ${ }^{14}$

Schwierig blieb für die Ausleger von Anfang an der anscheinend freie Wechsel zwischen christologischen und ethischen Aussagen im ersten Johannesbrief. Der innere Zusammenhang zwischen diesen Aussagen besteht in der Anthropologie, in der sich Verfasser und Gegner unter-

\footnotetext{
${ }^{9}$ Theodor HärING, Gedankengang und Grundgedanke des ersten Johannesbriefes, in: Adolf von Harnack u. a. (Hg.), Theologische Abhandlungen Carl von Weizsäcker zu seinem 70. Geburtstag, 11. December 1892, Freiburg 1892, 173-200; vgl. DERs., Die Johannesbriefe, Stuttgart 1927.

${ }^{10}$ Vgl. Johannes BeutLER, Die Johannesbriefe. Übersetzt und erklärt (RNT), Regensburg 2000,5 .

${ }^{11}$ Edward Malatesta, The Epistles of St. John. Greek Text and English Translation Schematically Arranged, Rom 1973.

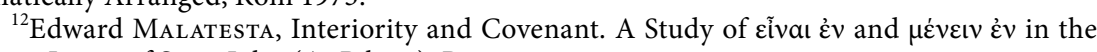
First Letter of Saint John (AnBib 69), Rom 1978.

${ }^{13}$ John Painter, 1, 2, and 3 John (Sacra Pagina 18), Collegeville 2002.

${ }^{14}$ Robert Law, The Tests of Life. A Study of the First Epistle of Saint John, Edinburgh 1909 ( ${ }^{3} 1982$ Reprint Grand Rapids).
} 
scheiden. Wer sich so sehr vom Geist erfüllt sieht, dass er keinen Erlöser Christus mehr braucht, der steht auch über dem Gebot. Beiden Fehleinschätzungen stellt der Verfasser des 1 Joh dann seine Auffassung gegenüber und entfaltet sie in drei Schritten. Zweimal steht am Anfang eines Hauptabschnitts ein Unterabschnitt „Bruch mit der Sünde“, der dann entfaltet wird, erst als „Wandel im Licht“ $(1,5-2,2)$, später dann als „Tun der Gerechtigkeit“ $(2,28-3,10)$. Im dritten Hauptabschnitt fehlt dieser Unterteil. Es folgt jeweils ein Abschnitt über das Halten der Gebote und die Bruderliebe (2,3-11;3,11-24; 4,7-21). Dann folgt abschließend ein Unterabschnitt über „Bruch mit der Welt, rechter Glaube“ $(2,12-27$; 4,1-6), dem im dritten Hauptteil entspricht: „In Glaube und Liebe Sieg über die Welt und Leben“" (5,1-13). Eine ähnliche Einteilung findet sich auch in der Revidierten Einheitsübersetzung. Nach dieser Einteilung befände sich dann der uns interessierende Abschnitt 1 Joh 4,7-21 am Anfang des dritten Hauptteils.

\subsection{Aufbau}

Um die Aussagen von 1 Joh 4,8.16 richtig zu verstehen, ist es nützlich, den Aufbau der Texteinheit zu kennen, in den sie eingebettet sind. Ich darf mich hier erneut auf meine Vorarbeiten stützen. ${ }^{15}$ Es wird sich dabei zeigen, dass der Vorschlag Augustins, die Aussagen zum Gott, der Liebe ist, im 1 Joh trinitarisch zu deuten, sich auch vom Text selbst her aufzeigen lässt, nicht nur aufgrund allgemeiner trinitätstheologischer Überlegungen, die z. T. auf Paulus zurückgreifen. Wie also ist der Abschnitt aufgebaut?

In den Versen 4,7f. findet sich die Einleitung des Abschnitts, mit einer ersten Antithese: Die Leser („Geliebte“) sollen einander lieben, denn die Liebe ist aus Gott; wer nicht liebt, hat Gott nicht erkannt, denn Gott ist Liebe. Im Folgenden wird das Thema der Liebe in drei Schritten entfaltet.

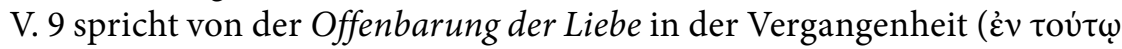
$\dot{\varepsilon} \varphi \alpha v \varepsilon \rho \dot{\omega} \theta \eta \dot{\eta} \alpha \dot{\gamma} \gamma \dot{\alpha} \pi \eta)$. Diese Liebe ist in der Sendung Jesu für unsere Sünden offenbar geworden. In den VV. 10-16 geht es um das Wesen der Liebe

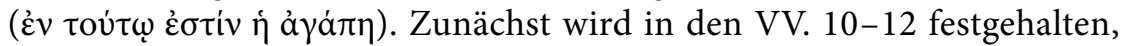
dass die entscheidende Antwort auf die Liebe Gottes in der wechselseitigen Liebe der Gemeindemitglieder untereinander besteht. Dann wird in den VV. 13-16 noch einmal aufgezeigt, wo und wie die Liebe Gottes er-

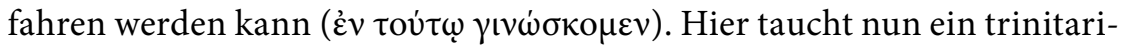

\footnotetext{
${ }^{15} \mathrm{Vgl}$. hierzu BeutLER, Johannesbriefe (Anm. 10) $107 \mathrm{f}$.
} 
sches Schema auf, das uns gleich noch beschäftigen soll. In aufsteigender Abfolge wird aufgezeigt, wie die Liebe Gottes in der Gabe des Geistes, in der Sendung Jesu und im Blick auf Gott Vater selbst gläubig erfahren werden kann. Die VV. 17-18 sprechen von der Vollendung der Liebe in der

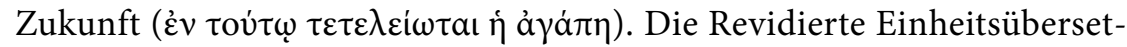
zung beginnt mitten in V. 16 mit einem neuen Unterabschnitt: „Furcht und Liebe“, der bis V. 21 reicht. Besser zieht man aber den ganzen V. 16 noch zum Vorhergehenden und sieht dann in VV. 17-18 das Thema "Vollendung der Liebe“ gegeben, im Anschluss an die Formulierung des Verfassers selbst. Inhaltlich bleibt richtig, dass sich die Liebe nicht zuletzt dadurch vollendet, dass sie die Furcht vor dem Gericht nimmt. Die VV. 19-21 bilden dann den Abschluss der Texteinheit. Positive Aussagen rahmen in einer neuen Antithese solche zu Menschen, die behaupten Gott zu lieben, aber ihren Bruder nicht lieben. Das wiederholte Gebot: „Wer Gott liebt, der soll auch seinen Bruder lieben“, bringt dann den Abschnitt zum Abschluss (V. 21). ${ }^{16}$

\subsection{Auslegung}

Vor der Auslegung der Einzelverse, vor allem derjenigen, in denen die Aussage "Gott ist Liebe“ begegnet, empfiehlt es sich, noch einmal einen Blick auf die gesamte Texteinheit zu werfen. Zunächst einmal ist von Bedeutung, dass sie in der Gesamtstruktur des Briefes den beiden anderen Abschnitten entspricht, in denen es um das „Halten der Gebote“ und die „Bruderliebe“ ging, also 1 Joh 2,3-11 und 3,11-24. Schon von hier aus wird deutlich, dass es sich in 1 Joh 4,7-21 nicht um einen dogmatischen, sondern um einen paränetischen Abschnitt handelt.

Ein Blick auf die syntaktische Struktur des Abschnitts bestätigt diesen Eindruck. Zwar fehlen in ihm Imperative, doch haben zwei Kohortative eine vergleichbare Bedeutung. Sie erklären sich aus der Tastsache, dass sich der Verfasser bei seinen Mahnungen an die Lesergemeinde stets selbst mit einschließt. Solche Kohortative finden sich bezeichnenderweise

\footnotetext{
${ }^{16}$ Einen etwas anderen Aufbau von 1 Joh 4,7-21 bietet Michael Theobald. Er sieht in den VV. 9-18 einen heilsgeschichtlichen Aufbau: V. 9 spricht von der Sendung des Sohnes in die Welt in der Inkarnation, V. 10 von seiner Hingabe für die Sünden am Kreuz, V. 13 von der Gabe des Geistes zu Ostern, und die VV. 17-18 sprechen dann von der Zuversicht am Tag des Gerichts. Vgl. Michael Tнеовацd, Angstfreie Religiosität. Röm 8,15 und 1 Joh 4,17f. im Licht der Schrift Plutarchs über den Aberglauben, in: ders., Studien zum Römerbrief (WUNT 136), Tübingen 2001, 432-454: 450-453; ähnlich DERs., Der Streit um Jesus als Testfall des Glaubens. Christologie im Ersten Johannesbrief, in: ders., Studien zum Corpus Iohanneum (WUNT 267), Tübingen 2010, 605-617: 614f.
} 
am Anfang und am Schluss des Abschnitts, also in den Einleitungsversen (gleich in 1 Joh 4,7) und in den abschließenden VV. 19-21, dort ebenfalls gleich zu Anfang $(4,19)$. Dabei ist davon auszugehen, dass die Worte $\eta \mu \varepsilon \varepsilon \tilde{\varsigma}$ $\grave{\alpha} \gamma \alpha \pi \tilde{\omega} \mu \varepsilon v$ als Aufforderung und nicht als Aussage zu verstehen sind. ${ }^{17}$ Indem diese Aufforderung den Abschnitt deutlich rahmt, erhält sie besonderes Gewicht und bestimmt auch die Eigenart des Textabschnittes. In der Mitte des Abschnittes gehört V. 11 noch zu den Aufforderungen des Verfassers mit dem ỏ $\varphi \varepsilon i \lambda o \mu \varepsilon v$ „wir müssen“. Diesem Satz kommt besondere Bedeutung zu, da er auf seine Weise den gesamten Abschnitt zusammenfasst: „Geliebte, wenn Gott uns so sehr geliebt hat, müssen auch wir einander lieben." Hier kommt besonders klar zum Ausdruck, worum es dem Verfasser in dem gesamten Abschnitt geht. Einerseits erinnert der Verfasser an die zuvorkommende Liebe Gottes zu ihm und den Adressaten. Auf der anderen Seite zieht er aus der erfahrenen Liebe Gottes nicht den logisch naheliegenden Schluss: „Wenn Gott uns so sehr geliebt hat, dann müssen auch wir ihn lieben." Die erste und entscheidende Antwort auf die erfahrene Liebe Gottes liegt vielmehr in der Liebe des Bruders und der Schwester in der Gemeinde. Die Begründung für die unerwartete Antwort auf die Gottesliebe durch die Bruderliebe wird vom Verfasser gleich zweimal gegeben. Zunächst erscheint sie in V. 12 im unmittelbaren Anschluss an das „wir müssen“ von V. 11: „Niemand hat Gott je gesehen. Wenn wir einander lieben, dann bleibt Gott in uns, und seine Liebe ist in uns vollendet." Die Liebe zum unsichtbaren Gott soll sich also erweisen in der Liebe zu dem sichtbaren Bruder und der sichtbaren Schwester. Der gleiche Gedanke wird wiederholt innerhalb des Schlussabschnittes, hier sogar noch verschärft: Wer behauptet, Gott zu lieben, aber seinen Bruder oder seine Schwester nicht liebt, erweist sich als Lügner, da er fälschlich behauptet, Gott zu lieben, ohne der näherliegenden Verpflichtung nachzukommen, die Bruderliebe zu üben (VV. 19f.).

Gehen wir nach diesem kurzen Blick die einzelnen Versgruppen noch einmal durch und fragen uns nach ihrer Bedeutung für unsere Ausgangsfrage nach dem "Gott der Liebe" im ersten Johannesbrief. Bislang ist schon deutlich geworden, dass sie im Dienst der katechetischen Ermahnungen des Verfassers stehen wird, nach Gottes Gebot den Bruder und die Schwester zu lieben.

\footnotetext{
${ }^{17}$ So mit der Einheitsübersetzung, Luther und der Bible de Jérusalem gegen eine Reihe von Übersetzungen und Kommentaren wie der Zürcher Bibel von 2007, der Revised Standard Version, Stephen Smalley, 1, 2, 3 John (WBC 51), Waco 1984 und Hans-Josef KlaucK, Der Erste Johannesbrief (EKKNT 23,1), Zürich/Neukirchen 1991, z. St.
} 
VV. $7 \mathrm{f}$.: Mit den VV. $7 \mathrm{f}$. beginnt, wie gesehen, der letzte große Hauptabschnitt des ersten Johannesbriefes. Er wird mit Recht von der Revidierten Einheitsübersetzung überschrieben „Gemeinschaft mit Gott in der Liebe“. Damit ist auch schon deutlich, dass nicht die zweimal wiederholte Aussage "Gott ist Liebe“ (4,8.16), sondern das Thema der Gemeinschaft mit Gott das beherrschende Thema ist. So wie in 1 Joh 1,5-2,27 diese Gemeinschaft mit Gott, der Licht ist, durch Wandel im Licht zugesagt werden kann und in 2,28-4,6 durch Wandel in der Gerechtigkeit, so nun durch Gemeinschaft mit Gott, der selbst Liebe ist.

Ein Blick auf die Syntax von VV. $7 \mathrm{f}$. zeigt, dass die Aussage, Gott sei Liebe, am Ende und in einem Nebensatz, d. h. einem Kausalsatz steht. Schon von hierher ist deutlich, dass diese Aussage nicht den Kern des Abschnitts, sondern nur seinen krönenden Abschluss darstellt. Die Versgruppe wird eingeleitet durch die Anrede „Geliebte“ (ả $\gamma \alpha \pi \eta \tau$ toí), die schon in 1 Joh 2,7 und in 4,1 begegnet war. Gerade an unserer Stelle kann sie auch einschließen, dass der Verfasser die Adressaten nicht nur als von sich, sondern auch und vielleicht zuerst als von Gott Geliebte anspricht. Es folgt die Aufforderung „wir wollen einander lieben“ mit der Begründung „denn die Liebe ist aus Gott". Sie wird erweitert durch den doppelten Hinweis „und jeder, der liebt, stammt aus Gott und erkennt Gott“. Hier greift der Verfasser auf bereits Gesagtes zurück. Von der „Zeugung" aus Gott war bereits in 1 Joh 2,29; 3,9 die Rede gewesen. Sie ist ein den Lesern der johanneischen Tradition seit dem Prolog des Evangeliums vertrautes Thema (vgl. Joh 1,12f.). Auch die Gewissheit der Erkenntnis Gottes bei rechtem Bundesverhalten ist den Lesern vertraut. Sie war in 1 Joh 2,3 und zuletzt in 4,6 begegnet und geht wohl zurück auf die Verheißung für Israel im Neuen Bund in Jer 31,34. Man kann sich fragen, ob nach dieser Stelle die Zeugung aus Gott aus der Liebe (des Bruders) folgt, doch das kann nicht der Sinn der Aussage sein. Vielmehr ist die Zeugung aus Gott aus dem Liebesverhalten erkennbar und ablesbar. Sie folgt aus ihm also nur logisch. Um dieses geht es dem Verfasser.

Hier setzt nun die erste Antithese ein. Dabei greift der Verfasser von den beiden vorangehenden Kennzeichen des wahrhaft Liebenden nur die zweite auf, die Erkenntnis Gottes. Dies dürfte damit zusammenhängen, dass sich die anzunehmenden Gegner weniger auf ihre Abstammung von Gott als auf ihre Gotteserkenntnis beriefen und sich ihrer rühmten. Eben diese Berufung entbehrt der Grundlage. Warum können diejenigen, die nicht lieben (im Sinne der Bruderliebe), Gott nicht erkennen? Weil Gott Liebe ist. Hier steht nun unser Kernsatz. Er dient also der Begründung einer Aussage über die behauptete Gotteserkenntnis. Der Gedanke ist 
einfach: Gott ist Liebe. Wer behauptet, ihn zu kennen, aber selbst ohne Liebe ist, kann nicht im Recht sein. Nur wer liebt, erkennt den Gott, der selber Liebe ist.

Rudolf Bultmann verweist in seinem Kommentar ${ }^{18}$ auf die logische Abfolge des Satzes: „Gott ist Liebe“. Sie ist nicht umkehrbar, so dass aus dem Verstehen dessen, was Liebe ist, auf Gott geschlossen werden könnte. Eine Erkenntnis Gottes, wie er in Wahrheit ist, durch Rückschlüsse aus menschlicher Erfahrung ist dem Menschen verwehrt. Bei Augustin ist diese Umkehrung „Liebe ist Gott“ auch nur dadurch möglich, dass er sich die Liebe trinitarisch denkt und sie für ihn letztlich mit dem Heiligen Geist gleichzusetzen ist. So gibt es auch hier keinen Schluss von der menschlichen Erfahrung auf das Wesen Gottes, sondern nur eine vom Glauben her ermöglichte Reflexion über Liebe als Wesen und Wirklichkeit Gottes.

V. 9: Woran zeigt sich, wie "offenbart" sich die Liebe Gottes „unter uns" (nicht nur „in uns“ ${ }^{19}$ )? Nach den Eingangsversen des Briefes (1 Joh 1,2) „offenbart" sich den Gläubigen das „Wort des Lebens". Hier nun ist es die „Liebe Gottes“, die offenbar wird. Es ist natürlich die Liebe, die Gott zu den Gläubigen hat, und nicht deren Liebe zu ihm. Ganz allgemein ist überall, wo im ersten Johannesbrief von der "Liebe Gottes“ die Rede ist, die Liebe gemeint, die Gott zu den Gläubigen hat. Das gilt auch von den Parallelstellen 1 Joh 2,5; 3,18 und 5,3. Es liegt ganz auf der Linie unseres Schreibens, dass es stets von der zuvorkommenden Liebe Gottes spricht und jede Liebe zu Gott nur vorsichtig zur Sprache bringt, so ganz am Ende unseres Abschnitts in 4,19-21, stets im Zusammenhang mit der gleichzeitigen Bruderliebe und nur als Antwort auf die zuvor erfahrene Liebe Gottes. Im Evangelium finden wir eine andere Sicht. In Joh 5,42 ist von der "Liebe Gottes" offensichtlich im Sinne der „Liebe zu Gott" die Rede. Doch sind dort Zusammenhang und Zielsetzung verschieden. Im Evangelium geht es um die rechte Treue zu Israel und seiner Glaubenstradition in der Auseinandersetzung mit judaistischen Tendenzen wohl auch innerhalb der Gemeinde selber (im Wortlaut den "Juden“). Sie können nicht zu Recht behaupten, sie hätten die Liebe zu Gott, wenn sie vor- und voneinander Ehre suchen und nicht von dem alleinigen Gott (vgl. V. 44).

\footnotetext{
${ }^{18}$ Vgl. Rudolf Bultmann, Die drei Johannesbriefe (KEK 14), Göttingen 1967, 71. Hier stimmt Bultmann grundsätzlich dem Exkurs von Rudolf SchnackenburG, „Die Liebe als Wesen Gottes“ zu, vgl. dessen Kommentar Die Johannesbriefe (HTKNT 13,3), Freiburg u. a. ${ }^{3} 1965,231-239$.

${ }^{19}$ So François Vouga, Die Johannesbriefe (HNT 15,3), Tübingen 1990, 65.
} 
Die Anspielung auf das Hauptgebot von Dtn 6,4 ist hier unüberhörbar. „Liebe Gottes“ kann hier also nur „Liebe zu Gott“ heißen. ${ }^{20}$

Wie hat Gott nach 1 Joh 4,9 den Gläubigen seine Liebe geoffenbart? Es geschah in der Sendung seines Sohnes. Gott hat den Gläubigen also nicht einfach mystisch die Tiefen seines Wesens gezeigt, sondern er offenbart sich geschichtlich in der Liebe zu seinem Volk und endgültig und unüberbietbar in der Sendung seines Sohnes. Die Ausleger verweisen an dieser Stelle auf Joh 3,16: „Denn Gott hat die Welt so sehr geliebt, dass er seinen einzigen Sohn hingab, damit jeder, der an ihn glaubt, nicht verloren geht, sondern ewiges Leben hat.“21 Die „Sendung“ des Sohnes durchzieht das ganze Johannesevangelium, doch nur an dieser Stelle wird sie auf die Liebe Gottes zurückgeführt. Sie äußert sich hier in der "Gabe“ des „einzigen Sohnes“, vielleicht in Anspielung auf die „Gabe“ Isaaks durch Abraham in Gen 22,2.12.16. Einige Elemente von Joh 3,16 fehlen in 1 Joh 4,9: so die Gabe des Sohnes für die ganze Welt und die Rolle des Glaubens für das Heil; auch der Gerichtsgedanke, der in Joh 3,17-19 zum Ausdruck kommt, wird im ersten Johannesbrief hier nicht aufgegriffen. Gemeinsam ist beiden Texten das „Leben“ als Ziel der Gabe Gottes in der Sendung des Sohnes.

VV. 10-16: In diesen Versen geht es um das Wesen der Liebe, wie gleich eingangs festgestellt wird. In den VV. 10-12 wird geklärt, wer zuerst geliebt hat: Gott oder die Menschen, und was daraus für die Gläubigen folgt. Die Frage der Priorität ist rasch beantwortet: Gott hat die Gläubigen zuerst geliebt, und sie können auf diese Liebe nur antworten. Der Erweis der zuvorkommenden Liebe Gottes besteht in der Sendung seines Sohnes Jesus Christus zur Sühne für die Sünde der Menschen. Das war schon in 1 Joh 2,2 zum Ausdruck gekommen. Der Gedanke ist eher paulinisch (vgl. Röm 3,25; Eph 1,7.14), klingt aber doch im Johannesevangelium in den Formeln an, die vom Lebenseinsatz Jesu "für" die Seinen sprechen (vgl. Joh 6,$51 ; 10,11.15$, auch 17 f.), wohl in der Sprache des vierten Gottesknechtsliedes (Jes 53,12).

Die Schlussfolgerung des Verfassers aus der zuvorkommenden Liebe Gottes mag überraschen. Die rechte Antwort der Gläubigen auf die erfahrene Liebe Gottes besteht zumindest zunächst nicht darin, dass sie nun ihrerseits Gott lieben, sondern darin, dass sie einander lieben. Diese

\footnotetext{
${ }^{20}$ Vgl. Johannes BeutLer, Das Hauptgebot im Johannesevangelium, in DERs., Studien zu den johanneischen Schriften (SBAB 25), Stuttgart 1998, 107-120; DERS., Das Johannesevangelium, Freiburg u. a. ${ }^{2} 2016,200$.

${ }^{21}$ Vgl. stellvertretend für andere den Beitrag von SöDing, „Gott ist Liebe“ (Anm. 1) 337-340.
} 
Wendung ist nur zu verstehen auf dem Hintergrund der Kontroverse, die im Hintergrund schwelt, nämlich der Auseinandersetzung mit Gemeindemitgliedern, die in pneumatischem Hochgefühl Gott lieben zu können meinten, ohne zugleich und vielleicht zuerst ihre Mitchristen zu lieben. Das Argument ist einfach: Es lässt sich leicht behaupten, den unsichtbaren Gott zu lieben, auch wenn man den sichtbaren Bruder oder die sichtbare Schwester nicht liebt. Hier wäre dann der Prüfstein für die eigene Glaubwürdigkeit gegeben. Können Christen diese Liebe leben und schenken, dann handeln sie nicht nur moralisch richtig, sondern dann zeigen sie ihre Verbindung mit dem Gott, dessen Wesen Liebe ist. So können sie sagen: „Gott bleibt in uns und seine Liebe ist in uns vollendet.“ Diese Vollendung der Liebe war schon angeklungen $(2,5)$ und wird erneut wieder aufgegriffen werden in den VV. $17 \mathrm{f}$.

Ist somit geklärt, von wem die wahre Liebe ausgeht und worin sie sich bei den Gläubigen erweist, kann der Verfasser nun noch einmal darauf zurückkommen, wie denn konkret Gott seine Liebe zu den Gläubigen erwiesen hat, durch die sie in Gemeinschaft mit ihm bleiben. Dies geschieht in den VV. 13-16. Seit dem Kommentar von Hans Windisch ${ }^{22}$ wird hier eine trinitarische Struktur erkannt, nach der der Erweis der Liebe Gottes in der Sendung des Geistes, in der Sendung des Sohnes und in der Zuwendung des Vaters selbst geschieht. Zunächst also können die Gläubigen die verlässliche Liebe Gottes in der Sendung des Geistes erkennen. Davon spricht V. 13. Schon hier wird deutlich, dass die Liebe Gottes nicht durch unmittelbare Schau seines Wesens erkennbar wird, sondern aus dem Werk des dreifaltigen Gottes zum Heil der Menschen in der Geschichte abgelesen werden muss. Im Gegensatz zu Augustin erlaubt uns der Verfasser hier noch keine unmittelbaren Schlüsse auf die innertrinitarischen Bezüge, sondern bleibt bei der Erfahrung der Dreifaltigkeit im Heilswerk. Die Gabe des Geistes ist durchgängige urchristliche Glaubenserfahrung. Sie mag ihren alttestamentlichen Ursprung in der Verheißung des Neuen Bundes in Ez 36,26 haben. Insgesamt zeigt unser Verfasser eine gewisse Scheu, vom Geist zu sprechen, wohl deshalb, weil die anzunehmenden Gegner sich auf ihn beriefen. Tut er es, dann vorzugsweise in traditionellen Formeln wie an unserer Stelle. Erneut ist hier u. a. an Röm 5,5 zu denken.

\footnotetext{
${ }^{22}$ Hans Windisch, Die Katholischen Briefe (HNT 15,3), dritte, stark umgearbeitete Auflage von Herbert Preisker, Tübingen 1951, 129. Hier rechnet Windisch freilich mit sekundärem Zusatz von V. 13, der gerade die trinitarische Dimension herstellen soll.
} 
Gott offenbart seine Liebe zu den Gläubigen aber nicht nur in der Sendung des Geistes, sondern auch in derjenigen des Sohnes. Davon sprechen die VV. 14 und 15. Er wird hier bezeichnet als „Retter der Welt“. Damit klingt das Glaubensbekenntnis der frischbekehrten Gläubigen von Sychar in Samaria an (Joh 4,42). Der Titel, vielleicht von römischem Kaiserkult beeinflusst, begegnet im Neuen Testament sonst im lukanischen Werk (Lk 2,11; Apg 5,31; 13,23) und in der Briefliteratur (vgl. Eph 5,23; Phil 3,20; 2 Tim 1,10; Tit 1,4; 2,13; 3,6; 2 Petr 1,1.11; 2,20; 3,2.18; Jud 25). Zentraler ist das Bekenntnis zu Jesus als Sohn Gottes, dem die bleibende Verbindung mit Gott verheißen ist.

Folgt man dieser aufsteigenden trinitarischen Linie weiter, so ist es nicht erstaunlich, dass sie zu Gott, dem Vater, hinführt. Dies ist in dem abschließenden V. 16 der Fall. Man sollte ihn als Einheit lesen und nicht mit Nestle-Aland ${ }^{28}$ und der Revidierten Einheitsübersetzung auseinanderreißen. Die erste Hälfte von V. 16 hält die Erkenntnis und den Glauben der Gemeindemitglieder fest, dass Gott sie liebt. Mit "Gott" dürfte hier der „Vater" gemeint sein. Er erweist seine Liebe nicht „in“ den Gläubigen, sondern eher „unter" ihnen. Gerade dadurch kommt die Gemeinde zustande und gelangt zu ihrer Glaubensgewissheit. Die zweite Hälfte von V. 16 fasst das seit Anfang in VV. $7 \mathrm{f}$. Gesagte zusammen und greift gerade deshalb auf die Kernaussage von V. 8 zurück: „Gott ist Liebe“. Zugleich greift sie aber den letzten Vers des Abschnittes auf, der vom „Bleiben“ in Gott und Gottes in den Gläubigen gesprochen hatte. So rundet sich das bisher Gesagte.

Die aufsteigende trinitarische Struktur der VV. 13-16 wird nicht allgemein gesehen, hat aber doch starke Gründe für sich. Eine Bestätigung findet sie in einem Abschnitt in der ersten Abschiedsrede Jesu in Joh 14,15-24. In diesem Abschnitt spricht Jesus von seinem erneuten Kommen zu den Seinen. Er wird zu ihnen kommen im Geist (Joh 14,15-19), persönlich (VV. 18f.) und zusammen mit dem Vater (V. 23). Es ist das endzeitliche Kommen Jesu, das vom vierten Evangelisten hier in die nachösterliche „Stunde des Glaubens" der Gemeinde verlegt wird. ${ }^{23}$

VV. $17 \mathrm{f} .:$ In den abschließenden Versen unseres Abschnitts vor den zusammenfassenden VV. 19-21 geht es um die Vollendung der Liebe. Der

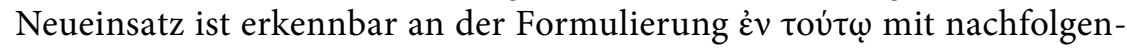
dem Verb, wie sie schon in den VV. 9, 10 und 13 begegnet war. Erneut

\footnotetext{
${ }^{23} \mathrm{Vgl}$. dazu Johannes Beutren, Habt keine Angst. Die erste johanneische Abschiedsrede (Joh 14) (SBS 116), Stuttgart 1984, 53.
} 
zeigt sich, dass eine Zäsur in der Mitte von V. 16 nicht gerechtfertigt erscheint. Worin zeigt sich also die Vollendung der Liebe? Sie vertreibt die Furcht und gibt Zuversicht im kommenden Gericht. Während im Johannesevangelium der Gedanke eines zukünftigen Endgerichts eher marginal erscheint (vgl. Joh 5,28f.), gehört er im ersten Johannesbrief doch zur Vorstellungswelt des Verfassers, wie ein Blick auf 1 Joh 2,28; vgl. 3,2 zeigt. Gerade an der zuerst genannten Stelle wird von der "Zuversicht" ( $\pi \alpha \rho \rho \eta \sigma i \alpha)$ gesprochen, die die Leser angesichts des Endgerichts bei der Parusie haben dürfen (dasselbe Wort noch in 1 Joh 3,21; 5,14). So auch hier in 1 Joh 4,17. In 1 Joh 2,28f. wird die Zuversicht der Leser vor allem in ihrem Bleiben in der Gerechtigkeit verankert, die sie mit Jesus verbindet, an unserer Stelle in 1 Joh 4,17 entsprechend dem Gesamtaufbau des Briefes offensichtlich in der Liebe. Dies ist wohl der Sinn des etwas kryptischen Satzes: „Denn wie er, so sind auch wir in dieser Welt.“ Wie in 1 Joh 2,29 in der dritten Person von „ihm“ und damit wohl von Christus gesprochen wird, so auch an unserer Stelle. Dabei ist daran zu erinnern, dass der Verfasser des ersten Johannesbriefes dort, wo er nicht traditionsgebunden formuliert, keine klare Unterscheidung zwischen Vater und Sohn erkennen lässt. Der Sohn ist die sichtbare Erscheinung des Vaters und damit Gottes in der Welt. So wie er in der Welt präsent ist, gilt dies auch von den Christen. An unserer Stelle wird hier wohl an die Präsenz der Liebe Gottes in der Welt gedacht, an der die Gläubigen teilhaben und die auch die Grundlage ihrer Zuversicht bildet.

Worin die "Zuversicht" der Gläubigen besteht, wird in V. 18 noch einmal negativ ausgedrückt. Sie vertreibt die Furcht vor Strafe. Schon Paulus kann davon sprechen, dass derjenige, der Böses tut, sich zu fürchten hat (Röm 13,4). Wer von der vollkommenen Liebe Gottes erfüllt ist, braucht diese Furcht nicht zu haben. Ihm droht keine Strafe (zum Wort noch Mt 25,46). Liest man unseren Text aufmerksam, dann fällt einem auf, dass den Gläubigen die Zuversicht im Gericht nicht einfach deswegen zugesagt wird, weil sie nichts Böses getan haben, sondern weil sie von der vollkommenen Liebe erfüllt sind. Nur so wird der Aufbau des gesamten Abschnittes ab 1 Joh 4,9 verständlich: von der „Offenbarung“ der Liebe Gottes über ihr „Wesen“ in V. 10 und im Zusammenhang damit ihr "Kennzeichen" nach V. 13 bis zu ihrer "Vollendung" jetzt ab V. 17. Gerade so kommt auch der Weg der Liebe selbst an sein Ziel.

VV. 19-21: Die VV. 19-21 schließen den ganzen Abschnitt 1 Joh 4,7-21 ab. Durch den erneuten Kohortativ zu Beginn greifen sie im Sinne einer Rahmung auf die Eingangsverse 7 f. zurück. Schon aus diesem Grunde

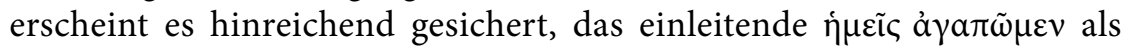


Aufforderung und nicht als Aussage zu verstehen. Vom Gesamtzusammenhang her erscheint es sinnvoll, die Aufforderung des Verfassers als eine erneute Einladung zur Bruderliebe zu verstehen, wie es auch die meisten Ausleger tun. Wenn es heißt, „wie er uns zuerst geliebt hat", dann ist hier wohl im Sinne von V. 10 an Gott gedacht. Er ist das Vorbild und der Urgrund der Liebe, die die Gläubigen erweisen. Im Sinne einer Antithese wird der von den Gläubigen geforderten Liebe derjenige gegenübergestellt, der von sich behauptet, er liebe Gott, dabei aber gleichzeitig seinen Bruder „hasst“, d. h. es ihm gegenüber an Liebe fehlen lässt (vgl. 1 Joh 2,9.11; 3,15). Dieser entlarvt sich als Lügner (vgl. 1,6). Der Grund ist leicht einzusehen: Wer den sichtbaren Bruder nicht liebt, darf nicht von sich behaupten, er liebe den unsichtbaren Gott.

Mit V. 21 schließt nicht nur der Schlussabschnitt, sondern die gesamte Texteinheit. Anders als in den beiden vorhergehenden Texteinheiten, die vom Thema der geschwisterlichen Liebe handelten (1 Joh 2,3-11; 3,11-24), war in 1 Joh 4,7-20 bisher nicht vom „Gebot" der geschwisterlichen Liebe die Rede gewesen. Dies wird nun im vorliegenden Schlussvers nachgeholt. Der strukturelle Aufbau des gesamten Schreibens wird damit noch einmal unterstrichen. Wenn gesagt wird, die Gläubigen hätten dies Gebot „von ihm“ erhalten, bleibt erneut in der Schwebe, wer hier gemeint sein könnte. Von der zweiten Vershälfte her liegt es nahe, hier an Gott $\mathrm{zu}$ denken. Doch erscheint in unserem Brief das Liebesgebot stets als zugleich eines Gottes des Vaters und Jesu. Das zeigt der vergleichende Blick auf 1 Joh 2,3-11 und 3,11-24. An der letzten Stelle heißt es: „Und das ist sein Gebot: Wir sollen an den Namen seines Sohnes Jesus Christus glauben und einander lieben gemäß dem Gebot, das er uns gegeben hat" (1 Joh 3,23). Es geht also sowohl um das Gebot Gottes als auch um das Gebot Jesu, wobei im Gedächtnis zu behalten ist, dass unser Verfasser dort, wo er nicht traditionsgebunden formuliert, keine klare Unterscheidung von Vater und Sohn im Sinne der späteren Trinitätstheologie vornimmt. Der Sohn ist eher die Erscheinungsweise Gottes des Vaters in der Welt.

Leserinnen und Leser des ersten Johannesbriefes erinnern sich natürlich an das Liebesgebot Jesu in den Abschiedsreden (Joh 13,34f.; $15,12-17)$. Es erscheint in 1 Joh 2,7f. zugleich als altes und neues Gebot Jesu, in 2 Joh 5 nicht mehr als neues, weil es nun zum festen Bestand der Glaubensunterweisung in der johanneischen Gemeinde gehört.

Wenn unser Verfasser seine Ermahnung mit den Worten schließt: „Und dies Gebot haben wir von ihm: Wer Gott liebt, soll auch seinen Bruder lieben" (V. 21), dann ist hier das Liebesgebot in die konkrete Ge- 
meindesituation übersetzt. ${ }^{24}$ Gottesliebe gibt es nicht ohne Bruderliebe, und damit ist der gegnerischen Position, die meinte, auf die Bruderliebe verzichten zu können, der Boden entzogen. „Reine“ Gottesliebe gibt es nicht.

\section{Zurück zum Thema}

Unsere Ausgangsfrage war die nach dem Gottesbild im ersten Johannesbrief, und der Versuch einer kurzen Antwort lag in der wiederholten Formel "Gott ist Liebe“ (1 Joh 4,8.16). Ein Blick auf die Texteinheit, in die diese wiederholte Aussage eingebettet ist, zeigt, dass der Verfasser unseres Briefes keine Wesensaussage über Gott treffen wollte, die vom Handeln Gottes absieht, wie es sich in der Geschichte offenbart. Nur in der Zuwendung Gottes zu den Menschen ist Gott als der liebende Gott erkennbar. Das bringt gleich nach den Einleitungsversen das Wort in 1 Joh 4,9 zum Ausdruck: „Darin offenbart sich die Liebe Gottes unter uns, dass Gott seinen einzigen Sohn in die Welt gesandt hat, damit wir durch ihn leben." Gottes Liebe erschließt sich „uns“, den Glaubenden, also im Heilswerk Gottes, in der Sendung des Sohnes, die zum Leben führt. Der Weg zur liebenden Vereinigung mit Gott führt nicht von unten nach oben, sondern von oben nach unten, wie der anschließende V. 10 erkennen lässt: „Darin besteht die Liebe: Nicht, dass wir Gott geliebt haben, sondern dass er uns geliebt und seinen Sohn als Sühne für unsere Sünden gesandt hat."

Nach der erneuten Aufforderung (wie schon in den Anfangsversen 4,7f.) beschreibt der Verfasser in den VV. 13-16, woran die Liebe Gottes erkannt werden kann. Wir hatten hier eine trinitarische Aussage entdeckt. Gott hat uns den Geist gegeben, er hat seinen Sohn zu unserem Heil gesandt und er selbst hat sich uns dadurch als der liebende Gott gezeigt ja, als der Gott, der Liebe ist, wie nun im Rückgriff auf V. 8 erneut ausgesagt werden kann. Gerade an dieser zweiten Stelle wird deutlich, dass sich die Erkenntnis, Gott sei Liebe, nur im Blick auf sein Handeln an den Menschen in der Heilsgeschichte gewinnen lässt. Gott zeigt sich als Dreifaltiger, aber nicht im Innenblick auf sein dreifaltiges Wesen (wie es Augustin später erschließt), sondern in der gläubigen Wahrnehmung seiner Offenbarung in der Geschichte, in der Gabe des Geistes und der

\footnotetext{
${ }^{24}$ Vgl. zu diesem Gebot bei Johannes jetzt Johannes BeutLer, Das Liebesgebot bei Johannes, in: Paul-Chummar Chittilappilly (Hg.), Horizonte gegenwärtiger Ethik (FS Josef Schuster), Freiburg u. a. 2016, 173-188.
} 
Sendung des Sohnes. Menschliche Liebe zu Gott kann nur Antwort auf die zuvor erfahrene Liebe Gottes zum Menschen sein. Mit dieser Einsicht schließt der Abschnitt $(4,19)$. 



\title{
Zwischen der Majestät auf dem Thron und dem Gott, der Liebe ist
}

\author{
Gott in der Johannesapokalypse und im Johannesevangelium
}

\author{
Jörg Frey
}

\section{Einleitung}

\subsection{Apokalypse und Evangelium - zwei Pole im Corpus Ioanneum?}

Die Frage nach dem wechselseitigen theologischen Verhältnis der johanneischen Schriften wird heute nur mehr selten aufgeworfen. Mit Recht, denn zu groß sind - trotz einiger auffälliger gemeinsamer Motive und Elemente - die Spannungen zwischen dem Johannesevangelium (und den Johannesbriefen) einerseits und der kanonischen, traditionell demselben Johannes zugeschriebenen Apokalypse andererseits. ${ }^{1}$ Wie es zur Zuschreibung dieser fünf Schriften an die eine und selbe Figur des Apostels Johannes gekommen ist und wann und in welcher Form diese Schriften tatsächlich als ein Corpus zusammen gesehen wurden, kann im vorliegenden Rahmen nicht erörtert werden. ${ }^{2}$ Vielmehr soll hier nur

\footnotetext{
${ }^{1}$ S. dazu meinen ausführlichen Beitrag: Jörg Frey, Erwägungen zum Verhältnis der Johannesapokalypse zu den übrigen Schriften im Corpus Johanneum, in: Martin Hengel, Die johanneische Frage. Ein Lösungsversuch, mit einem Beitrag von Jörg Frey (WUNT 67), Tübingen 1993, 326-429: 383-415, und neuerdings Jörg FreY, Das Corpus Johanneum und die Apokalypse des Johannes. Die Johanneslegende, die Probleme der johanneischen Verfasserschaft und die Frage der Pseudonymität der Apokalypse, in: Stefan Alkier/Thomas Hieke/Tobias Nicklas (Hg.), Poetik und Intertextualität der Apokalypse (WUNT 346), Tübingen 2015, 71-133. Einen weiteren Sachvergleich habe ich zur Rede von der Einwohnung Gottes vorgelegt: Jörg Frey, God's Dwelling on Earth: Shekhina-Theology' in Revelation 21 and in the Gospel of John, in: Christopher Rowland/Catrin H. Williams (Hg.), John's Gospel and Intimations of Apocalyptic, London u. a. 2013, 79-103. - An neueren Vergleichen sind zu berücksichtigen: Jens-Wilhelm TAEgER, Johannesapokalypse und johanneischer Kreis (BZNW 51), Berlin /New York 1989, und André Heinze, Johannesapokalypse und johanneische Schriften. Forschungs- und traditionsgeschichtliche Untersuchungen (BWANT 142), Stuttgart 1998.

${ }^{2}$ S. dazu die Erörterungen in Frey, Corpus (Anm. 1) 87-133; weiter auch Charles Hill, The Johannine Corpus in the Early Church, Oxford 2004.
} 
die spezielle Theologie, d.h. die Rede von Gott (dem Vater bzw. dem Allmächtigen) in der Apokalypse einerseits und im Evangelium (unter gelegentlicher Einbeziehung der Briefe) andererseits in vergleichender Absicht bedacht werden.

Ein solcher Vergleich ist schon in sich eine besondere Herausforderung, denn die johanneischen Schriften unterscheiden sich nicht nur in ihrer Gattung und Diktion erheblich, sie rekurrieren auch auf sehr unterschiedliche Traditionen und sprechen in unterschiedlichen Gemeindesituationen, obwohl sie alle vermutlich in nicht allzu großem zeitlichen Abstand und in derselben Region - der Asia bzw. Ephesus - entstanden sein dürften. ${ }^{3}$ Desto mehr frappieren die Differenzen in der Rede von Gott, die nicht selten zu der Frage geführt haben, ob denn der Gott der Apokalypse noch derselbe Gott sei, von dem Jesus im Evangelium als dem Vater redet und von dem der erste Johannesbrief klimaktisch aussagt, dass er schlechterdings „Liebe“ ist (1 Joh 4,8.16). In jedem Fall führt die Apokalypse ihre Leser in eine andere Welt als die Narration des vierten Evangeliums oder das „Hohelied der Liebe Gottes“ in 1 Joh 4 - nicht nur in dem Sinne, dass hier eine visionäre Welt, quasi ein Bilderbogen, vor Augen geführt wird, sondern auch sachlich-theologisch.

\footnotetext{
${ }^{3}$ Für die Apokalypse ist die Entstehung in der Asia weithin unbestritten, aber auch für das Evangelium und die Briefe ist dies angesichts der breiten und weit hinter Irenäus zurückreichenden kleinasiatischen Johannestradition historisch die bei weitem best bezeugte Annahme, s. dazu Martin Hengel, Die johanneische Frage. Ein Lösungsversuch, mit einem Beitrag von Jörg Frey (WUNT 67), Tübingen 1993, 13-26, sowie Bernhard Mutschler, Was weiß Irenäus vom Johannesevangelium? Der historische Kontext des Johannesevangeliums aus der Perspektive seiner Rezeption bei Irenäus von Lyon, in: Jörg Frey/Udo Schnelle (Hg.), Kontexte des Johannesevangeliums. Religions- und traditionsgeschichtliche Studien (WUNT 175), Tübingen 2004, 695-742. Hinsichtlich der Datierung der johanneischen Schriften (und ihrer Abfolge) werden vielfältige Varianten diskutiert. Während eine Abfassung um $100 \mathrm{n}$. Chr. für das Johannesevangelium und die Briefe weithin Zustimmung findet, gibt es zur Apokalypse einen größeren Spielraum in der Diskussion von der neronianischen bis zur hadrianischen Zeit, also von ca. 70 n. Chr. bis ca. 135 n. Chr. Doch sind weder die Gründe für eine Frühdatierung des Werkes noch die Gründe für eine erst hadrianische Ansetzung wirklich überzeugend, so dass ich auch hier eine Herausgabe am Anfang des 2. Jahrhunderts, vielleicht schon unter Trajan annehmen möchte. S. zum Problem auch Stephan Wiтетsснек, Ein weit geöffnetes Zeitfenster? Überlegungen zur Datierung der Johannesapokalypse, in: Jörg Frey/James A. Kelhoffer/Franz Tóth (Hg.), Die Johannesapokalypse. Kontexte - Konzepte - Rezeption (WUNT 287), Tübingen 2012, 79-115.
} 


\subsection{Die Frage nach dem Gottesbild als hermeneutische Herausforderung}

Daher sollen im Folgenden theologische Fragen im Zentrum stehen: Wie lassen sich die Gottesrede oder die Gottesbilder in der Apokalypse und im vierten Evangelium fassen und zueinander ins Verhältnis setzen? Fügen sie sich zu einem gemeinsamen Gottesbild zusammen, oder bleibt zwischen ihnen eine grundlegende Spannung, ja ein Gegensatz zwischen dem majestätischen und darin bedrohlichen Herrn der Geschichte und des kommenden Gerichts (in der Apokalypse) und dem liebenden Gott und Vater Jesu Christi (im Evangelium und den Johannesbriefen)?

Hermeneutische Selbstkritik ist hier allerdings unerlässlich: Verfallen wir, wenn wir diese beiden Gottesbilder so gegeneinander abheben, nicht der (vielleicht spezifisch neuzeitlichen) Gefahr, uns einen Gott „nach unserem Bild" und unseren Wünschen zu erschaffen und diesen uns genehmen Gott den uns fremden biblischen Bildern kritisch entgegenzusetzen? Dann würde der Gott Jesu Christi zum „Väterchen“4 oder gar zum harmlosen „Softie“, während der Gott der Apokalypse als ein bedrohlich weltnegativer, ja seine Feinde und diese ganze Welt unbarmherzig vernichtender Himmelstyrann erschiene. Eine solche, tendenziell markionitische Entgegensetzung hat Konjunktur bei populistischen Vertretern des religiösen Diskurses von Franz Alt ${ }^{5}$ bis Eugen Drewermann, ${ }^{6}$ und auch aus der Perspektive der Gender-Forschung kann aus dem Gott der Apokalypse

\footnotetext{
${ }^{4}$ So im Gefolge der von Joachim Jeremias einflussreich vertretenden Deutung des jesuanischen „Abba“-Rufs als Element der Kindersprache (grundlegend Joachim Jeremias, Abba, in: DERs., Abba. Studien zur neutestamentlichen Theologie und Zeitgeschichte, Göttingen 1966, 15-66; DERS., Neutestamentliche Theologie 1: Die Verkündigung Jesu, Gütersloh 1970. S. zur Kritik Georg Schelbert, ABBA Vater. Der literarische Befund vom Altaramäischen bis zu den späten Haggada-Werken (NTOA 81), Göttingen 2011, bes. 17-33; Ursula Schattner-Rieser, Das Aramäische zur Zeit Jesu, „ABBA!“ und das Vaterunser. Reflexionen zur Muttersprache Jesu anhand der Texte von Qumran und der frühen Targumim, in: Jörg Frey/Enno Edzard Popkes (Hg.), Jesus, Paulus und die Texte von Qumran (WUNT 2,390), Tübingen 2015, 81-144: 101-106; Jörg Frey, Das Vaterunser im Horizont antik-jüdischen Betens unter besonderer Berücksichtigung der Textfunde vom Toten Meer, in: Florian Wilk (Hg.), Das Vaterunser in seinen antiken Kontexten. Zum Gedenken an Eduard Lohse (FRLANT 266), Göttingen 2016, 1-24: 10-16.

${ }^{5}$ Franz Alt, Jesus - der erste neue Mann, München 1989.

${ }^{6}$ Zur Apokalypse hat sich Eugen Drewermann geäußert in DERs: Tiefenpsychologie und Exegese, Bd.2, Olten 1985, 541-591. Zur psychoanalytischen Kritik der Apokalypseauslegung Drewermanns s. Hartmut Raguse, Psychoanalyse und biblische Interpretation. Eine Auseinandersetzung mit Eugen Drewermanns Auslegung der Johannes-Apokalypse, Stuttgart u. a. 1993, vgl. auch Jörg FrEY, Eugen Drewermann und die biblische Exegese (WUNT 2,71), Tübingen 1995.
} 
eine "hypermaskuline“ Gottheit werden, ${ }^{7}$ deren Wirkung oder Instrumentalisierung zur Legitimation von Gewalt nicht leicht von der Hand zu weisen ist und gegenüber der sich der vermeintlich jesuanische, faktisch aber eher postmodern-postchristliche "Gott der Liebe“ nur allzu leicht absetzen lässt. Historisch ist dies freilich alles andere als angemessen. Auch der synoptische (und der historische) Jesus haben ihre ,dunklen' Seiten, die sich quellen- oder traditionskritisch nicht einfach wegerklären lassen, ${ }^{8}$ und dies gilt mutatis mutandis auch für den johanneischen Jesus, wenn dieser z. B. in der Szene beim letzten Mahl (Joh 13,27) Judas durch das Geben des Bissens geradezu leiblich den Satan „induziert" und ihn zu seinem Werk „beauftragt“.

Natürlich gibt es auch die andere Gefahr, dass Differenzen und systematische Konflikte zwischen biblischen Texten im Interesse einer „kanonischen" Auslegung harmonisiert werden und damit letztlich alle Schriften relativ unpräzise bzw. im Sinne eines traditionellen oder unkontrolliert erstellten Gesamtbildes gelesen werden und der prononcierten Position des einen oder anderen biblischen Autors damit ihre Stoßkraft genommen wird. ${ }^{9}$ Beiden Gefahren ist gleichermaßen zu widerstehen freilich scheint mir die zuerst genannte Tendenz heute in der kirchlichen Öffentlichkeit und in der akademischen Theologie größer zu sein, wo man sich bemüht, allzu harte Dualismen zu vermeiden und gegenüber den bedrängenden Bildern von Gericht und Vernichtung die Weltpositivität Gottes möglichst zu betonen.

\subsection{Zur bisherigen Forschung}

Spezialforschungen zum Gottesbild der Apokalypse sind im Vergleich zu den Arbeiten zur Christologie und Eschatologie spärlich. ${ }^{10}$ Dem Thema widmete sich daher vor kurzem eine in Wien von Martin Stowasser

\footnotetext{
${ }^{7}$ So Stephen D. Moore, The Beatific Vision as a Posing Exhibition: Revelation's Hypermasculine Deity, JSNT 60 (1996) 27-55. Vgl. auch Rebecca SKaggs/Thomas Doyle, Violence in the Apocalypse of John, CBR 5 (2007) 220-234, sowie besonders zur Rezeptionsgeschichte Joseph Verheyden/Andreas Merkt/Tobias Nicklas (Hg.), Ancient Christian Interpretations of ,Violent Texts` in the Apocalypse (NTOA 92), Göttingen 2011.

${ }^{8}$ S. dazu Jörg FreY, Jesus und die Apokalyptik, in: DERS., Von Jesus zur neutestamentlichen Theologie. Kleine Schriften 2, hg. von Benjamin Schließer (WUNT 368), Tübingen 2016, 85-157: 117-157.

${ }^{9}$ Diese Gefahr ist in der (Evangelium, Briefe und Apokalypse einschließenden) johanneischen Theologie von Paul A. Rainbow nicht zu übersehen: Paul A. Rainbow, Johannine Theology. The Gospel, the Epistles and the Apocalypse, Downers Grove, 2014.

${ }^{10}$ Aus der älteren Forschung ist v. a. der bedeutende Aufsatz von Traugott Holtz, Gott in der Apokalypse, in: Jan Lambrecht (Hg.), L'Apocalypse johannique et l'Apocalyptique dans
} 
initiierte Tagung, deren Beiträge das Feld abstecken, aber keineswegs erschöpfend behandeln. ${ }^{11}$ Interessanterweise ist der einzige neuere Vergleich zum Gottesbild der Apokalypse und des Johannesevangeliums vor wenigen Jahren ebenfalls hier in Wien von Martin Hasitschka vorgeführt worden. ${ }^{12}$ Sein Beitrag vergleicht Motiv um Motiv, doch bleiben diese Vergleiche notwendigerweise oft an der Oberfläche. Denn von vielen Sachverhalten ist zwar in beiden Schriften die Rede, doch sind diese je ganz anders eingeordnet und gewichtet, was an der unterschiedlichen Gattung und Gesamtperspektive beider Schriften liegen mag, aber auch im Rahmen der jeweiligen Entwürfe theologisch zu reflektieren ist.

Ich werde daher im Folgenden einige Aspekte zum Gottesbild der Apokalypse zusammenhängend behandeln (2.), um dann - im vorliegenden Rahmen nur sehr abgekürzt - ausgewählte Aspekte zum Gottesbild des Johannesevangeliums (unter Mitberücksichtigung des ersten Johannes-

le Nouveau Testament (BETL 53), Gembloux/Leuven 1980, 247-265 zu beachten, daneben Anton Vögtre, Der Gott der Apokalypse. Wie redet die christliche Apokalypse von Gott?, in: Joseph Coppens (Hg.), La notion biblique de Dieu (BETL 41), Gembloux/Leuven 1976, 377-398; weiter Richard BAUскнам, God in the Book of Revelation, PIBA 18 (1995) 40-53; Thomas SöDING, Heilig, heilig, heilig. Zur politischen Theologie der Johannes-Apokalypse, ZTK 96 (1999) 49-76; DERs., Gott und das Lamm. Theozentrik und Christologie in der Johannesapokalypse, in: Knut Backhaus (Hg.), Theologie als Vision. Studien zur JohannesOffenbarung (SBS 191), Stuttgart 2001, 77-120: 77-86; Christoph Gregor MüLLER, Gott wird alle Tränen abwischen - Offb 21,4. Anmerkungen zum Gottesbild der Apokalypse, ThGl 95 (2005) 275-297. Vieles findet sich in Arbeiten zu einzelnen Passagen, einiges zusammengefasst in Kommentaren und Theologien, s. Ulrich B. Müller, Die Offenbarung des Johannes (ÖTK 19), Würzburg u. a. 1984, 54-56; Akira SATAKE, Die Offenbarung des Johannes (KEK 16), Göttingen 2008, 73-79; Ferdinand Hahn, Theologie des Neuen Testaments 1: Die Vielfalt des Neuen Testaments. Theologiegeschichte des Urchristentums, Tübingen 2002, 459 f.; Ulrich Wilckens, Theologie des Neuen Testaments 1,4, NeukirchenVluyn 2005, 280-284; Udo Schnelle, Theologie des Neuen Testaments, Göttingen 2007; 713-715; Rainbow, Johannine Theology (Anm. 9) 72-114.

${ }^{11}$ Martin Stowasser (Hg.), Das Gottesbild in der Offenbarung des Johannes (WUNT 2,397), Tübingen 2015. Darin insbesondere: Beate Kowalski, Gottesbilder in Offb 21,1-8. Alttestamentliche Vernetzungen, 11-52; Martin Karrer, Das Gottesbild in der Offenbarung vor hellenistisch-frühkaiserzeitlichem Hintergrund, 53-81; Klaus WenGst, Protest als Zeugnis und Widerspruch. Soziale und politische Aspekte im Gottesbild der Offenbarung, 113-128; Konrad Huber, „Gott bete an!“(Offb 19,10; 22,9). Christusbild und Gottesbild der Johannesoffenbarung im Spannungsfeld von wesensmäßiger und funktionaler Einheit und Differenz, 129-147; Martin STOWASSER, Gottesepitheta als Christusepitheta. Überlegungen zur Gottheit Gottes in der Offenbarung des Johannes, 149-175. Hinzuweisen ist ebenfalls auf die Beiträge einer von Michael Sommer in Halle veranstalteten Tagung, die - zusammen mit anderen Beiträgen - voraussichtlich 2019 in einem von Christina Hoegen-Rohls, Uta Poplutz und Michael Sommer herausgegebenen Sammelband zur Apokalypseforschung in WUNT erscheinen werden.

${ }^{12}$ Martin Hasitschka, Zeugnis für Gott in der Offenbarung des Johannes und im Johannesevangelium. Gemeinsamkeiten und Unterschiede, in: Stowasser (Hg.), Gottesbild (Anm. 11) 177-197. 
briefs) anzufügen (3.) ${ }^{13}$ und nach einem Vergleich beider Entwürfe (4.) thesenhaft eine theologische Schlussreflexion (5.) zu versuchen.

\section{Das Gottesbild der Apokalypse}

\subsection{Einige Vorüberlegungen zu Charakter und Gestaltung des Werks}

Vor allen inhaltlichen Fragen sind der Charakter und die Gestaltungsweise des Textes zu bedenken: Die Apokalypse stellt ihren Leserinnen und Lesern eine eindrücklich dichte, in die Form eines Visionsberichts gekleidete, dynamische Folge von Bildern vor Augen. ${ }^{14}$ Deren Elemente sind weithin aus biblischen Texten geschöpft, aber nicht einfach „übernommen", sondern in frischen Kombinationen ausgestaltet, die z. T. den Rahmen des weltlich Vorstellbaren sprengen und gerade so zur Vorstellung des Unvorstellbaren anregen und ansprechen. ${ }^{15}$

Im Ganzen des Visionsberichts wird ein Wechselgeschehen zwischen Himmel und Erde vor Augen geführt, zwischen dem irdischen Geschehen, das den Inhalt der Mehrzahl der Visionen des Hauptteils (Offb 4,1-22,6) bildet, und dem Geschehen im himmlischen Heiligtum, das in einigen dazwischen eingestreuten, für die Wirklichkeitssicht der Apokalypse besonders wesentlichen ${ }^{16}$ Szenen beschrieben wird. Der Seher (bzw. implizite Autor) ist dabei in Interaktion mit der himmlischen Welt, er „vermittelt“ das von ihm beschriebene Wechselspiel, und mit seiner Figur sind die Lesenden oder besser ( $\mathrm{Zu}-$-)Hörenden (Offb 1,3) selbst in das Geschehen einbezogen. Ihnen wird also eine Wirklichkeitsschau vermittelt, in der die Welt der Menschen, Völker und Könige konkret: ihre eigene städtische, provinziale und imperiale Gesellschaft mit der himmlischen Welt in Beziehung steht, ja von dort aus „regiert“ wird. Rhetorisch zielt die Apokalypse darauf, ihren Adressaten diese Sicht „hinter die Kulissen“ zu vermitteln.

\footnotetext{
${ }^{13}$ Dazu s. meinen ausführlicheren Beitrag: Jörg Frey, Was trägt die johanneische Tradition zum christlichen Bild von Gott bei?, in: ders./Uta Poplutz (Hg.), Narrativität und Theologie im Johannesevangelium (BThSt 130), Neukirchen-Vluyn 2012, 217-257.

${ }^{14}$ S. dazu grundlegend Jörg Frey, Bildersprache der Johannesapokalypse, ZTK 98 (2001) 161-185; vgl. auch die Arbeit von Georg Glonner, Zur Bildersprache des Johannes von Patmos (NTAbh 34), Münster 1999, dazu meine Rezension in: TBei 30 (1999) 227-229.

${ }^{15}$ S. dazu jetzt am Beispiel von Offb 21,1-8 KowalsKI, Gottesbilder (Anm. 11) 11-52: 17.

${ }^{16}$ Zur Bedeutung dieser Himmelsszenen s. besonders Franz Tóтн, Der himmlische Kult. Wirklichkeitskonstruktion und Sinnbildung in der Johannesoffenbarung (ABIG 22), Leipzig 2006.
} 
Wesentlich ist daneben der Faktor Zeit. Die Perspektive der Apokalypse ist eindeutig eine Perspektive post Christum glorificatum: Das „inthronisierte Lamm", d.h. der gekreuzigte und erhöhte Christus, hat im Himmel seine Herrschaft angetreten (Offb 5,6). Damit ist das Endgeschehen inauguriert, und die Herrschaft von „Gott und dem Lamm" soll sich „bald“ (Offb 1,$1 ; 22,6$ ) auch auf Erden bzw. im Blick auf die irdische Welt durchsetzen und vollenden. Nur in Anbetracht dieser Gesamtperspektive können die einzelnen Themen wie Gott, Christus, Ekklesiologie oder Eschatologie thematisiert werden. ${ }^{17}$

Eine kurze Bemerkung zum religionsgeschichtlichen Kontext ist hier noch anzufügen: Obwohl die Apokalypse ihre Bilder und viele Formulierungen überwiegend aus dem Alten Testament zusammenfügt und obwohl sie in ihrem exklusiven Monotheismus und ihrer starken Rezeption kultischer Kategorien (z. B. von Reinheit und Unreinheit) besonders „judenchristlich“ erscheint, ist eine Kenntnis und Verarbeitung von Gegebenheiten und Traditionen der paganen Welt durchgehend anzunehmen. Entgegen einer verbreiteten Vorstellung lebten auch Jesusanhänger jüdischer Herkunft (wie das Diasporajudentum im Ganzen) nicht in einer sektiererisch-abgeschlossenen Eigenwelt, sondern waren Teil der Kultur ihrer Mitwelt, so dass die Kenntnis von Begriffen, Praktiken und mythologischen Vorstellungen der griechisch-römischen Kultur vorauszusetzen ist. ${ }^{18}$ Es ist damit zu rechnen, dass diese auch die Rede von Gott mit prägen.

\subsection{Der Gott Israels}

Dabei ist eindeutig, dass der Gott, von dem die Apokalypse redet, der biblische Gott der Schriften Israels ist, dessen Einzigkeit und Alleinverehrungsanspruch in der Apokalypse nachdrücklich reklamiert wird. Die dichten Anspielungen auf alttestamentliche Texte und Sprachbilder doku-

\footnotetext{
${ }^{17}$ S. zur eschatologischen Erwartung der Apokalypse ausführlich Jörg Frey, Was erwartet die Johannesapokalypse? Zur Eschatologie des letzten Buchs der Bibel, in: ders./James A. Kelhoffer/Franz Tóth (Hg.), Die Johannesapokalypse. Kontexte, Konzepte, Wirkungen (WUNT 287), Tübingen 2012, 473-552.

${ }^{18}$ Dies gilt für die Apokalypse wie auch für das Johannesevangelium, für das gelegentlich eine ähnlich sektiererische „Abgeschiedenheit“ vermutet wurde. Zu den Gottesvorstellungen der Offb s. jetzt die lucide Analyse bei Karrer, Gottesbild (Anm.11) eine umfassende Analyse zeitgeschichtlicher Anspielungen im Kontext von Offb 13 bietet Franz То́тн, Das Tier, sein Bild und der falsche Prophet. Untersuchungen zum zeitgeschichtlichen Hintergrund von Johannesoffenbarung 13 unter Einbeziehung des antiken Orakelwesens (BThSt 126), Neukirchen-Vluyn 2012.
} 
mentieren dies eindrücklich. Gottes Lebendigkeit (Offb 4,9f.; 7,2 u. ö.) ${ }^{19}$ und Schöpfermacht (vgl. Offb 4,11; 5,13 etc.) sowie seine Personalität im Sinne eines redenden (Offb 1,8; 21,5-7), in der Geschichte handelnden und entscheidenden Subjekts sind mit der biblischen Tradition selbstredend vorausgesetzt.

\subsection{Die fundamentale Theozentrik}

Von Gott ist schon im ersten Vers der Apokalypse die Rede, in der überschriftartigen Formulierung Offb 1,1: Das Buch enthält bzw. ist Niederschlag der ảંoкá $\lambda v \psi ı \varsigma$ Jesu Christi, „die Gott ihm gegeben hat“.

Damit ist von vorneherein klar, dass Gott selbst Ausgangspunkt des Offenbarungsgeschehens ist. ${ }^{20}$ Diesem „theozentrischen“ Anfang korrespondiert das Ende, wenn in der Vision vom Neuen Jerusalem gesagt wird, dass in dieser Gottesstadt Gott - allerdings in Gemeinschaft mit dem Lamm - die Mitte bildet und Gott über den Seinen leuchtet in Ewigkeit (22,5). Hier ist am Ende - wie in 1 Kor 15,28 - Gott „alles in allem." 21

An der Theozentrik der Apokalypse kann kein Zweifel sein, ${ }^{22}$ auch wenn man diese nicht gegen die hohe Christologie ausspielen darf. ${ }^{23}$ Denn der Dualität von „Gott und dem Lamm“ kommt im Handlungsgefüge der Apokalypse erhebliche Bedeutung zu, ja letztlich kann von Gott und seinem Heilshandeln nicht gesprochen werden, „ohne zugleich vom eschatologischen Sachwalter Gottes, und zwar von dem in Jesus schon gekommenen und zu gottgleicher Machtstellung erhöhten Heilsbringer zu sprechen“. ${ }^{24}$

\subsection{Gottes zeitübergreifende Wirklichkeit und Geschichtsmächtigkeit}

Die theozentrische Struktur des „,von Gott' her - ,zu Gott hin““ kommt sprachlich in den beiden das Buch rahmenden Alpha-et-Omega-Prädi-

\footnotetext{
${ }^{19}$ S. dazu Holtz, Gott (Anm. 10) 248.

${ }^{20}$ Vom Christusgeschehen ist hier nicht en détail die Rede.

${ }^{21}$ So mit Recht Wilckens, Theologie (Anm. 10) 281.

${ }^{22}$ „Der Seher plädiert für einen theozentrischen Identitätsentwurf des Christentums, der für ihn eine Integrationsverweigerung gegenüber der (reichsrömisch-kleinasiatischen) Welt einschließt" (Knut Backhaus, Die Vision vom ganz Anderen. Geschichtlicher Ort und theologische Mitte der Johannes-Offenbarung, in: ders. [Hg.], Theologie als Vision. Studien zur Johannes-Offenbarung [SBS 191], Stuttgart 2001, 10-53: 26).

${ }^{23}$ S. dazu Söding, Gott (Anm. 10) 116-120.

${ }^{24}$ Vögtle, Gott (Anm. 10) 386. S. auch Söding, Gott (Anm. 10).
} 


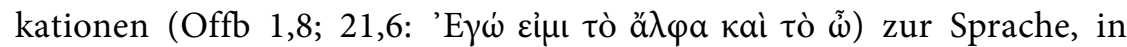
denen sich Gott in Anlehnung an alttestamentliche Offenbarungsformeln (Ex 3,14 sowie Jes 41,4; 43,10; 44,6; 48,12) machtvoll als Herr über Anfang und Ende, ${ }^{25}$ d. h. als der Herr der Geschichte präsentiert. Seine Zeit und Geschichte übergreifende Wirklichkeit und Geschichtsmächtigkeit ist vielleicht das herausragendste Kennzeichen der speziellen Theologie der Apokalypse. Dass diese Alpha-et-Omega-Formel anschließend in signifikanter Übertragung auch dem erhöhten Christus in den Mund gelegt wird und so die bewusste Übertragung göttlicher Würden auf den erhöhten und inthronisierten Christus zur Sprache bringt, ändert nichts an ihrem ursprünglichen Bezug auf den biblischen Gott, den Schöpfer und Herrn der Geschichte.

In Offb 1,8 ist die Formel zusätzlich verbunden mit weiteren Explikationen: zunächst der Kyrios-Prädikation (кúpıoৎ ó $\theta \varepsilon o ́ \varsigma)$, die natürlich hier das Tetragramm wiedergibt, aber zugleich - ganz im Sinne der LXX die universale Herrschaft des einen Gottes bezeichnet. ${ }^{26}$ Angefügt ist weiter die sprachlich sperrige und darin Aufmerksamkeit erweckende ${ }^{27}$ Dreizeitenformel: „Der ist, und der war und der kommt", die schon in Offb 1,4 - stilistisch noch anstößiger - eingeführt wurde (vgl. noch Offb 4,8). In ihr kommt das zeitenübergreifende Sein Gottes, ja seine Herrschaft über die Geschichte von der Schöpfung bis zur Vollendung, und damit seine unendliche qualitative Differenz gegenüber allen Geschöpfen zur Sprache. Dabei ist in der ersten Prädikation ó $\ddot{\omega} v$ die Wiedergabe des Gottesnamens von Ex 3,14 in der LXX aufgenommen, die bekanntlich gegenüber dem hebräischen Text eine signifikante Verschiebung impliziert, freilich ist der in der LXX von Ex 3,14 dominante stati-

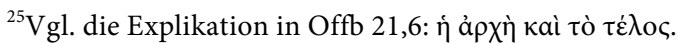

${ }^{26}$ Die Wiedergabe des Tetragramms durch das (artikellose) кúpıoৎ in der LXX signalisiert deutlich, dass der hier thematisierte Gott nicht nur der partikuläre Gott eines Volkes ist, sondern der eine und einzige, der Herr der Welt. S. dazu Jörg Frey, The Contribution of the Septuagint to New Testament Theology, in: Roland Deines (Hg.), Epiphanies of the Divine in the Septuagint and the New Testament: Mutual Perspectives (WUNT), Tübingen 2019 (im Druck).

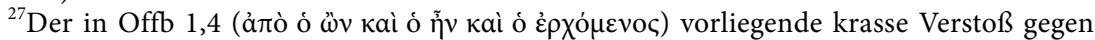
alle grammatikalischen Deklinationsregeln lässt sich nicht durch Unkenntnis des Verfassers erklären, da dieser sonst die grammatischen Regeln durchaus einzuhalten weiß. Schon das in 1,4 folgende Glied (кà̀ àं hier ein gewollter und darin programmatischer Anstoß vorzuliegen, ein in seiner Schroffheit unübersehbarer Hinweis, dass dieser Gott quasi „indeklinabel“" und somit von allen weltlichen Gegebenheiten wesenhaft unterschieden ist. S. dazu Frey, Erwägungen (Anm. 1) 360 f.
} 


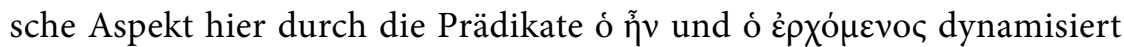
und auf die eschatologische Zukunft hin geöffnet. ${ }^{28}$

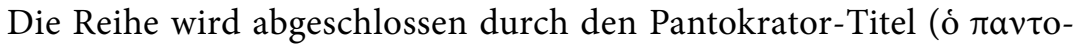
$\kappa \rho \alpha ́ \tau \omega \rho)$, mit dem Gott als Allherrscher prädiziert wird. Dieser Terminus kam im Alten Testament erst spät, in den Schriften der hellenistischen Zeit und in griechischer Sprache, auf, und er bringt die "Allmacht" Gottes interessanterweise gerade nicht im Interesse einer sakralen Überhöhung weltlicher Herrschaft, sondern umgekehrt als Gegeninstanz zu den scheinbar allmächtigen hellenistischen Herrschern zur Sprache. ${ }^{29}$ Die im NT einzigartige Bedeutung des Pantokrator-Titels in der Apokalypse zeigt, dass Gott hier von Anfang an im Gegensatz zu irdischen Herrschaftsansprüchen thematisiert wird.

Die drei die Alpha-et-Omega-Prädikation erweiternden Wendungen bringen je für sich und in ihrer Addition in besonders eindrücklicher Weise das die Zeiten übergreifende Wesen Gottes und seine die ganze Welt von der Schöpfung bis zur Vollendung umfassende Geschichtsmächtigkeit zur Sprache, die allen weltlichen Herrschaftsansprüchen gegenübersteht.

Wenn die Alpha-et-Omega-Prädikation am Ende des Buches in Offb 21,6 erneut aufgenommen wird, wieder in einer Selbstprädikation Gottes, dann ist sie nicht nur mit der sinngleichen Wendung „der Anfang

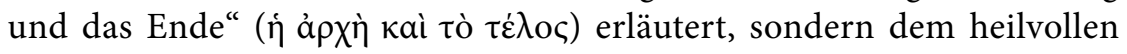
Inhalt des Schlussbildes gemäß mit einer biblisch geprägten Heilsverheißung verknüpft: „Ich werde dem Dürstenden von der Quelle des Lebenswassers zu trinken geben, umsonst." Die Verheißung, dass dieser geschichtsmächtige Gott, in dessen Händen "der Anfang und das Ende“ liegt, gratis den danach Dürstenden das Lebenswasser reichen will, zeigt deutlich, dass sich in der Apokalypse die herrschaftlichen Gottesprädikationen durchaus mit tröstlichen Aspekten verbinden können. Der Aspekt der Lebensverheißung, ja der „Gnade“ des majestätischen Schöpfers, des Geschichts- und Gerichtsherrn sollte daher im Gottesbild der Apokalypse nicht übersehen werden. ${ }^{30}$ Immerhin findet sich der Gnadenzuspruch

\footnotetext{
${ }^{28} \mathrm{Zu}$ dieser Formel s. auch SöDing, Gott (Anm. 10) 78-82.

${ }^{29}$ Dazu s. Reinhard Feldmeier/Hermann Spieckermann, Der Gott der Lebendigen. Eine biblische Gotteslehre (TOBITH 1), Tübingen 2011, 149-201. S. dort S. 179: „In der früh-

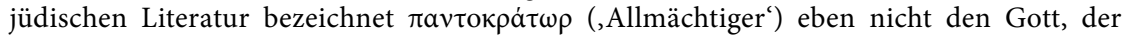
,immer mit den stärkeren Bataillonen' ist. Die Identifikation Gottes mit kosmischen oder gesellschaftlichen Mächten wird aufgebrochen; der Rede von Gottes (All-)Macht eignet zunehmend eine kontrafaktische Komponente, die dann das Neue Testament ganz entschieden aufnimmt."

${ }^{30}$ S. dazu Vögtle, Gott (Anm. 10) 387.
} 


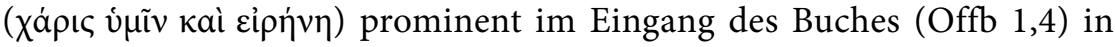
Verbindung mit dem ersten Beleg der Dreizeitenformel.

\subsection{Die unanschauliche Anschaulichkeit in der Thronvision}

Ein zweiter, hermeneutisch wichtiger Aspekt der Rede von Gott verbindet sich mit den apokalyptischen Himmelsszenen, zunächst mit der großen Thronszene in Offb 4-5. Hier wird bei aller apokalyptischen Bildhaftigkeit zunächst die Weltdistanz und Jenseitigkeit des thronenden Gottes vor Augen geführt.

Diese ist schon in der Kette von Offenbarungsinstanzen im einleitenden Satz Offb 1,1 erkennbar: Demnach wurde die „Enthüllung“

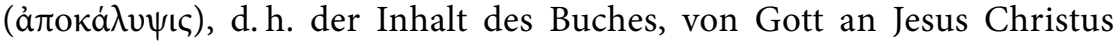
übergeben, der sie seinerseits durch seinen Engel dem Seher übermittelt hat, welcher sie nun für die Adressaten in ein Buch aufschreiben soll. Die fünfgliedrige Stufenfolge Gott - Christus - Offenbarungsengel - Visionär - Adressaten kommuniziert von Beginn an eine Vorstellung der Transzendenz Gottes, dessen Offenbarung nur über drei Mittlerinstanzen zu den Adressaten gelangen kann. Diese Transzendenz ist die Voraussetzung der Weltüberlegenheit und Geschichtsmächtigkeit Gottes.

Gott ist nicht nur dem natürlichen Auge entzogen, seine Gestalt sprengt auch das visuelle Vorstellungsvermögen. Dies zeigt sich besonders in der Gestaltung der „anschaulichen“ Szenen im himmlischen Thronsaal Offb 4-5: Zunächst ist dem Visionär die Schau des Thronsaals nur aufgrund einer speziellen Erlaubnis durch den Offenbarungsengel möglich (Offb 4,1f.): Eine Tür am Himmel wird geöffnet, eine Stimme gebietet ihm zu kommen, und der Geist ergreift ihn zu seiner Vision. Die Gottesschau steht mithin nicht in der Macht des Sehers, sondern kommt vom jenseitigen Raum her über ihn. Eine spezielle „Ekstase“ und ein visionärer Ortswechsel sind dieser visionären „Himmelsreise“ vorausgesetzt, die in ihrem Inhalt die kosmischen Reisen Henochs noch überbietet und „die direkte Versetzung in die unmittelbare Gottesgemeinschaft “ beinhaltet. ${ }^{31}$

Der Visionsinhalt ist dabei anschaulich und unanschaulich zugleich. Einerseits ist die Vision übersichtlich gegliedert: Erst wird ein Thron im Himmel erblickt (Offb 4,2), dann der auf dem Thron Sitzende $(4,3)$,

\footnotetext{
${ }^{31}$ So Gottfried Schimanowski, Die himmlische Liturgie in der Apokalypse des Johannes. Die frühjüdischen Traditionen in Offenbarung 4-5 unter Einschluß der Hekhalotliteratur (WUNT 2,154), Tübingen 2002, 68.
} 
dann 24 Throne und die darauf sitzenden „Ältesten“ (4,4), dann folgt die Beschreibung der Umgebung des Thrones (4,5f.), dann der „,inmitten des Thrones und ringsum " befindlichen vier Lebewesen $(4,7)$ und schließlich erklingen die Doxologien der vier Lebewesen und der Ältesten $(4,8-11)$. Danach fällt der Blick auf die Buchrolle (5,1), und ihr Problem wird emotional bedrängend artikuliert, bevor als „Lösung“ „das Lamm, wie geschächtet", präsentiert $(5,6)$ und schließlich kultische Verehrung der Lebewesen und Ältesten $(5,8-10)$, der Lobpreis einer riesigen Menge von Engeln um den Thron (5,11f.) und schließlich der Lobpreis aller Kreaturen und des ganzen Kosmos (5,13f.) vor Augen geführt und - im Zitat ihrer Hymnen - zu Gehör gebracht wird. Die Klarheit der Gliederung und die visuelle und auditive Anschaulichkeit will die Hörenden zu Augenund Ohrenzeugen machen, die das Geschilderte nicht nur mitverfolgen, sondern auch emotional miterleben ${ }^{32}$ und so selbst von der Wirklichkeit dieser jenseitigen Welt erfasst werden.

Andererseits bleibt das Geschaute in der Anschaulichkeit höchst unanschaulich: Der auf dem Thron Sitzende wird nicht näher dargestellt und nur in Licht- und Farberscheinungen beschrieben, wobei Vergleich-

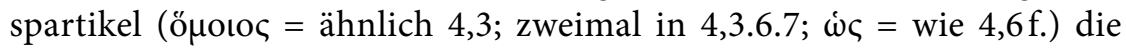
Unähnlichkeit der Gegebenheiten der himmlischen Welt mit den Gegenständen der irdischen Schöpfung festhalten. ${ }^{33}$

Als „der auf dem Thron Sitzende“ wird Gott in der Apokalypse insgesamt zwölfmal prädiziert. ${ }^{34}$ Damit nimmt das Werk in einzigartiger Dichte ein Sprachbild auf, das von der altorientalischen Thronratsvorstellung bis hin zu hellenistischen Herrschern und Abbildungen z. B. des Zeus, ${ }^{35}$ vertraut und schon im Alten Testament an einigen Stellen belegt ist (Jes 6, Ez 1; Dan 7,9; 2 Kön 22,19). Doch anders als die Thronvisionen von Ez 1 und Dan 7 (und auch anders als die Beschreibung des erscheinenden Christus in Offb 1,11-21 ${ }^{36}$ ) bietet Offb 4 keine nähere Beschreibung der Gestalt des Thronenden, sondern nur einen Vergleich

\footnotetext{
${ }^{32}$ Dies betont zu Recht Nils Neumann, Hören und Sehen. Die Rhetorik der Anschaulichkeit in den Gottesthron-Szenen der Johannesoffenbarung (ABIG 49), Leipzig 2016.

${ }^{33}$ Dies entspricht apokalyptischer Tradition, wie sie etwa im Danielbuch begegnet, vgl. Dan 7,13 LXX (variiert aufgenommen in Offb 1,13 und 14,14); Dan 10,18 LXX; 1 Hen 14,10 f.13.18; 17,1; 24,4; 32,4. S. dazu FreY, Erwägungen (Anm. 1) 351.

${ }^{34}$ Offb $4,2.9 .10 ; 5,1.7 .13 ; 6,16 ; 7,10.15 ; 19,4 ; 20,11 ; 21,5$. Die Präposition غ̇ंí ist dabei teils mit dem Dativ, teils mit dem Akkusativ konstruiert. S. dazu SchімаNowsкi, Liturgie (Anm.

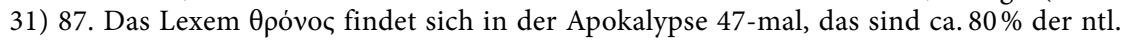
Belege (s. ebd., 91).

${ }^{35}$ S. dazu Karrer, Gottesbild (Anm. 11) 58f., der auf die Zeus-Statue in Olympia verweist.

${ }^{36}$ S. dazu FreY, Bildersprache (Anm. 14) $171 \mathrm{f}$.
} 
mit dem Leuchten zweier Edelsteine und eines Regenbogens (Offb 4,3). ${ }^{37}$ Die Unanschaulichkeit Gottes bleibt gerade so gewahrt, und durch die mosaikartige Kombination unterschiedlicher Bildaspekte entsteht eine die Vorstellungskraft überschreitende, geradezu surrealistische Darstellung. ${ }^{38}$

Im Rahmen dieses Sprachbildes kommen neben dem Trishagion (vgl. Jes 6,3), der wieder aufgenommenen Pantokrator-Prädikation (Offb 4,8) und der Dreizeitenformel (Offb 4,8) weitere Gottesprädikationen zur Sprache: Der königlich thronende Gott ist der, der ,in alle Ewigkeit lebt“ (Offb 4,9), d.h. der lebendige Gott der biblischen Offenbarung, dessen unablässiger ${ }^{39}$ Lobpreis durch himmlische Wesen nun vor Augen und Ohren geführt wird. Im abschließenden Gotteshymnus, der mit der auf-

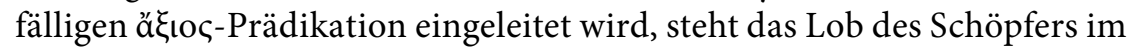
Mittelpunkt: „Denn du hast alle Dinge erschaffen, durch deinen Willen waren sie und wurden erschaffen" $(4,11)$. Als der Weltschöpfer ist Gott der Herr über die Geschichte, und als solcher wird er von den himmlischen Wesen jetzt schon und unablässig gepriesen.

\subsection{Die Dualität von Gott und dem Lamm}

Die eigentliche Klimax der Thronsaalvision in Offb 4-5 ist allerdings die Präsentation des erhöhten Christus als „Lamm“40 in Offb 5,6 und der universale Lobpreis Gottes und des Lammes. Dadurch wird dieses ganz aus der jüdisch-apokalyptischen Tradition von Ezechiel bis Henoch geschöpfte Visionsbild zu einem christlichen Bild, zu einer Proklamation der Würde des erhöhten Christus. Denn das „Lamm, wie geschächtet“,

\footnotetext{
${ }^{37}$ In einzelnen Aspekten nimmt diese Darstellung „Beschreibungen der himmlischen Welt im Rahmen des Henochbuches" auf (s. Schimanowski, Liturgie [Anm. 31] 100). In der Thronvision 1 Hen 14 dominieren Licht- und Farberscheinungen, und dann werden im Rahmen eines kosmischen Rundgangs sieben Berge von Edelsteinen erwähnt, darunter der Gottesberg "gleich dem Thron Gottes“, und „die Spitze des Thrones“ ist „von Saphir“ (1 Hen 18,8; vgl. Ez 1,26f.). Die Qeduscha, das Dreimalheilig der Thronwesen (Offb 4,8b), dokumentiert die Anlehnung an Jes 6,3, wohingegen die „Lebewesen“ selbst, die „vorn und hinten" (Offb 4,6) und an ihren Flügeln, zudem „ringsum und innen“ mit Augen übersät sind (Offb 4,8), auf die Keruben und die Räder des Thronwagens von Ez 1 zurückgehen (vgl. Ez 1,18; weiter Ez 10,12).

${ }^{38}$ S. FreY, Bildersprache (Anm. 14) 176.

${ }^{39}$ Offb 4,9; s. dazu SchimanowsKi, Liturgie (Anm. 31) 148-150.

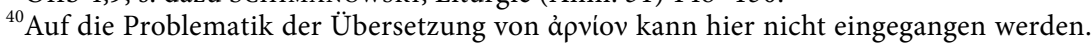
M. E. ist der Hinweis auf die tödliche Wunde ein klarer Hinweis auf Jesu Tod. Die Hörner und Augen des ả $\rho v i ́ o v$ sind zugleich Symbol seiner Macht und Lebendigkeit. D. h. hier liegt (anders als in Joh 1,29.36) kein Bild der Niedrigkeit und Hingabe, sondern ein Bild des Sieges vor.
} 
steht „,in der Mitte des Thrones und der vier Lebewesen“ (Offb 5,6), es ist der Throngenosse des einen Gottes und empfängt aus der rechten Hand des thronenden Gottes das „Buch“ (Offb 5,7). Ihm wird die (Mit-)Herrschaft über die Welt und Geschichte zuteil, so dass nun auch das Lamm von den himmlischen Wesen gleichermaßen und zusammen mit dem einen Gott (Offb 5,13) Lobpreis und Ehrerbietung empfängt.

Damit wird die zunächst ganz theozentrische Darstellung der Apokalypse in auffälliger Weise erweitert: ${ }^{41}$ Die hier in das Bild des thronenden Gottes eingezeichnete Präsentation des erhöhten Christus setzt in eigentümlicher Weise die „binitarische“ Rede von „dem, der auf dem Thron sitzt, und dem Lamm“ (Offb 5,13) aus sich heraus. In „programmatischen Parataxen " ${ }^{42}$ wird im Folgenden in einem Atemzug und nahezu auf gleicher Ebene von Gott und dem Lamm gesprochen. Im Blick auf die eschatologische Heilsvermittlung wie auch im Blick auf die Herrlichkeit und Verehrung ist stets gemeinsam von Gott und dem Lamm die Rede. Im Neuen Jerusalem steht der eine "Thron Gottes und des Lammes“ (Offb 22,3). Der erhöhte Christus erscheint hier als Throngenosse Gottes, ${ }^{43}$ allerdings ohne dass dadurch die fundamentale Theozentrik des Visionsbildes negiert würde. Immerhin erhält das Lamm das versiegelte Buch aus der Hand des thronenden Gottes. Seine Würde ist mithin eine von Gott, dem Schöpfer und Herrn der Welt verliehene, es ist eschatologische Mitherrschaft.

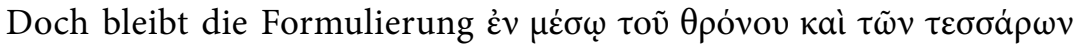
$\zeta \omega \omega \omega v$ in Offb 5,6 problematisch: Wie sollen sich die Lesenden und Hörenden die Szenerie vorstellen, in der das siegreiche „Lamm“, der Erhöhte, „mitten zwischen dem Thron und den vier Wesen" sitzt oder steht $(5,6)$ ? Ist das Lamm „auf“ dem Thron, neben, „zur Rechten“ oder gar im Schoß (vgl. Joh 1,18) des Vaters vorzustellen, und wo ist das „Zwischen“, wenn die vier Wesen ja nicht auf eigenen Thronen sitzen (wie die 24 Ältesten), sondern eher als lebendige Bestandteile des Gottesthrones selbst zu verstehen sind? Diese letztlich die räumliche Vorstellungskraft sprengende Aussage dürfte ebenfalls ein theologisches Signal setzen: Der erhöhte Christus ist dem Gottesthron noch näher als die vier lebendigen Wesen von Kap. 4. Die traditionelle, auf Ps 110 zurückgehende Formulierung

\footnotetext{
${ }^{41}$ SöDiNG, Gott (Anm. 10) 102, formuliert, dass „die Christologie die Theologie der Apokalypse nicht $[\ldots]$ irritiert, sondern intensiviert".

${ }^{42} \mathrm{Zu}$ diesen „programmatischen Parataxen“"s. SöpIng, Gott (Anm. 10) 110-116.

${ }^{43}$ S. dazu Martin Hengel, Die Throngemeinschaft des Lammes mit Gott in der Johannesapokalypse, in: DERs., Studien zur Christologie. Kleine Schriften IV (WUNT 201), Tübingen 2006, 368-385.
} 
vom Sitzen des Erhöhten „zur Rechten“ Gottes ${ }^{44}$ wird hier noch einmal überboten und eine unmittelbare Throngemeinschaft des Thronenden und des zum Thron Erhöhten zur Sprache gebracht. Dabei geht es nicht nur um einen Ausdruck der hohen Christologie (d.h. der Machtstellung des Erhöhten). Auch die Rede von Gott selbst, die Theologie, erhält durch die bleibende Koordination mit der Rede von dem „Lamm“ eine neue Dimension. Allein das Schöpferwirken wird ausschließlich Gott zugeschrieben, hingegen werden das eschatologische Heilswirken und die eschatologische Herrschaft stets mit dem "Lamm“ in Verbindung gebracht. So kann man nach der Apokalypse post Christum glorificatum von Gott nicht mehr „alleine“ sprechen, sondern nur noch in gleichzeitigem Bezug auf den gestorbenen, auferstandenen, zu Gottes Thron erhöhten und mit ihm herrschenden Christus. Die theologisch-christologische Herausforderung in dieser so stark judenchristlich geprägten Schrift bedürfte noch weiterer Reflexion.

\subsection{Gottes Weltherrschaft und das Weltgericht}

Die Herrschaft Gottes und die im Himmel schon angetretene Herrschaft des Lammes sollen sich durchsetzen. Dies ist das Thema der Visionsreihen in Offb 6-22, die letztlich über eine sich rhetorisch immer mehr zuspitzende Folge von Plagenvisionen ${ }^{45}$ auf den Sturz der Weltmacht "Babylon“ zulaufen. Der Fall Babylons (= Roms) ist das vom Autor konkret erhoffte Geschehen, er ist im Himmel schon beschlossen (Offb 14,8; 16,9 ) und wird dann in mehreren Versionen (Offb 16,17-21; 18,1-24) vor Augen geführt, beklagt und besungen. ${ }^{46}$

Ich kann hier nicht auf die Details der drei Plagenzyklen eingehen. ${ }^{47}$ Wesentlich ist hier nur, dass von dem Lamm, das ab Offb 6 die Siegel des versiegelten Buches öffnet, irdische Geschehnisse in Gang gesetzt werden. So wird die Überzeugung vermittelt, dass die irdischen Geschehnisse im Rahmen der nun eröffneten Endgeschichte - letztlich von der göttlichen „Schaltzentrale“ her bestimmt sind. Trotz der Undurchdringlichkeit

\footnotetext{
${ }^{44}$ S. dazu ausführlich Martin HeNGEL, „Setze dich zu meiner Rechten!“. Die Inthronisation Christi zur Rechten Gottes und Psalm 110,1, in: Ders., Studien zur Christologie. Kleine Schriften IV (WUNT 201), Tübingen 2006, 281-367.

${ }^{45}$ S. dazu FreY, Johannesapokalypse (Anm. 17) 511-514.

${ }^{46}$ S. dazu ebd., $527-529$.

${ }^{47}$ S. dazu ausführlich Michael Sommer, Der Tag der Plagen. Studien zur Verbindung der Rezeption von Ex 7 - 11 in den Posaunen- und Schalenvisionen der Johannesoffenbarung und der Tag des Herrn-Tradition (WUNT 2,387), Tübingen 2015.
} 
des Weltgeschehens, ja trotz der Anfechtung und Feindschaft gegenüber den Glaubenden wird verdeutlicht: Gott sitzt im Regiment und wird am Ende - und d.h. bald - seiner universalen Königsherrschaft auch auf Erden zur Durchsetzung verhelfen. Der wiederholte Blickwechsel zwischen den irdischen Geschehnissen und dem himmlischen Thronsaal hat rhetorisch die Funktion, zu vermitteln, dass das Weltgeschehen die Herrschaft der vermeintlichen Herren der Welt und die Leiden des Gottesvolkes (z. B. Offb 12,17) sowie aller Menschen - von der geglaubten Herrschaft Gottes und Christi über die Geschichte und über die Mächte umgriffen ist und dass Gottes Herrschaft sich letztlich durchsetzen wird.

Gottes Geschichtsmächtigkeit ist hier in Anlehnung an die Botschaft der großen Schriftpropheten in einer unüberbietbaren Deutlichkeit zur Geltung gebracht. Damit wird zugleich der Gegensatz zwischen der Weltherrschaft Gottes und der Herrschaft der Weltmächte evident. Eine Entflechtung von Gottesreich und Weltreich (wie sie etwa in Joh 18,36 vorgenommen wird) ${ }^{48}$ kann es hier nicht geben. Das irdische Weltreich, das sich selbst gottgleiche Ehren zuschreibt und von seinen Anhängern Loyalität fordert, ist daher zum Fall „verdammt“. Die Nachfolger Jesu hingegen werden aufgefordert, dieser Herrschaft die Loyalität zu verweigern, aus Babylon „auszuziehen" (Offb 18,4), um Bürger der Gottesstadt zu werden und nicht am Fall und der letztendlichen Zerstörung „Babylons“ teilzuhaben.

Dabei muss zugleich der für viele Zeitgenossen problematische Punkt erwähnt werden, dass dieses Geschehen in erheblicher Brutalität dargestellt wird und dass der Fall „Babylons“ von den himmlischen Stimmen mit offenkundiger und recht "unchristlicher" Schadenfreude kommentiert wird: „Gefallen, gefallen, Babylon die Große!“ (Offb 18,2), und „Halleluja! Und ihr Rauch steigt auf in alle Ewigkeit.“ (Offb 19,3). Spätestens an dieser Stelle lassen sich Bedenken formulieren, ob ein solches Buch noch „christlich“ ist, wenn es solche Gewalt feiert und dadurch letztlich legitimiert, ${ }^{49}$ und wie man denn einen Gott lieben kann, der seine Gegner im Feuersee zugrunde gehen lässt und seine Schöpfung preisgibt (Offb 20,11;21,1), um sie durch eine neue Welt zu „ersetzen“.

$\mathrm{Zu}$ bedenken ist immerhin, dass die irdische Gewalt - Verfolgung als konkrete oder auch nur tradierte und aufs Neue befürchtete Erfah-

\footnotetext{
${ }^{48}$ S. dazu Jörg Frey, Jesus und Pilatus. Der wahre König und der Repräsentant des Kaisers im Johannesevangelium, in: Gilbert van Belle/Joseph Verheyden (Hg.), Christ and the Emperor: The Gospel Evidence (BToSt 20), Leuven 2014, 337-393.

${ }^{49}$ Zur Diskussion von Gewalt und Offb siehe die o. Anm. 7 genannte Literatur.
} 
rung - sich auf Erden schon vorfindet und dass die Apokalypse dieser Erfahrung den Glauben an einen allmächtigen und am Ende siegreichen Gott entgegensetzt. Davon, dass sich Menschen oder gar Völker selbst in das geschilderte Gemetzel einschalten und selbst gegen eine wie auch immer definierte „Achse des Bösen“ kämpfen sollten, ist in diesem Buch nirgendwo die Rede. Andererseits wäre eine Eschatologie, die den endgültigen Sieg Gottes über die bösen Mächte im Unklaren lassen wollte, weder jüdisch noch christlich denkbar.

\subsection{Neuschöpfung und Vollendung: Gottes Einwohnung in seinem Volk}

Doch dürfen wir über den Gewalt-Aussagen die Klimax der Apokalypse nicht vergessen. Diese liegt in dem Schlussbild vom Neuen Jerusalem vor, $\mathrm{zu}$ dessen eingehender Betrachtung der Seher in Offb 21,9 eigens noch einmal „eingeladen“ wird und in dem die Verheißung der eschatologischen Gottesgemeinschaft ihre letzte Erfüllung findet. ${ }^{50}$

Das Gesamtbild - in seiner Stellung als „letztes Bild der Bibel“ besonders wirksam - begegnet zunächst in einer von Gottesrede geprägten ersten Schau $(21,1-8),{ }^{51}$ auf die dann als "Detailaufnahme“ der Rundgang des Sehers durch die Gottesstadt mit dem Deuteengel folgt (Offb 21,9-22,5)..$^{52}$

Mit dem Bild vom neuen Himmel und der neuen Erde kommt am Ende der Apokalypse der Aspekt der Vollendung als Neuschöpfung zur Sprache. Damit steht Gott in seiner Schöpfermacht im Zentrum, die eschatologisch - eine neue, nicht mehr von Unrecht korrumpierte Welt (vgl. auch 2 Petr 3,13) hervorbringt. Diese neue Schöpfung steht weniger in Kontinuität als vielmehr in Diskontinuität zur vorfindlichen Schöpfung: Die alte Welt ist geflohen vor Gottes Angesicht (Offb 20,11) und letztlich verschwunden (Offb 21,1), wenn die neue Welt erscheint. Und doch begegnen auch im Neuen Jerusalem immer wieder Figuren und Gegebenheiten der alten Welt. Offenbar kann von dem Neuen gar nicht anders als gleichnishaft mithilfe des Alten gesprochen werden. Zudem

\footnotetext{
${ }^{50}$ S. dazu FreY, Johannesapokalypse (Anm. 17) 539-545.

${ }^{51}$ S. zu den vielfältigen intertextuellen Bezügen zuletzt KowALSKI, Gottesbilder (Anm. 11).

${ }^{52} \mathrm{Zu}$ berücksichtigen ist dabei, dass die Schlusskapitel keine klare Ereignisfolge bieten, also keinen raum-zeitlich konsistenten Zusammenhang von Ereignissen wie Parusie, Millennium, Neues Jerusalem, vielmehr sind hier in Anlehnung an Schemata aus Ez 36-48 unterschiedliche Bilder eines (zeitlich begrenzten) Messiasreichs und des ewigen Gottesreichs aneinandergefügt. S. dazu FrEY, Johannesapokalypse (Anm. 17) 509-511.
} 
wird durch die Aufnahme der alttestamentlichen „Bundesformel“ in 21,3 auch an die Bundestreue Gottes und damit an die Geschichte Gottes mit seinem Volk erinnert, in der sich somit über den Bruch hinweg doch eine gewisse Kontinuität zeigt.

Entscheidend ist jedoch der Aspekt der unmittelbaren Gottesnähe, der nun - im strikten Gegensatz zur zuvor gegebenen „Weltferne“ und Transzendenz Gottes - ausgesprochen ist. Die neue Gottesstadt, das neue Heiligtum, oder besser Gott selbst als Heiligtum ist nun unter den Menschen. Eine Abgrenzung von heilig und profan und all die Grenzziehungen um das Heilige sind nun nicht mehr erforderlich. Hier ist die alte SchechinaTradition universal und eschatologisch vollendet: ${ }^{53}$ Gottes Einwohnung in seinem Volk aus allen Völkern kommt zur Verwirklichung: Gott ist den Menschen nah, und die Menschen sind Gott nah. Während in Offb 21,1-8 nur von Gott als dem eschatologischen Vollender die Rede ist und Christus unerwähnt bleibt, wird in der „Detailaufnahme“ des Neuen Jerusalem in Offb 21,9-22,6 wieder die Zweiheit von Gott und dem Lamm sichtbar: Gott, der Allherrscher, und das Lamm sind der Tempel der Gottesstadt (Offb 21,22), und von ihrem (gemeinsamen) Thron geht der Strom des Lebens aus (Offb 22,1). Wenn in diesem Zusammenhang Aspekte der Siegersprüche aus Offb 2-3 aufgenommen werden (Offb 21,7 u. ö.), dann wird deutlich, dass dies die Hoffnung der jetzt angefochtenen Gemeinden sein soll. Leid und Tod sollen beseitigt werden, und das Heil der Gottesund Christusgemeinschaft soll denen zuteilwerden, die jetzt oder in der noch bevorstehenden Bedrängnis leiden.

Im letzten Visionsbild der Apokalypse wird Gott nicht nur als Tröster der Leidenden vorgeführt, der alle Tränen abwaschen wird, ${ }^{54}$ sondern darüber hinaus als der eschatologische Retter, der Heil schafft, indem er das Böse beseitigt. Dies kommt im Höhepunkt des ganzen Buches zur Sprache, der einzigen direkten Rede des thronenden Gottes (Offb 21,5): „Und der auf dem Thron saß, sprach: Siehe, ich mache alles neu!" Gott präsentiert sich hier selbst als Neu-Schöpfer, als der Vollender des Heils nach dem Sieg über die bösen Mächte. Dieser Sieg, ja die „gewaltsame“ Vernichtung des Bösen gehört somit zum eschatologisch heilschaffenden Wirken Gottes.

Das Gotteswort von Offb 21,5, das die prophetisch überlieferte Gottesrede aus Jes 43,19 aufnimmt und durch die Hinzufügung von $\pi \dot{\alpha} v \tau$ ta noch ausweitet, bildet die innere Klimax der Apokalypse. Dieses Wort wird

\footnotetext{
${ }^{53}$ S. dazu Frey, God's Dwelling (Anm. 1).

${ }^{54}$ S. dazu MülLER, Gott (Anm. 10).
} 
durch eine andere Stimme noch einmal als „wahr und zuverlässig“ bekräftigt, bevor dann die Alpha-et-Omega-Prädikation wiederholt wird. ${ }^{55}$ In Wiederaufnahme von Offb 1,8 bringt auch sie den Aspekt des Trostes und der gnädigen Zuwendung zur Sprache, wenn die Formel durch die Verheißung erweitert ist: „Ich will dem Dürstenden Wasser des Lebens umsonst geben."

Gott als der eschatologische Vollender und Neuschöpfer, der seiner Gemeinde nahekommen und in der Einheit mit dem erhöhten Christus in ihr Wohnung nehmen will, bildet den Schlussakkord der Apokalypse und ihrer Rede von Gott. Über alle beängstigenden Bilder der Plagen und Gerichte, die das Gottesbild der Apokalypse dem eines absoluten und z. T. grausamen Herrschers nahekommen lassen, ist diese andere Seite nicht zu vernachlässigen: Der transzendente und geschichtsmächtige Gott, der Weltherrscher, ist zugleich der mächtige Retter und Weltvollender, der sich durch Christus eine Heilsgemeinde aus allen Völkern erwählt hat und dieser die bleibende Gemeinschaft mit ihm selbst und „dem Lamm“, d. h. Christus als ihrem Herrn, schenken wird.

\section{Das Gottesbild im Johannesevangelium}

Blicken wir von diesem Überblick ausgehend etwas knapper auf das Gottesbild des Johannesevangeliums, mit einigen notwendigen Seitenblicken zum ersten Johannesbrief, ${ }^{56}$ so lassen sich wesentliche Gemeinsamkeiten, aber auch signifikante Differenzen identifizieren. ${ }^{57}$

\footnotetext{
${ }^{55}$ Dieses ist von dem vorausgehenden Zitat, durch eine neue, personal etwas unbestimmte Redeeinleitung abgesetzt: „Und er spricht [...]“, so dass es in gewisser Weise als Fortsetzung der Gottesrede gelten kann, andererseits doch von 21,5 abgerückt ist.

${ }^{56}$ Die Johannesbriefe sind m. E. als historisch nächstliegender Kommentar zur Interpretation des vierten Evangeliums hinzuzuziehen. In ihnen kommt terminologisch auf den Punkt, was die Narration im Evangelium vor Augen führt. Zur Interpretation des Johannesevangeliums s. grundlegend Jörg FreY, Wege und Perspektiven der Interpretation des Johannesevangeliums. Überlegungen auf dem Weg zu einem Kommentar, in: DERS., Die Herrlichkeit des Gekreuzigten. Studien zu den johanneischen Schriften I, hg. von Juliane Schlegel (WUNT 307), Tübingen 2013, 3-44; zum Verhältnis von Evangelium und Briefen DERS., „Ethical“ Traditions, Family Ethos, and Love in the Johannine Literature, in: ebd., 767-802: 771-773.

${ }^{57}$ Auch das Gottesbild des Johannesevangeliums ist - abgesehen von einzelnen Teilthemen - bislang eher vernachlässigt worden. Zur Diskussion s. meinen eigenen Versuch: Jörg Frey, Tradition (Anm. 13) 217-257. S. weiter Marianne M. Thompson, The God of the Gospel of John, Grand Rapids 2001; Daniel Rathnakara SADAnanda, The Johannine Exegesis of God. An Exploration into the Johannine Understanding of God (BZNW 121),
} 


\subsection{Der Gott Israels}

Von Anfang an ist klar, dass die Rede von Gott im Johannesevangelium an die alttestamentlich-israelitische Tradition anschließt. Der Prolog beginnt mit einem Anklang an Gen 1,1 LXX und redet von Beginn an von (dem einen) Gott ( $\theta \varepsilon$ ćs) im Singular. Der Prolog nimmt seinerseits außer der Genesis Traditionen der Weisheitstheologie und der Sinaioffenbarung auf. Im Schlussvers des Prologs in Joh 1,18 wird dann ganz im Sinne der biblisch-jüdischen Tradition programmatisch die wesentliche Unsichtbarkeit und Unabbildbarkeit Gottes betont. Die Dichte der Aufnahme biblischer Sprachformen, Episoden und Gestalten im ganzen Evangelium lässt an der Identität Gottes als des Gottes der Schriften Israels keinen Zweifel. Auch im Johannesevangelium ist Gott der biblische Gott, der Schöpfer, dem der Logos als das uranfängliche Schöpfungswort zugeordnet ist (Joh 1,1), der „eine Gott“ (Joh 5,44), der „eine wahre Gott“ (Joh 17,3), der „lebendige“ Gott (Joh 6,57), der Gott Israels, der zu Mose geredet hat (Joh 9,29) und sein Wort an Israel ergehen ließ (Joh 10,35). Dies bestätigt zugleich die Aufnahme der älteren Jesustradition im vierten Evangelium: Der Gott und Vater des johanneischen Jesus ist kein anderer als der Gott und Vater Jesu von Nazareth, der Gott Israels.

Implizit weist die Rede von dem einen und wahren Gott allerdings darauf hin, dass diese Einzigkeit im hellenistisch-römischen Entstehungskontext des Evangeliums keineswegs selbstverständlich war. Doch könnte hier wie in 1 Kor 8,5 gesagt werden: Auch wenn in der Umwelt der Gemeinde viele Götter und Mächte Verehrung finden, so ist doch für die johanneische Tradition der wahre Gott der eine Gott Israels, und diese Einheit Gottes ist auch in Anbetracht der hohen Christologie, in der auch von Christus als $\theta \varepsilon$ ć ৎ geredet werden kann, für das Evangelium unstrittig und vorausgesetzt. Die Formulierung von Joh 10,30: „Ich und der Vater sind eins" - mit neutrischem $\tilde{\varepsilon} v$ - verdeutlicht dies.

Berlin/New York 2004; François D. Tolmie, The Characterization of God in the Fourth Gospel, JSNT 69 (1998) 57-75; Jean Zumstein, Das Gottesbild bei Jesus, Paulus und Johannes, TZ 62 (2006) 158-173. Besonderes Forschungsinteresse haben v. a. Fragen nach Gott als „Vater" sowie die Fragen nach Monotheismus und Christologie sowie Vorstufen trinitarischen Denkens an sich gezogen (dazu s. die Literatur in FreY, Tradition [Anm. 13] 220-222), sowie schließlich die Rede von Gott als „Liebe“, s. dazu Jörg FreY, „God is Love“: On the Textual Tradition and Semantics of a Core Expression of the Christian Notion of God, in: Reinhard G. Kratz/Hermann Spieckermann (Hg.), Divine Wrath and Divine Mercy in the World of Antiquity (FAT 2,33), Göttingen 2008, 203-227, und Enno E. PopKEs, Die Theologie der Liebe Gottes in den johanneischen Schriften (WUNT 2,197), Tübingen 2005. 


\subsection{Gottes Unsichtbarkeit und seine Offenbarung}

Strittig sind lediglich die Modi der Offenbarung bzw. der Erkenntnis Gottes. Wenn Joh 1,18 die grundlegende Unsichtbarkeit des biblischen Gottes betont, dann bestreitet das Evangelium implizit auch jeden Anspruch einer Gottesschau, wie sie für einzelne biblische Gestalten zumindest andeutungsweise beansprucht wurde (Jes 6,1-9; Ez 1; Dan 7,9; 2 Kön 22,19), und darüber hinaus die Erkenntnisse aller Visionäre und Himmelsreisender (wie Henoch), letztlich mit dem einen Ziel, die Exklusivität und eschatologische Gültigkeit der Offenbarung Gottes in der Person und Geschichte Jesu von Nazareth, des Gekreuzigten und Auferstandenen, zu betonen. In Jesus Christus hat sich für das vierte Evangelium das „Wohnen“ Gottes „unter uns" ereignet (Joh 1,14b). ${ }^{58}$ Nur in der Gestalt des Inkarnierten, oder besser in seiner Geschichte, seinem Wirken, Leiden, Sterben und Auferstehen, kann Gott, der Vater, in Wahrheit erkannt und (mit geistigen Augen) sogar gesehen werden (Joh 14,7.9). ${ }^{59}$

Damit ist natürlich ein Konflikt eröffnet. Jenen Zeitgenossen, die Jesu Sendung und seinen Anspruch abweisen und auf ihre Abrahamskindschaft (Joh 8,33) oder die Loyalität zur mosaischen Tradition (Joh 5,39.45; $9,29 \mathrm{f}$.) verweisen, wird entgegengehalten, sie hätten keine authentische Gotteserkenntnis, sie hätten Gottes Stimme nicht gehört, seine Gestalt nicht gesehen und sein Wort nicht bleibend in sich (Joh 5,37f.). Damit ist der Konflikt mit dem synagogalen Judentum scharf markiert. Zugleich markiert der Anspruch, dass die wahre Erkenntnis des unsichtbaren Gottes allein in der „Exegese“ Gottes durch den Inkarnierten gewonnen werden kann (Joh 1,18), einen Gegensatz zu allen anderen Offenbarungsansprüchen visionärer oder ekstatischer Provenienz. Dementsprechend ist ja auch das Wirken des Geistes nach Johannes gerade nicht wie bei Lukas ein Wirken in Träumen, Visionen, ekstatischen Worten und wunderbaren Taten, sondern ausschließlich ein erinnerndes, lehrendes und vergewisserndes und damit essentiell worthaftes Wirken (Joh 14,26; 16,13-15).

\footnotetext{
${ }^{58}$ S. dazu Jörg Frey, Joh 1,14, die Fleischwerdung des Logos und die Einwohnung Gottes in Jesus Christus. Zur Bedeutung der „Schechina-Theologie“ für die johanneische Christologie, in: Bernd Janowski/Enno E. Popkes (Hg.), Das Geheimnis der Gegenwart Gottes. Zur Schechina-Vorstellung im Judentum und Christentum (WUNT 318), Tübingen 2014, 231-256; DERs., God's Dwelling (Anm. 1).

${ }^{59}$ S. dazu Jörg Frey, „Wer mich sieht, der sieht den Vater“: Jesus als Bild Gottes im Johannesevangelium, in: Andrea Taschl-Erber/Irmtraud Fischer (Hg.), Vermittelte Gegenwart. Konzeptionen der Gottespräsenz von der Zeit des Zweiten Tempels bis Anfang des 2. Jahrhunderts n. Chr. (WUNT 367), Tübingen 2016, 179-208.
} 
Die Frage ist daher durchaus berechtigt, ob der vierte Evangelist den in der Johannesapokalypse vorgeführten Offenbarungsmodus der Vision als legitim hätte ansehen können. Kann wahre Gotteserkenntnis in Visionen gründen? Das Kriterium ist jedenfalls klar: Es kann keine andere Erkenntnis sein als die, die in der Person und in der Geschichte Jesu Christi gründet (vgl. Joh 16,14f.).

\subsection{Die Einheit von Vater und Sohn: Christozentrik und Theozentrik}

Das Zentrum der Gottesverkündigung im Johannesevangelium liegt in der Rede von Gott als dem Vater, der durch die enge Beziehung zu „dem Sohn" ausgezeichnet ist und letztlich durch sein Handeln in der Sendung des Sohnes in seinem Wesen zu erkennen ist. Dieses Wesen Gottes ist wie im Evangelium schon in 3,16.35 angedeutet und in 1 Joh 4,8-10 explizit formuliert wird, ganz undualistisch als „Liebe“ und „Beziehungswille“ gefasst. Der erste Johannesbrief und das vierte Evangelium vertreten gemeinsam (mit leicht unterschiedlichen Akzentsetzungen) eine „Theologie der Liebe Gottes". ${ }^{60}$

Die bei Johannes so wesentliche Prädikation Gottes als „Vater“61 geht natürlich auf den irdischen Jesus zurück, auch wenn sie keine exklusive Innovation Jesu darstellt. ${ }^{62}$ Dass die Rede von Gott als Vater in der frühen Theologiegeschichte immer breiteren Raum einnimmt und dann bei Johannes in besonderer Dichte begegnet, hat vielleicht damit zu tun, dass diese Redeweise Menschen im hellenistisch-römischen Kulturkreis leichter zugänglich war, wo man nicht zuletzt um Zeus als „Vater der Götter und Menschen" wusste. ${ }^{63}$ Allerdings ist Gott bei Johannes gerade nicht der Vater aller Menschen, sondern zunächst exklusiv Vater des Sohnes und dann - aufgrund des Christusgeschehens - Vater der Glaubenden

\footnotetext{
${ }^{60}$ S. dazu ausführlich Popkes, Theologie (Anm. 57).

${ }^{61}$ S. dazu Frey, Tradition (Anm. 13) 228-233; ausführlich zum Hintergrund und zur neutestamentlichen Verwendung Christiane Zimmermann, Die Namen des Vaters. Studien $\mathrm{zu}$ ausgewählten neutestamentlichen Gottesbezeichnungen vor ihrem frühjüdischen und paganen Sprachhorizont (AJEC 69), Leiden 2007, 41-166.

${ }^{62}$ Die verbreitete Meinung, dass die Vateranrede an Gott erst durch Jesus ,eingeführt" worden sei, ist unzutreffend. Vielmehr ist die Anrede Gottes als Vater schon in alttestamentlichen und (dann häufiger) in antik-jüdischen Schriften belegt. S. dazu ZimmermanN, Namen (Anm. 61) und Angelika Strotmann, Mein Vater bist Du! (Sir 51,10). Zur Bedeutung der Vaterschaft Gottes in kanonischen und nichtkanonischen frühjüdischen Schriften (FTS 39), Frankfurt a. M. 1991. Dass die frühchristliche Rede von Gott als Vater grundlegend mit der Verkündigung Jesu von Nazareth und seiner Gebetspraxis zu tun hat, sollte man allerdings nicht bezweifeln.

${ }^{63}$ So der Vorschlag von Zimmermann, Namen (Anm. 61) $69 \mathrm{f}$.
} 
(vgl. die sorgfältige Differenzierung in Joh 20,17) ${ }^{64}$ Die Rede von Gott als Vater im Johannesevangelium ist somit primär der christologischen Bestimmung Jesu als des (einen, einziggeborenen) Sohnes zugeordnet. Gott ist Vater, insofern Jesus „der Sohn“ ist, der „im Schoß des Vaters“ (Joh 1,18), d. h. in unüberbietbarer Nähe zu ihm ist.

Die Einheit (Joh 10,30), ja wechselseitige „Durchdringung“ (Joh 10,38; 14,10) von Vater und Sohn ${ }^{65}$ bestimmt die johanneische Christologie, aber zugleich auch die Rede von Gott, die spezielle Theologie. Gerade weil Jesus in intimster Weise mit dem Vater verbunden ist, ist er der einzige wahre Offenbarer, derjenige, in dem der unanschauliche Gott anschaulich sichtbar gemacht (Joh 14,7.9) und in seinem Wesen „,ausgelegt“

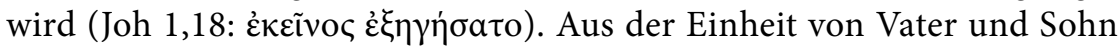
ergibt sich zugleich die Exklusivität der Offenbarungstheologie des vierten Evangeliums, nach dem der Zugang zum Vater ausschließlich durch den Sohn und nicht an ihm vorbei möglich ist (Joh 14,6) und das Leben allein durch den Sohn vermittelt wird (1 Joh 5,12). Eine hinter dieser Offenbarung durch den Sohn verborgene, eventuell noch ganz andere Seite Gottes kann es in Wahrheit nicht geben, wenn in seiner Geschichte der heilvolle Wille und das Wesen des biblischen Gottes gültig offenbart sind. Somit ist durch die enge Verbindung, ja Einheit (Joh 10,30) von Vater und Sohn auch das Wesen Gottes sachlich so bestimmt, dass von Gott post Christum nicht mehr anders als unter Bezug auf den Sohn und seinen Weg gesprochen werden kann, so dass jede Gotteserkenntnis, die von ihm absieht, als unvollständige, wenn nicht sogar unwahre zu gelten hat. Eine Rede von „Gott allein“ unter Absehung von der Christologie ist nach Johannes prinzipiell verfehlt.

\subsection{Die bleibende Theozentrik}

Die Christologie bestimmt im vierten Evangelium letztlich das Ganze. Von der anfänglichen Rede über den uranfänglichen Logos (Joh 1,1) bis zur eschatologischen Zielvorstellung in den letzten Worten des Abschiedsgebets Jesu, „dass sie meine Herrlichkeit schauen“ (Joh 17,24), von der Protologie bis zur Eschatologie ist durchgehend die Funktion und Würde Christi im Fokus, die ihrerseits terminologisch und narrativ in der

\footnotetext{
${ }^{64}$ So die treffende These von Frances BACK, Gott als Vater der Jünger im Johannesevangelium (WUNT 2,336), Tübingen 2012.

${ }^{65} \mathrm{~S}$. zu diesen Aussagen der „reziproken Immanenz" von Vater und Sohn besonders Klaus Scholtissek, In ihm sein und bleiben. Die Sprache der Immanenz in den johanneischen Schriften (HBS 21), Freiburg 2000.
} 
Relation zu Gott, dem Vater, zur Darstellung gebracht wird. Eine stärkere Christozentrik ist kaum vorstellbar.

Gleichwohl bleibt in einzelnen Punkten die Theozentrik unangetastet: Dies betrifft nicht nur das viel diskutierte Wort Joh 14,28: „Der Vater ist größer als ich", das man häufig im Sinne eines theologischen Subordinatianismus ins Feld geführt hat, was freilich im Ganzen des vierten Evangeliums kaum überzeugt. ${ }^{66}$ Gleichwohl ist im Prolog zwischen Gott als dem Schöpfer und dem Logos als dem Schöpfungsmittler sehr wohl unterschieden. Ausgangspunkt der Sendung des Sohnes ist natürlich der „Vater, der ihn gesandt hat" (Joh 5,37; 6,44 u. ö.), und die Vollmacht des Sohnes (Joh 17,2), seine Macht, Leben zu geben und das Gericht zu halten, ist ihm natürlich vom Vater gegeben (Joh 5,22.26). Insofern ist der letzte Grund der Autorisierung Jesu Gott selbst, der Ursprung des Heilsgeschehens sein Heilswille und der letzte Horizont der Christologie die vorzeitliche Liebe des Vaters zum Sohn (Joh 17,24). So ist letztlich, bei aller Fokussierung der Darstellung auf die Christologie, die fundamentale Theozentrik gewahrt.

\subsection{Das Zurücktreten anderer Gottesprädikate ${ }^{67}$}

Wohl aufgrund der christologischen Fokussierung treten andere Gottesprädikate im Johannesevangelium (im Vergleich mit den Synoptikern) auffällig zurück. Dazu gehört nicht zuletzt die Prädikation Gottes als Schöpfer. Wenn im vierten Evangelium die Schöpfung thematisiert wird, dann wird die Schöpfermacht des Logos herausgestellt (Joh 1,3.10). Von der "Grundlegung der Welt" wird nur noch relativ formelhaft geredet (Joh 17,24), um die vorzeitliche Liebe des Vaters zum Sohn auszusagen. Das Beispiel zeigt, dass bei Johannes einzelne traditionelle Motive letztlich nur verwendet werden, wenn es darum geht, eine christologische Aussage zu formulieren. Gleichwohl setzt der Gedanke der Schöpfungsmittlerschaft des Logos das Wissen um Gott als Schöpfer voraus.

Stark zurückgenommen ist bei Johannes auch die Rede von Gott als König und seiner Königsherrschaft, die im antiken Judentum von großer, nicht zuletzt liturgischer Bedeutung ist und natürlich den Hintergrund

\footnotetext{
${ }^{66}$ Vgl. Charles K. BARrett, „The Father is Greater than I“ (John 14:28): Subordinatianist Christology in the New Testament, in: DERs., Essays on John, London 1982, 19-36; Birger Olsson, Deus semper maior? On God in the Johannine Writings, in: Johannes Nissen/Sigfred Pedersen (Hg.), New Readings in John, Sheffield 1999, 143-171. Ein subordinatianistisches Verständnis wird auch von SADANANDA, Exegesis (Anm. 57) präferiert.

${ }^{67}$ S. dazu ausführlicher FreY, Tradition (Anm. 13) 233-235.
} 
der Verkündigung Jesu von der Königsherrschaft Gottes bildet. Doch wird dieses für die ältere Jesusüberlieferung so charakteristische Motiv bei Johannes nur zweimal in einem vermutlich traditionellen Logion aufgenommen (Joh 3,3.5) und dann weiter nicht mehr verwendet, während das Motiv des Königtums dann ganz auf Jesus als den „König Israels“ (Joh 1,49) bzw. „König der Juden“ (Joh 18,28-19,16) übergeht: ${ }^{68}$ Er ist der wahre König (Joh 18,37), und in seiner Königsherrschaft ist nach Johannes die Gottesherrschaft angebrochen. Deshalb kann das vierte Evangelium auch das Reich Gottes und die Reiche der Welt (Joh 18,36f.) stärker „entflechten“, als dies der Johannesapokalypse möglich ist. Hingegen kann die Rede von Gott als dem König und Herrn der Welt bei Johannes zurücktreten.

\subsection{Geist, Licht, Liebe}

Trotz der starken christologischen Fokussierung (v.a. im Evangelium), wird im Johannesevangelium und den Johannesbriefen letztlich doch eine größere Breite von Gottesaussagen erreicht. Dies ist an den „Spitzenaussagen" johanneischer Theo-logie, den drei nominalen Gottesprädikationen Geist, Licht und Liebe zu verdeutlichen.

Die Aussage "Gott ist Geist" (Joh 4,24), die unvermittelt in dem Gespräch Jesu mit der Samaritanerin begegnet, kann mit Udo Schnelle geradezu als „ein Spitzensatz hellenistischer Religionsgeschichte “69 gelten. In Joh 4 ist sie im Interesse der Überwindung der spezifischen Ortsbindung der Gottesverehrung (auf dem Zion oder dem Garizim) eingeführt, d. h. sie bezeichnet den überall präsenten und überall verehrbaren Gott, wie er eschatologisch im österlichen Glauben an Christus erschlossen ist. Doch ist mit der "Geist“-Prädikatikon zugleich in einer für hellenistische Leser nachvollziehbaren Weise die „Unweltlichkeit“, die Welttranszendenz des einen wahren Gottes ausgesagt, der von allen Geschöpfen kategorial unterschieden ist. Damit wird auf ganz andere Weise ausgesagt, was in der

\footnotetext{
${ }^{68}$ S. dazu Jörg FreY, Die johanneische Eschatologie. Band 3: Die eschatologische Verkündigung in den johanneischen Texten (WUNT 117), Tübingen 2000, 271-283; DERs., From the „Kingdom of God" to „Eternal Life“: The Transformation of Theological Language in the Fourth Gospel, in: Paul N. Anderson/Felix Just/Tom Thatcher (Hg.), John, Jesus, and History, Bd. 3: Glimpses of Jesus through the Johannine Lens, Atlanta 2016, 439-458; s. auch Martin Hengel, Reich Gottes und Weltreich im Johannesevangelium, in: Ders., Jesus und die Evangelien. Kleine Schriften V, hg. v. Claus-Jürgen Thornton (WUNT 211), Tübingen 2007.
}

${ }^{69}$ Udo Schnelle, Das Evangelium nach Johannes (THKNT 4), Leipzig ${ }^{4} 2009,103$. 
Johannesapokalypse im Bild des thronenden Gottes zur Sprache gebracht ist.

Die in 1 Joh 1,5 gebotene nominale Prädikation von Gott als Licht nimmt stärker alttestamentliche Traditionen auf. Licht ist mit der Schöpfung verbunden, es ist in der Tora gegeben, es symbolisiert Heil und ist schon in den Psalmen (Ps 27,1) und dann noch allgemeiner bei Philo mit Gott verbunden. ${ }^{70}$ Aber auch in anderen Kreisen des antiken Judentums (z. B. in den Trägerkreisen der Qumran-Bibliothek) und der hellenistischen Welt ist die Lichtmetaphorik religiös und ethisch vielfältig verwendet. In diesen Zusammenhängen symbolisiert das Licht zugleich das Gute, Reine und eschatologisch Bleibende. Auch die Lichtmetaphorik findet sich - in anderer Weise - in der Johannesapokalypse, wenn die Vision der himmlischen Welt und des thronenden Gottes durch Lichtund Farberscheinungen ausgestaltet ist. Andererseits steht der Bezug der Licht-Prädikation auf Gott im ersten Johannesbrief auch in Korrespondenz zur christologischen Aufnahme der Licht-Prädikation im Johannesevangelium, wo Christus selbst als "das Licht“ (Joh 8,12) erscheint und als solcher die Erkenntnis Gottes vermittelt. ${ }^{71}$

Mit der Prädikation "Gott ist Liebe“ in 1 Joh 4,8.16 ist wohl der Höhepunkt der johanneischen Gottesaussagen im Ganzen erreicht. Die Aussage markiert den Endpunkt einer längeren biblischen Traditionsgeschichte, in der sich die alte Spannung zwischen einem zürnenden und einem barmherzigen Handeln Gottes immer mehr „vereindeutigt “. ${ }^{72}$ Am Ende des Alten Testaments findet sich im Weisheitsbuch die Aussage der Liebe Gottes zu allen seinen Geschöpfen (Weish 11,24f.). Paulus bezieht dann erstmals die Liebesprädikation auf das Christusgeschehen (Röm 5,8), und das Johannesevangelium beschreibt den Weg des Sohnes in den Tod als Selbsthingabe, als „Liebe“ für seine Freunde (Joh 15,13) und als Ausdruck der Liebe Gottes zur Menschenwelt (Joh 3,16), was schließlich in der Sendungsformel 1 Joh 4,8.16 zusammengefasst wird in der Prädikation Gottes selbst als „Liebe“. Diese Liebe Gottes ist es, die sich - in paradoxer Weise - im Christusgeschehen (1 Joh 4,9) und konkret

\footnotetext{
${ }^{70}$ Philo, Somn. I 75: „Gott ist Licht.“

${ }^{71} \mathrm{Zu}$ den Hintergründen der Licht-Finsternis-Metaphorik im Johannesevangelium s. Jörg Frey, Recent Perspectives on Johannine Dualism and its Background, in: Ruth Clements/Daniel R. Schwartz (Hg.), Text, Thought, and Practice in Qumran and Early Christianity. Proceedings of the Ninth International Symposium of the Orion Center for the Study of the Dead Sea Scrolls and Associated Literature, Jointly Sponsored by the Hebrew University Center for the Study of Christianity, 11-13 January, 2004 (StTDJ 84), Leiden u. a. 2009, 127-157.

${ }^{72}$ S. dazu Frey, God (Anm. 57).
} 
in der sündentilgenden Wirkung seines Todes (1 Joh 4,10) manifestiert hat. Damit ist die Liebe als Urgrund des göttlichen Wesens ausgesagt und wenn die Christusoffenbarung die vollständige und eschatologisch letztgültige Offenbarung Gottes ist, hinter oder neben der es keine andersartige mehr geben kann, dann ist damit auch das wahre Wesen Gottes auf den Begriff gebracht.

\section{Aspekte zum Vergleich}

Damit scheint ein beträchtlicher Kontrast erreicht zu jenem Gottesbild, das die Apokalypse weithin beherrscht: Das Bild des geschichtsmächtigen, richtenden, ja seine Feinde ultimativ vernichtenden Gottes. Doch bevor der Kontrast zur Diastase wird, sind - eher thesenhaft - die Differenzen der Perspektive der beiden Bücher und eine Reihe fundamentaler Gemeinsamkeiten zu bedenken.

\subsection{Die unterschiedliche Perspektive}

Grundsätzlich ist bei einem Vergleich dieser beiden, augenscheinlich sehr verschiedenen Gottesbilder die unterschiedliche Gesamtperspektive zu betrachten, die vor allen theologischen Differenzen steht.

Das Johannesevangelium steht in der Jesusüberlieferung und schöpft aus ihr. Sein Stoff ist das Wirken, Sterben und Auferstehen Jesu, seine Geschichte, die aus der Perspektive der nachösterlichen Erinnerung (vgl. Joh 2,22; 12,16; 14,26) erzählt und gedeutet wird. Dabei ist das Hauptinteresse, die christologische Identität und Würde Jesu vor Augen zu stellen. Von Gott ist daher nicht zuletzt dazu die Rede, dass die Person Jesu zu ihm ins Verhältnis gesetzt werden kann.

Dieselbe hohe Christologie bestimmt auch die Johannesbriefe, wenngleich dort - in der direkten, nicht-narrativen Kommunikation - Gott auch stärker eigenständig zum Thema wird. Nicht zufällig begegnen daher auch zwei der drei nominalen Gottesprädikationen der johanneischen Schriften im ersten Johannesbrief.

Die Perspektive der Apokalypse ist eine ganz andere. Hier spielt der Rückblick auf die irdische Geschichte Jesu praktisch keine Rolle, und auch auf seinen Tod wird nur ganz marginal rekurriert. Der Fokus liegt allein auf der visionären Schau der Gegenwart (d. h. der Welt der Gemeinden und des Thronraums Gottes mit dem zum Gottesthron erhöhten Christus) und der „bald“ bevorstehenden Zukunft und Vollendung. In dieser 
Perspektive kommt Gott als Schöpfer, Weltherrscher und Vollender zur Sprache, wobei dann schon für die Aussagen über die Gegenwart und die eschatologische Zukunft die Zusammenordnung von „Gott und dem Lamm“ auffällt.

\subsection{Der Gott Israels}

Trotz dieser unterschiedlichen Perspektiven beziehen sich alle johanneischen Schriften auf den einen biblischen Gott, den Gott Israels und Jesu, zurück. ${ }^{73}$ Gottes Lebendigkeit, sein Schöpfertum, seine wesentliche Unsichtbarkeit und auch eine (in unterschiedlicher Konkretheit) erwartete Heilsvollendung sind in beiden Traditionskreisen vorausgesetzt. Nach beiden Schriften kommt der Gott Israels in und durch Christus zu einem universalen Gottesvolk. Beide vertreten eine ausgesprochen hohe Christologie, in der Prädikate Gottes auf Christus übertragen werden, und beide kommen in je unterschiedlicher Weise zu Spitzenaussagen über die enge Gemeinschaft des (erhöhten) Christus mit Gott (Joh 1,18; Offb 5,6; $21,22 f$.$) .$

\subsection{Die fundamentale Theozentrik und die hohe Christologie}

In beiden Traditionsbereichen ließ sich eine klare Theozentrik erkennen, die aber die Einbeziehung Christi und damit die Entwicklung einer binitarischen Zweiheit nicht ausschließt. Freilich zeigen sich im Detail Unterschiede:

Im Johannesevangelium sind Gott und sein Lieben Ausgangspunkt des Heilsgeschehens (Joh 3,16.35), und die Sendung Jesu markiert eine große Bewegung von Gott, dem Vater, her und wieder zu ihm zurück. Dabei umgreift die Einheit von Vater und Sohn (Joh 10,30) alle Zeitmodi: Sie begegnet in Aussagen über den Präexistenten (Joh 1,1;17,24), wird für das Wirken des Inkarnierten festgehalten (Joh 10,30) und für den Erhöhten formuliert (Joh 1,18). Der Glaube soll sich in nachösterlicher Zeit an Gott und Jesus richten (Joh 14,1), und dem Sohn gebührt gleiche Verehrung wie dem Vater (Joh 5,23). Mit der Aussage, dass der Erhöhte „im Schoß des Vaters" ist (Joh 1,18), wird eine intime Gemeinschaft zwischen Vater

\footnotetext{
${ }^{73}$ Darum sollte man auch sprachlich vermeiden, von einer Entgegensetzung von „Göttern“ (z. B. der Gott Jesu vs. der Gott des Alten Testaments; der Gott Jesu vs. der Gott der Apokalypse) zu reden, sosehr sich die Bilder dieses einen Gottes beträchtlich unterscheiden.
} 
und Sohn ausgesagt, wie sie sonst im Neuen Testament nur in der Throngemeinschaft von Gott und dem Lamm in Offb 5,6 ausgesprochen ist.

Auch in der Apokalypse ist Gott der Ausgangspunkt der Offenbarung (Offb 1,1) und letztlich auch der Weltvollender (Offb 21,5), so dass an der Theozentrik noch weniger als im Blick auf das Johannesevangelium zu zweifeln ist. Mit der Präsentation des Lammes in einer die räumlichen Vorstellungskategorien sprengenden Gottesnähe und der formelhaften Zusammenordnung von Gott und dem Lamm findet sich auch hier eine ausgesprochen hohe Christologie, und auch in der Apokalypse werden Worte Gottes (u. a. die Ego-eimi-Formel) dem erhöhten Christus in den Mund gelegt, analog zu den Ego-eimi-Worten des vierten Evangeliums. Der Erhöhte ist mit dem Thronenden verbunden in der gegenwärtigen Herrschaft und in der erhofften Gegenwart in seiner Gemeinde. Nur die Schöpfungsaussagen und damit auch die Aussagen der Neuschöpfung sprechen nicht von einer Beteiligung Christi.

\subsection{Modus und Zeit der Gottesoffenbarung}

Eine stärkere Differenz besteht im Modus der Gottesoffenbarung und ihrer zeitlichen Einordnung.

Im vierten Evangelium werden die Fülle der Gegenwart Gottes und die vollgültige Offenbarung seines Wesens in dem Inkarnierten, dem irdischen Jesus, lokalisiert (und in der Erinnerung der Jesusgeschichte je neu aktualisiert). Dies schließt nicht aus, dass für die Glaubenden, die sich noch auf dem Weg befinden, die Vollendung ihrer Gemeinschaft mit Gott und Christus noch aussteht (Joh 14,3; 17,24; 1 Joh 3,2). Andererseits ist in Christus bereits das Leben gegeben (Joh 5,24; 11,25f.), und das Gericht ergeht in der Begegnung mit Jesus bzw. seinem verkündigten Wort (Joh 3,18 u. ö.).

Während Joh 1,14 die Tradition der eschatologischen Einwohnung Gottes auf den Inkarnierten bezieht, wird diese in Offb 21,3 als eschatologische Hoffnung ausgesprochen. ${ }^{74}$ Anders als im vierten Evangelium ist aber auch die definitive Entscheidung über die eschatologische Zugehörigkeit, das "Gericht“, ein noch zu erwartender Akt im Rahmen des vielfältigen Endgeschehens, und die Zuteilung eschatologischen Lebens ist erst in diesem Rahmen zu erhoffen.

Insofern ist die Grundausrichtung und zugleich die Zuteilung eschatologischen Lebens in beiden Schriften sehr unterschiedlich. Die volle Ge-

\footnotetext{
${ }^{74}$ Dazu s. Frey, God's Dwelling (Anm. 1).
} 
genwart Gottes inmitten seines Volkes ist für die Adressaten der Apokalypse noch zukünftig und utopisch, während der Glaube im Evangelium seinen Haftpunkt in der vergangenen und in der Verkündigung der gegenwärtig erinnerten Geschichte Jesu besitzt. Die jeweils vorausgesetzte Unsichtbarkeit und Unzugänglichkeit Gottes wird in beiden Werken unterschiedlich überwunden - einerseits christologisch-inkarnatorisch, andererseits eschatologisch.

\subsection{Die bleibende Grundspannung}

Auch im Blick auf die Aussagen über Heil und Gericht lassen sich die beiden Werke nicht in einen völligen Gegensatz bringen. So sehr im vierten Evangelium die Verkündigung des Heils („,ewiges Leben“) dominiert (Joh 20,30f.) und die eindeutig heilvolle Zielsetzung der Sendung Jesu betont wird (Joh 3,17), weiß das Werk durchaus um die unheilvolle Kehrseite, um das „Gericht“ (Joh 3,18), um ein In-der-Finsternis-Bleiben des Unglaubens oder gar ein eschatologisches Verderben (Joh 3,36; 5,29; 15,6), wenngleich diese Aussagen vergleichsweise recht unbetont bleiben. Umgekehrt ist die Apokalypse trotz ihrer paränetisch-warnenden Zielrichtung bis zum Schluss bestimmt von der Verheißung des Heils für diejenigen, die sich als Jesusnachfolger rein halten und bewähren, während Untergang und Verderben über diejenigen kommen, die sich von den Gott widerstrebenden Mächten bestimmen lassen. Das „Drohpotential“ der Apokalypse mit ihren Plagen- und Gerichtsvisionen ist jedoch sehr viel größer, während die Verkündigung des Johannesevangeliums auf die Vergewisserung seiner Adressaten zielt.

So sehr also eine Aufteilung der beiden Bücher auf die Aspekte Heil und Gericht unangemessen ist, weil die eschatologische Entgegensetzung von Heil und Unheil und die Möglichkeit eines "doppelten Ausgangs“ in beiden vorausgesetzt sind, so besteht doch eine wesentliche Differenz zwischen beiden im Blick auf die Auflösung dieser Grundspannung. Von dem Gott, wie er in den letzten Visionsbildern der Apokalypse seine Feinde vernichtet, wird nicht gesagt, dass er "Liebe“ ist, und es bleibt fraglich, ob solches gesagt werden könnte. Hingegen wird im Johannesevangelium zwar auch mit der Möglichkeit eines eschatologischen Verderbens gerechnet, doch liegt der Akzent gerade darauf, dass Gott sein Äußerstes, seinen Sohn, gegeben hat, um die Welt vor diesem Verderben zu retten und die Menschen aus der Finsternis ans Licht zu bringen.

Insofern bleibt zwischen diesen beiden Schriften doch eine Grundspannung bestehen zwischen der Majestät auf dem Thron und dem Gott, 
der sich in der Geschichte Jesu, und nicht zuletzt im Kreuz, als die Liebe erwiesen hat.

\section{Theologische Schlussreflexion}

Damit stellt sich unausweichlich die theologische Frage nach der Gewichtung dieser unterschiedlichen Aussagen innerhalb des biblischen Kanons und im Rahmen einer christlichen Theologie. Wie lassen sich die Wahrheitsansprüche zueinander in Beziehung setzen? Wo finden sich Ansatzpunkt und Maßstab?

Ist es letztlich eine Frage der Wahl, des „theologischen Geschmacks“, wo die Priorität gesucht wird? Ist es sachgemäß, wenn religiös Konservative eher die Strenge des Gerichtsgedankens hervorheben, um eine wirksame Drohkulisse zu erzeugen, oder wenn Liberale den Liebesgedanken verabsolutieren, um die negativen Seiten des Gottesbildes loszuwerden? Auf dem Hintergrund der biblischen Tradition sind beide Wege gleichermaßen verkürzend und unangemessen. Ich kann hier nur thesenhaft andeuten, in welche Richtung meines Erachtens aufgrund des biblischen Gesamtzeugnisses gedacht werden könnte.

So sehr sich der Gedanke der Rettung letztlich nur auf dem Hintergrund eines wahrgenommenen oder drohenden Unheils begreifen lässt, so ist umgekehrt die Fluchtlinie der biblischen Tradition im Gemeinschaftswillen des Schöpfers, des Gottes Israels und des Vaters Jesu Christi $\mathrm{zu}$ sehen. Wenn das Kriterium christlicher Verkündigung letztlich in der Sendung und Geschichte Jesu von Nazareth und in der heilvollen Deutung seines Todes liegen muss, dann ist der Zielpunkt der biblischen Gottesaussagen tatsächlich in der Offenbarung der Liebe Gottes zu sehen.

Es wäre mithin die unverzichtbare Aufgabe einer theologischen Exegese, hier sachlich begründet zu gewichten, ohne willkürlich zu selektieren, und die particula veri des majestätischen Bildes des Allherrschers gegen alle irdischen Machtansprüche festzuhalten, und gleichwohl den Gedanken der in Christi Kreuz erwiesenen Liebe Gottes zu allen Menschen unverkürzt zur Geltung zu bringen. 



\section{Autorinnen und Autoren}

Dr. Johannes Beutler, em. Professor für Theologie des Neuen Testaments und Fundamentaltheologie, Philosophisch-Theologische Hochschule St. Georgen, Frankfurt am Main.

Dr. Veronika Burz-Tropper, Projektleiterin des Hertha Firnberg-Projektes „Gottes-Rede im Johannesevangelium“ (Austrian Science Fund [FWF]: T 627 G21), Institut für Bibelwissenschaft, Katholisch-Theologische Fakultät, Universität Wien.

Dr. Reinhard Feldmeier, Professor am Seminar für Neues Testament, Theologische Fakultät, Georg-August-Universität Göttingen.

Dr. Jörg Frey, Professor für Neutestamentliche Wissenschaft mit Schwerpunkt Antikes Judentum und Hermeneutik, Theologische Fakultät, Universität Zürich.

Dr. Christina Hoegen-Rohls, Professorin für Bibelwissenschaften und ihre Didaktik, Evangelisch-Theologische-Fakultät, Westfälische WilhelmsUniversität Münster.

Dr. Jutta Leonhardt-Balzer, Senior Lecturer, School of Divinity, History and Philosophy, University of Aberdeen.

Dr. Olivia Rahmsdorf, Junior Mitglied der Gutenberg Akademie und wissenschaftliche Mitarbeiterin am Seminar für Neues Testament, Evangelisch-Theologische Fakultät, Johannes Gutenberg-Universität Mainz.

Dr. Dr. hc. Hermann Spieckermann, Professor am Seminar für Altes Testament, Theologische Fakultät, Georg-August-Universität Göttingen.

Dr. Michael Theobald, em. Professor für Neues Testament, KatholischTheologische Fakultät, Eberhard Karls-Universität Tübingen.

Dr. Jan G. van der Watt, Professor for Textual Sources of Judaism and Christianity, Faculty of Theology, Radbound University Nijmegen.

Dr. Christiane Zimmermann, Professorin für Theologie- und Literaturgeschichte des Neuen Testaments, Christian-Albrechts-Universität zu Kiel. 
Dr. Ruben Zimmermann, Professor am Seminar für Neues Testament, Evangelisch-Theologische Fakultät, Johannes Gutenberg-Universität Mainz. 


\section{Stellenregister}

\section{Altes Testament}

\begin{tabular}{|c|c|c|c|}
\hline \multicolumn{2}{|l|}{ Genesis } & 33,22 & 93 \\
\hline \multirow{2}{*}{1} & \multirow{2}{*}{$\begin{array}{l}10,24-25,28,29,51, \\
55\end{array}$} & 34,6 & 25,38 \\
\hline & & 34,17 & 3 \\
\hline 1,1 & $\begin{array}{l}53 \\
29,51,147\end{array}$ & 40 & 39 \\
\hline $1,1 \mathrm{LXX}$ & 68,264 & $40,34 \mathrm{f}$ & 93 \\
\hline $1,2-5$ & $\begin{array}{l}00,204 \\
24\end{array}$ & $40,34-35$ & 39 \\
\hline 2,7 & 92 & & \\
\hline 3 & 94 & \multirow{2}{*}{\multicolumn{2}{|c|}{ Levitikus }} \\
\hline 3,8 & 92 & & \\
\hline $6,9-13$ & 35 & $9,6.23$ & 93 \\
\hline $9,11-17$ & 35 & 19,4 & 3 \\
\hline 6,17 & 36 & & \\
\hline 17,17 & 166 & & \\
\hline 21,5 & 166 & Numeri & \\
\hline $22,2.12 .16$ & 237 & $12,8 \mathrm{LXX}$ & 54 \\
\hline $24,7.40$ & 106 & $14,10.21 \mathrm{f}$. & 93 \\
\hline \multirow[t]{2}{*}{$28,10-22$} & \multirow[t]{2}{*}{53} & 16,19 & 93 \\
\hline & & 16,22 & 36 \\
\hline \multirow{2}{*}{\multicolumn{2}{|c|}{ Exodus }} & 16,28 & 140 \\
\hline & & 17,7 & 93 \\
\hline 3,14 & 253 & 20,6 & 93 \\
\hline $3,14 \mathrm{LXX}$ & 44,253 & 20,16 & 106 \\
\hline 4,22 & 182 & 27,16 & 36 \\
\hline 7,1 & 50 & & \\
\hline 15,8 & 25 & \multirow{2}{*}{\multicolumn{2}{|c|}{ Deuteronomium }} \\
\hline 16,7 LXX & 54 & & \\
\hline $16,7.10$ & 93 & 1,31 & 182 \\
\hline $19,13.16 .19$ & 47 & 4 & 20,35 \\
\hline 19,19 & 47 & 4,4 & 92 \\
\hline $20,3-6$ & 20 & $4,12.15$ & 35 \\
\hline $20,4 \mathrm{f}$. & 3 & $4,15-19$ & 3 \\
\hline 20,18 & 47 & 4,35 & 149 \\
\hline $23,20-23$ & 106 & $5,7-10$ & 20 \\
\hline 24,15-18 LXX & 55 & 5,8 & 3 \\
\hline $24,16 \mathrm{f}$ & 93 & 5,24 & 54,93 \\
\hline $27,9-19$ & 91 & $5,24 \mathrm{LXX}$ & 54 \\
\hline 29,43 & 93 & 5,26 & 35 \\
\hline 32 & 21 & 6,4 & $37,149,237$ \\
\hline $32,2-6$ & 22 & $6,4 \mathrm{f}$. & 17,227 \\
\hline 32,34 & 106 & 6,6 & 20 \\
\hline 33,11 & 140 & $7,12 \mathrm{f}$. & 17,227 \\
\hline
\end{tabular}




$\begin{array}{ll}9,5.10 & 20 \\ 10,2-4 & 20 \\ 13,1 & 20 \\ 14,1 & 182 \\ 17,18-19 & 20 \\ 18,15-22 & 20 \\ 27,3.8 .26 & 20 \\ 28,58.69 & 20 \\ 29,8.18 .28 & 20 \\ 30,1.11-14 & 20 \\ 30,14 & 26 \\ 30,15 & 26 \\ 32 & 26,94 \\ 32,5.19 & 182 \\ 32,6 \text { b LXX } & 182 \\ 32,18-19 & 182 \\ 32,46 & 27 \\ 32,47 & 27 \\ 34,10 & 20\end{array}$

2 Chronik

4,9

91

Nehemia

$9,6 \quad 92$

$9,17 \quad 39$

$13,22 \quad 39$

Tobit

$3,15 \quad 65,175$

$6,10.14 \quad 65$

$8,17 \quad 65,175$

\section{Makkabäer}

11,6-8 106

\section{Josua}

3,13.16

Ijob

$\begin{array}{ll}1,6-12 & 106 \\ 2,1-6 & 106 \\ 12,10 & 36\end{array}$

Richter

11,34

1 Samuel

2,6

3,1

2 Samuel

2,6

1 Könige

6,36

17

19,5-7

$22,19-23$

2 Könige

22,19

24,2
65

167

20

25

91

20

106

106

256,265

20

\section{Psalmen}

$1 \quad 34$

$2 \quad 182$

$2,6-7 \quad 28$

$2,7 \quad 30,182$

2,7 LXX $\quad 182$

$2,7 \mathrm{~b}-\mathrm{c}$ LXX $\quad 182$

2,7-9 44

$16,11 \quad 92$

$17,15 b$ LXX $\quad 54$

19(18 LXX) 34

$21,5 \quad 92$

$21,21 \quad 65$

$23 \quad 44$

$25,10 \quad 25$

$27,1 \quad 270$

27,1 (26,1 LXX) 54

$33 \quad 10,25,26,28,31,34,41$

33(32 LXX) 26

$33,1-3 \quad 25$

$33,4 \quad 25,28$

$33,4-6 \quad 20$

$33,5 \quad 25$

$33,5 / 32,5 \quad 26$ 
$33,5.18 .22$

$\begin{array}{ll}(32,5.18 .22 \text { LXX) } & 26 \\ 33,6 & 25\end{array}$

$33,6.9 \quad 39$

33,6-9 25

33,16-17 26

$33,18 \quad 26$

34,17 LXX 65

$36,10 \quad 92$

40,11-12 25

51(50 LXX),3 26

$51,12-14 \quad 37$

$56 \quad 20,34$

56,4-5.11-12 34

62,2b LXX 54

$69,14.17 \quad 39$

$76,17-21 \quad 47$

$76,19 \quad 47$

$78,13 \quad 25$

$78,39 \quad 36$

$81,6 \operatorname{LXX}(82,6) \quad 49,86$

$85,11 \quad 25$

$86,5 \quad 39$

$86,15 \quad 38$

88,28 LXX $\quad 182$

94 LXX $\quad 86$

$103,8 \quad 39$

$105 \quad 20$

105-107 34

$106,12.24 \quad 20$

$106,23 \quad 20$

109 LXX $\quad 183$

109,3 c LXX $\quad 182$

$110 \quad 182,258$

110,3

$119 \quad 20,34,35$

119(118 LXX) 34

$119,105 \quad 35$

119,105-117 35

$119,107 \mathrm{~b} \quad 35$

119,119-120 35

$119,120 \quad 35$

$130,5 \quad 20,35$

$138,2 \quad 25$

142,10 LXX $\quad 140$

$147 \quad 20$

147,15-20 35

148
Sprichwörter

8

8,1

$10,27-32,55$

$8,1.12$

$8,1-21$

29

27

28

$8,3 \quad 30$

$8,3.34 \quad 30$

$8,4 \quad 29$

$8,4.31 \quad 29$

$8,5-21 \quad 29$

$8,7-8 \quad 28$

$8,8-9 \quad 28$

$8,21 \mathrm{a} \quad 29$

8,21a LXX 29

$8,22 \quad 29$

8,22 LXX 29

8,22-31 28

$8,23 \quad 28,29$

8,24-25 28, 30

$8,25 \mathrm{~b}$ LXX $\quad 182$

$8,27 \quad 32$

$8,27 \mathrm{~b} \quad 30$

8,27b LXX $\quad 30$

8,30-31 MT 30

8,30-31 LXX 30

8,34-35 LXX 30

$8,35 \quad 29,30$

8,35 LXX $\quad 30$

$8,36 \quad 28$

$10,19 \quad 19$

$11,13 \quad 19$

$12,6 \quad 19$

$16,20 \quad 19$

$19,14 \quad 30$

24,26

25,11

$31,8-9 \quad 33$

Kohelet

1,8

20

$3,15 \quad 20$

\section{Weisheit}

$1-10 \quad 31$

$1,1 \quad 31$

$1,1-15 \quad 31$

$1,6 \quad 32$

$1,12-15 \quad 32$

$1,14 \quad 33$ 


\begin{tabular}{|c|c|}
\hline 1,15 & 33 \\
\hline $2,12-18$ & 183 \\
\hline 3,3 & 39 \\
\hline 3,4 & 39 \\
\hline $3,9.13$ & 39 \\
\hline 4,15 & 39 \\
\hline 5,5 & 183 \\
\hline $6,1-21$ & 32 \\
\hline 7,22 & 57 \\
\hline $7,22-23$ & 32 \\
\hline $7,22-25$ & 39 \\
\hline $7,22-10,21$ & 32 \\
\hline $7,24-8,1$ & 32 \\
\hline 7,26 & 32,39 \\
\hline 8,1 & 32 \\
\hline $8,2-4$ & 32 \\
\hline 9 & $10,27,33,34$ \\
\hline 9,1 & 32 \\
\hline $9,1-3$ & 33,34 \\
\hline 9,4 & 32 \\
\hline 9,8 & 33 \\
\hline 9,9 & 33 \\
\hline 9,10 & 33 \\
\hline $9,10-11$ & 33 \\
\hline 9,11 & $33,139,140$ \\
\hline 9,17 & 33,140 \\
\hline $9,17-18$ & 33 \\
\hline 9,18 & 33 \\
\hline 10 & 33 \\
\hline $10,10.17$ & 140 \\
\hline 10,21 & 33 \\
\hline $11,24 \mathrm{f}$. & 270 \\
\hline 18,15 & 34 \\
\hline
\end{tabular}

\section{Jesus Sirach}

$\begin{array}{ll}4,10 & 183 \\ 18,9 & 166 \\ 24 & 39,40 \\ 24,3 & 39 \\ 24,3-12 & 55 \\ 24,4 & 39 \\ 24,7 & 39 \\ 24,8 & 39 \\ 24,8-11 & 33 \\ 24,10-11 & 39 \\ 45,1 & 36 \\ 45,23 & 20\end{array}$

\section{Jesaja}

$1,2 \quad 182$

$1,4 \quad 182$

$2,3 \quad 19$

$5,19 \quad 20$

$6 \quad 256$

6,1-9 265

$6,3 \quad 257$

$6,9 \mathrm{f} . \quad 165$

$6,9-13 \quad 83$

$9 \quad 10,24,25$

$9,1 \quad 24$

$29,15 \quad 20$

$30,1 \quad 20$

31,1-3 34

40-55 94

$\begin{array}{ll}40,8 & 19\end{array}$

$41,4 \quad 253$

41,17-20 26

41,23 LXX $\quad 142$

42,5-7 26

$43,1-7 \quad 26$

$43,6 \quad 182$

$43,10 \quad 253$

43,18f. LXX $\quad 193$

43,18b.19b $\quad 193$

$43,19 \quad 262$

43,19b $\quad 194$

43,19e.f $\quad 194$

44,1-5.24-28 26

$44,6 \quad 253$

$45,11 \quad 182$

45,23 LXX $\quad 151$

$48,12 \quad 253$

$48,19 \mathrm{a} \quad 193$

$50,4 \quad 19$

51,9-11 26

$52,15 \quad 165$

$53 \quad 91$

$55,11 \quad 19,27$

$53,12 \quad 237$

$62,4 \mathrm{f} . \quad 95$

$63,8.16 \quad 182$

\section{Jeremia}

$\begin{array}{ll}1,9 & 19 \\ 2-3 & 95 \\ 3,4 & 182 \\ 5,14 & 19 \\ 15,16 & 19 \\ 23,28-30 & 19\end{array}$


31,31-34

31,33

31,34

Klagelieder

3,32

Ezechiel

1,18

$1,26 \mathrm{f}$.

7,26

10,12

11

11,19

11,19-20

16

22,26

22,30

34

36

36-48

$36 \mathrm{f}$.

36,26

$36,26 \mathrm{~b}$

$36,26-28$

$36,27 \mathrm{a}$

37

37,6

37,8

40-48

43,11

43,12

$44,5.24$
39

38

38

235

256, 257, 265

257

257

38

257

$10,36,37,38,41$

37

36

228

38

20

38,86

$36,37,38,41,129$

261

10

37,238

129

36,37

129

$10,36,38$

36

36

38

38

38

38

\section{Daniel}

3,25

106

7

145,256

7,9

256, 265

7,13 LXX 256

10,12.20-21 $\quad 106$

10,18 LXX 256

$12,2 \quad 205$

\section{Hosea}

$2,1 \quad 182$

2,21-22 95

$4 \quad 94$

$5 \quad 94$

$12,2-14 \quad 94$

Joël

$2,13 \quad 39$

$3,1 \quad 36$

$3,2 \quad 36$

$3,3-5 \quad 36$

Amos

3,7

19

Jona

4,2

39

Micha

4,2

19

$6,1-8$

94

\section{Pseudepigraphen}

\section{Jubiläen}

$1,22-25$

4,26

182

189

1 Henoch / Äthiopischer Henoch (1 Hen)

14

$14,10 \mathrm{f} .13 .18$
257

256
17,1

18,8

24,4

32,4

72,1

4 Makkabäer (4 Makk)

15,3

205

256

257

256

256

189 
Psalmen Salomos (PsSal)

3,12

205
Testament Daniels

6,2

150

\section{Qumran}

1QpHab 2,9f. $\quad 141$

1QS

III,15

4Q299

32,1

44

44
69,3

44

4Q417

2,I,8

$4 \mathrm{Q} 418$

$43,55,5$
44

44

\section{Neues Testament}

\section{Matthäus}

$\begin{array}{ll}4,16 & 24 \\ 5,48 & 158\end{array}$

$6,33 \quad 205$

$8,22 \quad 169$

$10,20 \quad 128$

11,27

18,3

18,8

18,15

25,41

84

178

203

136

25,46

203

203, 240

\section{Markus}

$\begin{array}{ll}3,17 & 47 \\ 3,29 & 203 \\ 4,12 \text { parr. } & 165 \\ 10,15 & 178 \\ 13,11 & 130,133 \\ 16,8 \text { v.l. } & 203\end{array}$

\section{Lukas}

1,79

2,11

3,8

7,12

8,42

9,38

9,60

10,22
24

239

45

65

65

65

169

84
$12,11 \mathrm{f}$.

12,12

12,32

15,24

15,31

15,32

16,9

17,9

18,17

24,35

Johannes

1

1-12

1-13

1,1

$1,1 \mathrm{~b}$

$1,1 \mathrm{c}$

$1,1,14$

$1,1.14 .18$

$1,1 \mathrm{f}$.

1,1 f.14.17

$1,1.18$

$1,1-18$

1,2

$1,2.10$

1,3

$1,3.10$

1,4
130

133

205

169

140

169

203

178

67
$10,13,24,25,27,29$,

$31,34,36,41$

84

50

$20,51,54,68,69,73$, $74,82,86,98,105,108$, $120,175,217,264,267$

68

68

101

73

68

68

$12,76,98$

69

20

$20,54,175,217$

94,268

$16,172,215,217$ 


\begin{tabular}{|c|c|c|c|}
\hline $1,4-5$ & 20 & $3,1-20$ & 90 \\
\hline 1,5 & 48 & $3,1-21$ & 177 \\
\hline 1,6 & 51,127 & 3,2 & $52,177,178$ \\
\hline $1,6-8$ & 24 & 3,3 & $53,177,178,179,181$ \\
\hline 1,7 & 20 & $3,3.5$ & $53,68,116,269$ \\
\hline 1,9 & 88 & 3,4 & 176,179 \\
\hline $1,9-13$ & 21 & 3,5 & $53,1,77,178,179,180$ \\
\hline 1,10 & 176 & 3,6 & 180 \\
\hline 1,11 & 94 & $3,6-8$ & 156 \\
\hline \multirow[t]{2}{*}{1,12} & $18,50,68,75,84,156$ & 3,8 & $178,179,180$ \\
\hline & 157,179 & 3,13 & 88,179 \\
\hline $1,12 \mathrm{f}$. & 176,235 & 3,14 & 154,220 \\
\hline $1,12-13$ & $176,177,185$ & $3,15.16 .36$ & 203 \\
\hline \multirow[t]{2}{*}{1,13} & $174,175,176,179$ & $3,15-18$ & 16 \\
\hline & $180,181,186$ & 3,16 & $41,74,76,98,114$ \\
\hline \multirow[t]{4}{*}{1,14} & $10,12,21,27,33,35$ & & $127,129,155,220$ \\
\hline & $37,38,39,40,54,55$ & & 237,270 \\
\hline & $56,65,69,93,94,100$ & $3,16 a$ & 220 \\
\hline & $157,174,176,177,273$ & $3,16 b$ & 220 \\
\hline $1,14 \mathrm{~b}$ & 265 & $3,16 c$ & 220 \\
\hline $1,14.18$ & $32,65,75,174,175$ & $3,16 \mathrm{c} . \mathrm{d}$ & 220 \\
\hline 1,15 & 38 & $3,16 \mathrm{~d}$ & 220 \\
\hline 1,16 & 40 & $3,16 \mathrm{f}$ & 156 \\
\hline \multirow[t]{2}{*}{1,17} & $12,21,23,35,40,42$ & $3,16.18$ & 65 \\
\hline & $47,50,69,70,109$ & $3,16.35$ & 266,272 \\
\hline \multirow[t]{8}{*}{1,18} & $11,12,21,35,40,48$ & 3,17 & $88,127,129,220,221$, \\
\hline & $51,57,59,61,64,65$, & & 274 \\
\hline & $66,67,68,69,70,71$ & $3,17 \mathrm{a}$ & 221 \\
\hline & $73,74,76,77,78,82$ & $3,17 b$ & 221 \\
\hline & $100,105,106,107$ & $3,17 c$ & 221 \\
\hline & $108,109,110,173$ & $3,17 \mathrm{f}$. & 220,221 \\
\hline & $174,175,185,258$ & $3,17-19$ & 237 \\
\hline & $264,265,267,272$ & 3,18 & 273,274 \\
\hline $1,18 \mathrm{a}$ & 68 & $3,18 \mathrm{a}$ & 221 \\
\hline $1,18 \mathrm{~b}$ & 68 & $3,18 b$ & 221 \\
\hline 1,24 & 127 & $3,18 \mathrm{c}$ & 221 \\
\hline 1,29 & 52 & $3,18 \mathrm{f}$ & 95 \\
\hline $1,29.36$ & $68,91,257$ & 3,20 & 136 \\
\hline 1,31 & 49 & 3,21 & 49,142 \\
\hline 1,33 & 92 & 3,22 & 128 \\
\hline $1,34.49$ & 154 & 3,28 & 127 \\
\hline $1,35-51$ & 90 & 3,29 & 95 \\
\hline 1,36 & 50 & 3,31 & 88 \\
\hline 1,49 & $52,68,269$ & 3,32 & 112,174 \\
\hline 1,51 & 53 & 3,33 & 56 \\
\hline $2-4$ & 95 & 3,34 & $88,92,216$ \\
\hline 2,1 & 95 & $3,34 \mathrm{a}$ & 95 \\
\hline $2,7 \mathrm{f}$ & 90 & 3,35 & 90,216 \\
\hline 2,11 & $49,93,94$ & 3,36 & $16,215,221,222,274$ \\
\hline 2,21 & 55 & $3,36 \mathrm{a}$ & 222 \\
\hline 2,22 & 272 & $3,36 b$ & 222 \\
\hline 3 & $16,53,177,178$ & $3,36 c$ & 222 \\
\hline
\end{tabular}




\begin{tabular}{|c|c|c|c|}
\hline 4 & 172,269 & 5,42 & 236 \\
\hline $4,1-15$ & 190 & 5,43 & 117 \\
\hline $4,1-42$ & 90 & 5,44 & $76,236,264$ \\
\hline 4,11 & 219 & 6,3 & 128 \\
\hline $4,14,36$ & 203 & $6,10.12$ & 90 \\
\hline \multirow[t]{2}{*}{4,24} & $17,173,180,181,227$ & $6,16-20$ & 90,93 \\
\hline & 269 & 6,19 & 93 \\
\hline 4,25 & 142 & 6,20 & 93 \\
\hline 4,34 & $91,127,153,216$ & 6,27 & 56,115 \\
\hline 4,38 & 127 & $6,27.40 \cdot 47.54 \cdot 68$ & 203 \\
\hline 4,42 & 97,239 & 6,28 & 52,216 \\
\hline 5,16 & 83 & $6,29.52$ & 88 \\
\hline 5,17 & 87 & 6,32 & 127,129 \\
\hline $5,17 \mathrm{f}$. & 86 & $6,32-34$ & 113 \\
\hline $5,17-30$ & 9,115 & 6,35 & 77,114 \\
\hline $5,17.30 .36$ & 153 & $6,35.48$ & 172,215 \\
\hline 5,18 & $52,76,103,144$ & $6,35.48 .51$ & 113 \\
\hline 5,19 & 92,53 & 6,38 & $88,114,118,216$ \\
\hline $5,19.30$ & 112 & $6,38.39$ & 127 \\
\hline $5,19-23$ & 109 & $6,38-40$ & 153 \\
\hline 5,20 & 2,16 & $6,39 \mathrm{f}$ & 142 \\
\hline \multirow[t]{2}{*}{5,21} & $15,92,161,172,217$ & $6,39.40,44$ & 143 \\
\hline & 222 & 6,40 & 118 \\
\hline $5,21-23$ & 111 & $6,40.47 .54$ & 219 \\
\hline $5,21-24$ & 185 & $6,40.54$ & 223 \\
\hline 5,22 & $94,216,221$ & $6,41-44$ & 177 \\
\hline $5,22.26$ & 268 & 6,44 & 90,268 \\
\hline $5,22.27$ & 118 & $6,44.57$ & 153 \\
\hline 5,23 & 272 & 6,46 & $54,70,73,76$ \\
\hline \multirow[t]{2}{*}{5,24} & $16,172,173,179,181$ & 6,47 & 77 \\
\hline & $215,221,222,273$ & 6,51 & $88,114,237$ \\
\hline $5,24 \mathrm{a}$ & 222 & 6,53 & 219 \\
\hline $5,24 b$ & 222 & 6,57 & $113,114,153,172,264$ \\
\hline $5,24 \mathrm{c}$ & 222 & 6,62 & 88 \\
\hline $5,24 \mathrm{~d}$ & 222 & 6,63 & $15,92,161,173,181$ \\
\hline $5,24.30$ & 127 & $6,63 b$ & 215 \\
\hline $5,24.39$ & 203 & 6,66 & 56 \\
\hline \multirow[t]{2}{*}{5,26} & $16,153,172,215,217$ & 6,68 & 216,219 \\
\hline & 219,220 & 6,69 & 52,100 \\
\hline $5,26 a$ & 215 & 7,4 & 49 \\
\hline $5,26 b$ & $215,219,222$ & 7,8 & 90 \\
\hline $5,28 \mathrm{f}$. & $142,221,240$ & 7,10 & 49 \\
\hline 5,29 & $143,215,217,274$ & $7,14-16$ & 118 \\
\hline 5,30 & 153,216 & $7,16.18 .33$ & 127 \\
\hline $5,31 \cdot 32 \cdot 36.37 .39$ & 132 & $7,16-17$ & 118 \\
\hline 5,33 & 127 & $7,16-18$ & 117 \\
\hline 5,35 & 48 & $7,17.28$ & 153 \\
\hline 5,36 & $88,91,216$ & 7,18 & 117 \\
\hline $5,36 \mathrm{f}$. & 153 & 7,20 & 103,108 \\
\hline 5,37 & $70,73,115,268$ & $7,28 \mathrm{f}$. & 88 \\
\hline $5,37 \mathrm{f}$. & 265 & 7,33 & 128 \\
\hline $5,39.45$ & 265 & 7,39 & 129 \\
\hline
\end{tabular}




\begin{tabular}{|c|c|c|c|}
\hline 8 & 58 & $10,17 \mathrm{f}$ & 237 \\
\hline \multirow[t]{2}{*}{8,12} & $77,113,114,215,219$ & $10,17-18$ & 111,114 \\
\hline & 270 & $10,17-21$ & 103 \\
\hline 8,16 & 118 & 10,18 & 219 \\
\hline $8,16.18$ & 153 & 10,20 & 103 \\
\hline 8,18 & 119 & 10,21 & 103,108 \\
\hline 8,19 & 84,155 & 10,22 & 91 \\
\hline $8,21-59$ & 9 & $10,22-29$ & 57 \\
\hline $8,26.29$ & 127 & $10,22-31$ & 85 \\
\hline 8,28 & $119,153,154$ & $10,22-42$ & 85 \\
\hline $8,28-29$ & 117 & 10,24 & 85 \\
\hline $8,31-59$ & 46 & 10,25 & 216 \\
\hline 8,33 & 265 & $10,25 \cdot 32.37 \mathrm{f}$. & 216 \\
\hline 8,38 & 153 & $10,27-30$ & 113 \\
\hline $8,38.42$ & 153 & 10,28 & 203 \\
\hline $8,41 \mathrm{f}$. & 156 & $10,28 \mathrm{f}$ & 90 \\
\hline 8,42 & 88 & $10,28-30$ & 107,112 \\
\hline 8,44 & 108 & 10,29 & $85,117,153,154,155$ \\
\hline 8,46 & 136 & 10,30 & $12,73,74,77,85,86$ \\
\hline $8,48.52$ & 103 & & $89,98,108,111,117$ \\
\hline $8,48-52$ & 103 & & $155,264,267,272$ \\
\hline 8,51 & 172 & $10,30.38$ & 86 \\
\hline 8,54 & $55,94,98$ & 10,31 & 86 \\
\hline 8,55 & 73 & $10,31-39$ & 115,118 \\
\hline $8,56-58$ & 46 & 10,32 & 86 \\
\hline 8,58 & 120 & $10,32.37$ & 92 \\
\hline 9,3 & 49 & $10,32-42$ & 85 \\
\hline $9,3 \mathrm{f}$. & 216 & 10,33 & $86,103,144$ \\
\hline 9,4 & 153 & $10,33.36$ & 76 \\
\hline 9,16 & 108 & 10,34 & 49 \\
\hline $9,24-34$ & 108 & $10,34 \mathrm{f}$. & 86 \\
\hline 9,29 & 264 & $10,34.35$ & 50 \\
\hline $9,29 \mathrm{f}$. & 265 & 10,35 & 264 \\
\hline 9,33 & 53 & 10,36 & $55,88,100,103112$ \\
\hline 9,39 & 88,94 & & $119,103,153$ \\
\hline $9,39-10,6$ & 85 & $10,37 \mathrm{f}$. & 153 \\
\hline $9,39-10,21$ & 85 & 10,38 & $87,154,267$ \\
\hline 10 & $57,89,90$ & 11,4 & 94 \\
\hline $10,1-18$ & 85 & $11,4.40$ & 98 \\
\hline $10,1-21$ & 57 & 11,22 & 53 \\
\hline 10,3 & 85 & 11,25 & $77,113,172,215,217$ \\
\hline $10,7.9$ & 77,113 & $11,25 \mathrm{f}$. & 273 \\
\hline $10,7.9 \cdot 11.14$ & 85 & 11,26 & 172 \\
\hline $10,7-21$ & 85 & $11,40-42$ & 113 \\
\hline 10,10 & $91,92,215,219$ & 11,42 & 88,129 \\
\hline $10,10.28$ & 90 & 11,43 & 51 \\
\hline $10,11.14$ & 77,113 & 11,52 & $52,156,181$ \\
\hline $10,11.14 \mathrm{f}$. & 155 & 11,54 & 128 \\
\hline $10,11.15$ & 237 & 12 & 94 \\
\hline $10,14-15.17-18$ & 113 & $12,12-26$ & 47 \\
\hline 10,15 & 98,153 & 12,16 & 271 \\
\hline 10,17 & 98,155 & 12,20 & 47 \\
\hline
\end{tabular}




\begin{tabular}{|c|c|c|c|}
\hline $12,20-27.32-44$ & 90 & $14,6.7 .9$ & 74 \\
\hline 12,24 & 119 & $14,6 b .7 .9$ & $12,73,77$ \\
\hline $12,24 \mathrm{f}$. & 100 & $14,6-24$ & 109 \\
\hline 12,25 & 117 & 14,7 & $83,84,110,113$ \\
\hline $12,25.50$ & 203 & $14,7.9$ & 265,267 \\
\hline $12,27-36$ & 47 & $14,8 \mathrm{f}$. & 83 \\
\hline 12,28 & $47,94,98,119$ & $14,8-10$ & 112 \\
\hline 12,29 & 47,107 & 14,9 & $4,11,54,70,74,77,84$ \\
\hline 12,31 & $107,108,129$ & & 100,155 \\
\hline $12,32.34$ & 154 & $14,9.30$ & 128 \\
\hline 12,35 & 95 & $14,9-11$ & 110 \\
\hline 12,36 & 48 & 14,10 & $111,113,118,153,267$ \\
\hline $12,44-45$ & 118 & $14,10 \mathrm{f}$. & 154,216 \\
\hline $12,44-46$ & 113,114 & $14,10.12$ & 153 \\
\hline 12,45 & 83 & $14,10-11$ & $108,109,111$ \\
\hline 12,46 & 88 & 14,11 & $84,92,178$ \\
\hline 12,48 & 143 & $14,12-14$ & 125,128 \\
\hline 12,49 & $98,118,153,216$ & 14,13 & 94 \\
\hline $12,49-50$ & 112 & $14,13-17$ & 126 \\
\hline 12,50 & $114,118,153,216$ & 14,15 & 128 \\
\hline 13 & 90,95 & $14,15.21 .23$ & 155 \\
\hline $13-16$ & 90 & $14,15.21 .23$ f.28 & 155 \\
\hline $13-17$ & 125,126 & $14,15-19$ & 239 \\
\hline $13,1-17$ & 157 & $14,15-20.22 .25$ & 133 \\
\hline 13,3 & $50,51,115,179$ & $14,15-24$ & 239 \\
\hline $13,3-19$ & 90 & $14,15-26$ & 126,128 \\
\hline 13,16 & 118,127 & 14,16 & $115,127,128,132$ \\
\hline 13,20 & 118 & $14,16 \mathrm{a}$ & 128 \\
\hline 13,23 & 65,100 & $14,16 \mathrm{~b}$ & 128,129 \\
\hline 13,27 & 248 & $14,16 \mathrm{c}$ & 128,129 \\
\hline 13,31 & 55,119 & $14,16 f$ & $14,128,129$ \\
\hline $13,31 \mathrm{f}$. & 94 & $14,16-17$ & 127 \\
\hline $13,31-38$ & 126 & $14,16-17.26$ & 83 \\
\hline $13,31-14,31$ & $124,125,126$ & $14,17 \mathrm{a}$ & 128,135 \\
\hline $13,31-17,26$ & 124,126 & $14,17 \mathrm{~b}$ & 128 \\
\hline 13,32 & 50,55 & $14,17 \mathrm{c}$ & 128 \\
\hline 13,33 & 128 & $14,17 \mathrm{~d}$ & 128 \\
\hline 13,34 & 74 & $14,17 \mathrm{e}$ & 128 \\
\hline $13,34 \mathrm{f}$. & 241 & $14,17 \mathrm{f}$ & 128,129 \\
\hline 14 & $110,131,132,133,134$ & $14,17 \mathrm{~g}$ & 128,129 \\
\hline $14-15.16$ & 143 & 14,18 & 129 \\
\hline $14-16$ & 53 & $14,18 \mathrm{f}$. & 239 \\
\hline $14-21$ & 50 & 14,20 & 155 \\
\hline 14,1 & 50,272 & $14,21.23$ & 155 \\
\hline $14,1-4$ & 110 & $14,21.23 \mathrm{f}$. & 134 \\
\hline $14,1-26$ & 126 & $14,21.24$ & 129 \\
\hline $14,2 \mathrm{f}$ & 126,128 & $14,21-23$ & 155 \\
\hline 14,3 & 273 & 14,23 & 129 \\
\hline 14,5 & 110 & 14,24 & 117 \\
\hline \multirow[t]{2}{*}{14,6} & $74,77,110,113,139$ & $14,25 \mathrm{f}$ & $14,127,130,132$ \\
\hline & $172,185,215,217,267$ & $14,25 \mathrm{a} / 26 \mathrm{f}$ & 130 \\
\hline $14,6 f$. & 60 & $14,25 a$ & 130 \\
\hline
\end{tabular}




\begin{tabular}{|c|c|c|c|}
\hline $14,25 b$ & 130 & $15,27 \mathrm{a}$ & 131 \\
\hline 14,26 & $126,129,132,265,271$ & $15,27 \mathrm{~b}$ & 131,133 \\
\hline $14,26 a$ & 130 & 16 & 134 \\
\hline $14,26 a-c$ & 135 & $16,1-4$ & 141 \\
\hline $14,26 \mathrm{~b}$ & 130 & 16,2 & 53 \\
\hline $14,26 c$ & 130 & 16,3 & 53 \\
\hline $14,26 \mathrm{~d}$ & 130,132 & 16,4 & 128,133 \\
\hline $14,26 \mathrm{e}$ & 130 & $16,4 \mathrm{e}$ & 134 \\
\hline $14,26 \mathrm{f}$ & 130 & $16,4 \mathrm{e} . \mathrm{f}$ & 141 \\
\hline 14,27 & 130 & $16,4 \mathrm{e}-15$ & 134 \\
\hline $14,27-31$ & 126 & $16,5 \mathrm{f}$ & 135 \\
\hline \multirow[t]{2}{*}{14,28} & $98,131,144,148,153$ & $16,5-7$ & 134 \\
\hline & 268 & 16,7 & 135 \\
\hline 14,30 & $107,108,129,130$ & $16,7 \mathrm{e}$ & 139 \\
\hline 14,31 & $108,119,126,155$ & $16,7.13$ & 83 \\
\hline 15 & 134 & $16,7-11$ & 127,135 \\
\hline $15-16$ & 125,145 & $16,8 b-d$ & 136 \\
\hline 15,1 & 76 & $16,8-11$ & $14,134,135$ \\
\hline $15,1.5$ & $77,78,113$ & $16,9-11$ & 136 \\
\hline $15,1-11$ & 134 & $16,10 \mathrm{a}$ & 135 \\
\hline $15,1-17$ & 131 & $16,10 \mathrm{~b}$ & 135 \\
\hline $15,1-16,4 d$ & 134 & $16,10 \mathrm{c}$ & 135 \\
\hline $15,4-7.9$ f. 16 & 131 & 16,11 & 129 \\
\hline $15,5-6$ & 177 & 16,12 & 136,139 \\
\hline 15,6 & 274 & $16,12 \mathrm{ff}$. & 142 \\
\hline $15,7-10$ & 113 & $16,12-15$ & $127,136,156$ \\
\hline 15,8 & $94,107,119,179$ & $16,[12] 13-15$ & 14,136 \\
\hline 15,9 & 100,155 & 16,13 & $137,138,139,224$ \\
\hline $15,9-17$ & 115 & $16,13 c$ & 137,138 \\
\hline 15,10 & 98,155 & 16,13 c.e & 130,139 \\
\hline 15,12 & 74 & $16,13 \mathrm{c} . \mathrm{g}$ & 139 \\
\hline $15,12-17$ & 241 & $16,13 d$ & 140 \\
\hline 15,13 & $119,155,219,270$ & $16,13 d-f$ & 139,140 \\
\hline $15,13-15$ & 156 & $16,13 \mathrm{e}$ & 137,138 \\
\hline 15,15 & 140,153 & $16,13 e . f$ & 139 \\
\hline $15,16.19$ & 90 & $16,13 \mathrm{~g}$ & 141,143 \\
\hline 15,18 & 131 & $16,13 \mathrm{f}$. & 142 \\
\hline $15,18-25$ & 131,141 & $16,13-15$ & 135,265 \\
\hline 15,19 & 181 & 16,14 & 94,140 \\
\hline 15,20 & 133 & $16,14 a$ & 136 \\
\hline 15,24 & 153,216 & $16,14 b$ & 136 \\
\hline 15,26 & $83,92,134$ & $16,14 \mathrm{c}$ & 136 \\
\hline $15,26 a$ & 131 & $16,14 c .15 \mathrm{e}$ & 139 \\
\hline $15,26 a-d$ & 132 & $16,14 \mathrm{f}$. & 139,266 \\
\hline $15,26 b$ & 131,132 & 16,15 & 219 \\
\hline $15,25 \mathrm{~b} . \mathrm{d}$ & 132 & $16,15 a$ & 136 \\
\hline $15,26 c$ & 131,135 & $16,15 a \cdot b$ & 140,144 \\
\hline $15,26 \mathrm{~d}$ & 131.132 & $16,15 b$ & 136 \\
\hline $15,26 \mathrm{e}$ & $131,133,135$ & $16,15 c$ & 136 \\
\hline $15,26 e-27$ & 132 & $16,15 d$ & 136 \\
\hline $15,26 \mathrm{f}$. & $14,127,131,133$ & $16,15 \mathrm{e}$ & 136 \\
\hline 15,27 & 128,133 & 16,16 & 134 \\
\hline
\end{tabular}




\begin{tabular}{|c|c|c|c|}
\hline $16,16-24$ & 134 & 18,4 & 141 \\
\hline 16,20 & 134 & 18,9 & 90 \\
\hline $16,23 \mathrm{~b} .24$ & 156 & 18,15 & 91 \\
\hline $16,23 \mathrm{f}$ & 83 & $18,28-19,16$ & 269 \\
\hline 16,25 & 60 & 18,36 & 260 \\
\hline $16,25 \mathrm{f}$. & 132 & $18,36 \mathrm{f}$ & 269 \\
\hline $16,25-33$ & 134 & $18,36-37$ & 116 \\
\hline 16,27 & 155 & 18,37 & $88,175,269$ \\
\hline $16,27-28$ & 179 & $19,1-34$ & 91 \\
\hline 16,28 & 88 & 19,5 & 97 \\
\hline 17 & $49,120,145$ & 19,7 & $76,103,144$ \\
\hline 17,1 & 107 & 19,10 & 219 \\
\hline $17,1.4$ & 119 & 19,11 & 91 \\
\hline $17,1.5$ & 119 & 19,17 & 86 \\
\hline $17,1.5 .22 .24$ & 94 & $19,24.28 .36$ & 91 \\
\hline 17,2 & $16,115,216,217,268$ & $19,26 \mathrm{f}$ & 100 \\
\hline $17,2 b$ & 216 & 19,30 & 91,92 \\
\hline $17,2 b^{\prime}$ & 216 & 19,36 & 91 \\
\hline $17,2 \mathrm{c}$ & 216 & $20,12-13$ & 107 \\
\hline $17,2 c^{\prime}$ & 216 & 20,17 & $18,88,98,115,120$ \\
\hline $17,2.3$ & 203 & & $156,177,267$ \\
\hline $17,2 \mathrm{ff}$. & 155 & 20,21 & $88,100,127$ \\
\hline 17,3 & $60,76,98,223,224$ & 20,22 & 92 \\
\hline & 264 & $20,24-29$ & 9 \\
\hline $17,3 \mathrm{a}$ & 223 & 20,28 & $11,12,53,70,98,108$ \\
\hline $17,3 b$ & 223 & & 155 \\
\hline $17,3 \mathrm{c}$ & 223 & $20,28-31$ & 45 \\
\hline $17,3.8 \cdot 18.21 .23 .25$ & 88 & $20,30 \mathrm{f}$. & 274 \\
\hline 17,4 & $91,94,153,216$ & 20,31 & 101,219 \\
\hline 17,5 & $94,98,120,219$ & $21,1-2$ & 49 \\
\hline 17,6 & 49,60 & $21,15-19$ & 100 \\
\hline $17,6.9$ & 90,115 & $21,22 \mathrm{f}$. & 142 \\
\hline $17,6.14$ & 116 & & \\
\hline 17,8 & 88,216 & \multirow{2}{*}{\multicolumn{2}{|c|}{ Apostelgeschichte }} \\
\hline $17,8.25$ & 153 & & \\
\hline 17,9 & 83 & 2,20 & 48 \\
\hline 17,10 & 140 & 5,31 & 239 \\
\hline $17,11-21$ & 108 & $5,32 \mathrm{a} . \mathrm{b}$ & 133 \\
\hline 17,12 & 128 & 10,8 & 67 \\
\hline $17,12.26$ & 115 & 13,23 & 239 \\
\hline 17,17 & 100 & $15,12,14$ & 67 \\
\hline 17,18 & 100 & 17,28 & 182 \\
\hline 17,19 & 119 & 21,19 & 67 \\
\hline 17,21 & $\begin{array}{l}13,81,99,154,178 \\
223\end{array}$ & 27,20 & 48 \\
\hline 17,22 & 98 & \multirow{2}{*}{\multicolumn{2}{|c|}{ Römer }} \\
\hline 17,23 & 155,223 & & \\
\hline $17,23-26$ & 155 & 1,7 & 209 \\
\hline 17,24 & $120,128,267,268$ & 1,13 & 208 \\
\hline & 272,273 & 1,18 & 204,208 \\
\hline 17,26 & 155 & $1,18-3,20$ & 207 \\
\hline $18,1-11$ & 49,53 & 1,20 & 192 \\
\hline
\end{tabular}




\begin{tabular}{|c|c|c|c|}
\hline $2,1-16$ & 203 & $6,3-11$ & 169 \\
\hline 2,6 & 204 & 6,4 & $170,171,210$ \\
\hline $2,6 f$. & $204,205,207$ & $6,4 b-c$ & 170 \\
\hline $2,6-11$ & 203 & 6,7 & 162 \\
\hline 2,7 & $16,171,203,204,214$ & $6,8-11$ & 171 \\
\hline $2,7.10$ & 204 & 6,9 & 170 \\
\hline 2,8 & 204 & 6,11 & 169,170 \\
\hline 2,9 & 204 & 6,12 & 170 \\
\hline 2,10 & 204,205 & $6,12 \mathrm{f}$ & 169 \\
\hline 2,11 & 204 & $6,12-13$ & 169,170 \\
\hline 3,21 & 207 & 6,13 & $169,170,71$ \\
\hline 3,24 & 206 & 6,17 & 208 \\
\hline 3,26 & 152 & 6,18 & 208 \\
\hline 3,25 & 237 & $6,18.22 \mathrm{a}$ & 208 \\
\hline 3,28 & 162 & $6,19.22$ & 209 \\
\hline 4,17 & $15,161,165,166$ & 6,22 & 208,209 \\
\hline 168 & & $6,22 a$ & 208,209 \\
\hline $4,17 \mathrm{a}$ & 166 & $6,22 b$ & 208,209 \\
\hline $4,17 \mathrm{~b}$ & 166 & $6,22 \mathrm{f}$ & $16,171,203,208,214$ \\
\hline $4,17-19$ & 167 & 6,23 & 209 \\
\hline 4,18 & 166 & $6,23 a$ & 208,210 \\
\hline $4,18-22$ & 166 & $6,23 b$ & $208,209,210$ \\
\hline 4,19 & 166,167 & 7,10 & 171 \\
\hline 4,24 & 166,167 & $8,2.6 .10$ & 171 \\
\hline $4,24 \mathrm{c}$ & 167 & 8,4 & 205 \\
\hline $5,1-11$ & $205,206,207$ & $8,5-17$ & 167 \\
\hline $5,1-21$ & 207 & $8,6 \mathrm{a}$ & 167 \\
\hline 5,1 & 206 & $8,6 b$ & 167 \\
\hline 5,5 & $228,229,230,238$ & 8,9 & 167,168 \\
\hline 5,8 & 206,270 & 8,10 & $168,169,173$ \\
\hline 5,9 & 205,206 & $8,10-11$ & 170 \\
\hline 5,10 & 206 & 8,11 & $15,161,165,167,168$, \\
\hline $5,10.17$ f. 21 & 171 & & 169,170 \\
\hline 5,11 & 206,207 & 8,15 & $152,184,233$ \\
\hline $5,12-21$ & $205,206,209$ & 8,17 & 152 \\
\hline 5,15 & 207 & $8,18-25$ & 209 \\
\hline 5,16 & 206 & 8,22 & 184 \\
\hline 5,18 & 206 & 8,31 & 150 \\
\hline 5,19 & 206 & $8,31-39$ & 152 \\
\hline 5,20 & 207 & 8,34 & 128 \\
\hline 5,21 & $16,203,205,206,207$ & 8,38 & 171 \\
\hline & 214 & 11,15 & 171 \\
\hline $5,21 \mathrm{a}$ & 206,207 & 11,36 & 195 \\
\hline $5,21 \mathrm{a} \cdot \mathrm{a}^{\prime}$ & 207 & 12,1 & 171 \\
\hline $5,21 a^{\prime}$ & 206,207 & 13,4 & 240 \\
\hline $5,21 \mathrm{~b}$ & 206,207 & 15,4 & 169 \\
\hline $5,21 \mathrm{~b} / 21 \mathrm{a}^{\prime}$ & 206 & 15,21 & 165 \\
\hline & 210 & & \\
\hline 6,2 & 169 & \multirow{2}{*}{\multicolumn{2}{|c|}{1 Korinther }} \\
\hline 6,3 & 169 & & \\
\hline $6,3 \mathrm{f}$. & 195 & 7,17 & 163 \\
\hline $6,3-4$ & 170 & $7,17-24$ & 163 \\
\hline
\end{tabular}




$\begin{array}{ll}8,4 & 149 \\ 8,5 & 264 \\ 8,6 & 149,151,194 \\ 11,3 & 149 \\ 11,12 & 194, \\ 11,24 \mathrm{f} . & 169 \\ 12,4-31 & 152 \\ 14,24 & 136 \\ 15,1-49 & 209 \\ 15,16.20 .22 & 162 \\ 15,20.23 & 175 \\ 15,21 & 164 \\ 15,22 & 15,164,165,166,168 \\ 15,22.36 & 161 \\ 15,23 & 164 \\ 15,23-28 & 149 \\ 15,28 & 149,252 \\ 15,44 & 170 \\ 15,45 & 161 \\ 15,51-57 & 209\end{array}$

5,17

$5,17 \mathrm{a}$

$5,17 a^{\prime}$

5,17a.a'

$5,17 \mathrm{a}-\mathrm{a}^{\prime}$

$5,17 \mathrm{a} . \mathrm{b}$

$5,17 \mathrm{~b}$

$5,17 \mathrm{c}$

5,17 c.e

$5,17 \mathrm{c}-\mathrm{e}$

$5,17 \mathrm{~d}$

$5,17 \mathrm{e}$

$5,17 \mathrm{f}$

5,17-19

$5,17.21$

5,18

$5,18 \mathrm{a}$

$5,18 \mathrm{~b}$

$5,18 \mathrm{~b} .19 \mathrm{a}$

$5,18 \mathrm{c}$

$5,18 \mathrm{f}$.

5,19

$5,19 \mathrm{a}$

$5,19 \mathrm{~b}$

$5,19 \mathrm{c}$

5,21

6,16

8,9

13,11

13,13

Galater

$\begin{array}{ll}1,1 & 201 \\ 1,3 \mathrm{a} & 201,202 \\ 1,3 \mathrm{~b} & 201,202 \\ 1,3 \mathrm{~b} . \mathrm{c} & 202 \\ 1,3 \mathrm{c} . & 201,202 \\ 1,3 \mathrm{f} . & 200,201 \\ 1,4 \mathrm{a} & 201,202 \\ 4, \mathrm{a} . \mathrm{b} & 202 \\ 1,4 \mathrm{~b} & 201.202 \\ 1,4 \mathrm{c} & 201,202 \\ 1,6 & 212 \\ 1,15 & 212 \\ 2,16 & 162 \\ 2,19 & 171,195,200 \\ 2,19-20 & 171 \\ 2,20 & 200 \\ 3,13 & 152 \\ 3,19 \mathrm{f} . & 15,149,152\end{array}$

$15,149,152$
$16,187,188,189,190$, $191,193,194,196$ 190, 191, 192, 195, 190

190

190

191

190, 191, 192, 193, 195

191

192, 193, 195

190,193

191, 192, 193

191,193

200

190

189

191

191, 194, 195, 196, 197

197, 198

198

197

197, 198

150

197,198

197,198

197

152

191

152

228

228

$4,6 \quad 191$

$4,17 \quad 203$

$5,1 \quad 203$

$5,1-10 \quad 209$

5,11-6,2 197

$5,14 \quad 194$

$5,14 \mathrm{a} \quad 197$

$5,14 \mathrm{c} \quad 195$

5,14c.d $\quad 195$

$5,14 \mathrm{~d} \quad 195$

5,14f. $\quad 195$

5,14-16 $\quad 195$

5,14-17 $\quad 196,197,198$

5,15

$5,15 \mathrm{a}$

$5,15 \mathrm{~b}$

$5,15 \mathrm{~b} . \mathrm{c}$

$168,169,197$

195

195,196

195

$5,15 \mathrm{c}$

195

5,16

196

$5,16 \mathrm{a}$

196

196 


\begin{tabular}{|c|c|c|c|}
\hline 3,21 & $161,165,168$ & Epheser & \\
\hline $3,23-4,11$ & 184 & $1,7.14$ & 237 \\
\hline 3,27 & 171, & 5,23 & 239 \\
\hline 3,28 & 189 & & \\
\hline $\begin{array}{l}4,4 \\
4,5\end{array}$ & $\begin{array}{l}184,200 \\
171\end{array}$ & \multirow{2}{*}{\multicolumn{2}{|c|}{ Philipper }} \\
\hline $\begin{array}{l}4,5 \\
4,6\end{array}$ & $\begin{array}{l}171 \\
184\end{array}$ & & \\
\hline 4,7 & 152 & $2,6-11$ & 15,151 \\
\hline 4,12 & 211 & 2,8 & 149 \\
\hline 4,21 & 211 & 2,9 & 151 \\
\hline 4,26 & 180 & $2,9-11$ & 209 \\
\hline 5,1 & 211 & 3,11 & 209 \\
\hline $5,1 \mathrm{a}$ & 212 & 3,14 & 180 \\
\hline $5,1-6,10$ & 211 & 3,20 & 239 \\
\hline 5,2 & 211 & $3,20 \mathrm{f}$. & 152,209 \\
\hline 5,5 & 199 & 4,13 & 152 \\
\hline $5,5 \mathrm{f}$. & 198 & & \\
\hline 5,6 & 199 & \multirow{2}{*}{\multicolumn{2}{|c|}{ Kolosser }} \\
\hline $5,6 a$ & 199 & & \\
\hline $5,6 \mathrm{~b}$ & 199 & 1,15 & 4 \\
\hline $5,6 \mathrm{c}$ & 199 & $1,18 \mathrm{c}$ & 175 \\
\hline 5,7 & 211 & 3,1 & 205 \\
\hline 5,13 & 211 & $3,1 \mathrm{f}$. & 180 \\
\hline $5,13 a$ & 212 & & \\
\hline $5,13 \mathrm{f}$ & 212 & & \\
\hline $5,13-6,10$ & 211 & \multicolumn{2}{|c|}{1 Thessalonicher } \\
\hline $5,19-21$ & 213 & $4,13-18$ & 209 \\
\hline 5,21 & 213 & $5,1-10$ & 209 \\
\hline $5,22 \mathrm{f}$. & 212 & 5,10 & 152 \\
\hline $\begin{array}{l}6,7 \\
6,7-10\end{array}$ & 211,213 & & \\
\hline $6,7-10$ & $210,211,213$ & & \\
\hline $\begin{array}{l}6,8 \\
6,8 a\end{array}$ & $\begin{array}{l}16,203,210,211,214 \\
211,213\end{array}$ & \multicolumn{2}{|c|}{2 Thessalonicher } \\
\hline $6,8 b$ & 211,213 & 2,8 & 48 \\
\hline $6,11-18$ & 198 & & \\
\hline 6,13 & 200 & \multirow{2}{*}{\multicolumn{2}{|c|}{1 Timotheus }} \\
\hline 6,14 & $199,200,201$ & & \\
\hline $6,14 a$ & 199 & 5,6 & 170 \\
\hline $6,14 b$ & 199,200 & 5,20 & 136 \\
\hline $6,14 \mathrm{c}$ & 199,200 & 6,14 & 48 \\
\hline $6,14 \mathrm{f}$. & 199 & & \\
\hline $6,14-15$ & 190 & & \\
\hline 6,15 & $\begin{array}{l}16,171,188,189,190 \\
198,199,200,201\end{array}$ & \multicolumn{2}{|l|}{2 Timotheus } \\
\hline $6,15 a$ & 199,200 & $1,9-10$ & 48 \\
\hline $6,15 b$ & 199 & 1,10 & 239 \\
\hline $6,15 c$ & 199 & & \\
\hline \multirow[t]{4}{*}{$6,15-16$} & 190 & \multicolumn{2}{|l|}{ Titus } \\
\hline & & 1,4 & 239 \\
\hline & & 2,13 & 239 \\
\hline & & 3,6 & 239 \\
\hline
\end{tabular}




\section{Hebräer}

1,6

6,1

7,25

9,14

11,17

Jakobus

1,17

2,9

2,17.26

3,17

1 Petrus

3,18

\section{Petrus}

\section{$1,1,11$}

2,20

$3,2.18$

3,13

\section{Johannes}

1,1

1,2

$1,2 \mathrm{a}$

$1,2 \mathrm{~b}$

$1,2 \mathrm{c}$

$1,2 \mathrm{~d}$

$1,2 \mathrm{e}$

$1,2 \mathrm{f}$

1,5

$1,5-2,2$

$1,5-2,27$

1,6

$1,20 \mathrm{~g}$

2,1

2,2

2,3

2,3-11

2,5

2,7

$2,7 \mathrm{f}$.

$2,9.11$

2,12-27
175

169

128

169

65

180

136

169

180

161

239

239

239

261

218

231

$16,203,218,219,236$

218

218

218

218, 2,19

218

218

$17,114,227,230,270$

232

231, 235

142,241

222

$123,127,128$

237

235

232, 233, 241

236, 238

235

241

241

232
2,18-23

2,23

2,25

2,28

$2,28 \mathrm{f}$.

2,29

$2,28-3,10$

$2,28-4,6$

2,29

3-5

3,1.2.10

3,2

3,9

3,11-24

3,14

3,15

3,18

3,21

3,23

3,24

4

4,1

4,1-6

4,6

4,7

$4,7 \mathrm{f}$.

4,7-20

$4,7-21$

$4,7-5,13$

4,8

$4,8.16$

$4,8-10$

$4,8-16$

4,9

4,9-13

4,9-18

4,10

4,10-12

4,10-16

4,11

4,12

4,13

$4,13.15$

4,13-16

4,14

4,15

4,16

4,17
142

219

203, 219

231, 240

240

173,240

232

231,235

235

181

156,273

240

173,235

232, 233, 241

172

203, 241

236

240

241

159

246

235

142,232

235

$173,230,234$

$232,235,239,240,242$

241

$232,233,240$

231

$17,156,229,230,231$, 239, 242

$17,95,227,230,232$, $235,242,246,270$

156

74

$65,232,233,236,237$, $239,240,270$

157

233

$233,239,240,241$

232, 237

232, 237

234

234

$233,238,2,39240$

159

$232,238,239,242$

156,239

239

159, 219, 230, 233, 239,240

240 


\begin{tabular}{|c|c|c|c|}
\hline $4,17 \mathrm{f}$. & $233,238,239$ & 4 & 256,258 \\
\hline $4,17-18$ & 233 & $4-5$ & 255,257 \\
\hline 4,18 & 154 & $4,1 \mathrm{f}$. & 255 \\
\hline $4,18 \mathrm{f}$. & 158,239 & $4,1-22,6$ & 250 \\
\hline 4,19 & 234,243 & 4,2 & 255 \\
\hline $4,19 \mathrm{f}$. & 234 & $4,2.9 .10$ & 256 \\
\hline $4,19-21$ & $233,234,236,239,240$ & 4,3 & $255,256,257$ \\
\hline 4,21 & 233,241 & $4,3.6 .7$ & 256 \\
\hline 4,23 & 239 & 4,4 & 256 \\
\hline $5,1.4 .18$ & 173 & 4,5 & 47 \\
\hline $5,11.13 .20$ & 203 & $4,5 \mathrm{f}$. & 256 \\
\hline $5,1-8$ & & 4,6 & 257 \\
\hline $5,1-13$ & 232 & $4,6 \mathrm{f}$. & 256 \\
\hline $5,1-18$ & 156 & 4,7 & 256 \\
\hline 5,3 & 236 & 4,8 & 253,257 \\
\hline 5,12 & $16,219,267$ & $4,8 \mathrm{~b}$ & 257 \\
\hline 5,14 & 240 & $4,8-10$ & 266 \\
\hline $5,14-21$ & 231 & $4,8-11$ & 256 \\
\hline 5,20 & $16,214,217,218,219$ & 4,9 & 257 \\
\hline $5,20 \mathrm{a}$ & 217,217 & $4,9 \mathrm{f}$ & 252 \\
\hline $5,20 \mathrm{~b}$ & $217-218$ & 4,11 & 252,257 \\
\hline $5,20 c$ & 217,218 & 5,1 & 256 \\
\hline $5,20 \mathrm{~d}$ & $217-218$ & $5,1.7 .13$ & 256 \\
\hline $5,20 \mathrm{e}$ & $217-218$ & 5,6 & $251,256,257,258$ \\
\hline $5,20 \mathrm{f}$ & $217-218$ & & $272-273$ \\
\hline $5,20 \mathrm{~g}$ & $217-218,219$ & 5,7 & 258 \\
\hline & & $5,8-10$ & 256 \\
\hline 2 Iohannes & & $5,11 \mathrm{f}$. & 256 \\
\hline 2 joriantries & & 5,13 & 252,258 \\
\hline 4 & 142 & $5,13 \mathrm{f}$. & 256 \\
\hline 5 & 241 & $6-22$ & 259 \\
\hline & & 6 & 259 \\
\hline & & 6,1 & 47 \\
\hline 3 Johannes & & 6,16 & 256 \\
\hline 4 & 142 & 7,2 & 252 \\
\hline & & $7,10.15$ & 256 \\
\hline & & 8,5 & 47 \\
\hline Judas & & $10,3-4$ & 47 \\
\hline & & 11,2 & 91 \\
\hline 25 & 239 & 11,19 & 47 \\
\hline & & 12,17 & 260 \\
\hline Offenharung & & 13 & 251 \\
\hline Offenbarung & & 14,2 & 47 \\
\hline 1,1 & $251,252,255,273$ & 14,8 & 259 \\
\hline 1,3 & 250 & 14,14 & 256 \\
\hline 1,4 & 253,255 & 16,9 & 259 \\
\hline 1,5 & 175 & $16,17-21$ & 259 \\
\hline 1,8 & $252,253,263$ & 16,18 & 47 \\
\hline $1,11-21$ & 256 & $18,1-24$ & 259 \\
\hline 1,13 & 256 & 18,2 & 260 \\
\hline $2-3$ & 262 & 18,4 & 260 \\
\hline 3,2 & 169 & 19,3 & 260 \\
\hline
\end{tabular}


19,4

256

21,9

261

19,6

47

21,9-22,5

261

20,11

256, 260, 261

21,9-22,6

262

21,1

260, 261

21,22

262

249, 261, 262

$21,22 \mathrm{f}$.

272

21,3

262,273

22,1

262

$21,5-7$

$256,262,263,273$

22,3

258

252, 253, 254

22,5

252

21,7

262

22,6

251 


\section{Autorenregister}

Agaësse, Paul 228-230

Ahearne-Kroll, Stephen P. 174

Aland, Barbara 57

Aland, Kurt 50, 57, 76

Albrecht, Felix 31

Alkier, Stefan 245

Alt, Franz 247

Anderson, Paul A. 116

Angelus Silesius 158

Appel, Kurt 96

Arendt, Hannah 228

Augenstein, Jörg 115

Augustyn, Wolfgang 3

Back, Frances 8, 76, 156, 177, 267

Backhaus, Knut 249, 252

Bahl, Patrick 205

Bahr, Petra 172, 187

Baldermann, Ingo 5

Ball, David M. 112

Ballenstedt, Heinrich Christian 43

Barrett, Charles K. $60,63,74,138,142$, 147, 268

Bauckham, Richard 249

Bauer, Walter 133, 207, 209

Baur, Ferdinand Chr. 125

Becker, Jürgen $123,124,139,140,142$, 150, 216

Berger, Klaus 189

Bergman, Jan 19

Berner, Ulrich 150

Betz, Hans Dieter 199, 200, 211, 212

Betz, Otto 124, 132, 141

Beutler, Johannes $63,67-70,74,231,232$, 237, 239, 242

Bieringer, Reimund $\quad 106,107,126,137$, 189, 197, 198

Blass, Friedrich $\quad 51,179,194,219$

Boal, Augusto 100

Boismard, Marie-Émile 67

Bons, Eberhard 183

Borgen, Peder 52

Bormann, Lukas 183

Braque, Rémi 19
Braunfels, Wolfgang 3

Breytenbach, Cilliers $\quad$ 195, 196, 198

Broich, Ulrich 72

Brooke, Goerge J. 47, 55

Brown, Raymond E. $\quad 63,123$

Brucker, Ralph 69, 70

Brueggemann, Walter 104

Bryant, Jacok 43

Buch-Hansen, Gitte 174

Büchsel, Friedrich $\quad 65,67$

Bühner, Jan-Adolf $19,140,215$

Bultmann, Christoph 44

Bultmann, Rudolf $2,4,9,62,63,136$, $138,141,236$

Burke, Trevor J. 184

Burkett, Delbert 55

Burkhalter, Stefan 126

Burnet, John 150

Burz-Tropper, Veronika $1,61,62,68,69$, 78

Busse, Ulrich $52,60,116,126$

Bynum, Randolph 75

Calvin, Johannes 148

Carson, Donald A. 52, 54

Chibici-Revneanu, Nicole 93

Chittilappilly, Paul-Chummar 242

Christophersen, Alf 187

Claussen, Carsten 187

Clements, Ruth 270

Collins, John J. 183

Coloe Mary L. 55

Conzelmann, Hans 4

Coppens, Joseph 60, 249

Corbin, Henry 105

Cranfield, Charles E.B. 205

Culpepper, R. Alan $61,82,88,91,109$, $114,116,156$

Dahl, Nils 6

Dalman, Gustaf $\quad 162,192$

de la Potterie, Ignace 67

Debrunner, Albert 19, 51, 179, 194, 219

Deines, Roland 56, 253 
Delcroix, Maurice 64

Denaux, Adelbert 137

Dettwiler, Andreas 125, 142

Devillers, Luc 67

Dietrich, Walter 44

Dietzfelbinger, Christian 63, 123, 124, $135,138,142$

Dinkler, Erich 62

Discherl, Erwin 96

DiTommaso, Lorenzo 105

Dodaro, Robert 229

Donini, Pierluigi 150

Donner, Herbert 30

Doyle, Thomas 248

Drapper, John A. 55

Drewermann, Eugen 247

Dunn, James D. G. $\quad$ 154, 183, 184

Ebner, Martin 4

Eco, Umberto 71

Egger, Wilhelm 71

Engeberg-Petersen, Troels 211

Erlemann, Kurt 6,7

Essen, Georg 96

Evang, Martin 198

Eynikel, Erik 50

Feldmeier, Reinhard $\quad 6,21,25,28,31,39$, $84,87,100,101,147,148,150,158,254$

Finnern, Sönke 89

Fischer, Georg 3

Fischer, Irmtraud 83, 265

Fischer-Lichte, Erika 90

Fitzmyer, Joseph A. $\quad 65,175$

Flannery, Frances 49

Flebbe, Jochen 166

Freitag, Eberhard 21

Frey, Jörg $2,9,45,48,55,56,60,64,75$, $78,83,84,86,91,92,97,116,141,142$, $173,177-179,183,185,187,214,215$, $223,245-248,250,251,253,256,257$, 259-266, 268-270, 273

Funk, Robert W. 52

Genette, Gérard 64

Gerber, Christine $\quad 187,209,210$

Gerleman, Gillis 19

Gese, Hartmut 66

Gesenius, Wilhelm 30

Gillmayer-Bucher, Susanne 72

Glonner, Georg 250

Gnilka, Joachim 5, 63
Griffith-Jones, Robin 49

Guardini, Romano 85

Güzelmansur, Timo 123,138

Haacker, Klaus 166

Haenchen, Ernst 52

Hahn, Ferdinand 5, 249

Haldimann, Konrad 7, 62, 70

Hallyn, Fernand 64

Häring, Theodor 231

Harnack, Adolf v. 231

Harris, Elizabeth 64

Harstine, Stan 109

Hasitschka, Martin 123, 249

Heckel, Ulrich 90

Heininger, Bernhard 150

Heinze, André 245

Held, Hans Ludwig 158

Hengel, Martin $\quad 182,245,246,258,259$, 269

Herms, Eilert 188

Hernitschek, Elisabeth 50

Herriger, Norbert 152

Hesslinger, Mark 3

Hieke, Thomas 71, 245

Hirsch-Luipold, Rainer 101, 150

Hoegen-Rohls, Christina 54, 123, 134, 172, 187, 190, 192, 196, 199-201, 203, $211,212,214,215,218,219,223,224,249$

Hofius, Otfried $\quad 66,177-181,185$

Hogeterp, Albert L. A. 106

Holloway, Paul A. 174

Holtz, Traugott 248, 252

Hoppe, Rudolf $\quad 60,83$

Hornig, Dieter 64

Hubbard, Moyer V. 190

Huber, Konrad 60, 68, 249

Hunt, Steven 61

Hunziker-Rodewald, Regine 86

Ibita, Ma. Marilou S. 189

Jacques, Georges 64

Jalabert, Louis 175

Janowski, Bernd 5, 45, 265

Jantsch, Torsten 151, 190

Jeremias, Gert 48

Jeremias, Joachim $\quad 162,192,247$

Johannson, Nils 124

Jones, Scott C. 35

Joubert, Stephan 126

Juel, Donald H. 6 
Kahl, Werner 183

Kaiser, Ursula Ulrike $\quad 174,176,180,186$

Kammler, Hans-Christian 177

Kanzian, Christian 60

Karrer, Martin 249, 251, 256

Keener, Craig S. 52, 54, 93, 123

Kelhoffer, James A. $\quad$ 174, 246, 251

Kertelge, Karl 198

Kittel, Gerhard 19

Klauck, Hans-Josef $\quad 60,123,204,211$, 218, 234

Klein, Anja 37

Kleinknecht, Hermann Martin 19

Knöppler, Thomas 187, 209

Knuf, Andreas 152

Köckert, Matthias 20

Koester, Craig R. 82

Kogler, Franz 1, 69

Kolesch, Doris 90

Körtner, Ulrich H. J. 60

Köstenberger, Andreas 123

Kowalski, Beate 249, 250, 261

Kratz, Reinhard G. 264

Kristeva, Julia 72

Kügler, Joachim 4, 66

Kuhn, Heinz-Wolfgang 48

Kunath, Friederike 97, 173

Kurbacher, Frauke-Annegret 228

Kurek-Chomycz, Dominica $\quad 106,107$

Labahn Michael 126

Lambrecht, Jan $\quad$ 198, 248

Larsson, Tord 8

Lataire, Bianca 66

Law, Robert 231

Lee, Dorothy 55, 101, 119

Leonhardt-Balzer, Jutta $\quad 43,50,55,56$

Leuschner, Eckhard 3

Levin, Christoph 44

Lietzmann, Heinrich $\quad$ 166, 168

Lieu, Judith 43

Lincoln, Andrew T. 94, 95

Lindars, Barnabas $\quad 63,65,74,106$

Lindemann, Andreas 164, 165

Lohse, Eduard 5, 166, 247

Longenecker, Bruce 187

Lührmann, Dieter 48

Luther, Martin 156

Lütkehaus, Ludger 228

Lutzmann, Heiner 19

Macaskill, Grant 50
Macholz, Christian 163, 192

Malatesta, Edward 231

Malina, Bruce J. 181

Maritz, Petrus 82, 119

Mauser, Ulrich 151

Meeks, Wayne A. 178

Meier, Samuel A. $\quad 105,106$

Mell, Ulrich 188,189

Memmert, Günter 71

Merk, Otto 211

Merklein, Helmut 198

Merkt, Andreas 248

Merz, Annette 72

Meyer, Paul W. 88

Meyer, Rudolf 30

Michel, Otto 166

Moore, Stephen D. 248

Morazzoni, Anna Maria 21

Moretti, Luigi 175

Moutarde, René 175

Mowinckel, Sigmund 124

Müller, Christoph Gregor 249

Müller, Peter 187, 209

Müller, Ulrich B. 124, 140, 142, 249, 262

Münch, Sophie 190

Muraoka, Takamitsu 30

Mußner, Franz 150, 215, 217-219

Mutschler, Bernhard 246

Najman, Hindi $\quad 47,55$

Nesselraht, Heinz-Günther 150

Neumann, Nils 256

Neusner, Jacob 52

Newsom, Carol A. 106

Nicklas, Tobias 71, 106, 245, 248

Niebuhr, Karl-Wilhelm 31, 56

Niederhofer, Veronika 50

Nissen, Johannes 7, 116, 268

Norelli, Enrico 132

Oberndorfer, Bernd $\quad 124,133$

Olsson, Birger 7, 116, 268

Onuki, Takashi 142

Orlov, Andrei 55

Painter, John 231

Pannenberg, Wolfhart 148

Parsinou, Eva 48

Pascut, Beniamin $\quad 163,193$

Pedersen, Sigfred $\quad 7,116,268$

Penner, Ingrid 1,69

Pesce, Mauro 132 
Petersen, Silke $\quad 78,112$

Pfister, Manfred 72

Popkes, Enno Edzard 45, 95, 247, 264-266

Popkes, Wiard 69

Poplutz, Uta 9, 60, 211, 223, 249, 250

Popp, Thomas 178

Porter, Stanley E. 184

Powers, Daniel G. 168

Procksch, Otto 19

Quell, Gottfried 19

Raguse, Hartmut 247

Rahner, Karl 5

Rainbow, Paul A. 248, 249

Rehfeld, Emmanuel L. 198

Rehkopf, Friedrich 51, 179, 194, 219

Reim, Günter 75,78

Reinhartz, Adele 8

Reiser, Marius 163, 193

Reiterer, Friedrich V. 106

Renssen, Toon 163, 193

Reynolds, Benjamin 95

Ringer, Alexander L. 21

Rissi, Mathias 130, 132

Robert, René 67

Roddy, Nicolae 49

Rohrbaugh, Richard L. 181

Rose, André 183

Roselt, Jens $\quad 89,90$

Rothschild, Clare K. $\quad 174,175$

Roukema, Riemer 49, 53

Rowland, Christopher 245

Roy Yoder, Christine 35

Rusam, Dietrich 182

Sadananda, Daniel Rathnakara $\quad 8,9,263$, 268

Sänger, Dieter 182,183

Satake, Akira 249

Schabert, Tilo 19

Schaede, Stephan 172,187

Schäfer, Peter $\quad 127,143,145$

Schattner-Rieser, Ursula 247

Schelbert, Georg 247

Schenke, Ludger $59,60,63,83,87,88,97$

Schewe, Susanne 198, 199, 211

Schimanowski, Gottfried 255-257

Schlegel, Juliane 263

Schmeller, Thomas 197

Schmidt, Werner H. 19
Schnabel, Eckhardt 65

Schnackenburg, Rudolf $62,63,72,123$, $124,140,141,236$

Schneider, Gerhard $\quad 67,189$

Schneider, Michael 72,73

Schnelle, Udo 2, 5, 6, 55, 59, 61-64, 69, $70,72,74-77,82,86,93,97,109,114$, $123,126,134,149,156,164,183,185$, 219, 246, 249, 269

Scholtissek, Klaus $7,62,70,87,110,112$, 267

Scholz, Stefan 72

Schönberg, Arnold 21-23, 41, 42

Schöpflin, Karin 106

Schrage, Wolfgang 151

Schreiber, Stefan 4, 106, 153, 159

Schrenk, Gottlob 19

Schröter, Jens 154,198

Schulte-Middelich, Bernd 72

Schwankl, Otto $\quad 85,114$

Schwartz, Daniel R. 270

Seim, Turid Karlsen $\quad$ 174, 176

Shantz, Colleen 49

Siebenrock, Roman 60

Siegert, Volker 183

Skaggs, Rebecca 248

Skinner, Christopher W. 109

Smalley, Stephen 234

Smit, Peter-Ben $\quad 163,193$

Söding, Thomas $71,86,98,154,227,237$, 249, 252, 254, 258

Sommer, Michael 50, 249, 259

Spieckermann, Hermann 6, 21, 25, 28, $31,35,39,84,100,101,147,148,158$, 254, 264

Staab, Karl 190

Stadelmann, Helge 67

Stare, Mira 74, 116

Stegemann, Hartmut 48

Steudel, Annette 182

Stewart, Roy A. 106

Stowasser, Martin 248, 249

Strotmann, Angelika 266

Strüder, Christof W. $\quad 189,190$

Stuckenbruck, Loren T. 47,55

Taeger, Jens-Wilhelm 245

Taschl-Erber, Andrea 83, 265

Teske, Roland 229,230

Theißen, Gerd 124, 208, 209

Theobald, Michael 1, 2, 60-63, 67-70, 123-125, 127, 131, 140, 142, 143, 145, 
$154,174,175,178,204,207,220-222$, 233

Thompson, Marianne M. $8,9,49-52,60$, 75, 78, 87, 88, 92, 98, 108, 114, 263

Thornton, Claus-Jürgen 269

Thrall, Margaret E. $\quad 188,189$

Thyen, Hartwig $70,74,123,125,178$

Tilly, Miachel 183

Tolmie, François D. 7, 61, 82, 84, 99, 109, 264

Tóth, Franz 246, 250, 251

Troll, Christian W. 138

Tuschling, Ruth M. M. 104-107

Ueberschaer, Nadine $74,189,190$, 194-197, 210, 214

Uhlig, Siegbert 189

Utzschneider, Helmut 71

van Belle, Gilbert $\quad 82,119$

van den Heede, Philippe 67

van der Watt, Jan G. 45, 61, 77, 82, 105, $107,109,114,116,119,156,215$

van Kooten, Georg H. 49

van Noppen, Jean-Pierre 96

Van Oyen, Gert 126

Verbeke, Gerard 19

Verheyden, Joseph $\quad 126,248,260$

Vögtle, Anton 249, 252, 254

von Bendemann, Reinhard 154

von Gemünden, Petra 208, 209

von Wahlde, Urban C. 63

Vouga, François 236
Wagener, Fredrik 90

Warstat, Matthias 90

Wassen, Cecilia 106

Watson, Duane E. F. 106

Weder, Hans 7, 62, 70

Wehr, Lothar 123

Weinrich, Harald 64

Weiß, Johannes 165,168

Welker, Michael 5

Wengst, Klaus 62, 63, 93, 249

Werline, Rodney A. 49

Wesch-Klein, Gabriele 209

Wick, Peter 71

Wilckens, Ulrich 249, 252

Wilk, Florian 193, 247

Williams, Catrin H. 50, 82, 93, 245

Windisch, Hans 238

Wischmeyer, Oda 72

Witetschek, Stephan 246

Wolter, Michael $166,169,170,175,198$, 204-210

Yarbro Collins, Adela 183

Zimmerli, Walter 20

Zimmermann, Christiane $6,7,65,164$, $166,177,184,187,191,192,195,199$, 201, 202, 211-213, 217, 220, 222, 266

Zimmermann, Ruben 3, 61, 75, 77, 78, 85, 86, 90, 91, 95, 100, 116, 126, 178

Zingg, Edith 8, 9, 76

Zirker, Hans 138

Zumstein, Jean $60,63,64,72,75,123$, $125,132,137,139,141,142,215,223,264$ 


\section{Antike Autoren}

Apuleius von Madaura

De Deo Socratis 150

Aratos von Solai

Phainomena 182

Aristoteles 144

Ethica Nicomachea 140,141

Aurelius Augustinus 228-230, 232, 236, 238, 242

De trinitate 229

In epistulam Iohannis 229

Clemens von Alexandrien $\quad 189,190$ Stromata 189

Didymus von Alexandria 190

Dio Chrysostomus

Orationes 182

Epiktet 182

Dissertationes 182

Eusebius von Emesa 190

Hierokles 117

On duties 117

Irenäus von Lyon

AdvHaer III 1,1 1

Irenäus von Lyonantike $\quad$ 1, 246
Kleanthes 182

Ökumenius von Trikka 190

Philon von Alexandrien $19,41,43-46$, $50,51,55-57,150,174,183,270$

Legum allegoriae 45

De agricultura 183

De confusione linguarum 183

De opificio mundi 56

De sacrificiis Abelis et Caini 50

De Somniis 52, 150, 270

De vita Moysis 140

Quaestioes et solutiones in Exodum 174

Quod deterius potiori insidiari soleat 45

Quod Deus sit immutabilis $\quad 45,183$

Platon 150, 158

De republica 165

Phaidros 140

Politeia 150

Symposion 150

Severian von Gabala 190

Sextus Empiricus 182

Xenokrates 150 


\section{Sachregister}

Abschiedsrede(n) $\quad 14,53,83,90,123,124$, $125,126,128,131,134,141,143,144$, $155,156,239,241$

Augustin(us) 17, 228, 229, 230, 232, 236, 238,242

aus Gott Gezeugtwerden $15,16,161,162$, $163,164,173,175,176,180,181,183$, $184,185,186,187$

aus Geist Gezeugtwerden 164

Bruderliebe 232, 234, 235, 242

Bund $38,191,227,228,231,235,238,262$

Bundesformel 262

Chaos 24, 25

Christologie, christologisch VII, 1, 2, 6, $7,9,11,12,13,14,15,18,48,57,59,60$, $70,73,74,77,78,81,83,84,85,88,89$, $90,93,99,105,107,108,111,112,115$, $117,121,124,127,129,131,147,148$, $149,154,157,159,172,215,225,231$, $248,252,258,259,264,267,268,269$, 270, 271, 272, 273

Christo-Theologie, christo-theologisch $12,13,85,89,91,95,96,100$

Christozentrik, christozentrisch 6,17 , $60,74,266,268$

Christus $4,21,23,35,40,41,42,57,69$, $70,79,85,107,128,139,142,147,148$, $149,150,151,152,153,157,158,163$, $164,165,168,169,170,171,175,176$, $178,180,181,184,185,189,191,192$, $194,195,196,197,199,200,201,202$, 205, 206, 207, 209, 210, 212, 214, 218 , $219,223,224,230,232,237,240,241$, $251,253,255,256,257,258,259,262$, $263,264,265,269,270,271,272,273$

Christusbild 86

Christusereignis $16,148,185$

Christuserfahrung 15, 161,

Corpus Johanneum 1, 2, 17, 64, 143, 245

Ditheismus (Zwei-Götter-Lehre) 76, 145, 146

Einziggeborener, einziggeboren $\quad 12,21$, $23,27,32,34,38,39,40,41,42,65,67$, $82,84,154,176,221,267$
Engel/Engelwesen $13,45,47,53,104$, $105,106,107,108,124,132,133,140$, 144, 145, 150, 255, 256, 261

Epiphanie 48, 93

erster Johannesbrief $2,17,74,155,156$, $157,159,203,214,219,220,227,228$, $229,230,231,232,233,234,235,236$, $237,240,241,242,246,263,266,270,271$ ewiges Leben $16,153,189,202,203,204$, 205, 206, 207, 208, 209, 210, 211, 213, $214,215,216,217,218,219,220,222$, $223,224,225,237,274$

Exeget des Vaters 12, 59, 68

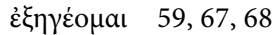

Filioque 125,133

Fleisch $10,23,34,35,36,37,38,40,41$, $56,68,69,92,93,97,101,176,180,181$, 196, 211, 213

Fleischgewordener 23, 24, 39, 40, 41, 73, 83,181

Fleischwerdung/Inkarnation $10,11,21$, $23,27,33,37,38,41,42,45,54,57,63$, $68,69,96,97,101,154,173,174,175$, 176,177

Geburt/-smetaphorik/-svorstellung 53, $65,156,161,163,167,175,176,182,184$

Geist $9,15,17,18,25,32,32,33,36,37$, $39,53,61,92,128,129,130,131,132$, $133,134,136,137,138,139,140,141$, $142,143,144,156,161,164,165,168$, $169,170,173,177,178,179,180,181$, $184,191,199,211,212,213,214,223$, $224,225,227,228,229,230,232,233$, $236,238,239,242,255,265,269$

Geschichte $6,26,33,41,44,45,48,58$, $96,127,142,148,149,157,159,206,238$, $242,247,252,253,257,258,260,262$, $265,266,267,271,274,275$

Gott VII, 1, 3, 4, 5, 6, 7, 8, 9, 10, 11, 12, $13,14,15,16,17,18,19,20,21,22,23$, $24,25,26,27,29,30,31,32,33,34,35$, $36,37,38,39,40,41,42,43,44,45,46$, $47,48,49,50,51,52,53,54,55,56,57$, $58,59,60,61,64,65,68,69,70,73,74$, 
$75,76,77,78,79,81,82,83,84,86,87$, $88,92,93,95,97,98,99,100,101,103$, $104,105,106,107,108,109,112,113$, $114,115,115,117,118,120,121,123$, $124,126,127,131,133,136,142,144$, $145,147,148,149,150,151,152,153$, $154,155,156,157,158,159,161,162$, $163,164,165,166,167,168,169,170$, $172,173,174,175,176,177,178,179$, $180,181,182,183,184,185,186,187$, $188,191,192,193,194,195,196,197$, $198,200,201,202,203,204,205,206$, 207, 208, 209, 210, 212, 213, 214, 215, $217,218,219,220,221,222,223,224$, $225,227,228,229,230,231,232,233$, $234,235,236,237,238,239,241,242$, $243,245,246,247,248,251,252,253$, $254,255,256,257,258,259,260,261$, $262,263,264,265,266,267,268,269$, $270,271,272,273$

- Vater VII, 4, 8, 9, 12, 13, 14, 8, 46, 52, $59,60,61,66,69,75,76,77,78,79,84$, $95,99,103,104,105,107,108,109$, $110,111,112,113,114,115,116,117$, $118,119,120,121,148,152,156$, $157-159,174,176,177,184,185,186$, 201, 214, 219, 220, 224, 233, 239, 246, 247, 264, 265, 266, 272

- Richter, richterliches Handeln Gottes 113, 6, 94-95, 203-210, 210-214, 214, 220, 221, 224,

- Retter 101, 205, 207, 224, 262, 263

- Versöhner 16, 197-198, 224

- Schöpfer/Schöpfergott/Neuschöpfer $15,16,60,104,187,191,194-198$, 201-202, 203-210, 210-214, 220, 252, 258, 261, 263, 264, 268, 272,

Gottesbild VII, 1, 2, 3, 4, 8, 9, 10, 11, 14, $17,18,43,44,51,57,58,60,69,70,75$, $76,78,82,86,89,124,127,143,162,163$, $171,188,201,202,210,224,227,242$, 247, 248, 249, 250, 254, 263, 271, 275,

Gotteskinder, Kinder Gottes 14, 52, 100, $147,153,156,173,176,178,179,181$, $182,183,185$

Gotteskindschaft $156,157,181,183,184$, 185

Gottesprädikate $13,17,54,96,100,152$, $231,268,272$

Gottesrede, Rede von Gott $1,5,6,11,12$, $14,16,43,44,45,46,53,60,70,76,81$, $96,145,148,149,155,187,188,190,191$,
$192,193,194,195,198,199,203,205$, $211,212,214,215,216,217,224,246$, $247,251,255,259,261,262,263,264$, 266, 267, 268, 269

Herz aus Fleisch $\quad 10,36,37,38,41$

Ich-bin-Worte $12,77,78,89,112,115$, 172

Immanenz, Immanenzaussagen, Immanenzformel $86,87,88,96,108$, $109,118,150,154,155,158,185,267$

Intratextualität, intratextuell $12,61,70$, $71,72,142$

Jesus $2,4,5,7,9,11,12,13,14,15,16,18$, $21,23,35,40,41,42,45,46,47,48,49$, $50,51,52,53,54,55,57,58,59,60,61$, $65,66,67,68,69,70,73,74,76,77,79$, $82,83,84,85,86,87,89,90,91,92,93$, $94,95,96,97,98,100,103,104,105,107$, $108,109,110,111,112,113,114,115$, $116,117,118,119,120,121,124,126$, $127,128,129,130,131,132,133,134$, $136,137,138,139,140,141,142,143$, $144,145,147,148,151,152,153,154$, $155,156,157,159,165,168,170,172$, $173,175,177,178,179,181,184,196$, $199,201,218,219,223,237,239,240$, $241,246,248,252,255,264,265,266$, $267,269,272,273$

Johannesapokalypse, Apokalypse 17, $245,246,247,248,249,250,251,252$, $253,254,256,258,259,261,262,263$, 266, 269, 270, 271, 272, 273, 274

Johannesevangelium VII, 1, 2, 3, 4, 7, 8, $9,10,11,12,13,14,15,16,17,18,19,20$, $43,45,46,47,48,49,50,51,52,53,54$, $55,56,58,59,60,61,62,67,68,69,70$, $71,73,75,76,77,78,79,81,82,84,90$, $92,96,97,99,103,125,148,153,154$, $157,158,161,164,171,172,173,175$, $177,178,181,185,186,203,214,218$, $219,222,227,237,240,245,246,249$, $251,263,264,266,267,268,269,270$, 271, 272, 273, 274

- Viertes Evangelium VII, 7, 8, 59, 69, $84,88,154,215,223,265,266,267$, 268, 269, 273, 274,

- Evangelium 125, 126, 139, 143, 147, $153,156,157,159,174,236,245,246$, $247,248,263,264,265,266,269,274$,

- Johannes $13,15,16,17,24,40,42,43$, $46,47,48,49,50,52,53,57,60,63,66$, $82,93,94,95,98,103,104,105,107$, 
$108,109,111,112,115,116,117,118$, $120,121,148,153,154,157,158,159$, $161,164,173,187,188,202,214,223$, $224,225,227,229,242,245,265,266$, 267, 268, 269

johanneisch $2,3,4,6,7,8,9,10,11,12$, $13,14,15,16,17,18,41,43,48,49,53$, $55,56,57,59,60,65,69,73,74,75,76$, $77,78,79,81,82,84,86,92,96,99,103$, $104,107,108,112,115,117,121,122$, $123,124,125,127,132,142,145,146$, $149,153,154,155,158,159,161,172$, $173,178,182,183,184,186,188,203$, $214,215,216,219,220,221,222,223$, $224,229,235,241,245,246,248,264$, 267, 269, 270, 271, 272,

Johannesoffenbarung, Offenbarung 2, 17 Johannesprolog $10,11,12,16,19,20,23$, $24,25,27,31,38,40,41,42,47,52,54$, $55,56,57,59,60,61,62,63,64,65,68$, $69,70,72,73,75,78,82,83,94,97,98$, $100,109,153,154,172,173,175,176$, $177,179,217,218,235,264,268$,

Lebendigmachen, lebendingmachend 15 , $161,164,165,166,167,168,169,170$, $171,172,181,185,186$

Liebe

- Gottes $11,13,15,17,18,25,26,27$, $28,35,38,39,40,41,67,74,79,87,95$, $100,111,131,151,152,154,155,156$, $157,158,159,199,205,206,212,219$, $220,227,228,229,230,231,232,233$, $234,235,236,237,238,239,240,241$, $242,243,245,246,248,264,266,268$, $269,270,271,274,275$

- Gottesliebe 234, 242

- Bruderliebe 232, 233, 234, 235, 236, 241, 242

Logos $5,10,11,12,16,18,19,23,27,38$, $40,41,43,45,48,49,51,52,54,55,56$, $57,59,65,68,69,70,72,73,74,76,79$, $86,88,94,95,98,145,147,150,153,154$, $157,158,173,174,175,176,177,181$, $183,185,214,215,217,218,219,220$, 224, 264, 267, 268

Mittler $14,15,19,20,83,148,149,150$, $152,153,154,159,180$

Mittlerwesen 45, 150

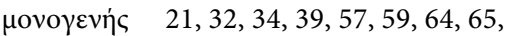
$68,73,76,79,82,105,109,174,175,176$, 181,185

Monotheismus, monotheistisch 13,14 ,
$15,44,65,69,70,76,82,86,103,105$, $106,107,108,109,118,124,145,146$, $148,149,150,151,157,251,264$

Montanismus, montanistisch 130, 139

Muhammad/Mohammed 138, 148

neue Schöpfung $16,183,187,188,189$, 191, 192, 193, 195, 198, 202, 224, 225, 261

Neuschöpfung $17,37,171,194,195,202$, $222,225,261,273$

Offenbarung $17,20,45,47,48,49,55,67$, $70,76,77,78,93,107,110,137,39,141$, $142,151,211,232,240,242,252,255$, 257, 264, 265, 267, 271, 273, 275

Paraklet $7,14,61,83,92,123,124,126$, $127,128,129,130,131,132,133,134$, $135,136,137,138,139,140,141,142$, $143,144,223$

Parakletspruch/-sprüche $11,14,123,124$, $126,127,128,130,131,135,137,138$, $139,140,142,143,147$

passivum divinum $154,163,173,192$, 205, 206, 208, 212, 220, 221

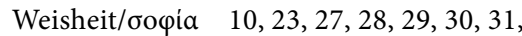
$32,33,34,39,40,41,57,140,180,182$ - personifizierte Weisheit 10, 27, 29, 32, 31, 34, 39,

Weisheitsspekulation, -vorstellungen, -tradition 55, 62, 69

Pneumatologie 6, 129, 224

rekreatorisches Handeln Gottes 14, 15, $16,161,186,187,194,196,197,198,202$, 205, 214, 221, 222, 223, 224, 225

Schechina 262

Schöpfung $10,11,23,24,25,28,29,30$, $31,33,39,41,56,58,94,176,181,182$, $184,187,188,189,212,217,224,253$, $254,256,260,261,268,270$

Schöpfungstheologie 10, 25, 92, 94, 205

Schöpfungsmittlerschaft Christi/des Logos 202, 268

Seins-/Wesens- und Handlungs-/Wirkeinheit $12,76,79,84$, $87,88,89,91,92,93,96,134,176,185$

Sendungshandeln (von Vater und Sohn) 214, 220, 221, 223, 225

Sohn $4,12,13,14,15,16,17,18,28,40$, $41,42,47,48,52,55,57,64,65,68,74$, $76,79,81,82,83,84,85,86,87,88,89$, $91,92,93,94,95,96,97,98,99,100,103$, $104,109,111,112,115,116,117,118$, $119,120,121,127,129,131,134,140$, $141,144,146,147,151,152,153,154$, 
$155,156,157,158,159,161,172,173$, $174,175,176,177,178,181,182,183$, $184,185,194,196,198,200,201,202$, $206,214,215,216,217,218,219,220$, $221,222,223,224,225,229,233,237$, $238,239,240,241,242,243,266,267$, 268, 270, 272, 273

Theo-Logie, spezielle Theologie, theologisch VII, 1, 4, 6, 7, 9, 10, 11, 12, 18, $59,61,62,70,71,73,75,78,79,163,246$, 267,269

Theozentrik, theozentrisch $14,17,18,60$,
$127,131,132,144,195,252,258,266$, 267, 268, 272, 273

Thron $17,18,30,32,33,34,124,128$, $245,255,256,257,258,259,262,271$, 274 ,

von oben Gezeugtwerden 15, 161, 173, $179,180,183,184,185,186$

Weltgericht 17,259

Weltherrschaft $17,259,260$

Wiedergeburt/Neugeburt 178

Wort Gottes 20, 22, 23, 25, 26, 34, 35, 86

Zelt, zelten $33,39,40,54,69$ 